\begin{tabular}{l|l} 
Universidad & Campus \\
Politécnica & de Excelencia \\
de Cartagena & Internacional
\end{tabular}

\title{
STUDY OF NEW MATERIALS, SURFACES AND INTERFACES IN TRIBOLOGY
}

\section{ESTUDIO DE NUEVOS MATERIALES, SUPERFICIES E INTERFASES EN TRIBOLOGÍA}

Doctorado en Tecnologías Industriales

Autor: María Dolores Avilés González

Directores: $M^{a}$ Dolores Bermúdez Olivares

Francisco José Carrión Vilches

Cartagena (2018) 



\section{Universidad \\ Politécnica \\ de Cartagena}

DT-16

\section{CONFORMIDAD DE SOLICITUD DEAUTORIZACIÓN DE DEPÓSITO DE}

\section{TESIS DOCTORAL POR EL/LA DIRECTOR/A DE LA TESIS}

Da. María Dolores Bermúdez Olivares y D. Francisco José Carrión Vilches, Directores de la Tesis doctoral ESTUDIO DE NUEVOS MATERIALES, SUPERFICIES E INTERFASES EN TRIBOLOGÍA

\section{INFORMA:}

Que la referida Tesis Doctoral, ha sido realizada por D ${ }^{\mathrm{a}}$ María Dolores Avilés González. dentro del Programa de Doctorado Tecnologías Industriales, dando mi conformidad para que sea presentada ante el Comité de Dirección de la Escuela Internacional de Doctorado para ser autorizado su depósito.

La rama de conocimiento en la que esta tesis ha sido desarrollada es:

$\square \quad$ Ciencias

Ciencias Sociales y Jurídicas

$\mathrm{X}$ Ingeniería y Arquitectura

En Cartagena, a 2 de julio de 2018

LOS DIRECTORES DE LA TESIS
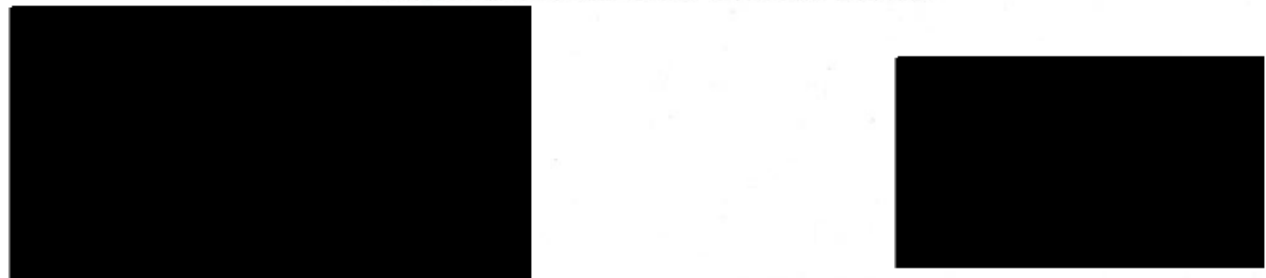

Fdo.: Francisco José Carrión Vilches

Fdo.: María Dolores Bermúdez Olivares

\section{COMITÉ DE DIRECCIÓN ESCUELA INTERNACIONAL DE DOCTORADO}





\section{Universidad \\ Politécnica \\ de Cartagena}

DT-17

\section{CONFORMIDAD DE DEPÓSITO DE TESIS DOCTORAL POR LA COMISIÓN ACADÉMICA DEL PROGRAMA}

D/D ${ }^{a}$. JUAN SUARDIAZ MURO, Presidente/a de la Comisión Académica del Programa TECNOLOGÍAS INDUSTRIALES.

\section{INFORMA:}

Que la Tesis Doctoral titulada, ESTUDIO DE NUEVOS MATERIALES,

SUPERFICIES E INTERFASES EN TRIBOLOGÍA ha sido realizada, dentro del mencionado Programa de Doctorado, por Da.MARÍA DOLORES AVILÉS GONZÁLEZ, bajo la dirección y supervisión del Dra.MARÍA DOLORES BERMÚDEZ OLIVARES Y Dr. FRANCISCO JOSÉ CARRIÓN VILCHES.

En reunión de la Comisión Académica, visto que en la misma se acreditan los indicios de calidad correspondientes y la autorización del Director/a de la misma, se acordó dar la conformidad, con la finalidad de que sea autorizado su depósito por el Comité de Dirección de la Escuela Internacional de Doctorado.

La Rama de conocimiento por la que esta tesis ha sido desarrollada es:

Ciencias

Ciencias Sociales y Jurídicas

$\mathrm{X}$ Ingeniería y Arquitectura

En Cartagena, a 11 de julio de 2018

EL PRESIDENTE DE LA COMISIÓN ACADÉMICA

$\begin{array}{ll}\text { JUAN| } & \begin{array}{l}\text { Firmado } \\ \text { digitalmente por }\end{array} \\ \text { SUARDIAZ| } & \text { JUAN|SUARDIAZ } \\ \text { MURO } & \text { MURO }\end{array}$

Fdo: JUAN SUARDIAZ MURO 



\section{Agradecimientos}

Quería agradecer a todas las personas e instituciones que han hecho posible la realización de este trabajo.

A la Dra. María Dolores Bermúdez y al Dr. Francisco José Carrión, directores de esta Tesis Doctoral, por su dedicación, disponibilidad y sabiduría. Sin su ayuda, este trabajo no habría sido posible.

A los miembros del grupo de investigación, Dr. José Sanes, Dr. Ramón Pamies, Dr. Joaquín Arias, Dra. Ana Eva Jiménez y Dr. Isidoro Martínez, por su ayuda e interés, tanto en el trabajo experimental como docente.

A la Dra. Tulia Espinosa y a la Dra. Noelia Saurín, mis maestras en el laboratorio y Luis Mínguez por su apoyo y sus ganas de aprender.

A Juan Ángel López y Fernando Ródenas, por su ayuda en la intendencia y en la preparación de muestras.

A los técnicos del Servicio de Apoyo a la Investigación Tecnológica de la UPCT, a Macarena López de la Universidad de Jaén, Cristina Almansa y Fernando Coloma de la Universidad de Alicante por su ayuda en la obtención de resultados y responder a todas mis peticiones.

A la Dra. Patricia Iglesias y al Kate Gleason College of Engineering, por permitirme hacer la estancia de investigación en el Rochester Institute of Technology. En especial al Dr. Vinnie Gupta, por enseñarme a utilizar el AFM.

Al Dr. Miguel Iglesias, de la Universidad Federal de Bahía (Brasil), por facilitarnos los líquidos iónicos próticos. A ILBOC Lube base oil S.A. y REPSOL S.A por suministrarnos los aceites lubricantes empleados en el trabajo.

A mi familia, en especial a mis padres y hermanos por apoyarme en cada aventura y por animarme.

A todos mis alumnos, porque cada día me enseñan algo nuevo. 
Ministerio de Economía, Industria y Competitividad (MINECO, Spain) (MAT2017-85130-P)

Ministerio de Economía, Industria y Competitividad (MINECO, Spain) (MAT2014-55384-P)

"Este trabajo es resultado de la actividad desarrollada en el marco del Programa de Ayudas a Grupos de Excelencia de la Región de Murcia, de la Fundación Séneca, Agencia de Ciencia y Tecnología de la Región de Murcia (19877/GERM/15)".

(BES-2015-074836) Ayudas a la formación de personal investigador (FPI). Ministerio de Economía, Industria y Competitividad (2015-2019)
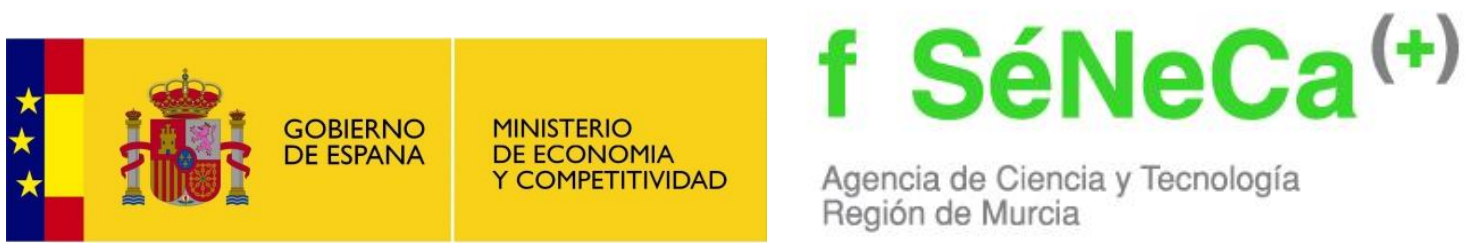


\section{RESUMEN}

La presente tesis doctoral recoge los resultados de los trabajos de investigación realizados sobre nanofluidos, nanofases de carbono y nanocomposites de matriz epoxi, su preparación, caracterización y aplicaciones en la reducción de los coeficientes de fricción, las tasas de desgaste y el daño superficial de materiales en distintas condiciones de deslizamiento bajo carga.

Se han utilizado cristales líquidos iónicos próticos derivados de ácidos grasos, así como otros líquidos iónicos próticos con aniones carboxilato también biocompatibles como citrato y succinato, para generar nuevos lubricantes base agua, así como nuevas dispersiones conteniendo grafeno y nanodiamantes.

La generación de películas finas de lubricante sobre las superficies por evaporación de agua en condiciones suaves, previas al deslizamiento, permite alcanzar prestaciones semejantes a las de los lubricantes puros, con un gran ahorro de líquido iónico.

La combinación de líquidos iónicos derivados de imidazolio disponibles comercialmente y grafeno ha dado lugar a dispersiones con un comportamiento reológico sin precedentes, ya que, en función de la concentración de grafeno, su viscosidad se mantiene constante o se incrementa con el aumento de temperatura.

Se ha estudiado la aplicación de dispersiones de grafeno en líquidos iónicos como aditivos de una base lubricante libre de aditivos y de un aceite de motor comercial totalmente formulado, mejorando considerablemente sus prestaciones incluso a alta temperatura.

Se han obtenido nuevos nanomateriales de matriz epoxi con comportamiento tribológico mejorado. La adición de un líquido iónico de cadena corta, da lugar a un material poroso que libera el líquido iónico bajo carga, presentando un comportamiento autolubricante y de autorreparación del daño superficial. Cuando se añaden líquidos iónicos de cadena larga, se obtienen dispersiones homogéneas que reducen los coeficientes de fricción y previenen el desgaste, incluso en condiciones muy severas de deslizamiento y abrasión.

Las nuevas dispersiones de líquido iónico o líquido iónico y grafeno en resina epoxi se han depositado sobre sustrato de resina epoxi sin modificar o de acero al carbono, con el fin de mejorar su resistencia a la fricción y al desgaste, sin 
modificar las propiedades del material base. En el primero de los casos, se obtienen materiales con un gradiente de composición, ya que los aditivos se localizan allí donde se necesitan, en la capa superficial.

En esta investigación ha sido necesaria la utilización de un gran número de técnicas experimentales, de ensayos normalizados y de caracterización de los materiales, así como la colaboración con otros grupos de investigación, tanto nacionales como internacionales. 


\section{ABSTRACT}

The present $\mathrm{PhD}$ thesis includes the results of the research works on the preparation and characterization of nanofluids, carbon nanophases and epoxy matrix nanocomposites, and their applications in the reduction of friction coefficients, wear rates and surface damage of materials under different sliding conditions.

Protic ionic liquid crystals with anions derived from fatty acids and other protic ionic liquids with biocompatible carboxylate citrate and succinate anions have been used in the development of new water-based lubricants, and in new dispersions containing graphene and nanodiamonds.

Thin lubricant films generated, before the sliding, on the surfaces after water evaporation under mild conditions have shown excellent tribological performances, similar to those of the neat ionic liquids, but using a minimum amount of them.

The combined use of commercial imidazolium ionic liquids and graphene gives rise to new dispersions with unprecedented rheological behaviour, as they present constant or increasing viscosity values under increasing temperature, as a function of graphene concentration.

The new graphene dispersions in ionic liquids have been used as additives in an additive-free lubricant basestock and in a fully-formulated commercial motor oil, achieving good results even at high temperatures.

New epoxy matrix nanocomposites have been obtained. The porous material obtained by addition of a short-chain protic ionic liquid shows a self-lubricating and self-healing behaviour. Uniform dispersions obtained when long-chain ionic liquids are added to the epoxy matrix, reduce friction coefficient and prevent wear even under very severe sliding or abrasion conditions.

The new dispersions of long-chain ionic liquids or ionic liquids and graphene have been deposited on unmodified epoxy resin or carbon steel substrates to improve their tribological performance without modifying their bulk properties. In the first case, new materials with gradient composition are obtained, where the additives are localized only where they are needed, that is at the material surface. 
The research work described here makes use of many experimental techniques, standard tests and characterization equipments, and has been possible thanks to the cooperation with national and international research groups. 


\section{ABREVIATURAS}

$\% R$ Porcentaje de recuperación viscoelástica

[EMIM][DCA] Dicianamida de 1-etil-3-metilimidazolio

[EMIM][TFSI] Bis(trifluorometanosulfonil)imida de 1-etil-3-metilimidazolio

[OMIM]BF 4 Tetrafluoroborato de 1-octil-3-metilimidazolio

OD 0 dimensiones

1D 1dimensión

2D 2 dimensiones

3D 3 dimensiones

AISI Acrónimo de American Iron and Steel Institute, normativa para calificación de aceros

B Aceite base isoparafínico

BL Lubricación límite

CNT Nanotubos de carbono

COF Coeficiente de fricción

CVD Deposición química en fase vapor

DCi Citrato de tri[bis(2-hidroxietil)amonio]

DEs Estearato de bis(2-hidroxietil)amonio

DGEBA Digliciléter de bisfenol A

DLC Carbono tipo diamante

DLS Análisis del tamaño de partículas mediante dispersión por láser

DMA Análisis dinámico-mecánico

DO Oleato de bis(2-hidroxietil)amonio

DPa Palmitato de bis(2-hidroxietil)amonio

DSC Calorimetría diferencial de barrido

DSu Succinato de di[bis(2-hidroxietil)amonio]

E' Módulo de almacenamiento

E" Módulo de pérdida

EDX Espectroscopía de energías dispersivas de rayos $\mathrm{X}$

EHL Lubricación elastohidrodinámica o mixta

F Fuerza lateral requerida para iniciar o mantener el movimiento

$F_{\mathrm{n}}$ Fuerza normal

FTIR Espectroscopía infrarroja por transformada de Fourier

G Grafeno

GIC Compuestos de grafito intercalados 
GO Óxido de grafeno

h Espesor de capa lubricante

HD Dureza Shore D

HDL Lubricación hidrodinámica

HPHT Crecimiento de microcristales de diamante a alta presión y alta temperatura

HV Dureza Vickers

LI Líquido iónico

LPE Exfoliación en fase líquida

MBE Epitaxia de haces moleculares

MEs Estearato de 2-hidroxietilamonio

MO Aceite totalmente formulado de alto rendimiento

MSU Succinato de di[2-hidroxietilamonio]

MWCNT Nanotubos de carbono de pared múltiple

$\mathrm{N}$ Número de deslizamientos

ND Nanodiamantes

NDWDEs Dispersión de un $0,1 \%$ de nanodiamantes en la emulsión de un $1 \%$ de líquido iónico estearato de bis(2-hidroxietil)amonio en agua

NDWDPa Dispersión de un $0,1 \%$ de nanodiamantes en la emulsión de un $1 \%$ de líquido iónico palmitato de bis(2-hidroxietil)amonio en agua

NDWMEs Dispersión de un $0,1 \%$ de nanodiamantes en la emulsión de un $1 \%$ de líquido iónico estearato de 2-hidroxietilamonio en agua

Pd Profundidad de penetración

PIB Producto interior bruto

PIL Líquido iónico prótico

$P_{\text {med }}$ Presión media de contacto

$\mathrm{P}_{\text {máx }}$ Presión máxima de contacto

PTFE Politetrafluoroetileno

PVD Deposición física en fase vapor

R Coeficiente de correlación

$R_{a}$ Rugosidad media superficial (a partir de una línea), según norma UNE-EN ISO 4287.

$\mathrm{Rd}$ Profundidad residual

RE Resina epoxi

$\mathrm{R}_{\mathrm{g}}$ Radio efectivo de las moléculas de un lubricante

RTIL Líquido iónico a temperatura ambiente

$S_{a}$ Rugosidad media superficial (a partir de una superficie), según norma UNE-EN ISO 25178 
SEM Microscopía electrónica de barrido

SLG Monocapa de grafeno

$\tan (\delta)$ Tangente de pérdida

Td Temperatura de degradación

TEM Microscopía electrónica de transmisión

Tf Temperatura de fusión

TFL Régimen de lubricación por película fina

Tg Temperatura de transición vítrea

TGA Análisis termogravimétrico

$\checkmark$ Velocidad de deslizamiento

V Voltaje

VFTH Modelo Vogel-Fulcher-Tammann-Hesse

WDEs Emulsión de un 1\% de líquido iónico estearato de bis(2-hidroxietil)amonio en agua

WDPa Emulsión de un 1\% de líquido iónico palmitato de bis(2-hidroxietil)amonio en agua

WMEs Emulsión de un 1\% de líquido iónico estearato de 2-hidroxietilamonio en agua

XPS Espectroscopía fotoelectrónica de rayos $\mathrm{X}$

ZDDP Ditiofosfato de cinc

$\Delta \mathrm{h}_{\mathrm{opt}}$ Evolución del espesor de película con el número de deslizamientos

$\delta$ Ángulo de fase

$\varepsilon$ Deformación

$\eta$ Viscosidad dinámica

$\sigma$ Esfuerzo (tensión)

$\mu$ Coeficiente de fricción

$\mu_{\mathrm{k}}$ Componente dinámico del coeficiente de fricción

$\mu_{s}$ Componente estático del coeficiente de fricción 


\section{ÍNDICE}

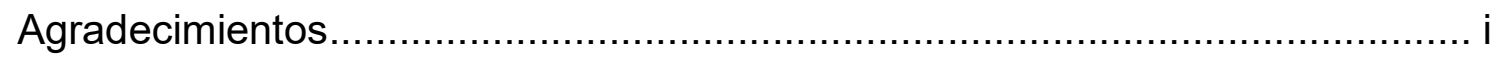

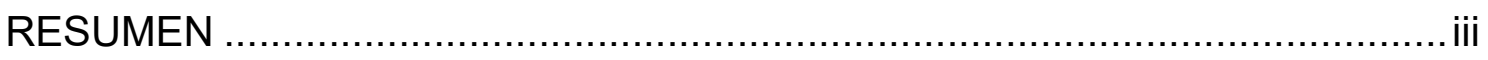

ABSTRACT …

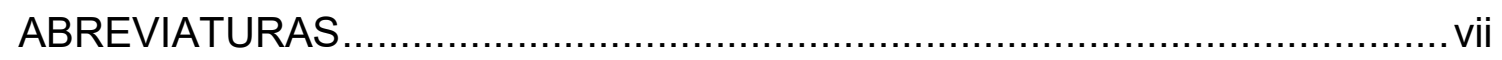

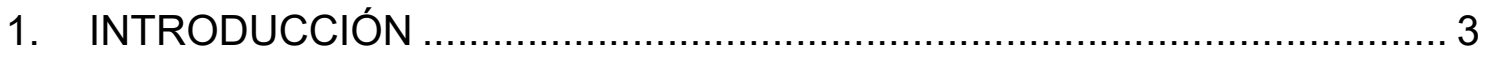

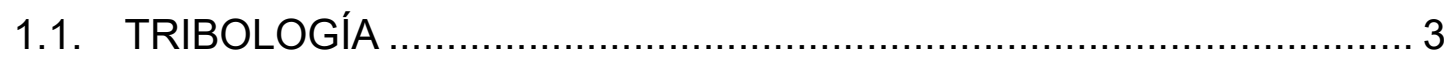

1.1.1. Historia de la tribología ................................................................ 3

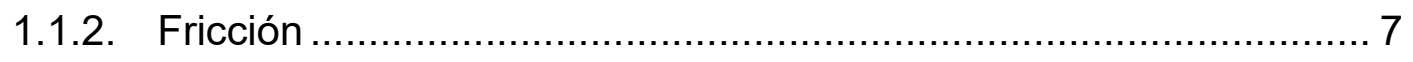

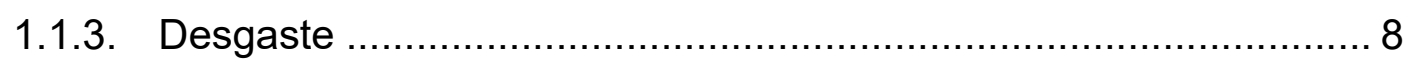

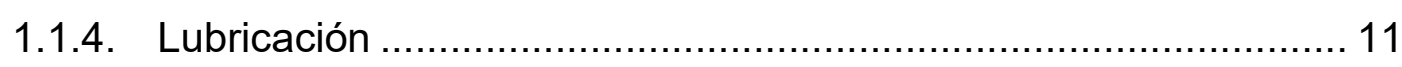

1.1.4.1. El modelo de lubricación de Stribeck .................................. 13

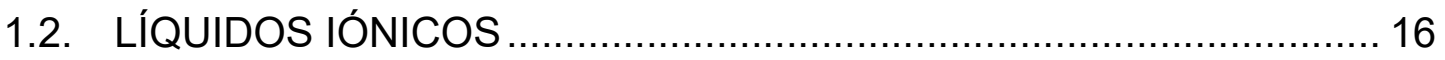

1.2.1. Líquidos iónicos como lubricantes .......................................... 18

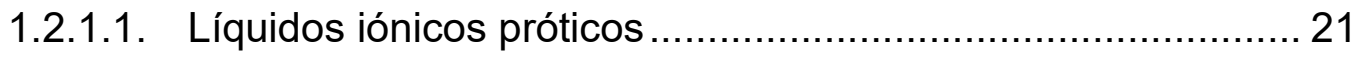

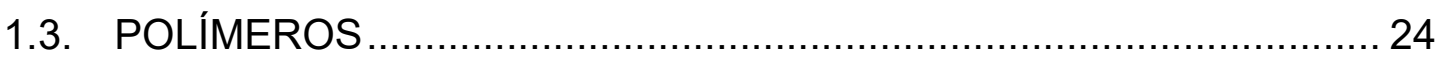

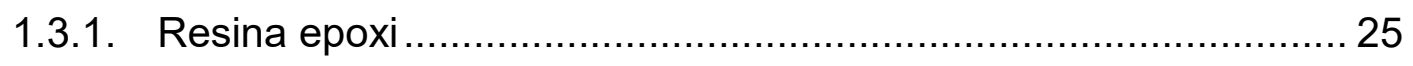

1.4. NANOFASES DE CARBONO [129]-[132] ….............................. 28

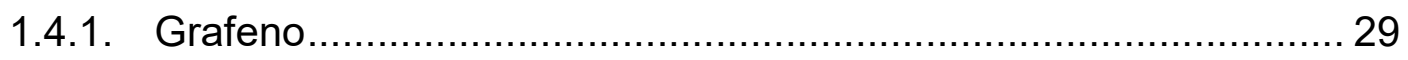

1.4.1.1. Métodos de obtención de grafeno ......................................... 30

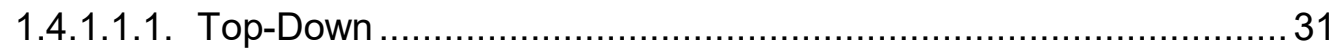

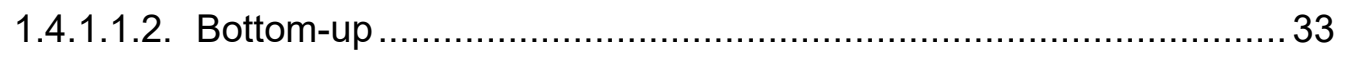

1.4.1.2. Aplicaciones del grafeno …............................................... 36

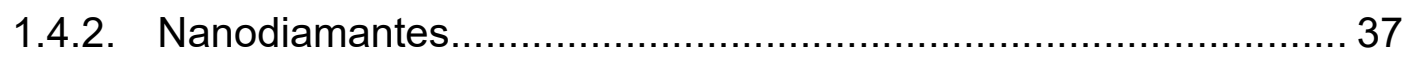


1.4.2.1. Métodos de obtención de nanodiamantes 38

1.4.2.2. Aglomeración y funcionalización de la superficie .................. 40

1.4.2.3. Aplicaciones de los nanodiamantes .................................... 41

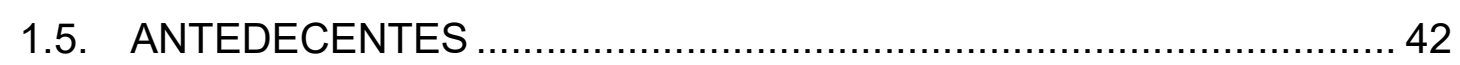

1.5.1. Líquidos iónicos como lubricantes y aditivos............................ 42

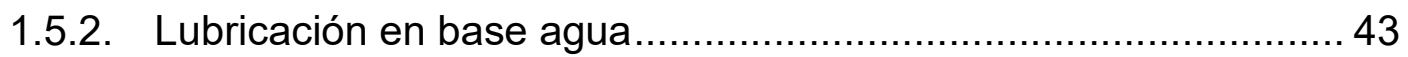

1.5.3. Nanofases de carbono en tribología ......................................... 44

1.5.4. Nanofluidos líquidos iónicos/nanofases de carbono .....................4 47

1.5.5. Nanocomposites, láminas delgadas y recubrimientos ................. 49

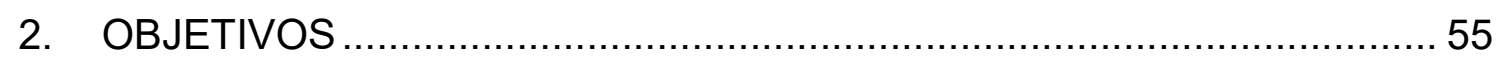

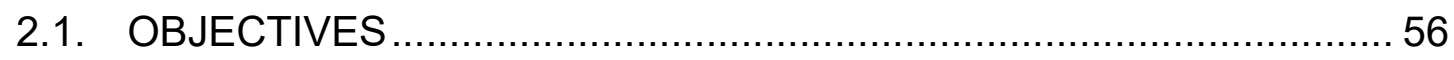

3. MATERIALES, EQUIPOS Y PROCEDIMIENTO EXPERIMENTAL ..........59

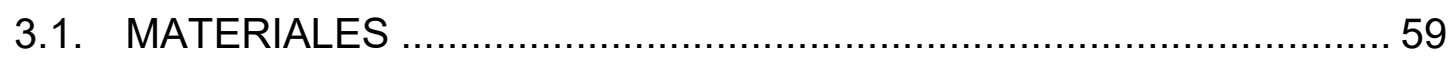

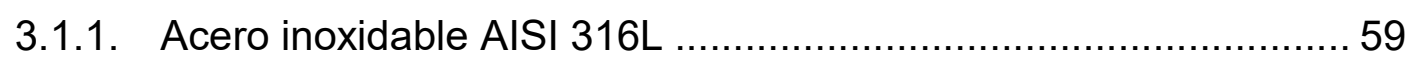

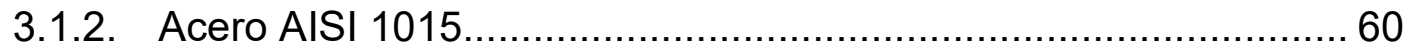

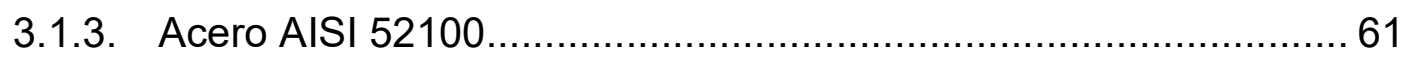

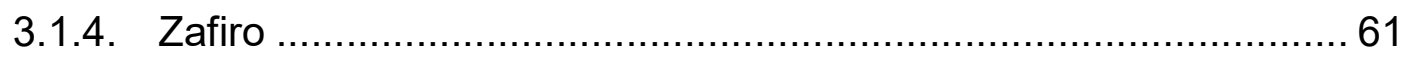

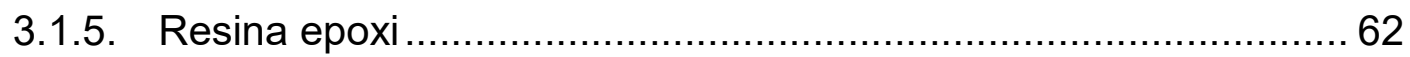

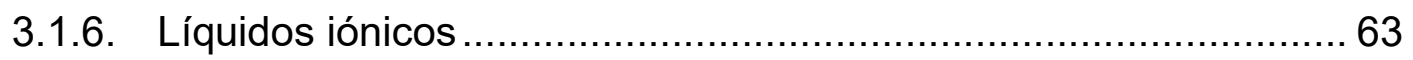

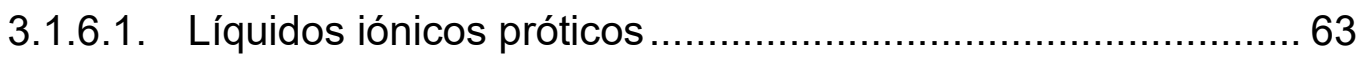

3.1.6.1.1. Estearato de bis(2-hidroxietil)amonio (DEs) ...............................63

3.1.6.1.2. Estearato de 2-hidroxietilamonio (MEs) ...................................... 66

3.1.6.1.3. Palmitato de bis(2-hidroxietil)amonio (DPa) .................................. 68

3.1.6.1.4. Succinato de di[bis(2-hidroxietil)amonio] (DSu)........................... 71

3.1.6.1.5. Citrato de tri[bis(2-hidroxietil)amonio] (DCi) ...............................72 
3.1.6.1.6. Oleato de bis(2-hidroxietil)amonio (DO)

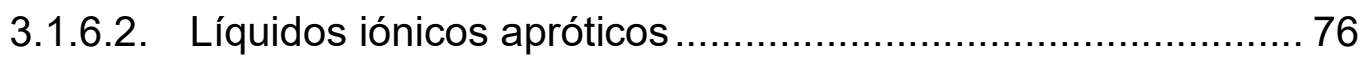

3.1.6.2.1. Dicianamida de 1-etil-3-metilimidazolio .................................... 76

3.1.6.2.2. Bis(trifluorometanosulfonil)imida de 1-etil-3-metilimidazolio .........77

3.1.6.2.3. Tetrafluoroborato de 1-octil-3-metilimidazolio ([OMIM]BF 4 ).........79

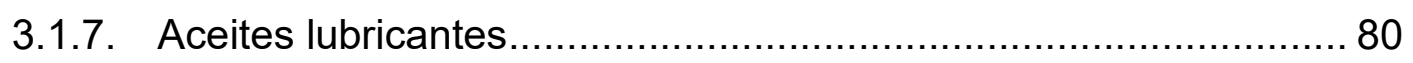

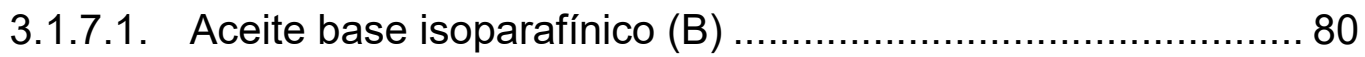

3.1.7.2. Aceite formulado de alto rendimiento $(\mathrm{MO}) \ldots \ldots \ldots \ldots \ldots \ldots \ldots . \ldots . \ldots . \ldots . \ldots$

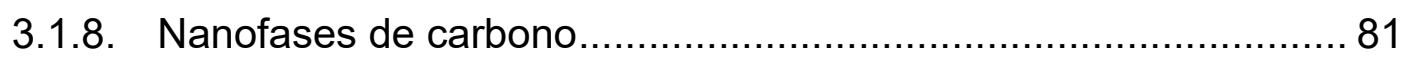

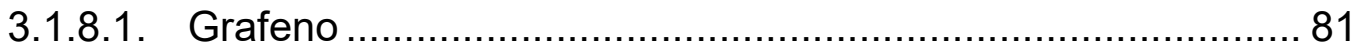

3.1.8.2. Nanodiamantes .................................................... 81

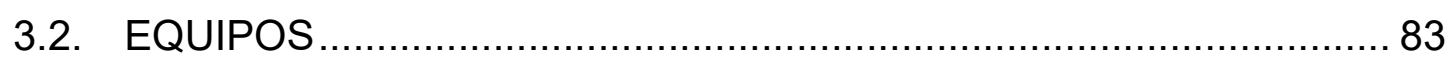

3.2.1. Equipos para la preparación de muestras ............................. 83

3.2.1.1. Balanza de precisión ............................................... 83

3.2.1.2. Cortadora de precisión ............................................ 84

3.2.1.3. Pulidora metalográfica ................................................ 84

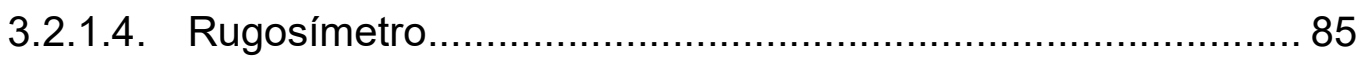

3.2.1.5. Homogeneizador ultrasónico....................................... 85

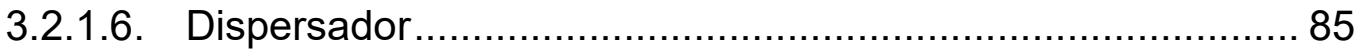

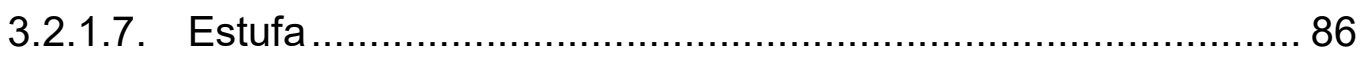

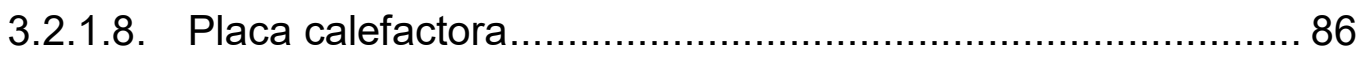

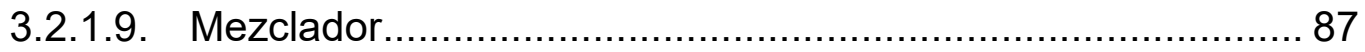

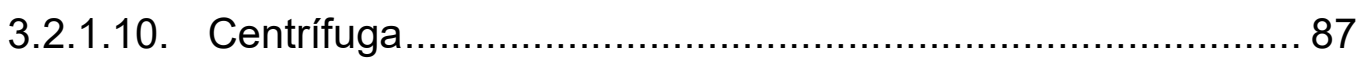

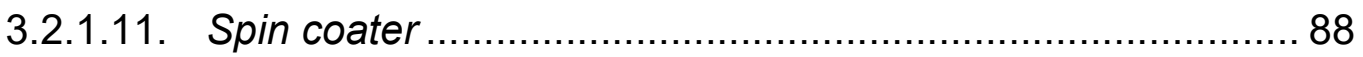


3.2.2. Equipos para caracterización y análisis 88

3.2.2.1. Espectrofotómetro infrarrojo (FTIR) ............................... 88

3.2.2.2. Calorímetro diferencial de barrido (DSC) ............................ 90

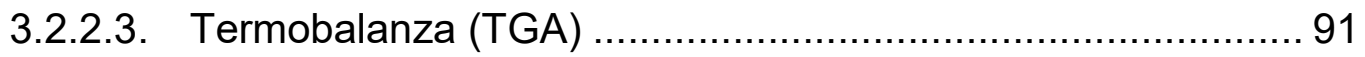

3.2.2.4. Analizador dinámico-mecánico (DMA) ............................... 92

3.2.2.5. Analizador de conductividad térmica................................... 93

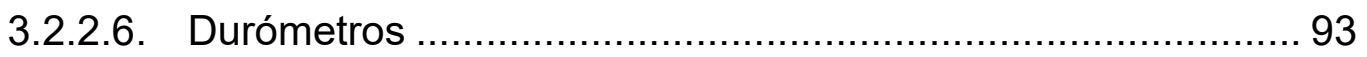

3.2.2.7. Medidor de ángulo de contacto ............................................. 94

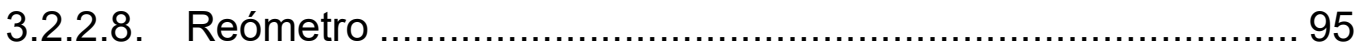

3.2.2.9. Medidores de $\mathrm{pH}$ y conductividad ........................................ 96

3.2.2.10. Analizador de parámetros semiconductores ......................96

3.2.2.11. Analizador de tamaño de partículas mediante dispersión por

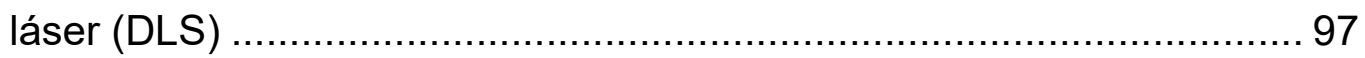

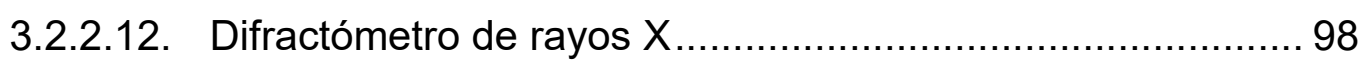

3.2.2.13. Interferómetro de película ultrafina .................................... 98

3.2.2.14. Microscopio de luz polarizada ......................................... 100

3.2.2.15. Microscopio electrónico de transmisión (TEM) ................... 101

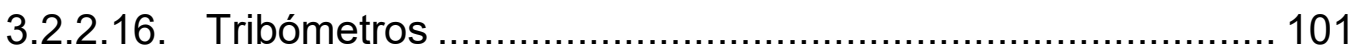

3.2.2.17. Equipo de ensayos de rayado ........................................ 104

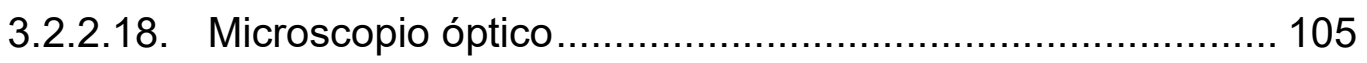

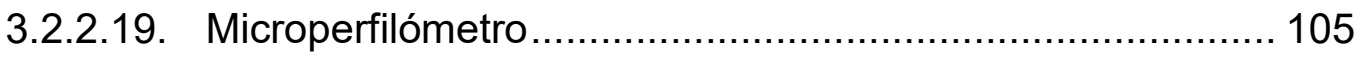

3.2.2.20. Microscopio electrónico de barrido (SEM) ......................... 106

3.2.2.21. Microscopio Raman confocal ......................................... 108 
3.2.2.22. Espectrómetro de fotoelectrones de rayos $X(X P S)$ 109

3.3. PROCEDIMIENTO EXPERIMENTAL 111

3.3.1. Lubricación con líquidos iónicos y/o nanofases de carbono 111

3.3.1.1. Preparación de nuevos lubricantes en base agua con aditivos derivados de ácidos grasos ........................................................ 111

3.3.1.1.1. Emulsiones de agua $+1 \%$ de líquido iónico. 111

3.3.1.1.2. Dispersiones de $0,1 \%$ de nanodiamantes en emulsiones de agua $+1 \%$ de líquido iónico.

3.3.1.2. Dispersiones con el líquido iónico DSu

3.3.1.3. Dispersiones de líquido iónico DCi con nanodiamantes

3.3.1.4. Dispersiones de líquidos iónicos apróticos derivados del catión 1-etil-3-metilimidazolio con grafeno 112

3.3.1.5. Dispersiones del líquido iónico tetrafluoroborato de 1-octil-3metilimidazolio y/o grafeno en aceites lubricantes

3.3.1.6. Preparación de capas finas.............................................. 113

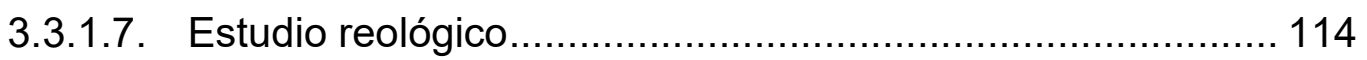

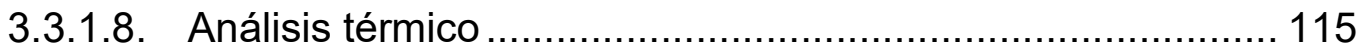

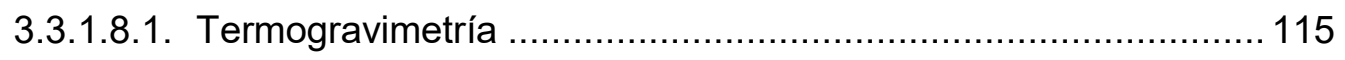

3.3.1.8.2. Calorimetría diferencial de barrido ........................................... 115

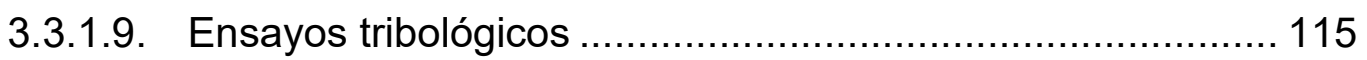

3.3.1.9.1. Preparación del sustrato metálico ........................................... 115

3.3.1.9.2. Estudio de la influencia de la velocidad .....................................116

3.3.1.9.3. Ensayos de lubricación externa en el contacto zafiro-acero inoxidable AISI 316L a velocidad constante.............................................. 120

3.3.1.10. Obtención de partículas de desgaste ............................... 122

3.3.2. Nuevos nanocomposites de matriz epoxi ............................... 122

3.3.2.1. Preparación de nuevos nanocomposites y recubrimientos de

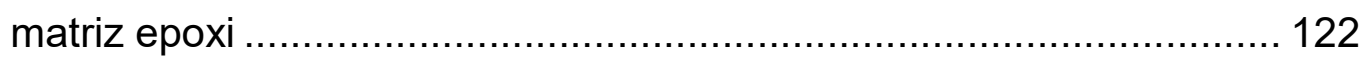


3.3.2.1.1. Preparación del nanocomposite de resina epoxi con un $9 \%$ de líquido iónico DCi (RE+9\%DCi). ....................................................... 122

3.3.2.1.2. Preparación de recubrimientos sobre resina epoxi ................... 123

3.3.2.1.3. Preparación de recubrimientos sobre acero AISI 1015 ............. 124

3.3.2.1.4. Preparación de nanocomposites en forma de films................... 125

3.3.2.2. Caracterización de los nanocomposites........................... 126

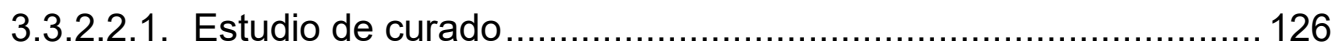

3.3.2.2.2. Propiedades térmicas .................................................... 127

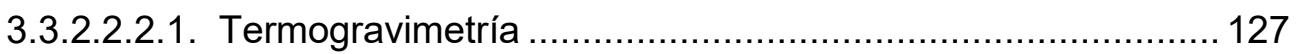

3.3.2.2.2.2. Calorimetría diferencial de barrido .................................. 127

3.3.2.2.3. Propiedades dinámico-mecánicas ...................................... 127

3.3.2.2.4. Ensayos tribológicos ................................................... 129

3.3.2.2.4.1. Ensayos de rayado ..................................................... 129

3.3.2.2.4.2. Ensayos tribológicos punzón sobre disco ......................... 131

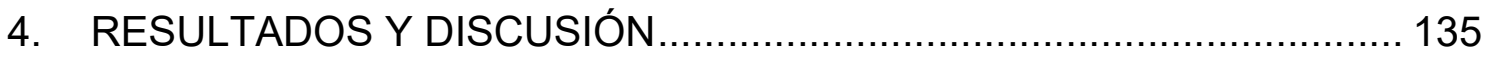

4.1. LUBRICACIÓN CON LÍQUIDOS IÓNICOS Y/O NANOFASES DE

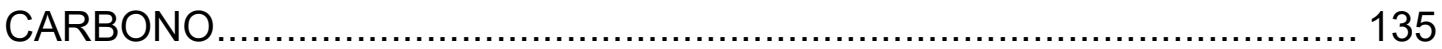

4.1.1. Lubricación base agua con aditivos derivados de ácidos grasos 135

4.1.1.1. Caracterización de las emulsiones y dispersiones.............. 135

4.1.1.1.1. Ángulo de contacto y tensión superficial ............................... 136

4.1.1.2. Medidas del tamaño de partícula.................................. 139

4.1.1.3. Estudio tribológico.............................................. 142

4.1.1.3.1. Medidas para la determinación del espesor de película lubricante y el coeficiente de fricción...................................................................... 142

4.1.1.3.2. Estudio de la influencia de la velocidad de giro ........................ 147

4.1.1.3.2.1. Comparativa de la evolución del coeficiente de fricción con la velocidad en el contacto AISI 316L-AISI 316 L....................................... 148

4.1.1.3.2.2. Comparativa de la evolución del coeficiente de fricción con la velocidad en el contacto AISI 52100-AISI 316L.................................... 151

4.1.1.3.2.3. Comparativa de la evolución del coeficiente de fricción con la velocidad en el contacto zafiro-AISI 316L......................................... 154

4.1.1.3.2.4. Estudio de las huellas de desgaste, mecanismos de desgaste y análisis superficial 155 
4.1.1.3.3. Estudio tribológico de emulsiones de cristales líquidos iónicos en agua en el contacto zafiro-AISI 316L a velocidad constante.

4.1.1.3.4. Estudio tribológico de dispersiones de nanodiamantes en emulsiones de cristales líquidos iónicos próticos en agua en el contacto zafiro-AISI 316 L a velocidad constante.

4.1.1.4. Conclusiones. 183

4.1.2. Dispersiones con el líquido iónico prótico DSu 185

4.1.2.1. Disolución de líquido iónico prótico DSu en agua 185

4.1.2.1.1. Ángulo de contacto 185

4.1.2.1.2. Estudio tribológico 186

4.1.2.2. Dispersiones del líquido iónico prótico DSu con grafeno ..... 194

4.1.2.2.1. Caracterización de las dispersiones 194

4.1.2.2.1.1. Análisis térmico 194

4.1.2.2.1.2. Estudio reológico. 195

4.1.2.2.1.3. Ángulo de contacto 198

4.1.2.2.1.4. Espectroscopía Raman 199

4.1.2.2.2. Estudio tribológico 202

4.1.2.3. Conclusiones. 207

4.1.3. Dispersiones de líquido iónico prótico DCi con nanodiamantes . 208

4.1.3.1. Caracterización de la dispersión .................................... 208

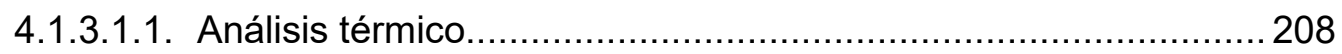

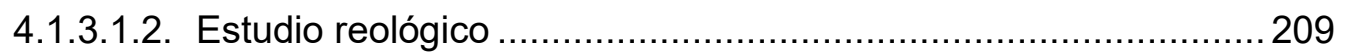

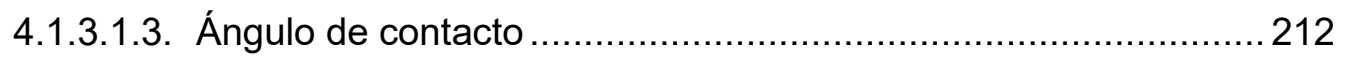

4.1.3.2. Estudio tribológico................................................ 213

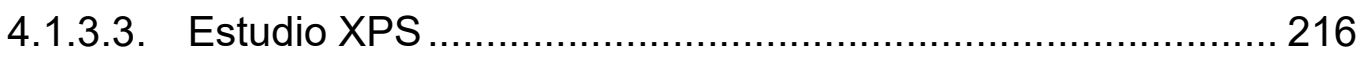

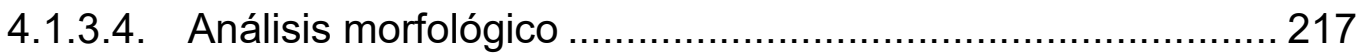

4.1.3.5. Conclusiones.................................................... 219

4.1.4. Dispersiones de líquidos iónicos apróticos derivados del catión 1etil-3-metilimidazolio con grafeno.............................................. 220 
4.1.4.1. Caracterización de las dispersiones................................. 220

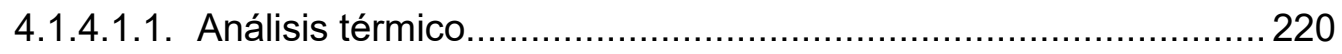

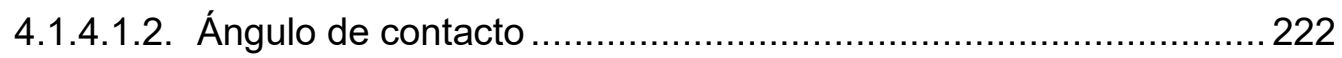

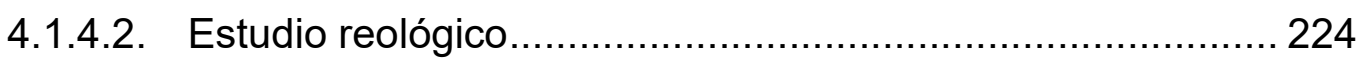

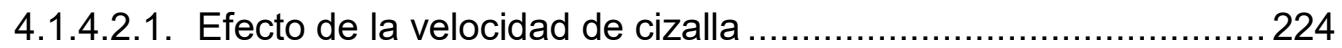

4.1.4.2.2. Valores de viscosidad en función de la temperatura ................... 225

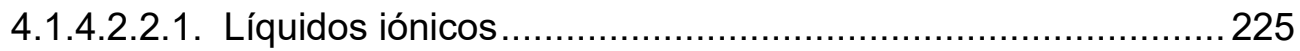

4.1.4.2.2.2. Dispersiones líquido iónico+grafeno …………………...... 227

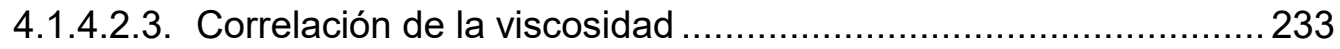

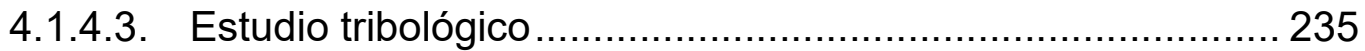

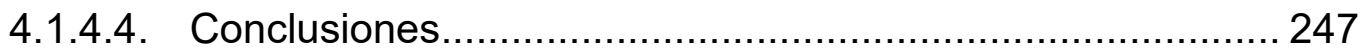

4.1.5. Dispersiones del líquido iónico tetrafluoroborato de 1-octil-3metilimidazolio y/o grafeno en aceites lubricantes ............................... 248

4.1.5.1. Dispersiones en aceite base isoparafínico libre de aditivos . 248

4.1.5.2. Dispersiones en aceite lubricante de alto rendimiento

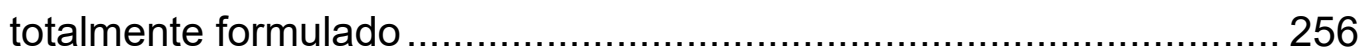

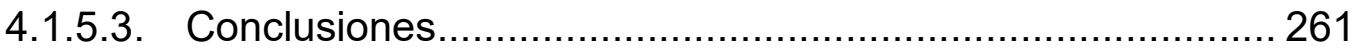

\subsection{ESTUDIO DE NUEVOS NANOCOMPOSITES DE MATRIZ EPOXI. 262}

4.2.1. Estudio tribológico de un nanocomposite de resina epoxi con un

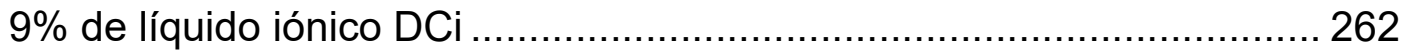

4.2.1.1. Estudio de curado del nuevo nanocomposite...................... 262

4.2.1.1.1. Estudio del proceso de curado mediante calorimetría diferencial de

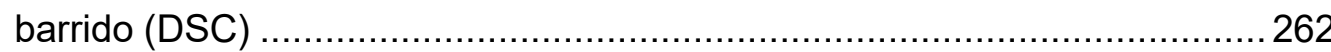

4.2.1.1.2. Estudio del proceso de curado mediante espectroscopía infrarroja por transformada de Fourier (FTIR) .................................................. 264

4.2.1.2. Distribución del líquido iónico prótico en la matriz epoxi ....... 266

4.2.1.3. Caracterización del nanocomposite .................................. 270

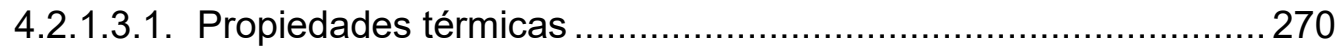

4.2.1.3.1.1. Calorimetría diferencial de barrido ...................................... 270 


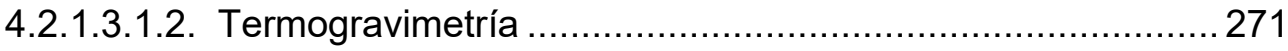

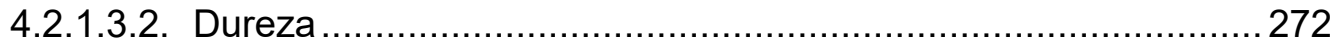

4.2.1.3.3. Propiedades dinámico-mecánicas ........................................ 272

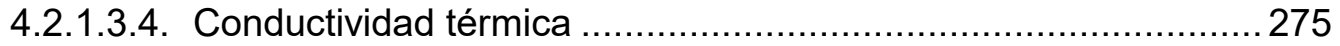

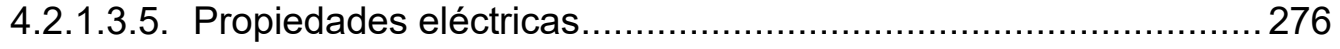

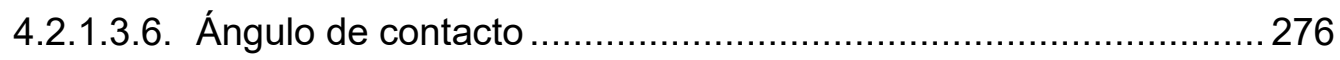

4.2.1.4. Ensayos tribológicos punzón sobre disco ........................ 277

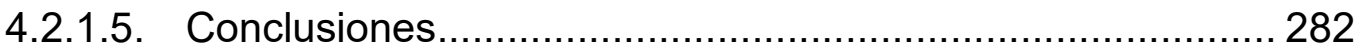

4.2.2. Caracterización y estudio tribológico de recubrimientos y films de resina epoxi con nanofases y nanofluidos.

4.2.2.1. Recubrimientos de resina epoxi con nanofases y nanofluidos sobre resina epoxi 282

4.2.2.1.1. Medida de la rugosidad y el espesor de los recubrimientos sobre resina epoxi 283

4.2.2.1.1.1. Espesor del recubrimiento de resina epoxi sin aditivos (RE) sobre resina epoxi 283

4.2.2.1.1.2. Espesor de recubrimiento de resina epoxi y grafeno (RE+0,05\%G) sobre resina epoxi. 284

4.2.2.1.1.3. Espesor de recubrimiento de resina epoxi y líquido iónico $\left(\mathrm{RE}+9 \%\left[\mathrm{OMIM}_{\mathrm{B}} \mathrm{F}_{4}\right)\right.$ sobre resina epoxi

4.2.2.1.1.4. Espesor de recubrimiento de resina epoxi, grafeno y líquido iónico $\left(\mathrm{RE}+9 \%\left(\left[\mathrm{OMIM}_{\mathrm{B}} \mathrm{BF}_{4}+0,1 \% \mathrm{G}\right)\right)\right.$ sobre resina epoxi .......................286

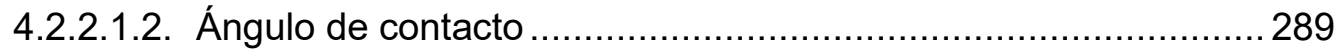

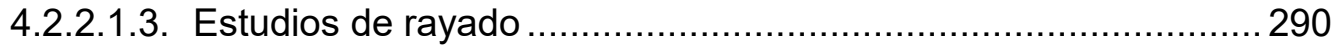

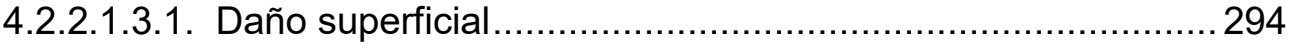

4.2.2.2. Recubrimientos de resina epoxi con nanofases y nanofluidos sobre acero AISI 1015................................................................. 296

4.2.2.2.1. Recubrimientos de una capa ............................................... 296

4.2.2.2.1.1. Medidas del espesor del recubrimiento ..............................296

4.2.2.2.1.2. Medidas del ángulo de contacto ........................................ 297

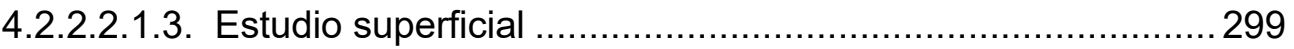

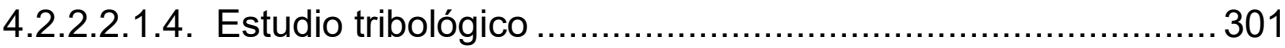

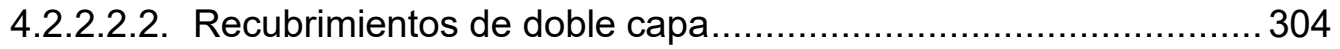

4.2.2.2.2.1. Espesor de los recubrimientos........................................ 304 


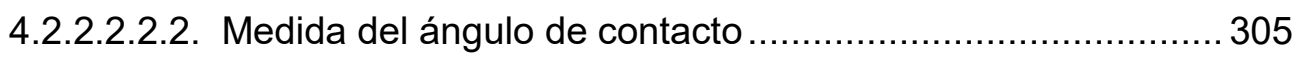

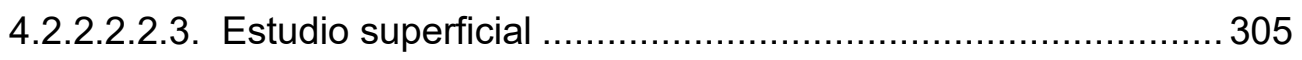

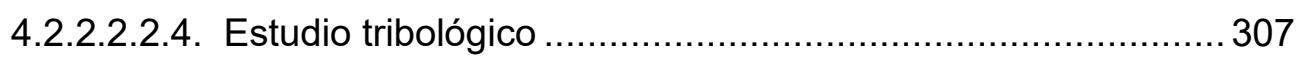

4.2.2.3. Caracterización de distintos nanocomposites de matriz epoxi en forma de film .................................................................. 311

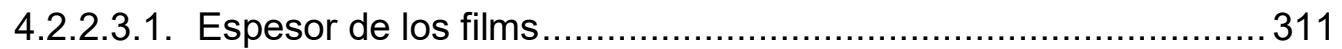

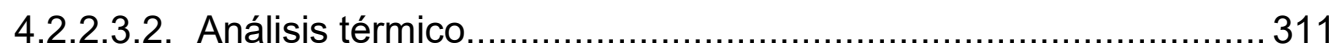

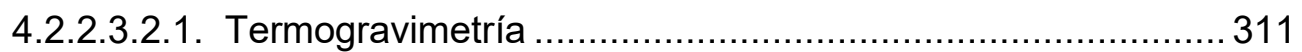

4.2.2.3.2.2. Calorimetría diferencial de barrido ...................................... 313

4.2.2.3.3. Análisis dinámico-mecánico .................................................. 314

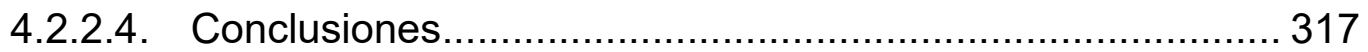

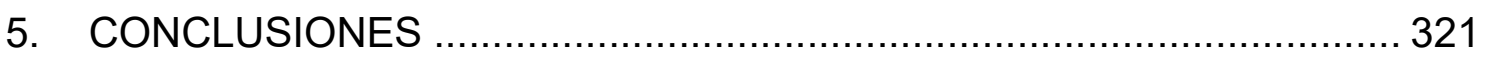

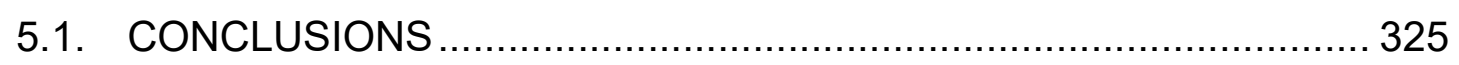

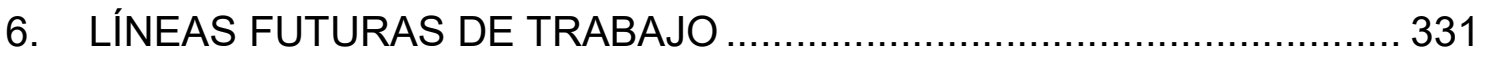

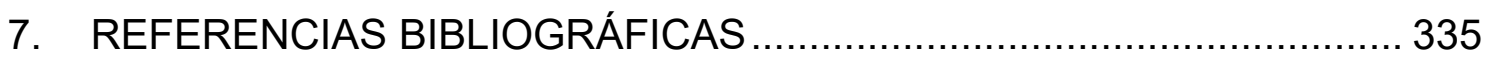

7.1. ANÁLISIS DE LA BIBLIOGRAFÍA UTILIZADA .......................... 356

7.2. PRODUCCIÓN CIENTÍFICA DERIVADA DE LA TESIS ................... 357 


\section{ÍNDICE DE FIGURAS}

Figura 1. Relieve egipcio. Primer uso de lubricantes documentado.....

Figura 2. Bocetos del estudio del efecto de la presión de contacto o del área de contacto.

Leonardo da Vinci. (Madrid I 173v, c. 1493-7, Biblioteca Nacional, Madrid) [11] ...................... 5

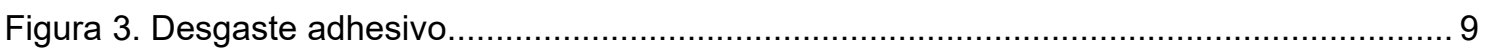

Figura 4. Desgaste abrasivo. a) Abrasión de dos cuerpos; b) Abrasión de tres cuerpos........... 10

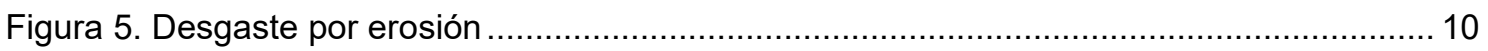

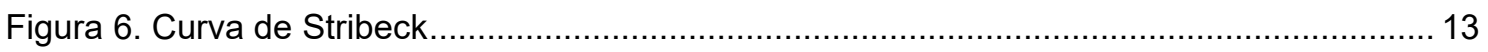

Figura 7. Mapa de lubricación propuesto por Luo [26] .............................................. 15

Figura 8. Modelo del régimen de lubricación en película fina (TFL) ................................... 15

Figura 9. Principales estructuras catiónicas de los líquidos iónicos ..................................... 17

Figura 10. Aplicaciones de los líquidos iónicos ....................................................... 18

Figura 11. Evolución del número de publicaciones científicas sobre el uso de líquidos iónicos

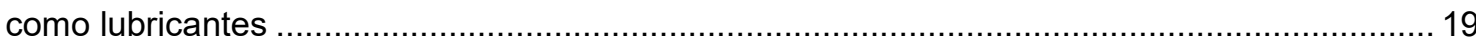

Figura 12. Interacción de los líquidos iónicos $[\mathrm{BMIN}]^{+}$y $[\mathrm{OMIM}]^{+}$con la superficie metálica en

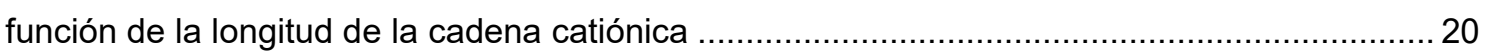

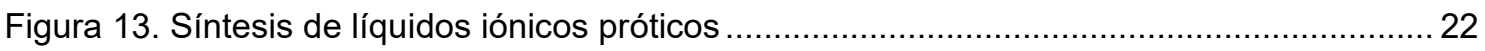

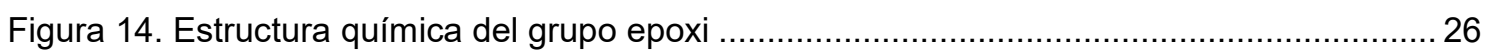

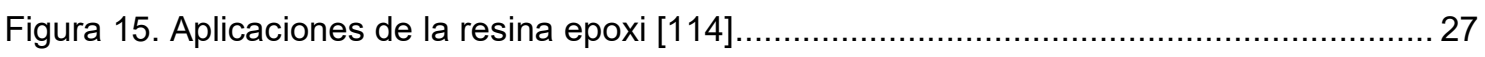

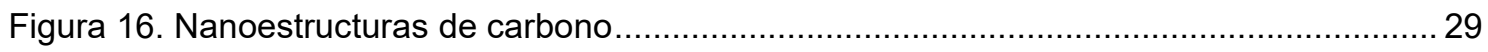

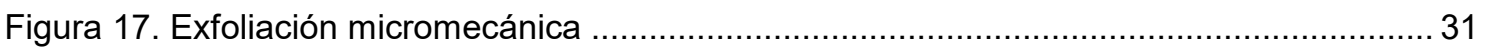

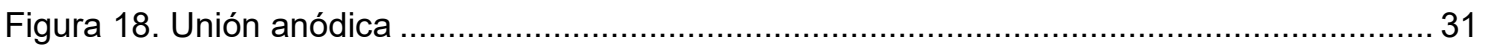

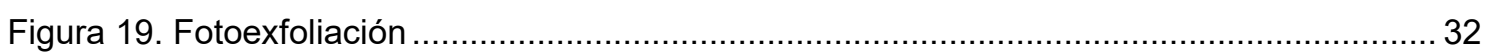

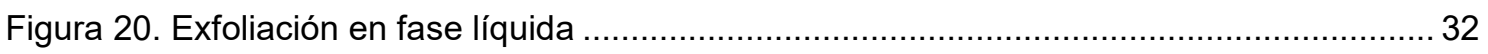

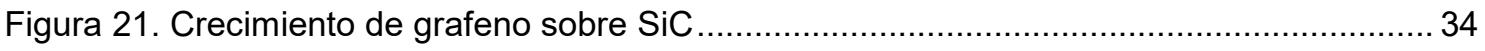

Figura 22. Crecimiento en metales por precipitación....................................................... 34

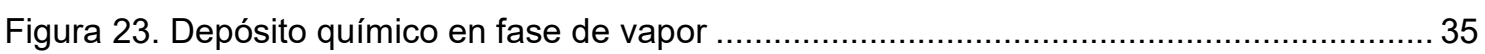

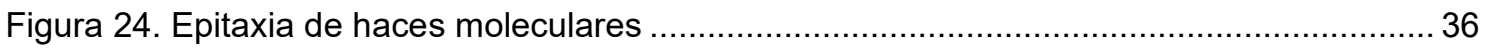

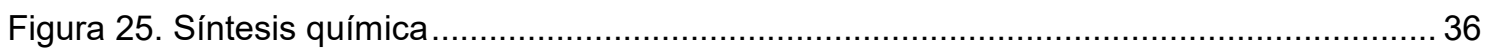

Figura 26. Esquema de la secuencia de formación de nanodiamantes [193] .......................... 39

Figura 27. Comparativa de la evolución del coeficiente de friccion con la distancia para el líquido iónico MSu, disolución de Agua+1\%MSu y MSu en capa fina [235].....

Figura 28. Simulación de la evolución temporal de la fricción para DLC deslizando sobre una superficie de grafeno-nanodiamante en ambiente seco y húmedo [237] ............................. 45

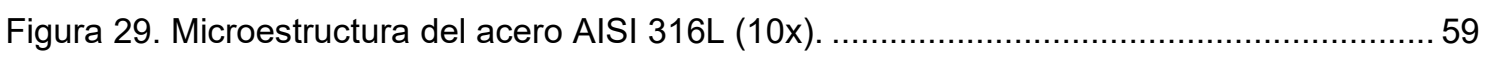

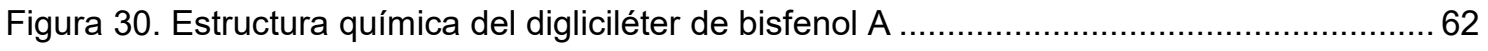

Figura 31. Mecanismo de formación de resina epoxi a partir de un agente de curado con grupos

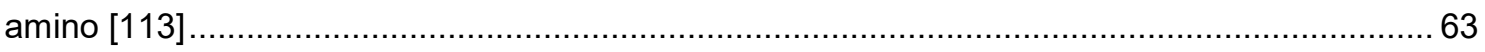

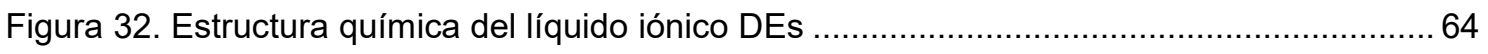

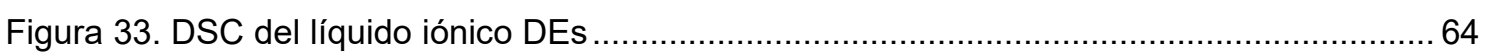

Figura 34. Micrografías obtenidas para DEs (20x) mediante microscopía de luz polarizada:

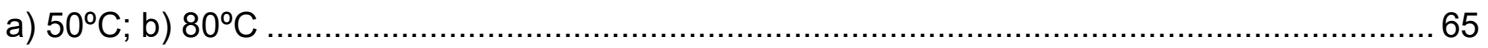

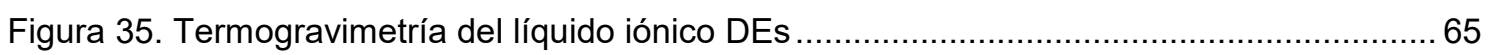

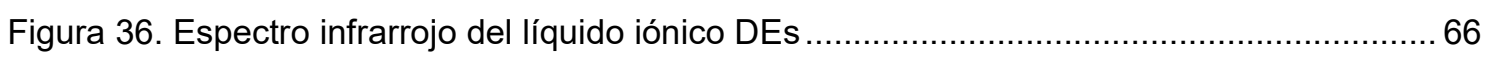




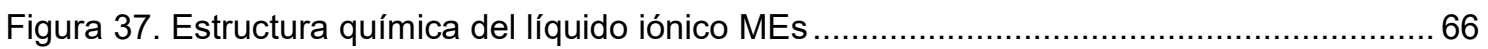

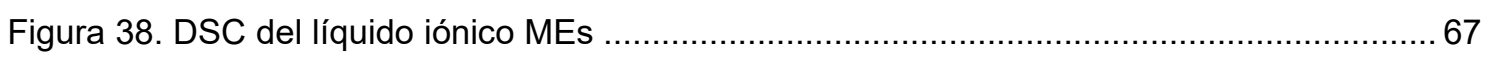

Figura 39. Micrografías obtenidas para MEs (20x) mediante microscopía de luz polarizada:

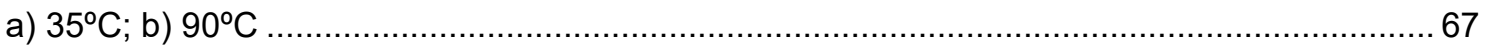

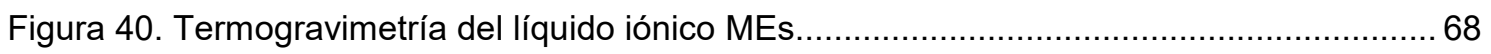

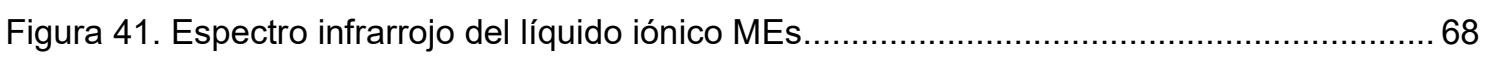

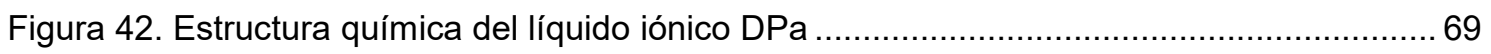

Figura 43. Termogravimetría del líquido iónico $\mathrm{DPa}$

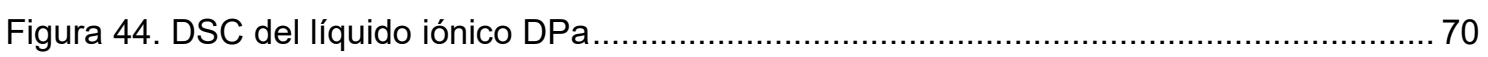

Figura 45. Micrografías obtenidas para DPa (20x) mediante microscopía de luz polarizada:

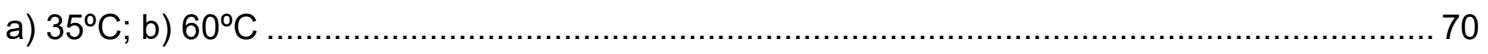

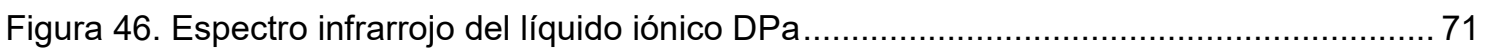

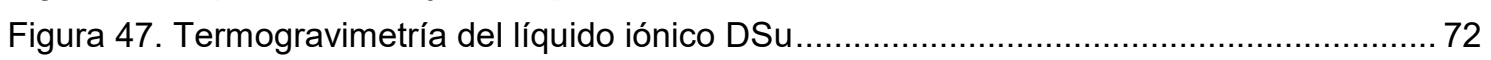

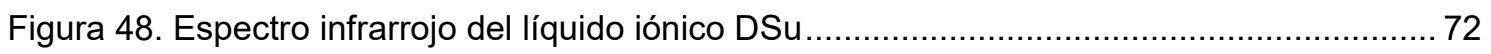

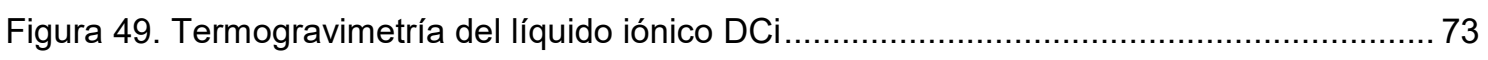

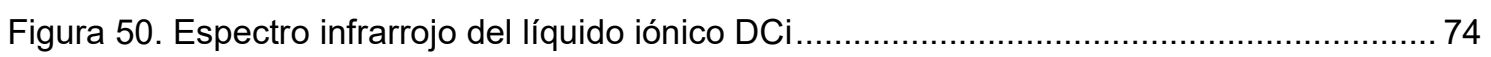

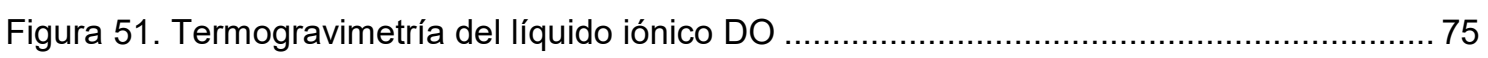

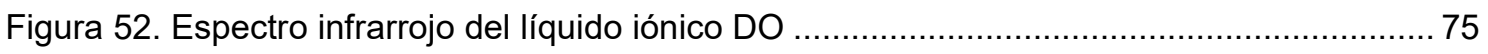

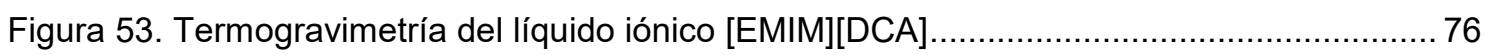

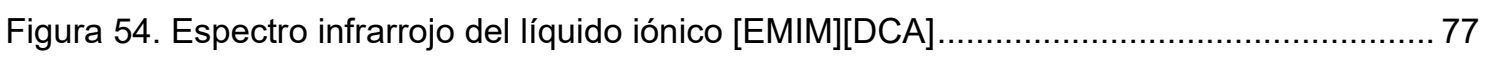

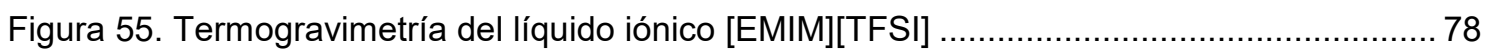

Figura 56. Espectro infrarrojo del líquido iónico [EMIM][TFSI] …............................................... 78

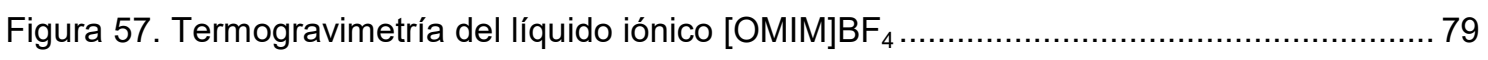

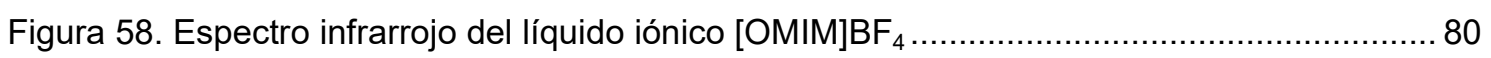

Figura 59. Estructura química del aceite base isoparafínico libre de aditivos ............................. 80

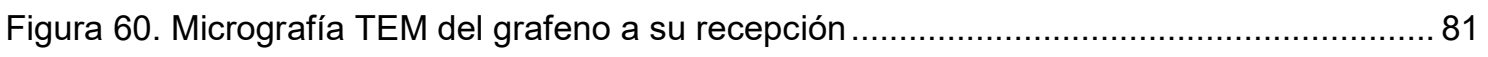

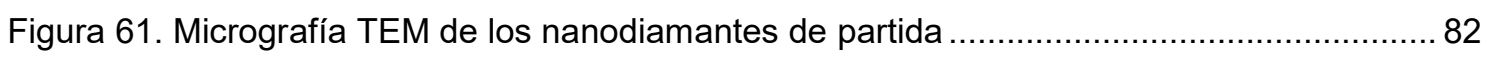

Figura 62. Espectro de difracción de rayos-X de los nanodiamantes de partida ......................... 83

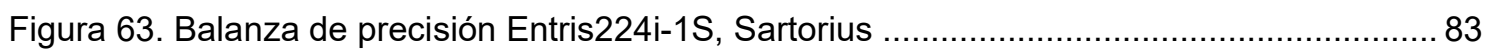

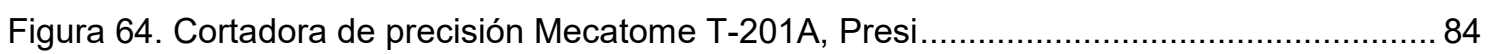

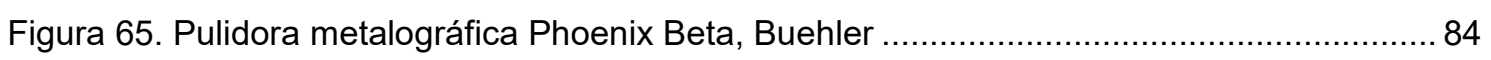

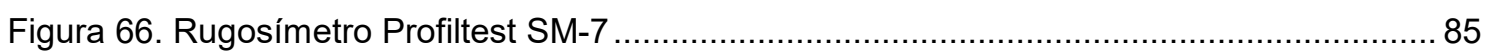

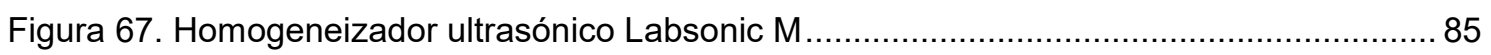

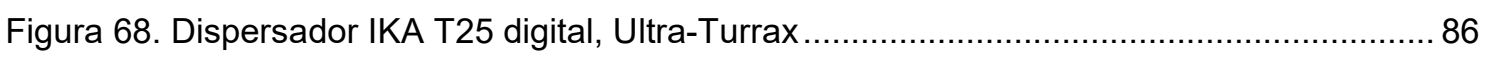

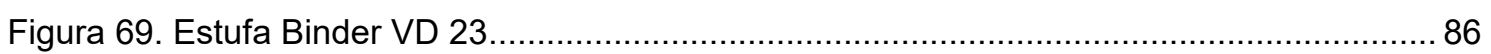

Figura 70. Agitador magnético con calefacción y placa calefactora IKA C-MAG HS7 ................ 87

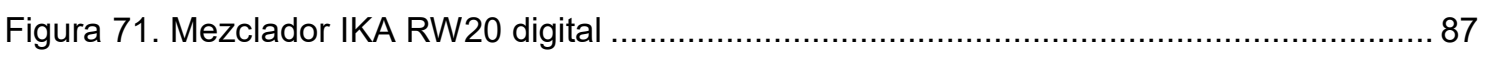

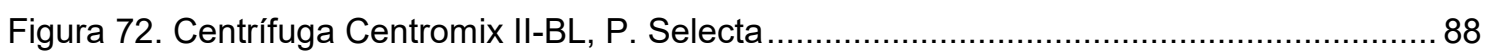

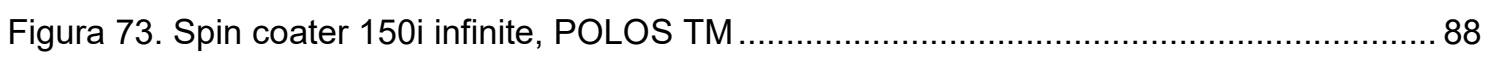

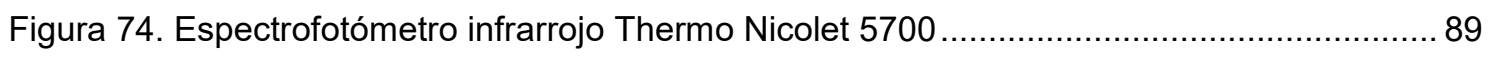

Figura 75. DSC 822e Mettler Toledo con detalle del portamuestras ............................................ 91

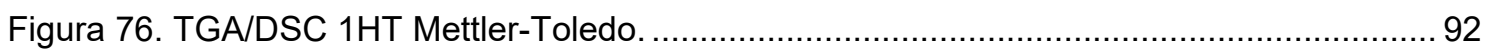

Figura 77. Analizador dinámico-mecánico DMA Q800, TA Instruments.................................... 92

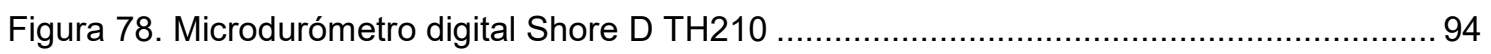

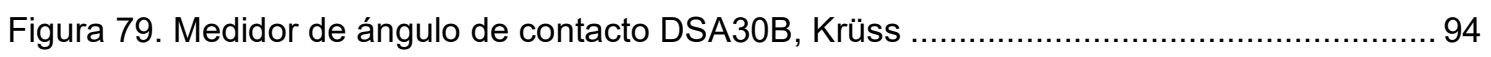




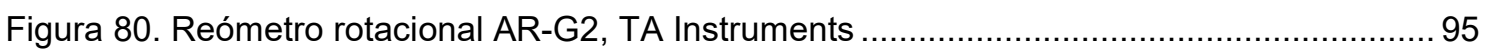

Figura 81. Analizador de parámetros semiconductores B1500A, Agilent .................................. 97

Figura 82. Difractómetro de rayos X D8 Advance, Bruker ...................................................... 98

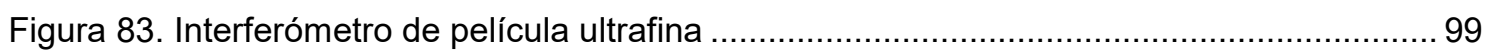

Figura 84. Esquema del equipo de interferometría de película ultrafina ....................................99

Figura 85. Microscopio electrónico de transmisión JEM-2010, JEOL ..................................... 101

Figura 86. Tribómetro punzón sobre disco ISC-200, Implant Sciences................................... 102

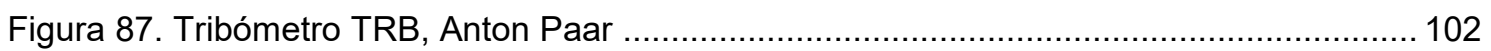

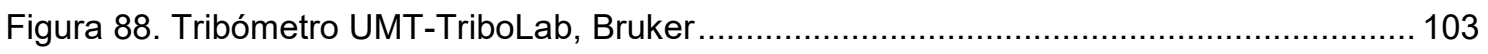

Figura 89. a) Tribómetro MT/30/SCMT, Microtest; b) Horno del tribómetro .............................. 104

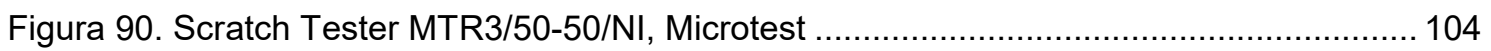

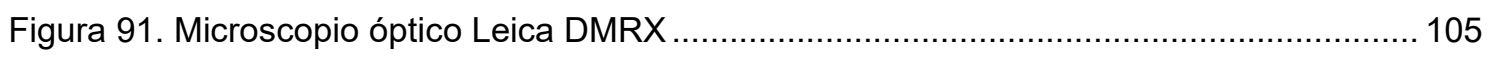

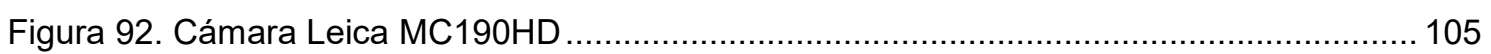

Figura 93. Microperfilómetro óptico Talysurf CLI 500, Taylor Hobson..................................... 106

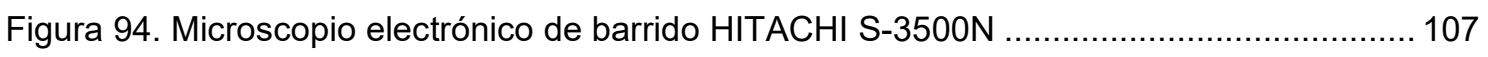

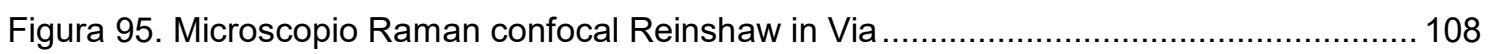

Figura 96. Espectrómetro fotoelectrónico de rayos X K-Alpha, Thermo-Scientific.................... 110

Figura 97. Procedimiento de obtención de capas finas en estufa ......................................... 113

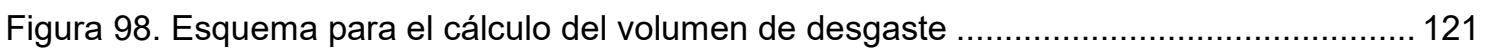

Figura 99. Esquema para el cálculo de la pérdida de material debida al desgaste ................. 122

Figura 100. Procedimiento de obtención de recubrimientos mediante spin coating ................ 124

Figura 101. Films de los nanocomposites: a) RE; b) RE+9\%[OMIM]BF ; c) RE+0,05\%G;

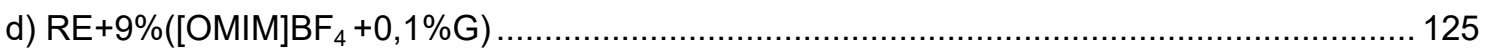

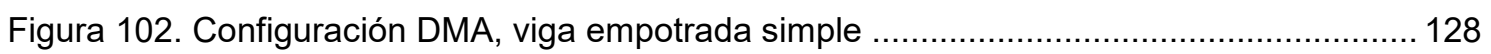

Figura 103. Configuración DMA, módulo de tensión para films.......................................... 129

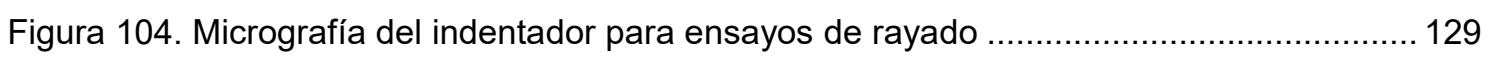

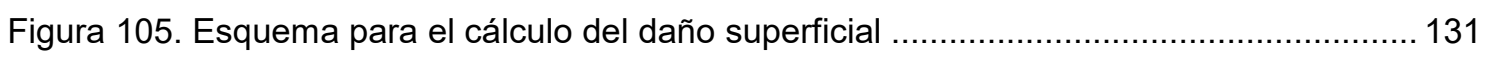

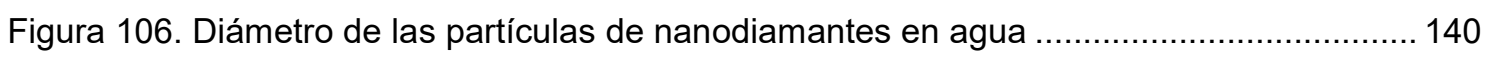

Figura 107. Diámetro de las partículas de la emulsión WDPa ............................................. 141

Figura 108. Diámetro de las partículas de la emulsión NDWDPa .......................................... 141

Figura 109. Evolución del espesor de película $\left(\Delta \mathrm{h}_{\mathrm{opt}}\right)$ con el número de deslizamientos

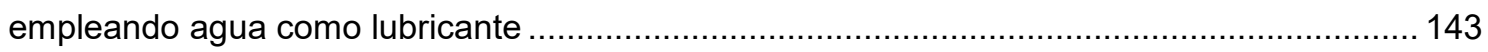

Figura 110. Evolución del espesor de película $\left(\Delta \mathrm{h}_{\mathrm{opt}}\right)$ con el número de deslizamientos

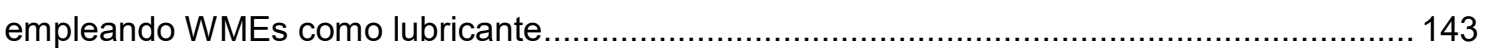

Figura 111. Evolución del espesor de película $\left(\Delta \mathrm{h}_{\mathrm{opt}}\right)$ con el número de deslizamientos empleando WDEs como lubricante....

Figura 112. Evolución del espesor de película ( $\Delta$ hopt) con el número de deslizamientos empleando WDPa como lubricante.

Figura 113. Evolución del espesor de película ( $\Delta$ hopt) con el número de deslizamientos empleando NDWDPa como lubricante

Figura 114. Evolución del coeficiente de fricción con el número de deslizamientos empleando agua como lubricante

Figura 115. Evolución del coeficiente de fricción con el número de deslizamientos empleando WMEs como lubricante 
Figura 116. Evolución del coeficiente de fricción con el número de deslizamientos empleando WDEs como lubricante.

Figura 117. Evolución del coeficiente de fricción con el número de deslizamientos empleando WDPa como lubricante. 146

Figura 118. Evolución del coeficiente de fricción con el número de deslizamientos empleando NDWDPa como lubricante 146

Figura 119. Evolución del coeficiente de fricción y del espesor de película para agua, WDEs, WMEs, WDPa y NDWDPa.

Figura 120. Curva COF vs. velocidad para agua, WMEs, WDEs, WDPa y NDWDPa en el contacto AISI 316L-AISI 316L

Figura 121. Porcentaje de resistencia eléctrica en el contacto AISI 316L-AISI 316L: a) Agua;

b) WMEs; c) WDEs; d) WDPa; e) NDWDPa. 150

Figura 122. Curva COF vs. velocidad para agua, WMEs, WDEs, WDPa y NDWDPa en el contacto AISI 52100-AISI 316L

Figura 123. Porcentaje de resistencia eléctrica en el contacto AISI 52100-AISI 316L: a) Agua;

b) WMEs; c) WDEs; d) WDPa; e) NDWDPa.

Figura 124. Curva COF vs. velocidad para agua, WMEs, WDEs, WDPa y NDWDPa en el contacto zafiro-AISI 316L

Figura 125. Micrografías SEM de la huella de desgaste empleando agua como lubricante en los contactos: a) AISI 316L-AISI 316L; b) AISI 52100-AISI 316L; c) Zafiro-AISI 316L

Figura 126. a) Imagen de perfilometría óptica de la huella de desgaste obtenida tras ensayo con agua en el contacto AISI 316L-AISI 316L; b) Sección transversal; c) Huella tras contacto con bola de AISI 52100; d) Huella tras contacto con bola de zafiro .

Figura 127. a) Bola de AISI 316L tras ensayo tribológico sobre disco de AISI 316L empleando

agua como lubricante; b) Magnificación de la bola de AISI 316L

Figura 128. Tasas de desgaste tras ensayos para la obtención de curvas COF vs. velocidad empleando agua, WMEs, WDEs, WDPa y NDWDPa en el contacto AISI 52100-AISI 316L ... 158 Figura 129. Micrografías SEM de la huellas de desgaste empleando WDEs como lubricante en Ios contactos: a) AISI 52100-AISI 316L; b) AISI 316L-AISI 316L; c) Zafiro-AISI 316L 159 Figura 130. a) Bola de zafiro tras ensayo con WDEs; b) Detalle de la bola de zafiro; c) Mapa elemental de Al y Fe; d) Mapa elemental de Al y C 160

Figura 131. Micrografías SEM de las huellas de desgaste empleando WMEs como lubricante.

a) Contacto 5200-AISI 316L; b) Contacto AISI 316L-AISI 316L; c) Contacto zafiro-AISI 316L 162 Figura 132. Micrografías SEM de las huellas de desgaste y topografía superficial empleando WDPa como lubricante. a) Contacto 5200-AISI 316L; b) Contacto AISI 316L-AISI 316L;

c) Contacto zafiro-AISI 316L 163

Figura 133. a) Micrografía SEM de la bola tras ensayo AISI 316L-AISI 316L empleando WDPa como lubricante; b) Mapa elemental de Fe y $\mathrm{C}$ de la bola. 164

Figura 134. a) Micrografía SEM de la huella de desgaste tras ensayo AISI 316L-AISI 316L empleando NDWDPa como lubricante; b) Detalle de la bola de acero AISI 316L ................... 164 Figura 135. Tasas de desgaste tras curvas COF vs. velocidad empleando agua, WMEs, WDEs, WDPa y NDWDPa en el contacto AISI 316L-AISI 316L 165 Figura 136. a) Micrografía SEM de la huella de desgaste tras ensayo en el contacto acero AISI 52100-316L empleando NDWDPa como lubricante; b) Topografía superficial ..... 165 
Figura 137. Bola de acero AISI 52100 y mapas elementales tras ensayo en el contacto acero AISI 52100-316L empleando NDWDPa como lubricante.

Figura 138. Tasas de desgaste tras obtención de curvas COF vs. velocidad empleando agua, WMEs, WDEs, WDPa y NDWDPa en el contacto zafiro-AISI 316L 166

Figura 139. Evolución del coeficiente de fricción empleando WDEs, WMEs, WDPa y agua como lubricantes tras ensayos en el contacto zafiro-AISI 316 L a velocidad constante. 167

Figura 140. Topografía superficial y sección transversal de las huellas de desgaste sobre acero AISI 316L tras lubricación con agua, WDEs, WMEs y WDPa a velocidad constante 169

Figura 141. a) Micrografía SEM de la huella desgaste sobre AISI 316L tras lubricación con

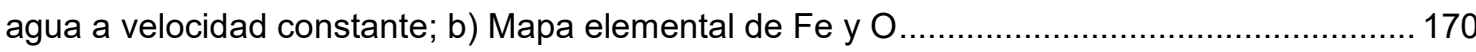

Figura 142. Análisis en línea de Fe y O sobre la huella de desgaste...................................... 171

Figura 143. Micrografía SEM y análisis puntual de las partículas de desgaste ....................... 171

Figura 144. a) Micrografía SEM de la huella de desgaste sobre AISI 316L tras lubricación con WDES a velocidad constante; b) Detalle de la huella; c) Mapa elemental de Fe y O

Figura 145. a) Micrografía SEM de la huella de desgaste sobre AISI 316L tras lubricación con WMES a velocidad constante; b) Mapa elemental de Fe y $\mathrm{O}$

Figura 146. a) Micrografía SEM de la huella de desgaste sobre AISI 316L tras lubricación con WDPa a velocidad constante; b) Mapa elemental de Fe y $\mathrm{O}$

Figura 147. Análisis en línea de $\mathrm{Fe}, \mathrm{O}$ y C cruzando la huella de desgaste tras lubricación con

WDPa

Figura 148. Espectro EDX dentro de la huella de desgaste tras lubricación con WDPa ......... 174

Figura 149. Análisis XPS del líquido iónico MEs

Figura 150. Evolución del coeficiente de fricción con la distancia para NDWDEs, NDWMEs, NDWDPa y agua en ensayos en el contacto zafiro-AISI 316L a velocidad constante .............. 177 Figura 151. Probeta AISI 316L tras $1000 \mathrm{~m}$ de ensayo usando NDWDPa como lubricante .... 178 Figura 152. Probeta AISI $316 \mathrm{~L}$ tras $1500 \mathrm{~m}$ de ensayo usando NDWDPa como lubricante.... 178 Figura 153. Evolución del coeficiente de fricción para NDWDEs, NDWMEs y NDWDPa tras ensayos a velocidad constante $(1000 \mathrm{~m})$.

Figura 154. Topografía superficial y sección transversal de las huellas de desgaste sobre acero AISI 316L tras lubricación con NDWDEs, NDWMEs y NDWDPa a velocidad constante. 180 Figura 155. a) Micrografía SEM de la huella de desgaste sobre AISI 316L tras lubricación con NDWDEs a velocidad constante; b) Mapa elemental de Fe; c) Mapa elemental de C;

d) Mapa elemental de $\mathrm{O}$

Figura 156. a) Micrografía SEM de la huella de desgaste sobre AISI 316L tras lubricación con NDWMEs a velocidad constante; b) Mapa elemental de Fe; c) Mapa elemental de C;

d) Mapa elemental de $\mathrm{O}$

Figura 157. a) Micrografía SEM de la huella de desgaste sobre AISI 316L tras lubricación con NDWDPa a velocidad constante; b) Mapa elemental de Fe; c) Mapa elemental de C;

d) Mapa elemental de O

Figura 158. Evolución del coeficiente de fricción con la distancia de deslizamiento para DSu,

Agua $+1 \%$ DSu y Capa fina de Agua $+1 \%$ DSu. 186

Figura 159. Tasas de desgaste sobre discos de acero inoxidable obtenidas tras lubricación con DSu y Agua $+1 \%$ DSu en capa fina y película gruesa 188 Figura 160. Perfiles superficiales en 3D de las huellas de desgaste y sección transversal tras lubricación con DSu, Agua+1\%DSu y capa fina de agua+1\%DSu. 
Figura 161. a) Micrografía SEM de la huella de desgaste tras lubricación con DSu. Mapas

elementales: b) Hierro; c) Oxígeno; d) Carbono . 189

Figura 162. a) Micrografía SEM de la huella de desgaste tras lubricación con Agua+1\%DSu;

b) Mapa elemental de Fe, $\mathrm{C}$ y $\mathrm{O}$ 190

Figura 163. a) Micrografía SEM de la huella de desgaste tras lubricación con capa fina de Agua+1\%DSu; b) Mapa elemental de Fe, C y O .

Figura 164. Espectro Raman del líquido iónico DSu

Figura 165. Espectro Raman de una zona del interior de la huella de desgaste tras lubricación con capa fina agua $+1 \% \mathrm{DS}$.

Figura 166. Evolución de la pérdida de peso con la temperatura para DSu, DSu+0,1\%G y

DSu+0,05\%G 195

Figura 167. Evolución de la viscosidad con la velocidad de cizalla a $25^{\circ} \mathrm{C}$ para DSu y sus dispersiones con grafeno

Figura 168. Evolución de la viscosidad con la velocidad de cizalla a $40^{\circ} \mathrm{C}$ para DSu y sus dispersiones con grafeno

Figura 169. Evolución de la viscosidad con la velocidad de cizalla a $100^{\circ} \mathrm{C}$ para DSu y sus dispersiones con grafeno

Figura 170. Espectro Raman de grafeno

Figura 171. Comparativa de los espectros Raman de grafeno, partículas DSu+0,1\%G y

partículas DSu+0,05\%G

Figura 172. Evolución del coeficiente de fricción con la distancia de deslizamiento para DSu,

DSu+0, $1 \%$ G y DSu+0,05\%G 202

Figura 173. Topografía superficial y perfil transversal de las huellas de desgaste obtenidas tras lubricación con DSu, DSu+0,1\%G y DSu+0,05\%G

Figura 174. Micrografía SEM y mapas elementales de hierro, oxígeno y carbono de la huella de desgaste tras lubricación con DSu+0,1\%G. 204

Figura 175. Micrografía SEM y mapas elementales de hierro, oxígeno y carbono de la huella de

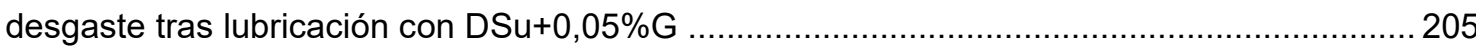

Figura 176. Espectros Raman en la huella de desgaste de DSu+0,05\%G, DSu y grafeno..... 205 Figura 177. Micrografías TEM de las partículas de grafeno de DSu+0,1\%G; a) antes del ensayo tribológico; b) después del ensayo 206

Figura 178. Micrografías TEM de las partículas de grafeno de DSu+0,05\%G; a) antes del ensayo tribológico; b) después del ensayo.

Figura 179. Termogravimetría de DCi y ND+DCi

Figura 180. Evolución de la viscosidad con la velocidad de cizalla a $25^{\circ} \mathrm{C}$ para DCi y dispersión $\mathrm{DCi}+\mathrm{ND}$ 210

Figura 181. Evolución de la viscosidad con la velocidad de cizalla a $40^{\circ} \mathrm{C}$ para DCi y dispersión $\mathrm{DCi}+\mathrm{ND}$

Figura 182. Evolución de la viscosidad con la velocidad de cizalla a $100^{\circ} \mathrm{C}$ para DCi y dispersión DCi+ND

Figura 183. Evolución del coeficiente de fricción con la distancia para los lubricantes DCi y $\mathrm{DCi}+\mathrm{ND}$

Figura 184. Topografía superficial de la huella de desgaste sobre el disco de acero tras ensayo con DCi+ND 
Figura 185. Topografía superficial de la huella de desgaste sobre el disco de acero tras ensayo

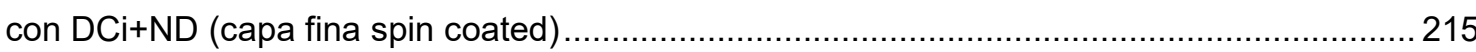

Figura 186. Topografía superficial de la huella de desgaste sobre el disco de acero tras ensayo

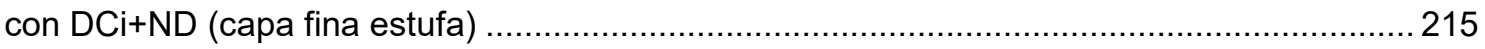

Figura 187. Micrografía TEM de los nanodiamantes antes del ensayo tribológico ................... 217

Figura 188. Micrografía TEM de los nanodiamantes después del ensayo tribológico .............. 218

Figura 189. Espectros Raman de los nanodiamantes antes del ensayo y en la huella de desgaste obtenida en la probeta de acero tras el ensayo tribológico con $\mathrm{DCi+ND} \mathrm{..................} 218$

Figura 190. Análisis termogravimétrico de [EMIM][DCA] y sus dispersiones con grafeno........ 221

Figura 191. Análisis termogravimétrico de [EMIM][TFSI] y sus dispersiones con grafeno........ 222 Figura 192. Evolución de la viscosidad con la velocidad de cizalla a $25^{\circ} \mathrm{C}$ : a) [EMIM][DCA] y sus dispersiones con grafeno; b) [EMIM][TFSI] y sus dispersiones con grafeno............................ 225

Figura 193. Evolución de la viscosidad con la temperatura para: a) [EMIM][DCA];

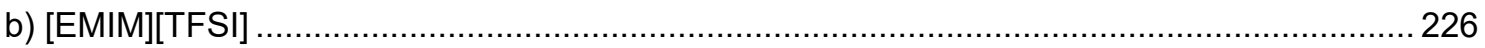

Figura 194. Evolución de la viscosidad con la temperatura para [EMIM][DCA]+0,5\%G .......... 227

Figura 195. Evolución de la viscosidad con la temperatura para [EMIM][DCA]+1\%G ............. 228

Figura 196. Evolución de la viscosidad con la temperatura para las dispersiones de

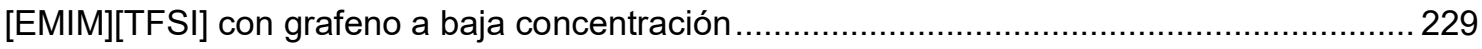

Figura 197. Evolución de la viscosidad con la temperatura para las dispersiones de

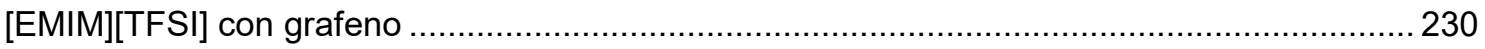

Figura 198. Evolución de la viscosidad en el ciclo de calentamiento-enfriamiento para [EMIM][DCA]+0,5\% G

Figura 199. Evolución de la viscosidad en el ciclo de calentamiento-enfriamiento para los líquidos iónicos $+1 \% \mathrm{G}$

Figura 200. Dispersiones de [EMIM][DCA]+1\%G a temperatura ambiente: a) Inicial; b) Tras 30 días; c) Tras 60 días.

Figura 201. Micrografía SEM de partículas de grafeno de la dispersión de [EMIM][TFSI]+grafeno

Figura 202. Mapas elementales de F, C, O y S de las partículas de grafeno obtenidas de la dispersión de [EMIM][TFSI]+grafeno

Figura 203. Evolución del coeficiente de fricción con la distancia para [EMIM][DCA] .............. 235

Figura 204. Evolución del coeficiente de fricción con la distancia para [EMIM][DCA]+0,5\%G 236 Figura 205. Evolución del coeficiente de fricción con la distancia para [EMIM][DCA]+1\%G ...236 Figura 206. Micrografías ópticas de las huellas de desgaste sobre discos de acero tras lubricación con: a) [EMIM][DCA]; b) [EMIM][DCA]+0,5\%G; c) [EMIM][DCA]+1\%G . 237 Figura 207. Topografía superficial sobre discos de acero tras lubricación con [EMIM][DCA]; [EMIM][DCA]+0,5\%G y [EMIM][DCA]+1\%G

Figura 208. Sección transversal de las huellas de desgaste sobre discos de acero tras lubricación con [EMIM][DCA]; [EMIM][DCA]+0,5\%G y [EMIM][DCA]+1\%G ..........................2. 238

Figura 209. Evolución del coeficiente de fricción con la distancia para [EMIM][TFSI] ..............239 Figura 210. Evolución del coeficiente de fricción con la distancia para [EMIM][TFSI] +0,5\%G 239 Figura 211. Evolución del coeficiente de fricción con la distancia para [EMIM][TFSI]+1\%G ...240 Figura 212. Micrografías ópticas de las huellas de desgaste sobre discos de acero tras lubricación con: a) [EMIM][TFSI]; b) [EMIM][TFSI]+0,5\%G; c) [EMIM][TFSI]+1\%G................ 241 Figura 213. Topografía superficial sobre discos de acero tras lubricación con [EMIM][TFSI].. 241 
Figura 214. Espectros Raman de grafeno, [EMIM][TFSI]+0,5\% y yuella de desgaste tras lubricación con [EMIM][TFSI]+0,5\%G

Figura 215. Espectros Raman de grafeno, [EMIM][TFSI]+1\%G y huella de desgaste tras lubricación con [EMIM][TFSI]+1\%G

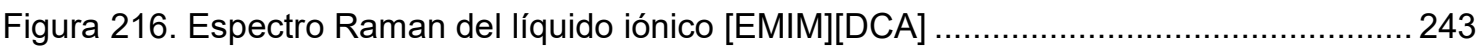

Figura 217. Espectros Raman de grafeno y dispersión [EMIM][DCA]+1\%G........................... 244

Figura 218. Espectro Raman en el interior de la huella de desgaste tras lubricación con [EMIM][DCA]+1\%G

Figura 219. Mapa elemental de $C$ obtenido mediante EDX de la huella sobre el disco de acero tras lubricación con [EMIM][DCA]+grafeno....

Figura 220. Micrografía SEM y mapa elemental de Fe de las partículas de desgaste obtenidas tras lubricación con [EMIM][DCA]

Figura 221. Micrografías TEM de las partículas de desgaste tras lubricación con:

a) $[E M I M][D C A]+0,5 \% G ;$ b) $[E M I M][D C A]+1 \% G$.

Figura 222. Evolución del coeficiente de fricción con la distancia de deslizamiento para los lubricantes con base isoparafínica a temperatura ambiente

Figura 223. a) Topografía superficial de las huellas de desgaste; b) Sección transversal de las huellas de desgaste para los lubricantes de base isoparafínica a temperatura ambiente ....... 251 Figura 224. a) Micrografía óptica de la huella de desgaste tras lubricación con B; b) Micrografía óptica de la bola de zafiro

Figura 225. Micrografía SEM y espectros EDX dentro y fuera de la huella de desgaste tras lubricación con B

Figura 226. a) Micrografía óptica de la huella de desgaste tras lubricación con $\mathrm{B}+\left[\mathrm{OMIM}_{\mathrm{B}} \mathrm{B}_{4}\right.$;

b) Micrografía óptica de la bola de zafiro

Figura 227. Micrografía SEM y espectros EDX dentro y fuera de la huella de desgaste tras lubricación con $\mathrm{B}+\left[\mathrm{OMIM}_{\mathrm{B} F}\right.$

Figura 228. a) Micrografía óptica de la huella de desgaste zafiro tras lubricación con $B+G$;

b) Micrografía óptica de la bola de zafiro

Figura 229. Micrografía SEM y espectros EDX dentro y fuera de la huella de desgaste tras lubricación con $B+G$

Figura 230. a) Micrografía óptica de la huella de desgaste tras lubricación con

$\left.\mathrm{B}+\left([\mathrm{OMIM}] \mathrm{BF}_{4}+\mathrm{G}\right) ; \mathrm{b}\right)$ Micrografía óptica de la bola de zafiro

Figura 231. Micrografía SEM y espectros EDX dentro y fuera de la huella de desgaste tras lubricación con $\mathrm{B}+\left(\left[\mathrm{OMIM}_{\mathrm{B}} \mathrm{BF}_{4}+\mathrm{G}\right)\right.$

Figura 232. Evolución del coeficiente de fricción con la distancia de deslizamiento para los lubricantes con aceite de motor de alto rendimiento a $150^{\circ} \mathrm{C}$

Figura 233. a) Topografía superficial; b) Sección transversal de las huellas de desgaste para los lubricantes de aceite de motor de alto rendimiento a $150^{\circ} \mathrm{C}$

Figura 234. Micrografías SEM de la huellas de desgaste: a) MO; b) MO+G. Mapas elementales:

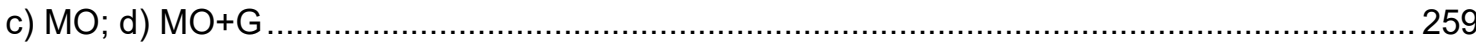

Figura 235. Espectro XPS sobre la huella de desgaste tras lubricación con $M O+G$............... 260 Figura 236. Espectros Raman de grafeno, aceite lubricante de alto rendimiento antes del ensayo y en la huella tras lubricación con $\mathrm{MO}+\mathrm{G}$

Figura 237. a) Entalpía residual de curado para RE+9\%DCi a $20 \mathrm{~min}$; b) $40 \mathrm{~min}$; c) $60 \mathrm{~min}$ del

inicio del curado. 
Figura 238. Espectros FTIR del nanocomposite RE+9\%DCi tras 20, 40 y 60 minutos del inicio

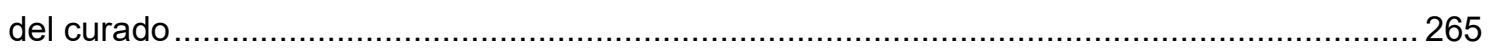

Figura 239. Detalle de la evolución de la banda del grupo epoxi ............................................. 266

Figura 240. Micrografía SEM de la superficie de fractura de RE+9\%DCi ................................ 266

Figura 241. Mapa elemental de la superficie de fractura de RE+9\%DCi .................................. 267

Figura 242. Superficie analizada mediante FTIR de RE+9\%DCi ............................................ 267

Figura 243. Espectro FTIR de la zona de la resina libre de cavidades ................................... 268

Figura 244. Espectro FTIR de DCi y DCi dentro de una microcavidad de RE+9\%DCi............ 268

Figura 245. Perfil topográfico de RE+9\%DCi mostrando la distribución de DCi ...................... 269

Figura 246. Imagen topográfica de la sección transversal de RE+9\% DCi ............................... 269

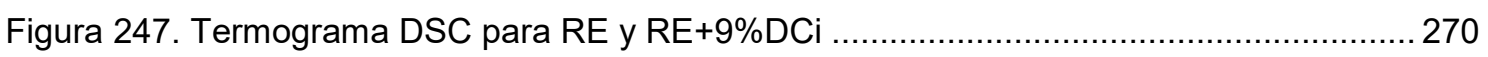

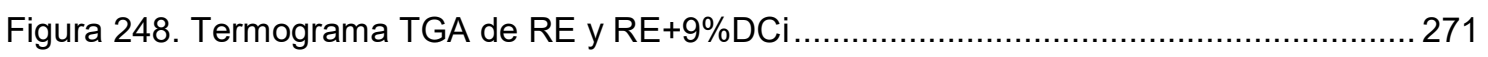

Figura 249. Evolución del módulo de almacenamiento para RE y RE+9\%DCi.......................2 273

Figura 250. Evolución del módulo de pérdida para RE y RE+9\%DCi ...................................2. 274

Figura 251. Evolución de la tangente de pérdida para RE y RE+9\%DCi ............................... 275

Figura 252. Evolución del coeficiente de fricción con la distancia para RE/AISI 316L y

$\mathrm{RE}+9 \% \mathrm{DCl}$ sin lubricante añadido y empleando $\mathrm{DCi}$ como lubricante externo en el contacto

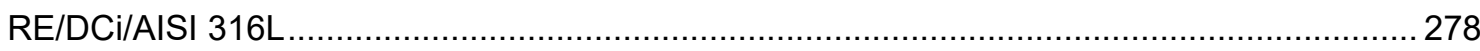

Figura 253. a) Micrografía SEM de la huella de desgaste de RE empleando DCi como

lubricante externo; b) Micrografía óptica de la bola de acero AISI 316L después del ensayo. 279 Figura 254. Huella de desgaste sobre RE tras ensayo en seco contra AISI 316L; a) Micrografía

SEM; b) Imagen de perfilometría [269]

Figura 255. Micrografía óptica de la bola de acero AISI 316L después del ensayo en seco contra la resina epoxi.

Figura 256. a) Micrografía SEM de RE+9\%DCi tras ensayo tribológico; b) Imagen de

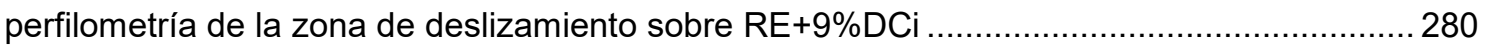

Figura 257. Micrografía SEM de RE+9\%DCi antes del ensayo tribológico ................................ 281

Figura 258. Micrografía óptica de la bola de acero AISI 316L tras el ensayo tribológico frente

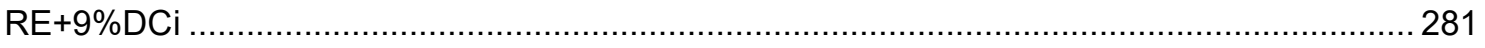

Figura 259. Sección transversal del recubrimiento de RE sobre resina epoxi ......................... 284

Figura 260. Sección transversal del recubrimiento de RE+0,05\%G sobre resina epoxi ........... 284

Figura 261. a) Micrografía SEM de la sección transversal del recubrimiento de

$\mathrm{RE}+9 \%\left[\mathrm{OMIM}_{\mathrm{B}} \mathrm{B}_{4}\right.$; b) Mapa elemental de flúor; c) Mapa elemental de carbono ...................... 285

Figura 262. Análisis en línea de flúor en el recubrimiento de $\mathrm{RE}+9 \%[\mathrm{OMIM}] \mathrm{BF}_{4}$ sobre $\mathrm{RE} \ldots .286$

Figura 263. a) Micrografía SEM de la sección transversal del recubrimiento de

$\mathrm{RE}+9 \%\left(\left[\mathrm{OMIM}_{\mathrm{BF}}+0,1 \% \mathrm{G}\right) ;\right.$ b) Mapa elemental de flúor; c) Mapa elemental de carbono ..... 287

Figura 264. Análisis en línea de flúor en el recubrimiento de RE+9\%([OMIM]BF $4+0,1 \% G)$

sobre RE

Figura 265. Evolución de la profundidad de penetración en ensayos de multirrayado para los recubrimientos de RE, RE+9\%[OMIM]BF 4 , RE+0,05\%G y RE+9\%([OMIM]BF $4+0,1 \% G) \ldots \ldots . .290$ Figura 266. Evolución de la profundidad residual en ensayos de multirrayado para los recubrimientos de $\mathrm{RE}, \mathrm{RE}+9 \%\left[\mathrm{OMIM}_{\mathrm{B}} \mathrm{BF}_{4}, \mathrm{RE}+0,05 \% \mathrm{G}\right.$ y $\mathrm{RE}+9 \%\left([\mathrm{OMIM}] \mathrm{BF} F_{4}+0,1 \% \mathrm{G}\right)$

Figura 267. Evolución del porcentaje de recuperación viscoelástica en ensayos de multirrayado para los recubrimientos de RE, RE+9\%[OMIM]BF $4, R E+0,05 \% G$ y $R E+9 \%\left([O M I M] B F_{4}+0,1 \% G\right)$ sobre resina epoxi 
Figura 268. Evolución del coeficiente de fricción en ensayos de multirrayado para los recubrimientos de $\mathrm{RE}, \mathrm{RE}+9 \%\left[\mathrm{OMIM}_{\mathrm{B}} \mathrm{BF}_{4}, \mathrm{RE}+0,05 \% \mathrm{G}\right.$ y $\mathrm{RE}+9 \%\left([\mathrm{OMIM}] \mathrm{BF}_{4}+0,1 \% \mathrm{G}\right) \ldots \ldots . .293$ Figura 269. Micrografías ópticas de las huellas tras multirrayado a $5 \mathrm{~N}$ para recubrimientos de

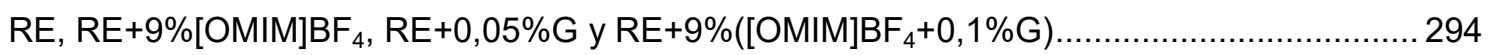

Figura 270. Sección transversal de la huella sobre el recubrimiento de RE ........................... 295

Figura 271. Sección transversal de la huella sobre el recubrimiento de RE+9\%[OMIM]BF $\ldots 295$

Figura 272. Sección transversal de la huella sobre el recubrimiento de RE+0,05\%G ............. 295

Figura 273. Sección transversal de la huella sobre el recubrimiento de $\mathrm{RE}+9 \%\left(\left[\mathrm{OMIM}_{\mathrm{B}} \mathrm{B}_{4}+0,1 \% \mathrm{G}\right)\right.$ 295

Figura 274. Evolución del coeficiente de fricción y de la resistencia eléctrica en el contacto durante el ensayo tribológico en el recubrimiento de RE sobre AISI 1015. 301

Figura 275. Evolución del coeficiente de fricción con la distancia para los recubrimientos de RE,

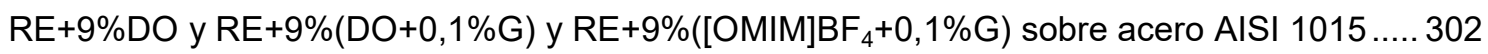
Figura 276. Micrografías ópticas de las huellas tras ensayo tribológico de los recubrimientos de una capa de RE, RE+9\%DO, RE+9\%(DO+0,1\%G) y RE+9\%([OMIM]BF $\left.{ }_{4}+0,1 \% \mathrm{G}\right)$. 303

Figura 277. Evolución del coeficiente de fricción con la distancia para los recubrimientos de doble capa de RE, RE+9\%DO y RE+9\%(DO+0,1\%G) sobre acero AISI 1015 307

Figura 278. Evolución del coeficiente de fricción y resistencia eléctrica en el contacto con la distancia para el recubrimiento de doble capa de RE+9\%DO sobre acero AISI 1015. 308

Figura 279. Micrografías SEM de las huellas de desgaste tras ensayo tribológico sobre recubrimientos de doble capa: a) RE; b) RE+9\%DO; c) RE+9\%(DO+0,1\%G) 309 Figura 280. Topografía superficial de las huellas de desgaste en recubrimientos de doble capa: a) RE; b) RE+9\%DO; c) RE+9\%(DO+0,1\%G)

Figura 281. Evolución de la pérdida de peso con la temperatura para los films de RE, $\mathrm{RE}+9 \%\left[\mathrm{OMIM}_{\mathrm{B} F}, \mathrm{RE}+0,05 \% \mathrm{G}\right.$ y $\mathrm{RE}+9 \%\left([\mathrm{OMIM}] \mathrm{BF}_{4}+0,1 \% \mathrm{G}\right)$.

Figura 282. DSC para films de RE, RE+9\%[OMIM]BF 4 , RE+0,05\%G y

$\mathrm{RE}+9 \%\left(\left[\mathrm{OMIM}_{\mathrm{B}} \mathrm{BF}_{4}+0,1 \% \mathrm{G}\right)\right.$

Figura 283. Evolución del módulo de almacenamiento con la temperatura para films de RE,

$\mathrm{RE}+9 \%\left[\mathrm{OMIM}_{\mathrm{B}} \mathrm{BF}_{4}, \mathrm{RE}+0,05 \% \mathrm{G}\right.$ y $\mathrm{RE}+9 \%\left([\mathrm{OMIM}] \mathrm{BF}_{4}+0,1 \% \mathrm{G}\right)$.

Figura 284. Evolución del módulo de pérdida con la temperatura para films de RE,

$\mathrm{RE}+9 \%[\mathrm{OMIM}] \mathrm{BF}_{4}, \mathrm{RE}+0,05 \% \mathrm{G}$ y RE+9\%([OMIM]BF $\left.4+0,1 \% \mathrm{G}\right)$.

Figura 285. Evolución de la $\tan (\delta)$ con la temperatura para films de $R E, R E+9 \%[O M I M] B_{4}$,

$\mathrm{RE}+0,05 \% \mathrm{G}$ y $\mathrm{RE}+9 \%\left([\mathrm{OMIM}] \mathrm{BF}_{4}+0,1 \% \mathrm{G}\right)$... 316

Figura 286. Ensayos tribológicos lineales oscilatorios empleando agua, DSu, Agua+1\%DSu y capas finas de DSu en el contacto AISI 52100-AISI 52100; a) Evolución del coeficiente de fricción; b) Tasa de desgaste

Figura 287. Imágenes AFM. a) Film RE; b) Film RE+9\%[OMIM]BF 4 ; c) Film RE+0,05\%G;

d) $\mathrm{RE}+9 \%\left(\left[\mathrm{OMIM}_{\mathrm{B}} \mathrm{F}_{4}+0,1 \% \mathrm{G}\right)\right.$

Figura 288. Análisis de la bibliografía empleada 356 


\section{ÍNDICE DE TABLAS}

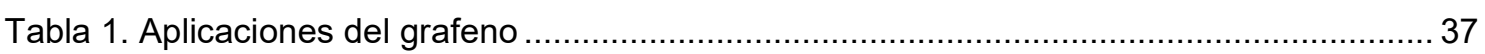

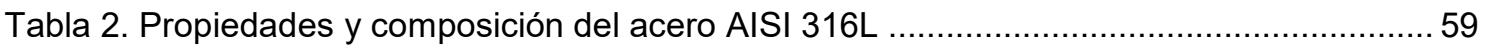

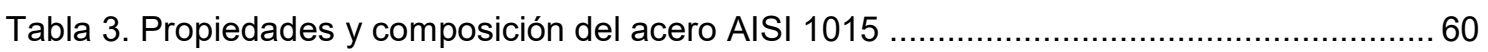

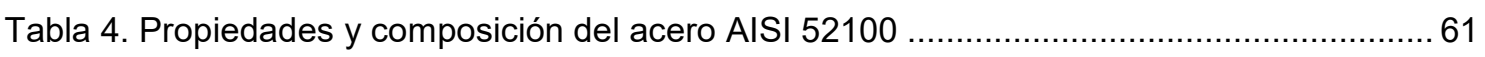

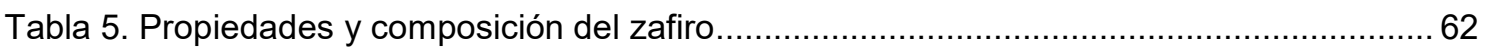

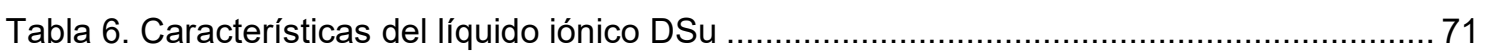

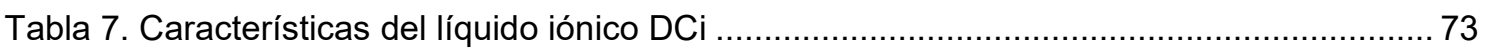

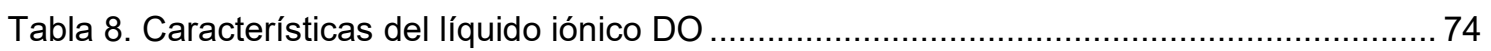

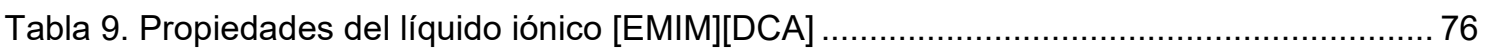

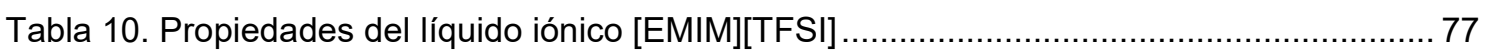

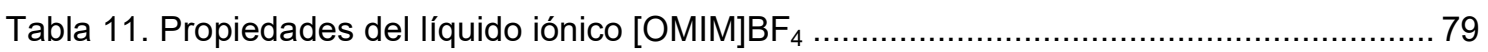

Tabla 12. Características del medidor de ángulo de contacto DSA30B, Krüss.......................... 95

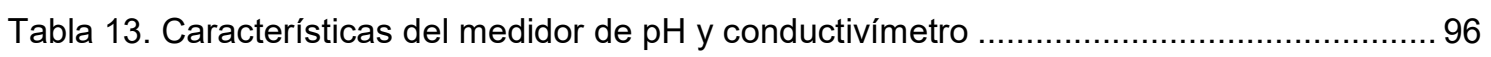

Tabla 14. Condiciones del ensayo para la obtención de la curva COF vs.velocidad en el contacto AISI 316L-AISI 316L

Tabla 15. Condiciones del ensayo para la obtención de la curva COF vs.velocidad en el contacto zafiro-AISI 316L

Tabla 16. Condiciones del ensayo para la obtención de la curva COF vs.velocidad en el contacto AISI 52100-AISI 316L

Tabla 17. Condiciones del ensayo para la obtención de la curva COF vs.velocidad en el contacto AISI 316L-AISI 316L usando agua como lubricante

Tabla 18. Condiciones del ensayo para la obtención de la curva COF vs.velocidad en el contacto zafiro-AISI $316 \mathrm{~L}$ usando agua como lubricante

Tabla 19. Condiciones del ensayo para la obtención de la curva COF vs.velocidad en el contacto acero AISI 52100-AISI 316 L usando agua como lubricante

Tabla 20. Condiciones de los ensayos punzón sobre disco en el contacto zafiro-acero inoxidable AISI 316L

Tabla 21. Condiciones de los ensayos de [OMIM]BF 4 y/o grafeno con aceite libre de aditivos y aceite totalmente formulado.

Tabla 22. Condiciones de los ensayos de multirrayado para los recubrimientos sobre resina epoxi

Tabla 23. Condiciones de los ensayos punzón sobre disco para RE+9\%DCi y recubrimientos sobre acero AISI 1015.

Tabla 24. Valores de $\mathrm{pH}$, viscosidad y conductividad para agua, WDEs, WMEs y WDPa ...... 136

Tabla 25. Valores de $\mathrm{pH}$, viscosidad y conductividad para NDWDEs, NDWMEs y NDWDPa. 136

Tabla 26. Ángulos de contacto de agua, WDEs, WMEs y WDPa sobre AISI 316L ................ 137

Tabla 27. Ángulos de contacto de NDWDEs, NDWMEs y NDWDPa sobre AISI 316L ............ 138

Tabla 28. Tensión superficial de WDEs, WMEs, WDPa, NDWDEs, NDWMEs y NDWDPa.... 139

Tabla 29. Valores de espesor de película obtenidos mediante interferometría óptica de película ultrafina

Tabla 30. Valores de coeficiente de fricción obtenidos mediante interferometría óptica de película ultrafina para agua, WMEs, WDEs, WDPa y NDWDPa 
Tabla 31. Valores de coeficiente de fricción y porcentaje de resistencia eléctrica en el contacto AISI 316L-AISI 316L

Tabla 32. Valores de coeficiente de fricción y porcentaje de resistencia eléctrica en el contacto

AISI 52100-AISI 316L

Tabla 33. Valores de coeficiente de fricción en el contacto zafiro-AISI 316L 154

Tabla 34. Tasas de desgaste $\left(\mathrm{mm}^{3} / \mathrm{N} \cdot \mathrm{m}\right)$ de los discos de AISI 316 en función de los lubricantes y los contactos empleados.

Tabla 35. Análisis XPS dentro y fuera de la huella de desgaste en el contacto zafiro-AISI 316L empleando WDEs como lubricante.....

Tabla 36. Coeficiente de fricción y tasa de desgaste para WDEs, WMEs, WDPa y agua tras ensayos en el contacto zafiro-AISI $316 \mathrm{~L}$ a velocidad constante. 168

Tabla 37. Valores de rugosidad después del ensayo tribológico tras lubricación con WDEs, WMEs y WDPa a velocidad constante.

Tabla 39. Análisis XPS dentro y fuera de la huella de desgaste sobre AISI 316L tras lubricación con WMEs. 176

Tabla 40. Coeficiente de fricción y tasa de desgaste para NDWDEs, NDWMEs, NDWDPa ... 179

Tabla 41. Ángulos de contacto de DSu, Agua y Agua+1\%DSu sobre AISI 316L 185

Tabla 42. Coeficientes de fricción y tasas de desgaste tras lubricación con DSu, Agua+1\%DSu en película gruesa y en capa fina 187

Tabla 43. Asignación de bandas del espectro Raman del líquido iónico DSu 191 Tabla 44. Análisis XPS dentro y fuera de la huella del disco de acero tras lubricación con capa fina Agua $+1 \% \mathrm{DSu}$ 193

Tabla 45. Temperaturas de degradación para DSu y sus dispersiones con grafeno. 195 Tabla 46. Valores de viscosidad (Peak Hold) obtenidos para DSu y sus dispersiones con grafeno a distintas temperaturas.

Tabla 47. Ángulo de contacto del líquido iónico DSu y sus dispersiones con grafeno sobre AISI $316 \mathrm{~L}$

Tabla 48. Números de onda y relación de intensidades de los espectros Raman de grafeno,

DSu+0, $1 \%$ G y DSu+0,05\%G 201

Tabla 49. Coeficientes de fricción y factor de desgaste para DSu y sus dispersiones con grafeno

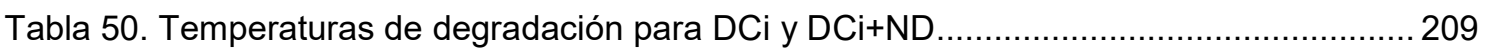

Tabla 51. Valores de viscosidad (Peak Hold) para DCi y DCi+ND a distintas temperaturas ... 212 Tabla 52. Ángulos de contacto de DCi y de la dispersión DCi+ND sobre acero inoxidable AISI 316L

Tabla 53. Coeficientes de fricción y tasas de desgaste para DCi, DCi+ND y las diferentes capas finas

Tabla 54. Análisis XPS dentro y fuera de la huella del disco de acero tras lubricación con $\mathrm{DCi}+\mathrm{ND}$

Tabla 55. Temperatura de degradación de [EMIM][DCA] y sus dispersiones con grafeno....... 221

Tabla 56. Temperatura de degradación de [EMIM][TFSI] y sus dispersiones con grafeno ...... 222 Tabla 57. Ángulos de contacto de [EMIM][DCA], [EMIM][TFSI] y sus dispersiones con grafeno sobre AISI 316L 
Tabla 58. Parámetros para la obtención de la viscosidad para líquidos iónicos y dispersiones con grafeno según el modelo VFTH

Tabla 59. Coeficientes de fricción y tasas de desgaste para [EMIM][DCA] y sus dispersiones con grafeno.

Tabla 60. Coeficientes de fricción y tasas de desgaste para [EMIM][TFSI] y sus dispersiones con grafeno.

Tabla 61. Viscosidad de las dispersiones en base isoparafínica.

Tabla 62. Coeficientes de fricción y áreas de la huella de desgaste para los lubricantes con base isoparafínica

Tabla 63. Análisis EDX dentro y fuera de la huella de desgaste tras ensayo tribológico de las dispersiones con base lubricante isoparafínica a temperatura ambiente ................................. 252

Tabla 64. Viscosidad de las dispersiones en aceite de motor de alto rendimiento ................... 257

Tabla 65. Coeficientes de fricción y áreas de la huella de desgaste para los lubricantes con

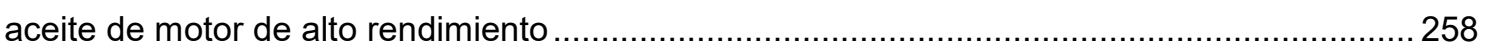

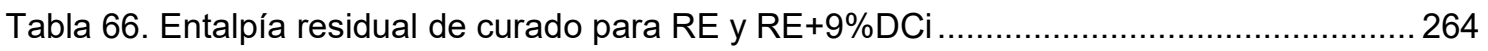

Tabla 67. Valores de temperatura de transición vítrea para RE y RE+9\%DCi........................ 271

Tabla 68. Valores de temperatura de degradación para RE y RE+9\%DCi ............................... 272

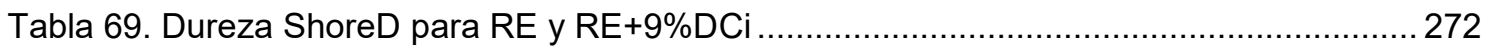

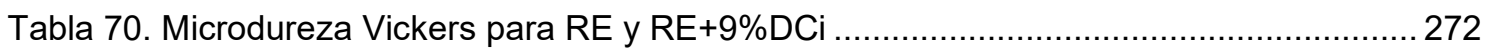

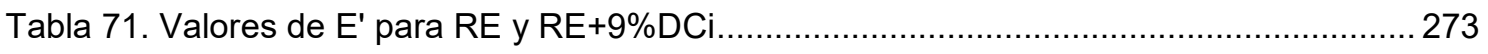

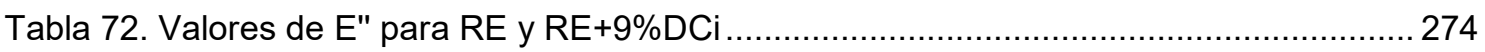

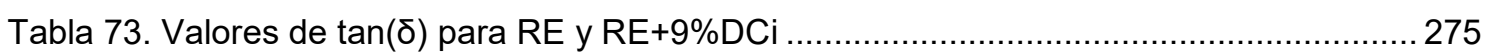

Tabla 74. Valores de conductividad térmica para RE y RE+9\%DCi....................................... 276

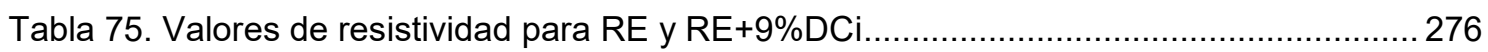

Tabla 76. Ángulo de contacto del líquido iónico DCi sobre resina epoxi ..................................... 277

Tabla 77. Ángulo de contacto de agua tipo II sobre resina epoxi+9\%DCi............................... 277

Tabla 78. Rugosidad de los recubrimientos de RE, RE+9\%[OMIM]BF 4 , RE+0,05\%G y

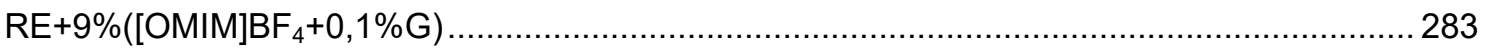

Tabla 79. Medidas de espesor obtenidas para los recubrimientos sobre resina epoxi ............. 288

Tabla 80. Ángulos de contacto iniciales y tras 5 minutos de agua tipo II en distintos recubrimientos sobre RE

Tabla 81. Valores obtenidos para el rayado número 15 para los recubrimientos de RE, $\mathrm{RE}+9 \%[\mathrm{OMIM}] \mathrm{BF}_{4}, \mathrm{RE}+0,05 \% \mathrm{G}$ y $\mathrm{RE}+9 \%\left([\mathrm{OMIM}] \mathrm{BF} F_{4}+0,1 \% \mathrm{G}\right)$ sobre resina epoxi .............. 293

Tabla 82. Daño superficial de los distintos recubrimientos sobre resina epoxi ......................... 296

Tabla 83. Espesor de los recubrimientos de nanocomposites de matriz epoxi de una capa sobre

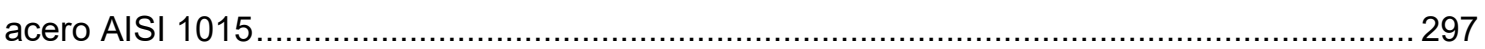

Tabla 84. Ángulo de contacto de agua tipo II sobre recubrimientos de una capa de matriz epoxi

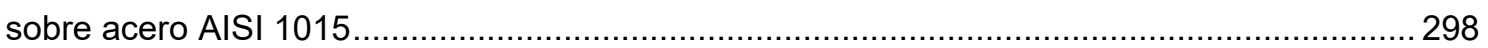

Tabla 85. Ángulo de contacto de los nanocomposites sobre acero AISI 1015 ......................... 299

Tabla 86. Rugosidad superficial y lineal de los recubrimientos de una capa sobre AISI 1015300

Tabla 87. Topografía superficial y porcentaje de área de defectos en los recubrimientos de una

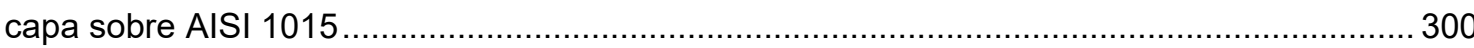

Tabla 88. Coeficientes de fricción y daño superficial para los recubrimientos de RE, RE+9\%DO y $R E+9 \%(D O+0,1 \% G)$ de una capa sobre acero AISI 1015 303 
Tabla 89. Espesor de los recubrimientos de doble capa de RE, RE+9\%DO y

$\mathrm{RE}+9 \%(\mathrm{DO}+0,1 \% \mathrm{G})$ sobre acero AISI 1015

Tabla 90. Ángulo de contacto de agua tipo II sobre recubrimientos de doble capa de matriz epoxi sobre acero AISI 1015

Tabla 91. Rugosidad superficial y lineal de los recubrimientos de matriz epoxi de doble capa sobre AISI 1015

Tabla 92. Topografía superficial y porcentaje de área de defectos en los recubrimientos de doble capa sobre AISI 1015

Tabla 93. Coeficientes de fricción y daño superficial para los recubrimientos de doble capa de

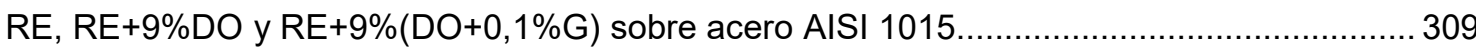

Tabla 94. Espesor de los films de los distintos nanocomposites de matriz epoxi

Tabla 95. Temperatura de degradación para los distintos nanocomposites en forma de films 312

Tabla 96. Temperatura de transición vítrea de los nanocomposites en forma de films 314

Tabla 97. Propiedades dinámico-mecánicas de films de RE, RE+9\%[OMIM]BF $4, R E+0,05 \% G$ y $\mathrm{RE}+9 \%\left([\mathrm{OMIM}] \mathrm{BF}_{4}+0,1 \% \mathrm{G}\right)$ 



\section{INTRODUCCIÓN}





\section{INTRODUCCIÓN}

\subsection{TRIBOLOGÍA}

Se define tribología como la ciencia y tecnología que estudia los fenómenos que tienen lugar en la interfase de contacto entre superficies en movimiento.

Esta disciplina se centra en el estudio de la fricción, el desgaste y la lubricación [1], aunque tiene una naturaleza multidisciplinar que incluye a la ingeniería mecánica (estudio de elementos de máquinas), ciencia de materiales (investigaciones sobre la resistencia al desgaste, tecnología de superficies o recubrimientos) y la química de los lubricantes y aditivos. A estas disciplinas se les ha unido recientemente la biotribología y la nanotribología, que se encargan de estudiar la fricción y el desgaste en sistemas biológicos y a escala nanométrica, respectivamente [2].

El término tribología, derivado del griego "tribos", frotamiento, fue acuñado por el profesor H.P. Jost autor de un informe presentado al parlamento británico en 1966. En dicho informe se estimaba que la industria británica podría ahorrar un $1,5 \%$ de su PIB (en datos de 1966) con la apropiada aplicación de los principios de la tribología [3]. Sin embargo, 45 años después, sólo se había logrado un $10 \%$ de este ahorro [4], pero incluso este pequeño porcentaje muestra una reducción enorme del gasto energético [5].

En la actualidad los esfuerzos en tribología se encaminan hacia el desarrollo de la "tribología sostenible", que pretende minimizar las pérdidas de energía y gestionar de manera efectiva los costes económicos que podrían reducirse mediante el mejor uso de máquinas y componentes en ingeniería [6]. Para lograrlo, se apuesta por el desarrollo de tribo-materiales biodegradables [7] o la mejora del diseño de los elementos de máquinas [8].

\subsubsection{Historia de la tribología}

Aunque el empleo del término tribología es relativamente reciente, la historia de esta ciencia es tan antigua como la propia Humanidad.

Si bien no se dispone de fuentes documentadas, se sabe que los primeros homínidos empleaban materiales naturales como grasas de animales o aceites de plantas para disminuir la fricción. Además, usaban herramientas equipadas 
con rodamientos hechos a partir de cornamentas de animales o huesos para perforar pozos o hacer fuego [9].

El transporte de grandes piedras para la construcción de edificios y monumentos requería el conocimiento de dispositivos friccionales y lubricantes. El primer uso de lubricantes del que se tiene constancia data del siglo XIX a.C. en el Antiguo Egipto. En un relieve de la tumba del faraón Djehutihotep se puede observar cómo 172 hombres tiran de una estatua situada sobre una especie de trineo mientras uno de ellos vierte un líquido, presumiblemente un lubricante, frente al trineo [10] (Figura 1).

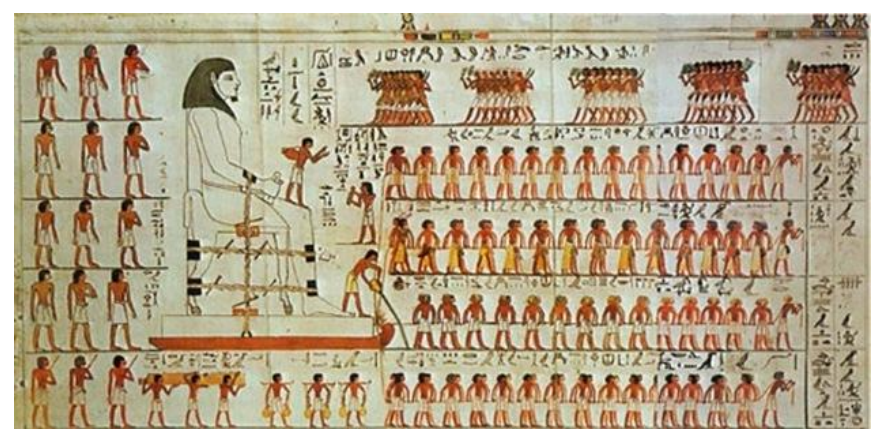

Figura 1. Relieve egipcio. Primer uso de lubricantes documentado

La invención de la rueda hacia el año 3500 a.C. indica la preocupación de los hombres del Paleolítico por reducir la fricción en los desplazamientos, ya que comprendieron que el movimiento de rotación requiere menor esfuerzo que el movimiento deslizante.

Durante el Imperio Romano y la Edad Media se emplearon principios tribológicos para idear tanto maquinaria de guerra como métodos de fortificación. Sin embargo, fue el genio del Renacimiento Leonardo da Vinci (1452-1519) el primero que dio un enfoque científico a la fricción con la formulación de las dos leyes básicas: "La fricción es independiente del área de contacto" y "La fricción es proporcional a la carga" [10]. Paradójicamente, su trabajo permaneció desconocido para los tribólogos hasta bien entrado el siglo $X X$, y por lo tanto, no tuvo influencia en el desarrollo de esta ciencia [11]. 


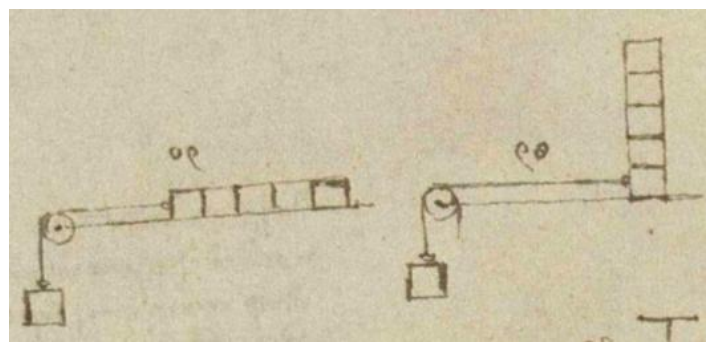

Figura 2. Bocetos del estudio del efecto de la presión de contacto o del área de contacto.

Leonardo da Vinci. (Madrid I 173v, c. 1493-7, Biblioteca Nacional, Madrid) [11]

En 1699 Guillaume Amontons redescubrió estas dos leyes de la fricción tras el estudio del contacto en seco entre dos superficies, el cual da lugar a la deformación y al desgaste entre dichas superficies. Sus observaciones fueron verificadas por Charles Coulomb (1736-1806), quién estableció la segunda ley de la fricción: "La fuerza debida a la fricción es proporcional a la fuerza de compresión". Posteriormente, Isaac Newton (1642-1727) en sus estudios macroscópicos para la determinación de las leyes básicas del movimiento, determinó que la fricción en movimiento era independiente de la velocidad, formulando así la tercera ley de la fricción [10]. Además, fue Newton quién postuló los principios esenciales de la mecánica de fluidos [9].

La Revolución Industrial supuso un gran avance para la Tribología. Por un lado, la industria de lubricantes comenzó en 1859 con la construcción del primer pozo petrolífero en Titusville, Pensilvania (EEUU). Edwin Drake usó un motor de vapor para perforar el suelo y extraer crudo, lo que supuso el punto de partida de una floreciente industria de lubricantes derivados del petróleo, ya que hasta esa fecha los lubricantes se obtenían de fuentes naturales (animales y vegetales) [10]. Posteriormente, se descubrió la lubricación hidrodinámica gracias a los estudios experimentales llevados a cabo en 1883 por Beauchamp Tower, mientras trabajaba en nuevos métodos de lubricación para ejes de ferrocarril y las interpretaciones teóricas de Osborne Reynolds sobre la distribución de la presión sobre una película de aceite (1886) [9].

La poca disponibilidad de petróleo en los años que transcurrieron entre el fin de la Primera Guerra Mundial y comienzos de la Segunda, impulsaron el desarrollo y comercialización de nuevos lubricantes sintéticos como las polialfaolefinas o los ésteres sintéticos, que no solo igualaban las propiedades de los aceites minerales, sino que las mejoraban en muchos aspectos. El punto de partida fue el desarrollo de un proceso de conversión de gas de síntesis en hidrocarburos ligeros de alta calidad llevado a cabo por Franz Fischer y Hans 
Tropsch en 1923. En la actualidad, los lubricantes sintéticos incluyen un amplio espectro de siliconas, naftalenos o poliéteres fluorados que poseen mayor estabilidad térmica, mejor capacidad lubricante y producen una menor fricción.

Durante esta época se llevó a cabo un gran desarrollo de los aditivos químicos, como el ZDDP (ditiofosfato de cinc). Estos aditivos se mezclaron con bases lubricantes con el fin de mejorar el rendimiento de los mismos, proporcionando mejores propiedades antioxidantes y antidesgaste, de inhibición de la corrosión o de modificación de la viscosidad. Gran parte del desarrollo de los aditivos fue debido al aumento en la popularidad del automóvil y la consecuente necesidad de aceites de motor con mejor rendimiento, líquidos de frenos y otros aceites y grasas [10].

Del desarrollo de la teoría de lubricación hidrodinámica a finales del siglo XIX surge la necesidad de predecir el rendimiento de los lubricantes en unas determinadas condiciones. Aunque el primer equipo tribológico para medir fricción y desgaste data del Renacimiento, no es hasta 1927 cuando se comercializa el primer tribómetro en configuración punzón sobre bloque en $\mathrm{V}$ para cuantificar las propiedades antidesgaste de los lubricantes. En la actualidad, los laboratorios de tribología cuentan con equipos que pueden determinar de manera rápida, fiable y reproducible las propiedades de los lubricantes.

A comienzos de siglo XX, Richard Stribeck publicó sus estudios sobre la transición entre los regímenes de lubricación hidrodinámica y lubricación límite, representados en la curva que lleva su nombre. Gracias a estos trabajos, se determinó la existencia de un tercer tipo de lubricación, la lubricación elastohidrodinámica. El estudio y comprensión de este régimen de lubricación ha supuesto un gran avance científico, ya que ha permitido el funcionamiento de vehículos y maquinaria en una amplia variedad de velocidades y cargas con muy poca fricción y desgaste [10].

Cuando es necesario trabajar en condiciones extremas de presión y temperatura, los lubricantes líquidos no son capaces de proporcionar una adecuada lubricación, protección contra la corrosión o resistencia química. Para estos casos, se desarrollaron lubricantes sólidos o autolubricados durante los años treinta y cuarenta del siglo $\mathrm{XX}$, como son el grafito, el disulfuro de molibdeno o el politetrafluoroetileno (Teflón). 
Desde la década de 1970, los especialistas en tribología se están enfrentando a los problemas de fricción y desgaste a nivel microscópico y nanoscópico, en parte como resultado del rápido desarrollo de la informática, la robótica y los mecanismos de precisión.

\subsubsection{Fricción}

Generalmente, se define fricción como la resistencia al movimiento de dos cuerpos que están en contacto [12]. Este término que proviene del latín fricare, frotar, se emplea con el objetivo de explicar la pérdida constante de energía cinética en forma de calor y en los procesos de desgaste y deformación que experimenta un cuerpo cuando éste se mueve en contacto con otro cuerpo.

La fuerza de fricción $\mathrm{F}$ es la fuerza lateral requerida para iniciar o mantener el movimiento, mientras $F_{n}$ es la fuerza normal de un cuerpo sobre el otro, por tanto, el coeficiente de fricción ( $\mu$ o COF) se define como la relación entre ambas fuerzas [13]:

$$
\mu=\frac{F}{F_{n}}
$$

\section{Ecuación 1. Coeficiente de fricción}

El valor del coeficiente de fricción puede variar entre 0,001 en un rodamiento con baja carga, hasta 10 en el contacto metal-metal en condiciones de vacío. Para la mayoría de materiales el valor del coeficiente de fricción varía entre 0,1 y 1 cuando se trabaja en atmósfera de aire [1].

La fricción está originada por fuerzas en la interfase entre dos cuerpos en contacto. Estas fuerzas tienen su origen en la carga, así como en las propiedades de los dos cuerpos y del área de contacto. Estos dos últimos factores dependen a su vez de las condiciones exactas de funcionamiento. Las propiedades de la superficie, la composición y la microestructura pueden ser muy difíciles de predecir, además, el área real de contacto es generalmente mucho más pequeña que el área perceptible de los cuerpos, ya que las superficies, a escala atómica, no son lisas.

Por tanto, determinar el origen de la resistencia al deslizamiento entre dos cuerpos continúa siendo uno de los principales retos de la tribología [12], [14], [15]. 
Existen dos coeficientes de fricción, el coeficiente de fricción estático y el coeficiente de fricción dinámico. El primero representa la fricción que se opone al inicio de movimiento relativo, mientras que el otro indica la relación entre la fuerza tangencial necesaria para mantener el movimiento relativo entre las superficies y la fuerza total aplicada [14]. El valor del coeficiente de fricción estático $\mu_{\mathrm{s}}$ es, en general, superior al del coeficiente de fricción dinámico, $\mu_{\mathrm{k}}$, ya que es necesaria una fuerza superior para poner en movimiento un cuerpo que esté en reposo, que para hacer que éste se mantenga en movimiento una vez que ya se esté desplazando [12]. Los resultados de coeficiente de fricción presentados en este trabajo hacen referencia al coeficiente de fricción dinámico.

\subsubsection{Desgaste}

El desgaste es el daño de la superficie o la eliminación del material de una o ambas superficies en contacto cuando éstas se encuentran en movimiento relativo [9]. Casi todas las máquinas pierden durabilidad y fiabilidad debido al desgaste. Por tanto, el control de esta magnitud es crucial, ya que junto con la corrosión, es la principal causa de pérdidas económicas en la industria [5], [16]-[18].

Durante el movimiento relativo, primero, el material en la superficie de contacto puede desplazarse, de modo que las propiedades del cuerpo sólido en la superficie se ven modificadas, aunque no se pierde apenas material. Posteriormente, el material se puede desprender de una de las superficies y puede adherirse a la otra superficie o puede separarse como una partícula de desgaste. En el caso de transferencia de una superficie a otra, el volumen neto o la pérdida de masa de la interfase es cero, aunque una de las superficies está desgastada. El daño por desgaste precede a la pérdida real de material, y también puede ocurrir de forma independiente. La definición de desgaste generalmente se basa en la pérdida de material, pero debe enfatizarse que el daño debido al desplazamiento del material en un cuerpo dado (observado mediante microscopía), sin cambio neto en el peso o volumen, también constituye desgaste [9].

Williams [18], propone la clasificación de los procesos de desgaste mecánico en cuatro categorías: desgaste por abrasión, por erosión, por adhesión y por fatiga superficial. Sin embargo, el mecanismo de desgaste dominante puede cambiar de un tipo a otro por razones que incluyen cambios en las propiedades 
superficiales del material y respuestas dinámicas de la superficie causadas por el calentamiento por fricción o la formación de una película química [16].

-Desgaste adhesivo. Se produce cuando dos superficies sólidas en deslizamiento se ponen en contacto bajo carga, debido a la transferencia de material de una superficie a la otra, creándose fuertes uniones adhesivas en los contactos entre asperezas. Por tanto, se produce la separación de un fragmento de una superficie y su fijación a la otra superficie. A medida que continúa el deslizamiento, los fragmentos transferidos pueden desprenderse de la superficie a la que se transfieren y volver de nuevo a la superficie original, o bien pueden formar partículas de desgaste [9].

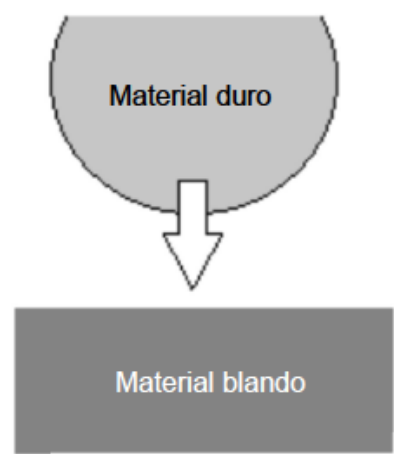

Aproximación

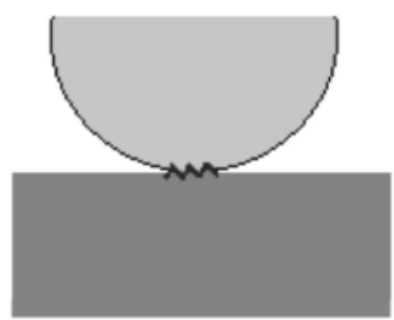

Adhesión
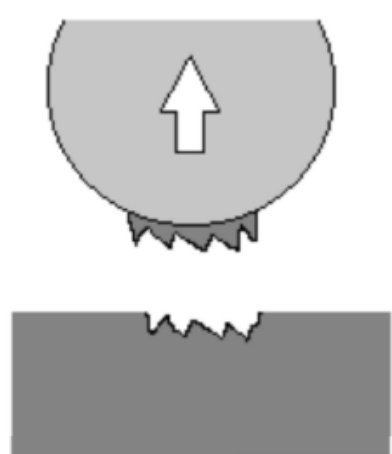

Transferencia

Figura 3. Desgaste adhesivo

Si se dispone de un contacto entre materiales de distinta dureza, normalmente la transferencia de material se realiza desde el material más blando al más duro (Figura 3), de forma rápida y a baja temperatura, llegando incluso a provocar el gripado de piezas móviles en máquinas. De hecho, el desgaste adhesivo es el principal responsable de la mayoría de roturas en contactos deslizantes metálicos y, por tanto, es necesario evitarlo de forma efectiva para garantizar el máximo rendimiento de la máquina [12].

-Desgaste abrasivo. Este tipo de desgaste ocurre debido a la presencia de partículas duras o protuberancias que se deslizan a lo largo de una superficie más blanda y dañan la interfase por deformación plástica o fractura [9].

Existen dos tipos de abrasión. En el primero de ellos, llamado abrasión de dos cuerpos, la superficie abrasiva es una de las dos superficies que está en contacto, como ocurre en operaciones mecánicas como el corte o el mecanizado. El otro tipo es el llamado abrasión de tres cuerpos, en el cual la 
partícula dura, generalmente una pequeña partícula de abrasivo, queda atrapada entre las otras dos superficies, pudiendo desgastar a ambas (Figura 4).

a)

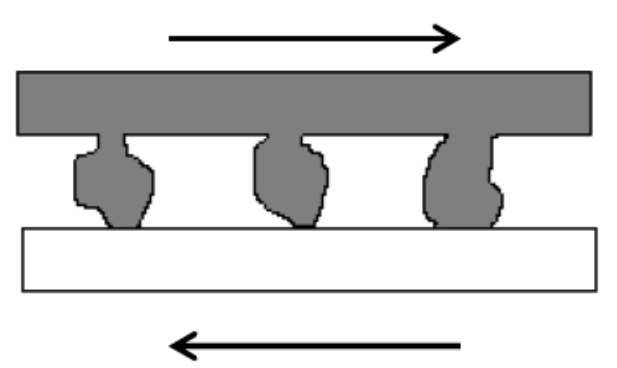

b)

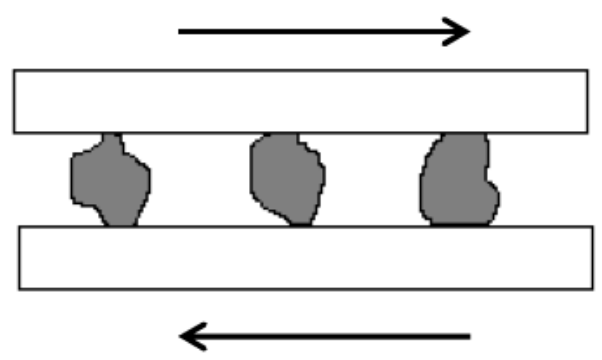

Figura 4. Desgaste abrasivo. a) Abrasión de dos cuerpos; b) Abrasión de tres cuerpos

En muchos casos, se produce inicialmente el desgaste adhesivo, que genera partículas de desgaste que quedan atrapadas en la interfase entre las dos superficies dando lugar posteriormente a desgaste abrasivo.

Cuando se produce este tipo de desgaste, es posible observar rayados, marcas profundas o ranuras en la dirección paralela a la dirección de deslizamiento.

-Desgaste por erosión. Se produce por el impacto de partículas sólidas que poseen una cierta velocidad sobre el material. La velocidad de la partícula y el ángulo de impacto combinados con el tamaño del abrasivo dan una medida de la energía cinética de las partículas incidentes responsables de este tipo de desgaste. Las partículas de desgaste formadas en la erosión se producen como resultado de impactos repetidos. Este tipo de desgaste se cuantifica en función de la pérdida de peso en relación al peso de la partícula incidente [9].

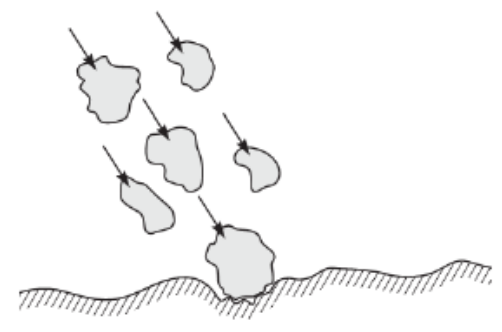

Figura 5. Desgaste por erosión

-Desgaste por fatiga. Cuando un material está sometido a repetidos ciclos de carga y descarga, se puede producir la formación de grietas subsuperficiales que se propagan y se conectan con otras grietas. Éstas pueden alcanzar la 
superficie y finalmente, después de un número crítico de ciclos, darán lugar a la ruptura de la misma debido al desprendimiento de fragmentos grandes [19].

Antes de llegar a este punto crítico (que puede ser de cientos, miles o incluso millones de ciclos), se produce un desgaste insignificante en contraposición al desgaste causado por los otros mecanismos.

Además de los diferentes tipos de desgaste mecánico comentados con anterioridad, es necesario mencionar otro tipo de desgaste que se puede dar en combinación con éstos, es el llamado desgaste por corrosión y/o oxidación.

Este tipo de desgaste químico ocurre tanto en contactos lubricados como no lubricados, cuando el deslizamiento ocurre en un ambiente corrosivo. En el aire, el agente corrosivo más dominante es el oxígeno. Por lo tanto, el desgaste químico en el aire generalmente se llama desgaste oxidativo. En ausencia de deslizamiento, los productos químicos de la corrosión formarían una película de menos de un micrómetro de espesor en las superficies, lo que tendería a ralentizar o incluso detener la corrosión. Sin embargo, cuando hay movimiento deslizante, éste impide la formación de esta capa de óxidos protectores, de manera que se seguirá produciendo el ataque químico.

Esta forma de desgaste se produce a una velocidad muy elevada y suele ir acompañada de un coeficiente de fricción reducido. Esta desviación entre la fricción y el desgaste es un identificador extremadamente útil de estos procesos de desgaste. Además este mecanismo es de gran importancia en el caso de operar en entornos industriales o costeros [9], [12].

Se estima que dos tercios de las pérdidas por desgaste en la industria son provocadas por mecanismos de desgaste abrasivos y adhesivos, favorecidos por las diferencias en la propiedades de los materiales en contacto, la presencia de otros cuerpos (partículas de desgate u óxidos); y condiciones de servicio (velocidad relativa, presión o temperatura). Por tanto, es de vital importancia que las superficies en contacto sean protegidas, ya sea mediante modificación superficial o mediante la separación de las mismas por medio de un lubricante [19].

\subsubsection{Lubricación}

Los lubricantes son aquellas sustancias que se sitúan entre dos superficies en contacto con el objetivo de prevenir cualquier influencia contraria al 
movimiento. Las principales funciones de los lubricantes, según Minami [20] son:

$>$ Control de la fricción: Aunque la reducción de la fricción y el desgaste y, por tanto, el fallo del material es la principal aplicación de los lubricantes, existen casos en los que es necesario disponer de alta fricción, como por ejemplo en frenos y embragues. Disponer de un lubricante adecuado para cada uno de los elementos de la máquina, permitiría mejorar el rendimiento de la misma.

$>$ Enfriamiento del contacto: El calor generado en el contacto puede provocar la transformación de la microestructura o fallo del material, es decir, influye de manera negativa en la superficie de los materiales. Esta acumulación de calor se puede evitar mediante la circulación de un lubricante líquido.

> Limpieza del contacto: La influencia negativa de la presencia de partículas de desgaste o suciedad generadas durante la operación de la máquina puede ser contrarrestada si se produce la circulación del lubricante o si se emplean lubricantes avanzados que ayuden en los procesos de limpieza.

La importancia de cada una de estas funciones va a depender de la aplicación. Por ejemplo, en rodamientos, lo importante es controlar la fricción, siendo la limpieza y el enfriamiento cuestiones secundarias. En el caso de emplear fluidos lubricantes para máquinas de corte ocurre al contrario, las funciones de enfriamiento y la capacidad de limpieza del contacto son prioritarias.

Existe una amplia variedad de materiales gaseosos, líquidos o sólidos que pueden emplearse como lubricantes. Aunque son los lubricantes líquidos los más ampliamente empleados. Éstos se pueden clasificar en lubricantes orgánicos naturales o lubricantes sintéticos. Entre los naturales se encuentran los aceites de procedencia animal como el aceite de ballena o de tiburón, las grasas animales, aceites minerales o vegetales. Los aceites minerales (procedentes del petróleo) incluyen las parafinas, naftalenos y aceites aromáticos, que son los lubricantes más usados en la actualidad. Los aceites sintéticos se desarrollaron en respuesta a las necesidades de la industria aeronáutica, ya que son capaces de soportar temperaturas extremas. En este grupo de lubricantes se encuentran los hidrocarburos sintéticos, ésteres, silanos o los perfluoropoliéteres (PFPEs) [21]. 
Ante la gran cantidad de lubricantes disponibles, surge la necesidad de distinguir entre los diferentes regímenes de lubricación en los que trabajan las máquinas [1]. Para ello, se emplean las curvas de Stribeck.

\subsubsection{El modelo de lubricación de Stribeck}

El modelo propuesto por Stribeck permite simular y explicar el comportamiento de los lubricantes. Este modelo relaciona el coeficiente de fricción con los parámetros de operación (velocidad y carga) y las propiedades del lubricante (viscosidad) a través del número de Hersey $\left(n \cdot v / F_{n}\right)$.

Como se puede observar en la Figura 6, la curva de Stribeck indica la existencia de diferentes regímenes de lubricación en función de la relación entre el espesor de la capa de lubricante, (h), y la rugosidad de las superficies en contacto $\left(R_{a}\right)$. En el caso de disponer de un lubricante con elevada viscosidad, la capa creada suele poseer elevado espesor, mientras que un lubricante con baja viscosidad proporciona una película más delgada entre las superficies en contacto [20].

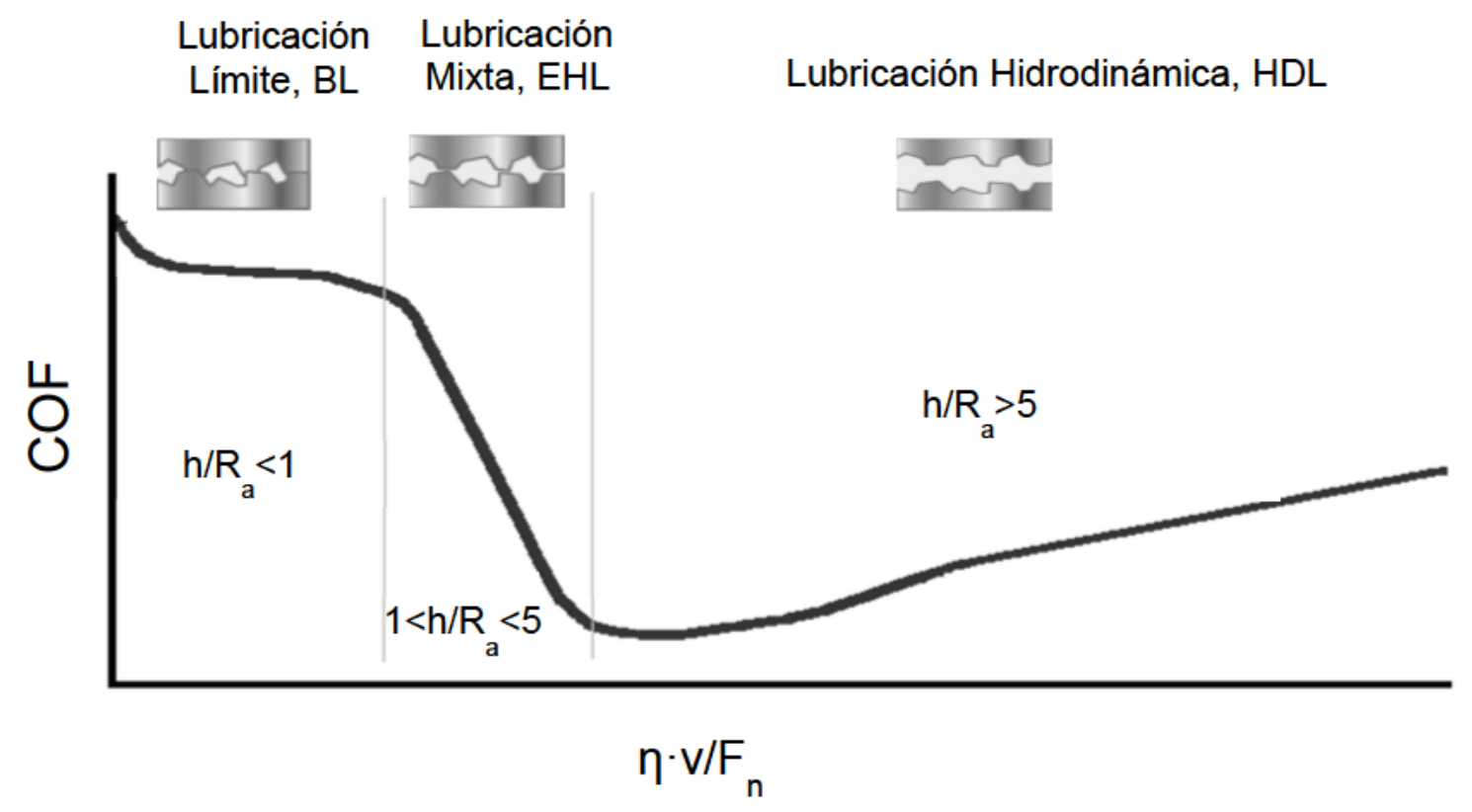

Figura 6. Curva de Stribeck

Si el espesor de la película de lubricante es muy superior a la rugosidad de la superficie $\left(h / R_{a}>5\right)$, las superficies pueden estar completamente separadas por el líquido. Por tanto, no hay contacto entre las superficies sólidas, eliminando el desgaste, y el coeficiente de fricción es bajo. Este régimen de lubricación se 
llama lubricación hidrodinámica (HDL), y la resistencia al movimiento es debida a los esfuerzos de cizalla producidos por la viscosidad del fluido [13].

Cuando el número de Hersey se hace más pequeño, existe lubricación límite $(\mathrm{BL})$. En este caso, el elevado coeficiente de fricción observado es debido a que las asperezas de una de las superficies entran en contacto con la otra superficie deslizante. Según la carga aplicada y las propiedades de los materiales, se pueden producir tanto deformación plástica como elástica e incluso en algunos casos, fractura. En este régimen de lubricación tienen lugar interacciones químicas y físicas entre las superficies y el lubricante. Los productos de reacción tienen un papel muy importante en la efectividad del lubricante, mientras que su viscosidad no afecta a la fricción o al desgaste. La carga es soportada por películas adsorbidas de lubricante de espesor nanométrico que presentan una alta tenacidad [22]. En este caso, la relación entre el espesor de la película y la rugosidad de las superficies es inferior a 1.

Si el espesor de la capa de lubricante es mayor que una decena de nanómetros, el régimen de lubricación es el mixto o elastohidrodinámico $(\mathrm{EHL})$, un régimen intermedio entre la lubricación hidrodinámica y la lubricación límite. Es este caso, la existencia de una capa de fluido entre las dos superficies en contacto se explica debido a la deformación elástica de las superficies bajo altas presiones y por el cambio de la viscosidad del fluido con la presión [23] .

Este modelo simplificado de la curva de Stribeck ayuda a entender el papel de cada componente en los sistemas de lubricación, aunque los fenómenos que ocurren en la práctica son más complejos. De hecho, para la elaboración de mapas de lubricación, la relación $h / R_{a}$ no puede emplearse cuando las superficies sólidas tienen una rugosidad muy baja [22].

Por ello, Wen en el año 1991 [24] y Luo en 2001 [25] propusieron un nuevo mapa de lubricación teniendo en cuenta, no solo el espesor de película y la rugosidad de las superficies, sino también el tamaño de las moléculas de lubricante. Como se puede observar en la Figura 7, se presentan los distintos regímenes de lubricación en función de las relaciones $h / R_{a}$ y $h / R_{g}$, siendo $h$ el espesor de la película de lubricante, $R_{a}$, la rugosidad de las dos superficies en movimiento relativo y $R_{g}$, el radio efectivo de las moléculas de lubricante. 


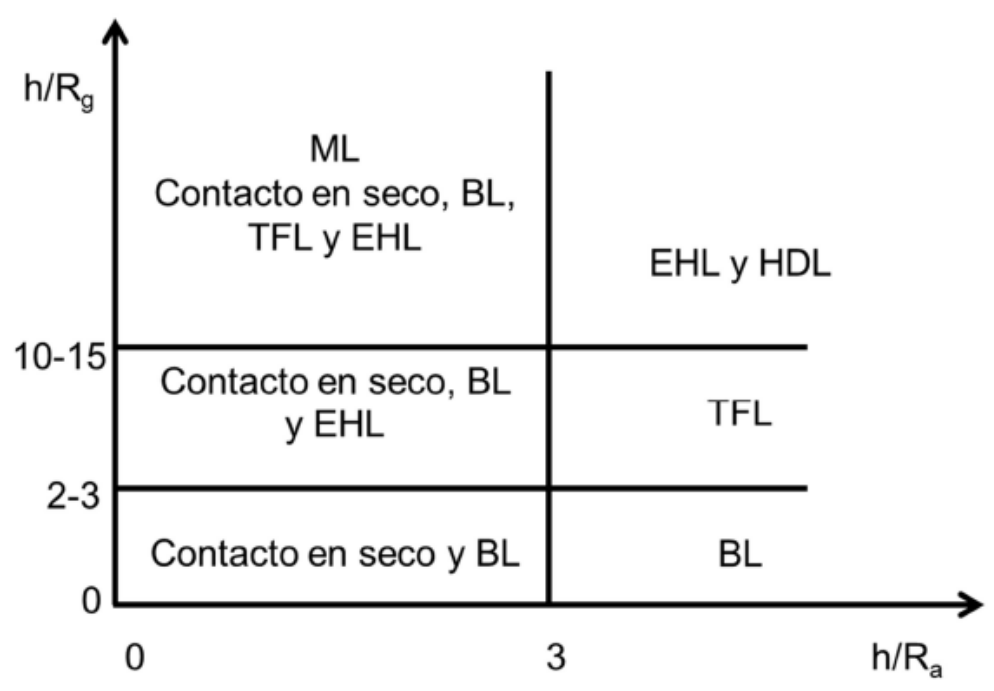

Figura 7. Mapa de lubricación propuesto por Luo [26]

El nuevo modelo de lubricación contempla la existencia del régimen de lubricación en película fina (TFL) que se encuentra entre la zona dominada por la lubricación límite y la elastohidrodinámica. En esta zona, la separación entre las superficies tiene un espesor que oscila de varios nanómetros a decenas de nanómetros. La película lubricante está dominada por el comportamiento molecular en diferentes micro/nano regiones, formando tres capas (Figura 8).

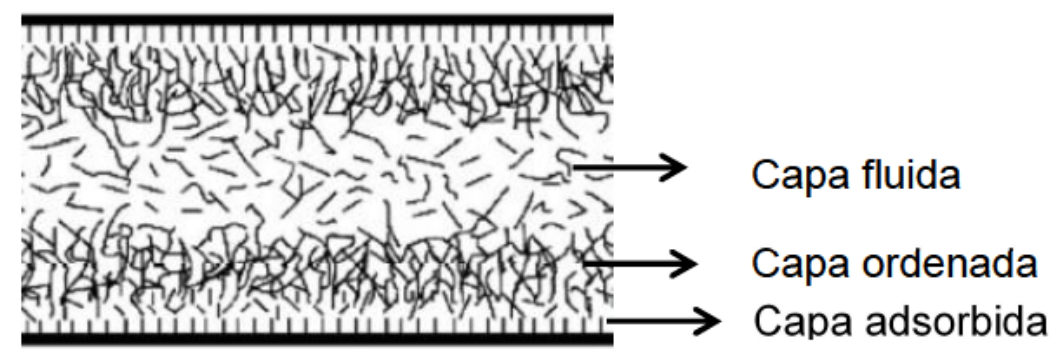

Figura 8. Modelo del régimen de lubricación en película fina (TFL)

La llamada capa adsorbida está constituida por moléculas que se adsorben y empaquetan en la superficie del sólido. En el régimen TFL, el lubricante es capaz de fluir entre los cuerpos, formando la llamada capa fluida, de ahí la importancia que adquiere la viscosidad. Entre ambas capas hay una región de transición llamada región ordenada, aunque dicho ordenamiento no es tan elevado como en la capa adsorbida.

El espesor de película y las propiedades tribológicas en el régimen TFL son diferentes a los presentados en la lubricación límite, el EHL y el HDL, aunque 
independientemente del régimen en el que se trabaje, se ven afectadas por una serie de factores, tales como el efecto hidrodinámico, el tamaño molecular y la polarización molecular [22].

Aunque las máquinas están diseñadas para trabajar en régimen de lubricación hidrodinámica en estado estacionario, éstas experimentan lubricación límite, al menos en las operaciones de arranque y parada. Por tanto, los lubricantes deben ser eficaces en todos los regímenes de lubricación, de ahí que se añadan diferentes aditivos incluyendo antioxidantes, detergentes, modificadores de la fricción, de la viscosidad y/o aditivos antidesgaste al lubricante base [27]. Los lubricantes comerciales, en general, presentan problemas medioambientales y no son adecuados para muchos materiales y condiciones, surgiendo la necesidad de emplear nuevos lubricantes que sean efectivos y respetuosos con el medio ambiente [28].

\subsection{LÍQUIDOS IÓNICOS}

Los líquidos iónicos (LI) son sales fundidas con una temperatura de fusión inferior a $100^{\circ} \mathrm{C}$, que están formados por un catión orgánico y un anión que puede ser orgánico o inorgánico. Estas sustancias poseen unas propiedades físicas y químicas únicas, como su baja inflamabilidad, alta estabilidad térmica y electroquímica, muy baja volatilidad, amplio rango de líquidus, alta conductividad iónica o baja presión de vapor [27], [29]-[31]. Además, estos fluidos son capaces de disolver un amplio rango de compuestos orgánicos e inorgánicos [32].

Como resultado de las reducidas fuerzas electroestáticas entre el anión y el catión en estas sales y su asimetría, es difícil formar estructuras cristalinas regulares, por tanto, son líquidos a temperatura ambiente [33]. La polaridad y su carácter hidrofílico o hidrofóbico pueden ser modificados empleando la combinación adecuada de catión y anión. Esta propiedad de los líquidos iónicos hace que sean conocidos como líquidos iónicos hechos a medida "task specific ionic liquids" [34]. Existe una gran cantidad de líquidos iónicos, de hecho, las combinaciones catión-anión pueden exceder el millón de posibilidades [21], siendo los cationes orgánicos imidazolio, piridinio, fosfonio, amonio, pirrolidinio, morfolinio y colinio los más empleados [30]. 
Según Torimoto [35], los líquidos iónicos se pueden clasificar en siete familias en función de las estructuras catiónicas que poseen, variando la longitud de la cadena y el anión (Figura 9).

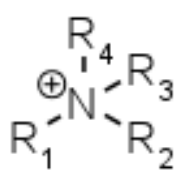

Tetraalquilamonio

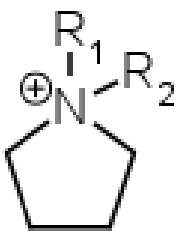

1,2,3-Trialquilimidazolio

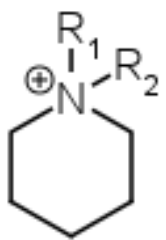<smiles>[R]c1n([R])cc[n+]1[R]</smiles><smiles>[R][n+]1ccccc1</smiles>

Alquilpiridinio<smiles>[R][Sb]([R])([R])[R]</smiles>

Dialquilpirrolidinio Dialquilpiperidinio Tetraalquilfosfonio Trialquilsulfonio

Figura 9. Principales estructuras catiónicas de los líquidos iónicos

Los líquidos iónicos son conocidos por diversos nombres: disolventes neotéricos, disolventes de diseño, fluidos iónicos o sales fundidas [34]. Este último término es el empleado para designar a los compuestos iónicos en estado líquido, pero no es exactamente un sinónimo de líquido iónico. Por ejemplo, los líquidos iónicos normalmente presentan interacciones anión-catión que no son observadas en las sales fundidas a alta temperatura. Por tanto, sería idóneo el empleo del término "sal fundida a temperatura ambiente" como sinónimo de líquido iónico [36].

El primer líquido iónico a temperatura ambiente, $\left[\mathrm{EtNH}_{3}\right]\left[\mathrm{NO}_{3}\right]$, fue descubierto en 1914 por Walden [37], sin embargo, no fue hasta el descubrimiento de los líquidos iónicos binarios obtenidos a partir de mezclas de cloruro de aluminio (III) y $\mathrm{N}$-alquilpiridinio o 1,3-dialquilimidazolio cuando adquirieron un mayor interés [36].

Los líquidos iónicos han sido ampliamente empleados en todos los campos de la química y la ingeniería química. Además, su uso como fluidos de ingeniería ha aumentado en los últimos tiempos, debido principalmente a su carácter de fluidos "verdes", concepto introducido por Anastas [38], [39], que propone el empleo de productos y procedimientos químicos que permitan la reducción y 
eliminación de sustancias peligrosas. Gracias a propiedades como su baja volatilidad, que los hace más compatibles con el medio ambiente, los líquidos iónicos presentan multitud de aplicaciones. En la Figura 10 se pueden observar algunas de éstas [40], [41], [50]-[55], [42]-[49].

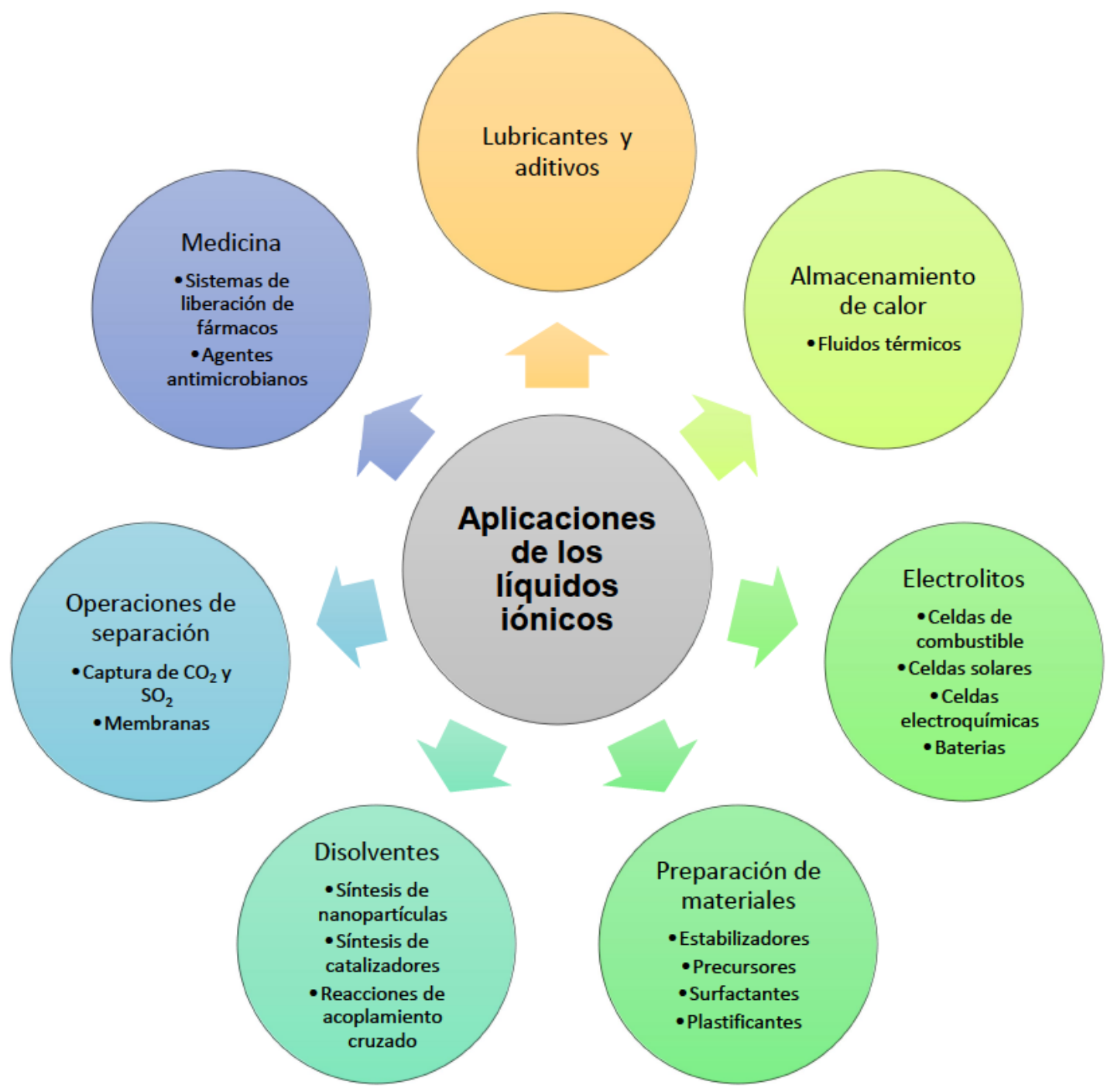

Figura 10. Aplicaciones de los líquidos iónicos

\subsubsection{Líquidos iónicos como lubricantes}

El primer trabajo donde se describe el uso de sales fundidas como lubricantes data de 1961. En él Smith [56] emplea una mezcla de LiF, $\mathrm{BeF}_{2}$ y $\mathrm{UF}_{4}$ como lubricante a alta temperatura. En 1992, Wilkes y Zaworotko desarrollaron el primer líquido iónico estable en presencia de aire y humedad, derivado del anión tetrafluoroborato [57]. 
En el campo de la lubricación, el uso efectivo de líquidos iónicos comenzó a principios del presente siglo, cuando Ye et al. [58] y Liu et al. [59] estudiaron el uso de tetrafluoroboratos de alquilimidazolio como lubricantes en diversos contactos con muy buenos resultados. A partir de ese momento, el interés por el estudio de los líquidos iónicos como lubricantes se incrementa exponencialmente, como se puede observar en la Figura 11, donde se muestra la evolución del número de publicaciones hasta agosto de 2018, cuyos datos se han obtenido de la base de datos ISI Web of Science.

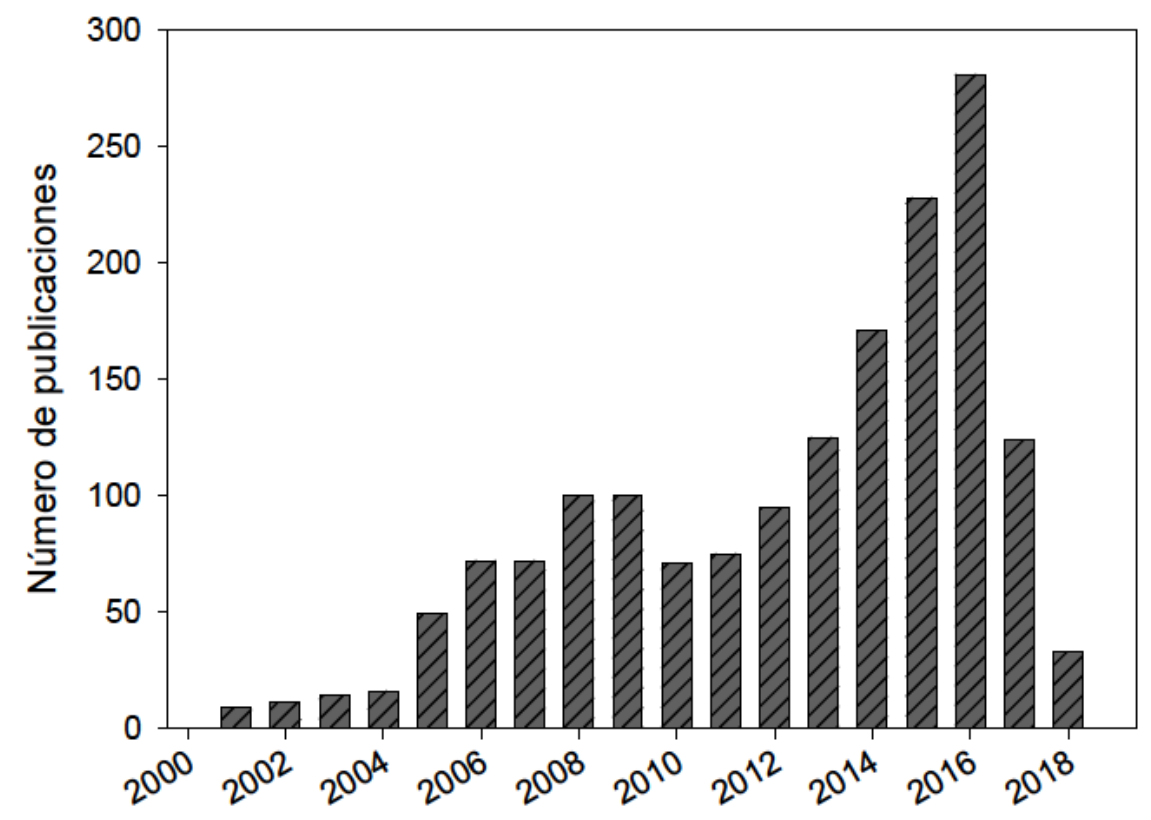

Figura 11. Evolución del número de publicaciones científicas sobre el uso de líquidos iónicos como lubricantes

Las propiedades físicas, químicas y térmicas que poseen los líquidos iónicos como la alta capacidad calorífica específica (que aumenta con el peso molecular), alta miscibilidad en disolventes polares y apolares, densidad superior a la del agua, alta conductividad térmica y calor de vaporización, muy baja inflamabilidad, elevada estabilidad térmica o capacidad de inhibición de la corrosión, contribuyen notablemente a mejorar sus propiedades lubricantes [60]. Los líquidos iónicos que más se han empleado en lubricación son los derivados de los cationes fosfonio [61], [62], imidazolio [63], [64], amonio [65], [66] y piridinio [67], [68], mientras que los aniones más empleados son el tetrafluoroborato $\left(\mathrm{BF}_{4}^{-}\right)$[68], [69] y hexafluorofosfato $\left(\mathrm{PF}_{6}^{-}\right)$[68], [70].

Estos compuestos presentan un gran potencial como lubricantes o aditivos de lubricantes, habiéndose estudiado su comportamiento en diversos contactos. 
Se ha comprobado que la presencia de aniones más hidrofóbicos incrementa el efecto lubricante y la estabilidad termo-oxidativa [20], [71]. En general, las fuertes interacciones de los líquidos iónicos con la superficie proporcionan una mejor capacidad de lubricación en la interfase sólido-líquido. Con la presencia de la película de lubricante en el área de contacto real, adsorbida sobre la superficie, la capacidad de soportar carga de esta capa límite reduce el esfuerzo de cizalla, reduciendo la fuerza de fricción. Este mecanismo de contacto, propuesto por Bowden y Tabor [72] adquiere una gran importancia cuando el lubricante posee una elevada viscosidad, ya que aumenta notablemente su capacidad de soportar carga, mejorando el comportamiento antifricción y antidesgaste.

El comportamiento tribológico de los líquidos iónicos se ve influenciado por las reacciones químicas que se dan a nivel molecular. Los procesos de adsorción atómica de los líquidos iónicos sobre los sustratos se ven acelerados por la energía térmica y mecánica en condiciones de lubricación límite y mixta [33]. La energía calorífica generada durante el movimiento relativo del par deslizante provoca reacciones químicas en la interfase y la formación de tribocapas [73]. En resumen, las fuertes interacciones de los líquidos iónicos y las superficies metálicas fomentan la formación de capas de moléculas orientadas densamente empaquetadas con la adecuada capacidad de soportar carga, lo que contribuye a la reducción de la fricción y el desgaste [21], [74], [75]. La longitud de las cadenas alquílicas de los líquidos iónicos también tiene un importante papel en este proceso. Las cadenas más largas tienden a formar películas ordenadas y más densamente empaquetadas, debido a las uniones mediante fuerzas de Van der Waals entre las mismas [33], [76].

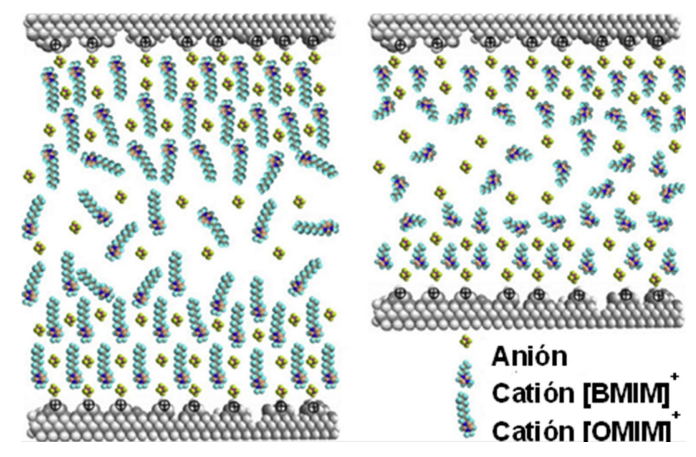

Figura 12. Interacción de los líquidos iónicos $[\mathrm{BMIN}]^{+}$y $[\mathrm{OMIM}]^{+}$con la superficie metálica en función de la longitud de la cadena catiónica 
Se han comentado con anterioridad las propiedades que hacen de los líquidos iónicos excepcionales lubricantes, sin embargo, también presentan una serie de desventajas. Indican Palacio y Bushman [21] que debido a la gran cantidad de líquidos iónicos disponibles, el estudio de sus propiedades tribológicas es bastante difuso. Además, algunos de estos compuestos son sensibles a la humedad, pudiéndose descomponer fácilmente, $\mathrm{o}$ se pueden generar productos durante su calentamiento que pueden ser inflamables. Sin embargo, es la producción de subproductos altamente tóxicos, como $\mathrm{HF}, \mathrm{HCl} \circ \mathrm{H}_{3} \mathrm{BO}_{3}$, procedentes de la descomposición hidrolítica de los líquidos iónicos que poseen haluros en su estructura, lo que conlleva importantes riesgos medioambientales y provoca la corrosión de los sustratos mediante reacciones triboquímicas [60], [77]. De hecho, Deettlefs et al. afirman que aunque los líquidos iónicos han sido diseñados para ser sustancias "verdes", la mayoría de ellos no lo son [78], ya que esta cualidad depende no solo de ellos mismos, sino de su síntesis y sus aplicaciones específicas [79]. Se ha determinado que la longitud de la cadena catiónica y la hidrofobicidad de la misma influyen notablemente en la toxicidad de los líquidos iónicos, así como el tipo de catión empleado (siendo los líquidos iónicos derivados del catión fosfonio los más tóxicos) y la lipofilicidad e inestabilidad del anión [30].

Se ha observado además, que los líquidos iónicos presentan una baja biodegradabilidad [79]-[82]. Disponer de cadenas alquílicas no ramificadas más largas y la presencia de grupos hidrolizables (ésteres) y grupos fácilmente oxidables (alcoholes y ácidos carboxílicos) son las características que presentan los líquidos iónicos más fácilmente biodegradables. Además, la presencia de heterociclos, así como la presencia de pequeños cambios en la estructura pueden, en algunos casos, inhibir en gran medida la biodegradabilidad [83].

Por todo esto, junto con el elevado coste de producción que dificulta su implementación a gran escala [84], en los últimos tiempos se está trabajando en la línea de desarrollar nuevos líquidos iónicos que sean respetuosos con el medioambiente, biocompatibles y biodegradables como los líquidos iónicos libres de haluros y líquidos iónicos próticos [85].

\subsubsection{Líquidos iónicos próticos}

Los líquidos iónicos próticos (PILs), también llamados líquidos iónicos de segunda generación, son un tipo de líquidos iónicos que se preparan mediante 
una reacción de neutralización estequiométrica entre ciertos ácidos de Brønsted y bases de Brønsted (Figura 13). La característica clave de este tipo de líquidos iónicos es la presencia de al menos un protón disponible en el catión [86]. Por convenio, el resto de LI se clasifican como líquidos iónicos apróticos [86].

De esta manera, Bicak sintetizó un líquido iónico a partir de la neutralización de monoetanolamina y ácido fórmico [87] y posteriormente Greaves et al. obtuvieron diferentes líquidos iónicos próticos a partir de aminas primarias y ácidos orgánicos e inorgánicos [88]. Iglesias y colaboradores han sintetizado una familia de estos PILs mediante la modificación de cadenas alifáticas de ácidos orgánicos usando hidroxiaminas secundarias y terciarias [84], [89]-[95].

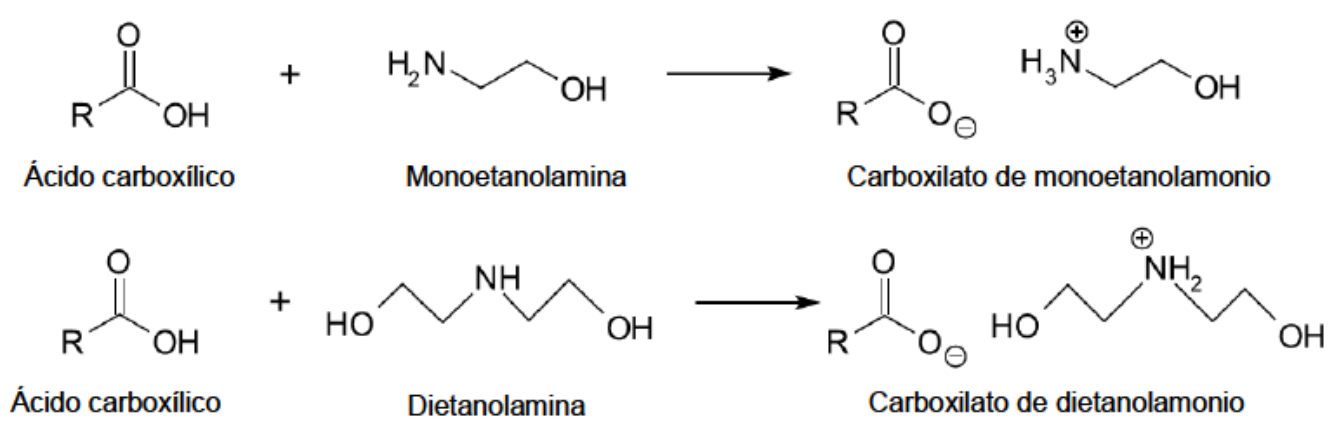

Figura 13. Síntesis de líquidos iónicos próticos

Hay que tener en cuenta que en la síntesis es posible que la transferencia de protones sea incompleta, dando lugar a otras especies moleculares. Además, en el proceso de secado puede que se elimine más de un ion que del otro en el $\mathrm{PIL}$, dando lugar a una mezcla no estequiométrica, enriquecida en las especies precursoras menos volátiles [86].

Muchos líquidos iónicos próticos poseen una nanoestructura líquida compleja que posee dominios polares y apolares, que influyen en sus propiedades y en su interacción con el medio [86]. Estos compuestos poseen además una alta conductividad, una moderadamente alta viscosidad [92] y además son solubles en agua [96].

Los líquidos iónicos próticos se han empleado como electrolitos en celdas de combustible y otros dispositivos de almacenamiento de energía, operaciones de separación y procesos de auto-ensamblaje molecular [88], [97]. Sin embargo, su uso principal sigue siendo como disolventes y/o catalizadores de 
reacciones orgánicas [86] gracias a su elevada solubilidad en agua, y en disolventes polares [92].

Ha habido un importante crecimiento de publicaciones referidas a líquidos iónicos próticos, particularmente describiendo muchas aplicaciones donde se considera a los PILs como relativamente baratos y fáciles de sintetizar.

Los líquidos iónicos próticos, que poseen aminas sustituidas como cationes y ácidos orgánicos deprotonados con diferente número de átomos de carbono como aniones, objeto del presente estudio, son compuestos potencialmente biodegradables en agua ya que no poseen grupos moleculares complejos ni potencialmente peligrosos como heterociclos o elementos halógenos [84].

Dentro de este grupo de líquidos iónicos próticos se encuentran los líquidos iónicos próticos derivados de ácidos grasos. Éstos son sustancias con un bajo impacto ambiental, y se podrían definir como "bioproductos sostenibles". Las ácidos grasos, de donde proceden, se obtienen como subproductos en el proceso de refinado de aceites vegetales, como el aceite de palma, debido a la hidrólisis de las moléculas de triacilglicerol [98].

Debido al aumento de la producción a gran escala de los aceites vegetales, el uso de este tipo de líquidos iónicos es de especial relevancia, ya que permitiría obtener líquidos iónicos de forma sencilla, gestionar un subproducto de forma respetuosa con el medio ambiente y expandir la aplicabilidad de los líquidos iónicos al procesado de alimentos [31].

Estos líquidos iónicos de cadena larga presentan mesofases cristal líquido asociadas a comportamientos reológicos complejos, a menudo caracterizados por flujos no Newtonianos. Debido a su naturaleza marcadamente asimétrica, este tipo de compuestos puede organizarse en estructuras cristalinas por encima del punto de fusión, a pesar de presentar propiedades características del estado líquido [31]. Por ello, podrían ser empleados como surfactantes, en productos cosméticos [99] o farmacéuticos, como biolubricantes o en sistemas de liberación de medicamentos [98]. Incluso pueden emplearse en la industria alimentaria o de bioproductos, ya que son consideradas sustancias seguras [98]-[100].

Por las características comentadas con anterioridad, bajo coste, facilidad de síntesis y composición (sólo poseen $\mathrm{C}, \mathrm{H}, \mathrm{O}$ y $\mathrm{N}$ ), se presentan como unos 
excelentes sustitutos de los líquidos iónicos apróticos en su uso como lubricantes [101]-[107].

\subsection{POLÍMEROS}

Según la IUPAC, una macromolécula o polímero es una molécula de elevada masa molecular relativa, cuya estructura comprende esencialmente la repetición múltiple de unidades derivadas de otras moléculas llamadas monómeros que poseen una baja masa molecular relativa [108]. Muchos de estos materiales son compuestos orgánicos formados principalmente por carbono, hidrógeno y otros elementos no metálicos como O, N o Si.

Estos materiales suelen tener bajas densidades, bajas temperaturas de procesado y bajo coste, mientras que sus características mecánicas son generalmente diferentes a las de los materiales metálicos y cerámicos: no son tan rígidos ni tan resistentes como estos tipos de materiales. Además, muchos de los polímeros son extremadamente dúctiles y flexibles, facilitando la fabricación de geometrías complejas. En general, son relativamente inertes químicamente y no reactivos en una gran cantidad de entornos. Su tendencia a reblandecerse y/o descomponerse a temperaturas moderadas es su inconveniente principal. Además, tienen baja conductividad eléctrica y no son magnéticos [109].

Los polímeros han sido los protagonistas relevantes de la revolución tecnológica que tiene lugar en casi todos los sectores industriales. Actualmente, siguen apareciendo nuevas y ventajosas aplicaciones de estos materiales en las industrias de la electricidad, electrónica, de la construcción, naval, del automóvil, etc.

La constante búsqueda de nuevas aplicaciones ha fomentado la incorporación de aditivos, refuerzos y rellenos a las matrices poliméricas con el fin de mejorar ciertas propiedades de estos materiales [110].

Los polímeros se pueden clasificar en función de su origen, su composición química, su relación producción-coste o su comportamiento térmico-mecánico, siendo esta última clasificación una de las más ampliamente utilizadas.

Según el comportamiento de los polímeros con el aumento de la temperatura, es posible clasificarlos en termoplásticos o termoestables. 
Los polímeros termoplásticos se ablandan cuando se calientan y se endurecen cuando se enfrían. A nivel molecular, a medida que aumenta la temperatura, las fuerzas de unión secundarias disminuyen (al aumentar el movimiento molecular) de modo que el movimiento relativo de las cadenas adyacentes se facilita cuando se aplica una tensión. Debido a este comportamiento, estos materiales pueden moldearse por inyección, extruirse y reciclarse con facilidad. La degradación irreversible de los termoplásticos se produce cuando se someten a una temperatura demasiado elevada.

En general, este tipo de polímeros posee un elevado peso molecular y presentan cadenas lineales o estructuras ramificadas con cadenas flexibles. Sus propiedades físicas dependen de su historial térmico, de manera que éstas se ven mermadas si se reprocesan varias veces.

A diferencia de los termoplásticos, los polímeros termoestables reaccionan químicamente para formar enlaces cruzados covalentes, que limitan el movimiento de las cadenas.

Durante el proceso de curado, estos enlaces unen las cadenas entre sí con el objetivo de resistir los movimientos vibratorios y de rotación a altas temperaturas. Por lo tanto, estos polímeros no se ablandan cuando se calientan. La reticulación suele ser extensa, ya que del $10 \%$ al $50 \%$ de las unidades de repetición de cadena están reticuladas. Solo el calentamiento a temperaturas excesivas provocará la ruptura de estos enlaces de reticulación y la degradación del polímero.

Los polímeros termoestables son generalmente más duros, tienen mejores propiedades mecánicas, son más resistentes a las altas temperaturas y a los disolventes que los termoplásticos y tienen una mayor estabilidad dimensional. Sin embargo, presentan unas pobres propiedades tribológicas, alta fragilidad y un relativamente largo proceso de preparación [109], [111].

\subsubsection{Resina epoxi}

Las resinas epoxi son polímeros termoestables, de bajo peso molecular, que poseen más de un grupo epoxi situado terminalmente, cíclicamente o internamente en su estructura. Estas resinas se pueden convertir en materiales sólidos a través de una reacción termoendurecible [112]-[114]. 


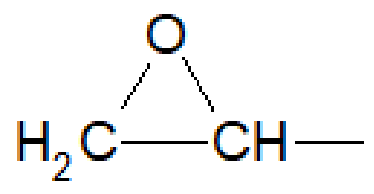

Figura 14. Estructura química del grupo epoxi

La síntesis de las resinas epoxi se lleva a cabo mediante reacciones de entrecruzamiento, siendo necesario disponer de un prepolímero, (el más empleado es el diglicildiéter del bisfenol A) y un agente de curado o endurecedor que facilita la reticulación de las cadenas poliméricas, formando una red tridimensional [115].

El prepolímero diglicildiéter del bisfenol A (DGEBA), cuyas propiedades dependen del número de moléculas repetidas, se obtiene a partir de la reacción del bisfenol A con epiclorhidrina. Con respecto a los agentes de curado, éstos pueden clasificarse, en función de su composición química, en agentes de curado tipo amina, álcali, anhídridos o catalíticos. Los más empleados son los de tipo amina, que reaccionan con el prepolímero mediante adición nucleofílica [113].

El proceso de curado de las resinas epoxi se ve influenciado notablemente por la temperatura. Cuando se emplean agentes de curado de tipo amina, el curado puede darse a temperatura ambiente, obteniéndose temperaturas de transición vítrea $(\mathrm{Tg})$ del producto final bajas y materiales con elevada flexibilidad y alta resistencia al impacto [116], [117]. También se puede realizar un proceso de curado a temperatura, que normalmente se divide en dos etapas, una a alta temperatura y otra generalmente a temperatura ambiente. Los termoestables así obtenidos presentan mayores valores de $\mathrm{Tg}$, mayor resistencia térmica y a la tracción [118].

Las resinas epoxi son materiales amorfos, cuyas propiedades dependen del prepolímero y el agente de curado que se emplee [114], [119]-[121]. En general, las resinas epoxi poseen buenas propiedades mecánicas, con una resistencia a la tracción, a la compresión y rigidez superior a la presentada por los polímeros termoplásticos [113], [114].

Además, los materiales de matriz epoxi presentan una excelente resistencia química y térmica, alta capacidad de adhesión a diferentes sustratos gracias a 
la presencia de numerosos grupos polares (hidroxilo) y resistencia a la corrosión, de ahí que hayan sido empleadas en multitud de aplicaciones (Figura 15) [113].

El desarrollo histórico de los compuestos epoxi se remonta a finales del siglo $\mathrm{XIX}$, aunque, no fue hasta mediados del siglo XX cuando su produjo su desarrollo comercial [112]. En la actualidad, los sectores que más ampliamente usan este tipo de materiales son la industria electrónica, siendo empleada para la realización de circuitos integrados de sobremoldeo, transistores y circuitos híbridos, y en la fabricación de placas de circuitos impresos [122]-[124], el sector de los adhesivos, la industria aeroespacial o el de las pinturas y recubrimientos superficiales (bidones, tubos de acero, fibrocemento o latas metálicas) [125], [126] (Figura 15).

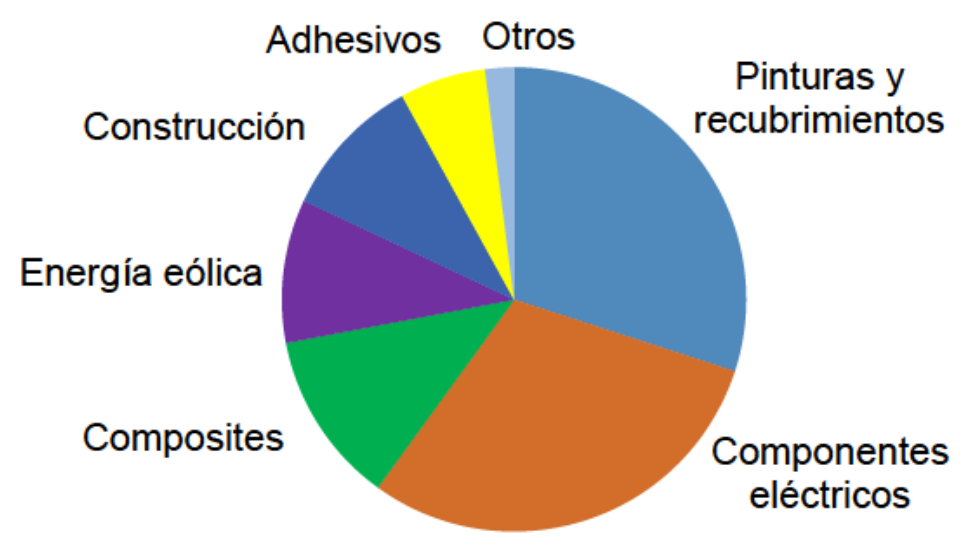

Figura 15. Aplicaciones de la resina epoxi [114]

Por otra parte, las resinas epoxi exhiben una baja conductividad eléctrica, y la alta densidad de reticulación de sus cadenas reduce intrínsecamente la tenacidad y la resistencia al impacto, lo que las hace vulnerables a las microgrietas producidas en servicio y limita sus aplicaciones. Multitud de aditivos entre los que se encuentran las nanofibras de carbono, el grafeno, nanoarcillas, sílice, óxido de zinc o alúmina, se han utilizado para modificar las resinas epoxi con el fin de mejorar sus propiedades mecánicas, de resistencia al desgaste, conductividad térmica, propiedades magnéticas, ópticas e ignifugas [127][128]. 


\subsection{NANOFASES DE CARBONO [129]-[132]}

El desarrollo de la nanociencia y la nanotecnología ha generado avances considerables en muchas industrias, como la de los materiales compuestos, la electrónica o la medicina. El término nanociencia se refiere al estudio de las estructuras y propiedades de materiales a escala nanométrica, mientras que la nanotecnología se encarga de la síntesis, el control, la aplicación y la manipulación de los nanomateriales.

Las nanoestructuras de carbono son las que más interés han despertado en la comunidad científica centrada en el estudio de las propiedades y aplicaciones potenciales de estos materiales.

El carbono es uno de los elementos más abundantes y versátiles del universo. Este elemento tiende a unirse en estructuras multiatómicas dando lugar a diferentes formas alotrópicas en función de las diversas ordenaciones espaciales de sus orbitales en los distintos tipos de hibridación. En la naturaleza es posible encontrar el carbono en forma de diamante $\left(\mathrm{sp}^{3}\right)$, grafito $\left(s p^{2}\right)$ o carbón.

Los compuestos derivados de las nanoestructuras de carbono pueden presentar muy buenas propiedades mecánicas, conductividad eléctrica y térmica o de resistencia a la corrosión, características deseables en aplicaciones biomédicas, ópticas, electroquímicas, electrónicas o tribológicas. Dichas propiedades van a depender de la estructura que presenten, por tanto, en función de la aplicación, se podrá emplear un tipo de nanoestructura u otra.

En la Figura 16 se muestran diferentes nanoestructuras de carbono, incluidos los fullerenos de dimensión cero (OD), los nanotubos de carbono (CNT) unidimensionales (1D), el grafeno bidimensional (2D) y los nanodiamantes tridimensionales (3D).

A continuación se describen los nanodiamantes y el grafeno, las nanoestructuras de carbono que han sido empleadas en el presente estudio. 


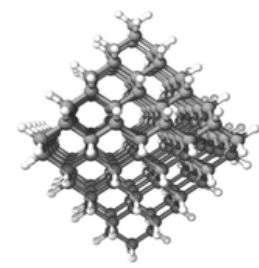

Nanodiamantes

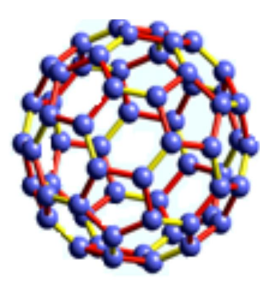

Fullereno $\mathrm{C}_{60}$

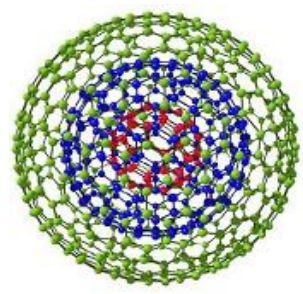

Nano-cebollas

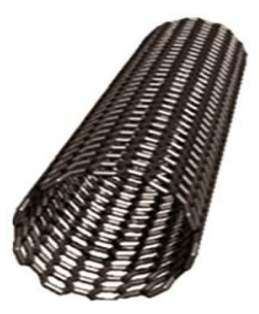

Nanotubos de carbono

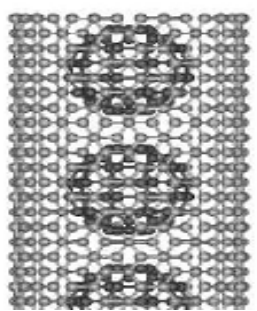

Nanovainas

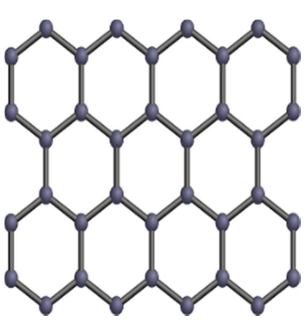

Grafeno

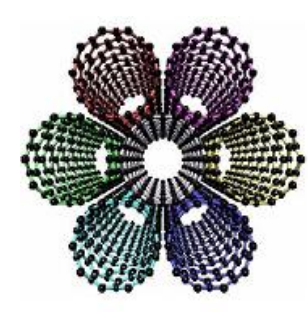

Nanohaces

Figura 16. Nanoestructuras de carbono

\subsubsection{Grafeno}

El grafeno está formado por una única capa de átomos de carbono con hibridación $\mathrm{sp}^{2}$ dispuestos en una estructura $2 \mathrm{D}$ hexagonal plana o en forma de panal de abeja, en el que cada átomo de carbono está aproximadamente a $0,142 \mathrm{~nm}$ de sus tres átomos vecinos [129], [133]-[137].

Esta nanoestructura se puede considerar como la base de los materiales de carbono grafítico ya que las láminas de grafeno se pueden apilar en 3D formando grafito, enrollarse en nanotubos de carbono (1D) o envolverse en forma de fullerenos (OD) [138].

Este nuevo material fue descubierto en 2004 por K. Novoselov y A. Geim [136], y su descubrimiento ha impulsado la investigación en nanociencia y nanotecnología gracias a las excepcionales propiedades eléctricas, mecánicas y químicas que presenta [129].

El grafeno es el primer material bidimensional estable a temperatura ambiente. Esta estabilidad puede ser atribuida a ondulaciones o arrugas que presenta a 
nivel microscópico que evitan que la superficie se enrolle en forma de tubo y además eliminan las vibraciones térmicas [139].

Este material posee una alta conductividad eléctrica y alta movilidad de los portadores de carga, entre $2000-5000 \mathrm{~cm}^{2} \mathrm{~N} \cdot \mathrm{s}$ [140]. El grafeno también ofrece una transparencia óptica de hasta el 97,7\% [141] y una elevada conductividad térmica $(5000 \mathrm{~W} / \mathrm{m} \cdot \mathrm{K})$ [137]. Con respecto a sus propiedades mecánicas, gracias a las fuertes uniones $\mathrm{C}-\mathrm{C}$, este material presenta un elevado módulo de Young ( 1 TPa) [142], una tensión de rotura de 130 GPa y una superficie específica extraordinariamente grande, $2630 \mathrm{~m}^{2} / \mathrm{g}$ [143]. Además presenta una elevada impermeabilidad a los líquidos y gases [144], estabilidad ambiental y es fácilmente funcionalizable.

\subsubsection{Métodos de obtención de grafeno}

Existen diferentes métodos para la síntesis y producción de grafeno. Dependiendo del tipo y la calidad, las propiedades del material producido pueden variar mucho, sobre todo el tamaño, la forma, el grosor y la densidad de los defectos, por tanto, las propiedades mecánicas y tribológicas se verán afectadas [145].

A continuación, se recogen los métodos de producción de grafeno divididos en dos grupos: top-down y bottom-up [129], [146]-[148]. Los métodos top-down se basan en la ruptura de las fuerzas de Van der Waals que mantienen unidas las láminas de grafeno que conforman el grafito, aunque también se puede obtener el grafeno a partir de óxido de grafeno u óxido de grafito. Son técnicas topdown la exfoliación seca y exfoliación en fase líquida. Los principales inconvenientes de estas técnicas son la imposibilidad de controlar tanto el número de capas de carbono como la calidad del material obtenido.

El segundo de los grupos de producción de grafeno engloba a aquellos métodos que consisten en el crecimiento de láminas de grafeno mediante la combinación de unidades estructurales básicas empleando métodos de síntesis orgánica, lo que permite el crecimiento de grafeno directamente a través de precursores orgánicos moleculares. Dentro del grupo bottom-up se encuentran las técnicas de formación química de depósitos en fase de vapor, epitaxia de haces moleculares, síntesis química, crecimiento en $\mathrm{SiC}$ y crecimiento en metales por precipitación. La principal limitación de estas técnicas es su coste y 
la imposibilidad de obtener grafeno en grandes cantidades y de forma uniforme [129].

\subsection{Top-Down}

\section{Exfoliación seca}

Este método consiste en la obtención de láminas de grafeno de espesor atómico mediante fuerzas mecánicas, electroestáticas o electromagnéticas en atmósfera de aire, vacío o inerte [149].

La exfoliación micromecánica (Figura 17) fue el método empleado por Novoselov et al. [140] para la obtención de una única capa de grafeno (SLG) usando una cinta adhesiva sobre grafito. Este método se ha optimizado, de manera que es posible producir capas de alta calidad, con un tamaño limitado por los granos del grafito inicial, normalmente del orden de milímetros [150]. Aunque la exfoliación micromecánica sigue siendo el método de producción para realizar estudios fundamentales, no es práctica para aplicaciones a gran escala.

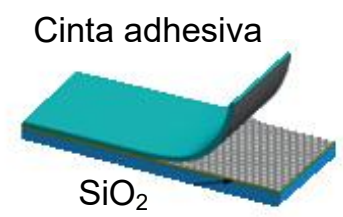

Figura 17. Exfoliación micromecánica

Cuando se emplea la técnica de unión anódica para producir grafeno es necesario presionar el grafito sobre un sustrato de vidrio y aplicar una diferencia de potencial entre el grafito y el contacto metálico. Posteriormente se calienta el sustrato de vidrio durante $10-20$ minutos a $200^{\circ} \mathrm{C}$, creándose un campo eléctrico en la interfase. De esta manera las capas de grafeno, incluidas monocapas de grafeno (SLG), se adhieren al vidrio por interacción electrostática. El número de capas obtenidas se puede controlar en función de la temperatura y la tensión empleada [151].

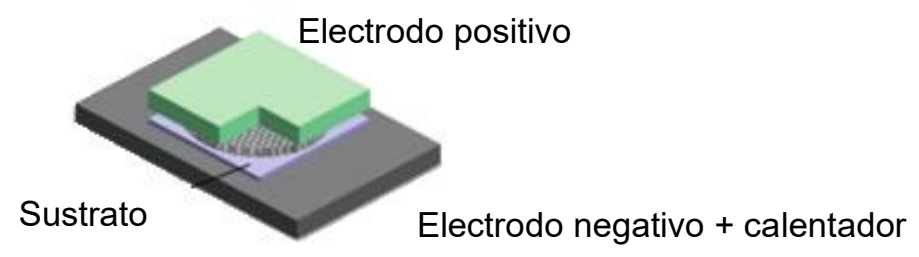

Figura 18. Unión anódica 
Mediante la fotoexfoliación y ablación láser (Figura 19) es posible exfoliar grafito para la obtención de una única capa de grafeno, ajustando la energía láser empleada. Se ha observado además, que la ablación láser en el aire tiende a oxidar las capas de grafeno, por lo que hay que recurrir a condiciones inertes o de vacío [152].

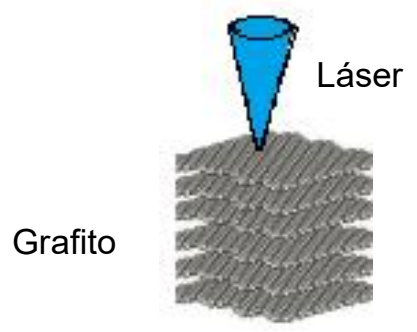

Figura 19. Fotoexfoliación

\section{Exfoliación en fase líquida (LPE)}

Es posible obtener láminas individuales de grafeno mediante la exfoliación de grafito en medio líquido mediante ultrasonidos. Este proceso en general, consta de tres etapas: dispersión del grafito en un disolvente, exfoliación y purificación. Este último paso emplea la ultracentrifugación para separar las láminas exfoliadas de las no exfoliadas.

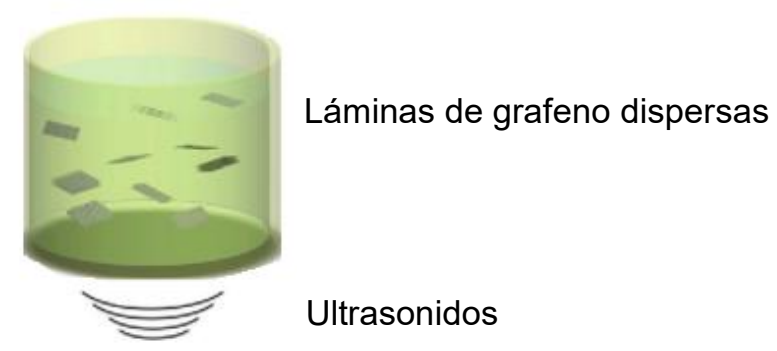

Figura 20. Exfoliación en fase líquida

Como disolvente se puede emplear agua o disolventes orgánicos, siendo el ideal aquel que minimice la tensión interfacial entre el líquido y las láminas de grafeno [153]. Se ha determinado que los mejores disolventes para lograr la dispersión del grafeno son aquellos que presentan una tensión superficial en torno a $40 \mathrm{mN} / \mathrm{m}$ [154]. Por tanto, en el caso de emplear agua, cuya tensión superficial es de $72 \mathrm{mN} / \mathrm{m}$ [153], es necesario que las láminas de grafeno sean estabilizadas frente a la reagregación mediante fuerzas electroestáticas empleando surfactantes de cadena lineal [155]. 
La LPE es una técnica barata y fácilmente utilizable a escala industrial, ya que no requiere el empleo de costosos sustratos. Además, es ideal para producir tintas [156], películas finas [154] o nanocomposites [157].

Las láminas de grafeno obtenidas tienen un tamaño limitado debido al procedimiento de exfoliación y al proceso de purificación [149].

Con esta técnica no solo es posible exfoliar grafito, también es posible la exfoliación del óxido de grafito y de los compuestos de grafito intercalados (GICs), los cuales tienen propiedades diferentes a las que presenta el grafito puro.

El grafito puede oxidarse por diferentes procedimientos, en presencia de ácidos fuertes, obteniendo óxido de grafito. Brodie en 1859 fue el primero en tratar el grafito con una mezcla de $\mathrm{KClO}_{3}$ y $\mathrm{HNO}_{3}$ [158] para obtener óxido de grafito. Posteriomente, Hummers y Offeman encontraron un método más seguro, rápido y eficiente que el propuesto por Brodie, empleando ácido sulfúrico, nitrato sódico y permanganato potásico [159]. En este proceso de oxidación, las láminas de óxido de grafito son funcionalizadas con grupos epoxi e hidroxi [160], de manera que la distancia entre las láminas aumenta, con lo que la energía entre las capas se reduce, pudiéndose obtener óxido de grafeno muy fácilmente mediante la aplicación de ultrasonidos.

Posteriormente, es necesario llevar a cabo un proceso de reducción para disminuir la concentración de oxígeno. De esta manera, se restituyen las propiedades eléctricas y térmicas, obteniendo así unas propiedades más similares a las presentadas por el grafeno [149].

\subsection{Bottom-up}

\section{Crecimiento sobre SiC}

El método de producción de films de grafeno por descomposición térmica de $\mathrm{SiC}$ a $1000^{\circ} \mathrm{C}$ es conocido además como crecimiento epitaxial, ya que el material depositado adquiere la misma estructura cristalina que el sustrato [148]. Debido al calentamiento del sustrato de $\mathrm{SiC}$, se produce la sublimación del silicio y el crecimiento en la cara Si (0001) de una capa llamada "buffer layer" rica en grafeno, formando una estructura de átomos de carbono en disposición de panal de abeja, pero sin las propiedades eléctricas que presenta el grafeno, porque el $30 \%$ de las uniones covalentes son con átomos de $\mathrm{Si}$ 
[161]. Esta capa puede separarse del sustrato mediante la intercalación de hidrógeno, obteniéndose una monocapa de grafeno (SLG) (Figura 21) [162].

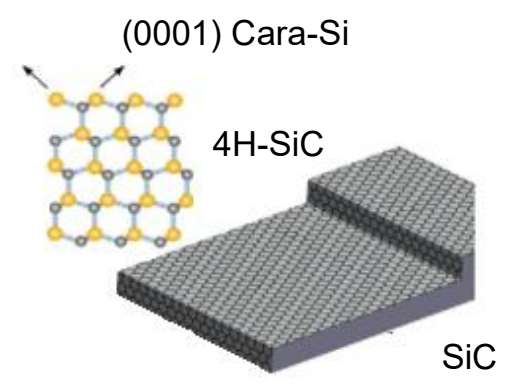

Figura 21. Crecimiento de grafeno sobre SiC

\section{Crecimiento en metales por precipitación}

Esta técnica consiste en depositar carbono en una superficie metálica de $\mathrm{Ni}$, Co, Ir o Pt mediante evaporación flash, spin coating o depósito químico en fase vapor [149]. Se produce la difusión del carbono en la superficie del metal hasta que se alcanza el límite de solubilidad a alta temperatura, y posteriormente, se lleva a cabo el enfriamiento y la precipitación del grafeno [163].

El crecimiento del grafeno mediante esta técnica requiere un control cuidadoso del espesor y la microestructura del metal, del rango de enfriamiento y del tiempo de difusión. Uno de los principales problemas de esta técnica reside en la dificultad de separar el grafeno producido del sustrato.

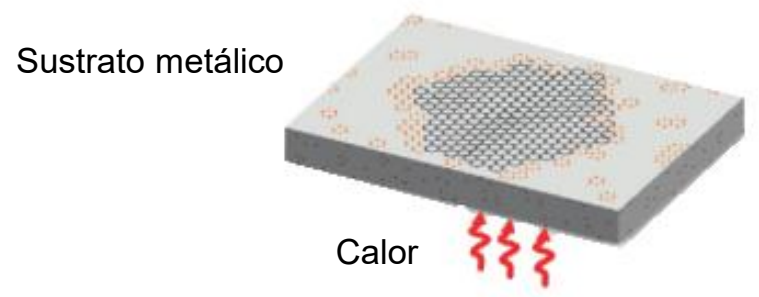

Figura 22. Crecimiento en metales por precipitación

\section{Depósito químico en fase de vapor (CVD)}

El depósito químico en fase de vapor es una técnica experimental empleada principalmente para depositar o crear películas finas de materiales amorfos 0 cristalinos a partir de precursores químicos, normalmente en fase de vapor.

Fue en 1984 cuando se desarrolló lo que podría ser el primer depósito químico en fase de vapor para el crecimiento de grafeno en una superficie de iridio. En este caso, se pretendía estudiar las propiedades catalíticas y termoiónicas de 
este elemento en presencia de carbono. Sin embargo, sucesivos estudios determinaron que aunque el Ir podía emplearse como sustrato para la obtención de grafeno debido a su baja solubilidad en carbono, era difícil transferir el grafeno a otros sustratos debido a su elevada estabilidad química [164] [165].

En general, el metal empleado como sustrato en la técnica CVD es el $\mathrm{Cu}$, ya que permite un crecimiento uniforme y superficies relativamente grandes de grafeno. Este proceso consiste en la descomposición térmica de un hidrocarburo y posterior nucleación y crecimiento de átomos de carbono sobre la superficie metálica formando láminas de grafeno [166].

Este método de producción de grafeno requiere elevadas temperaturas y bajas presiones lo que conlleva un importante coste.

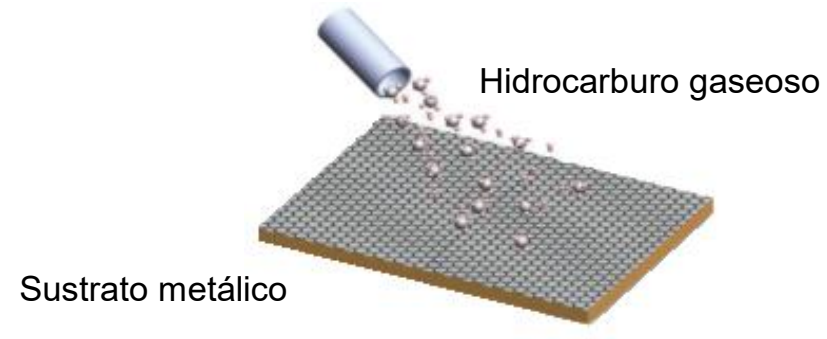

Figura 23. Depósito químico en fase de vapor

\section{Epitaxia de haces moleculares (MBE)}

La epitaxia de haces moleculares es una técnica ampliamente usada en la creación de depósitos y crecimiento de compuestos semiconductores [167]. Resulta improbable que los métodos tradicionales de MBE permitan la creación de una única lámina de grafeno (SLG) con la suficiente calidad como para competir con las otras técnicas de producción de este nanomaterial. Esto es debido a que esta técnica es un proceso químico que se basa en la incidencia de haces atómicos de elementos (carbono) sobre sustratos y es difícil evitar que éste se deposite en áreas donde ya ha crecido el grafeno previamente, de manera que las láminas obtenidas presentan muchos defectos y diferencias notables de espesor debido a la imposibilidad de control del mismo [168]. 


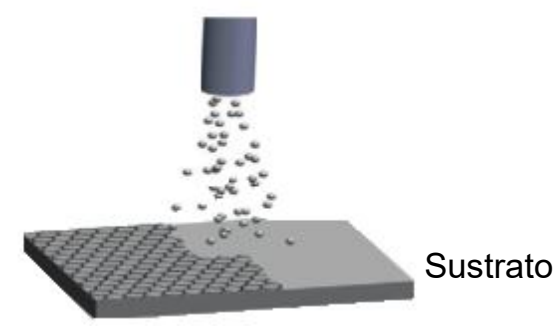

Figura 24. Epitaxia de haces moleculares

\section{Síntesis química}

El grafeno también puede sintetizarse químicamente ensamblando hidrocarburos policíclicos aromáticos (PAHs) [169]-[171]. Una de las técnicas estudiadas, emplea la reacción de Suzuki-Miyaura para producir pequeños dominios llamados nanografeno a partir de ácido bromobenzoico [171]. Otro de los métodos de síntesis emplea la pirólisis de hidrocarburos aromáticos policíclicos [170].

Esta técnica permite un cierto control a nivel atómico, así como la obtención de grandes superficies, sin embargo, el nanografeno obtenido tiende a formar agregados insolubles debido a las fuertes fuerzas de atracción entre las láminas [169], [171].

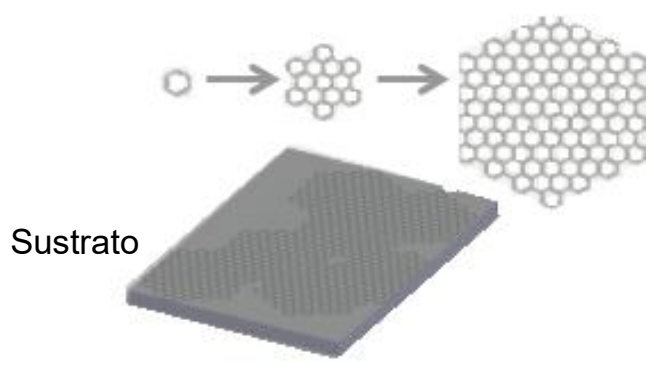

Figura 25. Síntesis química

\subsubsection{Aplicaciones del grafeno}

El descubrimiento, así como el desarrollo de los métodos de producción del grafeno, han aportado una nueva dimensión al desarrollo de la tecnología, ya que cada vez se requieren dispositivos más rápidos, más delgados, más fuertes y flexibles, en definitiva, con mejores prestaciones. 
Este material ha demostrado su potencial en multitud de campos gracias a sus excepcionales propiedades. En la Tabla 1 se recogen algunas de sus potenciales aplicaciones.

Tabla 1. Aplicaciones del grafeno

\begin{tabular}{cc}
\hline Dispositivos electrónicos & Transistores [172], [173] \\
& Láseres ultrarrápidos [174], [175] \\
Computación cuantica [176] \\
Dispositivos de memoria digital [177]
\end{tabular}

\subsubsection{Nanodiamantes}

El término nanodiamante (ND) se emplea para referirse a una gran cantidad de materiales, desde los cristales de nanodiamantes encontrados en meteoritos [189], [190], granos de capas de diamante policristalinas hasta polvos [191] y suspensiones [192].

En general, los nanodiamantes son partículas que poseen un tamaño entre 2 y $10 \mathrm{~nm}(0 \mathrm{D})$, con una estructura compleja que posee tres capas. Un núcleo con un alto ordenamiento cúbico similar al del diamante, formado por carbono $\mathrm{sp}^{3}$ con espesor de 2-3 nm que posee entre un 70 y un $90 \%$ de los átomos de carbono de la estructura y puede tener átomos de nitrógeno en forma de 
inclusiones. Posee además, una capa intermedia, con un espesor de entre 0,4 y $1 \mathrm{~nm}$ que contiene hasta un $30 \%$ de carbono amorfo $\mathrm{sp}^{2}$. La superficie externa de los nanodiamantes posee grupos carbonados así como átomos de oxígeno, hidrógeno y nitrógeno [193]-[197].

Los átomos superficiales forman parte de grupos funcionales muy reactivos químicamente, como hidroxilo, carbonilo o amino y su presencia se debe a las condiciones de obtención y purificación del material [195].

Los nanodiamantes fueron obtenidos por primera vez mediante detonación en la URSS en la década de 1960, sin embargo, su descubrimiento permaneció desconocido para el resto del mundo hasta unos 20 años después [198], [199]. Desde finales del siglo $X X$ se ha producido un significativo aumento de publicaciones científicas gracias a las notables propiedades que presenta este nanomaterial.

Los nanodiamantes son materiales biocompatibles, con propiedades ópticas y de fluorescencia (relacionada con la presencia de nitrógeno y grupos funcionales oxigenados en su superficie) [193], [200], alta estabilidad química y una dureza y módulo de Young superior al presentado por el diamante. Además, poseen una forma esférica, y tienen un tamaño pequeño y uniforme, de manera que no es necesario fraccionarlos, como ocurre con otras nanofases de carbono como el grafeno, lo que disminuye notablemente su coste [193].

\subsubsection{Métodos de obtención de nanodiamantes}

Existen numerosas técnicas de obtención de nanodiamantes, incluyendo la detonación, ablación láser, crecimiento de microcristales de diamante a alta presión y alta temperatura (HPHT), creación de depósitos químicos en fase de vapor (CVD), síntesis en autoclave de fluidos supercríticos, clorinación de carburos o cavitación ultrasónica. Son las tres primeras técnicas las principalmente empleadas para la producción de nanodiamantes a gran escala [201].

\section{Síntesis mediante detonación}

Los nanodiamantes de detonación se pueden obtener a partir de la descomposición (debido a la detonación) de explosivos con balance negativo de oxígeno. Por ejemplo, la detonación de la mezcla de $60 \%$ trinitrotolueno 
$\left(\mathrm{C}_{6} \mathrm{H}_{2}\left(\mathrm{NO}_{2}\right)_{3} \mathrm{CH}_{3}\right)$ y $40 \%$ de hexógeno $\left(\mathrm{C}_{3} \mathrm{H}_{6} \mathrm{~N}_{6} \mathrm{O}_{6}\right)$ proporciona el carbono y la energía necesaria para la obtención de los nanodiamantes [202], [203].

Los nanodiamantes se forman durante la detonación según un mecanismo propuesto por Danilenko [199]. En la Figura 26 se observa una representación esquemática de la propagación de la onda de detonación en el interior de una cámara cerrada de acero llena de una gas inerte (síntesis seca) o agua (hielo) (síntesis húmeda) que actúa como refrigerante. La zona I muestra el frente de onda de choque causada por la explosión. En la zona II se produce la descomposición de los explosivos mediante reacción química. El plano Chapman-Jouguet (zona III) indica las condiciones de presión y temperatura en las que la reacción es completa. En la zona IV aparecen los productos de detonación en expansión, la formación de nanoclusters de carbono en la zona $\checkmark$ y la coagulación de nanogotas en la zona $V I$ y finalmente la zona donde se produce la cristalización, crecimiento y aglomeración de los nanodiamantes (Zona VII) [204].

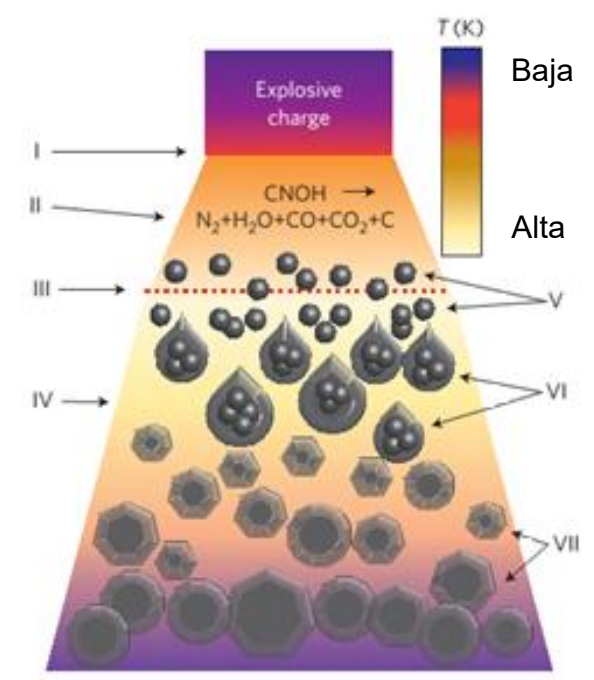

Figura 26. Esquema de la secuencia de formación de nanodiamantes [193]

El producto obtenido está compuesto por una mezcla de partículas de diamante de 4-5 nm de diámetro con otros alótropos de carbono e impurezas producidas por la presencia del agente empleado para iniciar la detonación (partículas de $\mathrm{Pb}, \mathrm{Ag}, \mathrm{Cu}$ ) y hierro y otros metales procedentes de las paredes del reactor [193]. Por tanto, tras la detonación es necesario separar y purificar los nanodiamantes. Generalmente, el proceso de purificación consta de varias etapas: separación magnética, filtración, oxidación y lavado. Normalmente se 
emplea el ácido nítrico, aunque se pueden emplear otros métodos menos agresivos de purificación [196].

\section{$\underline{\mathrm{HPHT}}[201]$}

Las nanopartículas de diamante obtenidas mediante molienda de alta energía en molino de bolas a alta presión y temperatura (HPHT) tienen un tamaño aproximado de $10 \mathrm{~nm}$. Para el empleo de esta técnica es necesario utilizar presiones de $6 \mathrm{GPa}$ y $1500^{\circ} \mathrm{C}$ de temperatura para convertir el polvo de grafito en diamantes en presencia de un catalizador. Sin embargo, se pueden emplear otros precursores, como fullerenos o nanotubos de carbono de manera que las condiciones experimentales sean menos agresivas.

\section{Ablación láser [196]}

Otra técnica empleada para la preparación de nanodiamantes es la ablación láser, normalmente llevada a cabo en una atmósfera inerte o en condiciones de vacío. Este método consiste en enfocar un láser a través de un líquido (agua o acetona) sobre la superficie de un material, de manera que se crea una columna de ablación a partir de la interacción del pulso láser con el objetivo y el líquido circulante.

La columna de ablación contiene pequeñas cantidades de líquido evaporado que forma microburbujas y algo de material objetivo evaporado atrapado en su interior. Las burbujas se expanden hasta que se alcanza una cierta combinación crítica de temperatura y presión, lo que provoca su colapso. Durante la destrucción de la burbuja, las partículas de material en su interior están sometidas a una temperatura y presión muy altas, lo que da como resultado la creación de un nuevo material.

Este procedimiento implica importantes ventajas con respecto a otros métodos de obtención de nanodiamantes. Es un proceso más controlable y respetuoso con el medio ambiente, ya que se crean nanopartículas "más limpias", sin necesidad de purificarlas [205], sin embargo el rendimiento es muy bajo [206].

\subsubsection{Aglomeración y funcionalización de la superficie}

Como se ha comentado con anterioridad, en la parte más externa de las partículas de nanodiamantes es posible encontrar grupos funcionales oxigenados (-COOH, $-\mathrm{C}=\mathrm{O}$, o -O-), así como carbono en forma amorfa $\left(\mathrm{sp}^{2}\right)$ en 
función del método de producción y purificación empleado [207]. Por tanto, muchas de las aplicaciones propuestas para los nanodiamantes explotan la versatilidad que ofrece la compleja química superficial de estas partículas, siendo necesario a veces realizar un control preciso de los grupos funcionales presentes en la superficie [198].

Para ciertos usos, la superficie de los nanodiamantes debe ser lo más homogénea posible, por ello, se recurre a la funcionalización con el objetivo de lograr dicha homogeneización y la inmovilización covalente o no covalente de las diferentes fracciones [207].

Dependiendo de la funcionalización de la superficie y el entorno, las partículas de ND pueden interactuar más fuertemente entre sí que con el disolvente [208], lo que conduce a la aglomeración de partículas. De hecho, las suspensiones comerciales de nanodiamantes contienen grandes aglomerados, que normalmente, pueden dispersarse mediante tratamiento con ultrasonidos. Existen otras técnicas para la eliminación de los agregados que van desde tratamientos mecánicos con pequeñas partículas de $\mathrm{ZrO}_{2}$ hasta la reacción química para la modificación de la superficie de los aglomerados. Para la producción de suspensiones coloidales de nanodiamantes con menos de 10 nm se emplea el mezclado mecánico de nanodiamantes con cloruro sódico [196], [209].

\subsubsection{Aplicaciones de los nanodiamantes}

Los nanodiamantes se han empleado para recubrimientos metálicos, electrolíticos y no electrolíticos durante años [203]. En los últimos tiempos, se ha propuesto su uso como agentes de adsorción en cromatografía [210], espectroscopía de masas [211] y en sensores de humedad [212].

Gracias a su biocompatibilidad y no toxicidad se han empleado en el campo de la medicina como soportes para síntesis de péptidos en fase sólida [213], en operaciones de separación y desintoxicación y como disolventes. Además, se emplean para la obtención de imágenes de resonancia magnética y gracias a su fluorescencia, para la obtención de imágenes biomédicas [198].

En los procesos de administración localizada de medicamentos su empleo ha despertado el interés de la comunidad científica [214], [215]. De hecho, se ha estudiado su uso para procesos de quimioterapia para el tratamiento del cáncer 
[216]. Gracias a su pequeño tamaño, núcleo estable, su capacidad para autoensamblarse y baja citotoxicidad, los nanodiamantes se podrían emplear para imitar a las proteínas globulares, es decir, para realizar la función de transporte de las proteínas además de administrar medicamentos en las células [217], [218].

Gracias a sus propiedades mecánicas y térmicas unidas a su rica química superficial, los nanodiamantes se han convertido en excelentes materiales de refuerzo para la obtención de nuevos nanocomposites. Se ha estudiado su uso como aditivos en matrices poliméricas, con muy buenos resultados [193].

\subsection{ANTEDECENTES}

En esta sección se recogen los antecedentes del presente trabajo, que se centra en el estudio del comportamiento tribológico de líquidos iónicos, tanto en disolución acuosa como su combinación con nanofases de carbono con el fin de obtener lubricantes capaces de disminuir la fricción, el desgaste y proteger las superficies en contacto de forma menos tóxica, más respetuosa con el medioambiente e, incluso, biocompatible.

Además, se han preparado, caracterizado y estudiado el uso en tribología de nanocomposites y recubrimientos protectores de matriz epoxi con nanofases y nanofluidos dispersos, sobre resina epoxi y acero al carbono.

\subsubsection{Líquidos iónicos como lubricantes y aditivos.}

Como se ha comentado con anterioridad, los líquidos iónicos presentan un gran potencial para multitud de aplicaciones incluyendo la tribología y la lubricación [21], [27], [28], [33], [35], [58], [74], [92], [219]. Aunque muchas de las publicaciones científicas se centran en el estudio de estos líquidos iónicos como lubricantes puros, es su uso como aditivos de lubricantes lo que ha centrado los esfuerzos en los últimos tiempos [20], [61], [220]-[222].

Algunas importantes líneas de investigación se están desarrollando en torno a la sustitución de los líquidos iónicos apróticos convencionales (que poseen elementos halógenos en su estructura química) por otros líquidos iónicos más respetuosos con el medio ambiente, es decir, por líquidos iónicos próticos o apróticos libres de haluros [223]-[225], así como la combinación de líquidos iónicos y nanofases de carbono con el fin de crear un efecto sinérgico para la mejora de las propiedades tribológicas y de protección de la superficie [65]. 


\subsubsection{Lubricación en base agua}

El agua posee ciertas características que la convertirían en un buen lubricante, como su bajo coste o su gran capacidad de refrigeración, sin embargo, al dar lugar a altos coeficientes de fricción y a procesos corrosivos, su uso para la mayoría de aplicaciones tribológicas resulta inadecuado [226]. Por ello, con el fin de mejorar su rendimiento como lubricante, se utilizan diferentes aditivos que contribuyen a la reducción de la fricción y el desgaste, de manera que es posible disminuir las pérdidas de energía y el fallo del material debido tanto a procesos mecánicos como biológicos [221], [227]-[230].

En muchos procesos de fabricación, como el pulido o el corte, es necesario disponer de fluidos de trabajo capaces de lubricar y enfriar el contacto de forma simultánea. Los fluidos lubricantes de base agua son capaces de realizar ambas funciones y a menor coste que los lubricantes basados en aceites, siempre que se trabaje en contactos no metálicos o resistentes a la corrosión [44]. Entre los aditivos con mayor potencial para mejorar las propiedades del agua se encuentran los líquidos iónicos. En los últimos tiempos, debido a la necesidad de emplear lubricantes más respetuosos con el medio ambiente y biocompatibles, la combinación de líquidos iónicos no tóxicos y biodegradables y una base lubricante como el agua es de gran interés, no sólo en el ámbito de la ingeniería de materiales y fabricación sino también en el procesado de alimentos o en la industria farmacéutica [231].

Los líquidos iónicos próticos obtenidos a partir de la reacción química de ácidos y bases de Brønsted [84], [89], [91], [92], [232], [233], que contienen grupos amonio y carboxilato, con una estructura química que solo posee elementos como $\mathrm{C}, \mathrm{H}, \mathrm{N}$ y $\mathrm{O}$, se convierten en candidatos idóneos para el desarrollo de la lubricación verde.

En el grupo de líquidos iónicos próticos con amonio en su estructura, se ha observado que aquellos derivados de ácidos grasos presentan comportamiento de cristales líquidos iónicos [31], [98]. Es decir, son líquidos iónicos que presentan comportamiento mesogénico. Las fases de cristal líquido ordenadas, la alta polaridad de las moléculas, que son capaces de formar capas adsorbidas en la superficie y su miscibilidad con el agua son las principales ventajas para su empleo como aditivos de lubricantes. 
En trabajos previos del grupo de investigación, se han realizado estudios para determinar el comportamiento tribológico de disoluciones de líquidos iónicos próticos en agua a una concentración del $1 \%$ en peso, como el caso del succinato de di[2-hidroxietilamonio] (MSu) (Figura 27), observándose la disminución del periodo de alta fricción inicial (running-in) y la consiguiente reducción de la fricción y el desgaste una vez que se ha evaporado el agua debido a las altas temperaturas alcanzadas en el contacto [102], [234], [235]. Para la obtención de bajos coeficientes de fricción desde el comienzo del deslizamiento, era necesario emplear los líquidos iónicos próticos puros, tanto en lubricación de película gruesa, como en capa fina, tras la evaporación controlada del agua en condiciones estáticas, lo que se traduce en un aumento del coste.

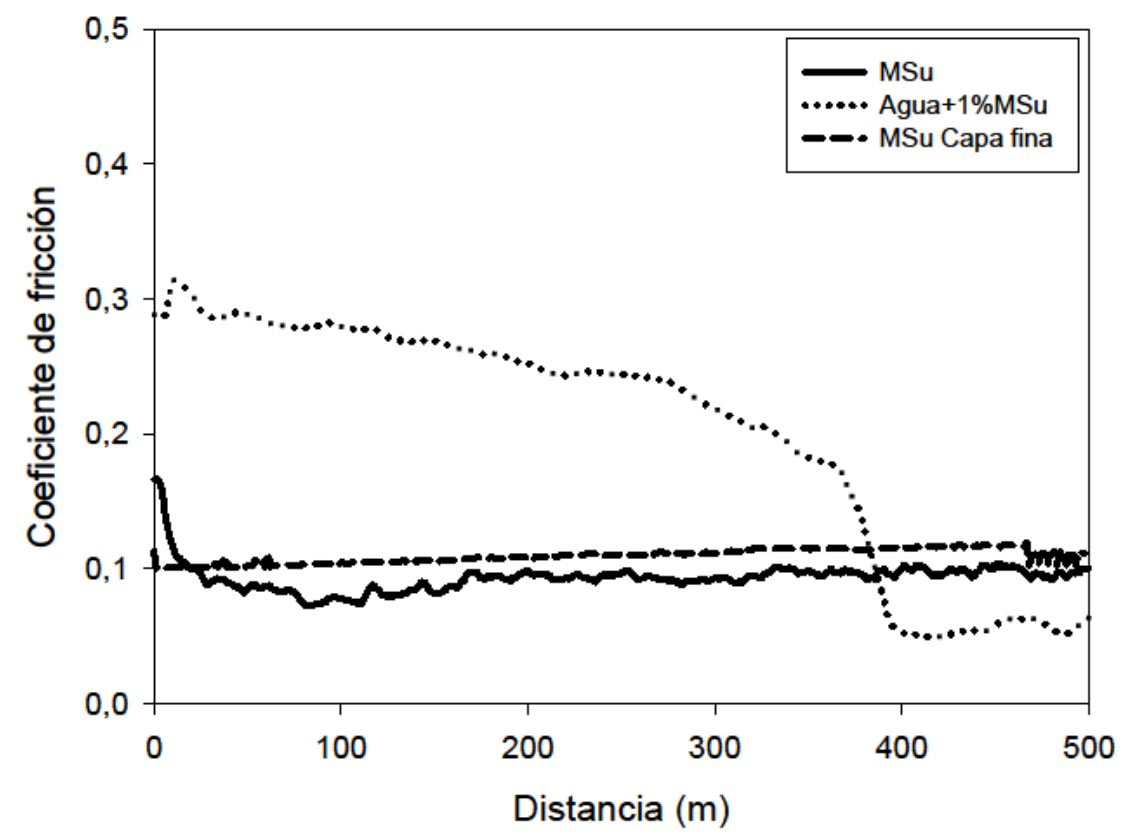

Figura 27. Comparativa de la evolución del coeficiente de friccion con la distancia para el líquido iónico MSu, disolución de Agua+1\%MSu y MSu en capa fina [235]

\subsubsection{Nanofases de carbono en tribología}

Los lubricantes orgánicos sintéticos han sido ampliamente usados, sin embargo, el estudio de su comportamiento tribológico está produciendo nuevos e interesantes resultados. Recientemente, Erdemir et al. [236] han demostrado que en ciertas condiciones de trabajo los aceites lubricantes forman tribocapas similares a DLC (carbono tipo diamante). El mecanismo propuesto consiste en la deshidrogenación catalítica de las olefinas lineales presentes en los aceites lubricantes mediante el recubrimiento de materiales nanocristalinos, seguida de 
la rotura de los enlaces carbono-carbono y la recombinación y crecimiento de capas lubricantes amorfas antidesgaste.

Resultados como este ilustran la importancia de las nanofases de carbono en la tribología. De hecho, Berman et al. [237] han observado coeficientes de fricción ultrarreducidos para DLC, con valor de 0,004, lo que se llama superlubricación, en un sistema formado por nanodiamantes y grafeno. La combinación de estas nanofases de carbono forma "nanoscrolls" que no aparecen en presencia de agua, de manera que se inhibe la superlubricación, produciendo un aumento del coeficiente de fricción.
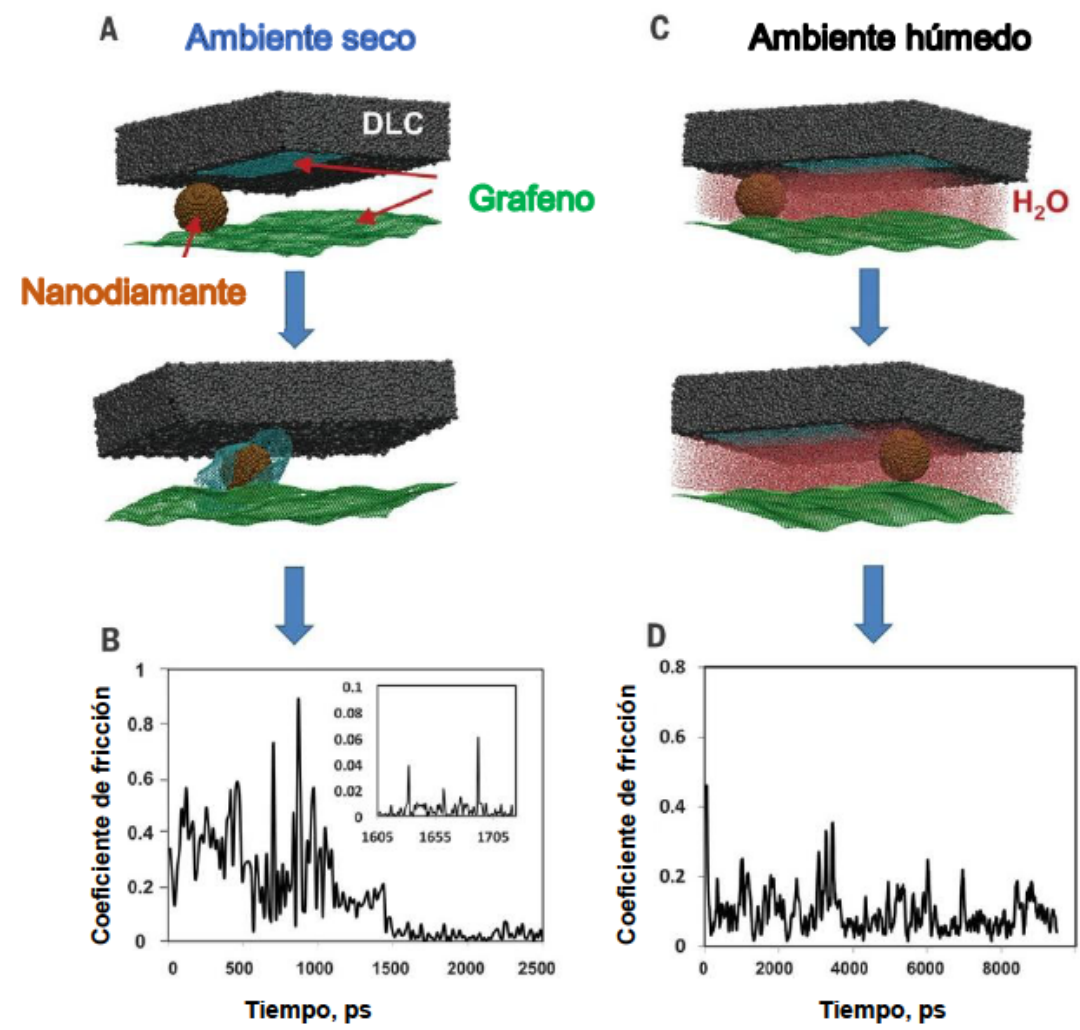

Figura 28. Simulación de la evolución temporal de la fricción para DLC deslizando sobre una superficie de grafeno-nanodiamante en ambiente seco y húmedo [237]

En el caso del grafeno, la calidad y la pureza de este material es crucial para la reducción de las fuerzas laterales, es más, se produce un aumento significativo de la fricción cuando el grafeno está oxidado [238]. Los mismos autores han confirmado que la fricción ultrarreducida se logra cuando una única capa de grafeno crece mediante CVD sobre una capa de dióxido de silicio. Este resultado es debido a la buena adhesión que se logra entre el grafeno obtenido mediante esta técnica y el sustrato, confirmando la influencia el proceso de obtención en el comportamiento tribológico de las nanofases. 
Entre sus variadas aplicaciones emergentes [239], el grafeno y los nanomateriales de carbono $2 \mathrm{D}$ han sido estudiados como aditivos en lubricantes [240], tanto en aceites como en grasas, obteniendo una reducción de la fricción y el desgaste, así como una mejora de la capacidad de soportar carga con respecto a los materiales de partida.

Las láminas de grafeno se han usado como aditivos lubricantes en superficies de acero [241], encontrando un efecto sinérgico que podría explicarse debido a las fuerzas de cizalla de las capas de grafeno en las interfases y la formación de una película protectora en la superficie.

Fan et al. [242] obtuvieron mejores resultados al emplear grafeno de múltiples capas como aditivo en un lubricante en forma de grasa, con respecto al empleo de líquido iónico o grafito como aditivos. La mejora del rendimiento se atribuyó en ese caso, a la formación de una película lubricante límite.

El empleo de nanodiamantes como aditivos de lubricantes ha sido ampliamente estudiado, constituyendo la tribología una de las principales aplicaciones de esta nanofase de carbono. La presencia de nanodiamantes en los lubricantes contribuye a la formación de capas lubricantes con elevada densidad que evitan el contacto entre las superficies mejorando los resultados de fricción y desgaste. Gracias al aumento de la viscosidad del lubricante al añadir los nanodiamantes, la capacidad de soportar carga aumenta, por tanto, el comportamiento tribológico mejora. Además, estas nanopartículas de carbono presentan una gran estabilidad térmica favoreciendo su uso como lubricante [243].

De esta manera, se logra un aumento de la eficacia y compatibilidad de los aceites lubricantes, así como una mejora desde el punto de vista medioambiental, ya que estos aditivos no poseen elementos metálicos o fluorados en su composición [244].

Como estas nanopartículas presentan carbono grafítico en su capa superficial, se asumió que el grafito actuaba como lubricante mientras que los nanodiamantes reducían la fricción al pulir las asperezas de las superficies en contacto [244]. Inicialmente, se pensó que los nanodiamantes actuaban como "rodamientos de bolas", mejorando el comportamiento tribológico gracias a su pulido superficial y su dureza [245]. Sin embargo, en estudios más recientes se sugiere la existencia de diferentes mecanismos de lubricación en función del 
tipo de sistema [198]. Por ejemplo, se ha encontrado que en el caso de emplear acero al carbono, la reducción de la fricción obtenida es debida a la incrustación de partículas de nanodiamante en la zona de contacto. Pero en el caso de emplear un sustrato de aleación de aluminio, la mejora es debida a la viscosidad de la mezcla lubricante que posee nanodiamantes en su composición [246].

Uno de los puntos que a priori puede resultar problemático es la tendencia a agregarse que presentan los nanodiamantes. Generalmente, cuando son obtenidos mediante la técnica de detonación, presentan un comportamiento típicamente hidrofílico, debido a la elevada relación superficie-volumen y a su carga superficial, por tanto son fácilmente solubles en disolventes polares como el agua. Sin embargo, es complicado dispersarlos en disolventes no polares debido a su agregación. Por ello, varios autores [243] [247] han recurrido a la modificación superficial de los nanodiamantes con ácido oleico para lograr la separación de los aglomerados y lograr una dispersión estable de nanodiamantes en aceite lubricante con buenas propiedades lubricantes en el contacto alúmina-acero y acero-acero a alta temperatura.

Por otro lado, cuando los nanodiamantes están aglomerados, también es posible reducir la fricción y el desgaste, incluso con mejores resultados que empleando nanodiamantes dispersos, aunque hay que tener en cuenta que la cantidad necesaria de nanodiamantes sería 10 veces superior. Se propone la aplicación de un lubricante con etilenglicol y nanodiamantes en forma de spray sobre la superficie de acero [248].

También se ha estudiado el comportamiento tribológico de las nanopartículas de diamante en agua en el contacto carburo de wolframio-acero con diferentes concentraciones, observándose una disminución del coeficiente de fricción con el número de ciclos, debido a la incrustación de los nanodiamantes en la superficie de contacto, creando una superficie protectora [249].

\subsubsection{Nanofluidos líquidos iónicos/nanofases de carbono}

En la literatura es posible encontrar resultados muy relevantes del empleo de líquidos iónicos y nanofases de carbono en tribología [250]-[252]. La combinación de líquidos iónicos y nanomateriales, desde partículas metálicas, cerámicas o nanofases de carbono, especialmente grafeno y nanotubos de 
carbono ha sido ampliamente estudiada en trabajos anteriores del grupo [234], [253]-[255].

Fan et al. [256] utilizaron líquidos iónicos de imidazolio con aniones que contienen flúor para obtener óxido de grafeno modificado y grafeno exfoliado, que luego fueron utilizados como aditivos lubricantes. El excelente rendimiento antidesgaste obtenido se atribuyó a la formación de tribocapas de grafeno que contenían líquido iónico dentro de las huellas de desgaste, lo que evitaría el contacto directo entre las asperezas.

Khare et al. [257] utilizaron sales de haluro de imidazolio, en particular, el yoduro de 1-butil-3-metilimidazolio, altamente viscoso, para desarrollar nuevos nanolubricantes de grafeno-líquido iónico. El rendimiento tribológico fue nuevamente explicado por las interacciones entre las fases que modificaron las características fisicoquímicas y estructurales del líquido iónico.

El efecto de la estructura del grafeno ha sido analizado por Saurín et al. [255] comparando dos tipos de grafeno comerciales, uno de 1-2 capas y otro de 1-10 capas como aditivos en tetrafluoroborato de 1-octil-3-metilimidazolio en contactos acero-resina epoxi y zafiro-acero. El grafeno de 1 a 2 capas dio lugar a desgaste por abrasión debido a la formación de grandes aglomerados, mientras que para el grafeno de 1 a 10 capas se observó que evita el desgaste al evitar el contacto directo entre las asperezas.

La fabricación in situ de láminas de grafeno funcionalizadas mediante exfoliación electroquímica de grafito en un disolvente líquido de tetrafluoroborato de imidazolio se ha propuesto como un método para superar los dos problemas principales del empleo de grafeno como aditivo lubricante: su baja dispersabilidad y la baja estabilidad de las dispersiones a largo plazo [258]. Nuevamente, se propone la existencia de sinergias entre el líquido iónico y el grafeno multicapa que contribuyen a la formación de películas adsorbidas físicamente y capas creadas por reacciones triboquímicas como mecanismos para mejorar el comportamiento tribológico.

Los nanomateriales iónicos híbridos de líquido iónico y grafeno fueron desarrollados por Gusain et al. [259] generando enlaces covalentes entre los anillos de imidazolio del líquido iónico y el grafeno. Esta funcionalización covalente permitió la dispersión de grafeno en polietilenglicol, utilizado como lubricante base, reduciendo así los coeficientes de fricción y las tasas de 
desgaste al inhibir la pérdida de material. Los autores propusieron la formación de tribocapas delgadas protectoras sobre las superficies en contacto deslizante como las responsables de la mejora de las propiedades tribológicas.

La combinación de diferentes nanofases de carbono con líquidos iónicos ha logrado un aumento del rendimiento con respecto a los resultados obtenidos para cada uno de ellos por separado [260]. Zhang et al. [260], [261] describieron el efecto sinérgico entre el óxido de grafeno y los nanotubos de carbono de pared múltiple para reducir la fricción y el desgaste de superficies de carbono tipo diamante (DLC), incluso en condiciones de alto vacío. El mecanismo propuesto es la intercalación de los nanotubos entre las capas de grafeno para mantenerlos exfoliados [262].

Las dispersiones de nanotubos de carbono de pared múltiple (MWCNT) en líquidos iónicos también se usaron como lubricantes en contactos de polímeroacero, demostrando que la adición de esta nanofase de carbono puede reducir los coeficientes de fricción y evitar daños en la superficie [253].

La capacidad de los líquidos iónicos para interactuar con las nanofases de carbono puede permitir incluso la transformación de un tipo de nanofase de carbono en otra. Kleinschmidt et al. [263] estudiaron la apertura y desenrollado de nanotubos de carbono para obtener nanoestructuras de grafeno, observando que este proceso depende del líquido iónico. Finalmente, estos autores describieron la preparación de nanocomposites de matriz epoxi con las nuevas nanopartículas de carbono obtenidas.

El estudio de las dispersiones de líquidos iónicos y nanodiamantes en tribología es muy escaso [101], [262], aunque sí se ha estudiado la habilidad que poseen los líquidos iónicos de modificar y formar geles con nanodiamantes [264] y la capacidad de estas nanofases para reducir la viscosidad de ciertos líquidos iónicos [265].

\subsubsection{Nanocomposites, láminas delgadas y recubrimientos}

Los materiales poliméricos, como la resina epoxi, son empleados frecuentemente en aplicaciones industriales gracias a su facilidad de procesado, bajo coste y peso ligero [266]. Sin embargo, las resinas presentan otras propiedades, como por ejemplo, su alto coeficiente de aislamiento térmico que puede llegar a ser una desventaja en aplicaciones electrónicas, ya que no 
sería posible disipar el calor generado y el aumento de la temperatura podría destruir el equipo. Por tanto, en ciertas aplicaciones es necesario variar las propiedades de los polímeros para que se adapten a las diferentes condiciones de trabajo y para ello, se pueden emplear aditivos, que se introducen en la matriz polimérica con el objetivo de modificar dichas propiedades [267].

La adición de nanofases de carbono y/o líquidos iónicos a la matriz epoxi para mejorar las propiedades mecánicas, térmicas, de barrera y de resistencia a la corrosión y a la abrasión, ha despertado el interés de la comunidad científica [128].

El efecto sinérgico de la combinación de nanotubos de carbono de pared simple y líquidos iónicos se ha observado, lográndose una mejora en el rendimiento tribológico de la resina epoxi [268], al reducir la fricción y el desgaste, además de aumentar la estabilidad térmica y la densidad de reticulación de la resina.

Saurín et al. [269] han comparado las reducciones de fricción y desgaste empleando grafeno y tetrafluoroborato de 1-octil-3-metilimidazolio por separado, así como la mezcla de ambos, con respecto a la resina sin modificar. La mayor reducción tanto de fricción como de desgaste se logró para el nuevo nanocomposite de matriz epoxi con grafeno. Además, se observó que el líquido iónico produce un efecto plastificante, mientras que el grafeno aumenta la estabilidad térmica y la rigidez de la matriz termoestable, lo que limita el daño superficial.

El interés por el desarrollo de láminas delgadas o films se ha incrementando en los últimos tiempos debido a la necesidad de crear dispositivos más pequeños, más delgados y más ligeros para aplicaciones en los campos de la microelectrónica, la óptica y la nanotecnología [267].

Las láminas delgadas permiten reducir el espesor del material empleado, ya que se pueden crear capas con espesores que van desde un nanómetro hasta varios micrómetros. Estos films son esenciales para muchos procesos, como la preparación de revestimientos de barrera térmica y protección contra el desgaste, mejora de la vida útil de la herramienta y la protección frente al ambiente [270], [271]. 
Se han descrito diferentes métodos para la obtención de películas delgadas como revestimiento por inmersión [272], recubrimiento con gotas [273], inmersión capilar [274] y creación de depósitos mediante electroforesis [275]. Sin embargo, estos métodos presentan una velocidad de obtención relativamente lenta y no se logran recubrimientos uniformes ni en una gran superficie. Por tanto, otros procedimientos de obtención de recubrimientos como el spin coating se presentan como una opción óptima para la creación de capas protectoras sobre diferentes tipos de sustratos.

Los recubrimientos de epoxi-PTFE que contienen óxido de grafeno y el líquido iónico bis-(trifluorometanosulfonil)imida de 1-decil-3-metilimidazolio [276] mostraron también el efecto sinérgico de la presencia de ambas nanofases en su comportamiento tribológico. Se propuso que el efecto plastificante del líquido iónico aumentaba el área de contacto, generando un régimen de lubricación límite. En estas condiciones, las láminas de óxido de grafeno se orientan y reducen su comportamiento abrasivo, lo que contribuye a reducir el coeficiente de fricción.

Mo et al. [218] estudiaron las propiedades mecánicas y de mojabilidad de films de grafeno y líquido iónico a escala nanométrica, observando que el tipo de anión del líquido iónico juega un papel importante en las mismas. También se han creado films de nanocomposite de matriz epoxi con grafeno mediante la aplicación de spray, consiguiendo una mejora de las propiedades barrera, incluso en presencia de humedad [277], así como la creación de recubrimientos de grafeno y resina epoxi sobre sustratos de acero inoxidable que protegen frente a la corrosión y son estables a la luz ultravioleta [278].

Nanocomposites de resina epoxi con nanotubos de carbono y líquido iónico también han sido estudiados como recubrimientos, adhesivos y escudos de interferencia electromagnética [279].

También se ha estudiado el comportamiento tribológico de recubrimientos realizados a partir de nanocomposites de matriz epoxi con un alto contenido en nanofases. Kumar et al. [280] estudian el comportamiento frente a la fricción y desgaste de recubrimientos sobre acero de nanocomposites de matriz epoxi con un $10 \%$ de grafito y un $10 \%$ de grafeno y con $25-35$ micrómetros de espesor, obteniéndose una mejora significativa de la fricción al emplear grafeno. 
Con respecto al empleo de líquidos iónicos próticos como aditivos para la obtención de materiales compuestos de matriz epoxi o de recubrimientos protectores sobre acero, temas que se abordan en el presente trabajo, no se han encontrado precedentes en la bibliografía. Por tanto, resulta un tema de gran interés y totalmente novedoso. 
2. OBJETIVOS 



\section{OBJETIVOS}

1.- Utilizar nuevos líquidos iónicos próticos con cationes amonio y aniones carboxilato, tanto de cadena corta como derivados de ácidos grasos, como aditivos de nuevos lubricantes de base agua.

2.- Estudiar el efecto de la dispersión de nanodiamantes en líquidos iónicos próticos puros o como aditivos en agua, sobre las prestaciones de los lubricantes.

3.- Reducir el volumen de líquido iónico prótico necesario para reducir los coeficientes de fricción y las tasas de desgaste, mediante la obtención de capas finas.

4.- Estudiar las propiedades reológicas y comparar el comportamiento tribológico de líquidos iónicos apróticos puros y con distintas concentraciones de grafeno.

5.- Desarrollar, caracterizar y estudiar el comportamiento tribológico de nuevos materiales y recubrimientos de matriz epoxi modificada por la adición de líquidos iónicos, grafeno o dispersiones de grafeno en líquido iónico. 


\subsection{OBJECTIVES}

1.- To use new protic ionic liquids with ammonium cations and carboxylate anions, both with short alkyl chains and long chain fatty acids derivatives, as additives of new water-based lubricants.

2.- To study the effect of the dispersion of nanodiamonds in protic ionic liquids, both pure and as additives in water, on the tribological performance of the lubricants.

3.- To reduce the volume of ionic liquids necessary to decrease friction coefficients and wear rates by the use of thin layer lubricants.

4.- To study the rheological properties and to compare the tribological performance of neat aprotic ionic liquids and their dispersions containing graphene.

5.- To develop, characterize and study the tribological performance of new materials and epoxy resin coatings modified by the addition of ionic liquids, graphene or graphene dispersions in ionic liquids. 


\section{MATERIALES, EQUIPOS $Y$ PROCEDIMIENTO EXPERIMENTAL}





\section{MATERIALES, EQUIPOS $Y$ PROCEDIMIENTO EXPERIMENTAL}

\subsection{MATERIALES}

\subsubsection{Acero inoxidable AISI $316 \mathrm{~L}$}

Para la realización de los ensayos tribológicos de lubricación externa se han empleado discos de acero inoxidable AISI 316L. Este tipo de acero ha sido seleccionado por que posee un bajo contenido en carbono, lo que le proporciona una elevada resistencia a la corrosión.

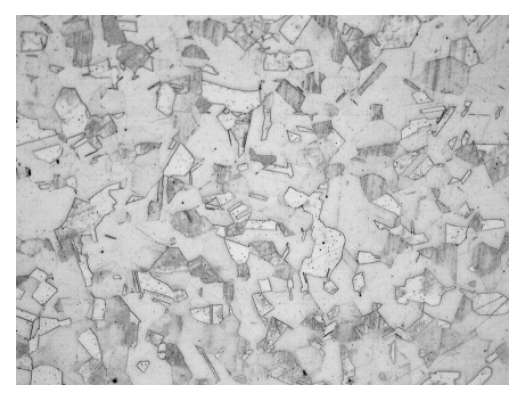

Figura 29. Microestructura del acero AISI 316L (10x).

En la Tabla 2 se recogen la composición y propiedades de este tipo de acero.

Tabla 2. Propiedades y composición del acero AISI 316L

\begin{tabular}{cc}
\hline Composición & $\begin{array}{r}<0,03 \% \mathrm{C} ; 16-18,5 \% \mathrm{Cr} ; 10-14 \% \mathrm{Ni} ; 2-3 \% \mathrm{Mo} ;<2 \% \mathrm{Mn} ; \\
<1 \% \mathrm{Si} ;<0,045 \% \mathrm{P} ;<0,03 \% \mathrm{~S} ; \text { Resto } \mathrm{Fe}\end{array}$ \\
\hline Módulo de Young & $190-205 \mathrm{GPa}$ \\
\hline $\begin{array}{c}\text { Coeficiente de Poisson } \\
\text { Resistencia a la } \\
\text { tracción }\end{array}$ & $0,265-0,275$ \\
\hline $\begin{array}{c}\text { Temperatura máxima de } \\
\text { servicio }\end{array}$ & $480-620 \mathrm{MPa}$ \\
\hline Dureza & $170-310 \mathrm{MPa}$ \\
\hline Punto de fusión & $170-220 \mathrm{HV}$ \\
\hline Límite elástico & $750-925^{\circ} \mathrm{C}$ \\
\hline
\end{tabular}

Se han usado discos de diversas dimensiones. En el caso de los ensayos realizados para el estudio de la influencia de la velocidad en el coeficiente de 
fricción de las emulsiones de líquidos iónicos próticos derivados de ácidos grasos en agua, se han empleado discos de $45 \mathrm{~mm}$ de diámetro y $5 \mathrm{~mm}$ de espesor. Para el resto de ensayos, los discos utilizados proceden de una chapa y poseen $25 \mathrm{~mm}$ de diámetro y un espesor de $5 \mathrm{~mm}$ o $2,5 \mathrm{~mm}$. En todos los casos, las probetas han sido pulidas para obtener una rugosidad media superficial $\left(R_{a}\right)$ inferior a $0,1 \mu \mathrm{m}$.

En el caso de los ensayos tribológicos en el contacto acero AISI 316L-resina epoxi, tanto para el nuevo nanocomposite de matriz epoxi como para los recubrimientos y en los ensayos realizados para estudiar la evolución del coeficiente de fricción con la velocidad de giro empleando como lubricantes las emulsiones de líquidos iónicos en agua en el contacto acero AISI 316L-acero AISI 316L, se han empleado bolas de este tipo de acero con un diámetro de 1,6 $\mathrm{mm}$ proporcionadas por Goodfellow (Reino Unido).

\subsubsection{Acero AISI 1015}

Se han empleado probetas con forma de disco de $25 \mathrm{~mm}$ de diámetro y $5 \mathrm{~mm}$ de espesor de acero AISI 1015 como sustrato para los recubrimientos de los diferentes nanocomposites de matriz epoxi. Se trata de un acero al carbonomanganeso que pertenece al grupo de los aceros estructurales, muy empleado en el sector de la construcción. En la Tabla 3 se muestran las propiedades y composición de este acero.

Tabla 3. Propiedades y composición del acero AISI 1015

\begin{tabular}{cc}
\hline Composición & $\begin{array}{c}<0,17 \% \mathrm{C} ;<0,4 \% \mathrm{Mn} ;<0,01 \% \mathrm{P} ;<0,012 \% \mathrm{Cr} ; \\
<0,036 \% \mathrm{Ni} ; \text { Resto } \mathrm{Fe}\end{array}$ \\
\hline Módulo de Young & $205-215 \mathrm{GPa}$ \\
\hline Coeficiente de Poisson & $0,285-0,295$ \\
\hline Resistencia a la tracción & $380-470 \mathrm{MPa}$ \\
\hline Punto de fusión & $1490-1530^{\circ} \mathrm{C}$ \\
\hline Límite elástico & $300-355 \mathrm{MPa}$ \\
\hline $\begin{array}{c}\text { Temperatura máxima de } \\
\text { servicio }\end{array}$ & $344-357^{\circ} \mathrm{C}$ \\
\hline Dureza & $118-138$ \\
\hline
\end{tabular}


Este material ha sido seleccionado como sustrato debido a su baja resistencia a la corrosión y a la elevada rugosidad que presenta en su estado de suministro. Estas propiedades favorecen la formación de los recubrimientos,

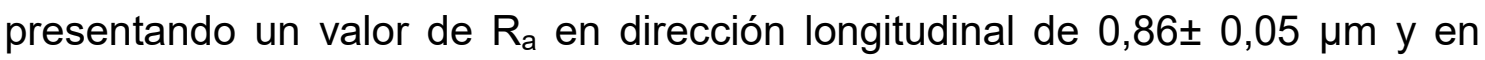
dirección transversal de 1,25 $\pm 0,09 \mu \mathrm{m}$.

\subsubsection{Acero AISI 52100}

Se han utilizado bolas de acero AISI 52100 de $1,6 \mathrm{~mm}$ de diámetro suministradas por Goodfellow (Reino Unido) en los ensayos punzón sobre disco para la obtención de las curvas de Coeficiente de fricción vs. velocidad de las emulsiones de cristales líquidos iónicos en agua. Este tipo de material posee una elevada dureza y resistencia a la abrasión, es relativamente fácil de mecanizar y se utiliza en una gran cantidad de aplicaciones industriales.

Tabla 4. Propiedades y composición del acero AISI 52100

\begin{tabular}{cc}
\hline Composición & $\begin{array}{c}0,95-1,05 \% \mathrm{C} ; 1,30-1,65 \% \mathrm{Cr} ; 0,25-0,45 \% \mathrm{Mn} ; 0,15- \\
0,35 \% \mathrm{Si} ;<0,027 \% \mathrm{P} ;<0,025 \% \mathrm{~S}, \text { Resto Fe }\end{array}$ \\
\hline Módulo de Young & $190-210 \mathrm{GPa}$ \\
\hline Coeficiente de Poisson & $0,27-0,30$ \\
\hline $\begin{array}{c}\text { Resistencia a la } \\
\text { tracción }\end{array}$ & $650-880 \mathrm{MPa}$ \\
\hline Límite elástico & $190-210 \mathrm{GPa}$ \\
\hline $\begin{array}{c}\text { Temperatura máxima de } \\
\text { servicio }\end{array}$ & $150^{\circ} \mathrm{C}$ \\
Dureza & $732 \mathrm{HV}$ \\
\hline Punto de fusión & $1424^{\circ} \mathrm{C}$ \\
\hline
\end{tabular}

\subsubsection{Zafiro}

Para el estudio del contacto tribológico cerámico-acero, se han empleado bolas de zafiro de 1,5 mm de diámetro, suministradas de Goodfellow (Reino Unido). Las principales características de este material quedan recogidas en la Tabla 5. 
Tabla 5. Propiedades y composición del zafiro

\begin{tabular}{cc}
\hline Composición & $\mathrm{Al}_{2} \mathrm{O}_{3}(99,9 \%)$ \\
\hline Módulo de Young & $430-460 \mathrm{GPa}$ \\
\hline Coeficiente de Poisson & $0,21-0,27$ \\
\hline Resistencia a la tracción & $248-273 \mathrm{MPa}$ \\
\hline Límite elástico & $248-273 \mathrm{MPa}$ \\
\hline Temperatura máxima de servicio & $1800-1950^{\circ} \mathrm{C}$ \\
\hline Dureza & $2500-3000 \mathrm{HV}$ \\
\hline Punto de fusión & $1970-2070^{\circ} \mathrm{C}$ \\
\hline
\end{tabular}

\subsubsection{Resina epoxi}

Los diferentes nanocomposites de matriz epoxi estudiados en el presente trabajo han sido preparados empleando los dos productos de partida que conforman la resina epoxi, un prepolímero y un agente de curado, fabricados por SP Systems y suministrados por JEMG Gazechim Composites Iberica bajo el nombre comercial de Ampreg 22.

En este caso, el prepolímero empleado es el digliciléter de bisfenol A (DGEBA) (Figura 30), obtenido en la reacción de condensación entre la epiclorhidrina y el bisfenol A en presencia de un catalizador básico. El agente de curado, también llamado endurecedor, promueve o controla la reacción de curado [113], favoreciendo el entrecruzamiento de las redes epoxi. Ha sido empleado un agente de curado rápido, en una proporción del $28 \%$ en peso, formado por una mezcla de cuatro aminas:
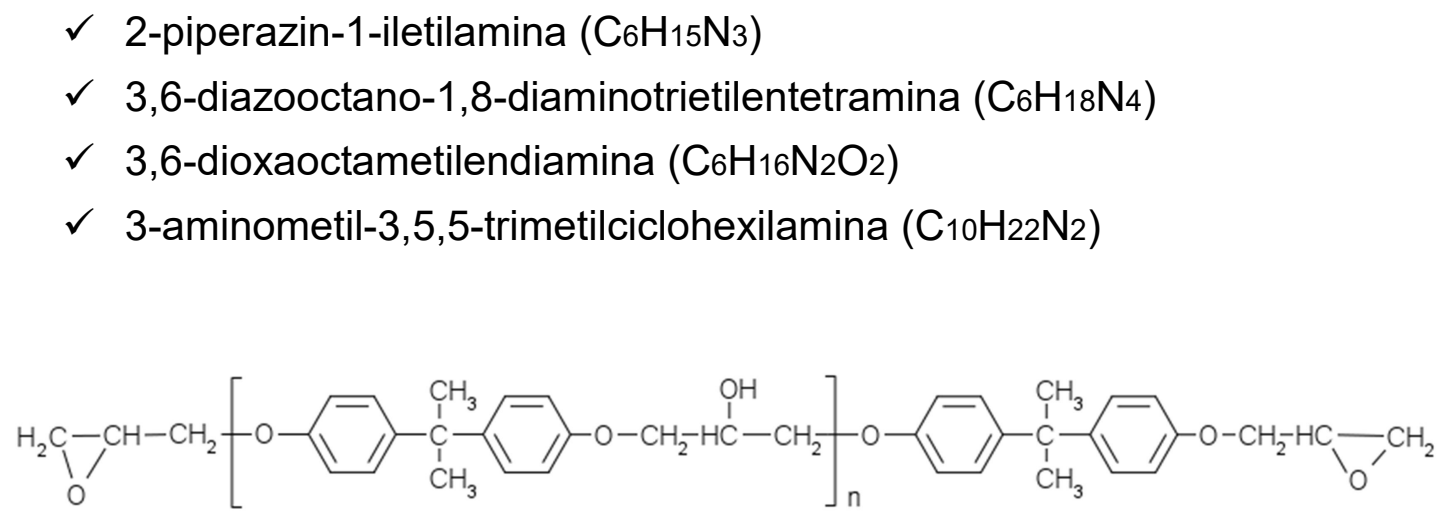

Figura 30. Estructura química del digliciléter de bisfenol A 
Los grupos amino del agente de curado reaccionan con los grupos epoxi presentes en el prepolímero mediante una reacción de adición nucleofílica generando grupos hidroxilo como puede observase en la Figura 31.

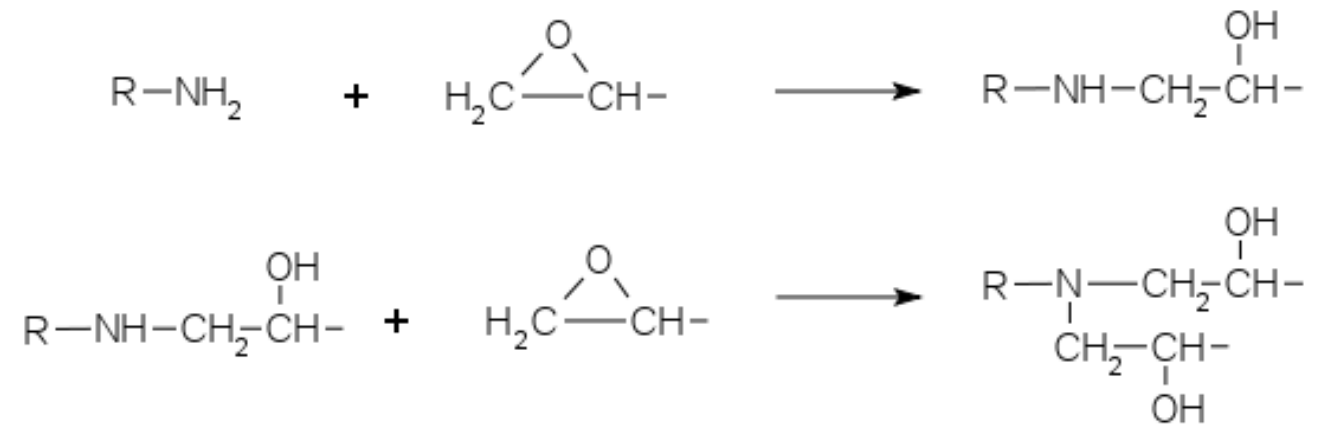

Figura 31. Mecanismo de formación de resina epoxi a partir de un agente de curado con grupos amino [113]

\subsubsection{Líquidos iónicos}

\subsubsection{Líquidos iónicos próticos}

En el presente trabajo se ha estudiado el comportamiento como lubricantes de una serie de líquidos iónicos próticos, en estado puro, en disolución acuosa, como agentes dispersantes de nanofases de carbono y como aditivos de nanocomposites de matriz epoxi.

Estos líquidos iónicos solo contienen los elementos $\mathrm{C}, \mathrm{H}, \mathrm{N}$, y $\mathrm{O}$ en su estructura. Debido a que no hay presencia de elementos halógenos, fósforo o azufre en su composición son totalmente respetuosos con el medio ambiente. Todos estos líquidos iónicos fueron proporcionados por el Dr. Miguel Iglesias (Universidad Federal de Bahía, Brasil) y se emplearon tal y como fueron recibidos.

\subsection{Estearato de bis(2-hidroxietil)amonio (DEs)}

El cristal líquido iónico estearato de bis(2-hidroxietil)amonio, se ha estudiado como lubricante en forma de emulsión en agua al $1 \%$ en peso. Además, se ha estudiado el comportamiento frente a fricción y desgaste de una dispersión de nanodiamantes en la emulsión anterior. 
Como se observa en la Figura 32, este líquido iónico prótico proviene de un ácido graso de cadena larga (ácido esteárico) y de la dietanolamina y su síntesis fue descrita por Santos et al. [232]. Se trata de un cristal líquido iónico, ya que presenta mesofases cristal líquido [31] y se encuentra en estado sólido a temperatura ambiente.

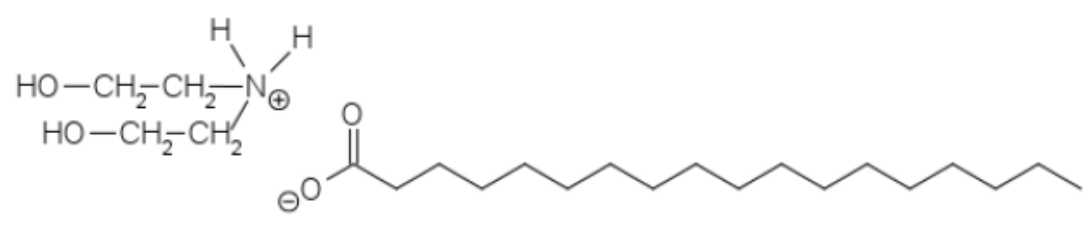

Figura 32. Estructura química del líquido iónico DEs

Se ha realizado un análisis térmico mediante calorimetría diferencial de barrido, con el objetivo de determinar el perfil de fusión del nanofluido (Figura 33).

En el termograma se observa un primer pico correspondiente a una temperatura de onset de $53,3^{\circ} \mathrm{C}$. Posteriormente, a una temperatura de onset de $101,8^{\circ} \mathrm{C}$ se observa un segundo pico correspondiente a la fusión de la mesofase.

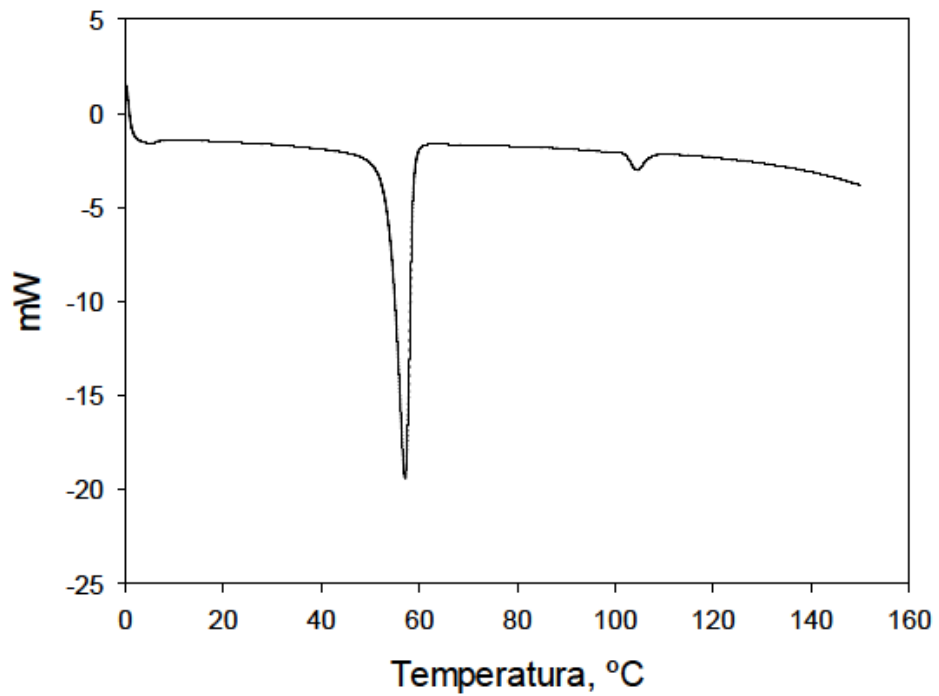

Figura 33. DSC del líquido iónico DEs

Las mesofases han sido evaluadas mediante termomicroscopía de luz polarizada observándose las estructuras que se muestran en la Figura 34. A temperaturas inferiores a la temperatura de fusión se observa una mesofase con textura oleosa, que posteriormente evoluciona hacia la formación de 
Capítulo 3. Materiales, equipos y procedimiento experimental pequeñas cruces de malta y líneas ordenadas horizontalmente. Posteriormente se produce la fusión total del material a temperaturas superiores a $101,8^{\circ} \mathrm{C}$.

a)

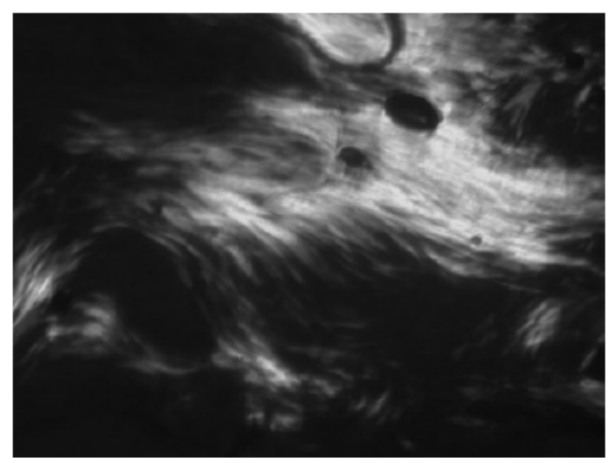

b)

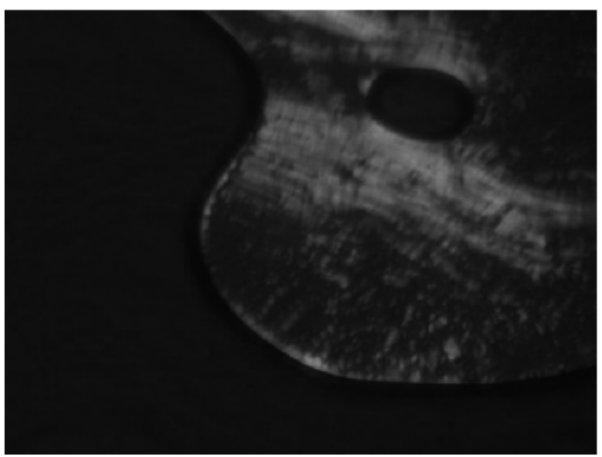

Figura 34. Micrografías obtenidas para DEs (20x) mediante microscopía de luz polarizada:

a) $50^{\circ} \mathrm{C}$; b) $80^{\circ} \mathrm{C}$

Se ha determinado la temperatura de degradación de este nanofluido mediante termogravimetría, presentando una pérdida de masa del $50 \%$ a $308,14^{\circ} \mathrm{C}$. Además presenta una descomposición en varias etapas como se observa en la Figura 35.

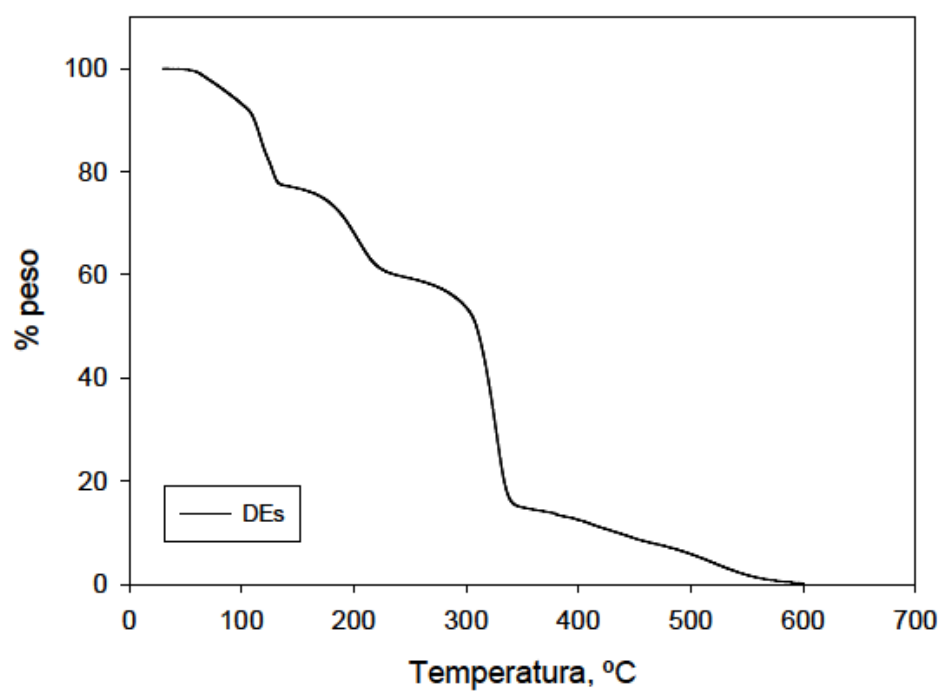

Figura 35. Termogravimetría del líquido iónico DEs

Con respecto al estudio de infrarrojo, que se presenta en la Figura 36, se observan las bandas características de los grupos carboxilato, hidroxilo y amonio. 


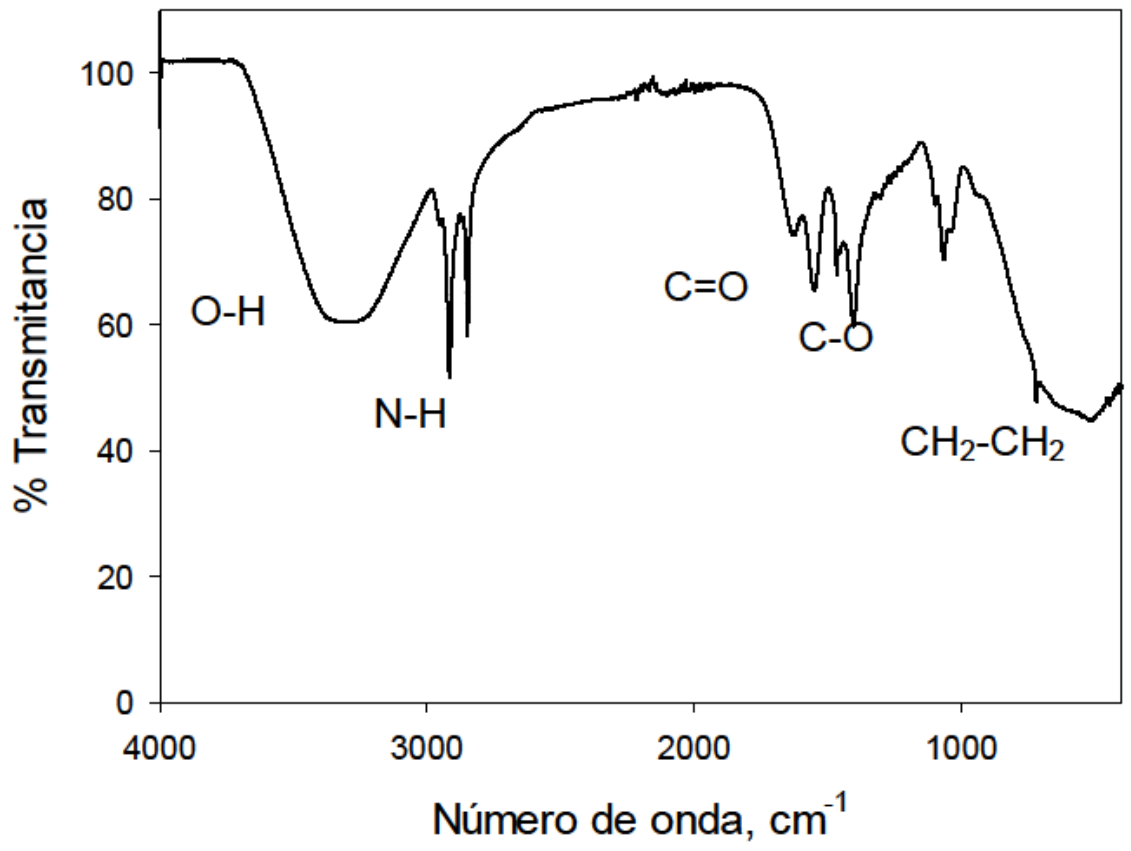

Figura 36. Espectro infrarrojo del líquido iónico DEs

\subsection{Estearato de 2-hidroxietilamonio (MEs)}

En el caso del MEs, estearato de 2-hidroxietilamonio (Figura 37) [232], se trata de otro líquido iónico derivado del ácido esteárico que se encuentra en estado sólido a temperatura ambiente.

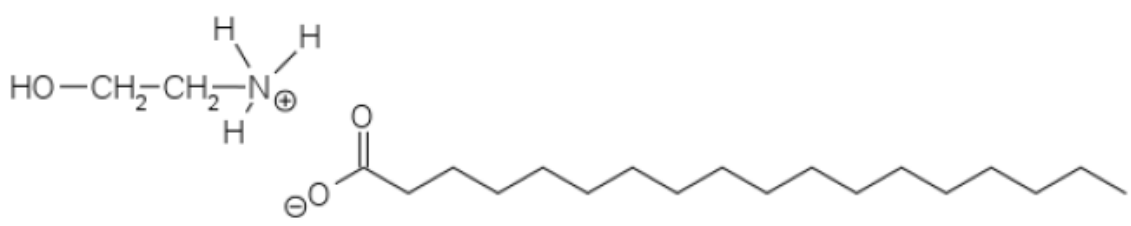

Figura 37. Estructura química del líquido iónico MEs

Se observa que al igual que el DEs, se trata de un cristal líquido iónico. Con respecto a su perfil de fusión, presenta una temperatura de transición desde la fase sólida de $52,73^{\circ} \mathrm{C}$ (medida en el onset) y la temperatura de fusión de la fase cristal líquido a $98,5^{\circ} \mathrm{C}$ (Figura 38 ). 
Capítulo 3. Materiales, equipos y procedimiento experimental

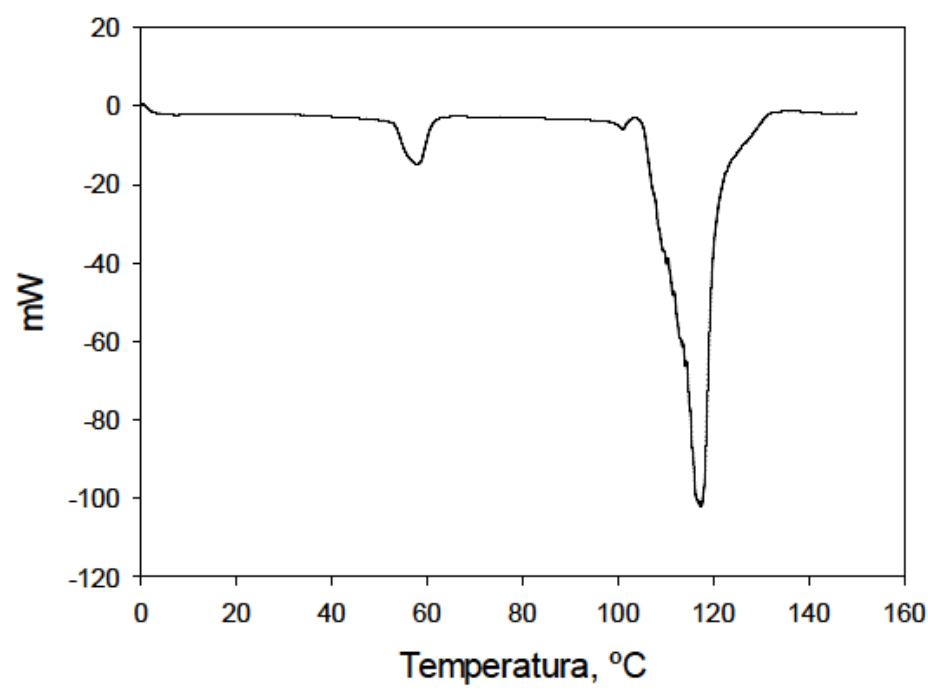

Figura 38. DSC del líquido iónico MEs

Se han obtenido termomicrografías mediante luz polarizada a diferentes temperaturas. Se observan cambios en las texturas de las mesofases desde una apariencia más homogénea a $35^{\circ} \mathrm{C}$, pasando a una textura de tipo mosaico hasta la fusión de la fase de cristal líquido en torno a $98^{\circ} \mathrm{C}$.

a)

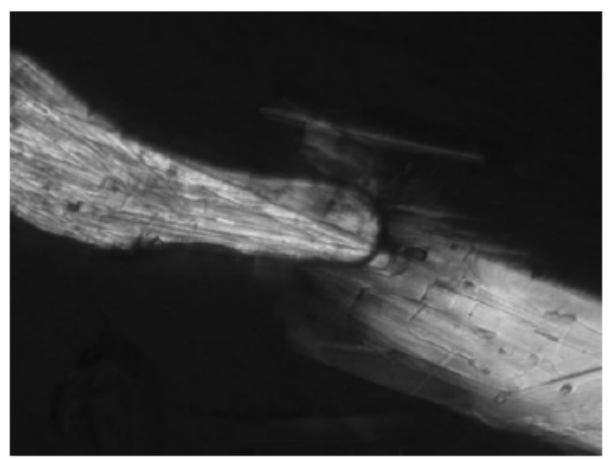

b)

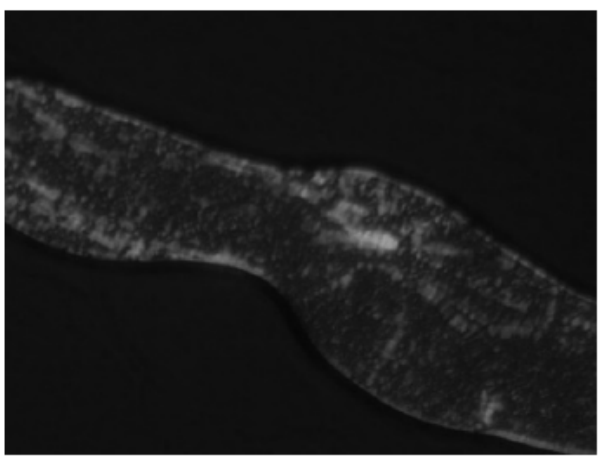

Figura 39. Micrografías obtenidas para MEs (20x) mediante microscopía de luz polarizada:

a) $35^{\circ} \mathrm{C}$; b) $90^{\circ} \mathrm{C}$

Como se puede observar en la Figura 40, el líquido iónico MEs presenta una descomposición en dos etapas y la temperatura a la que pierde el $50 \%$ de su masa $\left(225,41^{\circ} \mathrm{C}\right)$, es inferior a la que presenta el cristal líquido iónico DEs. 


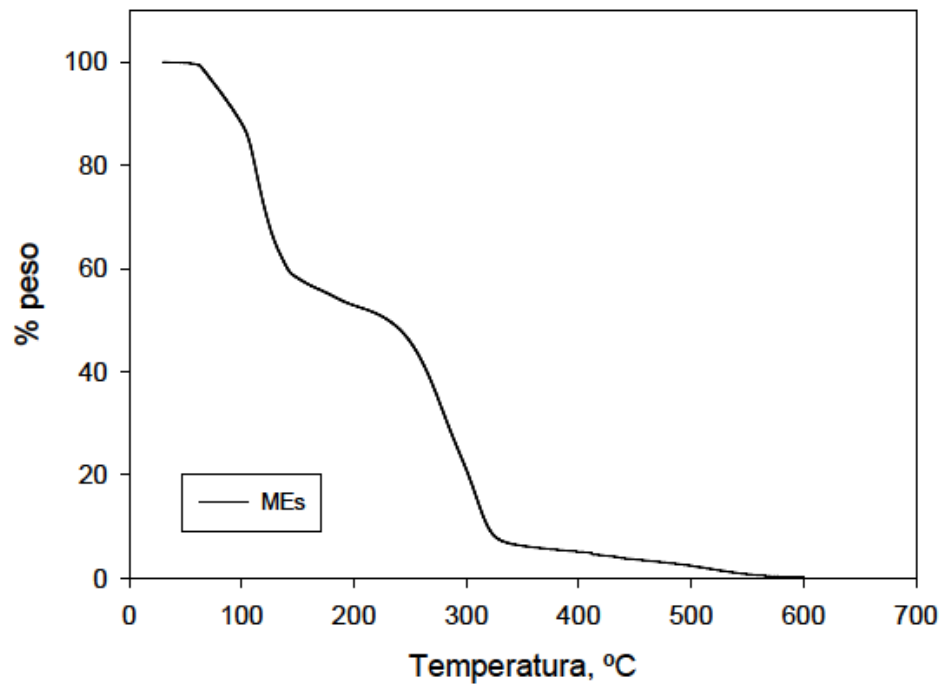

Figura 40. Termogravimetría del líquido iónico MEs

Con respecto al espectro infrarrojo (Figura 41), se pueden observar los grupos funcionales carboxilo, hidroxilo y amonio. Estos resultados están en concordancia con los descritos en la bibliografía [232].

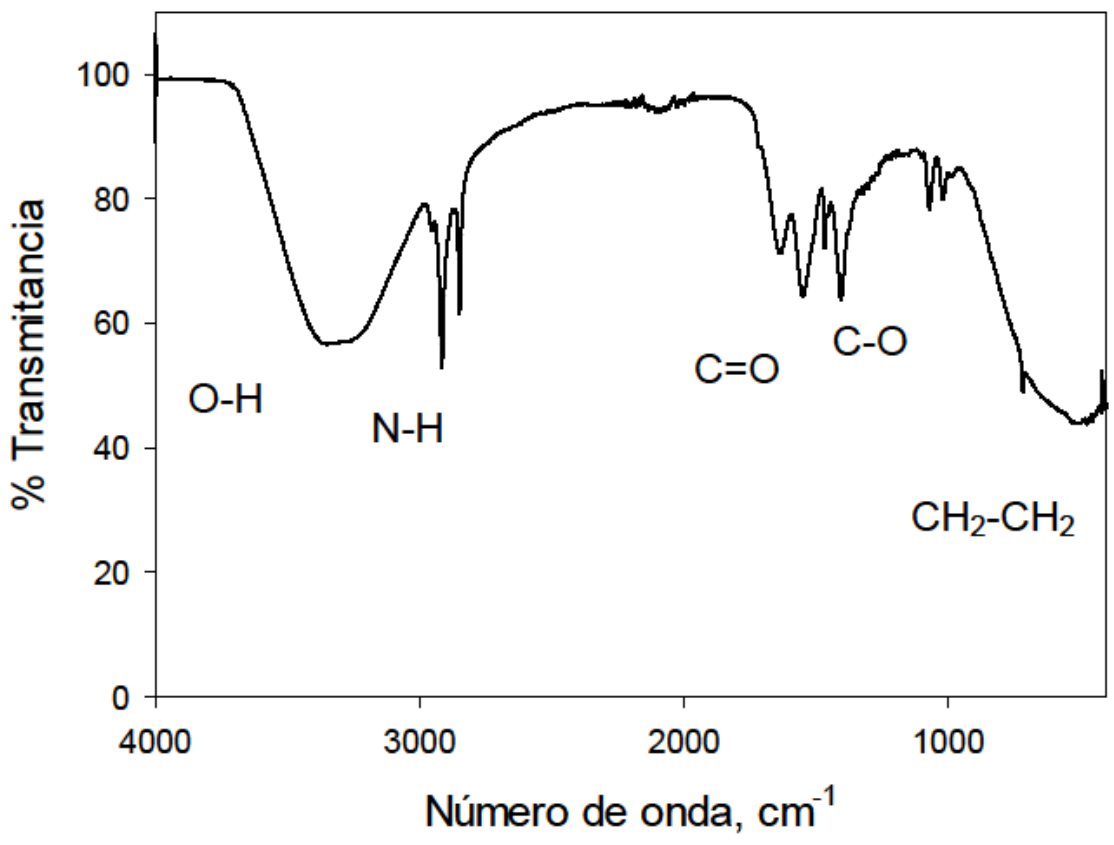

Figura 41. Espectro infrarrojo del líquido iónico MEs

\subsection{Palmitato de bis(2-hidroxietil)amonio (DPa)}

El líquido iónico palmitato de bis(2-hidroxietil)amonio [98], DPa, es un cristal líquido iónico derivado del ácido palmítico. 


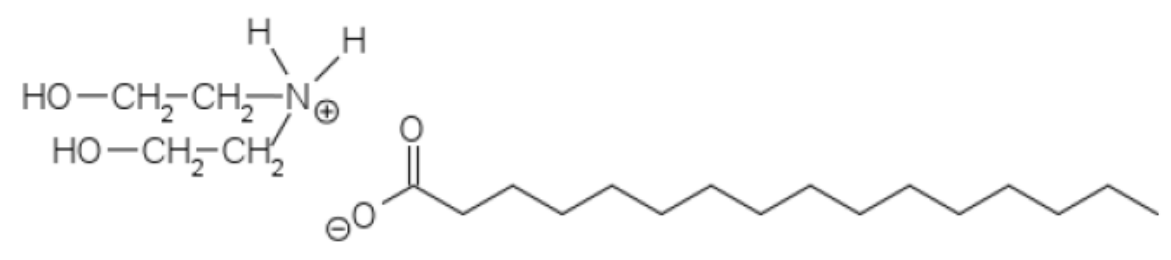

Figura 42. Estructura química del líquido iónico DPa

Como se observa en la termogravimetría (Figura 43), este líquido iónico presenta una temperatura de degradación intermedia $\left(293,91^{\circ} \mathrm{C}\right)$ entre los líquidos iónicos derivados del ácido esteárico presentados anteriormente.

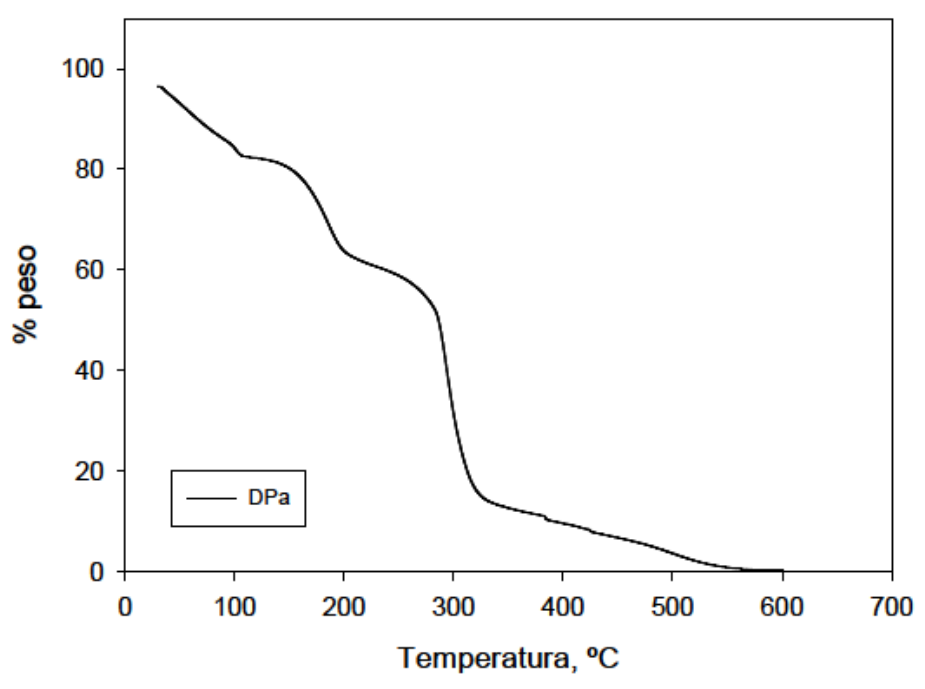

Figura 43. Termogravimetría del líquido iónico DPa

Con respecto al termograma obtenido mediante calorimetría diferencial de barrido, este líquido iónico presenta una temperatura de transición de $39,6^{\circ} \mathrm{C}$, (obtenida a partir del onset). La fusión de la fase cristal líquido se produce a $90,26^{\circ} \mathrm{C}$ (Figura 44). Al poseer un catión con una cadena más corta que los otros líquidos iónicos derivados de ácidos grasos, la temperatura de transición a la fase cristal líquido es inferior y el rango de temperatura de la fase cristal líquido es más elevado. 


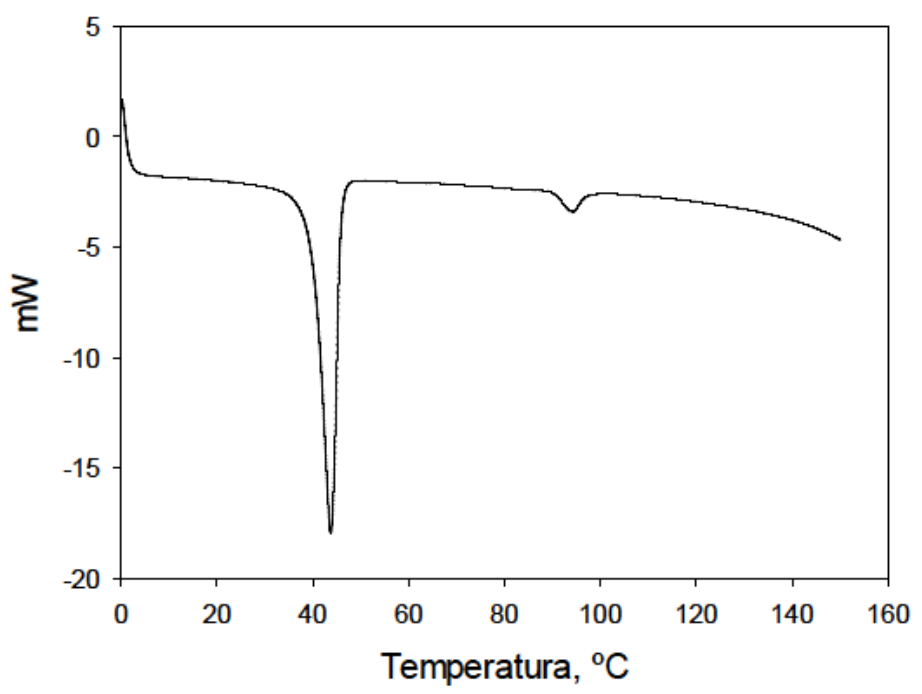

Figura 44. DSC del líquido iónico DPa

La textura de las mesofases se muestra en las termomicrografías de la Figura 45 , obtenidas mediante microscopía de luz polarizada. Es posible observar en el caso de este líquido iónico una textura oleosa a baja temperatura que se transforma en cruces de malta que desaparecen en torno a $90^{\circ} \mathrm{C}$.

a)

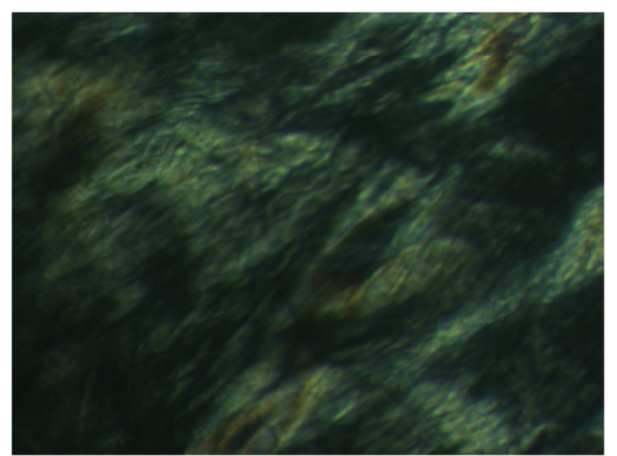

b)

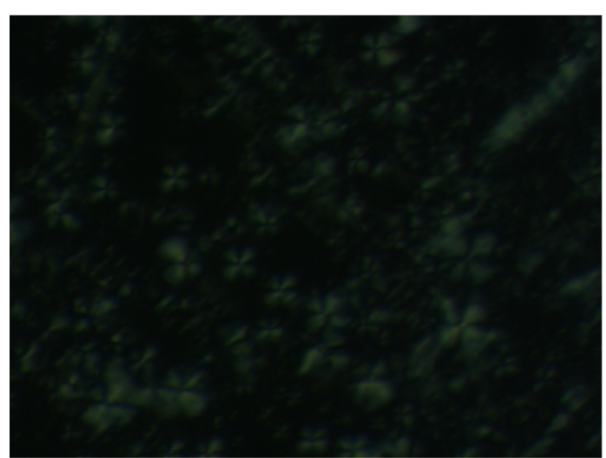

Figura 45. Micrografías obtenidas para DPa (20x) mediante microscopía de luz polarizada:

a) $35^{\circ} \mathrm{C}$; b) $60^{\circ} \mathrm{C}$

En la Figura 46 se observa el espectro infrarrojo del líquido iónico DPa, presentando los mismos grupos funcionales que los líquidos iónicos derivados de ácidos grasos que se han presentado anteriormente. 


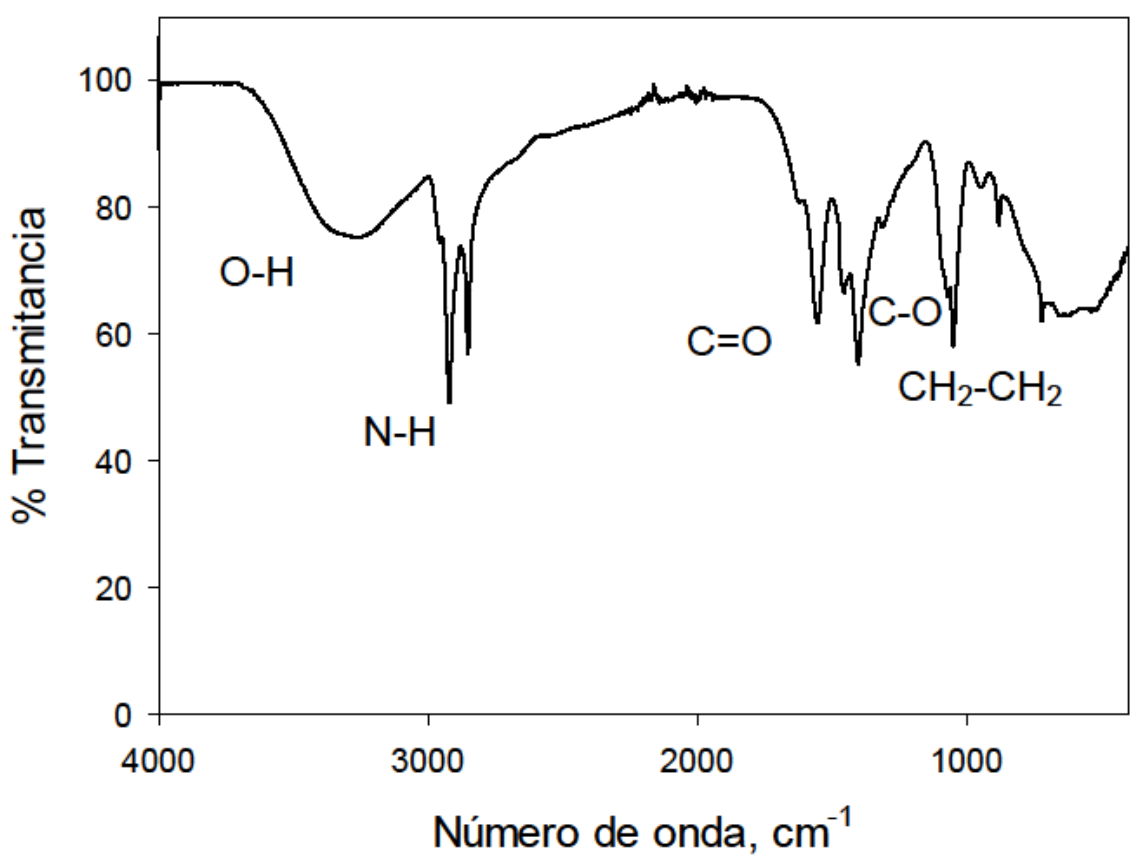

Figura 46. Espectro infrarrojo del líquido iónico $\mathrm{DPa}$

\subsection{Succinato de di[bis(2-hidroxietil)amonio] (DSu)}

Se ha estudiado el comportamiento tribológico del líquido iónico succinato de di[bis(2-hidroxietil)amonio] [281] como lubricante puro y en disolución acuosa, tanto con película gruesa como en película fina. También se ha estudiado el empleo como lubricante de sus dispersiones con un $1 \%$ y $0,5 \%$ de grafeno, respectivamente.

Tabla 6. Características del líquido iónico DSu
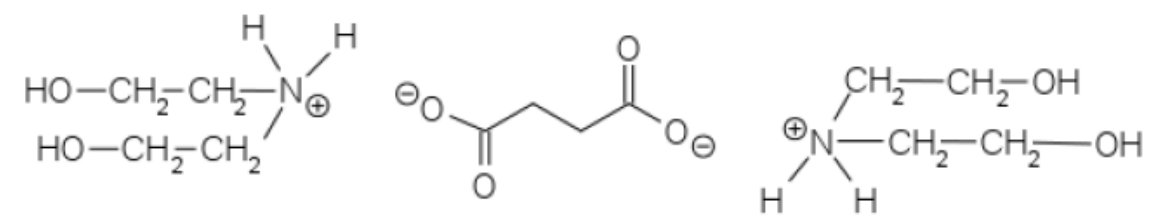

\begin{tabular}{cc}
\hline Viscosidad $\left(\mathrm{a} 20^{\circ} \mathrm{C}\right)$ & $0,285 \mathrm{~Pa} \cdot \mathrm{s}$ \\
\hline Conductividad $\left({\left.\mathrm{a} 20^{\circ} \mathrm{C}\right)}^{1,68 \mathrm{mS} / \mathrm{cm}}\right.$ \\
\hline
\end{tabular}

Este líquido iónico prótico presenta una temperatura de degradación, correspondiente a la pérdida del $50 \%$ de su masa, de $297,02^{\circ} \mathrm{C}$ (Figura 47 ). 


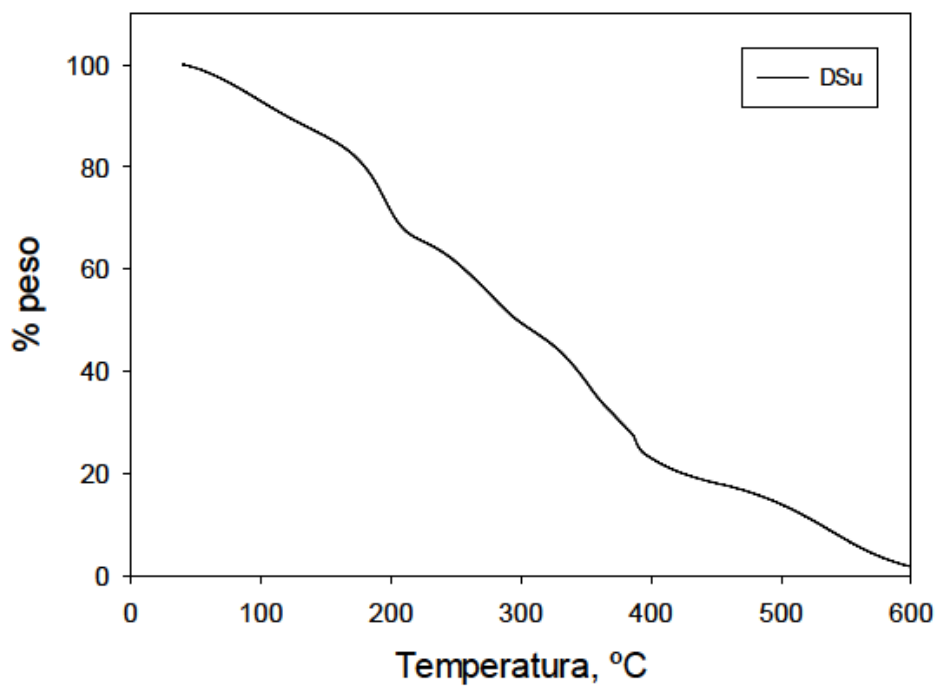

Figura 47. Termogravimetría del líquido iónico DSu

A continuación, se muestra el espectro infrarrojo del líquido iónico DSu (Figura 48). Se puede observar que este líquido iónico presenta los mismos grupos funcionales que los líquidos próticos mostrados anteriormente.

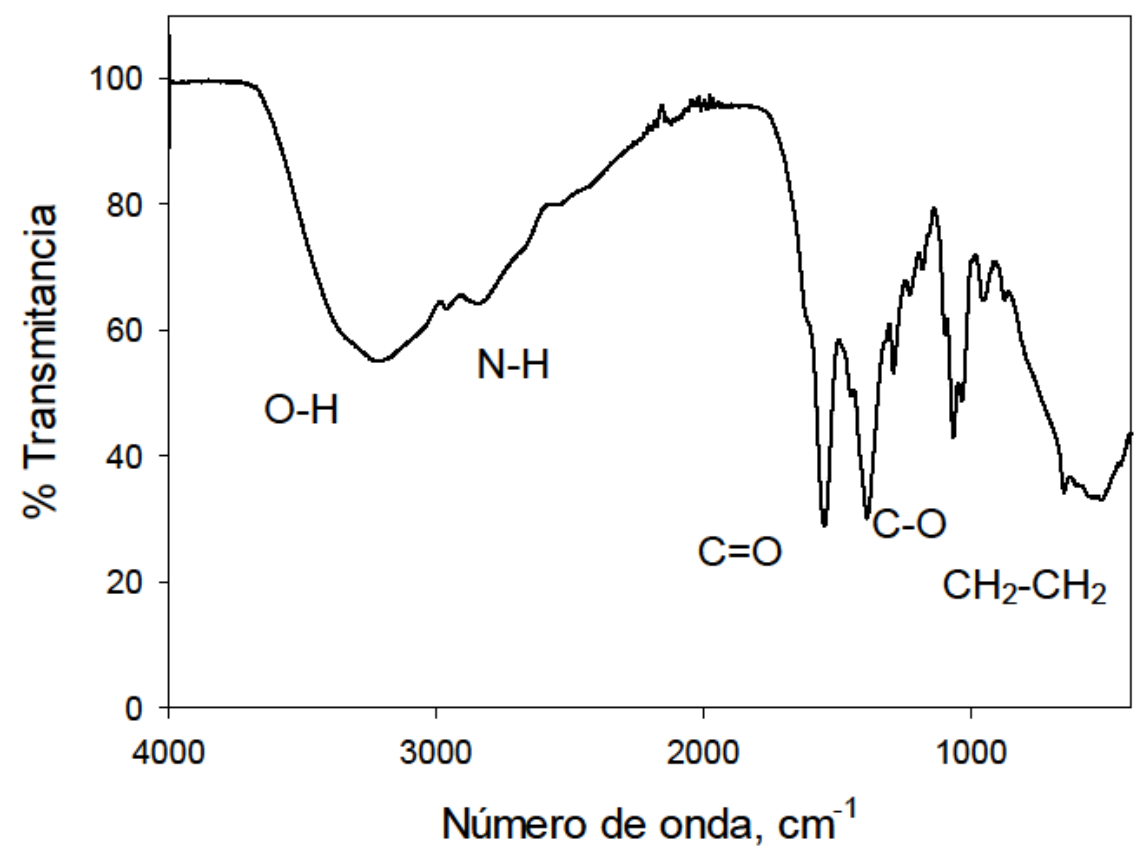

Figura 48. Espectro infrarrojo del líquido iónico DSu

\subsection{Citrato de tri[bis(2-hidroxietil)amonio] (DCi)}

Se ha utilizado el líquido iónico citrato de tri[bis(2-hidroxietil)amonio] como lubricante externo en el contacto acero AISI 316L-resina epoxi y como aditivo para la formación de un nuevo nanocomposite de matriz epoxi. 
Capítulo 3. Materiales, equipos y procedimiento experimental

Además, la dispersión con $0,1 \%$ en peso de nanodiamantes en este líquido iónico también ha sido estudiada como lubricante externo, tanto en capa fina como en película gruesa, en el contacto zafiro-acero inoxidable AISI 316L.

En la Tabla 7 se muestran las características principales de este líquido iónico.

Tabla 7. Características del líquido iónico DCi

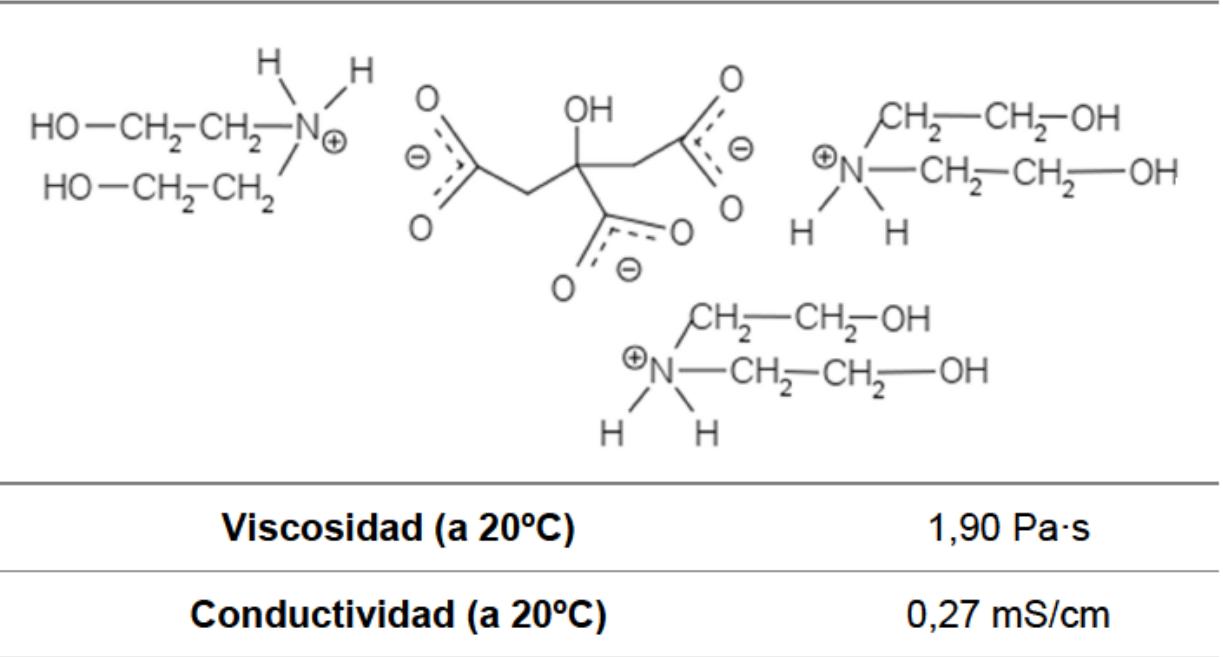

Los resultados de la termogravimetría realizada indican que este líquido iónico presenta una temperatura de degradación de $234^{\circ} \mathrm{C}$, correspondiente a la pérdida del $50 \%$ de su masa (Figura 49 ).

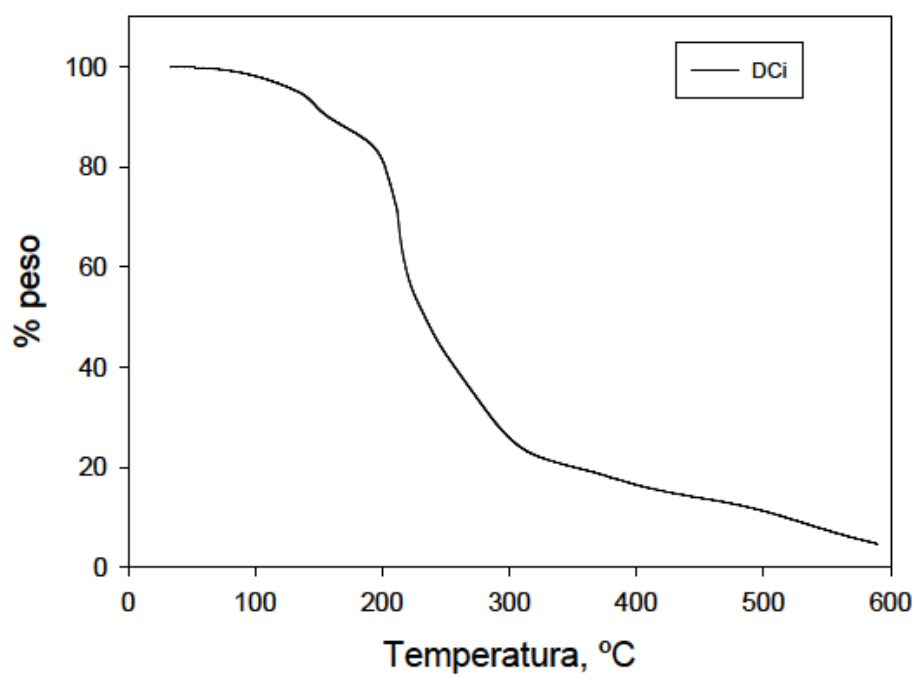

Figura 49. Termogravimetría del líquido iónico DCi 
Se ha realizado el espectro infrarrojo del líquido iónico DCi (Figura 50), donde se observa la presencia de los enlaces $\mathrm{O}-\mathrm{H}, \mathrm{N}-\mathrm{H}, \mathrm{C}=\mathrm{O}, \mathrm{C}-\mathrm{O}$, presentes en el líquido iónico.

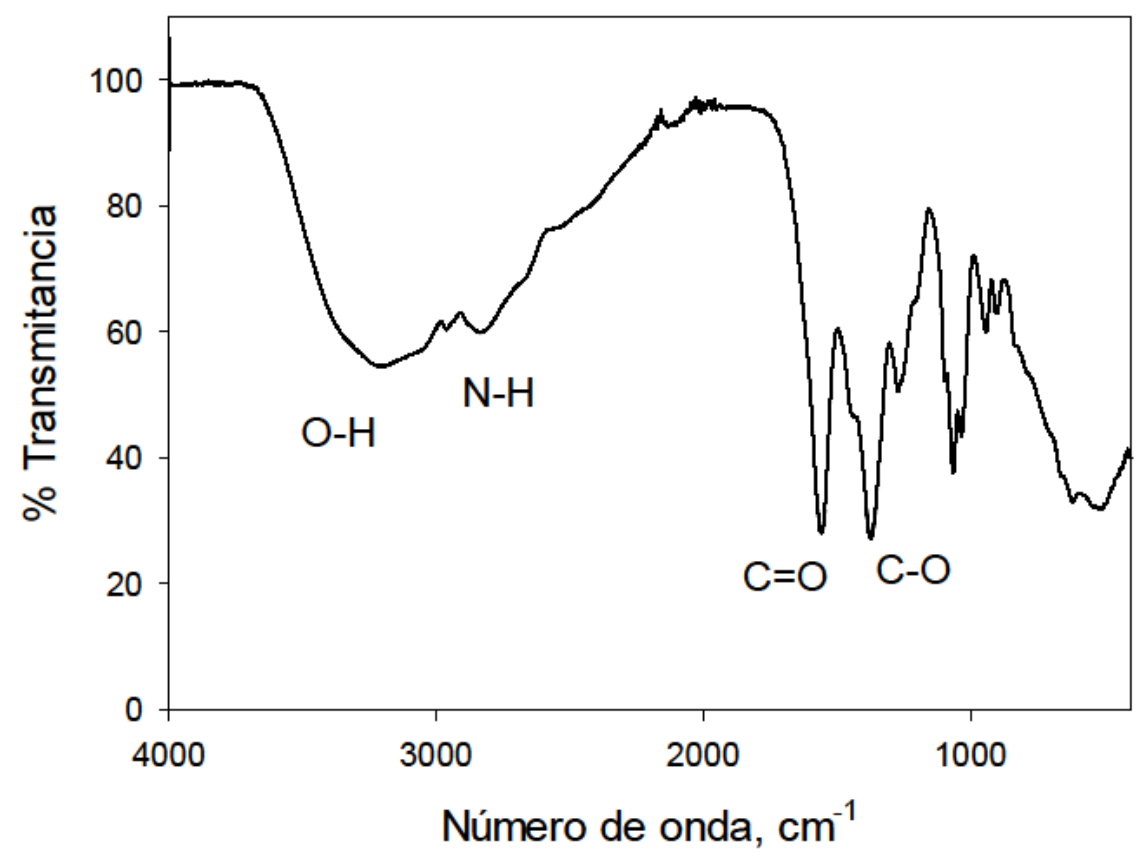

Figura 50. Espectro infrarrojo del líquido iónico DCi

\subsection{Oleato de bis(2-hidroxietil)amonio (DO)}

Un líquido iónico formado por un catión amónico diprótico y el anión oleato se ha empleado como aditivo para la formación de un nuevo nanocomposite de matriz epoxi, cuyo comportamiento como recubrimiento ha sido estudiado en este trabajo. Las características de este líquido iónico se pueden observar en la Tabla 8.

Tabla 8. Características del líquido iónico DO

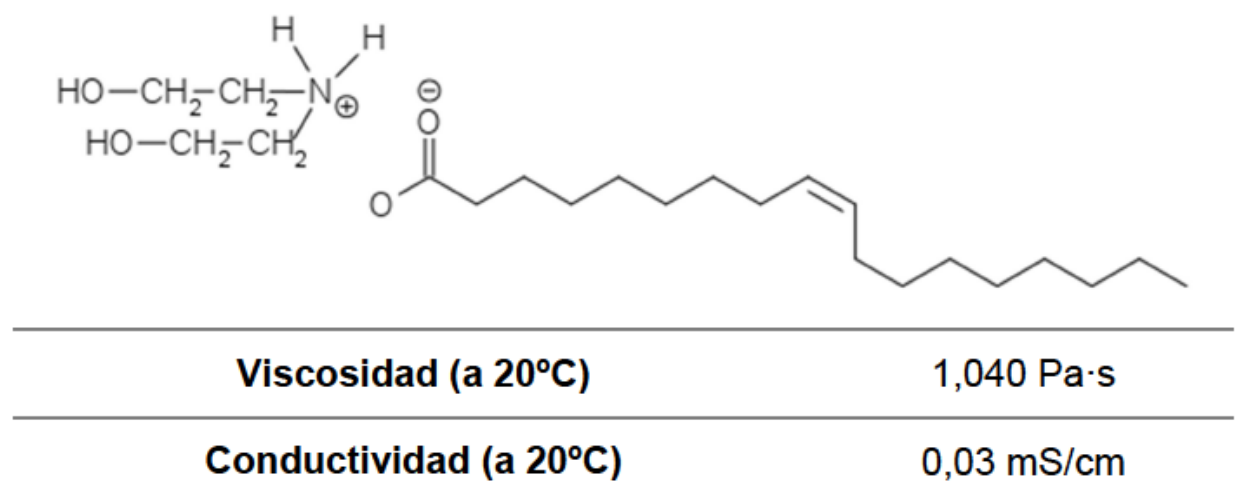


La temperatura de degradación (pérdida de un $50 \%$ de masa) de este líquido iónico prótico es de $343^{\circ} \mathrm{C}$ (Figura 51).

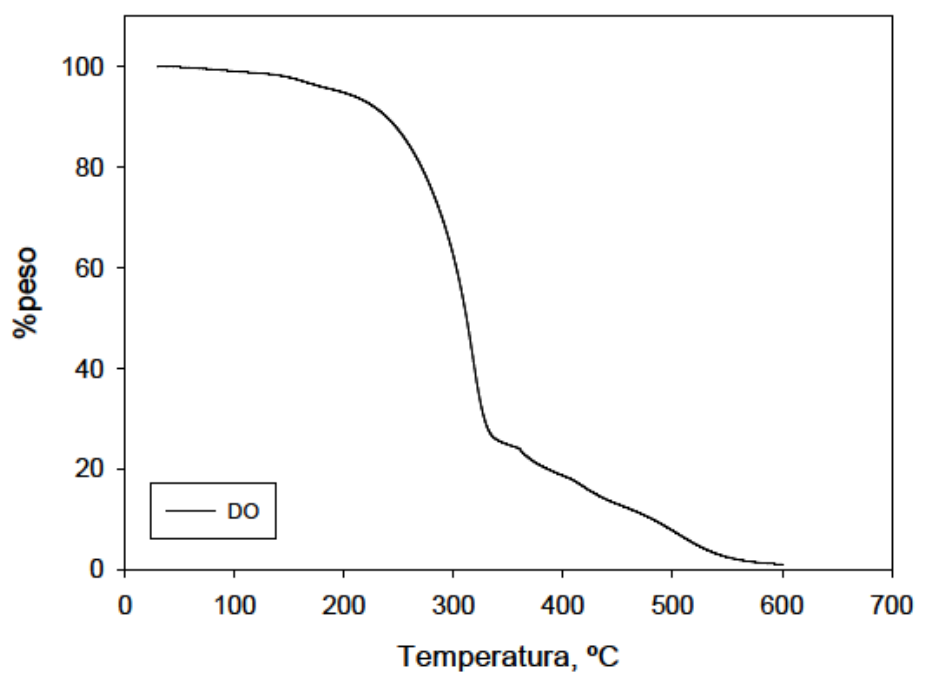

Figura 51. Termogravimetría del líquido iónico DO

Se puede observar el espectro infrarrojo del líquido iónico DO en la Figura 52, donde quedan reflejados los grupos funcionales presentes en el nanofluido.

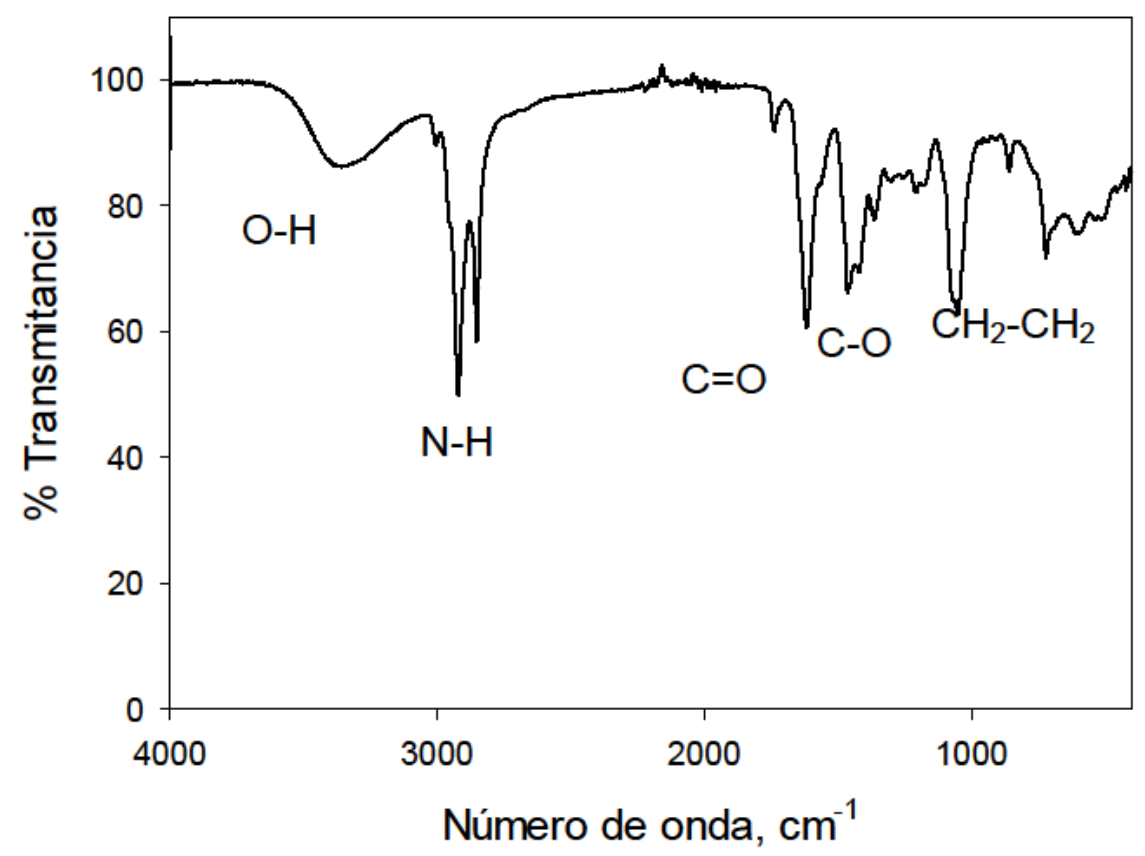

Figura 52. Espectro infrarrojo del líquido iónico DO 


\subsubsection{Líquidos iónicos apróticos}

\subsection{Dicianamida de 1-etil-3-metilimidazolio}

Se ha empleado el líquido iónico dicianamida de 1-etil-3-metilimidazolio [EMIM][DCA] suministrado por la compañía io-li-tec $\mathrm{GmbH}$ (Alemania) y sus dispersiones con grafeno al $1 \%$ y $0,5 \%$ en peso como lubricantes. Su fórmula molecular es $\mathrm{C}_{8} \mathrm{H}_{11} \mathrm{~N}_{5}$ y su masa molar es de $177,21 \mathrm{~g} / \mathrm{mol}$. Las propiedades de este líquido iónico aprótico se presentan en la Tabla 9.

Tabla 9. Propiedades del líquido iónico [EMIM][DCA]

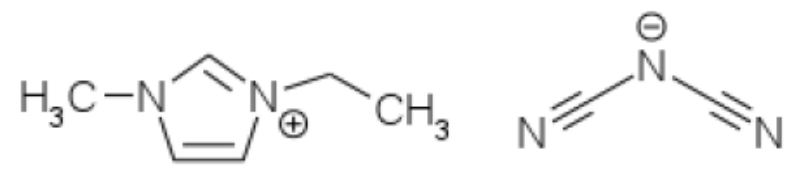

\begin{tabular}{cc}
\hline Viscosidad $\left(25^{\circ} \mathrm{C}\right)$ & $14,6 \mathrm{mPa} \cdot \mathrm{s}$ \\
\hline $\mathrm{T}^{\mathrm{a}}$ de fusión & $-21^{\circ} \mathrm{C}$
\end{tabular}

El líquido iónico [EMIM][DCA] presenta una temperatura de degradación de $361,5^{\circ} \mathrm{C}$ (pérdida del $50 \%$ de su masa). Se puede observar la termogravimetría en la Figura 53.

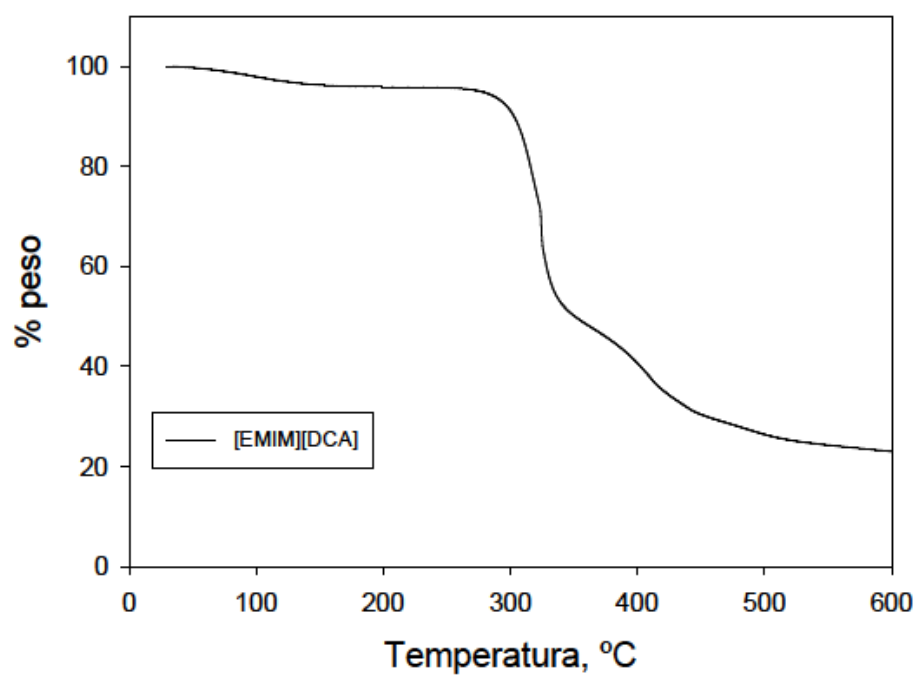

Figura 53. Termogravimetría del líquido iónico [EMIM][DCA] 
Se ha obtenido además, el espectro infrarrojo de este líquido iónico (Figura 54), presentado unas bandas de absorción análogas a las encontradas en la bibliografía [282].

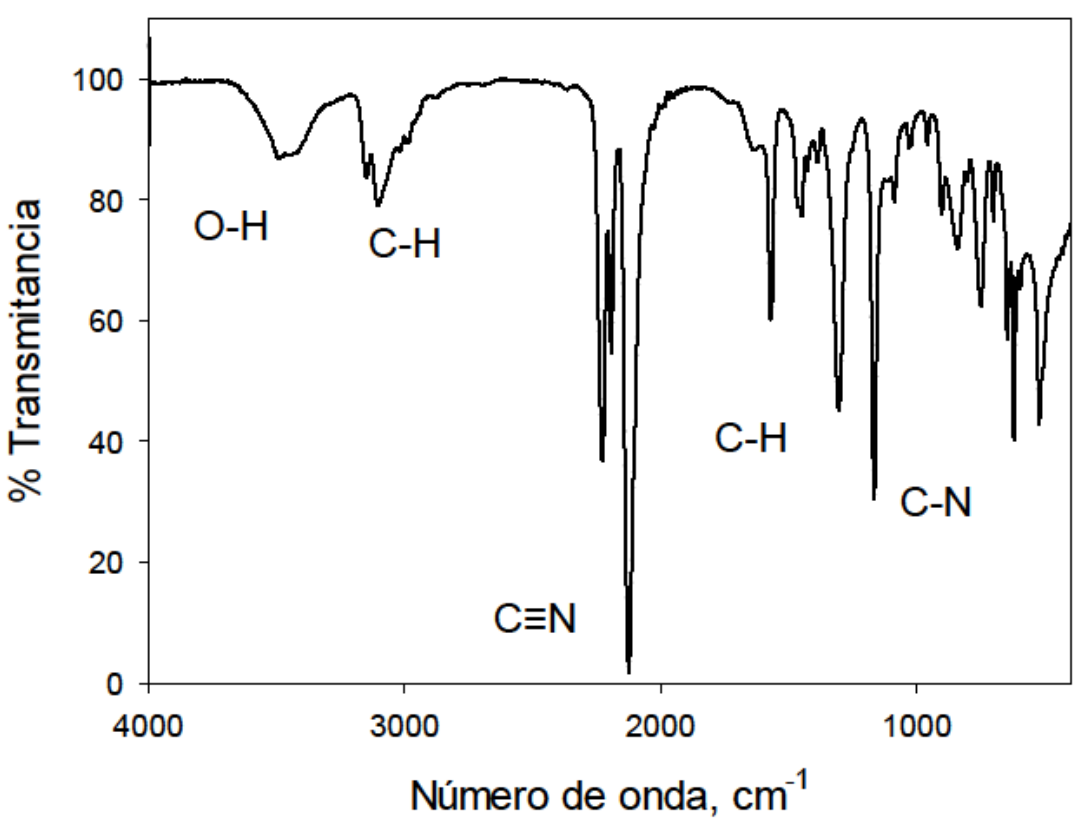

Figura 54. Espectro infrarrojo del líquido iónico [EMIM][DCA]

\subsection{Bis(trifluorometanosulfonil)imida de 1-etil-3-metilimidazolio}

El líquido iónico bis(trifluorometanosulfonil)imida de 1-etil-3-metilimidazolio, [EMIM][TFSI], ha sido proporcionado por la empresa Solvionic (Francia). Se ha empleado este líquido iónico como lubricante, y como agente dispersante de grafeno al $1 \%$ y al $0,5 \%$ en peso.

Tabla 10. Propiedades del líquido iónico [EMIM][TFSI]

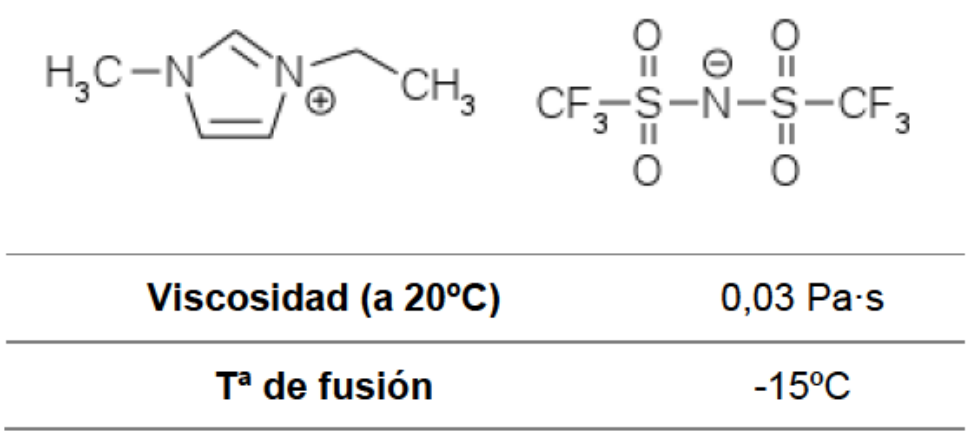


María Dolores Avilés González

Universidad Politécnica de Cartagena

Tras la realización del análisis termogravimétrico (Figura 55), se observa que la temperatura a la cual este líquido iónico pierde la mitad de su masa es $484,14^{\circ} \mathrm{C}$.

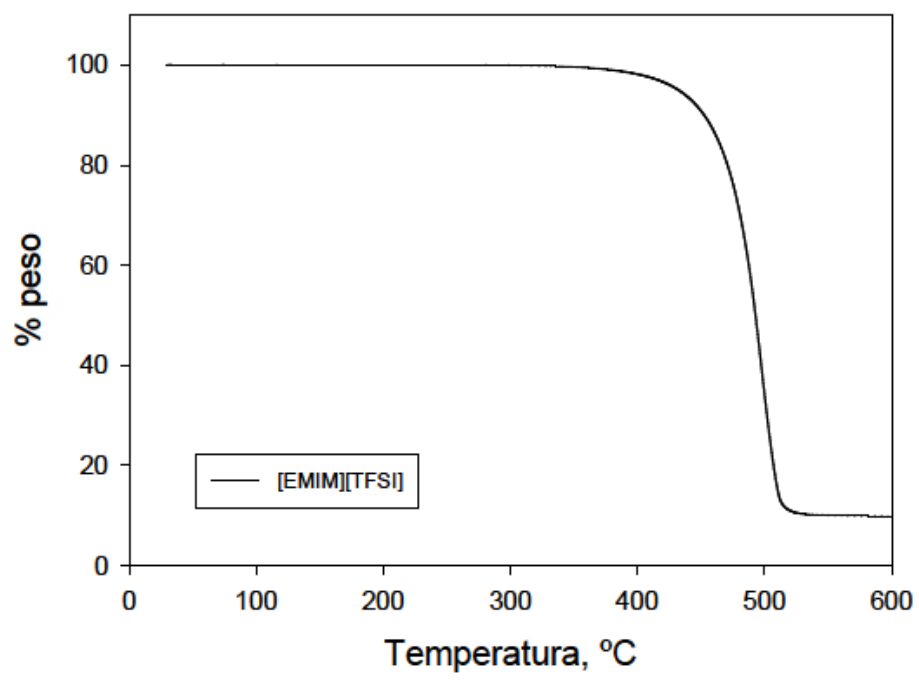

Figura 55. Termogravimetría del líquido iónico [EMIM][TFSI]

En la Figura 56 se puede observar el espectro infrarrojo del líquido iónico [EMIM][TFSI], que está fuertemente dominado por las contribuciones del anión [TFSI]. Los resultados son similares a los encontrados en la literatura [283].

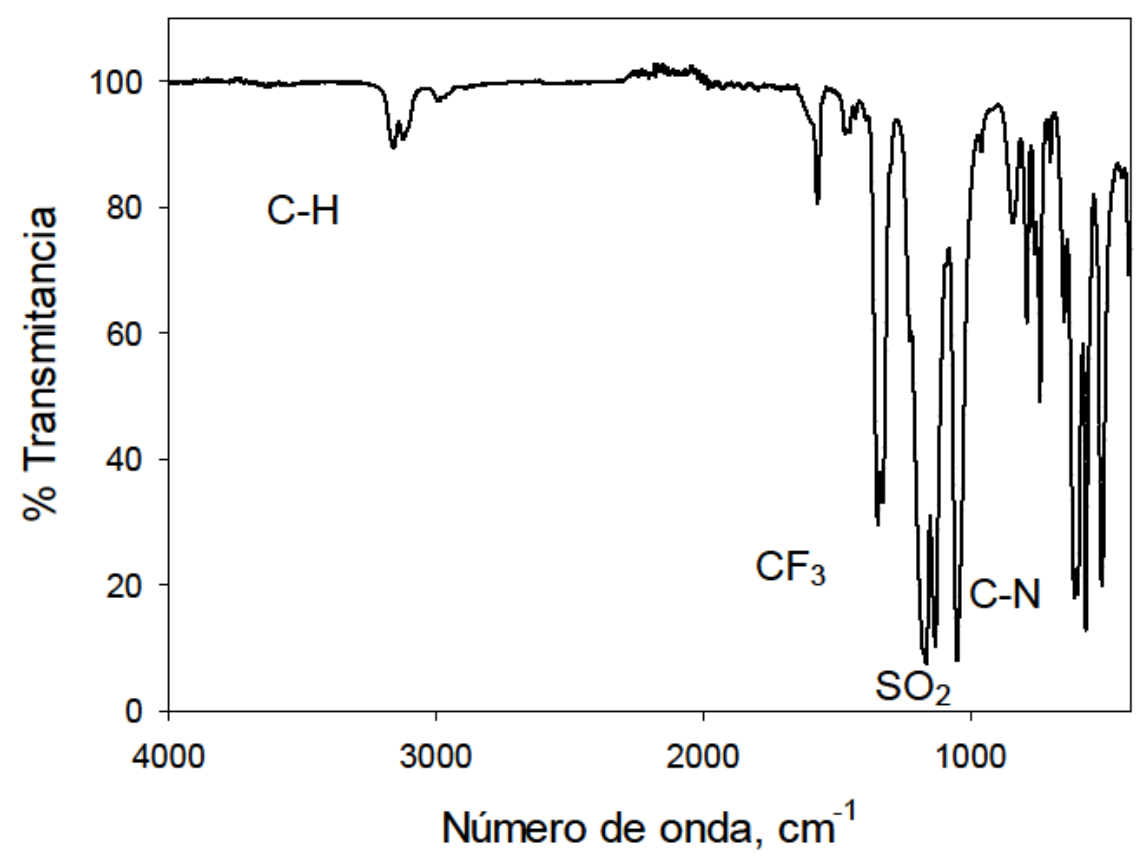

Figura 56. Espectro infrarrojo del líquido iónico [EMIM][TFSI] 


\subsection{Tetrafluoroborato de 1-octil-3-metilimidazolio $\left([\mathrm{OMIM}] \mathrm{BF}_{4}\right)$}

El líquido iónico tetrafluoroborato de 1-octil-3-metilimidazolio ([OMIM]BF 4 ) ha sido empleado como aditivo en aceites lubricantes y en la obtención de recubrimientos y films de resina epoxi, en estado puro y en combinación con grafeno.

Se trata de un líquido iónico comercial, con un $99 \%$ de pureza, proporcionado por io-li-tec (Alemania) y presenta las características que se muestran en la Tabla 11.

Tabla 11. Propiedades del líquido iónico $\left[{\mathrm{OMIM}] \mathrm{BF}_{4}}\right.$

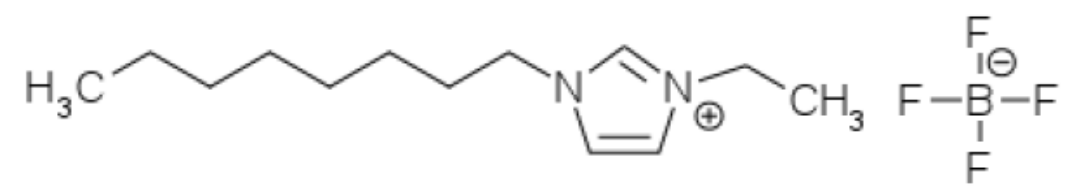

\begin{tabular}{cc}
\hline Viscosidad $\left(\mathrm{a} 20^{\circ} \mathrm{C}\right)$ & $0,20 \mathrm{~Pa} \cdot \mathrm{s}$ \\
\hline $\mathrm{T}^{\mathrm{a}}$ de fusión & $-82^{\circ} \mathrm{C}$ \\
\hline
\end{tabular}

El [OMIM]BF 4 presenta una temperatura de degradación de $417^{\circ} \mathrm{C}$, correspondiente a la pérdida del $50 \%$ de su masa (Figura 57 ).

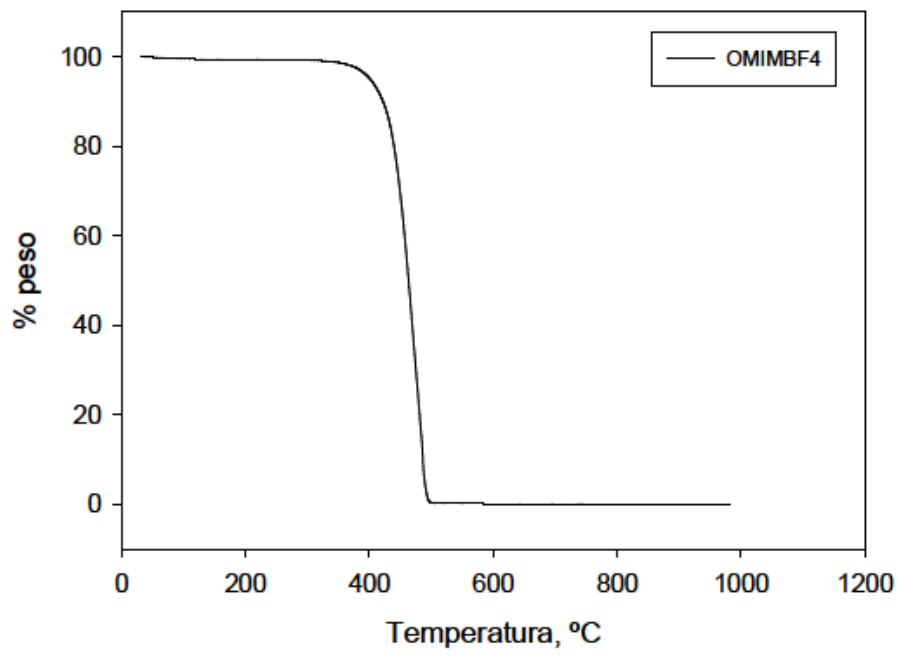

Figura 57. Termogravimetría del líquido iónico $[\mathrm{OMIM}] \mathrm{BF}_{4}$

Este líquido iónico ha sido anteriormente estudiado como lubricante puro y en combinación con grafeno en contactos zafiro-acero [255] con muy buenos 
resultados en fricción y desgaste. Además, se ha empleado como aditivo en resina epoxi observándose propiedades de autorrecuperación frente al desgaste abrasivo [284]. En la Figura 58 se muestra su espectro infrarrojo.

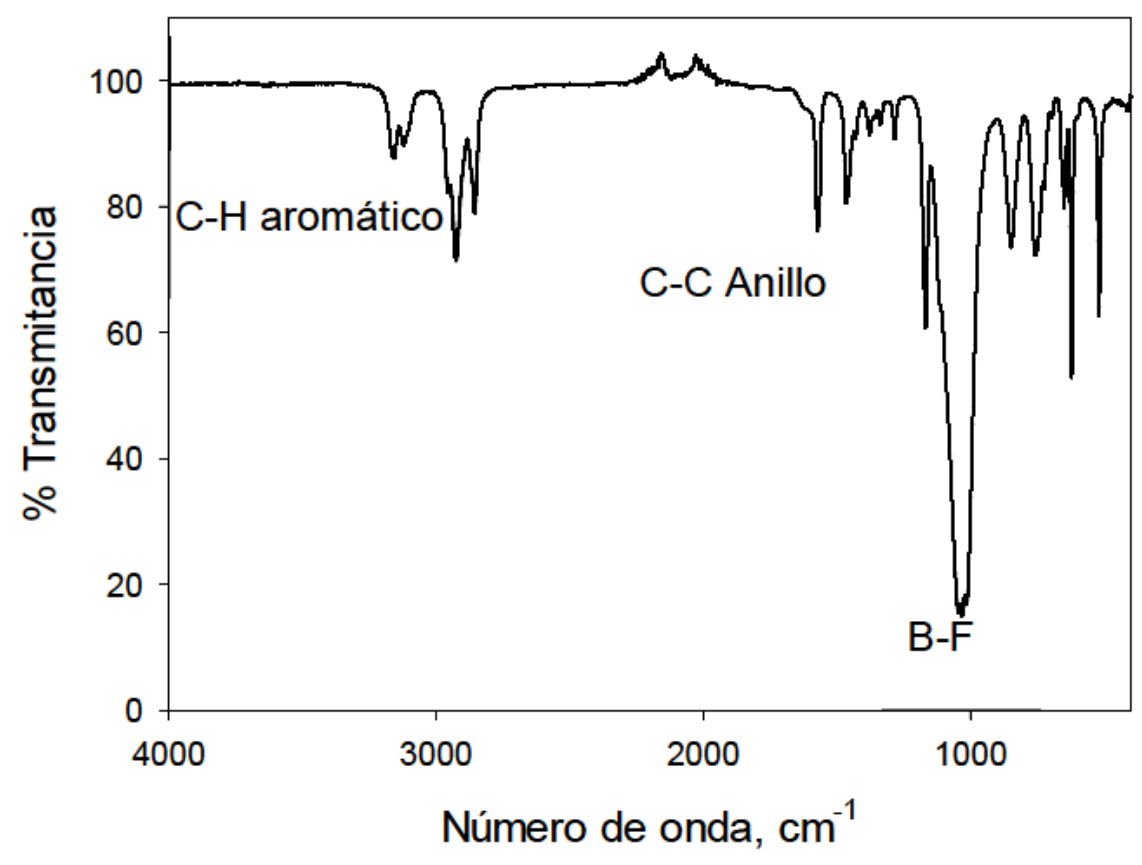

Figura 58. Espectro infrarrojo del líquido iónico $[\mathrm{OMIM}] \mathrm{BF}_{4}$

\subsubsection{Aceites lubricantes}

\subsubsection{Aceite base isoparafínico (B)}

Al aceite base isoparafínico, suministrado por lberian Lube Base Oils Company (ILBOC) S.A. (España), se han añadido grafeno, líquido iónico ([OMIM]BF 4 ) y una combinación de ambos con el fin de mejorar sus propiedades lubricantes.

Esta base lubricante está libre de aditivos y posee un contenido en azufre inferior al $0,03 \%$. Presenta una viscosidad a $25^{\circ} \mathrm{C}$ de $21 \mathrm{mPa} \cdot \mathrm{s}$.

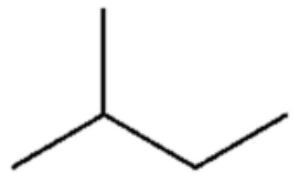

Figura 59. Estructura química del aceite base isoparafínico libre de aditivos

\subsubsection{Aceite formulado de alto rendimiento (MO)}

Se ha empleado el aceite comercial formulado de alto rendimiento SAE 10W30 proporcionado por Repsol S.A. (España) como base lubricante al que se le ha 
añadido líquido iónico ([OMIM]BF 4 ) y/o grafeno con el objetivo de mejorar su comportamiento tribológico.

Este lubricante presenta una viscosidad a $150^{\circ} \mathrm{C}$ de $43 \mathrm{mPa} \cdot \mathrm{s}$.

\subsubsection{Nanofases de carbono}

\subsubsection{Grafeno}

El grafeno utilizado en el presente trabajo fue fabricado y suministrado por la compañía io-li-tec (Alemania). Según las especificaciones, este producto (CP0080), posee de 1 a 10 capas, un espesor entre 0,6 y 3,8 nm, una pureza superior al $99 \%$ y un área superficial específica entre 500 y $1000 \mathrm{~m}^{2} / \mathrm{g}$.

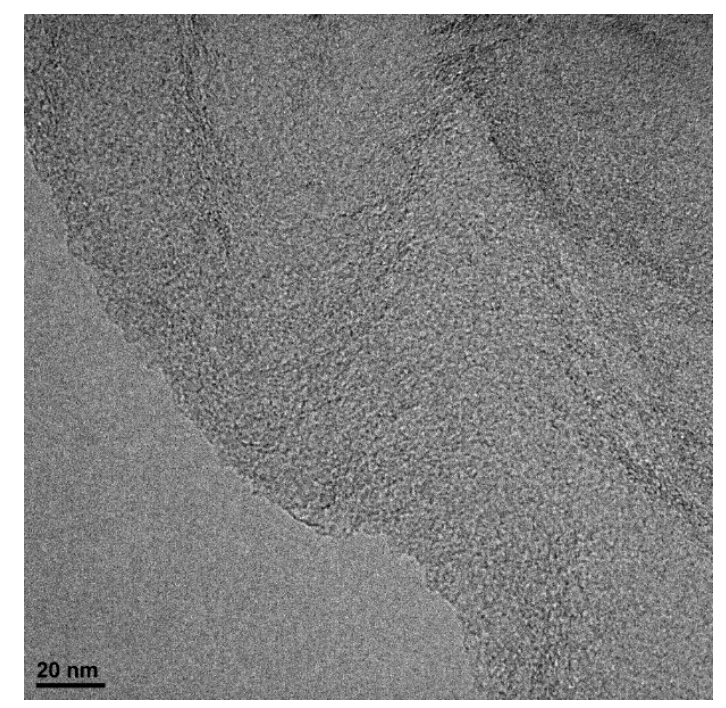

Figura 60. Micrografía TEM del grafeno a su recepción

\subsubsection{Nanodiamantes}

Se han empleado nanodiamantes purificados, grado G01 tanto sólidos como en disolución en agua al 4\% en peso. En ambos casos, fueron suministrados por PlasmaChem (Alemania). Las características que presentan, según el fabricante, se recogen a continuación:

$\checkmark$ Densidad aparente: $0,69 \mathrm{~g} / \mathrm{cm}^{3}$.

$\checkmark$ Tamaño medio del clúster: ca.4 $\mathrm{nm}$.

$\checkmark$ Superficie específica (BET): $\min .350 \mathrm{~m}^{2} / \mathrm{g}$.

$\checkmark$ Contenido de Carbono no-diamante: trazas. 
$\checkmark$ Elementos presentes (\%): $\mathrm{Fe}<0,3 ; \quad \mathrm{Cu}<0,01 ; \mathrm{Zn}<0,01 ; \quad \mathrm{Mn}<0,01 ;$ $\mathrm{Si}+\mathrm{Cr}+\mathrm{Ca}+\mathrm{Ti}<0,01$.

$\checkmark$ Pérdidas en revenido: $\max 2,4 \%$.

$\checkmark$ Contenido de cenizas $<1,4 \%$.

$\checkmark$ Densidad picnométrica: $3,18 \mathrm{~g} / \mathrm{cm}^{3}$.

$\checkmark$ Potencial Zeta: $-50 \pm 5 \mathrm{mV}$.

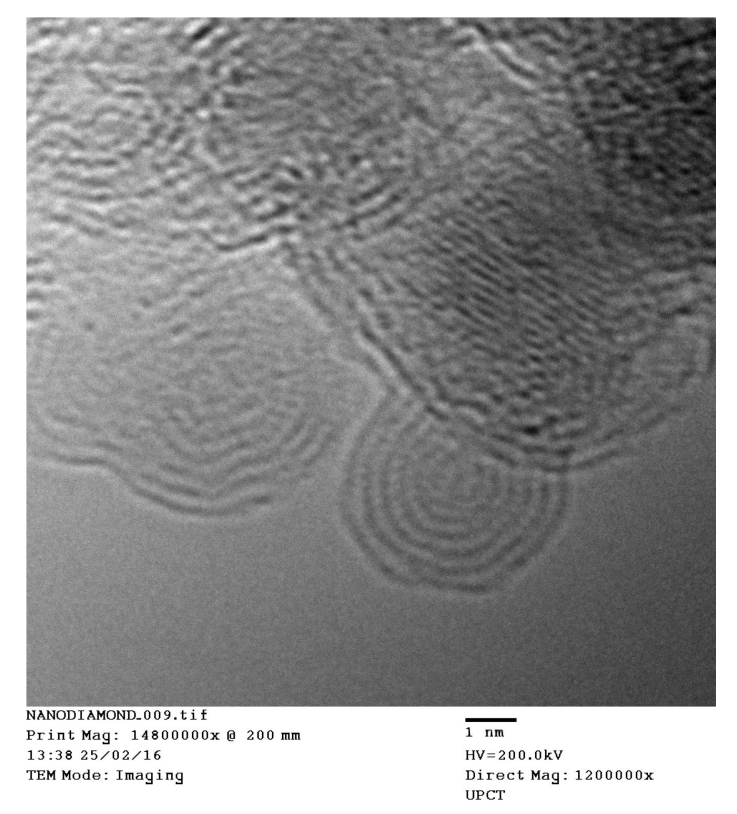

Figura 61. Micrografía TEM de los nanodiamantes de partida

La Figura 62 muestra los resultados obtenidos tras realizar un análisis de difracción de rayos- $X$ de la muestra de nanodiamantes con una longitud de onda de $1,5406 \hat{A}$ en el rango de $10^{\circ}$ a $100^{\circ}$ de $2 \theta$.

Se observa una intensa difracción en torno a $44^{\circ}$ correspondiente al plano cristalográfico (1 11 1). Además, es posible observar las intensidades asignables a los planos $\left(\begin{array}{l}2 \\ 2\end{array}\right.$ 0) y (3 11 1) en la zona comprendida entre $70^{\circ}$ y $100^{\circ}$ [285]. Los nanodiamantes pueden presentar impurezas originadas en el proceso de detonación, sobre todo metales pesados y agentes oxidantes empleados para la eliminación del carbono, como el $\mathrm{HCl}$ [198], justificando así la presencia de $\mathrm{AgCl}$ en el espectro de difracción de rayos $\mathrm{X}$. 
Capítulo 3. Materiales, equipos y procedimiento experimental

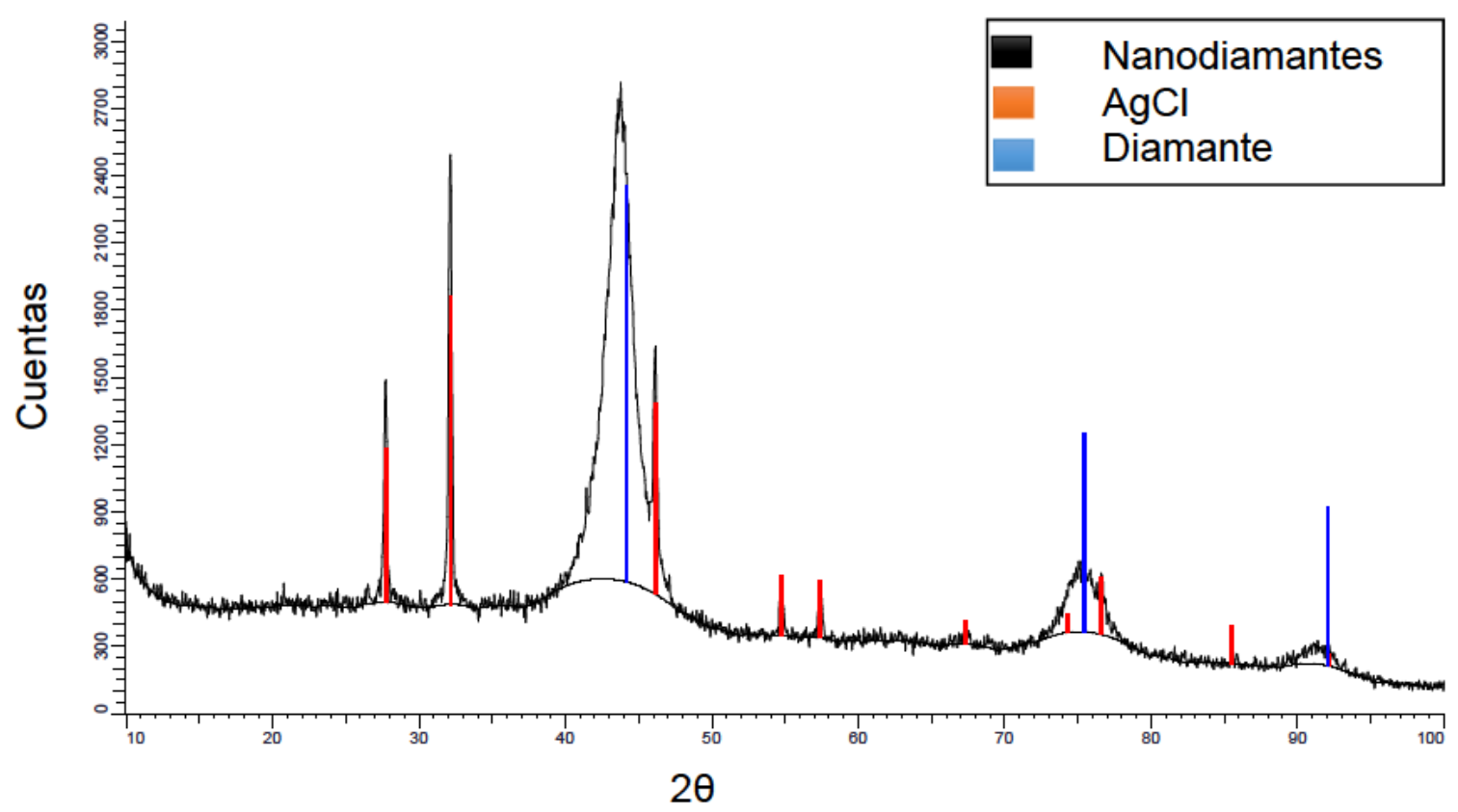

Figura 62. Espectro de difracción de rayos-X de los nanodiamantes de partida

\subsection{EQUIPOS}

\subsubsection{Equipos para la preparación de muestras}

\subsubsection{Balanza de precisión}

Se ha empleado la balanza de precisión Sartorius Entris224i-1S (Figura 63) para la preparación de las dispersiones y nuevos nanocomposites y en general, para realizar las medidas de masa necesarias para llevar a cabo todos los estudios. La balanza posee un rango de pesada de $220 \mathrm{~g}$ con un rango de tara de $0,0001 \mathrm{~g}$. Está provista de una cámara de pesada de $230 \mathrm{~mm}$ de altura.

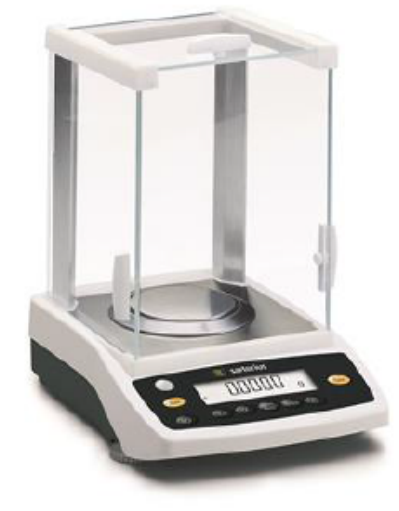

Figura 63. Balanza de precisión Entris224i-1S, Sartorius 


\subsubsection{Cortadora de precisión}

Para realizar el corte de las probetas de los nuevos nanocomposites se ha empleado la máquina de corte con avance automático Mecatome T-201A de Presi (Figura 64).

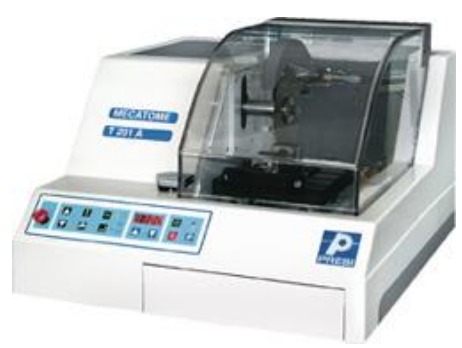

Figura 64. Cortadora de precisión Mecatome T-201A, Presi

Este equipo posee un panel de control electrónico que permite memorizar la velocidad de rotación, la velocidad de avance y la longitud de corte. La velocidad de rotación varía entre 300 y $5000 \mathrm{rpm}$ y el movimiento vertical de los discos de corte permite adaptarse a las diversas geometrías que pueden presentar las muestras. Posee además retorno automático que se inicia al finalizar el corte. La potencia del motor es de $750 \mathrm{~W}$ y está equipada con un depósito de refrigerante de $5 \mathrm{I}$.

\subsubsection{Pulidora metalográfica}

Para la preparación de los discos de acero inoxidable AISI 316L con la rugosidad deseada, se procedió al desbaste y pulido de los mismos con la pulidora metalográfica Buehler, modelo Phoenix Beta (Figura 65).

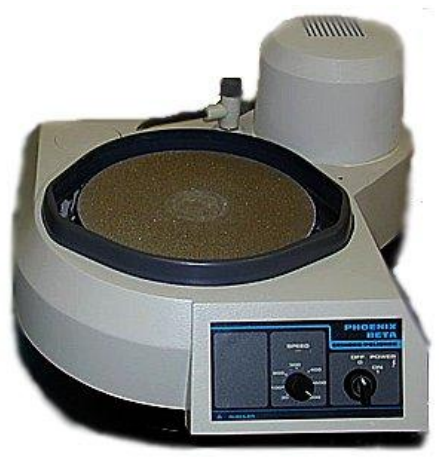

Figura 65. Pulidora metalográfica Phoenix Beta, Buehler 


\subsubsection{Rugosímetro}

La rugosidad de las piezas ha sido determinada empleando el rugosímetro de laboratorio Profiltest SM-7 según la norma DIN4768 (Figura 66).

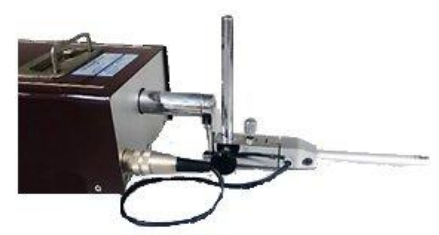

Figura 66. Rugosímetro Profiltest SM-7

\subsubsection{Homogeneizador ultrasónico}

Con el fin de lograr la correcta dispersión de las nanofases de carbono en los líquidos iónicos para la obtención de nuevos nanolubricantes, se ha empleado el homogeneizador ultrasónico de Sartorius Group, modelo Labsonic M (Figura 67). Este equipo permite regular la intensidad de los ultrasonidos entre un $20 \mathrm{y}$ un $100 \%$ de la potencia nominal. El período activo por segundo puede establecerse entre 0,2 y 1 segundos, ayudando a prevenir problemas de calentamiento o formación de espumas. La sonda del equipo está fabricada con una aleación de titanio.

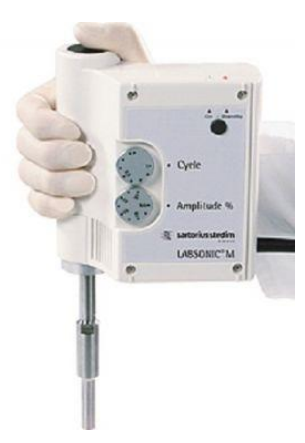

Figura 67. Homogeneizador ultrasónico Labsonic M

\subsubsection{Dispersador}

Se ha empleado el dispersador IKA T25 digital Ultra-Turrax (Figura 68) para la preparación de las dispersiones de líquido iónico y nanofases de carbono en agua y en aceite base, así como para homogeneizar las matrices poliméricas de los nuevos nanocomposites. Este equipo permite trabajar con velocidades entre 3000 hasta $25000 \mathrm{rpm}$ y con volúmenes entre 2 a $2000 \mathrm{ml}$. 


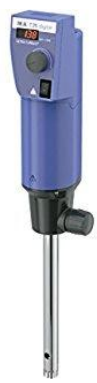

Figura 68. Dispersador IKA T25 digital, Ultra-Turrax

\subsubsection{Estufa}

Para llevar a cabo el curado de los nuevos materiales de matriz epoxi, así como la preparación de capas finas de lubricante, se ha empleado la estufa Binder VD 23 (Figura 69). Este equipo posee una potencia de $800 \mathrm{~W}$ y permite trabajar desde temperatura ambiente hasta $200^{\circ} \mathrm{C}$ con una precisión de $\pm 3^{\circ} \mathrm{C}$. Además, tiene la posibilidad de conexión a vacío, con una presión mínima soportada de 0,01 mbar.

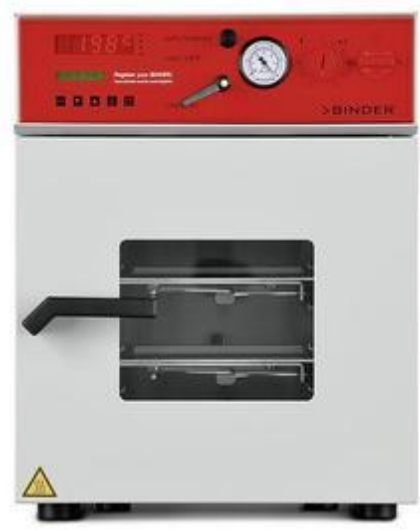

Figura 69. Estufa Binder VD 23

\subsubsection{Placa calefactora}

En la preparación de los nuevos nanolubricantes se ha usado el agitador magnético con calefacción y placa calefactora de vitrocerámica de IKA, modelo C-MAG HS7 (Figura 70). Permite calentar hasta $500^{\circ} \mathrm{C}$ y posee una potencia de calefacción de $1000 \mathrm{~W}$. 


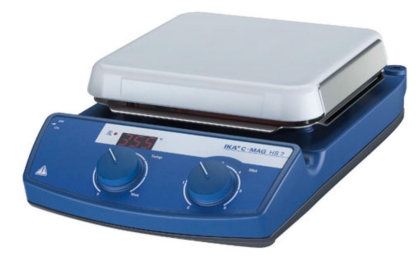

Figura 70. Agitador magnético con calefacción y placa calefactora IKA C-MAG HS7

\subsubsection{Mezclador}

Con el objetivo de lograr una mezcla homogénea de los reactivos en la preparación de los nanocomposites de matriz epoxi, se ha empleado el mezclador IKA RW20 digital (Figura 71), al que se le ha acoplado una varilla agitadora de hélice revestida de PTFE. Este equipo puede trabajar a velocidades entre 60 y $2000 \mathrm{rpm}$.

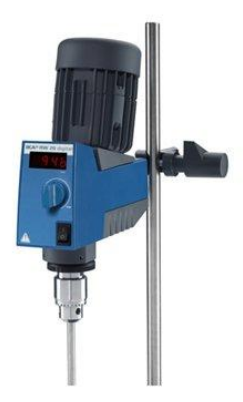

Figura 71. Mezclador IKA RW20 digital

\subsubsection{Centrífuga}

Para la extracción de partículas, tanto procedentes de las dispersiones como las recuperadas tras los ensayos tribológicos, se ha empleado la centrífuga Centromix II-BL de P. Selecta (Figura 72), cuyas características se indican seguidamente:

$\checkmark$ Velocidad angular máxima de $440 \mathrm{rpm}$.

$\checkmark$ Volumen máximo de $120 \mathrm{ml}$.

$\checkmark$ Capacidad máxima de 8 tubos de $15 \mathrm{ml}$.

$\checkmark$ Modelo con cabezales y adaptadores intercambiables.

$\checkmark$ Mueble exterior en aleación DUR-AL.

$\checkmark$ Cubeta estampada en acero inoxidable AISI 304. 


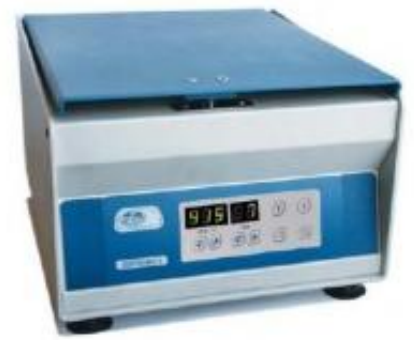

Figura 72. Centrífuga Centromix II-BL, P. Selecta

\subsubsection{Spin coater}

El equipo Spin coater 150i infinite de POLOS TM (Figura 73) ha sido el empleado para la obtención de los recubrimientos de nanocomposites de matriz epoxi sobre probetas de acero al carbono AISI 1015 y de resina epoxi, así como para la obtención de films y de capas finas de nanolubricantes sobre acero inoxidable AISI 316L.

El spin coater permite trabajar con sustratos desde $5 \mathrm{~mm}$ a $150 \mathrm{~mm}$ de diámetro. Está fabricado en polipropileno y posee un software integrado que permite el diseño de diferentes secuencias de operación variando la velocidad, aceleración o tiempo de trabajo. El equipo cuenta con una conexión que permite trabajar en condiciones de vacío.

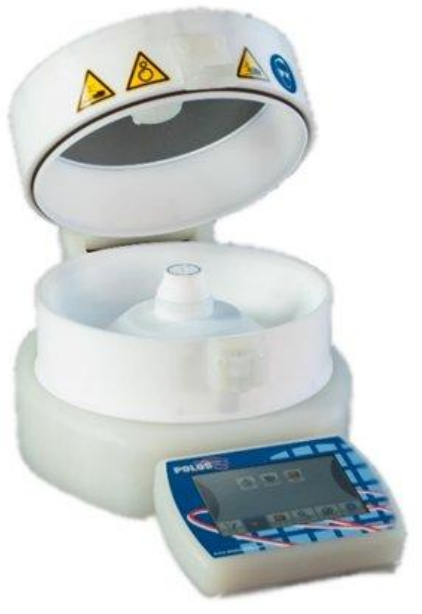

Figura 73. Spin coater 150i infinite, POLOS TM

\subsubsection{Equipos para caracterización y análisis}

\subsubsection{Espectrofotómetro infrarrojo (FTIR)}

La espectroscopía de absorción infrarroja emplea la región del espectro electromagnético comprendida entre $12800 \mathrm{~cm}^{-1}$ y $10 \mathrm{~cm}^{-1}$ como medio para 
identificar todo tipo de compuestos tanto orgánicos como inorgánicos. Además permite determinar la composición molecular y los grupos funcionales presentes en la muestra.

El equipo empleado, Thermo Nicolet 5700 (Figura 74), posee un sistema óptico que emplea el principio del interferómetro de Michelson de barrido continuo con conducción de espejo móvil mediante colchón neumático generado por el propio mecanismo interferométrico y dispone de una bancada óptica monobloque. A continuación, se citan sus principales características:

$\checkmark$ Alineamiento automático y autoalineamiento dinámico continuo asistido por láser.

$\checkmark$ Resolución superior a $0,5 \mathrm{~cm}^{-1}$.

$\checkmark$ Velocidad de barrido del espejo móvil comprendida entre 0,158 y 5,06 $\mathrm{cm} / \mathrm{s}$.

$\checkmark$ Precisión en longitud de onda por encima de $0,01 \mathrm{~cm}^{-1}$ para cada dato, medida a $2000 \mathrm{~cm}^{-1}$ y controlada por láser.

$\checkmark$ Precisión en ordenadas superior al $0,07 \%$ de desviación, medida a 4 $\mathrm{cm}^{-1}$ con lámina de poliestireno de $8 \mu \mathrm{m}$.

$\checkmark$ Fuente infrarroja cerámica, trabajando a $1798^{\circ} \mathrm{C}$, con un intervalo espectral de 9600 a $15 \mathrm{~cm}^{-1}$.

$\checkmark$ Láser de referencia de helio-neón, operando a $15798 \mathrm{~cm}^{-1}$, prealineado y de alta capacidad.

$\checkmark$ Generador de gas de purga, para eliminar la contribución espectral ambiental.

$\checkmark$ Programa Omnic, para la evaluación y manipulación de espectros.

$\checkmark$ Accesorio Smart Orbit, para el análisis por reflexión total atenuada (ATR) de sólidos y líquidos.

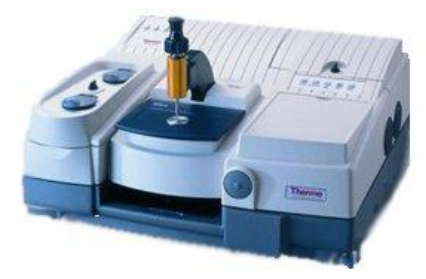

Figura 74. Espectrofotómetro infrarrojo Thermo Nicolet 5700

Mediante esta técnica se ha llevado a cabo el estudio del grado de curado del nanocomposite de matriz epoxi $\mathrm{RE}+9 \% \mathrm{DCi}$. Para ello, se mezcla el líquido iónico, prepolímero y endurecedor y se vierte una pequeña cantidad sobre celdas desmontables de polietileno y se colocan en una estufa a $60^{\circ} \mathrm{C}$. Cuando 
han trascurrido 20,40 y 60 minutos, respectivamente, se llevan a cabo los análisis de infrarrojo en modo de transmisión.

Por otra parte, el espectro infrarrojo de los líquidos iónicos se ha obtenido mediante reflexión total atenuada, colocando la muestra en contacto con un cristal denso de $\mathrm{ZnSe}$ altamente refractivo, de manera que el haz infrarrojo se dirige hacia un extremo biselado del cristal y se refleja internamente a lo largo de éste con una o más reflexiones.

Para el estudio de la distribución de las nanofases en el nuevo nanocomposite de matriz epoxi se ha empleado el espectrofotómetro infrarrojo Vertex 70/70v de Bruker acoplado a un microscopio óptico Hyperion 2000 dotado con un objetivo infrarrojo de $15 x$ y con objetivos ópticos 10x y 15x.

Las características de este aparato son las siguientes:

$\checkmark$ Un rango espectral que abarca desde los $7500 \mathrm{~cm}^{-1}$ hasta los $370 \mathrm{~cm}^{-1} \mathrm{y}$ resolución de $0,5 \mathrm{~cm}^{-1}$.

$\checkmark$ Condiciones óptimas de funcionamiento entre $18-35^{\circ} \mathrm{C}$ y humedad relativa $\leq 80 \%$.

$\checkmark$ Purga continua de aire seco en el compartimento de la muestra y el banco óptico (compartimento del detector y el interferómetro).

$\checkmark$ Detector DLaTGS con dos ventanas de $\mathrm{KBr}$.

$\checkmark$ Diámetro de apertura variable.

$\checkmark$ Láser que genera un haz de luz monocromática de $633 \mathrm{~nm}$.

$\checkmark$ Interferómetro Rocksolid alineado permanentemente (modula el haz de luz para generar una señal sinusoidal).

$\checkmark$ Cartuchos desecantes en el compartimento del detector y en el del interferómetro.

$\checkmark$ Accesorio ATR (Reflexión Total Atenuada) de germanio.

En este caso, el espectro infrarrojo obtenido procede de una muestra de material de $40 \mu \mathrm{m}$ de espesor y se ha realizado en modo de transmisión.

\subsubsection{Calorímetro diferencial de barrido (DSC)}

La calorimetría diferencial de barrido es una técnica de análisis que permite determinar los episodios térmicos que sufre una muestra cuando se somete a un programa de temperatura controlado, comparado con un material de referencia. El calorímetro diferencial empleado para comprobar los puntos de fusión de los diferentes lubricantes, determinar las temperaturas de transición 
vítrea de los nanocomposites y estudiar el grado de curado de éstos últimos, es el modelo DSC 822e de Mettler Toledo (Figura 75).

Las características principales del equipo se indican a continuación:

$\checkmark$ Intervalo de temperatura de -150 a $700^{\circ} \mathrm{C}$.

$\checkmark$ Exactitud térmica de $\pm 0,2^{\circ} \mathrm{C}$.

$\checkmark$ Reproducibilidad térmica $<0,1^{\circ} \mathrm{C}$.

$\checkmark$ Velocidad de calentamiento de 0 a $200^{\circ} \mathrm{C} / \mathrm{min}$ en incrementos de $0,01^{\circ} \mathrm{C}$

$\checkmark$ Tiempo de respuesta $<2,3 \mathrm{~s}$.

$\checkmark$ Resolución de 0,04 $\mu \mathrm{W}$.

$\checkmark$ Temperatura modulada.

$\checkmark$ Robot automuestreador de 34 posiciones.

$\checkmark$ Controlador de gases de purga.

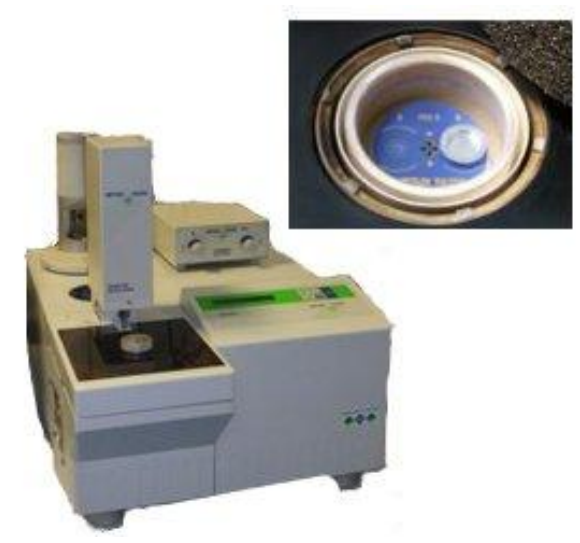

Figura 75. DSC 822e Mettler Toledo con detalle del portamuestras

\subsubsection{Termobalanza (TGA)}

La termogravimetría es un tipo de análisis térmico que permite cuantificar la masa de la muestra en función de la temperatura o el tiempo mientras se somete a dicha muestra a un programa de temperatura controlado en una atmósfera específica.

Esta técnica permite detectar procesos en los que se produce una variación de la masa, como es el caso de sublimaciones, descomposiciones u oxidaciones.

Los análisis termogravimétricos realizados en el presente trabajo, tanto de los nuevos nanocomposites como de los nanolubricantes se han realizado en el equipo TGA/DSC 1HT de Mettler-Toledo (Figura 76), que posee las siguientes especificaciones: 
$\checkmark$ Horno horizontal, con un rango de temperatura de trabajo desde temperatura ambiente hasta $1600^{\circ} \mathrm{C}$.

$\checkmark$ Exactitud térmica de $\pm 0,5^{\circ} \mathrm{C}$.

$\checkmark$ Reproducibilidad térmica de $\pm 0,3^{\circ} \mathrm{C}$.

$\checkmark$ Carga máxima de $1 \mathrm{~g}$.

$\checkmark$ Registro simultáneo de la señal de flujo de calor.

$\checkmark$ Resolución de 0,1 $\mu \mathrm{g}$.

$\checkmark$ Deriva de la línea de base.

$\checkmark$ Robot automuestreador de 34 posiciones.

$\checkmark$ Controlador automático de gases de purga, de 0 a $200 \mathrm{ml} / \mathrm{min}$.

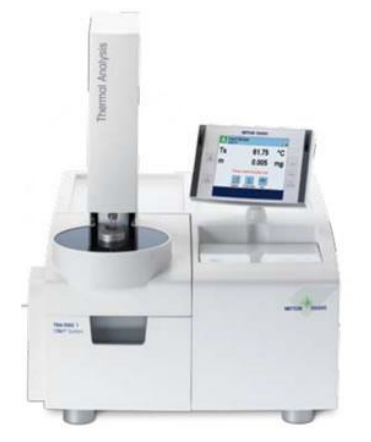

Figura 76. TGA/DSC 1HT Mettler-Toledo.

\subsubsection{Analizador dinámico-mecánico (DMA)}

El analizador dinámico-mecánico modelo DMA Q800 de TA Instruments (Figura 77) ha sido el empleado para estudiar el comportamiento viscoelástico de los nanocomposites de matriz epoxi empleando pruebas oscilatorias dinámicas. De este modo, se ha determinado la evolución del módulo de almacenamiento ( $\left.E^{\prime}\right)$, del módulo de pérdida (E”) y el factor de pérdida $(\tan (\delta))$ en función de la temperatura.

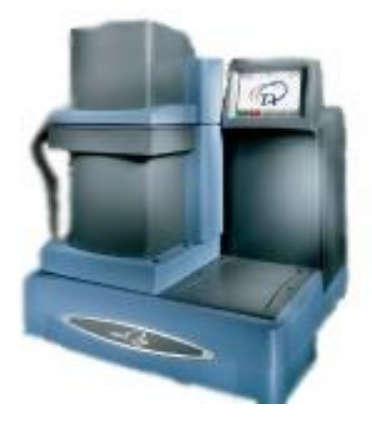

Figura 77. Analizador dinámico-mecánico DMA Q800, TA Instruments 
El equipo dispone de un diseño de transductor y motor combinados, que incorpora un motor de accionamiento lineal sin contacto con el fin de controlar el esfuerzo y medir la deformación con un lector óptico de alta sensibilidad. Además, consta de un horno de bobina de doble filamento con apertura y cierre automático y un dispositivo de enfriamiento con gas, por lo que permite su funcionamiento en un amplio rango de temperaturas. Sus principales características se indican a continuación:

$\checkmark$ Rango de fuerza: $10^{-4} \mathrm{~N}-18 \mathrm{~N}$.

$\checkmark$ Resolución de fuerza: $10^{-5} \mathrm{~N}$.

$\checkmark$ Resolución de deformación: $1 \mathrm{~nm}$.

$\checkmark$ Rango de módulo: $10^{3}-3 \cdot 10^{12} \mathrm{~Pa}$.

$\checkmark$ Precisión de módulo: $1 \%$.

$\checkmark$ Rango de frecuencia: 0,01-200 Hz.

$\checkmark$ Rango de temperatura: $-150^{\circ} \mathrm{C}-600^{\circ} \mathrm{C}$.

$\checkmark$ Velocidad de calentamiento/enfriamiento: 0,01-20 ${ }^{\circ} \mathrm{C} / \mathrm{min}$.

$\checkmark$ Estabilidad isotérmica: $\pm 0,1^{\circ} \mathrm{C}$.

\subsubsection{Analizador de conductividad térmica}

Para determinar la conductividad térmica del nuevo nanocomposite de matriz epoxi, se ha empleado el analizador de conductividad térmica modelo C-Therm TCi de Mathis Instrumentos, provisto de sensor universal.

Esta técnica se basa en la medida experimental de la difusividad térmica de la muestra. Para realizar esta determinación, un sensor de área perfectamente conocida induce, mediante una resistencia eléctrica, un cambio en la temperatura, tanto del sensor como de la muestra, que varía con el tiempo. La variación de la temperatura con el tiempo se relaciona con la difusividad del sensor (conocida mediante calibración) y de la muestra, lo que permite la determinación de la misma.

\subsubsection{Durómetros}

La dureza del nanocomposite de matriz epoxi RE+9\%DCi se ha medido en escala Shore D (HD) mediante del durómetro digital TH210 (Figura 78) siguiendo la norma ISO 868. Éste posee un rango de trabajo de 0 a $100 \mathrm{HD}$ y la medida presenta un error de $\pm 1 \mathrm{HD}$, entre 20 y $90 \mathrm{HD}$. 


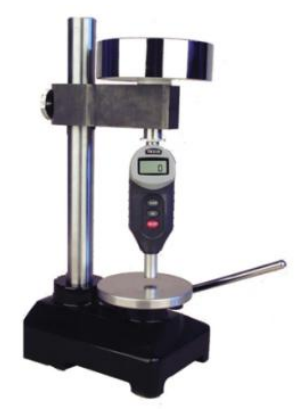

Figura 78. Microdurómetro digital Shore D TH210

Además, se midió la dureza de este mismo material en escala Vickers (HV) con el microdurómetro digital FM-310 de Future Technologies. Este equipo permite aplicar cargas entre 10 gramos y 1 kilogramo mediante un indentador de punta de diamante de base cuadrada con ángulos de $136^{\circ}$ entre sus caras, con una velocidad de $60 \mu \mathrm{m} / \mathrm{s}$. La huella generada es un rombo cuyas longitudes se miden con ayuda de un microscopio que dispone de lentes de 10 y 50 aumentos.

La carga empleada para medir ambos tipos de dureza ha sido de 25 gramos.

\subsubsection{Medidor de ángulo de contacto}

Para realizar el estudio de las interacciones superficiales, de gran importancia en tribología, se han medido los ángulos de contacto de los nuevos lubricantes sobre los sustratos metálicos con el equipo DSA30B de Krüss (Figura 79). Además, se ha empleado esta técnica de análisis para determinar el efecto de los aditivos sobre el ángulo de contacto del agua sobre los diferentes nanocomposites.

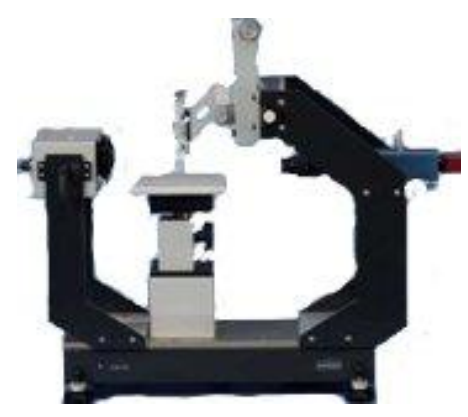

Figura 79. Medidor de ángulo de contacto DSA30B, Krüss

El equipo DSA (Drop Shape Analyzer) consta de una videocámara CCD con zoom óptico 6,5x, que permite obtener hasta 311 imágenes por segundo. Con este instrumento es posible, además, medir la tensión superficial de los 
diferentes lubricantes mediante el método de la gota pendiente. A continuación, se indican las principales características del equipo (Tabla 12).

Tabla 12. Características del medidor de ángulo de contacto DSA30B, Krüss

\begin{tabular}{ccc}
\hline & Rango de medidas & Resolución \\
\hline $\begin{array}{c}\text { Ángulo de } \\
\text { contacto }\end{array}$ & $1-180^{\circ}$ & $0,01^{\circ}$ \\
\hline Tensión superficial & $0,01-1000 \mathrm{mN} / \mathrm{m}$ & $0,01 \mathrm{mN} / \mathrm{m}$ \\
\hline
\end{tabular}

Para realizar las medidas del ángulo de contacto de los nuevos nanofluidos sobre los discos de acero AISI 316 y de agua sobre los recubrimientos de matriz epoxi, se deja caer una gota sobre el sustrato con una jeringuilla de 0,5 $\mathrm{mm}$ de diámetro y se mide el ángulo inicial, como un promedio de los ángulos izquierdo y derecho. El ángulo final se corresponde con el obtenido una vez transcurridos 5 minutos.

\subsubsection{Reómetro}

El equipo empleado para llevar a cabo los ensayos reológicos ha sido el reómetro rotacional AR-G2 de TA Instruments (Figura 80). El equipo posee un sistema de cojinete axial magnético, que permite un control muy preciso del par de torsión.

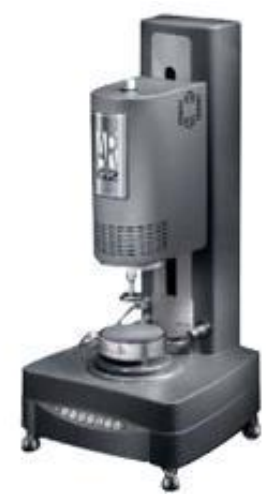

Figura 80. Reómetro rotacional AR-G2, TA Instruments

Sus características y especificaciones son las siguientes:

$\checkmark$ Capacidad para realizar experimentos a velocidad controlada y a esfuerzo controlado. 
$\checkmark$ Capacidad para realizar estudios de viscoelasticidad de materiales y comportamiento cinético de reacciones de polimerización.

$\checkmark$ Amplio rango de control de fuerza normal: 0,01-50 N.

$\checkmark$ Rango de par de fuerzas en oscilación: $3 \cdot 10^{-6}-200 \mathrm{mN} \cdot \mathrm{m}$.

$\checkmark$ Rango de par de fuerzas en cizalla: $10^{-5}-200 \mathrm{mN} \cdot \mathrm{m}$.

$\checkmark$ Resolución del par de fuerzas: 0,1 nN·m.

$\checkmark$ Inercia del motor: $18 \mu \mathrm{N} \cdot \mathrm{m} \cdot \mathrm{s}$.

$\checkmark$ Rango de velocidad angular en esfuerzo controlado: 0 - $300 \mathrm{rad} / \mathrm{s}$.

$\checkmark$ Rango de velocidad angular en deformación controlada: $1,4 \cdot 10^{-9}-300$ $\mathrm{rad} / \mathrm{s}$.

$\checkmark$ Rango de frecuencias: 7,5 $10^{-7}-628 \mathrm{rad} / \mathrm{s}$.

$\checkmark$ Resolución en el desplazamiento: $25 \mathrm{nrad}$.

$\checkmark$ Tiempo necesario para cambio en la velocidad: $7 \mathrm{~ms}$.

$\checkmark$ Tiempo necesario para cambio en la deformación: $30 \mathrm{~ms}$.

$\checkmark$ Rango de temperatura con plato Peltier: $-20-200^{\circ} \mathrm{C}$.

$\checkmark$ Rango de temperatura con platos calientes: $30-400^{\circ} \mathrm{C}$.

\subsubsection{Medidores de $\mathrm{pH}$ y conductividad}

Para la medida del $\mathrm{pH}$ y de la conductividad con el objetivo de caracterizar los distintos líquidos iónicos y sus dispersiones se han empleado el medidor de $\mathrm{pH}$ pH600 y el conductivímetro cond600, ambos de Eutech Instruments. Sus características se recogen en la Tabla 13:

Tabla 13. Características del medidor de $\mathrm{pH}$ y conductivímetro

\begin{tabular}{cccc}
\hline & $\begin{array}{c}\text { Rango de } \\
\text { medidas }\end{array}$ & $\begin{array}{c}\text { Resolución y } \\
\text { precisión }\end{array}$ & $\begin{array}{c}\text { Rango de } \\
\text { temperaturas } \\
\left({ }^{\circ} \mathbf{C}\right)\end{array}$ \\
\hline Medidor de pH & $-2-19,99$ & $0,1 / 0,01 \pm 0,01 \mathrm{pH}$ & $-10-110$ \\
\hline Conductivímetro & $\leq 200 \mathrm{mS} / \mathrm{cm}$ & $0,1 / 0,01 \mu \mathrm{S} / \mathrm{cm} \pm 1 \%$ & $-10-110$ \\
\hline
\end{tabular}

\subsubsection{Analizador de parámetros semiconductores}

Para determinar la resistividad del nanocomposite $\mathrm{RE}+9 \% \mathrm{DCi}$, se ha empleado el analizador de parámetros semiconductores B1500A de Agilent (Figura 81). Con este equipo es posible llevar a cabo medidas paramétricas que incluyen trazados de curvas intensidad-voltaje, como se ha realizado en este caso, 
además de análisis de impedancias o medidas de capacidad-voltaje y capacidad-frecuencia.

Las medidas se han realizado sobre una estación o mesa de puntas de Süss Microtec, modelo EP4, asegurando así el correcto contacto entre los bornes del analizador y las muestras.

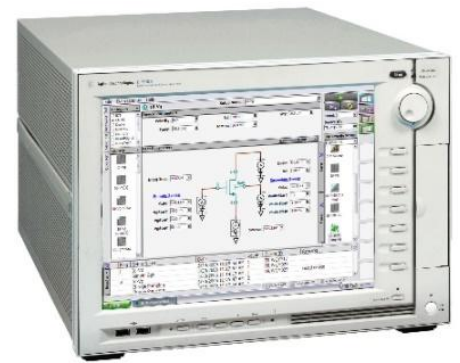

Figura 81. Analizador de parámetros semiconductores B1500A, Agilent

Para llevar a cabo las medidas de resistividad del nuevo nanocomposite, éste se coloca sobre la mesa de puntas para el correcto contacto con el analizador de parámetros semiconductores. Previamente se metaliza con Pt la zona de la muestra donde se va a realizar el contacto. Se aplica una curva tensiónintensidad desde $0 \mathrm{~V}$ a $-50 \mathrm{~V}$ en corriente continua y posteriormente se calcula el valor de resistividad.

\subsubsection{Analizador de tamaño de partículas mediante dispersión por láser (DLS)}

Para el estudio de la distribución del tamaño de partícula de las dispersiones lubricantes se ha empleado la técnica de DLS (Dynamic Light Scattering). El equipo Malvern 4800 Autosizer (Malvern Instruments Limited) usa un correlacionador digital 7132 con un láser iónico de argón de 30 mW y 558 nm.

El equipo mide la fluctuación en la intensidad de la luz causada por el movimiento browniano para detectar las partículas en suspensión. Además, el analizador supone que las partículas detectadas tienen forma esférica, de manera que emplea los datos de intensidad de la luz para determinar el diámetro hidrodinámico y la distribución del tamaño, en función de la intensidad, el volumen y el número de partículas.

Como referencia se emplea una muestra de poliestireno monodispersado de $200 \mathrm{~nm}$ (Sigma-Aldrich cat. no. 95581). Los resultados se analizan con el software (PCS v1.61). 
Los ensayos realizados para la determinación del tamaño de partícula de la dispersión de nanodiamantes en agua, la emulsión de DPa en agua y la dispersión de nanodiamantes en WDPa se llevaron a cabo a $25^{\circ} \mathrm{C}$, previo acondicionamiento de 5 minutos. Se efectuó una primera medida tras someter a la muestra a ultrasonidos durante 30 minutos y otra posterior tras 24 horas.

\subsubsection{Difractómetro de rayos $\mathrm{X}$}

Para llevar a cabo los análisis de difracción de rayos $X$ para la caracterización de los nanodiamantes se ha utilizado el difractómetro de rayos $X$ Bruker D8 Advance con radiación CuKa (Figura 82).

Este equipo consta de un goniómetro theta/theta vertical, con una amplitud de paso mínimo de $0,0001^{\circ}$ y un rango de medida en 2theta de $0^{\circ}$ a $168^{\circ}$. Posee además un generador de rayos X Kristallofex K 760-80F de $3000 \mathrm{~W}$ de potencia, tensión y corriente regulables de forma continua entre 20 y $60 \mathrm{kV}$ y 5 y $80 \mathrm{~mA}$, respectivamente, y estabilidad de $\pm 0,001 \%$.

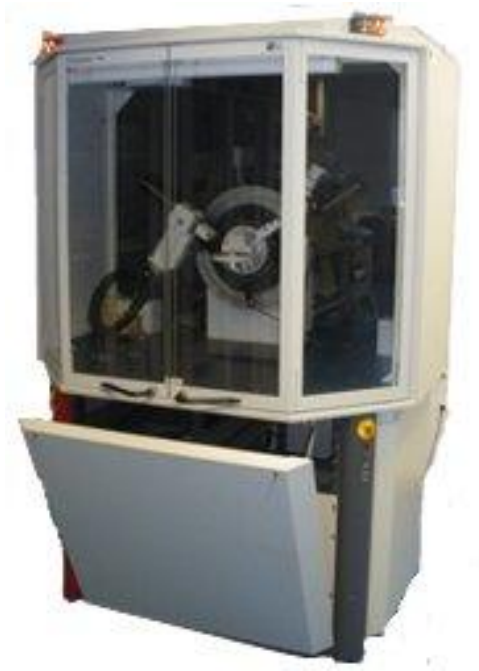

Figura 82. Difractómetro de rayos X D8 Advance, Bruker

\subsubsection{Interferómetro de película ultrafina}

El espesor de película y coeficiente de fricción de las emulsiones y dispersiones lubricantes se ha calculado mediante un interferómetro de película ultrafina (Figura 83). 


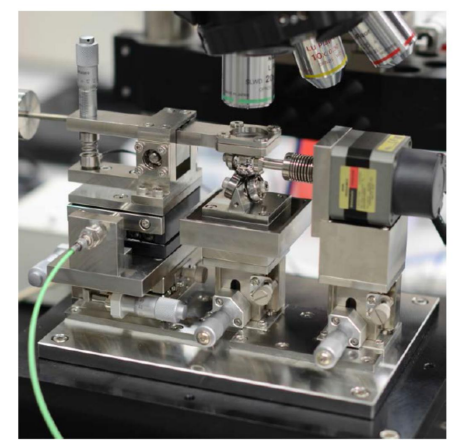

Figura 83. Interferómetro de película ultrafina

Este aparato usa un punto de deslizamiento entre una bola de acero AISI 52100 de $19,1 \mathrm{~mm}\left(R_{\mathrm{a}}=16 \mathrm{~nm}\right.$ ) y una placa de vidrio (borosilicato) de $25 \mathrm{~mm}$ de diámetro y $2 \mathrm{~mm}$ de espesor $\left(R_{a}=4 \mathrm{~nm}\right)$, la cual es lubricada por un menisco del lubricante. El vidrio está recubierto con una capa fina de cromo que actúa como una capa semirreflectante y con una película de óxido de aluminio de $550 \mathrm{~nm}$ de espesor en la parte superior, que trabaja como una lámina espaciadora.

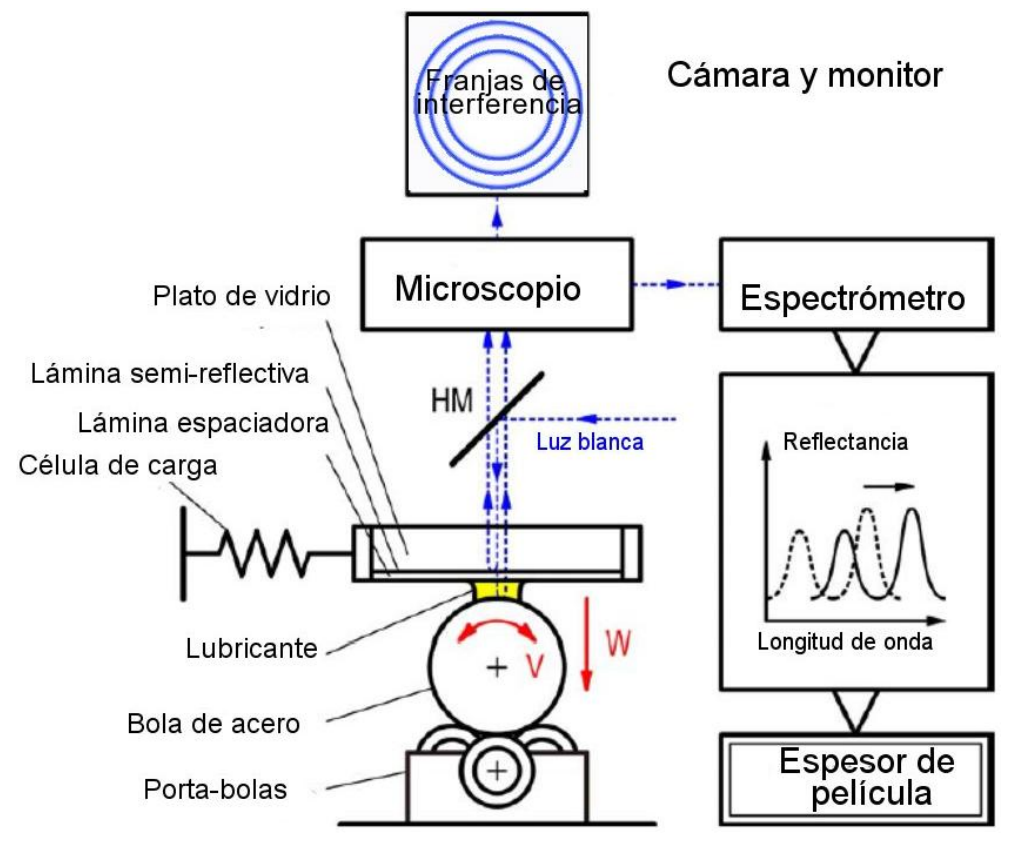

Figura 84. Esquema del equipo de interferometría de película ultrafina

Permite trabajar con cargas desde 2 a $20 \mathrm{~N}$, velocidades entre 0,1 y $1000 \mathrm{~mm} / \mathrm{s}$ y una relación de deslizamiento de 2. La célula de carga, de alta rigidez (40 $\mathrm{N} / \mu \mathrm{m}$ ) de Kistler posee una resolución de 0,001 N. Este equipo proporciona valores de espesor de película inferiores a $1 \mathrm{~nm}$ con una resolución por debajo de $1 \mu \mathrm{m}$. 
La bola de acero está instalada en un portabolas que consta de tres rodamientos inclinados. El portabolas, además de soportar a las bolas, permite el giro de la bola de acero con una pequeña fricción. La placa de vidrio es presionada contra una bola de acero mediante un mecanismo de palanca en una guía lineal, donde una célula de carga controla la carga normal entre la bola de acero y la placa de vidrio. La bola se hace girar mediante un motor a través de un árbol de accionamiento con movimiento alternativo. La célula de carga colocada sobre la guía lineal controla la fuerza tangencial en el contacto deslizante.

Para medir el espacio óptico entre la bola y la capa semirreflectante de la placa en el centro del contacto, este aparato utiliza interferometría de película ultrafina. La luz blanca se refleja en el contacto. Parte de esta luz se refleja a partir de la capa semirreflectante, mientras que otra parte pasa a través de la capa espaciadora y la película lubricante y se refleja en la bola de acero. Los dos haces se recombinan e interfieren entre sí. La capa espaciadora asegura que se producirán interferencias incluso si no hay película lubricante presente. La luz interferida, que pasa a través de un orificio con un diámetro de $20 \mu \mathrm{m}$, es enviada a un espectrómetro a través de una fibra de vidrio y el espectrómetro obtiene el espectro de reflectancia. Un programa informático determina entonces el espacio óptico entre la bola y la capa semirreflectora de la placa en el centro del contacto, de manera que el espectro teórico de reflectancia en un modelo óptico del contacto se corresponde con el obtenido experimentalmente. La disminución de la separación óptica del valor inicial indica que existe desgaste. Por otra parte, el aumento de la separación óptica indica la formación de la película lubricante.

Los ensayos llevados a cabo para obtener el espesor de película de las emulsiones de líquidos iónicos próticos y la dispersión con nanodiamantes se han realizado a temperatura ambiente, y se ha empleado una carga de $2 \mathrm{~N}$, una velocidad de $6 \mathrm{~mm} / \mathrm{s}$ y una cantidad de lubricante de $0,4 \mathrm{ml}$.

\subsubsection{Microscopio de luz polarizada}

Las imágenes de la microscopía de luz polarizada para evaluar las mesofases cristal líquido de los líquidos iónicos, se obtuvieron a través del microscopio Olympus BH-2, con lente 20x, provisto de la cámara Leica MC190HD. El comportamiento térmico se motorizó mediante el equipo Mettler FP-90 
equipado con pletina calefactora FP-82 $\mathrm{HT}$ desde $25^{\circ} \mathrm{C}$ hasta $120^{\circ} \mathrm{C}$, con una velocidad de calentamiento de $2^{\circ} \mathrm{C} / \mathrm{min}$.

\subsubsection{Microscopio electrónico de transmisión (TEM)}

Con el objetivo de caracterizar y determinar la morfología de las nanofases de carbono y sus dispersiones, se ha empleado el microscopio electrónico de transmisión (TEM) modelo JEM-2010 de JEOL (Figura 85). El equipo puede trabajar en los modos de tensión de aceleración 100, 120, 160, 200 kV y permite la resolución entre líneas de 0,14 nm y entre puntos de 0,25 nm.

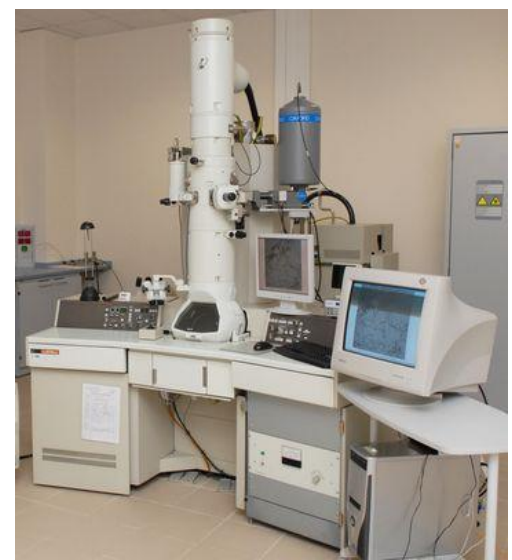

Figura 85. Microscopio electrónico de transmisión JEM-2010, JEOL

Para la obtención de las micrografías se ha empleado la cámara de adquisición Gatan modelo Orius SC600 que se encuentra montada en eje con el microscopio en la parte inferior y está integrada dentro del programa de adquisición y tratamiento de imágenes Gatan Digital Micrograph 1.80.70 para GMS 1.8.0.

\subsubsection{Tribómetros}

Los ensayos tribológicos de fricción y desgaste en nanocomposites de matriz epoxi, y los ensayos de lubricación externa se han llevado a cabo bajo configuración punzón sobre disco en el tribómetro modelo ISC-200 de Implant Sciences (Figura 86), cuyas especificaciones aparecen a continuación:

$\checkmark$ Radio de punzón: 1,6 - 6,3 mm.

$\checkmark$ Presión máxima: $2 \mathrm{GPa}$.

$\checkmark$ Tamaño máximo del disco: $76,2 \mathrm{~mm}$.

$\checkmark$ Velocidad máxima: $150 \mathrm{rpm}$.

$\checkmark$ Fuerza normal: $0,05-5 \mathrm{~N}$. 
$\checkmark$ Software PC-Stripchart para registro del coeficiente de fricción con respecto a la distancia.

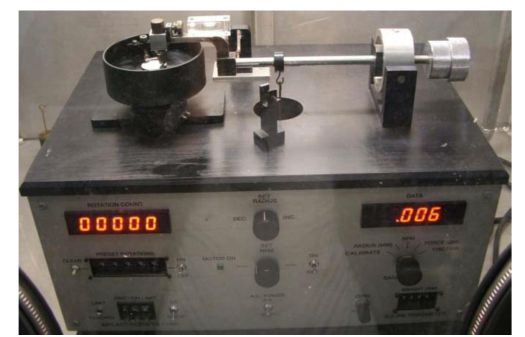

Figura 86. Tribómetro punzón sobre disco ISC-200, Implant Sciences

En el caso de los ensayos de lubricación con los líquidos iónicos [EMIM][TFSI], [EMIM][DCA] y el estudio tribológico de los recubrimientos de nanocomposites de matriz epoxi se ha empleado el tribómetro rotacional TRB de Anton Paar (Figura 87).

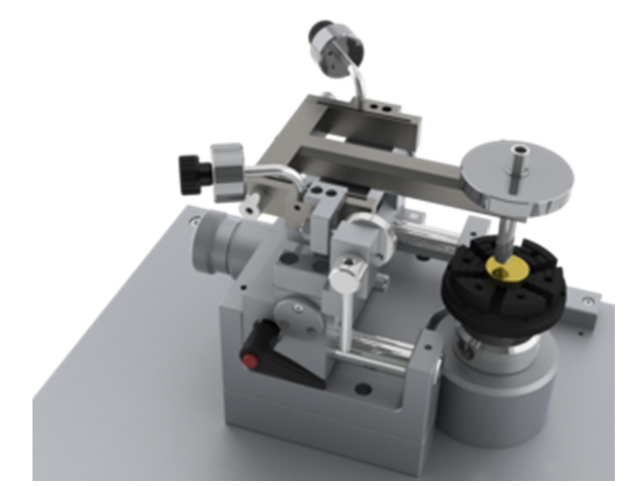

Figura 87. Tribómetro TRB, Anton Paar

Este equipo posee las siguientes especificaciones y características:

$\checkmark$ Fuerza de fricción máxima: $20 \mathrm{~N}$.

$\checkmark$ Velocidad de giro máxima: $1500 \mathrm{rpm}$.

$\checkmark$ Par de torsión máximo: $450 \mathrm{~N} \cdot \mathrm{mm}$.

$\checkmark$ Módulo de medida de resistencia eléctrica en el contacto: hasta $1000 \Omega$.

$\checkmark$ Módulo de deslizamiento lineal oscilatorio: 0,01-10 Hz, con módulo de calentamiento de $200^{\circ} \mathrm{C}$.

$\checkmark$ Medida online de la profundidad de desgaste.

$\checkmark$ Módulo de calentamiento para líquidos.

$\checkmark$ Soporte de muestras con diámetro ajustable hasta $60 \mathrm{~mm}$ de diámetro.

$\checkmark$ Módulo de movimiento angular oscilatorio.

$\checkmark$ Adquisición de datos de fricción de forma continua y a tiempo real durante la medida. 
$\checkmark$ Aplicación de carga normal independiente y diseño de la medida de fuerza de fricción para evitar la influencia entre las señales de las diferentes fuerzas.

$\checkmark$ Brazo elástico y altamente preciso para las medidas de fricción.

$\checkmark$ Frecuencia de adquisición de datos de hasta $400 \mathrm{~Hz}$.

Para la realización de los ensayos para el estudio de la evolución del coeficiente de fricción con la velocidad de giro, se empleó el tribómetro UMTTriboLab de Bruker en configuración punzón sobre disco (Figura 88). El tribómetro va equipado con un módulo de rotación que permite emplear velocidades entre 0,1 y $5000 \mathrm{rpm}$, una carga máxima de $2000 \mathrm{~N}$, un par de torsión máximo $>5 \mathrm{~N} \cdot \mathrm{m}(100 \mathrm{rpm}), 2,5 \mathrm{~N} \cdot \mathrm{m}(5000 \mathrm{rpm})$ y temperaturas de trabajo entre $25^{\circ} \mathrm{C}$ y $1000^{\circ} \mathrm{C}$.

El equipo dispone de un dispositivo contenedor de líquidos (Standard w/ ROTDRIVE) para la realización de ensayos de lubricación externa. Este tribómetro proporciona información del coeficiente de fricción, de la resistencia eléctrica en el contacto (ERC) y de la emisión acústica (AE).

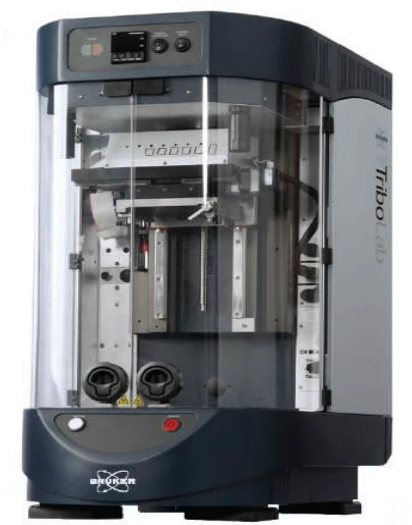

Figura 88. Tribómetro UMT-TriboLab, Bruker

Los ensayos punzón sobre disco para la determinación de las propiedades tribológicas de las dispersiones de grafeno y/o líquido iónico en aceite de motor comercial totalmente formulado se realizaron en el tribómetro modelo MT/30/SCMT de Microtest. Este equipo dispone de un horno para la realización de ensayos a alta temperatura. 

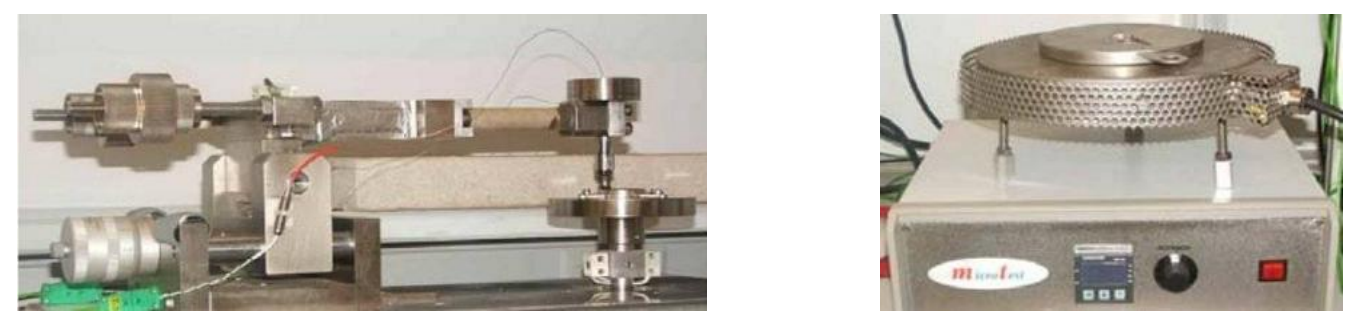

Figura 89. a) Tribómetro MT/30/SCMT, Microtest; b) Horno del tribómetro

\subsubsection{Equipo de ensayos de rayado}

Los ensayos tribológicos para determinar la resistencia a la abrasión de los recubrimientos de matriz epoxi sobre resina epoxi se han realizado en el equipo Scratch Tester de Microtest, modelo MTR3/50-50/NI (Figura 90). La resistencia a la abrasión es un parámetro que es indispensable conocer en aquellos materiales que vayan a ser utilizados en aplicaciones donde las propiedades superficiales sean de vital importancia.

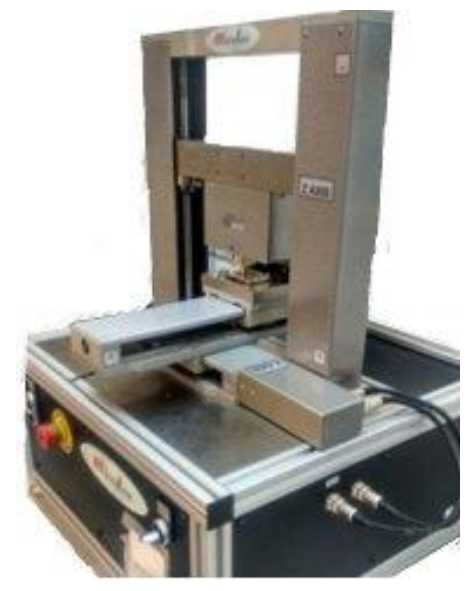

Figura 90. Scratch Tester MTR3/50-50/NI, Microtest

Con este equipo es posible controlar la velocidad y longitud del rayado. Además, se pueden realizar tres tipos diferentes de ensayos: indentación, multirrayado y carga progresiva. Dispone de un indentador de tipo Rockwell de diamante de $200 \mu \mathrm{m}$ de diámetro, $120^{\circ}$ entre sus caras y forma cónica. Sus características principales son las siguientes:

$\checkmark$ Rango de fuerza normal: hasta 50 N. Resolución: 0,005 N.

$\checkmark$ Rango de fuerza de fricción: hasta 50 N. Resolución 0,005 N.

$\checkmark$ Rayado máximo (en el eje $x$ ) y amplitud (eje y): $120 \mathrm{~mm}$.

$\checkmark$ Velocidad de los ejes $x$ e $y: 150 \mathrm{~mm} / \mathrm{min}$. 
$\checkmark$ Desplazamiento vertical máximo (eje z): $150 \mathrm{~mm}$.

$\checkmark$ Velocidad del eje z: $50 \mathrm{~mm} / \mathrm{min}$.

\subsubsection{Microscopio óptico}

El microscopio óptico Leica DMRX (Figura 91) ha sido el empleado para realizar el estudio morfológico de los materiales ensayados. El equipo posee un rango de magnificación desde 2,5x hasta 50x.

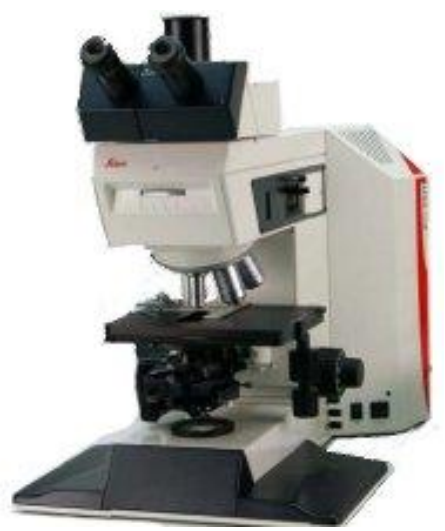

Figura 91. Microscopio óptico Leica DMRX

Las imágenes han sido tomadas a través de una cámara modelo LEICA MC190HD (Figura 92) con una resolución máxima de 3648×2736 pixeles. Cuenta además, con el software LAS (Leica Application Suite v4.9.) para la adquisición y adecuación de las imágenes tomadas, con posibilidad de escalar la imagen, medir en la misma y ajustar parámetros, entre otras funciones.

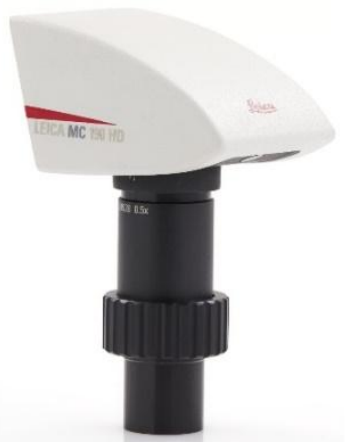

Figura 92. Cámara Leica MC190HD

\subsubsection{Microperfilómetro}

Las imágenes topográficas de las huellas de desgaste se han obtenido mediante el microperfilómetro óptico Taylor Hobson Talysurf CLI 500 (Figura 93). Con este equipo se ha podido calcular la pérdida de volumen en el disco, 
la tasa de desgaste y el daño superficial en los ensayos tribológicos gracias al medidor de aberración cromática de la luz (CLA) que posee.

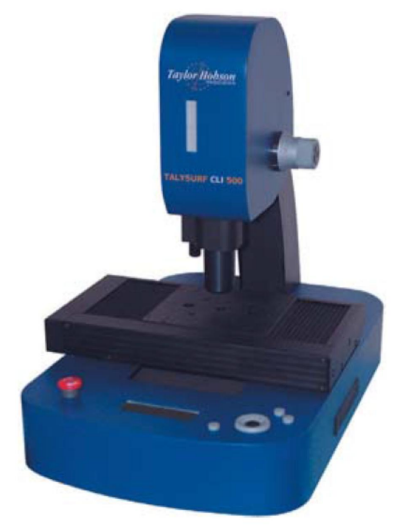

Figura 93. Microperfilómetro óptico Talysurf CLI 500, Taylor Hobson

Las características del equipo son las siguientes:

$\checkmark$ Dimensiones máximas de la muestra: $50 \times 50 \times 50 \mathrm{~mm}$.

$\checkmark$ Peso máximo de la muestra: $10 \mathrm{~kg}$.

$\checkmark$ Alcance del foco: $1000 \mu \mathrm{m}$.

$\checkmark$ Distancia de trabajo: $10 \mathrm{~mm}$.

$\checkmark$ Resolución espacial: 0,5 $\mu \mathrm{m}$.

$\checkmark$ Velocidades de medida: $30,15,10,5,1$ y $0,5 \mathrm{~mm} / \mathrm{s}$

$\checkmark$ Velocidad de posicionamiento máxima: $30 \mathrm{~mm} / \mathrm{s}$.

El equipo está provisto del software Talymap a través del cual es posible analizar los resultados obtenidos, pudiéndose determinar el tamaño y consistencia del granulado, calcular áreas, volúmenes, rugosidades y microalturas.

\subsubsection{Microscopio electrónico de barrido (SEM)}

Para llevar a cabo el estudio superficial de las muestras ensayadas se ha empleado el microscopio electrónico de barrido HITACHI S-3500N (Figura 94). 


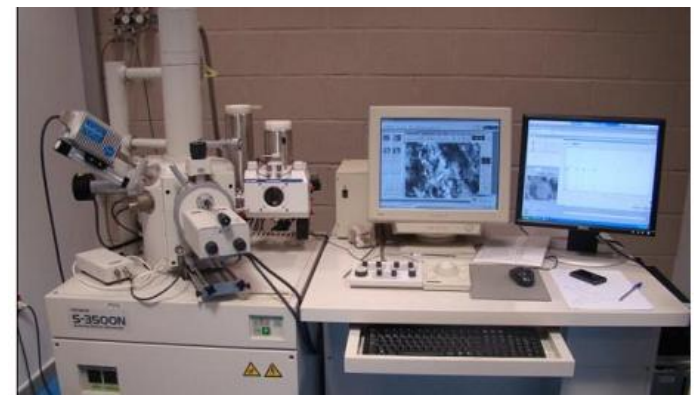

Figura 94. Microscopio electrónico de barrido HITACHI S-3500N

Este equipo permite la obtención de imágenes en alto vacío y con presión variable. A continuación, se detallan las principales características que posee el mismo.

$\checkmark$ Cañón de electrones con un voltaje acelerador de 0,5 a $30 \mathrm{kV}$, ajustable por pasos.

$\checkmark$ Fuente de electrones con filamento de wolframio, polarización automática y alineamiento electrónico del cañón.

$\checkmark$ Sistema de lentes con supresión de histéresis. Corriente de sonda con ajuste manual o automático, ajustable de $1 \mathrm{pA}$ a $1 \mathrm{~mA}$. Corrección de astigmatismo manual y electrónica.

$\checkmark$ Movimientos motorizados en los ejes X e Y.

$\checkmark$ Resolución de imagen de electrones secundarios de al menos 3,0 nm, en modo de alto vacío.

$\checkmark$ Resolución de imagen de electrones retrodispersados de al menos 5,0 $\mathrm{nm}$, en modo de presión variable. Este detector trabaja en modo composicional o topográfico.

$\checkmark$ Rango de magnificación desde 18x hasta 300000x, en más de 60 etapas.

$\checkmark$ Cámara infrarroja.

$\checkmark$ Sistema de vacío con control de evacuación, provisto de una bomba difusora y dos bombas rotatorias.

$\checkmark$ Enfoque manual y automático con ajuste grueso y fino. Rastreo automático del foco.

Además, el microscopio lleva acoplado un analizador por energías dispersivas de rayos X (EDX), XFlash 5010 de Bruker AXS Microanalysis con una resolución de $129 \mathrm{eV}$ en el pico Ka del $\mathrm{Mn}$ a la mitad de su altura, un área activa de $10 \mathrm{~mm}^{2}$ y es capaz de registrar hasta $750000 \mathrm{cps}$. Está equipado con la aplicación informática Espirit Quantax 400 que permite manejar espectros de energías dispersivas de rayos $\mathrm{X}$, perfiles de distribución de elementos a lo largo 
de una línea y mapas de distribución de elementos en un área seleccionada, mapping.

Para la obtención de imágenes y análisis en muestras no conductoras, es posible trabajar a medio vacío (70 MPa) y obtener imágenes mediante la señal procedente de electrones retrodispersados, mientras que en otros casos es necesario metalizar la muestra con Pt mediante la técnica de sputter coating en el equipo SC7610 de Quorum Technologies.

\subsubsection{Microscopio Raman confocal}

Para determinar la composición química y estructural de los líquidos iónicos, las nanofases de carbono y las dispersiones de éstas en líquidos iónicos se ha empleado el microscopio Raman confocal Reinshaw in Via (Figura 95).

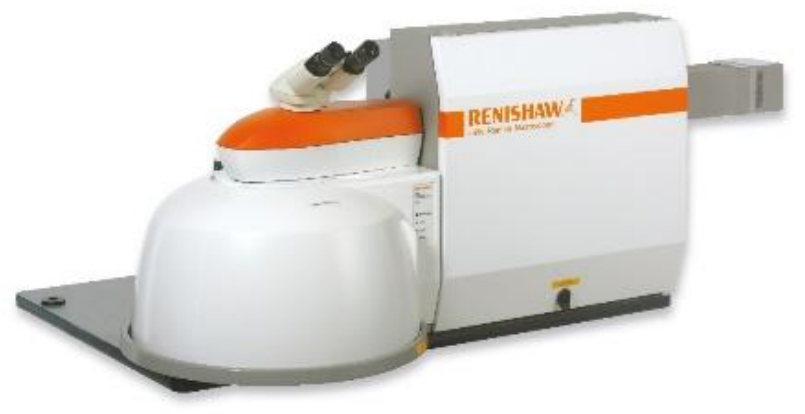

Figura 95. Microscopio Raman confocal Reinshaw in Via

Este equipo posee dos fuentes de excitación, un diodo láser de $785 \mathrm{~nm}$ y un láser de argón de $514 \mathrm{~nm}$ de Láser-Physics, ambos refrigerados por aire y con potencias de salida de $300 \mathrm{~mW}$ y $20 \mathrm{~mW}$ respectivamente.

Además, este el microscopio Raman incorpora dos redes de difracción de alta resolución, una de $1200 \mathrm{l} / \mathrm{mm}$ para el láser de $785 \mathrm{~nm}$ y otra de $1800 \mathrm{l} / \mathrm{mm}$ para el láser de $514 \mathrm{~nm}$. También posee dos juegos de lentes intercambiables. Las principales especificaciones del equipo son las siguientes:

$\checkmark$ Rango espectral hasta 4000 para el láser de $785 \mathrm{~nm}$ y hasta 9000 para láser de $514 \mathrm{~nm}$.

$\checkmark$ Resolución espectral superior a $1 \mathrm{~cm}^{-1}$.

$\checkmark$ Precisión de la medida de la frecuencia Raman: $0,2 \mathrm{~cm}^{-1}$. 
$\checkmark$ Spot láser variable de 1 a $300 \mu$ m según el objetivo y la longitud de onda.

$\checkmark$ Función extended Scan. Detector cámara CCD ampliada para NIR y UV, refrigerada por sistema Peltier $\left(-70^{\circ} \mathrm{C}\right)$.

$\checkmark$ Microscopio confocal Leica DMLM con confocalidad totalmente controlada via software y resolución espacial de $1 \mu \mathrm{m}$ lateral y $2 \mu \mathrm{m}$ en profundidad. Dispone de objetivos N-PLAN de 5x, 20x, 50x y 100x.

$\checkmark$ Referencia interna de silicio y fuente de calibración multilínea (mezcla de He y Ar).

$\checkmark$ Plataforma motorizada XYZ para mapping.

$\checkmark$ Software Wire 2.0 para control del instrumento y tratamiento de los datos.

En todos los análisis realizados en este trabajo se ha empleado el láser de longitud de onda de $514 \mathrm{~nm}$.

\subsubsection{Espectrómetro de fotoelectrones de rayos X (XPS)}

La espectroscopía fotoelectrónica de rayos $X$ es uno de los métodos análisis de superficies más empleados en la actualidad. Gracias a esta técnica analítica es posible proporcionar información cualitativa y cuantitativa de todos los elementos presentes en la muestra, excepto $\mathrm{H}$ y $\mathrm{He}$, hasta $10 \mathrm{~nm}$ de profundidad.

Para el análisis del nanocomposite de matriz epoxi (RE+9\%DCi) y el estudio superficial de la huella de desgaste tras lubricación con DCi+ND se ha empleado el equipo ESCA5701 de Physical Electronics (PHI) compuesto por:

$\checkmark$ Analizador/Detector de energía hemisférico (SCA) Modelo PHI 10-360.

$\checkmark$ Analizador de energías de precisión/Detector multicanal (16 Canales).

$\checkmark$ Sistema de ultra alto vacío, incluye cámara de análisis con bomba iónica de $220 \mathrm{l} / \mathrm{s}$ y sublimador de titanio; precámara de introducción de muestras con bomba rotativa Balzers DUO-2.5 y bomba turbomolecular Balzers TPU-062 de $60 \mathrm{l} / \mathrm{s}$.

$\checkmark$ Fuente de rayos $\mathrm{X}$ estándar con dos ánodos $\mathrm{Mg}$ y $\mathrm{Al}$, modelo $\mathrm{PHI}$ 04548.

$\checkmark$ Cañón de iones diferencial modelo PHI 04-303A variable hasta $5 \mathrm{keV}$ y de raster hasta $10 \mathrm{~mm} \times 10 \mathrm{~mm}$, para la realización de perfiles de profundidad. Se emplea gas argón.

$\checkmark$ Cañón de electrones modelo PHI 10-110 con voltaje variable de 0,5 a 5 keV y diámetro del haz $<10 \mu \mathrm{m}$ para hacer espectroscopía de electrones Auger. 
$\checkmark$ Neutralizador de muestras modelo PHI 04-090.

$\checkmark$ Monitor de TV con microscopio y fuente de luz para aumentar y enfocar el punto de análisis.

$\checkmark$ Precámara para la preparación de muestras equipada con dos controladores de flujo, calentamiento de muestras y equipo de ultra alto vacío (rotativa Alcatel y turbomolecular Varian de $70 \mathrm{l} / \mathrm{s}$ ) para la transferencia directa de la muestra a la cámara de análisis.

En el caso del análisis superficial de huellas de desgaste sobre acero y de los líquidos iónicos, el equipo utilizado fue el K-Alpha de Thermo-Scientific (Figura 96). En este caso, todos los espectros fueron tomados mediante radiación Al-K monocromatizada (1486,6 eV) por un monocromador de cristal gemelo, produciendo un punto de rayos $X$ enfocado (de forma elíptica con una longitud de eje principal de $400 \mu \mathrm{m}$ ) a $3 \mathrm{~mA} \times 12 \mathrm{kV}$. El analizador hemisférico alfa opera en modo de energía constante con energías de paso de exploración de sondeo de $200 \mathrm{eV}$ para medir toda la banda de energía y $50 \mathrm{eV}$ en una exploración estrecha para la medida selectiva de los elementos particulares. Los datos XPS obtenidos se analizaron con el software Avantage. Se utilizó una función de fondo inteligente para aproximar los fondos experimentales y la composición elemental de superficie se calculó a partir de áreas de pico suplantadas en segundo plano.

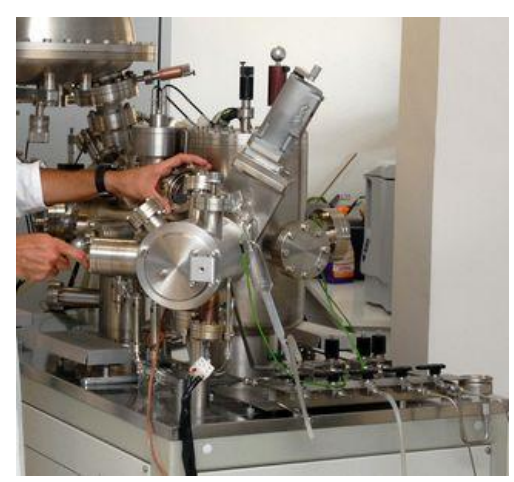

Figura 96. Espectrómetro fotoelectrónico de rayos X K-Alpha, Thermo-Scientific

En todos los casos, las energías se han corregido referenciándolas al pico 285 eV para el C1s usado como estándar interno [286], [287]. 


\subsection{PROCEDIMIENTO EXPERIMENTAL}

\subsubsection{Lubricación con líquidos iónicos y/o nanofases de carbono}

\subsubsection{Preparación de nuevos lubricantes en base agua con aditivos} derivados de ácidos grasos

\subsection{Emulsiones de agua+1\% de líquido iónico}

Para la obtención de las emulsiones en agua tipo II de un 1\% en peso de los líquidos iónicos DEs, MEs y DPa, en adelante WDEs, WMEs y WDPa, se pesan las cantidades correspondientes de soluto y agua en un vial. A continuación, la emulsión resultante se pone en un baño con agitación magnética (Placa calefactora modelo C-MAG HS 7 de IKA) y ultrasonidos (Homogeneizador ultrasónico Labsonic M) (1 ciclo/100\% de amplitud) a $30^{\circ} \mathrm{C}$ durante 30 minutos.

\subsection{Dispersiones de $0,1 \%$ de nanodiamantes en emulsiones de} agua $+1 \%$ de líquido iónico

Se preparan dispersiones de un $0,1 \%$ en peso de nanodiamantes sólidos en las emulsiones de los líquidos iónicos al 1\%. Posteriormente se ponen en un baño de agua con agitación magnética y ultrasonidos ( 1 ciclo/100\% de amplitud) a $30^{\circ} \mathrm{C}$ durante 30 minutos, obteniendo así las dispersiones NDWDEs, NDWMEs y NDWDPa.

\subsubsection{Dispersiones con el líquido iónico DSu}

Se ha estudiado el comportamiento tribológico de la disolución de un $1 \%$ en peso de DSu en agua tipo II. Para ello se coloca en un vial la cantidad correspondiente de líquido iónico y se añade agua. Una vez preparada, se homogeneiza con el dispersador (3.2.1.6) durante $30 \mathrm{~s}$.

Se han preparado dispersiones de grafeno al $0,1 \%$ y al $0,05 \%$ en peso en el líquido iónico DSu. Para ello, se pesan las cantidades correspondientes de grafeno y líquido iónico y se mezclan mecánicamente con ayuda de un mortero de ágata durante diez minutos, siguiendo el procedimiento propuesto por Fukushima para la dispersión de líquidos iónicos y nanotubos de carbono [288]. Posteriormente la dispersión es sometida a ultrasonidos en el homogeneizador durante treinta minutos a un ciclo y $100 \%$ de amplitud. 


\subsubsection{Dispersiones de líquido iónico DCi con nanodiamantes}

Además de grafeno, también se han empleado nanodiamantes para la obtención de una dispersión del líquido iónico prótico citrato de tri[bis(2hidroxietil)amonio] con $0,1 \%$ en peso de nanodiamantes (DCi+ND). Para ello, se toma un $2,5 \%$ de una suspensión acuosa comercial que contiene un $4 \%$ en peso de nanodiamantes y se añade al DCi. La mezcla se ultrasónica a $30^{\circ} \mathrm{C}$ durante 30 minutos a un ciclo con un $100 \%$ de amplitud con ayuda del homogeneizador ultrasónico de Labsonic M (apartado 3.2.1.5).

\subsubsection{Dispersiones de líquidos iónicos apróticos derivados del catión 1-etil-3-metilimidazolio con grafeno}

El mismo procedimiento empleado para la obtención de dispersiones de grafeno en DSu se ha utilizado para llevar a cabo dispersiones de los líquidos iónicos dicianamida de 1-etil-3-metilimidazolio [EMIM][DCA] y bis(trifluorometanosulfonil)imida de 1-etil-3-metilimidazolio [EMIM][TFSI] al 0,5 y $1 \%$ en peso de grafeno.

\subsubsection{Dispersiones del líquido iónico tetrafluoroborato de 1-octil-3- metilimidazolio y/o grafeno en aceites lubricantes}

Se han realizado también dispersiones del líquido iónico [OMIM]BF 4 y/o grafeno en un aceite base isoparafínico libre de aditivos (B) y en un aceite de motor totalmente formulado (MO). Para la obtención de las disoluciones de las bases lubricantes con un $5 \%$ en peso de líquido iónico, $\mathrm{B}+\left[\mathrm{OMIM}_{\mathrm{B}} \mathrm{F}_{4}\right.$ y $\mathrm{MO}+\left[\mathrm{OMIM}_{\mathrm{B}} \mathrm{BF}_{4}\right.$, se mezclan las cantidades idóneas de líquido iónico y aceite, se aplican ultrasonidos durante 90 minutos con agitación magnética a $30^{\circ} \mathrm{C}$. Posteriormente, la mezcla se dispersa durante $30 \mathrm{~s}$ a $16000 \mathrm{rpm}$. En el caso de las dispersiones de un $0,005 \%$ grafeno en los aceites lubricantes, $B+G$ y $\mathrm{MO}+\mathrm{G}$, la mezcla de la nanofase con el aceite base se somete a mezcla mecánica en un mortero de ágata durante 5 minutos y se sigue el mismo procedimiento descrito para las dispersiones de [OMIM]BF 4 . También se han preparado dispersiones de líquido iónico y grafeno en los aceites lubricantes, $\mathrm{B}+\left([\mathrm{OMIM}] \mathrm{BF}_{4}+\mathrm{G}\right)$ y $\mathrm{MO}+\left([\mathrm{OMIM}] \mathrm{BF}_{4}+\mathrm{G}\right)$. Para ello, se realiza la dispersión de $0,1 \%$ en peso de grafeno en líquido iónico $[\mathrm{OMIM}] \mathrm{BF}_{4}$ mediante mezcla mecánica en mortero de ágata durante 5 minutos y posterior sonicación durante 30 minutos. A continuación, se toma un $5 \%$ en peso de la dispersión 
preparada y se añade al aceite lubricante. Se dispersa durante 30 segundos a $16000 \mathrm{rpm}$.

\subsubsection{Preparación de capas finas}

Se han preparado capas finas de dispersiones lubricantes mediante dos técnicas:

- Evaporación de agua de la dispersión en una estufa de vacío

- Spin coating

En todos los casos, se ha estimado, mediante diferencia de peso, el espesor final de la capa fina, siendo inferior a $10 \mu \mathrm{m}$.

El primer método se ha empleado para la obtención de capas finas de las dispersiones de Agua+1\%DSu y $0,1 \%$ de nanodiamantes en DCi (Capa fina ND+DCi estufa).

Para ello, se vierten unas gotas de la dispersión sobre probetas de acero inoxidable AISI 316L, de manera que se cubra toda la superficie del acero. Posteriormente, se introducen en la estufa de vacío durante 3 horas a $60^{\circ} \mathrm{C}$ y 200 mbar hasta que se evapore el agua. Tras extraer las probetas de la estufa, se dejan durante $24 \mathrm{~h}$ en un desecador.

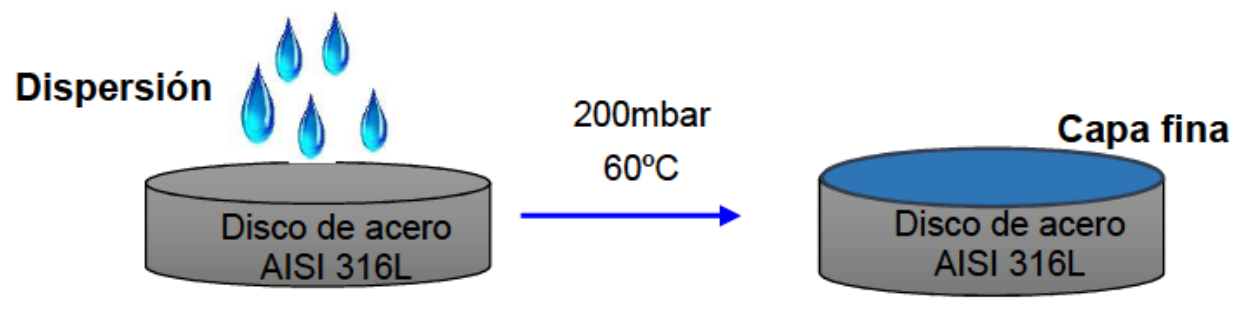

Figura 97. Procedimiento de obtención de capas finas en estufa

Sólo se han podido obtener capas finas mediante spin coating sobre AISI 316L en el caso de la dispersión de un $0,1 \%$ de nanodiamantes en DCi debido a su elevada viscosidad, permitiendo la creación de la capa sobre el sustrato metálico.

Para ello, se vierten $0,5 \mathrm{ml}$ de la dispersión de $\mathrm{DCi}$ con un $0,1 \%$ de nanodiamantes sobre la superficie de acero inoxidable AISI 316L. Con ayuda del equipo de spin coating (apartado 3.2.1.11) a una velocidad de $1000 \mathrm{rpm}$ y una aceleración de $2000 \mathrm{rpm} / \mathrm{s}$ durante 30 segundos, se obtiene la capa fina sobre la superficie metálica (DCi+ND capa fina spin coated). 


\subsubsection{Estudio reológico}

Se han realizado estudios para determinar el comportamiento reológico de los líquidos iónicos y sus dispersiones con nanofases de carbono.

En el caso de DSu, DSu+0,1\%G y DSu+0,05\%G, así como la dispersión $\mathrm{DCi}+\mathrm{ND}$, se realizaron ensayos de flujo en el reómetro rotacional AR-G2 de TA Instruments (3.2.2.8) en disposición plato sobre plato de $20 \mathrm{~mm}$ de diámetro a $25^{\circ} \mathrm{C}, 40^{\circ} \mathrm{C}$ y $100^{\circ} \mathrm{C}$ bajo las siguientes condiciones:

- Etapa 1: Rampa continua de velocidad de cizalla de $1 \cdot 10^{-3}$ a $300 \mathrm{~s}^{-1}$, durante 5 minutos.

- Peak Hold a $300 \mathrm{~s}^{-1}$ durante 1 minuto.

- Etapa 2: Rampa continua de velocidad de cizalla de 300 a $1 \cdot 10^{-3} \mathrm{~s}^{-1}$, durante 1 minuto.

Este mismo procedimiento ha sido el empleado para medir la viscosidad a $25^{\circ} \mathrm{C}$ de las emulsiones WDEs, WMEs y WDPa, las dispersiones resultantes de añadir un $0,1 \%$ de nanodiamantes a estas emulsiones y las dispersiones de $\left[\mathrm{OMIM}_{\mathrm{B}} \mathrm{BF}_{4} \mathrm{y} / \mathrm{o}\right.$ grafeno en aceite base isoparafínico (B). La viscosidad a $150^{\circ} \mathrm{C}$ de las dispersiones de [OMIM]BF 4 y/o grafeno en aceite lubricante totalmente formulado (MO) también fue determinada mediante este método.

La disposición de doble plato emplea un plato inferior de tipo Peltier sobre el que se deposita la muestra y se encarga de controlar la temperatura del ensayo y un plato superior que gira. De esta forma, se genera un gradiente de flujo debido a la fuerza centrífuga y una deformación que es nula en el centro y máxima en el extremo de la placa.

La viscosidad que se representa en las diferentes figuras mostradas en el capítulo 4 del presente trabajo corresponde a la etapa 1 de los ensayos, con gradiente de cizalla creciente. El valor numérico proporcionado se calcula como la media aritmética del valor de peak hold de tres ensayos en las mismas condiciones.

Los ensayos realizados para determinar el comportamiento reológico de los líquidos iónicos [EMIM][DCA] y [EMIM][TFSI] y sus dispersiones con grafeno se realizaron también en configuración plato sobre plato, con plato rotatorio de 60 $\mathrm{mm}$ de diámetro y distancia entre platos de $1000 \mu \mathrm{m}$. Se han realizado dos tipos de experimentos. En primer lugar, se obtuvieron curvas de flujo a $25^{\circ} \mathrm{C}$ y $100^{\circ} \mathrm{C}$ con una velocidad de cizalla entre $10^{-3}$ y $500 \mathrm{~s}^{-1}$ en estado estacionario. 
También, se determinó la evolución de la viscosidad con la temperatura entre 25 y $120^{\circ} \mathrm{C}$ con una velocidad de cizalla constante de $50 \mathrm{~s}^{-1}$ y una velocidad de calentamiento y enfriamiento de $1^{\circ} \mathrm{C} / \mathrm{min}$.

\subsubsection{Análisis térmico}

\subsection{Termogravimetría}

Para la determinación de la temperatura de degradación tanto de líquidos iónicos como de dispersiones, se ha empleado el analizador termogravimétrico descrito en el apartado 3.2.2.3. De esta manera, se ha determinado la temperatura a la cual el lubricante pierde el $50 \%$ de su masa.

En todos los casos, se realiza un análisis dinámico con calentamiento desde temperatura ambiente hasta $600^{\circ} \mathrm{C}$ a una velocidad de $10^{\circ} \mathrm{C} / \mathrm{min}$ en atmósfera de $\mathrm{O}_{2}$ empleando un crisol de aluminio.

\subsection{Calorimetría diferencial de barrido}

La obtención del perfil de fusión de los líquidos iónicos próticos derivados de ácidos grasos, presentados anteriormente, se ha realizado mediante calorimetría diferencial de barrido (DSC). En primer lugar, se realiza un calentamiento en crisol de aluminio desde $0^{\circ} \mathrm{C}$ hasta $150^{\circ} \mathrm{C}$, se estabiliza a esta temperatura durante 5 minutos, se enfría desde $150^{\circ} \mathrm{C}$ hasta $0^{\circ} \mathrm{C}$ y finalmente se calienta de nuevo hasta $150^{\circ} \mathrm{C}$ a $10^{\circ} \mathrm{C} / \mathrm{min}$ en atmósfera de $\mathrm{N}_{2}$, con un flujo de $50 \mathrm{ml} / \mathrm{min}$. Los termogramas mostrados son los obtenidos en el segundo calentamiento.

\subsubsection{Ensayos tribológicos}

\subsection{Preparación del sustrato metálico}

Antes de realizar los ensayos tribológicos es necesario preparar el sustrato de acero inoxidable AISI $316 \mathrm{~L}$ sobre el cual se realiza el ensayo. Para ello, en primer lugar, se procede al desbaste y pulido de los discos de acero inoxidable AISI 316L hasta obtener una desviación media del perfil de rugosidad $\left(R_{\mathrm{a}}\right)$ de las probetas inferior o igual a $0,1 \mu \mathrm{m}$, medidos con el rugosímetro de contacto. Se emplearon diferentes platos de desbaste de carburo de silicio de $20 \mathrm{~cm}$ de diámetro con tamaño de grano entre 400 y $4000 \mu \mathrm{m}$. El proceso de pulido consta a su vez de dos etapas, prepulido y pulido empleando como agente 
abrasivo alúmina de $1 \mu \mathrm{m}$ (Topol 1, Buehler) y 0,25 $\mu \mathrm{m}$ (Topol 3, Buehler) respectivamente.

\subsection{Estudio de la influencia de la velocidad}

Para llevar a cabo el estudio de la influencia de la velocidad en el coeficiente de fricción usando los lubricantes WDEs, WMEs, WDPa y NDWDPa se empleó el tribómetro UMT-TriboLab de Bruker en configuración punzón sobre disco. En todos los casos, los ensayos fueron realizados en inmersión empleando un volumen de lubricante promedio de $25 \mathrm{~cm}^{3}$ y una carga aplicada de $1 \mathrm{~N}$.

Se estudiaron tres contactos diferentes sobre discos de acero inoxidable AISI $316 \mathrm{~L}$ con $45 \mathrm{~mm}$ de diámetro y $5 \mathrm{~mm}$ de espesor:

$\checkmark$ Bola de acero AISI 316L de 1,6 mm de diámetro sobre el disco de acero del mismo material ( $\left.P_{\operatorname{med}}=1,01 \mathrm{GPa} ; P_{\max }=1,51 \mathrm{GPa}\right)$.

$\checkmark$ Bola de acero AISI 52100 de 1,6 mm de diámetro sobre disco de AISI 316L ( $\left.P_{\text {med }}=1,03 \mathrm{GPa} ; \mathrm{P}_{\max }=1,55 \mathrm{GPa}\right)$.

$\checkmark$ Bola de zafiro de $1,5 \mathrm{~mm}$ de diámetro sobre disco de AISI 316L $\left(P_{\text {med }}=1,3 \mathrm{GPa} ; P_{\max }=1,95 \mathrm{GPa}\right)$.

Para obtener las tres curvas de un mismo lubricante, una por cada tipo de contacto, se empleó la misma probeta de acero y se varió el radio de giro. Cada uno de los ensayos programados tenía la misma duración y el mismo número de ciclos.

Las condiciones del ensayo en el contacto AISI 316L-AISI 316 empleando como lubricantes las dispersiones de líquidos iónicos derivados de ácidos grasos en agua o con nanodiamantes dispersos (WDEs, WMEs, WDPa y NDWDPa) se recogen en la Tabla 14.

Para el estudio de la influencia de la velocidad en el contacto zafiro-AISI 316L para los lubricantes iónicos, el radio empleado fue de $18 \mathrm{~mm}$ y las condiciones se muestran a continuación (Tabla 15). 
Tabla 14. Condiciones del ensayo para la obtención de la curva COF vs.velocidad en el contacto AISI 316L-AISI 316L

\begin{tabular}{|c|c|c|c|c|}
\hline \multicolumn{5}{|c|}{ Radio 16 mm } \\
\hline $\begin{array}{l}\text { Velocidad angular } \\
\text { (rpm) }\end{array}$ & $\begin{array}{l}\text { Velocidad lineal } \\
\qquad(\mathrm{mm} / \mathrm{s})\end{array}$ & $\begin{array}{l}\text { Tiempo } \\
\text { (s) }\end{array}$ & Ciclos & $\begin{array}{c}\text { Distancia } \\
\text { (mm) }\end{array}$ \\
\hline 0,1 & 0,2 & 2400,0 & 4 & 402,1 \\
\hline 0,3 & 0,5 & 800,0 & 4 & 402,1 \\
\hline 0,8 & 1,3 & 600,0 & 8 & 804,2 \\
\hline 2,5 & 4,2 & 192,0 & 8 & 804,2 \\
\hline 7 & 11,7 & 171,4 & 20 & 2010,6 \\
\hline 20 & 33,5 & 60,0 & 20 & 2010,6 \\
\hline 60 & 100,5 & 20,0 & 20 & 2010,6 \\
\hline 100 & 167,6 & 12,6 & 21 & 2111,2 \\
\hline 175 & 293,2 & 13,7 & 40 & 4021,2 \\
\hline 450 & 754,0 & 5,3 & 40 & 4021,2 \\
\hline \multirow[t]{2}{*}{650} & 1089,1 & 3,7 & 40 & 4021,2 \\
\hline & Total & $71,1 \mathrm{~min}$ & 225 ciclos & $22,6 \mathrm{~m}$ \\
\hline
\end{tabular}

Tabla 15. Condiciones del ensayo para la obtención de la curva COF vs.velocidad en el contacto zafiro-AISI 316L

\begin{tabular}{ccccc}
\hline \multicolumn{5}{c}{ Radio 18 $\mathbf{~ m m}$} \\
\hline $\begin{array}{c}\text { Velocidad angular } \\
(\mathbf{r p m})\end{array}$ & $\begin{array}{c}\text { Velocidad lineal } \\
(\mathbf{m m} / \mathbf{s})\end{array}$ & $\begin{array}{c}\text { Tiempo } \\
\mathbf{( s )}\end{array}$ & Ciclos & $\begin{array}{c}\text { Distancia } \\
\mathbf{( m m})\end{array}$ \\
\hline 0,1 & 0,2 & 2400,0 & 4 & 452,4 \\
\hline 0,3 & 0,6 & 800,0 & 4 & 452,4 \\
\hline 0,8 & 1,5 & 600,0 & 8 & 904,8 \\
\hline 2,5 & 4,7 & 192,0 & 8 & 904,8 \\
\hline 7 & 13,2 & 171,4 & 20 & 2262,0 \\
\hline 20 & 37,7 & 60,0 & 20 & 2262,0 \\
\hline 60 & 113,1 & 20,0 & 20 & 2262,0 \\
\hline 120 & 226,2 & 10,5 & 21 & 2375,0 \\
\hline 175 & 329,9 & 13,7 & 40 & 4523,9 \\
\hline 400 & 754,0 & 6,0 & 40 & 4523,9 \\
\hline 600 & 1131,0 & 4,0 & 40 & 4523,9 \\
\hline & Total & $\mathbf{7 1 , 1} \mathbf{~}$ in & $\mathbf{2 2 5}$ ciclos & $\mathbf{2 5 , 4} \mathbf{~ m}$ \\
\hline
\end{tabular}

Para el contacto AISI 52100-AISI 316 L las condiciones empleadas fueron las siguientes (Tabla 16). 
Tabla 16. Condiciones del ensayo para la obtención de la curva COF vs.velocidad en el contacto AISI 52100-AISI 316L

\begin{tabular}{ccccc}
\hline \multicolumn{5}{c}{ Radio $\mathbf{2 0} \mathbf{~ m m}$} \\
\hline $\begin{array}{c}\text { Velocidad angular } \\
(\mathbf{r p m})\end{array}$ & $\begin{array}{c}\text { Velocidad lineal } \\
(\mathbf{m m} / \mathbf{s})\end{array}$ & $\begin{array}{c}\text { Tiempo } \\
\mathbf{( s )}\end{array}$ & Ciclos & $\begin{array}{c}\text { Distancia } \\
(\mathbf{m m})\end{array}$ \\
\hline 0,1 & 0,2 & 2400,0 & 4 & 502,7 \\
\hline 0,3 & 0,6 & 800,0 & 4 & 502,7 \\
\hline 0,8 & 1,7 & 600,0 & 8 & 1005,3 \\
\hline 2,5 & 5,2 & 192,0 & 8 & 1005,3 \\
\hline 7 & 14,7 & 171,4 & 20 & 2513,3 \\
\hline 20 & 41,9 & 60,0 & 20 & 2513,3 \\
\hline 60 & 125,7 & 20,0 & 20 & 2513,3 \\
\hline 100 & 209,4 & 12,6 & 21 & 2638,9 \\
\hline 175 & 366,5 & 13,7 & 40 & 5026,6 \\
\hline 375 & 785,4 & 6,4 & 40 & 5026,6 \\
\hline 550 & 1151,9 & 4,4 & 40 & 5026,6 \\
\hline & Total & $\mathbf{7 1 , 1}$ min & $\mathbf{2 2 5}$ ciclos & $\mathbf{2 8 , 3} \mathbf{~ m}$ \\
\hline
\end{tabular}

En el caso de los ensayos empleando el agua como lubricante las velocidades de giro alcanzadas fueron inferiores debido a restricciones de fricción del equipo. Por tanto, las condiciones de los ensayos para el contacto AISI 316LAISI 316L empleando agua como lubricante se recogen en la Tabla 17.

Tabla 17. Condiciones del ensayo para la obtención de la curva COF vs.velocidad en el contacto AISI 316L-AISI 316L usando agua como lubricante

\section{Radio $14 \mathrm{~mm}$}

\begin{tabular}{ccccc}
\hline $\begin{array}{c}\text { Velocidad angular } \\
(\mathbf{r p m})\end{array}$ & $\begin{array}{c}\text { Velocidad lineal } \\
(\mathbf{m m} / \mathbf{s})\end{array}$ & $\begin{array}{c}\text { Tiempo } \\
\mathbf{( s )}\end{array}$ & Ciclos & $\begin{array}{c}\text { Distancia } \\
(\mathbf{m m})\end{array}$ \\
\hline 0,1 & 0,1 & 2400,0 & 4 & 352,8 \\
\hline 0,3 & 0,4 & 800,0 & 4 & 352,0 \\
\hline 0,8 & 1,2 & 600,0 & 8 & 703,7 \\
\hline 2,5 & 3,7 & 192,0 & 8 & 704,0 \\
\hline 7 & 10,3 & 171,4 & 20 & 1765,2 \\
\hline 20 & 29,3 & 60,0 & 20 & 1756,4 \\
\hline 60 & 88,0 & 20,0 & 20 & 1750,5 \\
\hline 120 & 175,9 & 13,0 & 26 & 2287,1 \\
\hline 300 & 439,8 & 6 & 30 & 2638,9 \\
\hline & Total & $\mathbf{7 1 , 1} \mathbf{m i n}$ & $\mathbf{1 4 0}$ ciclos & $\mathbf{1 2 , 3 1} \mathbf{~}$ \\
\hline & & & &
\end{tabular}


En el caso del contacto zafiro-acero AISI 316L usando agua como lubricante se muestran en la Tabla 18.

Tabla 18. Condiciones del ensayo para la obtención de la curva COF vs.velocidad en el contacto zafiro-AISI 316L usando agua como lubricante

\begin{tabular}{ccccc}
\hline \multicolumn{5}{c}{ Radio $\mathbf{2 0} \mathbf{~ m m}$} \\
\hline $\begin{array}{c}\text { Velocidad angular } \\
(\mathbf{r p m})\end{array}$ & $\begin{array}{c}\text { Velocidad lineal } \\
(\mathbf{m m} / \mathbf{s})\end{array}$ & $\begin{array}{c}\text { Tiempo } \\
\mathbf{( s )}\end{array}$ & Ciclos & $\begin{array}{c}\text { Distancia } \\
(\mathbf{m m})\end{array}$ \\
\hline 0,1 & 0,2 & 2400,0 & 4 & 502,7 \\
\hline 0,3 & 0,6 & 800,0 & 4 & 502,7 \\
\hline 0,8 & 1,7 & 600,0 & 8 & 1005,3 \\
\hline 2,5 & 5,2 & 192,0 & 8 & 1005,3 \\
\hline 7 & 14,7 & 171,4 & 20 & 2513,3 \\
\hline 20 & 41,9 & 60,0 & 20 & 2513,3 \\
\hline 60 & 125,7 & 20,0 & 20 & 2513,3 \\
\hline 120 & 251,324 & 15,6 & 31 & 3920,7 \\
\hline & Total & $\mathbf{7 1} \mathbf{~ m i n}$ & $\mathbf{1 1 5}$ ciclos & $\mathbf{1 4 , 4 8} \mathbf{~ m}$
\end{tabular}

Las condiciones experimentales de los ensayos AISI 52100-AISI 316L con agua como agente lubricante se muestran en la Tabla 19.

Tabla 19. Condiciones del ensayo para la obtención de la curva COF vs.velocidad en el contacto acero AISI 52100-AISI 316L usando agua como lubricante

\begin{tabular}{ccccc}
\hline \multicolumn{5}{c}{ Radio $\mathbf{1 8} \mathbf{~ m m}$} \\
\hline $\begin{array}{c}\text { Velocidad angular } \\
(\mathbf{r p m})\end{array}$ & $\begin{array}{c}\text { Velocidad lineal } \\
(\mathbf{m m} / \mathbf{s})\end{array}$ & $\begin{array}{c}\text { Tiempo } \\
\mathbf{( s )}\end{array}$ & Ciclos & $\begin{array}{c}\text { Distancia } \\
(\mathbf{m m})\end{array}$ \\
\hline 0,1 & 0,2 & 2400,0 & 4 & 452,4 \\
\hline 0,3 & 0,6 & 800,0 & 4 & 452,4 \\
\hline 0,8 & 1,5 & 600,0 & 8 & 904,8 \\
\hline 2,5 & 4,7 & 192,0 & 8 & 904,8 \\
\hline 7 & 13,2 & 171,4 & 20 & 2262,0 \\
\hline 20 & 37,7 & 60,0 & 20 & 2262,0 \\
\hline 60 & 113,1 & 20,0 & 20 & 2262,0 \\
\hline 120 & 226,2 & 10,5 & 31 & 3551,2 \\
\hline & Total & $\mathbf{7 1} \mathbf{~ m i n}$ & $\mathbf{1 1 5}$ ciclos & $\mathbf{1 3 , 0 6} \mathbf{~ m}$ \\
\hline
\end{tabular}

Una vez realizados los ensayos tribológicos, se ha calculado la tasa de desgaste. Para ello, se ha medido la anchura de las huellas de desgaste (tomando al menos 10 medidas) obtenidas mediante microscopía electrónica 
de barrido. El volumen de desgaste se ha obtenido mediante la ecuación que se especifica en la norma ASTM G99 [289].

$$
W=2 \pi R\left[r^{2} \operatorname{arcsen}\left(\frac{d}{2 r}\right)-\frac{d}{4}\left(4 r^{2}-d^{2}\right)^{\frac{1}{2}}\right]
$$

Ecuación 2. Cálculo del volumen de desgaste a partir de la anchura de huella

Siendo, $\mathrm{W}$ el volumen de desgaste $\left(\mathrm{mm}^{3}\right)$, $\mathrm{R}$ el radio de giro del punzón sobre el disco $(\mathrm{mm})$, d la anchura media de la huella de desgaste $(\mathrm{mm})$ y $\mathrm{r}$ el radio esférico del punzón $(\mathrm{mm})$.

\subsection{Ensayos de lubricación externa en el contacto zafiro-acero inoxidable AISI $316 \mathrm{~L}$ a velocidad constante}

Para llevar a cabo los ensayos de lubricación externa a velocidad constante, una vez confirmado el valor de rugosidad del disco y preparados los lubricantes, se realizan los ensayos tribológicos bajo la configuración punzón sobre disco en el contacto zafiro-acero AISI 316L en el tribómetro ISC, en las siguientes condiciones (Tabla 20).

Tabla 20. Condiciones de los ensayos punzón sobre disco en el contacto zafiro-acero inoxidable AISI 316L

\begin{tabular}{cc}
\hline Carga & $0,98 \mathrm{~N}$ \\
\hline Distancia recorrida & $1500 \mathrm{~m}$ \\
\hline Velocidad & $0,01 \mathrm{~m} / \mathrm{s}$ \\
\hline Radio de giro & $9 \mathrm{~mm}$ \\
\hline Radio esférico de la bola & $0,75 \mathrm{~mm}$ \\
\hline Presión media de contacto & $1,30 \mathrm{GPa}$ \\
\hline Presión máxima de contacto & $1,95 \mathrm{GPa}$ \\
\hline Lubricantes & WDEs, WMEs, WDPa, NDWDEs, NDWMEs, \\
& NDWDPa, DSu, Agua+DSu, Capa fina \\
& Agua+DSu, DSu+0, $\%$ G, DSu+0,05\%G, DCi+ND \\
\hline
\end{tabular}

En el caso de los ensayos tribológicos para los líquidos iónicos [EMIM][DCA] y [EMIM][TFSI] y sus dispersiones con grafeno se han empleado discos de acero inoxidable AISI $316 \mathrm{~L}$ con $2,5 \mathrm{~mm}$ de espesor y una rugosidad media de 0,12 $\mu \mathrm{m}$. Los ensayos en este caso, se han realizado en el tribómetro Anton Paar.

Tras los ensayos tribológicos se procede a la limpieza de los discos con agua y etanol y a su secado con aire. Al menos se han realizado tres repeticiones de 
cada ensayo, con las mismas condiciones experimentales a temperatura ambiente y con una humedad relativa de $40 \pm 10 \%$.

La medida del desgaste que experimenta el disco de acero se realiza mediante microperfilometría óptica. El equipo Talysurf CLI (apartado 3.2.2.19) permite medir el volumen de pico y hueco de la huella generada en el disco.

Como se puede observar en laFigura 98, se llama volumen de pico al volumen de material que se ha depositado por encima del nivel medio de la superficie $\left(V_{2}+V_{3}\right)$, mientras que se conoce como volumen de hueco $\left(V_{1}\right)$, al volumen de material arrancado por debajo de la línea media.

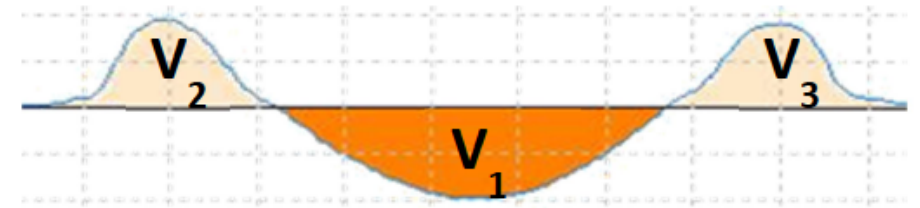

Figura 98. Esquema para el cálculo del volumen de desgaste

Una vez determinados dichos volúmenes, el volumen de desgaste se obtiene como la diferencia entre ambos $\left[V_{1}-\left(V_{2}+V_{3}\right)\right]$. El factor de desgaste o tasa de desgaste en $\mathrm{mm}^{3} / \mathrm{N} \cdot \mathrm{m}$ se obtiene a partir del dato de volumen de desgaste.

Los ensayos punzón sobre disco en el contacto zafiro-AISI 316L, para la determinación de las propiedades tribológicas de las dispersiones de líquido iónico [OMIM]BF 4 y/o grafeno en un aceite isoparafínico $(B)$ y en el lubricante de alto rendimiento totalmente formulado $(\mathrm{MO})$, se han realizado en las condiciones que se especifican en la Tabla 21.

Tabla 21. Condiciones de los ensayos de [OMIM] $\mathrm{BF}_{4}$ y/o grafeno con aceite libre de aditivos y aceite totalmente formulado

\begin{tabular}{ccc}
\hline Condiciones & $\begin{array}{c}\text { Aceite libre de } \\
\text { aditivos (B) }\end{array}$ & $\begin{array}{c}\text { Aceite totalmente formulado } \\
\text { (MO) }\end{array}$ \\
\hline Carga & $0,98 \mathrm{~N}$ & $1,96 \mathrm{~N}$ \\
\hline Distancia recorrida & $500 \mathrm{~m}$ & $1000 \mathrm{~m}$ \\
\hline Velocidad & $0,10 \mathrm{~m} / \mathrm{s}$ & $0,10 \mathrm{~m} / \mathrm{s}$ \\
\hline Radio de giro & $9 \mathrm{~mm}$ & $6 \mathrm{~mm}$ \\
\hline Radio esférico de la bola & $0,75 \mathrm{~mm}$ & $0,75 \mathrm{~mm}$ \\
\hline Presión máxima de contacto & $1,93 \mathrm{GPa}$ & $2,44 \mathrm{GPa}$ \\
\hline Presión media de contacto & $1,29 \mathrm{GPa}$ & $1,62 \mathrm{GPa}$ \\
\hline Temperatura & $23 \pm 1^{\circ} \mathrm{C}$ & $150^{\circ} \mathrm{C}$ \\
\hline
\end{tabular}


Después de los ensayos tribológicos, los materiales se limpian en un baño de ultrasonidos con acetona o hexano durante un minuto y se secan con aire.

Para el estudio de la topografía superficial y la medida del área de la sección transversal de las huellas de desgaste, se ha empleado el microperfilómetro Talysurf CLI. La determinación de la pérdida de material debida al desgaste se ha llevado a cabo como la diferencia entre las áreas de hueco $\left(A_{1}\right)$ y pico $\left(A_{2}+A_{3}\right)$.

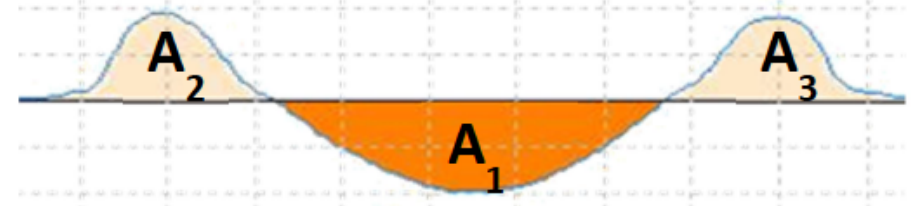

Figura 99. Esquema para el cálculo de la pérdida de material debida al desgaste

\subsubsection{Obtención de partículas de desgaste}

Para la obtención tanto de partículas de desgaste, como del grafeno procedente de las dispersiones para su posterior análisis mediante TEM, SEM o espectroscopía Raman, se toma una pequeña cantidad de la dispersión y lava con etanol de alta pureza. Se centrifuga a una velocidad de $4400 \mathrm{rpm}$ durante 3 minutos. Después de realizar 5 lavados, se deja en el interior de la estufa a $80^{\circ} \mathrm{C}$ durante 24 horas hasta la evaporación del disolvente.

\subsubsection{Nuevos nanocomposites de matriz epoxi}

\subsubsection{Preparación de nuevos nanocomposites y recubrimientos de matriz epoxi}

\subsection{Preparación del nanocomposite de resina epoxi con un $9 \%$ de líquido iónico DCi (RE+9\%DCi).}

Se ha preparado el nuevo material de matriz epoxi con un $9 \%$ del líquido iónico prótico citrato de tri[bis(2-hidroxietil)amonio] (DCi) según la norma UNE-ENISO-3673-2 [290]. En primer lugar, se dispersa la cantidad correspondiente a un $9 \%$ en peso de líquido iónico en el prepolímero DGEBA durante 30 segundos a $16000 \mathrm{rpm}$ en el equipo IKA T25 digital Ultra-Turrax. Posteriormente, se añade un $\mathbf{2 8 \%}$ en peso del endurecedor, se aplica vacío al recipiente y se agita a $1000 \mathrm{rpm}$ durante un minuto en el equipo IKA RW20. La mezcla se vierte en un molde formado por dos placas de acero inoxidable de 
dimensiones $8 \mathrm{~cm} \times 12,5 \mathrm{~cm}$ y se procede a un curado durante 2 horas a $60^{\circ} \mathrm{C}$ en la estufa Binder, seguido de un postcurado de 24 horas a temperatura ambiente.

\subsection{Preparación de recubrimientos sobre resina epoxi}

Se han preparado recubrimientos de nuevos nanocomposites de matriz epoxi, que poseen líquido iónico y/o grafeno sobre resina epoxi, cuyo comportamiento se comparará con el de un recubrimiento de resina sin aditivos. En primer lugar, se preparan los nanocomposites que actuarán como recubrimientos siguiendo el siguiente procedimiento:

$\checkmark$ Resina epoxi (RE). Se mezcla un $72 \%$ de prepolímero del sistema Ampreg 22 con un $28 \%$ de agente de curado. La relación prepolímeroendurecedor es la empleada para todos los nanocomposites de matriz epoxi obtenidos.

$\checkmark$ Resina epoxi con un 9\% de líquido iónico tetrafluoroborato de 1-octil-3metilimidazolio $\left(\mathrm{RE}+9 \%[\mathrm{OMIM}] \mathrm{BF}_{4}\right)_{2}$. Se toma el líquido iónico y se mezcla el $9 \%$ en peso del total con el prepolímero y se agita manualmente. Posteriormente se añade el agente de curado.

$\checkmark$ Resina epoxi con un $0,05 \%$ de grafeno (RE+0,05\%G). Se mezcla el grafeno con el prepolímero, se agita mecánicamente durante 10 minutos en un mortero de ágata y posteriormente se dispersa durante 30 segundos. A continuación, se mezcla con el endurecedor.

$\checkmark$ Resina epoxi con un $9 \%$ de la dispersión de líquido iónico [OMIM]BF 4 con un $0,1 \%$ de grafeno $\left(\mathrm{RE}+9\left(\mathrm{OMIM}\left[\mathrm{BF}_{4}\right]+0,1 \% \mathrm{G}\right)\right.$ ). En primer lugar, se realiza la dispersión de $0,1 \%$ de grafeno en el líquido iónico. Para ello, se toman ambas nanofases, se agitan mecánicamente en un mortero de ágata durante 10 minutos y se sonican durante 30 minutos. Posteriormente, se toma un $9 \%$ de esta dispersión de líquido iónico y grafeno, se añade el prepolímero y se agitan. Finalmente, a la mezcla obtenida se le añade el endurecedor.

Una vez preparadas las mezclas, se agitan manualmente durante 3 minutos y se procede al depósito del recubrimiento sobre probetas de resina epoxi de dimensiones $25 \mathrm{~mm}$ × $25 \mathrm{~mm}$ x $10 \mathrm{~mm}$ que actuarán como sustrato, mediante la técnica de spin coating. Para ello, la muestra de sustrato se coloca centrada dentro de la base interior del spin coater y se fija a dicha superficie mediante una bomba de vacío. 
El material de recubrimiento es introducido en la abertura superior, cuya localización coincide con el centro de la base interior. De esta manera cuando empieza a girar el equipo el recubrimiento se irá extendiendo desde el centro a los extremos de la probeta (Figura 100).

Los ensayos se han realizado en las mismas condiciones:

- Régimen de giro: $3000 \mathrm{rpm}$.

- Aceleración angular: $2500 \mathrm{rpm} / \mathrm{s}$.

- Tiempo de centrifugación: 60 segundos.
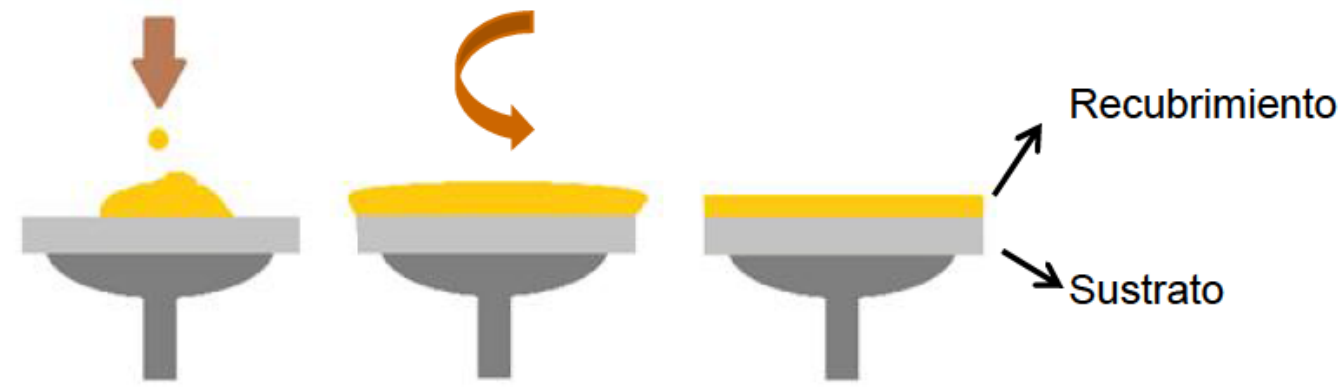

Figura 100. Procedimiento de obtención de recubrimientos mediante spin coating

\subsection{Preparación de recubrimientos sobre acero AISI 1015}

Se han preparado recubrimientos sobre acero al carbono AISI 1015 de nuevos nanocomposites de líquido iónico prótico en matriz epoxi de una capa y dos capas, y su comportamiento se ha comparado con el obtenido para recubrimientos de resina epoxi sin aditivos.

Para la obtención de recubrimientos de resina epoxi con un $9 \%$ de líquido iónico prótico DO y $9 \%$ de la dispersión de DO+0,1\%Grafeno se ha empleado el mismo procedimiento descrito anteriormente (apartado 3.3.2.1.2).

El procedimiento para obtener los recubrimientos de RE+9\%DO consta de una primera etapa de pesado de la cantidad correspondiente a un $9 \%$ de líquido iónico sobre la masa total del recubrimiento. Después, se añade prepolímero en una proporción del $72 \%$ respecto a la masa sin aditivos y se agita. Posteriormente, se añade el endurecedor, se agita durante 3 minutos y se realiza el recubrimiento en el equipo de spin coating.

Para preparar el nanocomposite de líquido iónico y grafeno, en primer lugar se realiza la dispersión de $\mathrm{DO}+0,1 \% \mathrm{G}$, pesando las cantidades correspondientes de ambos materiales en un mortero de ágata, mezclando mecánicamente durante 10 minutos y agitando con ultrasonidos durante 30 minutos. Una vez 
preparada la mezcla se procede de igual forma que para la obtención del recubrimiento de $\mathrm{RE}+9 \% \mathrm{DO}$.

La obtención de los recubrimientos de doble capa se realiza de forma similar a los de una capa. Se crea el recubrimiento de una capa y tras el curado de ésta durante 90 minutos en la estufa, se realiza un nuevo recubrimiento con el mismo método explicado anteriormente.

\subsection{Preparación de nanocomposites en forma de films}

Además, se han preparado nanocomposites de matriz epoxi en forma de films. Se han comparado sus características térmicas y dinámico-mecánicas con las presentadas por los films de resina epoxi sin aditivos.

Se han preparado films de RE, RE+9\%[OMIM]BF 4 , RE+0,05\%G y $\mathrm{RE}+9 \%\left([\mathrm{OMIM}] \mathrm{BF}_{4}+0,1 \% \mathrm{G}\right)$, por lo que el procedimiento y cantidades empleadas es similar a llevado a cabo para los recubrimientos sobre matriz epoxi. La única diferencia estriba en que en este caso, como sustrato se han empleado discos de poliestireno de $40 \mathrm{~mm}$ de diámetro.

Una vez creados los recubrimientos sobre los discos de poliestireno, se procede a su curado en la estufa a $60^{\circ} \mathrm{C}$ durante 2 horas y un postcurado de 24 h a temperatura ambiente. Finalmente se extraen los films separándolos del sustrato de poliestireno (Figura 101).

a)

\section{Universidad Politécnica de Cartagena}

c)

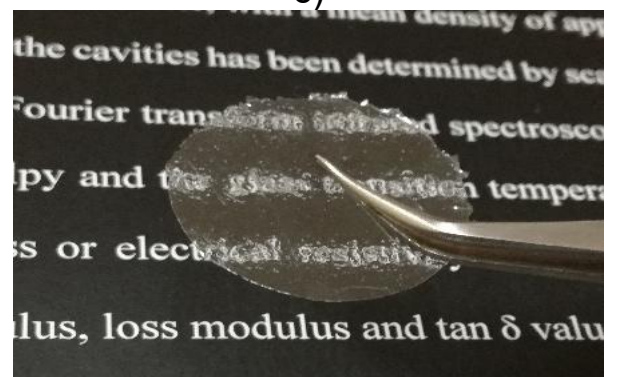

b)

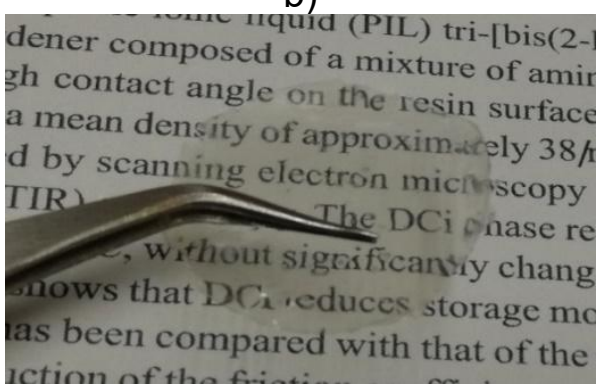

d)

\section{Universidad Politécnica de Cartagena}

Figura 101. Films de los nanocomposites: a) RE; b) $R E+9 \%[O M I M] B F_{4}$; c) $R E+0,05 \% G$;

d) $\mathrm{RE}+9 \%\left(\left[\mathrm{OMIM}_{\mathrm{B} F}+0,1 \% \mathrm{G}\right)\right.$ 
Se puede observar cómo los films de RE son transparentes (Figura 101a) y la adición de líquido iónico no afecta a dicha transparencia (Figura 101b). En el caso del nanocomposite con $0,05 \%$ de grafeno, el film se vuelve más opaco (Figura 101c).

\subsubsection{Caracterización de los nanocomposites}

\subsection{Estudio de curado}

Para determinar el grado de curado del nuevo nanocomposite de matriz epoxi con un $9 \%$ de $\mathrm{DCi}$, se realiza un estudio mediante calorimetría diferencial de barrido (DSC) y espectroscopía infrarroja (FTIR).

Los análisis de DSC sirven para determinar la entalpía residual de curado de la muestra tras someterla a un proceso isotermo a $60^{\circ} \mathrm{C}$ durante 20,40 y 60 minutos, unas condiciones similares a las del proceso de curado de la resina (2 horas en estufa a $60^{\circ} \mathrm{C}$ ). Dicha entalpía se ha calculado como el área limitada por la curva DSC y la línea base, una vez sobrepasada la temperatura de transición vítrea del material. De este modo, es posible comprobar el grado de curado del nuevo nanocomposite, ya que el valor de la entalpía residual de curado varía desde su valor previo al curado hasta valores próximos a 0 para resinas totalmente curadas.

En este caso, los ensayos se han realizado en atmósfera de nitrógeno, con un flujo de $50 \mathrm{ml} / \mathrm{min}$. Se realiza un calentamiento desde $25^{\circ} \mathrm{C}$ hasta $60^{\circ} \mathrm{C}$ con una velocidad de calentamiento de $20^{\circ} \mathrm{C} / \mathrm{min}$. Posteriormente, se mantiene dicha temperatura de $60^{\circ} \mathrm{C}$ durante $20,40 \circ 60$ minutos, después se enfría hasta $0^{\circ} \mathrm{C}$, también con una velocidad de $20^{\circ} \mathrm{C} / \mathrm{min}$. Finalmente, se lleva a cabo un segundo calentamiento hasta $150^{\circ} \mathrm{C}$ con una velocidad de calentamiento de $10^{\circ} \mathrm{C} / \mathrm{min}$.

Como se ha comentado anteriormente, también se ha empleado la espectroscopía infrarroja para la determinación del grado de curado del nuevo material estudiando la evolución de las bandas características de cada grupo funcional con el tiempo. Para ello se realizan análisis de infrarrojo en modo transmisión sobre celdas desmontables de polietileno. 


\subsection{Propiedades térmicas}

\subsection{Termogravimetría}

A través de la técnica de termogravimetría se ha determinado la temperatura de degradación de los nuevos nanocomposites, entendiendo ésta como la temperatura a la cual la muestra pierde un $50 \%$ de su peso inicial. Para ello, se ha realizado un ensayo dinámico, en el cual se han medido los cambios de peso de la muestra al calentarla desde temperatura ambiente hasta $800^{\circ} \mathrm{C}$, con una velocidad de calentamiento de $10^{\circ} \mathrm{C} / \mathrm{min}$ en atmósfera de nitrógeno, con un flujo de $50 \mathrm{ml} / \mathrm{min}$.

\subsection{Calorimetría diferencial de barrido}

Mediante la calorimetría diferencial de barrido es posible determinar los episodios térmicos que experimenta una muestra gracias a la diferencia del flujo de calor entre dicha muestra y un crisol de referencia cuando ambos están sometidos al mismo programa de temperatura.

Para los nuevos nanocomposites de matriz epoxi se ha determinado la temperatura de transición vítrea $(\mathrm{Tg})$, temperatura a que se incrementa la movilidad de las cadenas poliméricas pasando el material de un estado vítreo a un estado elastomérico.

La metodología empleada sigue la establecida en la norma ISO 11357-2 [291], que consta de un calentamiento inicial hasta una temperatura inferior a la temperatura de degradación del polímero, en este caso de 0 a $250^{\circ} \mathrm{C}$, con una velocidad de $10^{\circ} \mathrm{C} / \mathrm{min}$. Seguidamente, se mantiene esta temperatura durante 5 minutos y se produce un enfriamiento de la muestra hasta $0^{\circ} \mathrm{C}$ también a $10^{\circ} \mathrm{C} / \mathrm{min}$ con el fin de borrar el historial térmico del material. Después se realiza una isoterma de 5 minutos a $0^{\circ} \mathrm{C}$ y finalmente el valor de la temperatura de transición vítrea se determina en el segundo calentamiento de 0 a $250^{\circ} \mathrm{C}$, con una velocidad de calentamiento de $10^{\circ} \mathrm{C} / \mathrm{min}$. Los ensayos se realizan en atmósfera de nitrógeno, con un flujo de $50 \mathrm{ml} / \mathrm{min}$.

\subsection{Propiedades dinámico-mecánicas}

Los ensayos dinámico-mecánicos permiten medir la respuesta de un material cuando se ve sometido a un esfuerzo sinusoidal mientras se aplica un programa de temperatura y como respuesta a este esfuerzo, el material se 
deforma. Debido a la naturaleza viscoelástica de los materiales poliméricos, la onda de carga y la onda de deformación están desfasadas en un ángulo entre $0^{\circ}$ (desfase que presentaría un material elástico) y $90^{\circ}$ (desfase que presentaría un material viscoso).

Por tanto, se define un módulo complejo $\left(E^{*}\right)$ que posee una parte real, denominada módulo de almacenamiento (E') y una parte imaginaria (E'), el módulo de pérdida (Ecuación 3).

$$
E^{*}=E^{\prime}+E^{\prime \prime} i
$$

Ecuación 3. Módulo viscoelástico

Estos diferentes módulos permiten realizar una mejor caracterización del material polimérico, porque es posible determinar la capacidad del material para almacenar energía de forma reversible (E'), su habilidad para perderla debido a la fricción intermolecular entre las cadenas ( $E$ ") así como, la relación entre ambas a partir de la tangente $(\delta)=E$ "' $E$ '. Este parámetro es un indicador de la energía disipada por el material cuando hay fricción interna o se produce el reordenamiento de sus cadenas [292].

Para la determinación de las propiedades dinámico-mecánicas del nanocomposite de matriz epoxi $(\mathrm{RE}+9 \% \mathrm{DCi})$ se han ensayado muestras de una geometría de $30 \times 7,0 \times 3,5 \mathrm{~mm}$ bajo la configuración de viga empotrada simple (Figura 102). Se ha realizado un calentamiento desde $25^{\circ} \mathrm{C}$ hasta $120^{\circ} \mathrm{C}$, con una velocidad de calentamiento de $3^{\circ} \mathrm{C} / \mathrm{min}$, una variación de un $1 \%$ de la tensión aplicada y una frecuencia oscilatoria de $1 \mathrm{~Hz}$.

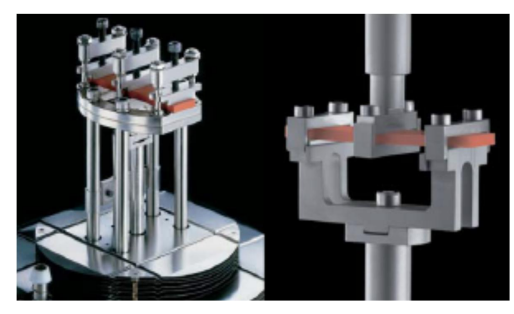

Figura 102. Configuración DMA, viga empotrada simple

Se ha determinado también, el comportamiento dinámico-mecánico de los films de matriz epoxi empleando una configuración de tensión especial para materiales de pequeño espesor, en el cual la muestra se sitúa tensionada entre una mordaza fija y otra móvil, tal y como aparece en la Figura 103. La mordaza 
móvil adopta un movimiento oscilante con una frecuencia determinada mientras se varía la temperatura según un programa preestablecido.
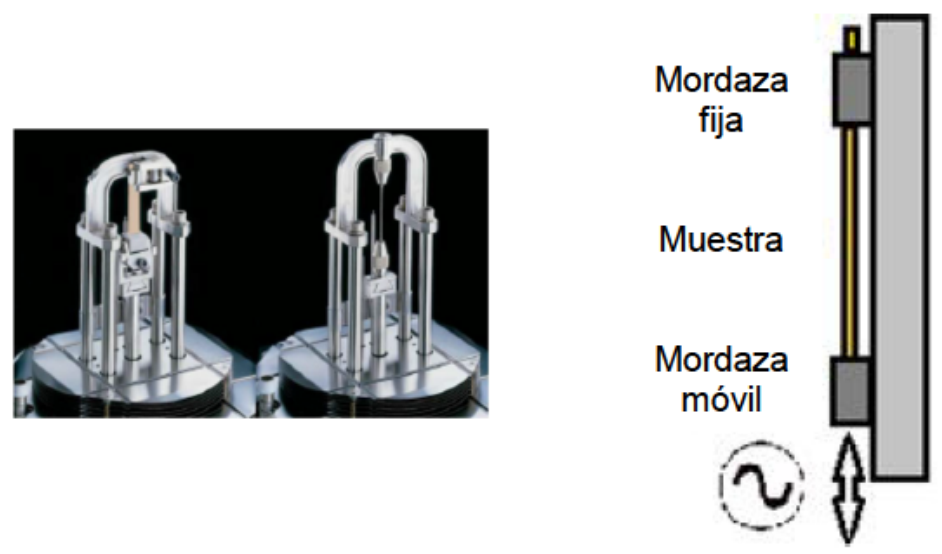

Figura 103. Configuración DMA, módulo de tensión para films

Las condiciones de frecuencia, rango de temperatura y velocidad de calentamiento empleadas para los films han sido similares a las usadas para el nanocomposite de matriz epoxi RE+9\%DCi. En este caso, se emplea una fuerza de precarga de $0,1 \mathrm{~N}$, una force track de $125 \%$ y una amplitud de deformación de $10 \mu \mathrm{m}$.

\subsection{Ensayos tribológicos}

\subsection{Ensayos de rayado}

Los ensayos de rayado se han llevado a cabo con el equipo microrrayador de Microtest, como se indicó en el apartado 3.2.2.17.

Este equipo posee un punzón de diamante de forma cónica con un ángulo de $120^{\circ}$ tipo Rockwell y un diámetro de $200 \mu \mathrm{m}$, como se puede apreciar en la Figura 104.

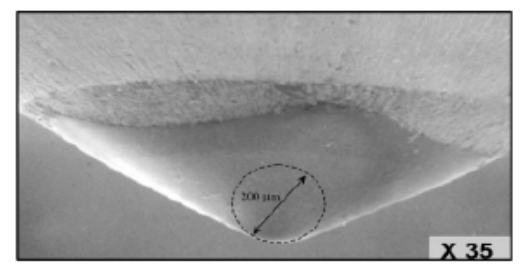

Figura 104. Micrografía del indentador para ensayos de rayado

Para cada rayado se determinan las siguientes variables: 
Profundidad de penetración $(\mathrm{Pd})$ : Profundidad a la que penetra el indentador sobre el material al aplicarle la carga establecida, considerando como referencia la información topográfica recopilada en el barrido inicial.

Profundidad residual ( $R d$ ): Profundidad sobre la superficie del material una vez transcurridos 30 segundos desde la aplicación de la carga, y teniendo en cuenta la información topográfica del barrido inicial.

Porcentaje de recuperación viscoelástica $(\% \mathrm{R})$ : Se calcula a partir de los valores de profundidad de penetración y profundidad residual (Ecuación 4).

$$
\% R=\frac{P_{d}-R_{d}}{P_{d}} \cdot 100
$$

Ecuación 4. Cálculo del porcentaje de recuperación viscoelástica

Coeficiente de fricción (COF): Valor del coeficiente de fricción entre la superficie del material y el indentador.

Este equipo se ha empleado para determinar la resistencia a la abrasión de recubrimientos de nuevos nanocomposites de matriz epoxi mediante ensayos de multirrayado. Éstos se realizan para comprobar la respuesta de la superficie del material a la acción de la carga vertical del rayador en múltiples pasadas a una misma carga, lo que permite comprobar la variación de la resistencia a la penetración del material durante la aplicación de los sucesivos ensayos. Los parámetros introducidos en los ensayos de multirrayado han sido los siguientes:

Tabla 22. Condiciones de los ensayos de multirrayado para los recubrimientos sobre resina epoxi

\begin{tabular}{cc}
\hline Carga & $5 \mathrm{~N}$ \\
\hline Número de rayados & 15 \\
\hline Longitud del rayado & $5 \mathrm{~mm}$ \\
\hline Velocidad de avance & $5 \mathrm{~mm} / \mathrm{min}$ \\
\hline Condiciones ambientales & $\begin{array}{c}\text { Temperatura: } 25^{\circ} \mathrm{C} \\
\text { Humedad: } 50 \% \mathrm{HR}\end{array}$ \\
\hline
\end{tabular}




\subsection{Ensayos tribológicos punzón sobre disco}

Los ensayos tribológicos para la determinación de la fricción y el desgaste del nanocomposite $\mathrm{RE}+9 \% \mathrm{DCi}$ se han realizado en el tribómetro ISC-200 (3.2.2.16) bajo la configuración punzón sobre disco en el contacto acero inoxidable AISI 316L - resina epoxi.

Aunque los ensayos tribológicos de los recubrimientos de nanocomposites de resina epoxi sobre discos de acero AISI 1015 se llevan a cabo en el tribómetro Anton Paar, las condiciones de funcionamiento son similares en ambos casos, y se recogen en la Tabla 23.

Tabla 23. Condiciones de los ensayos punzón sobre disco para RE+9\%DCi y recubrimientos sobre acero AISI 1015

\begin{tabular}{cc}
\hline Carga & $0,49 \mathrm{~N}$ \\
\hline Distancia de deslizamiento & $500 \mathrm{~m}$ \\
\hline Velocidad & $0,1 \mathrm{~m} / \mathrm{s}$ \\
\hline Radio de giro & $9 \mathrm{~mm}$ \\
\hline Radio esférico de la bola & $0,8 \mathrm{~mm}$ \\
\hline Presión media de contacto & $0,07 \mathrm{GPa}$ \\
\hline Presión máxima de contacto & $0,11 \mathrm{GPa}$ \\
\hline Condiciones ambientales & Temperatura: $25^{\circ} \mathrm{C}$ \\
& Humedad: $50 \% \mathrm{HR}$ \\
\hline
\end{tabular}

Una vez finalizados los ensayos tribológicos, tanto los de rayado, como realizados en configuración punzón sobre disco, se ha estudiado la superficie de la huella obtenida mediante microscopía electrónica de barrido y microperfilometría. Se ha cuantificado el daño superficial que experimentan las probetas tras los ensayos tribológicos a partir de la suma del área exterior $\left(A_{2}+A_{3}\right)$ y área interior $\left(A_{1}\right)$ de cada huella como se representa en la Figura 105.

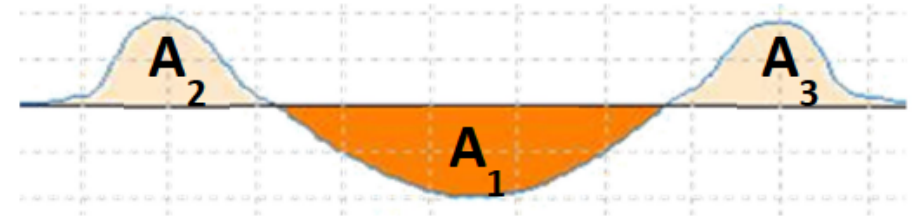

Figura 105. Esquema para el cálculo del daño superficial 



\section{RESULTADOS Y DISCUSIÓN}





\section{RESULTADOS Y DISCUSIÓN}

\subsection{LUBRICACIÓN CON LÍQUIDOS IÓNICOS YIO NANOFASES DE CARBONO}

\subsubsection{Lubricación base agua con aditivos derivados de ácidos grasos}

Se han obtenido emulsiones de un $1 \%$ en peso de líquidos iónicos próticos derivados de ácidos grasos (estearato de bis(2-hidroexietil)amonio (DEs), estearato de 2-hidroxietilamonio (MEs) y palmitato de bis(2-hidroexietil)amonio (DPa)) en agua. Las emulsiones obtenidas (WDEs, WDPa y WMEs) se han caracterizado, se ha medido el espesor de película mediante interferometría de película ultrafina y se ha estudiado la influencia de la velocidad de giro en el coeficiente de fricción mediante ensayos en configuración punzón sobre disco para dos contactos metálicos (AISI 316L-AISI 316L, AISI 52100-AISI 316L) y contacto cerámico-metal (zafiro-AISI 316L). Además, se ha medido el desgaste tras estos ensayos y se ha realizado un análisis superficial.

Como la emulsión de DPa en agua era la que presentaba mejores características lubricantes, se ha estudiado el espesor de película y se ha estudiado la evolución del coeficiente de fricción con la velocidad de giro para los diferentes contactos de una dispersión de $0,1 \%$ de nanodiamantes en NDWDPa para determinar si la presencia de esta nanofase mejoraba su comportamiento frente a fricción y desgaste.

Además, se han realizado ensayos tribológicos punzón sobre disco en el contacto zafiro-AISI $316 \mathrm{~L}$ a velocidad constante $(0,1 \mathrm{~m} / \mathrm{s})$ para determinar el coeficiente de fricción y la tasa de desgaste empleando las emulsiones WDEs, WMEs y WDPa. Las dispersiones de un $0,1 \%$ de nanodiamantes en estas emulsiones (NDWDEs, NDWMEs y NDWDPa) también se han estudiado, llevando a cabo un estudio superficial los estos ensayos tribológicos realizados.

\subsubsection{Caracterización de las emulsiones y dispersiones}

En la Tabla 24 se muestran los datos de $\mathrm{pH}$, conductividady viscosidad a $300 \mathrm{~s}^{-1}$ del agua y de las emulsiones de los líquidos iónicos DEs, MEs y DPa en agua. Todas las emulsiones presentan valores de $\mathrm{pH}$ similares y son de carácter básico. La emulsión de un $1 \%$ de DEs en agua es la que presenta valores de conductividad y viscosidad mayores que el resto de lubricantes. 
Tabla 24. Valores de pH, viscosidad y conductividad para agua, WDEs, WMEs y WDPa

\begin{tabular}{cccc}
\hline & $\mathbf{p H}$ & Conductividad $(\boldsymbol{\mu S} / \mathbf{c m})$ & Viscosidad $(\mathbf{m P a} \cdot \mathbf{s})$ \\
\hline WDEs & 9,78 & $170,3( \pm 6,6)$ & $6,2( \pm 2,3)$ \\
\hline WMEs & 9,86 & $155,5( \pm 3,5)$ & $1,8( \pm 1,1)$ \\
\hline WDPa & 9,88 & $109,2( \pm 5,9)$ & $4,2( \pm 0,1)$ \\
\hline Agua & 5,85 & $3,3( \pm 0,6)$ & $1,2( \pm 0,4)$
\end{tabular}

En el caso de las dispersiones de $0,1 \%$ de nanodiamantes en las emulsiones al $1 \%$ de líquido iónico en agua (Tabla 25 ), se observa cómo la adición de la nanofase hace que disminuya ligeramente el $\mathrm{pH}$ y aumente el valor de la conductividad, quizás debido a que las partículas de nanodiamantes están funcionalizadas.

Con respecto a la viscosidad, disminuye para NDWDEs y NDWDPa y aumenta para NDWMEs.

Tabla 25. Valores de $\mathrm{pH}$, viscosidad y conductividad para NDWDEs, NDWMEs y NDWDPa

\begin{tabular}{lccc}
\hline & pH & Conductividad $(\boldsymbol{\mu S} / \mathbf{c m})$ & Viscosidad $(\mathbf{m P a} \cdot \mathbf{s})$ \\
\hline NDWDEs & 9,31 & $242,2( \pm 2,1)$ & $2,2( \pm 0,3)$ \\
\hline NDWMEs & 9,48 & $214,1( \pm 1,7)$ & $2,4( \pm 0,4)$ \\
\hline NDWDPa & 9,48 & $177,3( \pm 8,9)$ & $1,8( \pm 0,5)$ \\
\hline
\end{tabular}

\subsubsection{1. Ángulo de contacto y tensión superficial}

Se ha medido el ángulo de contacto de las emulsiones de los líquidos iónicos derivados de ácidos grasos en agua sobre acero inoxidable AISI 316L, obteniéndose los resultados que se muestran en la Tabla 26. 
Tabla 26. Ángulos de contacto de agua, WDEs, WMEs y WDPa sobre AISI 316L

\begin{tabular}{|c|c|c|c|}
\hline & $\begin{array}{l}\text { Ángulos de } \\
\text { contacto }\end{array}$ & Inicial & Final \\
\hline $\begin{array}{l}\text { WDEs } \\
\text { sobre } \\
\text { acero } \\
\text { AISI } \\
316 L\end{array}$ & $\begin{array}{l}\text { Ángulo inicial } \\
82,2( \pm 2,9)^{\circ} \\
\text { Ángulo final } \\
59,7( \pm 0,9)^{\circ}\end{array}$ & & \\
\hline $\begin{array}{c}\text { WMEs } \\
\text { sobre } \\
\text { acero } \\
\text { AISI } \\
316 L\end{array}$ & $\begin{array}{l}\text { Ángulo inicial } \\
76,7( \pm 2,4)^{\circ} \\
\text { Ángulo final } \\
47,9( \pm 1,5)^{\circ}\end{array}$ & & \\
\hline $\begin{array}{l}\text { WDPa } \\
\text { sobre } \\
\text { acero } \\
\text { AISI } \\
316 L\end{array}$ & $\begin{array}{l}\text { Ángulo inicial } \\
61,8( \pm 4,3)^{\circ} \\
\text { Ángulo final } \\
29,9( \pm 1,1)^{\circ}\end{array}$ & & \\
\hline $\begin{array}{c}\text { Agua } \\
\text { sobre } \\
\text { acero } \\
\text { AISI } \\
316 \mathrm{~L}\end{array}$ & $\begin{array}{l}\text { Ángulo Inicial } \\
48,2( \pm 2,1)^{\circ} \\
\text { Ángulo Final } \\
42,4( \pm 1,8)^{\circ}\end{array}$ & & \\
\hline
\end{tabular}

En todos los casos, los ángulos de contacto de las emulsiones son inferiores a $90^{\circ}$, por lo que mojan la superficie del acero inoxidable. Mientras que los derivados del ácido esteárico (WDEs y WMEs) presentan un ángulo de contacto superior al presentado por el agua sobre el AISI 316L, el DPa es el único aditivo que incrementa la mojabilidad del agua sobre este sustrato metálico, reduciendo el ángulo de contacto en un 30\% con respecto al agua, lo que implicaría una fuerte interacción entre las moléculas del líquido iónico DPa y la superficie de acero.

Aunque no se observa una relación directa entre los valores de viscosidad y los ángulos de contacto, el lubricante más viscoso (WDEs) presenta el mayor ángulo de contacto. 
Además, se ha medido el ángulo de mojado de las dispersiones de estos líquidos iónicos a las que se ha añadido un 0,1\% de nanodiamantes (Tabla 27).

Tabla 27. Ángulos de contacto de NDWDEs, NDWMEs y NDWDPa sobre AISI 316L

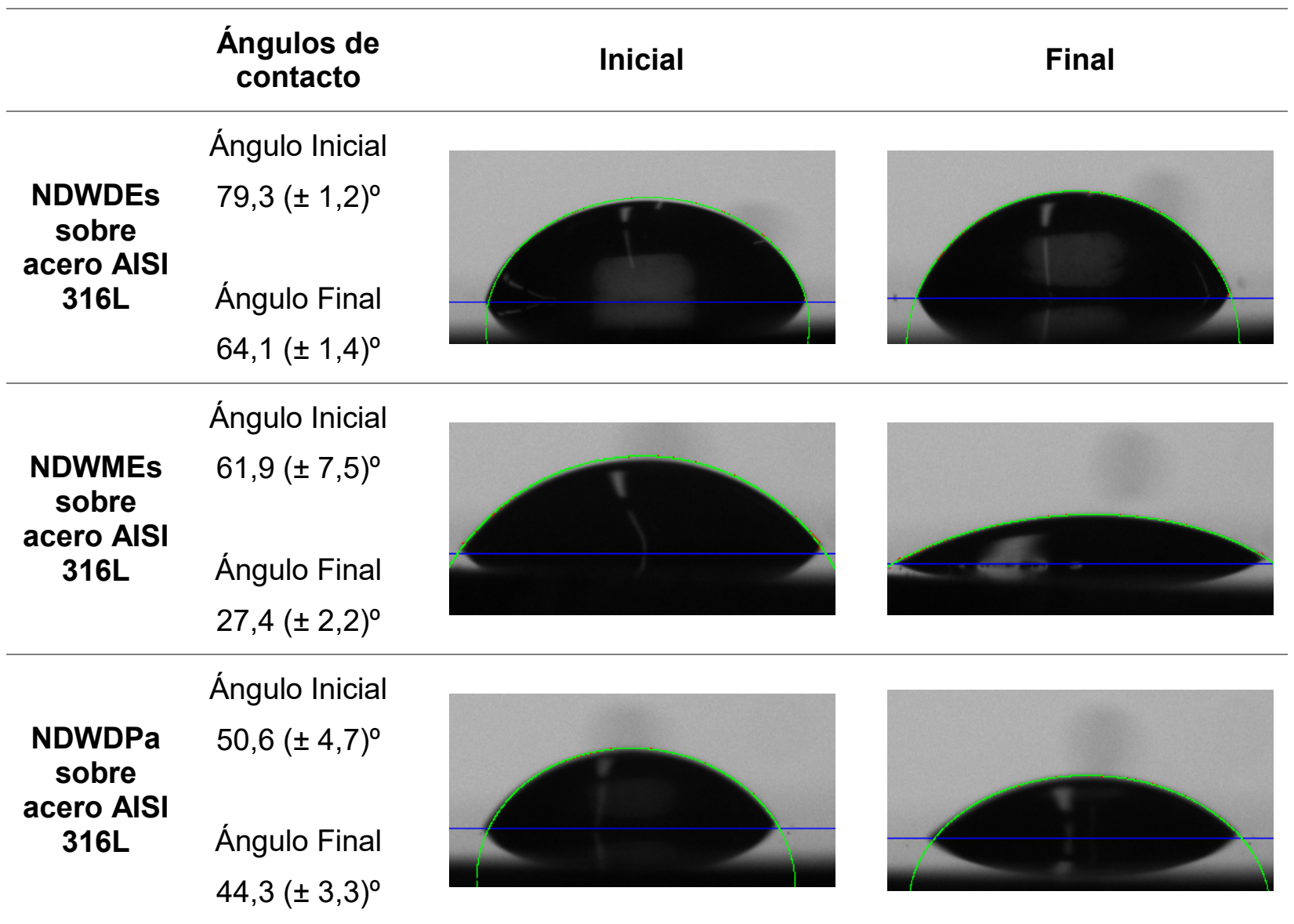

En este caso, la dispersión NDWMEs presenta un ángulo de contacto con el acero inoxidable AISI 316 inferior al presentado por la emulsión en agua del mismo líquido iónico una vez transcurridos 5 minutos. Excepto en este caso, la adición de nanodiamantes no varía significativamente el ángulo de contacto sobre el acero inoxidable. Sigue siendo la dispersión que contiene DEs la que presenta un mayor ángulo de contacto que el resto.

Se ha determinado el valor de la tensión superficial de las emulsiones y dispersiones de estos líquidos iónicos. Como se muestra en la Tabla 28, al añadir la nanofase en todos los casos la tensión superficial disminuye. Las dispersiones que contienen DPa son también las que presentan un valor inferior de tensión superficial y las de MEs las que presentan un valor superior. 
Tabla 28. Tensión superficial de WDEs, WMEs, WDPa, NDWDEs, NDWMEs y NDWDPa

\begin{tabular}{|c|c|c|c|}
\hline Lubricante & $\begin{array}{c}\text { Tensión } \\
\text { superficial } \\
\text { (mN/m) }\end{array}$ & Lubricante & $\begin{array}{c}\text { Tensión } \\
\text { superficial } \\
\text { (mN/m) }\end{array}$ \\
\hline WDEs & $\begin{array}{c}55,1 \\
( \pm 1,2)\end{array}$ & NDWDEs & $\begin{array}{c}51,8 \\
( \pm 2,4)\end{array}$ \\
\hline WMEs & $\begin{array}{c}69,9 \\
( \pm 0,9)\end{array}$ & NDWMEs & $\begin{array}{c}67,1 \\
( \pm 1,3)\end{array}$ \\
\hline WDPa & $\begin{array}{c}34,8 \\
( \pm 1,9)\end{array}$ & NDWDPa & $\begin{array}{c}30,8 \\
( \pm 0,3)\end{array}$ \\
\hline
\end{tabular}

\subsubsection{Medidas del tamaño de partícula.}

Se han realizado medidas mediante la técnica de dispersión dinámica de luz (DLS) con el objetivo de determinar si la adición de nanodiamantes supone la modificación del tamaño de las partículas de la emulsión de WDPa. Además, se ha estudiado si el tiempo transcurrido influye en el diámetro medio aparente de las micelas. Como se indicaba en el apartado 3.2.2.11, el equipo proporciona información del tamaño mediante tres tipos de distribución, en intensidad, en número o en volumen.

La distribución en intensidad es sensible a la presencia de grandes partículas. En cambio, la distribución en número muestra la presencia de partículas pequeñas, mientras que la distribución en volumen indica la porción de masa de la muestra que presenta cada tipo de estructura [293]. Se ha considerado que la distribución en volumen proporciona una información más global de la distribución del tamaño de las micelas, por tanto, a continuación se representan los resultados obtenidos en este tipo de distribución. 
En la Figura 106 se muestra el diámetro medio de las partículas de una dispersión de $0,1 \%$ en peso de nanodiamantes en agua. Se observa cómo la dispersión es estable, es decir, no se produce apenas variación del valor del diámetro de las partículas con el tiempo, pasando de un diámetro aparente de $15,3 \mathrm{~nm}(14,4 \%)$ a $13 \mathrm{~nm}(14,4 \%)$ una vez transcurridas 24 horas.

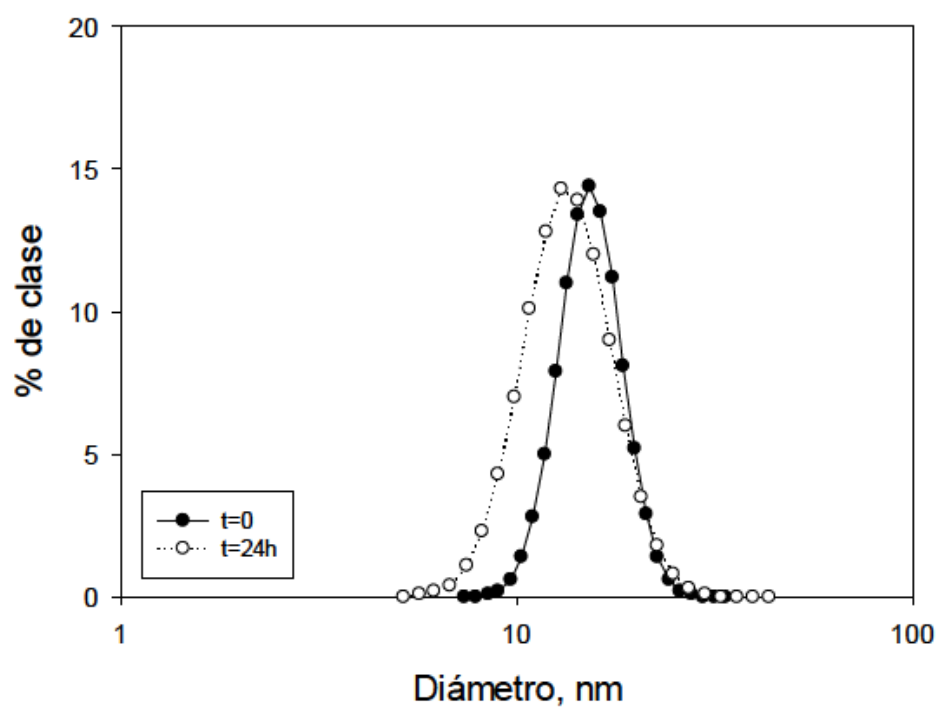

Figura 106. Diámetro de las partículas de nanodiamantes en agua

En el caso de la emulsión WDPa, se observan mayores diferencias en el diámetro de las partículas con el tiempo transcurrido desde su sonicación (Figura 107). Se observa un elevado porcentaje (13,5\%) de partículas con un diámetro de 10,2 nm tras la sonicación. Sin embargo, transcurridas 24 horas, se observa la presencia de partículas con diámetro aparente de $12,8 \mathrm{~nm}(9,7 \%)$ y otras de mayor tamaño, de $532,9 \mathrm{~nm}(5,6 \%)$ y $2366,3 \mathrm{~nm}(5,4 \%)$, debido a la formación de agregados, lo que podría corresponderse con la formación de micelas de las moléculas de líquido iónico en agua. 


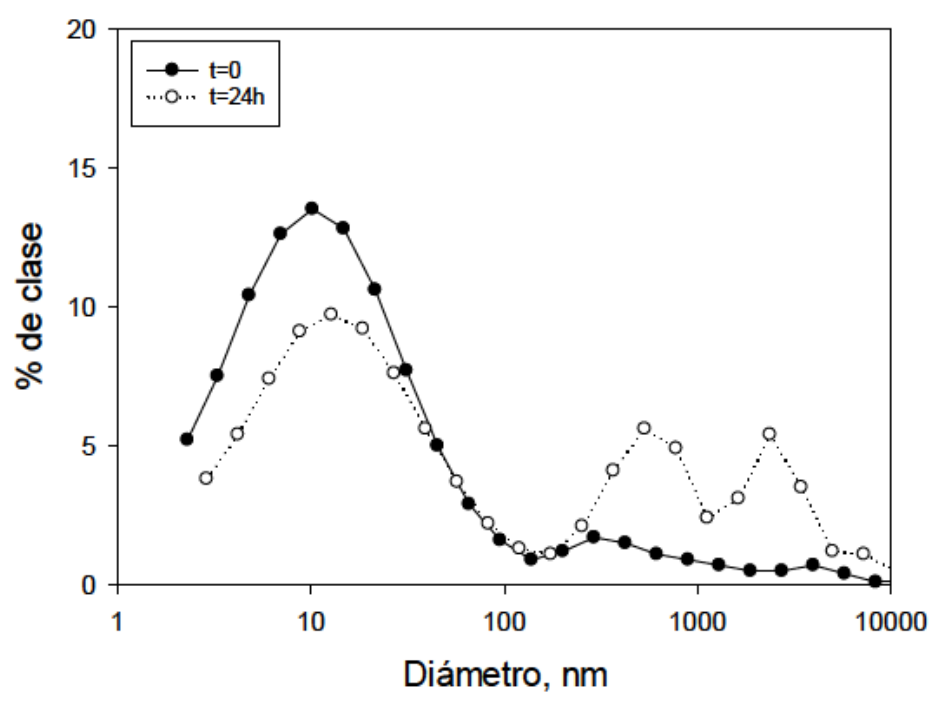

Figura 107. Diámetro de las partículas de la emulsión WDPa

En la Figura 108 se observa el diámetro de las partículas de la dispersión de $0,1 \%$ en peso de nanodiamantes en la emulsión al $1 \%$ del líquido iónico $\mathrm{DPa}$ en agua (NDWDPa).

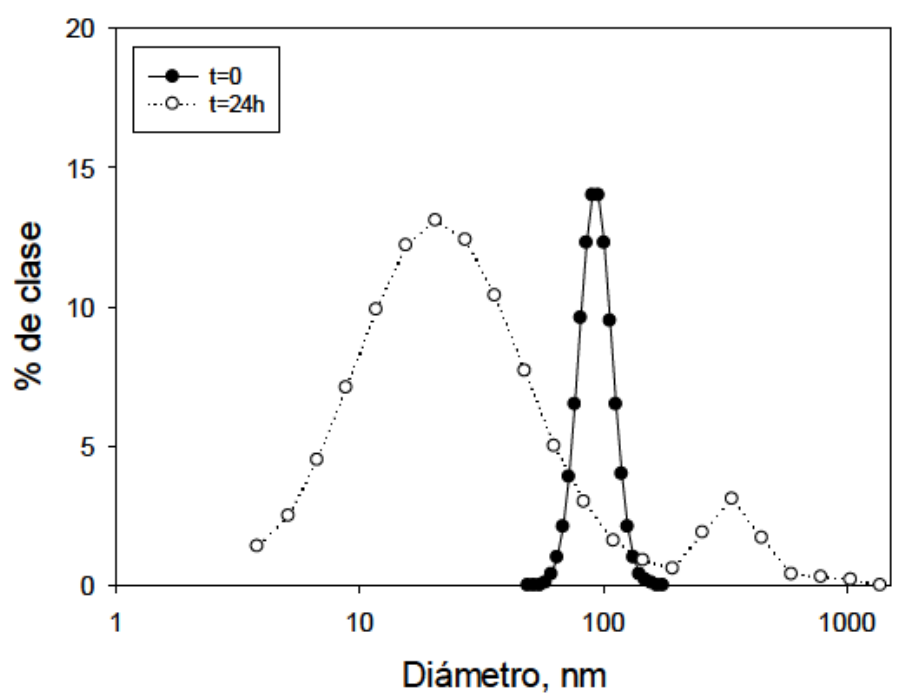

Figura 108. Diámetro de las partículas de la emulsión NDWDPa

Cuando la muestra está recién sonicada $(t=0)$, las partículas de la dispersión presentan un tamaño homogéneo y superior al que presentan la nanofase y el líquido iónico por separado, siendo de 92,8 nm (14\%). Este pico se corresponde con la presencia de agregados y puede ser debido a las interacciones entre las moléculas de DPa y los nanodiamantes. Sin embargo, tras 24 horas, hay mayor dispersión de los datos, observándose partículas de pequeño tamaño $(20,5 \mathrm{~nm}, 13,1 \%)$ y aglomerados más grandes $(338,3 \mathrm{~nm}$, 
$3,1 \%)$. Por tanto, la muestra se hace más heterogénea, coexistiendo pequeñas nanopartículas con grandes agregados.

\subsubsection{Estudio tribológico}

\subsection{Medidas para la determinación del espesor de película lubricante y el coeficiente de fricción}

La interferometría óptica de película ultrafina es una técnica que permite determinar la formación de películas lubricantes a partir de la separación óptica entre una bola de acero AISI 52100 con movimiento rotatorio alternativo y un plato de vidrio recubierto de una capa de alúmina y otra de cobre sobre el cual se coloca el lubricante.

Se ha medido el espesor de película del agua de las emulsiones de un $1 \%$ de líquidos iónicos DEs, MEs y DPa en agua, así como para el nanolubricante obtenido a partir de la dispersión de un $0,1 \%$ de nanodiamantes en la emulsión de DPa (NDWDPa) (Tabla 29).

Tabla 29. Valores de espesor de película obtenidos mediante interferometría óptica de película ultrafina

\begin{tabular}{cccccc}
\hline \multicolumn{7}{c}{ Espesor de película $(\mathbf{n m})$} & & \\
\hline $\begin{array}{c}\text { Número de } \\
\text { deslizamientos (N) }\end{array}$ & Agua & WMEs & WDEs & WDPa & NDWDPa \\
\hline $\mathbf{0}$ & $-21,705$ & $-5,051$ & $-0,627$ & $-5,427$ & 6,332 \\
\hline $\mathbf{1}$ & $-41,442$ & $-17,075$ & 15,362 & $-3,333$ & 12,890 \\
\hline $\mathbf{2}$ & $-62,000$ & $-17,737$ & 27,844 & 7,824 & 4,319 \\
\hline $\mathbf{3}$ & $-76,109$ & $-10,275$ & 27,848 & 19,688 & 10,092 \\
\hline $\mathbf{4}$ & $-95,860$ & $-16,243$ & 35,415 & 13,237 & 10,439 \\
\hline $\mathbf{5}$ & $-116,784$ & $-13,424$ & 39,988 & 32,158 & 20,266 \\
\hline $\mathbf{6}$ & $-128,989$ & $-15,731$ & 37,872 & 25,967 & 21,005 \\
\hline $\mathbf{7}$ & $-158,219$ & $-12,549$ & 44,259 & 18,999 & 23,262 \\
\hline $\mathbf{8}$ & $-191,621$ & $-15,266$ & 42,822 & 9,808 & 23,705 \\
\hline $\mathbf{9}$ & $-229,763$ & $-12,738$ & 46,257 & 32,820 & 24,265 \\
\hline $\mathbf{1 0}$ & $-267,780$ & $-14,566$ & 46,540 & 13,121 & 28,157 \\
\hline
\end{tabular}

En la lubricación con agua (Figura 109), se observa que se produce desgaste, es decir, el espesor de la película presenta un valor negativo que se incrementa, en valor absoluto, con el número de deslizamientos $(\mathrm{N})$. 


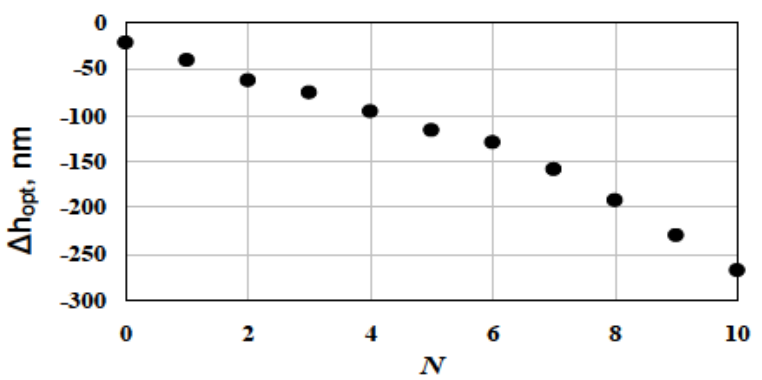

Figura 109. Evolución del espesor de película $\left(\Delta \mathrm{h}_{\mathrm{opt}}\right)$ con el número de deslizamientos empleando agua como lubricante

La emulsión de WMEs sigue presentando un valor de espesor de película inferior a 0, por lo que no se forma película lubricante (Tabla 29 y Figura 110). Los valores de espesor obtenidos están entre $-5,051$ y $-17,737 \mathrm{~nm}$, pero sin presentar una relación directa con el número de deslizamientos.

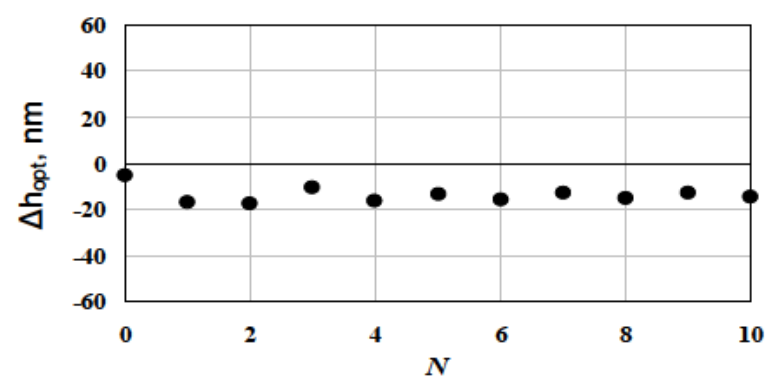

Figura 110. Evolución del espesor de película $\left(\Delta \mathrm{h}_{\mathrm{opt}}\right)$ con el número de deslizamientos empleando WMEs como lubricante

EI WDEs (Figura 111) muestra una separación eficaz de las superficies, con valores de espesor de película positivos, los cuales se incrementan con el número de deslizamientos.

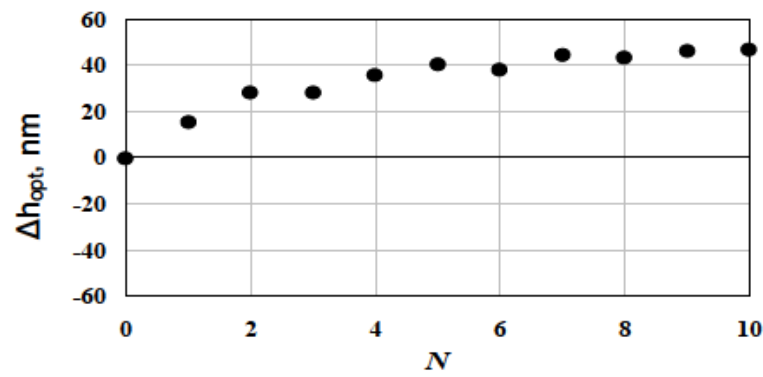

Figura 111. Evolución del espesor de película $\left(\Delta \mathrm{h}_{\mathrm{opt}}\right)$ con el número de deslizamientos empleando WDEs como lubricante 
En el caso de emplear el mismo catión (bis[(2-hidroxietil)amonio], la sustitución del anión estearato por el palmitato hace que el lubricante WDPa presente una mayor dispersión de los valores de espesor de película (Figura 112 y Tabla 29), con valores mayores que 0 desde $\mathrm{N}=2$, pero con valores de espesor de película más bajos que los obtenidos para el estearato diprótico DEs.

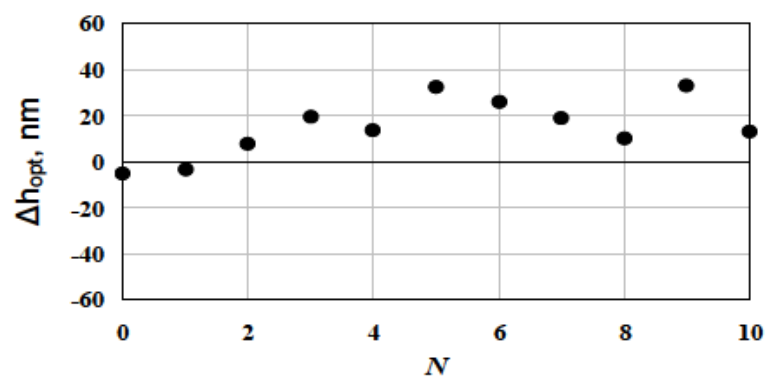

Figura 112. Evolución del espesor de película ( $\Delta$ hopt) con el número de deslizamientos empleando WDPa como lubricante

La adición de un $0,1 \%$ de nanodiamantes a la emulsión WDPa (Figura 113) (NDWDPa) muestra un espesor de película positivo, con un incremento de la pendiente desde $\mathrm{N}=2$ hasta $\mathrm{N}=10$.

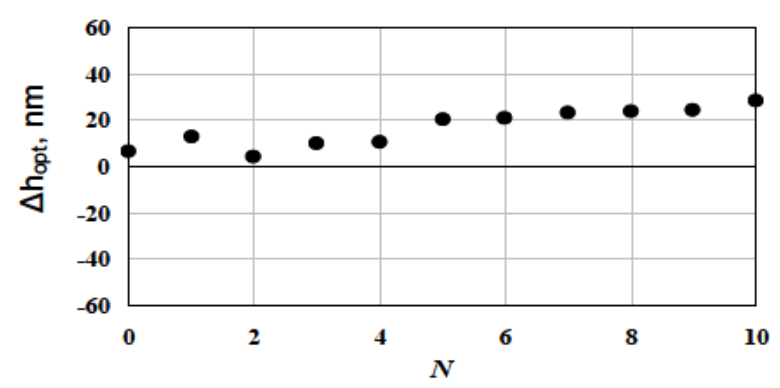

Figura 113. Evolución del espesor de película ( $\Delta$ hopt) con el número de deslizamientos empleando NDWDPa como lubricante

Comparando el comportamiento de los dos aditivos dipróticos, DEs y DPa, se puede observar que el átomo de carbono adicional en la cadena alquílica del estearato incrementa el espesor de película lubricante con respecto al palmitato. Para el mismo anión estearato, sólo se logra una lubricación efectiva para el catión diprótico bis[(2-hidroxietil)amonio], mientras que la emulsión WMEs no es capaz de separar las superficies en deslizamiento, como podía preverse debido a su baja viscosidad. 
También se han medido los coeficientes de fricción en función del número de deslizamientos en el interferómetro de película ultrafina (apartado 3.2.2.13), cuyos resultados se indican en la Tabla 30 .

Tabla 30. Valores de coeficiente de fricción obtenidos mediante interferometría óptica de película ultrafina para agua, WMEs, WDEs, WDPa y NDWDPa

\begin{tabular}{cccccc}
\hline \multicolumn{6}{c}{ Coeficientes de fricción } \\
\hline $\begin{array}{c}\text { Número de } \\
\text { deslizamientos } \\
\text { (N) }\end{array}$ & Agua & WMEs & WDEs & WDPa & NDWDPa \\
\hline $\mathbf{2}$ & 0,462 & 0,202 & 0,198 & 0,152 & 0,091 \\
\hline $\mathbf{4}$ & 0,497 & 0,151 & 0,194 & 0,134 & 0,136 \\
\hline $\mathbf{6}$ & 0,599 & 0,151 & 0,187 & 0,111 & 0,170 \\
\hline $\mathbf{8}$ & 0,710 & 0,155 & 0,185 & 0,097 & 0,163 \\
\hline $\mathbf{1 0}$ & 0,871 & 0,156 & 0,184 & 0,094 & 0,150 \\
\hline
\end{tabular}

Con respecto al coeficiente de fricción, el agua (Figura 114) presenta mayores valores según aumenta el número de deslizamientos, desde 0,462 hasta 0,871.

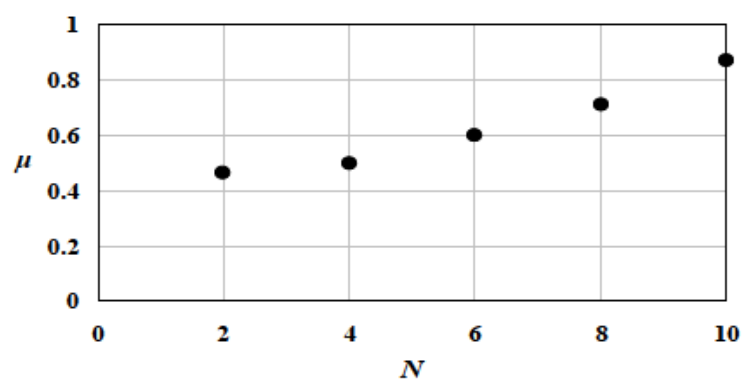

Figura 114. Evolución del coeficiente de fricción con el número de deslizamientos empleando agua como lubricante

WMEs presenta un valor inicial de coeficiente de fricción de 0,2 , sin embargo, se alcanza un valor de coeficiente de fricción constante de 0,15 desde $\mathrm{N}=4$ a $\mathrm{N}=10$ (Figura 115 y Tabla 30).

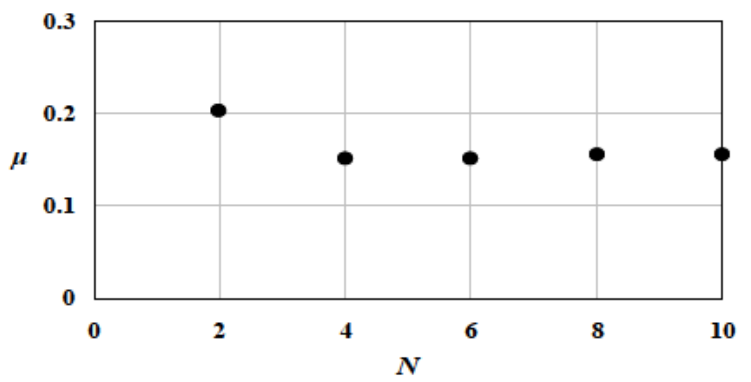

Figura 115. Evolución del coeficiente de fricción con el número de deslizamientos empleando WMEs como lubricante 
La adición de un $1 \%$ en peso de DEs al agua disminuye el coeficiente de fricción a valores de 0,19-0,2 desde $\mathrm{N}=2$ a $\mathrm{N}=10$ (Tabla 30 y Figura 116).

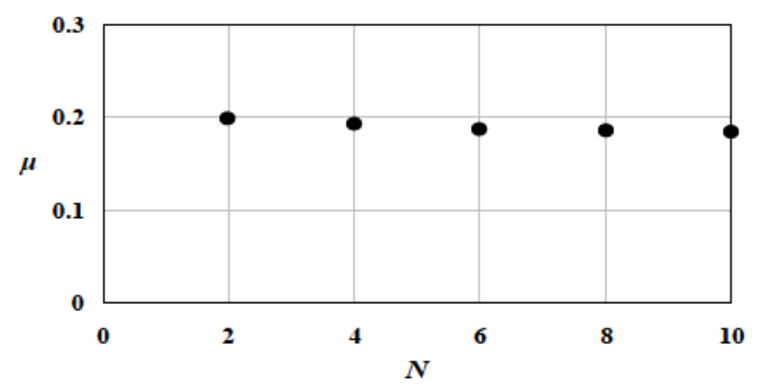

Figura 116. Evolución del coeficiente de fricción con el número de deslizamientos empleando WDEs como lubricante

El DPa es el único aditivo capaz de reducir la fricción para cada ciclo de carga, desde 0,15 en el primer ciclo de carga hasta 0,094 para N=10 (Figura 112).

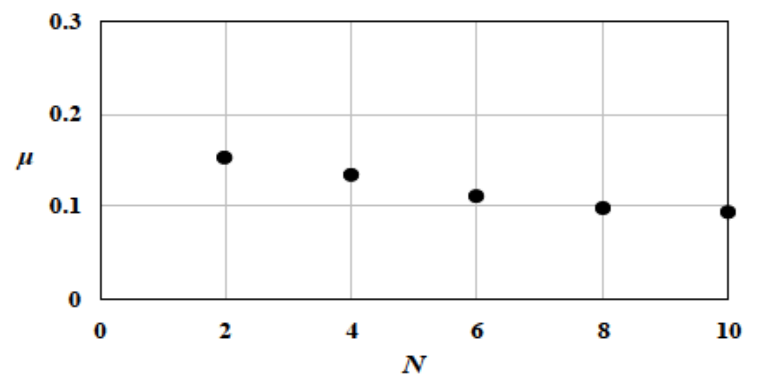

Figura 117. Evolución del coeficiente de fricción con el número de deslizamientos empleando WDPa como lubricante

Al añadir un $0,1 \%$ de nanodiamantes a la emulsión WDPa, se observa una importante reducción del coeficiente de fricción. En este caso, se ha obtenido un valor de coeficiente de fricción de 0,091, el más bajo de los observados para los lubricantes estudiados. Sin embargo, esta reducción sólo se observa para el primer deslizamiento, alcanzando una fricción muy alta $(0,17)$ para $\mathrm{N}=6$ (Figura 118 y Tabla 30).

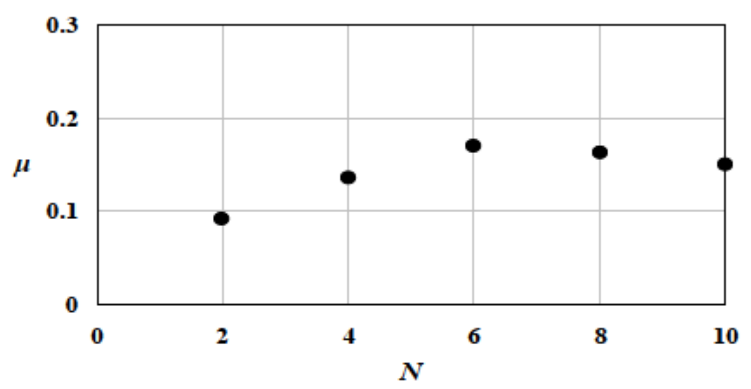

Figura 118. Evolución del coeficiente de fricción con el número de deslizamientos empleando NDWDPa como lubricante 
La Figura 119 resume el comportamiento de los lubricantes estudiados. La fuerte influencia prácticamente lineal con el número de deslizamientos que se observa para el agua, no la presentan el resto de aditivos. Las emulsiones que poseen líquidos iónicos con cationes amónicos dipróticos (WDEs, WDPa y NDWDPa) presentan un mejor comportamiento lubricante que el que posee un catión amónico triprótico.

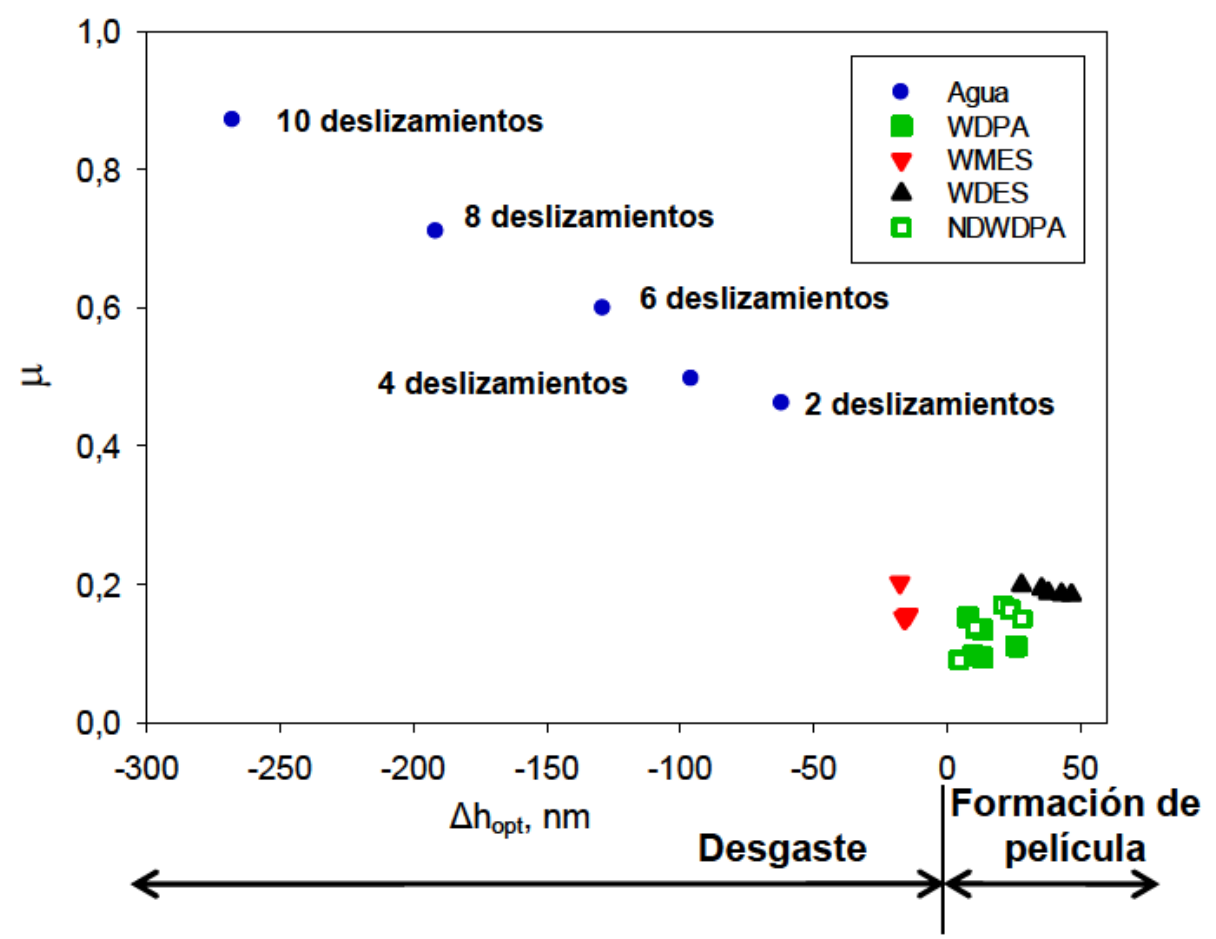

Figura 119. Evolución del coeficiente de fricción y del espesor de película para agua, WDEs, WMEs, WDPa y NDWDPa.

\subsection{Estudio de la influencia de la velocidad de giro}

Se ha estudiado la evolución del coeficiente de fricción con respecto a la velocidad de giro con el fin de determinar la región de lubricación elastohidrodinámica o mixta, en la que la deformación elástica de las asperezas y la resistencia del lubricante soportan la carga. En esta región, se obtienen los valores más bajos de fricción y desgaste.

El tribómetro UMT-TriboLab de Bruker ha sido el equipo en el que se han realizado los ensayos, bajo la configuración punzón sobre disco manteniendo la carga constante y variando la velocidad de giro.

Además, se estudiaron tres contactos diferentes sobre discos de acero inoxidable AISI 316L: con una bola de acero AISI 52100, una bola de acero 316L y una bola de zafiro. Estas curvas se han obtenido para el agua, así como 
para las emulsiones de los líquidos iónicos de MEs, DEs, DPa en agua y la dispersión de 0,1\% de nanodiamantes en la emulsión de DPa. Se ha calculado la tasa de desgaste tras estos ensayos en función de la anchura de la huella de desgaste(apartado 3.3.1.9.2).

4.1.1.3.2.1. Comparativa de la evolución del coeficiente de fricción con la velocidad en el contacto AISI 316L-AISI 316L

Los valores de coeficiente de fricción y porcentaje de resistencia eléctrica en el contacto a velocidades de giro variables (Tabla 14 y Tabla 17), se presentan en la Tabla 31, correspondientes al contacto metálico, bola de AISI 316 frente disco del mismo material $\left(P_{\max }=1,51 \mathrm{GPa}\right.$ y $\left.\mathrm{P}_{\text {med }}=1,01 \mathrm{GPa}\right)$.

Tabla 31. Valores de coeficiente de fricción y porcentaje de resistencia eléctrica en el contacto AISI 316L-AISI 316L

\begin{tabular}{cccccccccc}
\hline & \multicolumn{3}{c}{ Coeficiente de Fricción } & \multicolumn{5}{c}{ \% Resistencia eléctrica en el contacto } \\
\hline Agua & WMEs & WDEs & WDPa & NDWDPa & Agua & WMEs & WDEs & WDPa & NDWDPa \\
\hline- & 0,11 & 0,12 & 0,10 & 0,10 & - & 37,15 & 50,47 & 40,44 & 36,01 \\
\hline 0,32 & 0,11 & 0,11 & 0,10 & 0,10 & 64,61 & 41,15 & 58,14 & 51,42 & 43,79 \\
\hline 0,31 & 0,10 & 0,11 & 0,10 & 0,10 & 47,15 & 41,34 & 44,83 & 41,59 & 44,02 \\
\hline 0,44 & 0,10 & 0,11 & 0,10 & 0,10 & 18,25 & 24,53 & 25,14 & 23,46 & 25,84 \\
\hline 0,47 & 0,10 & 0,10 & 0,10 & 0,10 & 11,13 & 20,38 & 20,54 & 18,34 & 18,60 \\
\hline 0,45 & 0,10 & 0,10 & 0,10 & 0,10 & 10,41 & 17,04 & 18,34 & 11,62 & 14,69 \\
\hline 0,45 & 0,10 & 0,10 & 0,10 & 0,10 & 9,36 & 10,41 & 13,82 & 8,53 & 11,33 \\
\hline 0,44 & 0,10 & 0,10 & 0,09 & 0,09 & 8,36 & 8,73 & 12,41 & 7,85 & 10,52 \\
\hline 0,44 & 0,09 & 0,09 & 0,09 & 0,09 & 8,42 & 8,55 & 12,90 & 7,21 & 10,16 \\
\hline 0,43 & 0,09 & 0,09 & 0,08 & 0,08 & 8,68 & 8,05 & 11,48 & 7,03 & 10,28 \\
\hline
\end{tabular}

La representación gráfica de los coeficientes de fricción, que poseen una desviación estándar inferior a 0,05 en el caso del agua, e inferior a 0,01 en el caso de las emulsiones, se muestra en la Figura 120. 


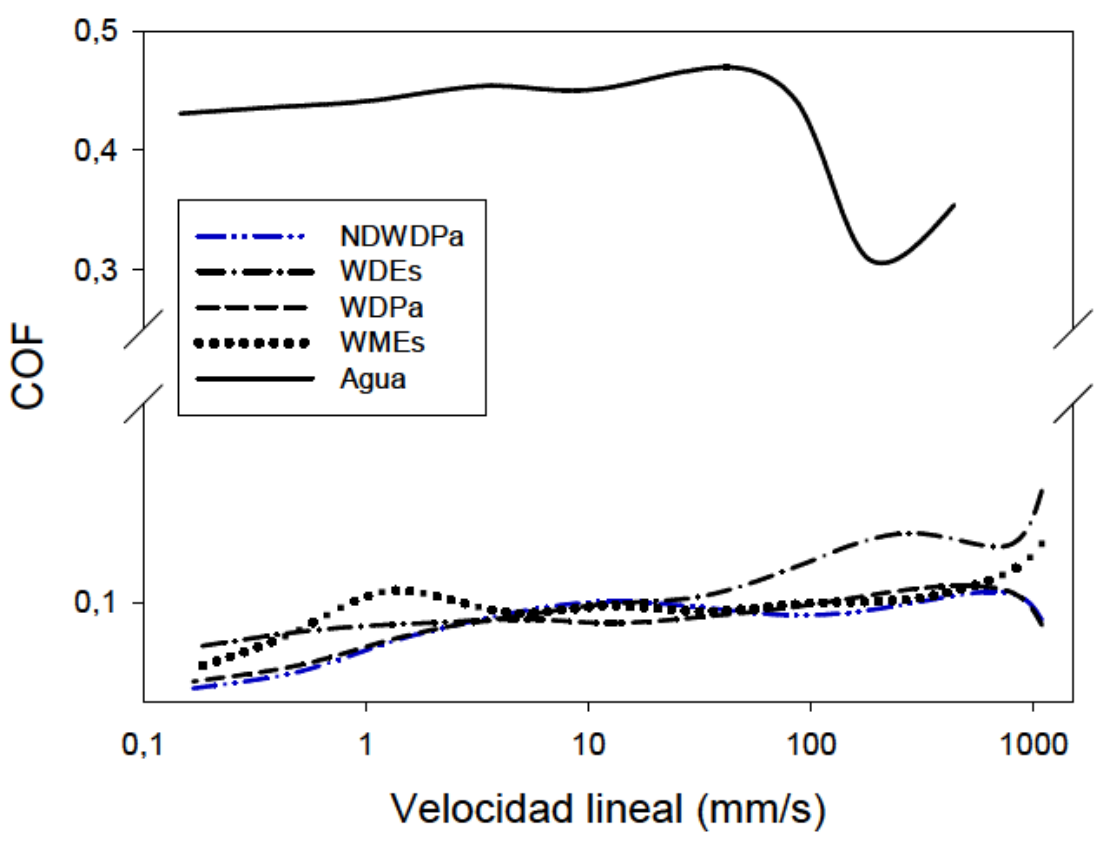

Figura 120. Curva COF vs. velocidad para agua, WMEs, WDEs, WDPa y NDWDPa en el contacto AISI 316L-AISI 316L

La curva COF vs. velocidad para el agua muestra una evolución constante del coeficiente de fricción con el aumento de la velocidad, con valores por encima de 0,4 . Sin embargo, para velocidades superiores a $100 \mathrm{~mm} / \mathrm{s}$ se produce una disminución significativa de la fricción.

Al emplear WDEs y WMEs se observa una tendencia ascendente del valor de del coeficiente de fricción con la velocidad de giro, presentando valores superiores a 0,1 a la máxima velocidad estudiada. EI WDPa y la dispersión con nanodiamantes presentan a su vez el mismo comportamiento, los coeficientes de fricción se incrementan desde 0,08 a baja velocidad hasta 0,1 a velocidades superiores a $100 \mathrm{~mm} / \mathrm{s}$.

La Figura 121 muestra la evolución del porcentaje de resistencia eléctrica en el contacto para todos los lubricantes estudiados en el par acero AISI 316L-AISI 316L. A velocidades bajas, el contacto eléctrico es elevado debido al rozamiento directo entre las asperezas superficiales, indicativo del régimen de lubricación límite y por tanto la resistencia eléctrica es baja. Al aumentar la velocidad por encima de $100 \mathrm{~mm} / \mathrm{s}$ se produce un incremento de la resistencia, así que, existe una mayor separación entre los materiales. Esta transición se observa claramente para el agua (Figura 121a). 
María Dolores Avilés González

Universidad Politécnica de Cartagena

a)

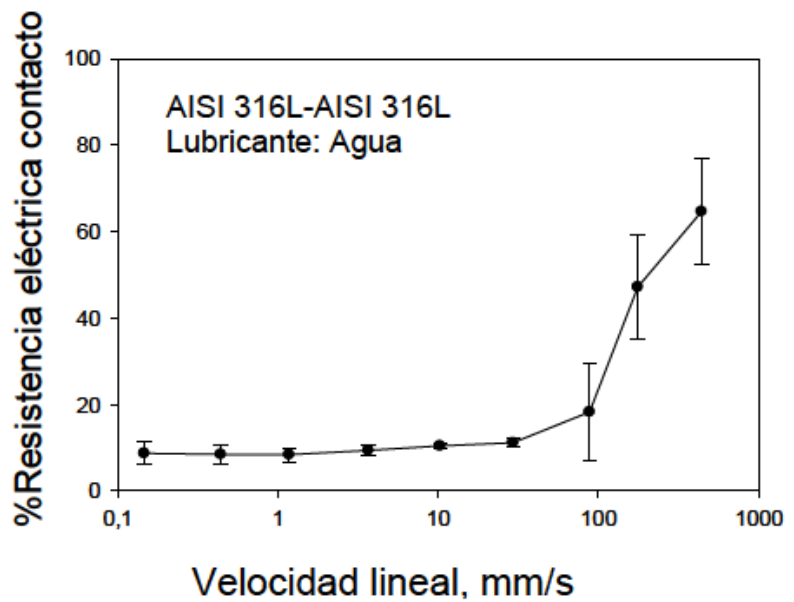

c)

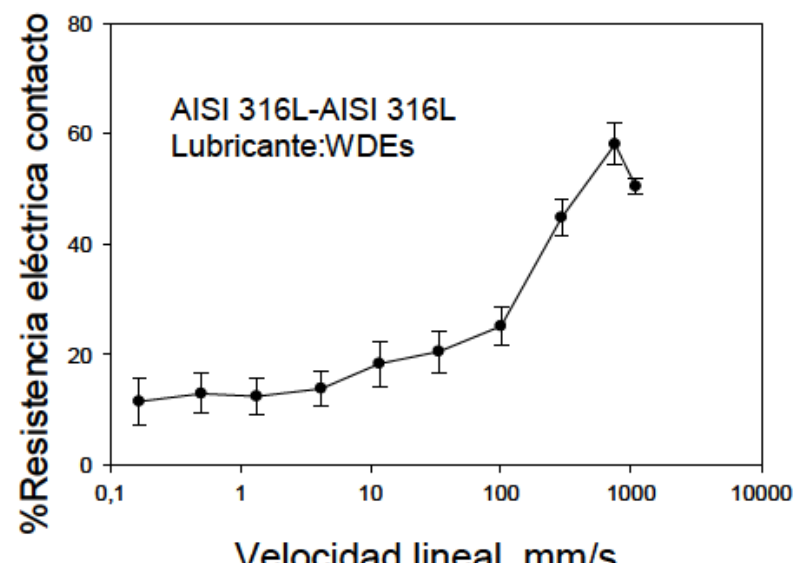

Velocidad lineal, $\mathrm{mm} / \mathrm{s}$

b)

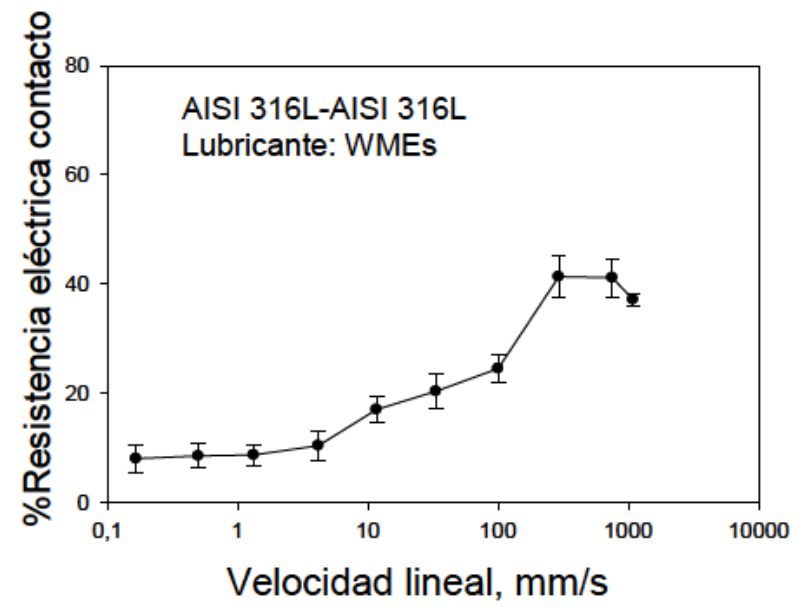

d)

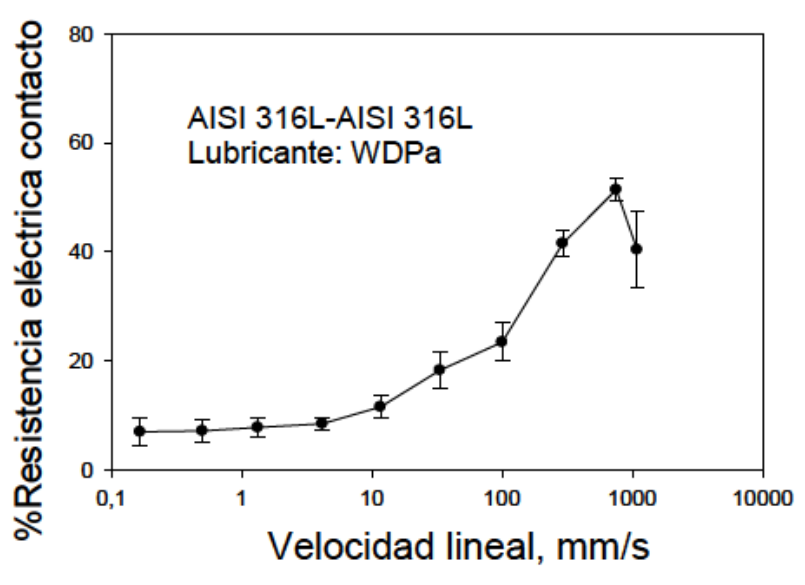

e)

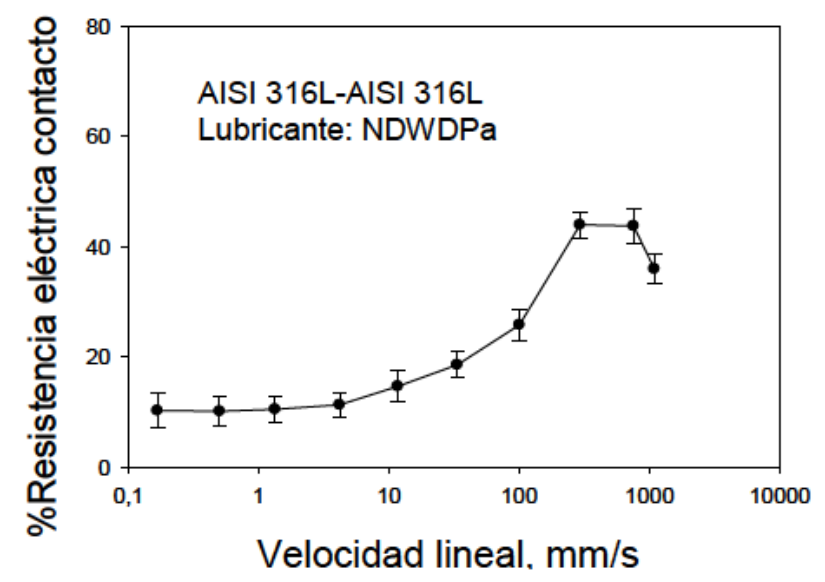

Figura 121. Porcentaje de resistencia eléctrica en el contacto AISI 316L-AISI 316L: a) Agua;

b) WMEs; c) WDEs; d) WDPa; e) NDWDPa 
El empleo de los nuevos lubricantes con líquidos iónicos próticos derivados de ácidos grasos supone una reducción del porcentaje de resistencia eléctrica a alta velocidad con respecto al agua en el contacto AISI 316L-AISI 316L. El valor final más bajo de resistencia eléctrica a alta velocidad en todo el rango de velocidades estudiadas lo presenta la dispersión NDWDPa. Estos resultados pueden asociarse a la alta conductividad eléctrica y la baja viscosidad de esta dispersión, lo que podría dar lugar a capas lubricantes más delgadas y más conductoras.

4.1.1.3.2.2. Comparativa de la evolución del coeficiente de fricción con la velocidad en el contacto AISI 52100-AISI 316L

Los resultados obtenidos en el caso de emplear bola de acero AISI 52100, un material de gran dureza, frente a discos de acero inoxidable AISI 316L $\left(P_{\max }=1,55 \mathrm{GPa}\right.$ y $P_{\text {med }}=1,03 \mathrm{GPa}$ ) empleando como lubricantes agua, las emulsiones en agua de los líquidos iónicos próticos y NDWDPa a velocidades de giro variables (Tabla 16 y Tabla 19), se muestran en la Tabla 32. Los valores presentan una desviación estándar inferior a 0,05 en el caso del agua e inferior a 0,01 para el resto de lubricantes y se representan en la Figura 122.

Tabla 32. Valores de coeficiente de fricción y porcentaje de resistencia eléctrica en el contacto AISI 52100-AISI 316L

\begin{tabular}{cccccccccc}
\hline \multicolumn{4}{c}{ Coeficiente de Fricción } & \multicolumn{5}{c}{$\%$ Resistencia eléctrica en el contacto } \\
\hline Agua & WMEs & WDEs & WDPa & NDWDPa & Agua & WMEs & WDEs & WDPa & NDWDPa \\
\hline- & 0,10 & 0,11 & 0,10 & 0,10 & - & 28,96 & 52,66 & 43,36 & 46,76 \\
\hline- & 0,11 & 0,12 & 0,11 & 0,10 & - & 35,66 & 53,75 & 42,96 & 46,84 \\
\hline 0,31 & 0,11 & 0,12 & 0,11 & 0,11 & 73,17 & 40,27 & 48,23 & 43,44 & 43,33 \\
\hline 0,34 & 0,10 & 0,11 & 0,10 & 0,11 & 61,83 & 30,99 & 23,07 & 23,60 & 20,86 \\
\hline 0,43 & 0,10 & 0,11 & 0,11 & 0,11 & 12,39 & 23,16 & 19,32 & 12,90 & 14,15 \\
\hline 0,42 & 0,10 & 0,10 & 0,11 & 0,10 & 10,08 & 17,18 & 18,05 & 10,25 & 11,56 \\
\hline 0,43 & 0,10 & 0,09 & 0,11 & 0,09 & 9,45 & 12,86 & 14,95 & 8,01 & 10,23 \\
\hline 0,44 & 0,09 & 0,09 & 0,11 & 0,09 & 8,53 & 10,72 & 13,20 & 7,43 & 9,86 \\
\hline 0,45 & 0,09 & 0,09 & 0,10 & 0,09 & 8,44 & 9,42 & 10,06 & 7,40 & 9,12 \\
\hline 0,46 & 0,09 & 0,08 & 0,10 & 0,08 & 8,76 & 8,20 & 14,17 & 7,69 & 8,85 \\
\hline
\end{tabular}

Cuando se emplea agua como lubricante, los coeficientes de fricción obtenidos son muy elevados, superiores a 0,4 cuando la velocidad de giro es inferior a $100 \mathrm{~mm} / \mathrm{s}$. Estos valores de fricción se ven reducidos notablemente al añadir un $1 \%$ de líquido iónico derivado de ácidos grasos. Cuando se emplea la 
emulsión de WDEs se observa una cierto aumento del coeficiente de fricción con la velocidad de giro, quizás debido a la mayor viscosidad que presenta este nanofluido. Sin embargo, ocurre lo contrario cuando se usa como lubricante la emulsión con el líquido iónico DPa. Al añadir nanodiamantes al WDPa, se logra la disminución de los valores del coeficiente de fricción a bajas velocidades.

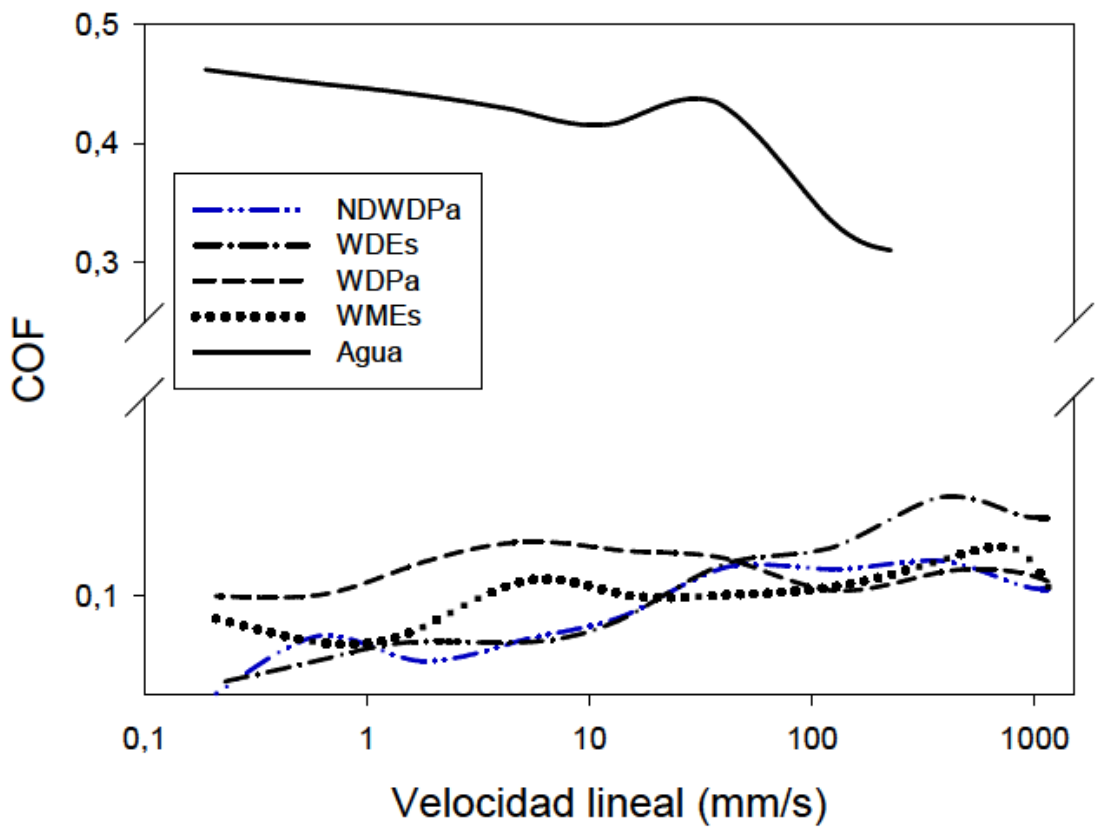

Figura 122. Curva COF vs. velocidad para agua, WMEs, WDEs, WDPa y NDWDPa en el contacto AISI 52100-AISI 316L

Además, se han obtenido los valores de resistencia eléctrica en el contacto que se presentan en la Figura 123. Como se puede observar de acuerdo con los valores de fricción obtenidos, el porcentaje de resistencia eléctrica (considerando que un $100 \%$ de resistencia eléctrica se corresponde con 1077,6 $\Omega$ ) aumenta a velocidades superiores a $100 \mathrm{~mm} / \mathrm{s}$. Por tanto, queda reflejado el cambio de régimen de lubricación, desde lubricación límite, en el que existe un contacto directo entre las asperezas y por tanto unos valores bajos de porcentaje de resistencia eléctrica hasta otro régimen en el que se logra una separación más efectiva de las superficies, por tanto, una mayor resistencia eléctrica en el contacto.

Todos las emulsiones presentan un aumento gradual del porcentaje de resistencia eléctrica con la velocidad, siendo los valores máximos encontrados inferiores a los que presenta el agua a alta velocidad. 
a)

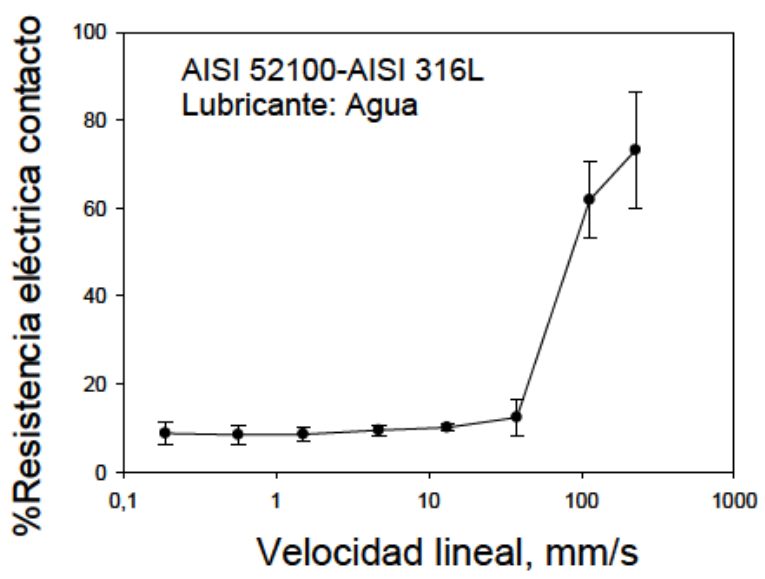

c)

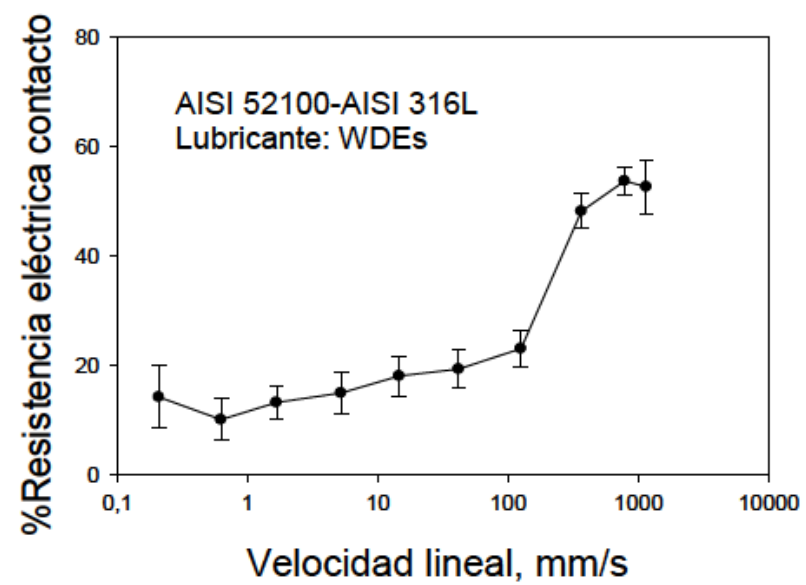

b)

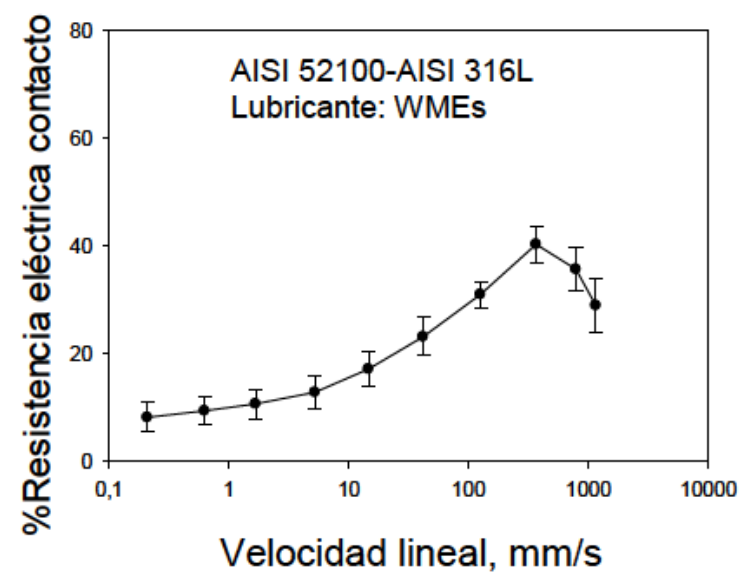

d)

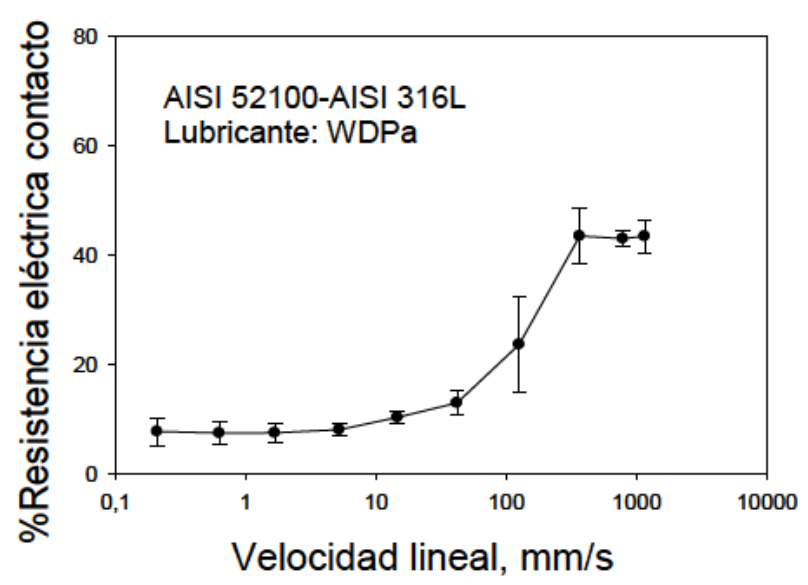

e)

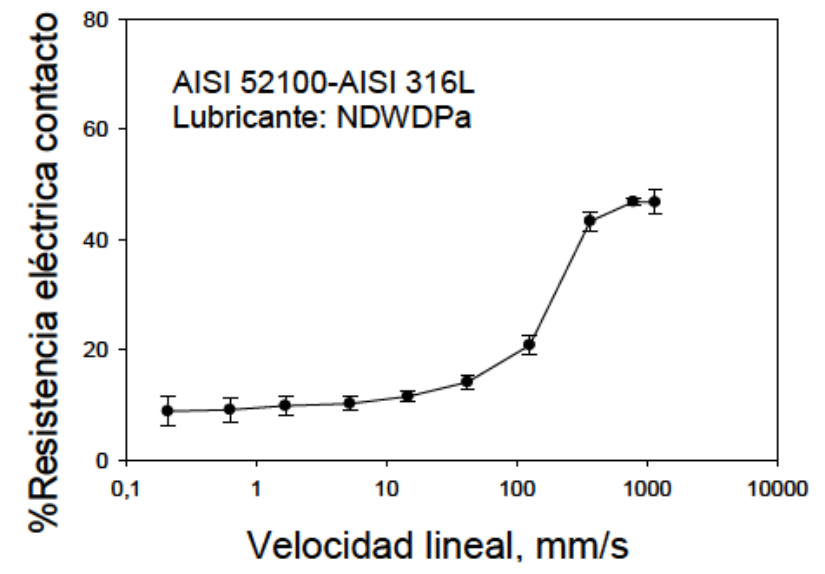

Figura 123. Porcentaje de resistencia eléctrica en el contacto AISI 52100-AISI 316L: a) Agua; b) WMEs; c) WDEs; d) WDPa; e) NDWDPa 
4.1.1.3.2.3. Comparativa de la evolución del coeficiente de fricción con la velocidad en el contacto zafiro-AISI 316L

En la Tabla 33 se muestran los valores de coeficiente de fricción obtenidos para el contacto zafiro-AISI 316 empleando como lubricantes agua, WDEs, WMEs, WDPa y NDWDPa a velocidades de giro variables (Tabla 15 y Tabla 18).

Tabla 33. Valores de coeficiente de fricción en el contacto zafiro-AISI 316L

\begin{tabular}{ccccc}
\hline \multicolumn{5}{c}{ Coeficientes de Fricción } \\
\hline Agua & WMEs & WDEs & WDPa & NDWDPa \\
\hline- & 0,11 & 0,14 & 0,08 & 0,09 \\
\hline- & 0,13 & 0,16 & 0,09 & 0,09 \\
\hline 0,50 & 0,13 & 0,15 & 0,10 & 0,10 \\
\hline 0,40 & 0,12 & 0,13 & 0,12 & 0,10 \\
\hline 0,35 & 0,11 & 0,12 & 0,12 & 0,10 \\
\hline 0,38 & 0,11 & 0,12 & 0,12 & 0,11 \\
\hline 0,39 & 0,11 & 0,11 & 0,12 & 0,11 \\
\hline 0,40 & 0,11 & 0,11 & 0,11 & 0,11 \\
\hline 0,41 & 0,10 & 0,10 & 0,12 & 0,10 \\
\hline 0,41 & 0,10 & 0,10 & 0,13 & 0,11 \\
\hline
\end{tabular}

Las curvas COF vs. velocidad en estas condiciones se muestran en la Figura 124.

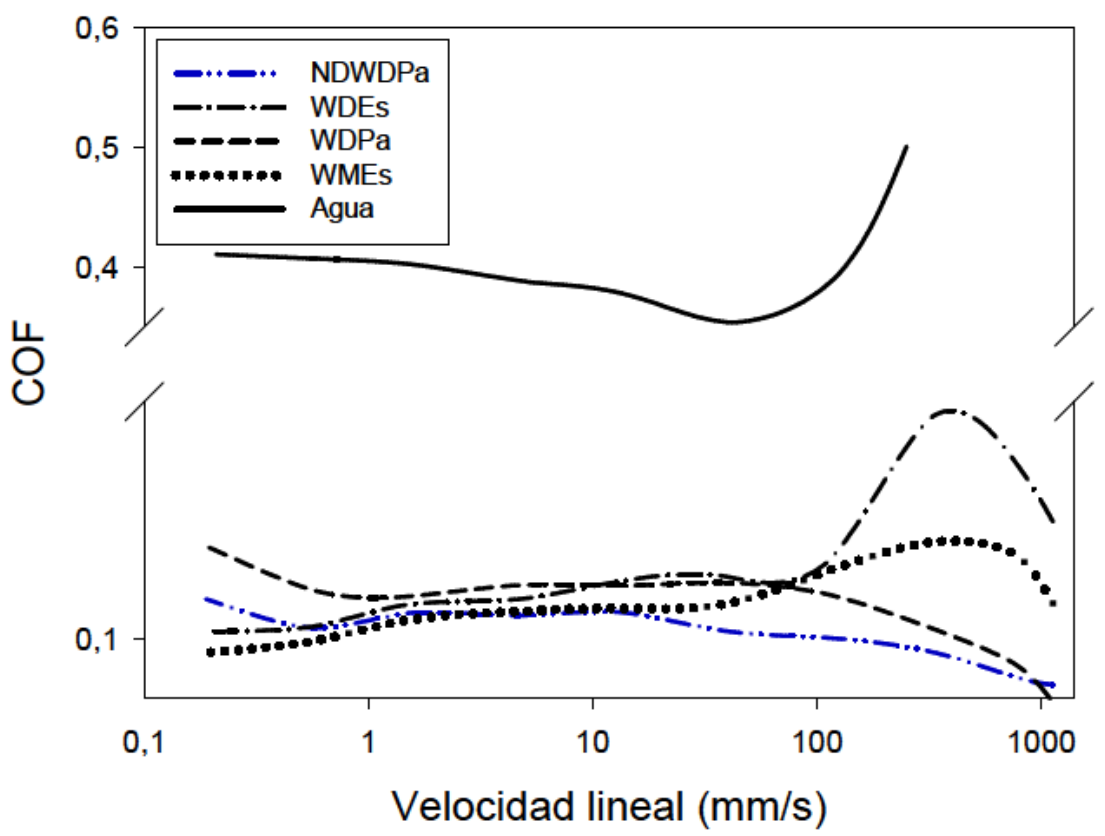

Figura 124. Curva COF vs. velocidad para agua, WMEs, WDEs, WDPa y NDWDPa en el contacto zafiro-AISI 316L 
En el caso del agua, a diferencia de los contactos metálicos, en el par zafiroAISI 316L se ha observado como los valores de los coeficientes de fricción aumentan conforme aumenta la velocidad de giro, presentando un valor de 0,5 en el caso de la velocidad más alta.

Se puede observar como la adición de un $1 \%$ de líquido iónico supone una importante reducción del coeficiente de fricción para todas las velocidades estudiadas. A bajas velocidades de giro el comportamiento de las tres emulsiones es similar, con valores del coeficiente de fricción en torno a 0,1 . Sin embargo, cuando la velocidad supera los $100 \mathrm{~mm} / \mathrm{s}$, se observan diferentes comportamientos según el tipo de líquido iónico presente en la emulsión. Se obtienen coeficientes de fricción más elevados para el lubricante WDEs. La dispersión con nanodiamantes (NDWDPa) presenta una tendencia similar a la que presenta la emulsión del líquido iónico DPa, aunque los coeficientes de fricción son inferiores.

4.1.1.3.2.4. Estudio de las huellas de desgaste, mecanismos de desgaste y análisis superficial

Como se ha comentado con anterioridad, la tasa de desgaste se ha calculado a partir de la medida de anchura de huella, según la norma ASTM G99-17. Los resultados se muestran en la Tabla 34.

Tabla 34. Tasas de desgaste $\left(\mathrm{mm}^{3} / \mathrm{N} \cdot \mathrm{m}\right)$ de los discos de AISI $316 \mathrm{~L}$ en función de los lubricantes y los contactos empleados.

\begin{tabular}{cccccc}
\hline \multirow{2}{*}{ Bola } & \multicolumn{5}{c}{ Lubricante } \\
\cline { 2 - 6 } & Agua & WMEs & WDEs & WDPa & NDWDPa \\
\hline \multirow{2}{*}{ AISI 316L } & $1,42 \times 10^{-2}$ & $2,79 \times 10^{-4}$ & $1,07 \times 10^{-4}$ & $1,45 \times 10^{-4}$ & $5,07 \times 10^{-5}$ \\
& $\left( \pm 4 \times 10^{-4}\right)$ & $\left( \pm 7 \times 10^{-6}\right)$ & $\left( \pm 4 \times 10^{-6}\right)$ & $\left( \pm 5 \times 10^{-6}\right)$ & $\left( \pm 1,5 \times 10^{-6}\right)$ \\
\hline \multirow{2}{*}{ AISI } & $4,31 \times 10^{-3}$ & $2,43 \times 10^{-4}$ & $1,09 \times 10^{-4}$ & $3,41 \times 10^{-4}$ & $2,11 \times 10^{-4}$ \\
52100 & $\left( \pm 5,3 \times 10^{-4}\right)$ & $\left( \pm 1,1 \times 10^{-5}\right)$ & $\left( \pm 3 \times 10^{-6}\right)$ & $\left( \pm 1,1 \times 10^{-5}\right)$ & $\left( \pm 7 \times 10^{-6}\right)$ \\
\hline \multirow{2}{*}{ Zafiro } & $9,42 \times 10^{-3}$ & $4,80 \times 10^{-4}$ & $7,36 \times 10^{-4}$ & $3,64 \times 10^{-4}$ & $2,04 \times 10^{-4}$ \\
& $\left( \pm 5,9 \times 10^{-4}\right)$ & $\left( \pm 1,3 \times 10^{-5}\right)$ & $\left( \pm 1,8 \times 10^{-5}\right)$ & $\left( \pm 3 \times 10^{-6}\right)$ & $\left( \pm 5 \times 10^{-7}\right)$ \\
\hline
\end{tabular}

Como se puede observar, para la lubricación con agua, las tasas de desgaste se incrementan con el aumento de las presiones de contacto, desde el empleo de una bola de acero hasta la bola de zafiro. El mayor valor de la tasa de desgaste, calculada a partir de la anchura de la huella, se obtiene en el contacto de acero inoxidable-acero inoxidable. Aunque la micrografía SEM 
(Figura 125a) muestra una huella de desgaste más ancha que las observadas para las bolas de AISI 52100 y zafiro (Figura 125 b y c), la topografía superficial de la bola de AISI 316L tras el ensayo indica la existencia de una tribocapa que cubre la huella de desgaste (Figura 126 a).

a)

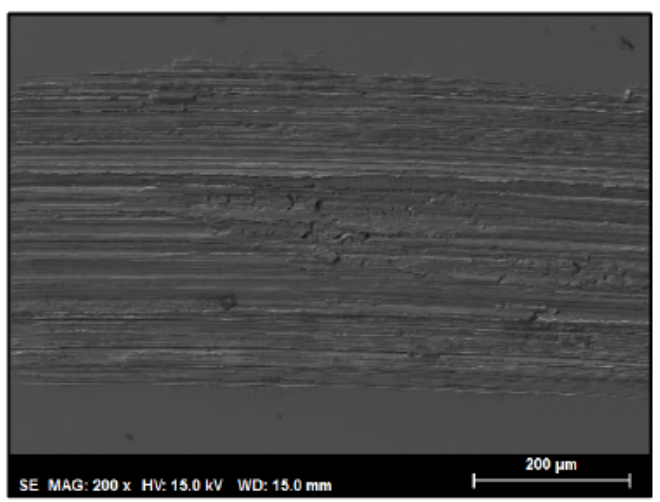

b)

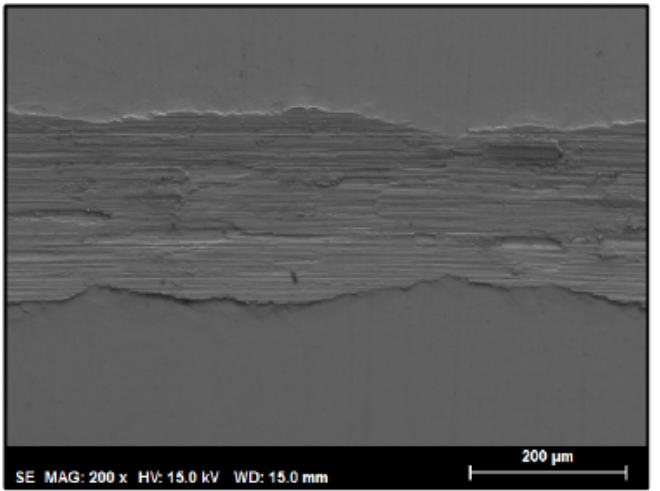

c)

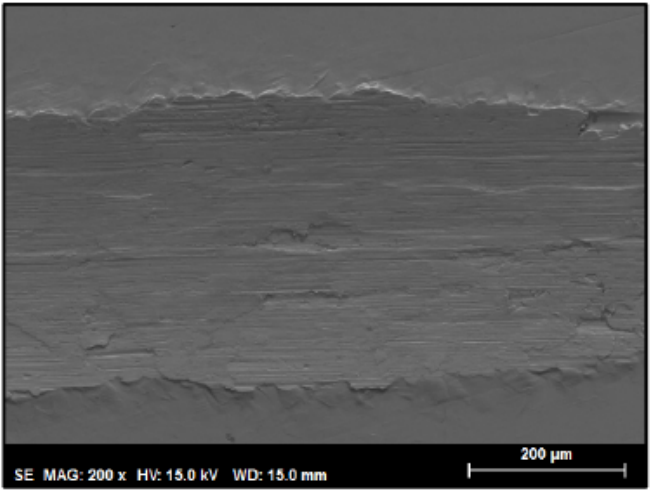

Figura 125. Micrografías SEM de la huella de desgaste empleando agua como lubricante en los contactos: a) AISI 316L-AISI 316L; b) AISI 52100-AISI 316L; c) Zafiro-AISI 316L

Como se muestra con detalle en la Figura 126b, la sección transversal de la huella obtenida tras la lubricación con agua en el contacto acero inoxidableacero inoxidable indica la formación de una tribocapa de material por encima de la línea base. De hecho, si se calcula el volumen de desgaste como la diferencia entre el volumen perdido por debajo de la línea base $\left(V_{1}\right)$ y el volumen acumulado por encima de la línea base $\left(V_{2}\right)$, tanto en el centro, como en los extremos de la huella, el resultado sería negativo. 
a)

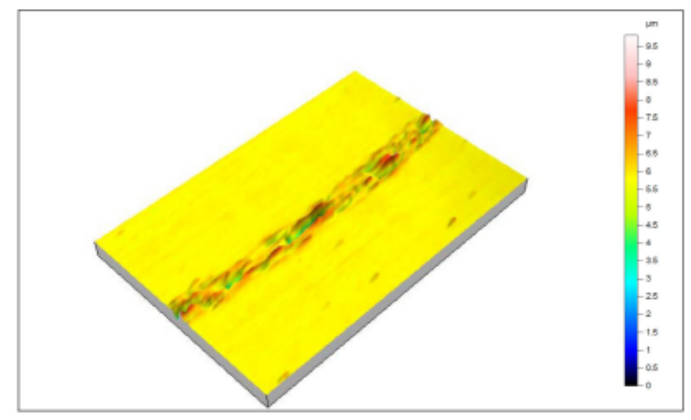

b)

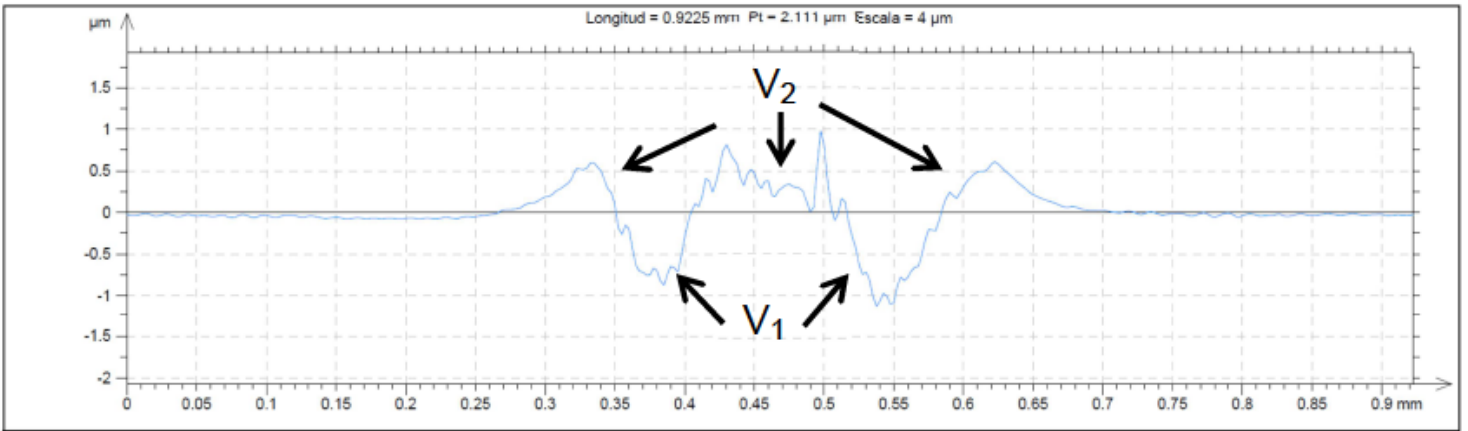

c)

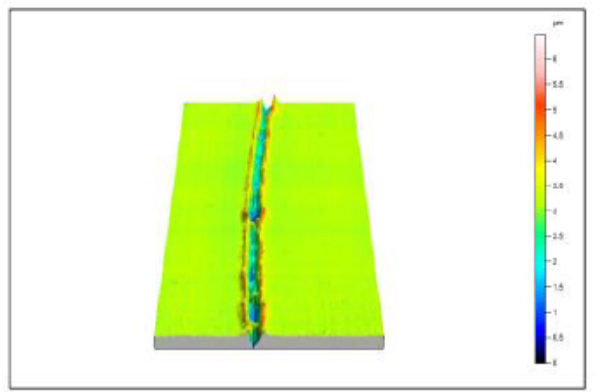

d)

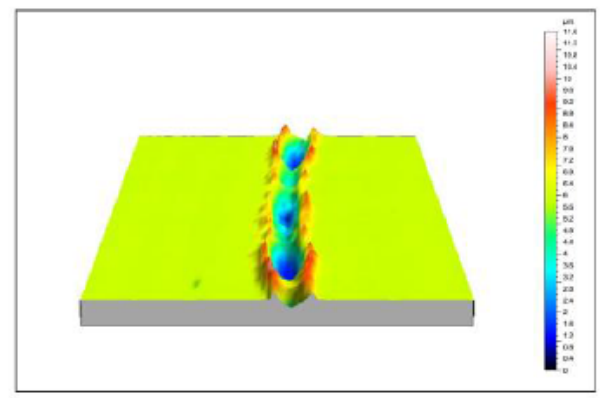

Figura 126. a) Imagen de perfilometría óptica de la huella de desgaste obtenida tras ensayo con agua en el contacto AISI 316L-AISI 316L; b) Sección transversal; c) Huella tras contacto con bola de AISI 52100; d) Huella tras contacto con bola de zafiro

El efecto anteriormente comentado, podría deberse al desgaste severo y a la transferencia de material desde la bola de acero inoxidable AISI $316 \mathrm{~L}$ como se puede observar en la Figura 127. El desgaste en la bola de AISI 316L incrementa el área de contacto con el disco, aumentando la anchura de la huella, pero reduciendo la presión de contacto y la profundidad de la misma. Por tanto, la adhesión entre el disco de acero inoxidable y la bola provoca la formación de una tribocapa en la interfase entre las dos superficies deslizantes. Sin embargo, en el caso de emplear el otro contacto metálico o el contacto zafiro-acero, no se aprecia la formación de esta tribocapa (Figura 126 c y d), 
observándose una severa deformación plástica en la huella de desgaste (Figura $125 \mathrm{~b}$ y $\mathrm{c}$ ).
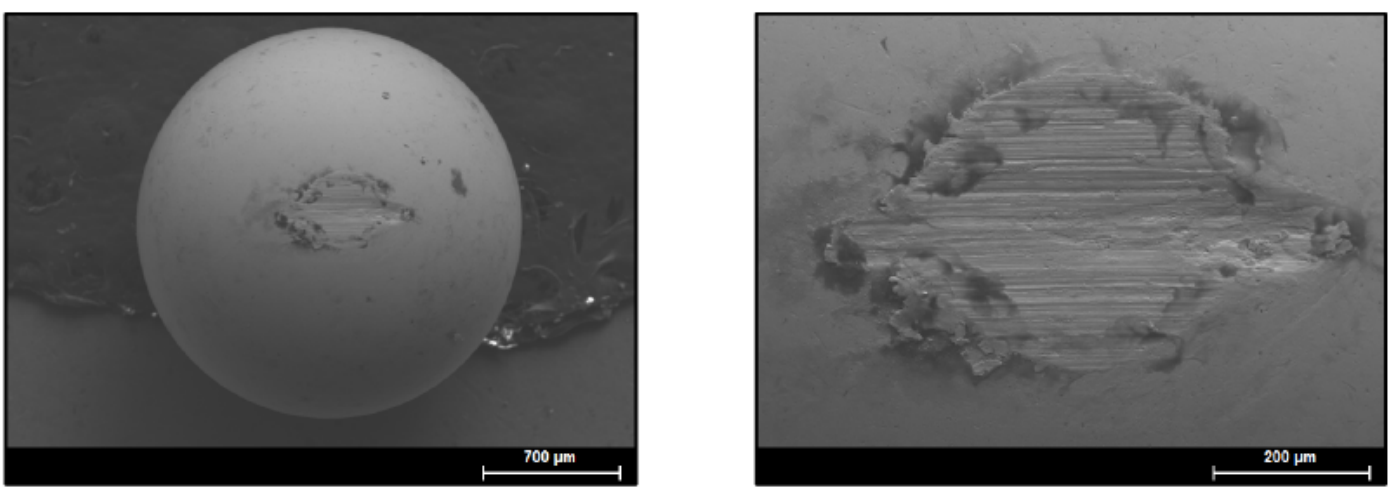

Figura 127. a) Bola de AISI 316L tras ensayo tribológico sobre disco de AISI 316L empleando agua como lubricante; b) Magnificación de la bola de AISI 316L

Al añadir un $1 \%$ de los líquidos iónicos DEs, MEs y DPa al agua, se produce una significativa reducción de las tasas de desgaste con respecto a las obtenidas para el agua. Como se esperaba, el mayor desgaste se ha encontrado en el contacto zafiro-acero inoxidable, ya que la presión de contacto es superior (Tabla 34).

El aditivo DEs proporciona tasas de desgaste similares para ambos contactos metálicos. De hecho, en el caso del contacto AISI 52100-AISI 316L (Figura 128 ) es tras la lubricación con WDEs cuando se logra una menor tasa de desgaste.

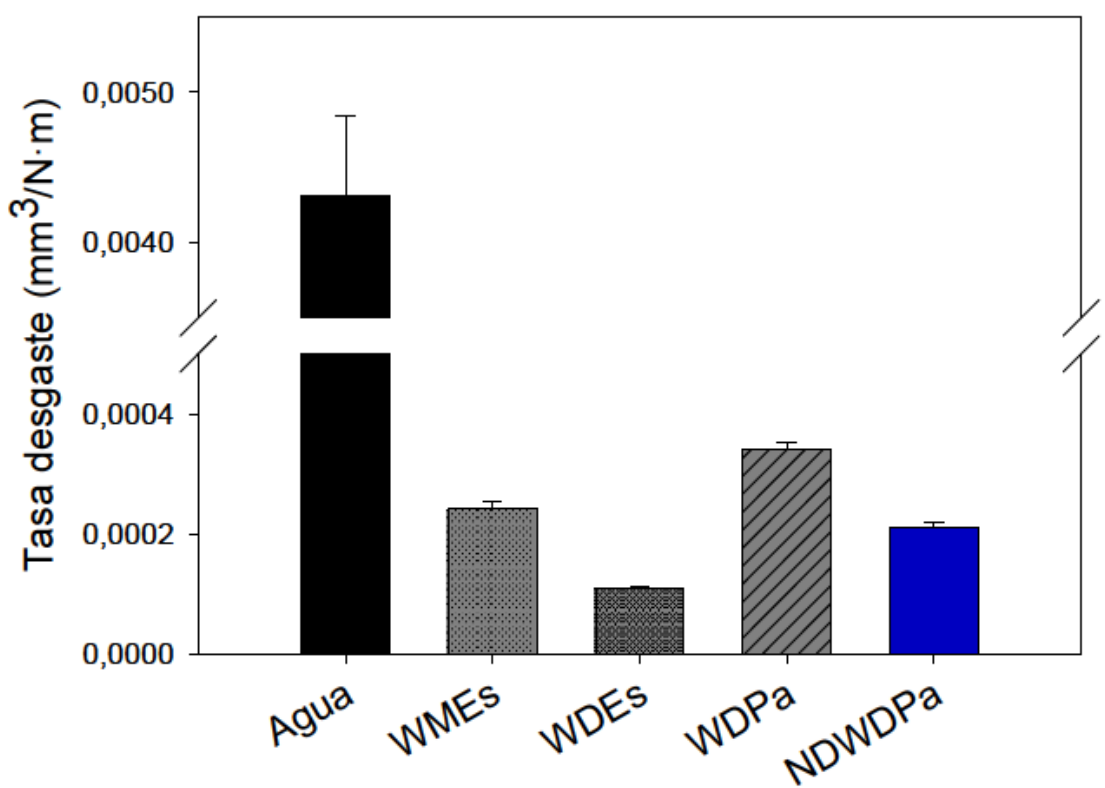

Figura 128. Tasas de desgaste tras ensayos para la obtención de curvas COF vs. velocidad empleando agua, WMEs, WDEs, WDPa y NDWDPa en el contacto AISI 52100-AISI 316L 
Este resultado está en relación con el valor del espesor medido mediante interferometría de película ultrafina, ya que para una bola del mismo material se observa la formación de capas lubricantes al emplear WDEs como lubricante.

En la Figura 129 se observan las huellas de desgaste tras emplear la emulsión con un $1 \%$ de DEs en agua para todos los contactos estudiados. Se puede ver que en el ensayo con la bola de zafiro la anchura de la huella es mayor, de ahí que presente la mayor tasa de desgaste de las observadas para todos los lubricantes, a excepción del agua (Tabla 34), lo que podría deberse al severo daño abrasivo sufrido, como se muestra en la Figura 129.

a)

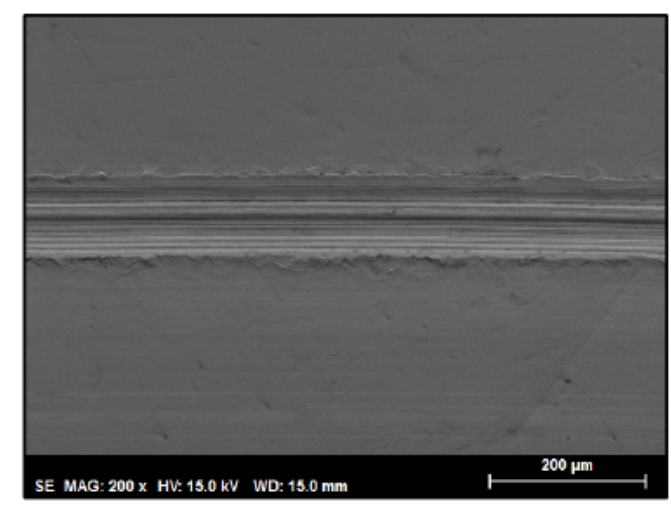

b)

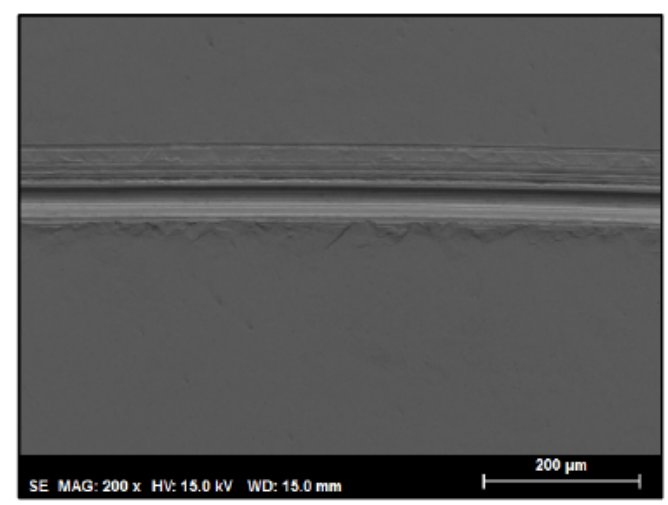

c)

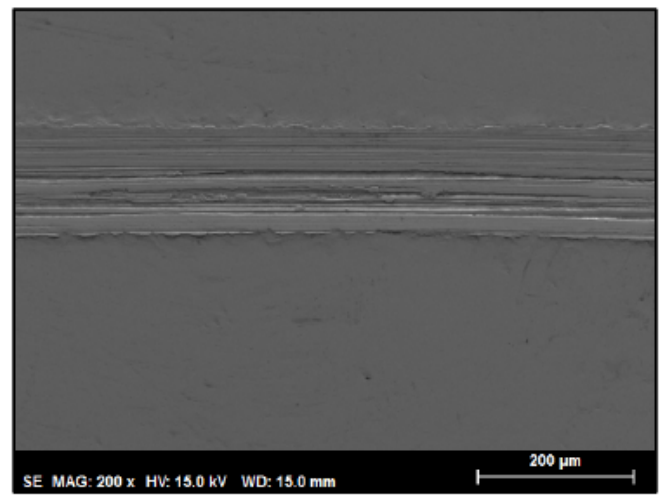

Figura 129. Micrografías SEM de la huellas de desgaste empleando WDEs como lubricante en los contactos: a) AISI 52100-AISI 316L; b) AISI 316L-AISI 316L; c) Zafiro-AISI 316L

Si se estudia la bola de zafiro empleada, es posible observar la adhesión de hierro en la superficie de la misma. Es interesante señalar además, que las regiones ricas en hierro también lo son en carbono, lo cual podría deberse a la modificación de la superficie del acero inoxidable debido a la presencia del líquido iónico (Figura 130). 
a)

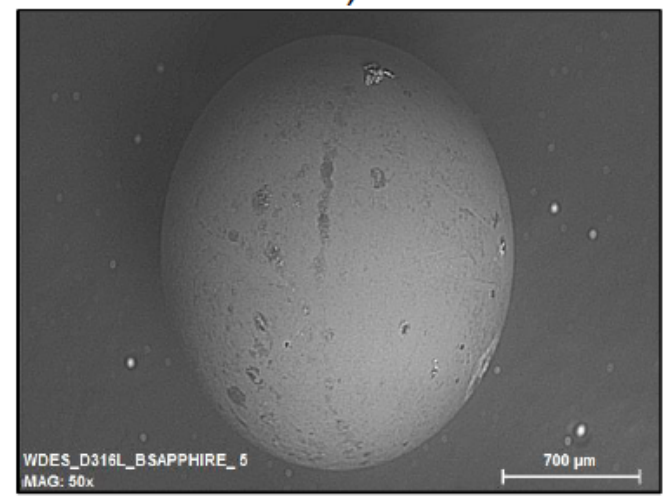

c)

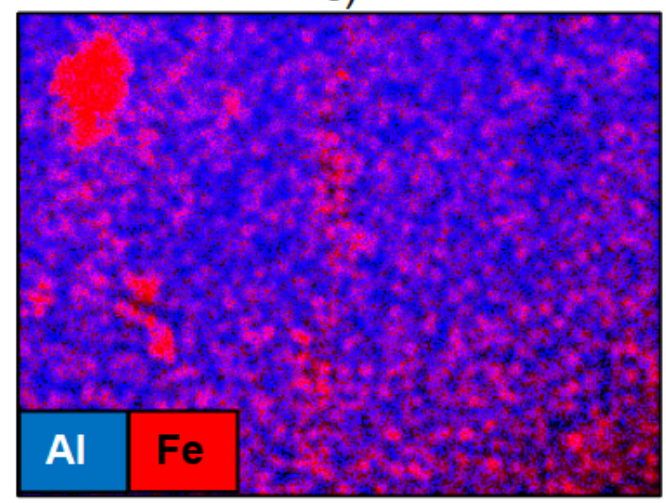

b)

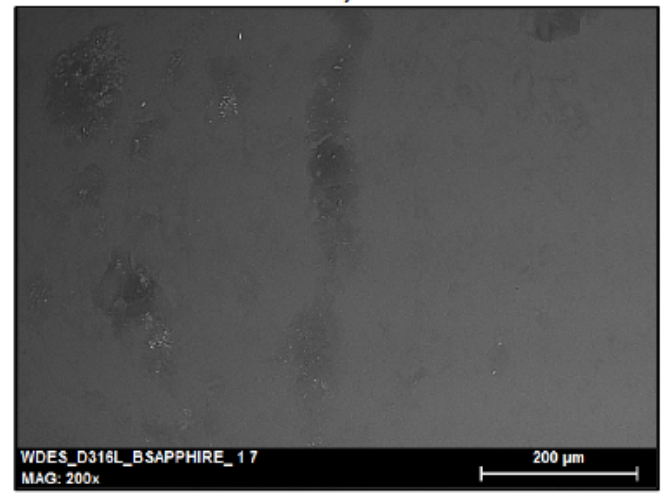

d)

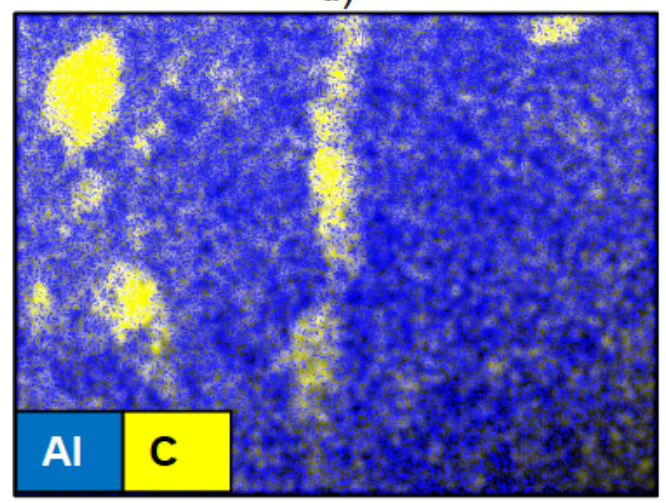

Figura 130. a) Bola de zafiro tras ensayo con WDEs; b) Detalle de la bola de zafiro; c) Mapa elemental de Al y Fe; d) Mapa elemental de Al y C

La Tabla 35 muestra los resultados del análisis XPS en el disco de acero inoxidable tras la lubricación con WDEs contra la bola de zafiro.

La energía de ligadura del C1s a $285 \mathrm{eV}$ se puede asignar a C-C, C=C y C-H, a $285,8 \mathrm{eV}$ a C-O o C-N y a $286,8 \mathrm{eV}$ a C=O. El pico a $289,1 \mathrm{eV}$ encontrado dentro de la huella de desgaste, que no se encontró fuera, se puede asignar al grupo COO. Los picos para el O1s a 530 y $531 \mathrm{eV}$ corresponden a óxidos metálicos o hidróxidos y a $\mathrm{O}=\mathrm{C}$. Las energías de aproximadamente $532 \mathrm{eV}$ y $533 \mathrm{eV}$ podrían ser debidas a grupos COO y C-O. El pico O1s a 531,78 eV no se observa en la huella de desgaste y podría ser asignado a agua adsorbida, 0 a $\mathrm{C}=\mathrm{O}$. Los picos $\mathrm{N} 1 \mathrm{~s}$ en torno a $400 \mathrm{eV}$ son asignables a grupos $\mathrm{N}-\mathrm{H}$. Las energías a 574 y $576 \mathrm{eV}$ se corresponden al $\mathrm{Cr} 2 \mathrm{p}_{3 / 2}$ del cromo metálico y el óxido de cromo, mientras que la energía a $586 \mathrm{eV}$ se asignaría al $\mathrm{Cr} 2 \mathrm{p}_{1 / 2}$ del óxido de cromo, siendo todas las señales similares dentro y fuera de la huella. No hay diferencias significativas para las energías de ligadura del $\mathrm{Fe} 2 \mathrm{p}_{3 / 2}$, con picos a $707 \mathrm{eV}$, correspondientes al hierro metálico y a $710 \mathrm{eV}$, asignables al óxido de hierro [294]. 
Tabla 35. Análisis XPS dentro y fuera de la huella de desgaste en el contacto zafiro-AISI 316L empleando WDEs como lubricante

\begin{tabular}{|c|c|c|c|c|}
\hline \multirow[t]{2}{*}{ Elemento } & \multicolumn{2}{|c|}{ Fuera de la huella } & \multicolumn{2}{|c|}{ Dentro de la huella } \\
\hline & $\begin{array}{c}\text { Energía de ligadura } \\
(\mathrm{eV})\end{array}$ & $\%$ atómico & $\begin{array}{c}\text { Energía de ligadura } \\
(\mathrm{eV})\end{array}$ & $\%$ atómico \\
\hline \multirow[t]{5}{*}{ C1s } & 285,00 & 38,01 & 285,00 & 37,59 \\
\hline & 285,85 & 5,75 & 285,88 & 6,58 \\
\hline & 286,88 & 1,31 & 286,86 & 2,32 \\
\hline & 288,58 & 1,87 & 288,27 & 1,79 \\
\hline & - & - & 289,07 & 1,40 \\
\hline \multirow[t]{3}{*}{ N1s } & 398,10 & 0,12 & - & - \\
\hline & 398,97 & 0,22 & 398,61 & 0,26 \\
\hline & 400,22 & 0,43 & 400,14 & 0,45 \\
\hline \multirow[t]{5}{*}{ 01s } & 529,97 & 14,49 & 529,99 & 14,55 \\
\hline & 531,02 & 5,01 & 531,35 & 7,63 \\
\hline & 531,78 & 6,37 & - & - \\
\hline & 532,56 & 5,90 & 532,34 & 7,70 \\
\hline & 533,44 & 1,22 & 533,32 & 2,13 \\
\hline \multirow[t]{3}{*}{ Cr2p } & 573,86 & 0,16 & 574,01 & 0,26 \\
\hline & 576,37 & 2,68 & 576,45 & 2,21 \\
\hline & 586,14 & 1,40 & 586,21 & 1,16 \\
\hline \multirow[t]{2}{*}{$\mathrm{Fe} 2 \mathrm{p}$} & 707,26 & 5,91 & 707,11 & 5,78 \\
\hline & 710,37 & 4,03 & 710,20 & 3,37 \\
\hline
\end{tabular}

En el caso de la lubricación con MEs, los valores de desgaste obtenidos en los contactos metálicos son muy similares entre sí, al igual que ocurría en el caso de las emulsiones con DEs. En la Figura 131 se observan las huellas de desgaste obtenidas tras la lubricacion con WMEs en los tres contactos estudiados, observándose marcas de abrasión y deformación plástica en los bordes de las huellas. 
a)

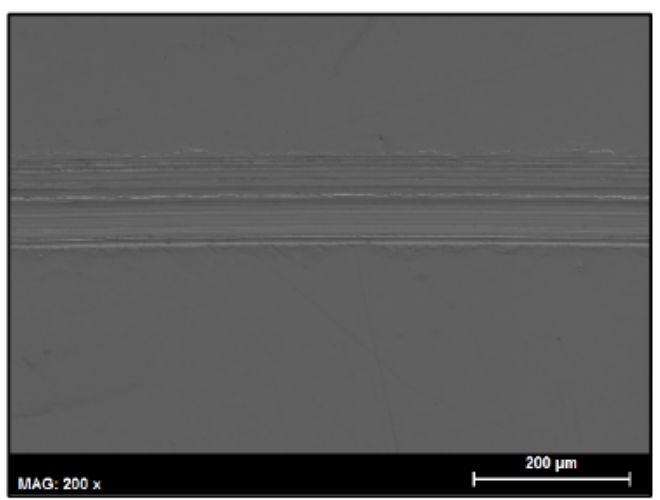

b)

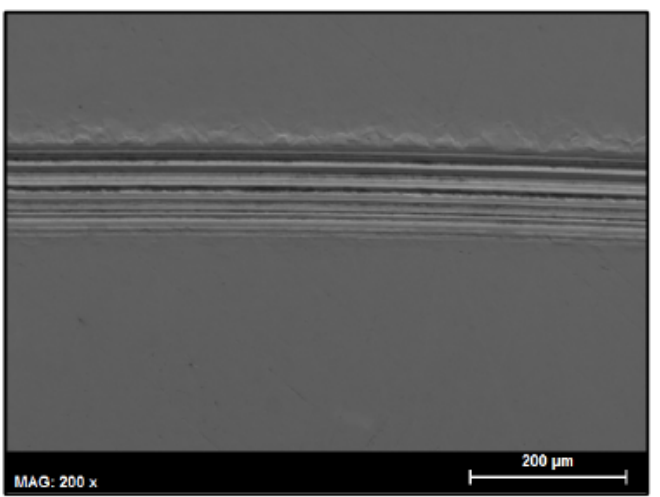

c)

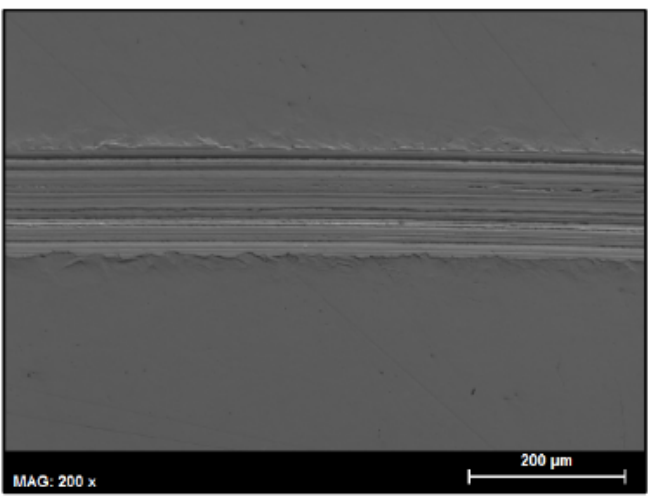

Figura 131. Micrografías SEM de las huellas de desgaste empleando WMEs como lubricante.

a) Contacto 5200-AISI 316L; b) Contacto AISI 316L-AISI 316L; c) Contacto zafiro-AISI 316L

Por su parte, la emulsión WDPa muestra unos valores de tasa de desgaste que se incrementan con la presión de contacto desde el acero inoxidable AISI $316 \mathrm{~L}$ hasta el AISI 52100 y el zafiro, aunque no de forma proporcional (Tabla 34).

En las huellas de desgaste y topografía superficial obtenidas tras estos ensayos de lubricación, se observa acumulación de material en los bordes de la huella (Figura 132). 
a)
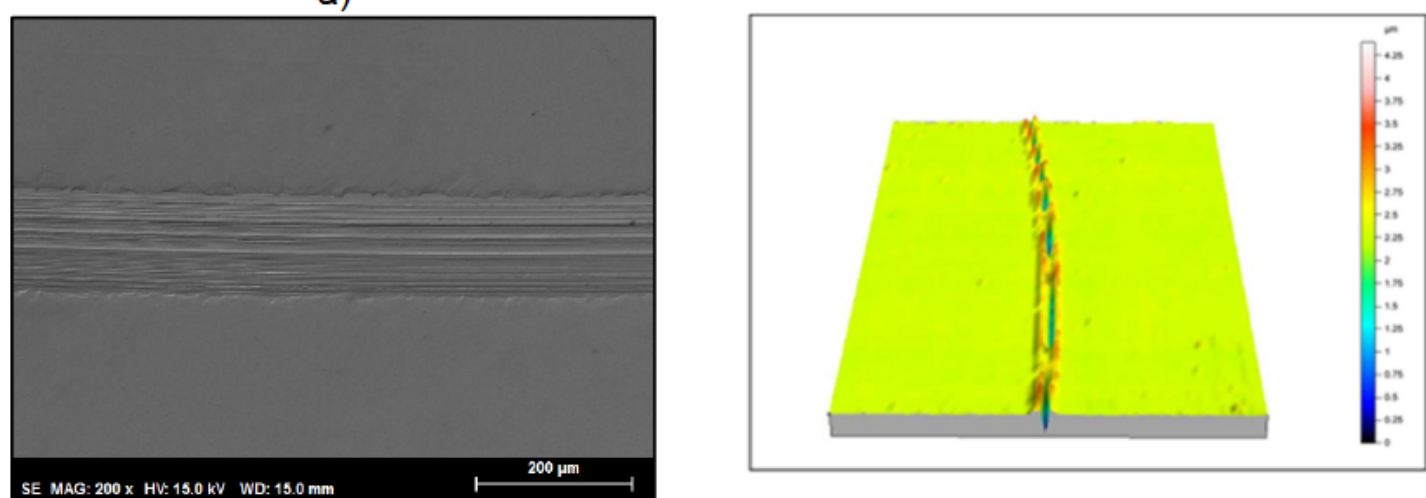

b)
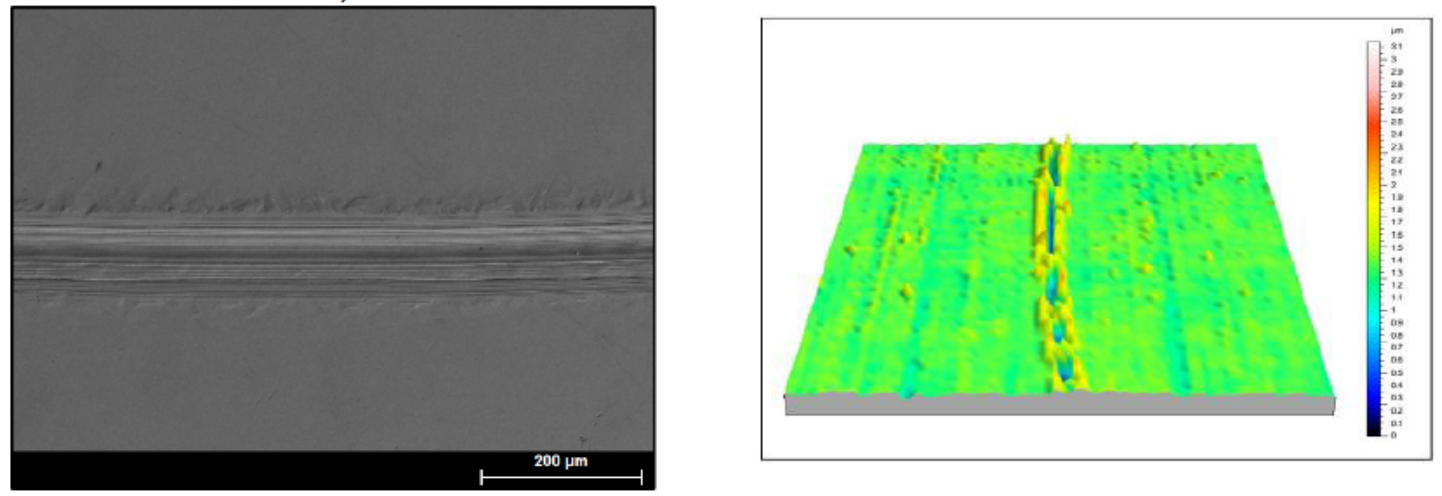

c)
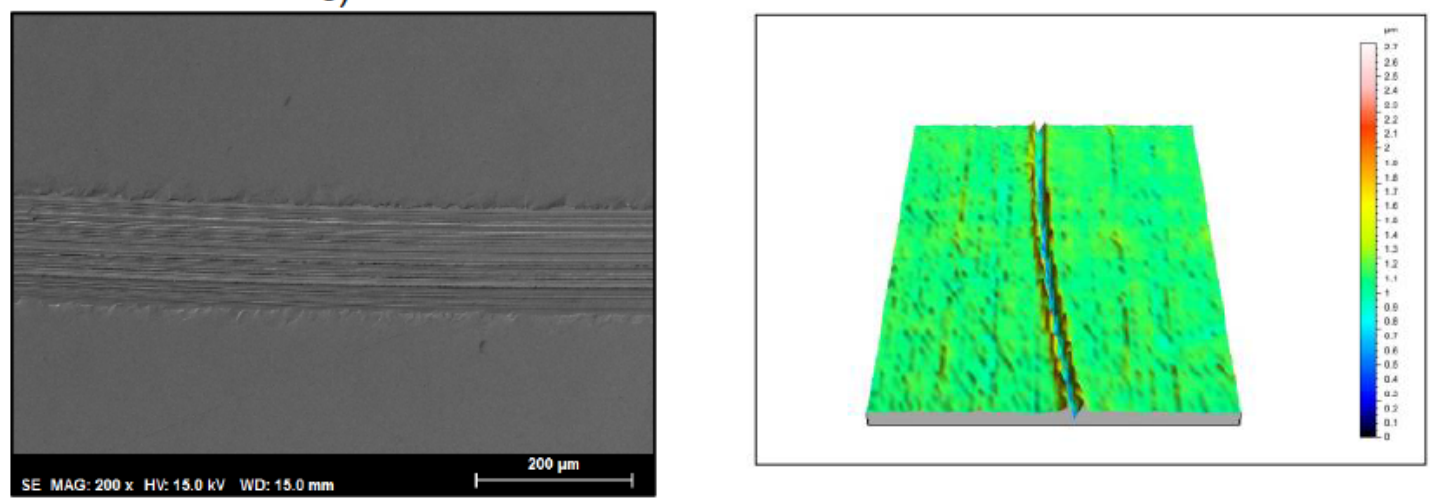

Figura 132. Micrografías SEM de las huellas de desgaste y topografía superficial empleando WDPa como lubricante. a) Contacto 5200-AISI 316L; b) Contacto AISI 316L-AISI 316L; c) Contacto zafiro-AISI $316 \mathrm{~L}$

Tras el ensayo realizado en el contacto AISI 316L-AISI 316L empleando WDPa, la bola muestra marcas de abrasión. En el mapa elemental de la misma se muestra acumulación de carbono, presumiblemente procedente del líquido iónico (Figura 133). 
a)

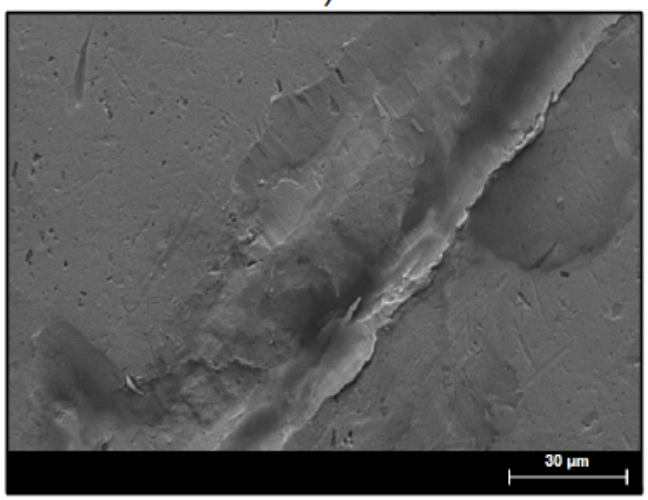

b)

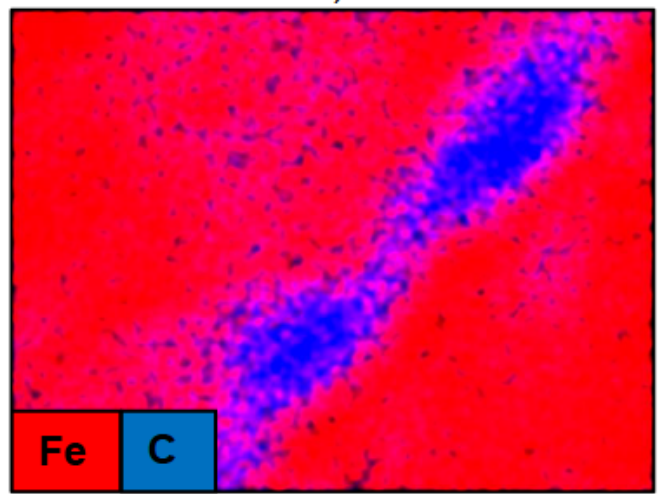

Figura 133. a) Micrografía SEM de la bola tras ensayo AISI 316L-AISI 316L empleando WDPa como lubricante; b) Mapa elemental de Fe y $\mathrm{C}$ de la bola

La adición de un $0,1 \%$ de nanodiamantes a la emulsión con un $1 \%$ de DPa en agua reduce la tasa de desgaste en todos los contactos estudiados, dando los valores de desgaste más bajos en el caso de emplear bolas de AISI 316L y de zafiro (Tabla 34). En la Figura 134 se observa la huella de desgaste y la bola empleada en los ensayos del contacto metálico AISI 316L-AISI 316L empleando NDWDPa. Se puede ver cómo es abrasión el mecanismo de desgaste que ha tenido lugar entre las dos superficies en contacto.

a)

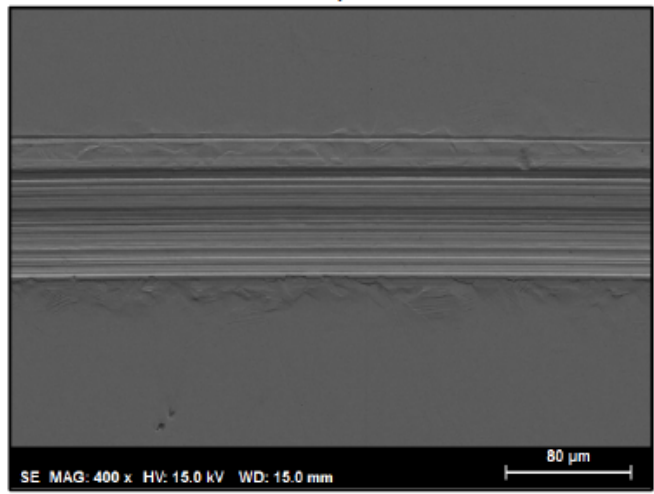

b)
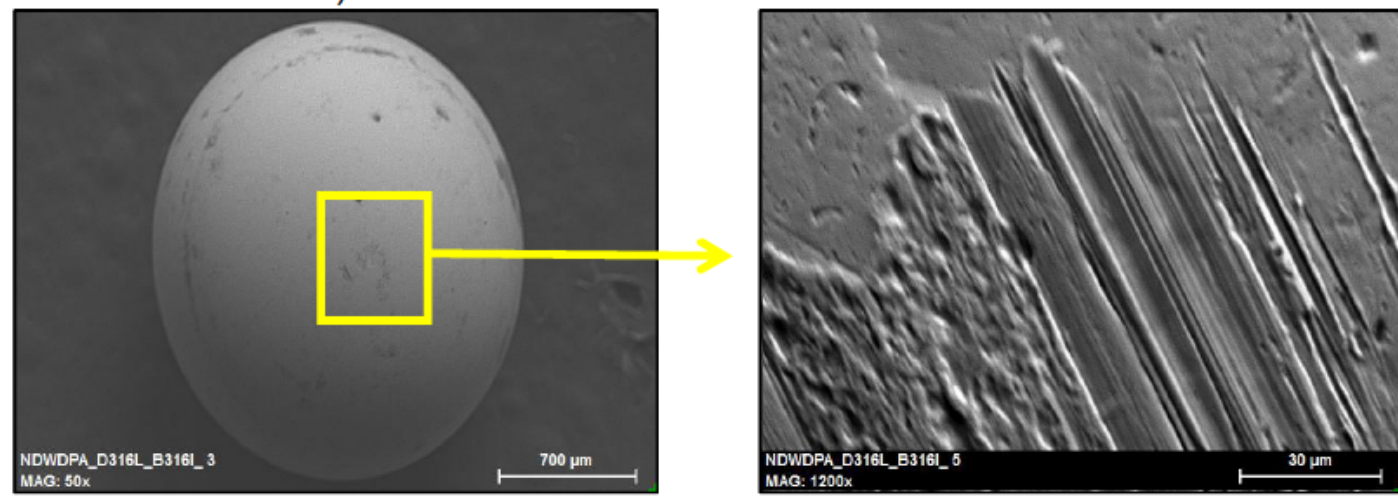

Figura 134. a) Micrografía SEM de la huella de desgaste tras ensayo AISI 316L-AISI 316L empleando NDWDPa como lubricante; b) Detalle de la bola de acero AISI 316L 
Además, es en este contacto (AISI 316L-AISI 316L) y empleando NDWDPa donde se alcanza el valor de tasa de desgaste más bajo de todos los ensayos realizados. Por tanto la adición de un $0,1 \%$ de nanodiamantes supone una mejora del comportamiento frente al desgaste del $65 \%$ respecto a la dispersión sin nanofase (Figura 135).

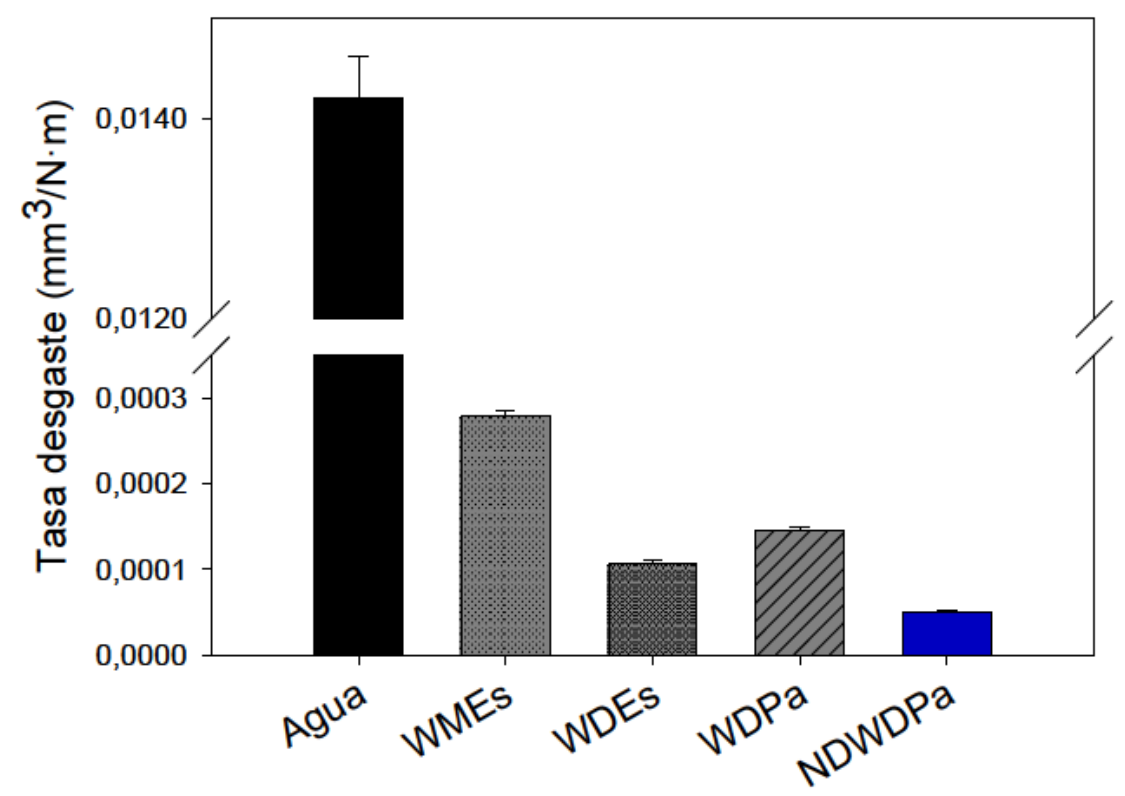

Figura 135. Tasas de desgaste tras curvas COF vs. velocidad empleando agua, WMEs, WDEs, WDPa y NDWDPa en el contacto AISI 316L-AISI 316L.

Cuando se emplea una bola de un material más duro, como el acero AISI 52100, al usar NDWDPa como lubricante, el daño en el disco es más severo, observándose deformación plástica y abrasión en la huella (Figura 136).

a)

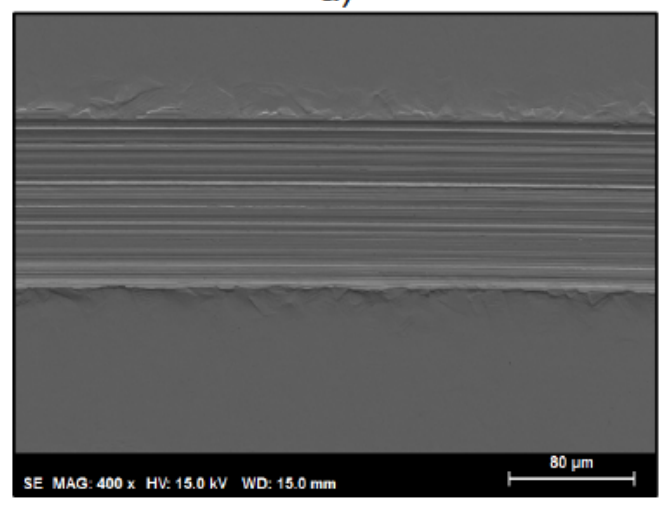

b)

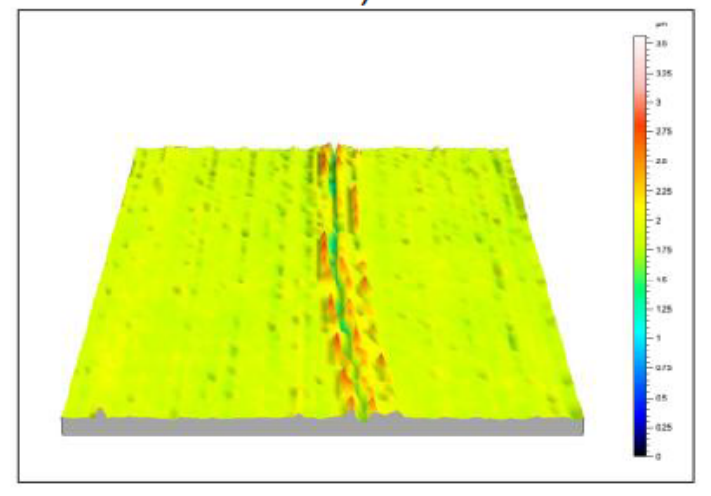

Figura 136. a) Micrografía SEM de la huella de desgaste tras ensayo en el contacto acero AISI 52100-316L empleando NDWDPa como lubricante; b) Topografía superficial

Las imágenes de los mapas elementales obtenidos mediante EDX sobre la bola de AISI 52100, empleando NDWDPA, muestran regiones con elevadas 
concentraciones de carbono y oxígeno debido a la reactividad del acero con la dispersión (Figura 137).
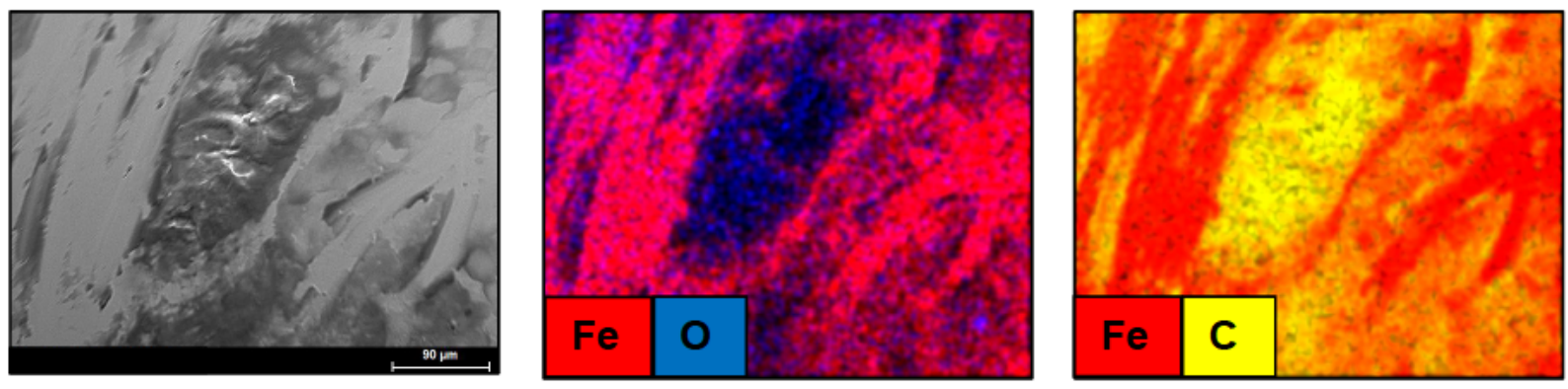

Figura 137. Bola de acero AISI 52100 y mapas elementales tras ensayo en el contacto acero AISI 52100-316L empleando NDWDPa como lubricante.

En la Figura 138 se muestra una comparativa de las tasas de desgaste obtenidas tras la lubricación con las diferentes emulsiones en el contacto cerámico-acero. El desgaste sufrido por el disco de acero, cuantificado según el procedimiento que se indica en el apartado 3.3.1.9.2, muestra como la adición de líquido iónico supone una disminución muy significativa de la tasa de desgaste con respecto al agua ( $92 \%$ en el caso del WDEs). La adición de un $0,1 \%$ de nanodiamantes al lubricante WDPa produce una reducción del $44 \%$ en la tasa de desgaste, presentado esta dispersión el mejor comportamiento tribológico en este contacto.

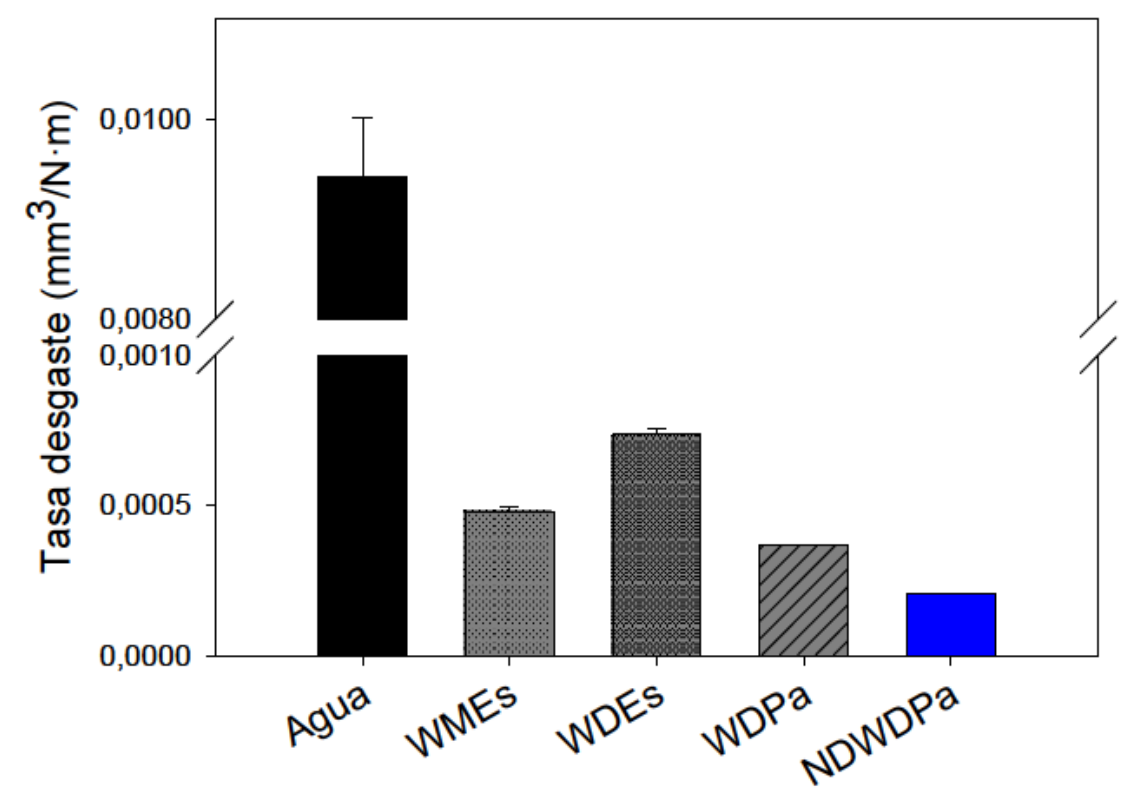

Figura 138. Tasas de desgaste tras obtención de curvas COF vs. velocidad empleando agua, WMEs, WDEs, WDPa y NDWDPa en el contacto zafiro-AISI 316L 
4.1.1.3.3. Estudio tribológico de emulsiones de cristales líquidos iónicos en agua en el contacto zafiro-AISI $316 \mathrm{~L}$ a velocidad constante

Se muestra en el siguiente apartado el estudio tribológico de las emulsiones de un $1 \%$ de los líquidos iónicos DEs, MEs y DPa en agua tipo II. Los ensayos se han realizado bajo la configuración punzón sobre disco con bola de zafiro frente a discos de acero inoxidable AISI 316L. Se han seleccionado estos materiales ya que las presiones de contacto son más elevadas ( $P_{\max }=1,95 \mathrm{GPa}$ y $P_{\text {med }}=1,30 \mathrm{GPa}$ ) y no se produce interacción entre los materiales, como sí ocurre en los contactos metal-metal.

De los resultados de las curvas COF vs. velocidad para este contacto (apartado 4.1.1.3.2.3), se observa que es a la velocidad de $100 \mathrm{~mm} / \mathrm{s}$ cuando se presenta un menor valor del coeficiente de fricción para todos los lubricantes estudiados. Por ello, ésta ha sido la velocidad estudiada en los ensayos que se muestran a continuación.

En la Figura 139 se observa la evolución del coeficiente de fricción para las emulsiones de líquidos iónicos próticos derivados de ácidos grasos y se comparan con la obtenida para el agua.

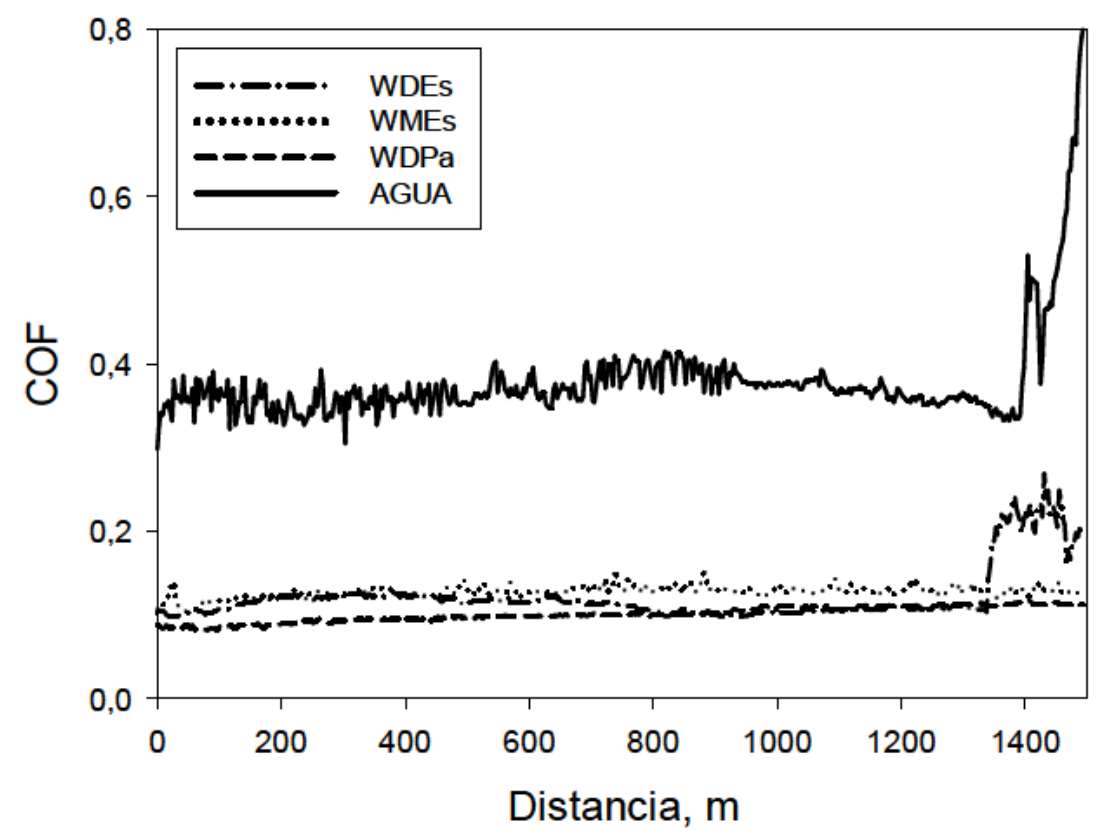

Figura 139. Evolución del coeficiente de fricción empleando WDEs, WMEs, WDPa y agua como lubricantes tras ensayos en el contacto zafiro-AISI $316 \mathrm{~L}$ a velocidad constante

En el caso de la lubricación con agua, se alcanza un elevado coeficiente de fricción por encima de 0,39 al principio del ensayo. Una vez recorrida una 
distancia de deslizamiento de 1387 m, debido a la evaporación del agua en el contacto [105], se produce un incremento del coeficiente de fricción hasta un valor de 0,81 .

Se puede observar que todos los aditivos son capaces de reducir el coeficiente de fricción del agua hasta en un $80 \%$. La emulsión del líquido iónico derivado del ácido palmítico (WDPa) es la que presenta un mejor comportamiento frente a la fricción, con una evolución constante durante todo el ensayo. Un comportamiento similar presenta la dispersión WMEs, pero como se puede observar en la Tabla 36, con un coeficiente de fricción superior. Para el WDEs, la emulsión con mayor viscosidad, el coeficiente de fricción se mantiene en valores en torno a 0,1 durante la mayor parte del ensayo, sin embargo, cuando han transcurrido unos $1340 \mathrm{~m}$ de distancia de deslizamiento, el coeficiente de fricción aumenta, debido a la evaporación de agua de la emulsión provocada por las altas temperaturas que se alcanzan en el contacto. Aún así, el valor máximo de coeficiente de fricción es de 0,203 , un $75 \%$ inferior al presentado por el agua.

Este comportamiento es radicalmente opuesto al presentado por otras emulsiones de líquidos iónicos próticos en agua [102], [235]. En estos casos existía una etapa inicial de alta fricción y al evaporarse el agua el coeficiente de fricción disminuía notablemente. Para los cristales líquidos iónicos derivados de ácidos grasos, la fricción se mantiene en valores bajos durante todo el ensayo, y al evaporarse el agua, el coeficiente de fricción aumenta, ya que estos cristales líquidos iónicos son sólidos en estado puro.

Tabla 36. Coeficiente de fricción y tasa de desgaste para WDEs, WMEs, WDPa y agua tras ensayos en el contacto zafiro-AISI 316 L a velocidad constante

\begin{tabular}{ccc}
\hline & $\begin{array}{c}\text { Coeficiente } \\
\text { de fricción }\end{array}$ & $\begin{array}{c}\text { Tasa de desgaste } \\
\left(\mathbf{m m}^{3} / \mathbf{N} \cdot \mathbf{m}\right)\end{array}$ \\
\hline WDEs & $0,117( \pm 0,005)$ & $3,67 \times 10^{-6}\left( \pm 1,8 \times 10^{-7}\right)$ \\
\hline WMEs & $0,129( \pm 0,003)$ & $2,63 \times 10^{-6}\left( \pm 9,0 \times 10^{-7}\right)$ \\
\hline WDPa & $0,107( \pm 0,006)$ & $2,27 \times 10^{-6}\left( \pm 5 \times 10^{-8}\right)$ \\
\hline Agua & 0,378 & $1,86 \times 10^{-5}\left( \pm 1,7 \times 10^{-6}\right)$ \\
\hline
\end{tabular}

Con respecto a los valores de tasa de desgaste (Tabla 36), todas las emulsiones de cristales líquidos iónicos disminuyen notablemente el desgaste sufrido por la superficie de acero inoxidable con respecto al agua. El WDPa 
presenta un mejor comportamiento frente al desgaste, mientras que los líquidos iónicos derivados del ácido esteárico presentan valores superiores de daño superficial, sobre todo en el caso del WDEs, debido a la evaporación del agua en la interfase (Figura 139).

Se puede apreciar con más detalle la topografía superficial y la sección transversal de las huellas de desgaste tras la lubricación con WDEs, WMEs, WDPa y agua en la Figura 140. Se muestra que tras la lubricación con agua se obtiene un desgaste muy severo sobre la superficie del disco de AISI 316L si se compara con el resultado obtenido para el resto de las emulsiones. Se observa tras la lubricación con los nanofluidos iónicos, acumulación de material en los bordes de la huella, sobre todo en el caso de emplear WDEs y WMEs como lubricantes.
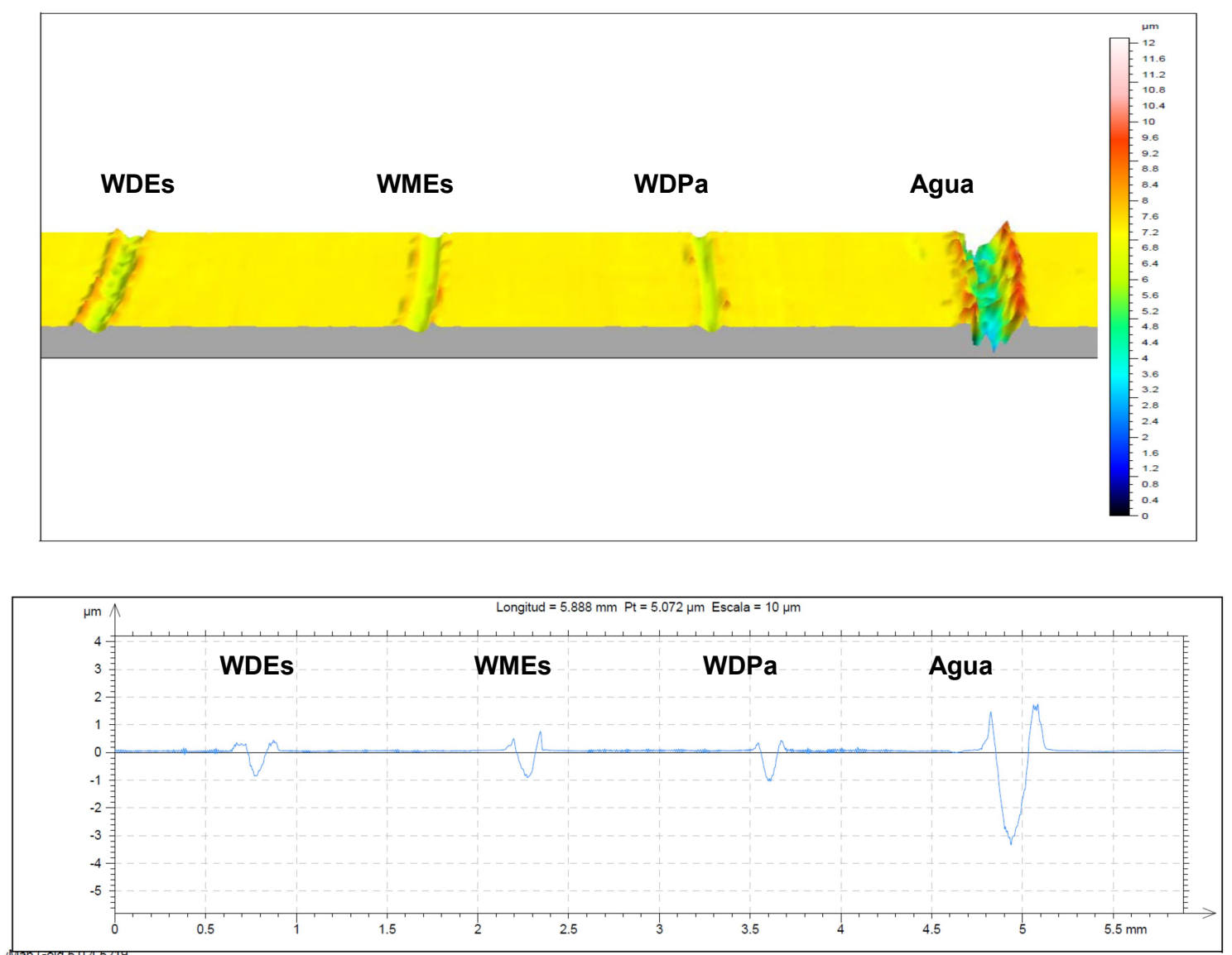

Figura 140. Topografía superficial y sección transversal de las huellas de desgaste sobre acero AISI 316L tras lubricación con agua, WDEs, WMEs y WDPa a velocidad constante

En la Tabla 37 se muestran los valores de rugosidad obtenidos mediante perfilometría óptica dentro y fuera de la huella, observándose un valor de 
rugosidad dentro de la huella en el caso de lubricación con WDEs superior, quizás debido al factor de desgaste que presenta.

Tabla 37. Valores de rugosidad después del ensayo tribológico tras lubricación con WDEs, WMEs y WDPa a velocidad constante

\begin{tabular}{ccc}
\hline & $\begin{array}{c}\text { Rugosidad }\left(\boldsymbol{R}_{\mathrm{a}}\right) \text { fuera } \\
\text { de la huella }(\boldsymbol{\mu m})\end{array}$ & $\begin{array}{c}\text { Rugosidad }\left(\mathbf{R}_{\mathrm{a}}\right) \text { en la huella } \\
(\boldsymbol{\mu} \mathbf{m})\end{array}$ \\
\hline WDEs & $0,034\left( \pm 2,1 \times 10^{-3}\right)$ & $0,55\left( \pm 2,3 \times 10^{-2}\right)$ \\
\hline WMEs & $0,034\left( \pm 2,1 \times 10^{-3}\right)$ & $0,51\left( \pm 4,6 \times 10^{-2}\right)$ \\
\hline WDPa & $0,033\left( \pm 2,8 \times 10^{-3}\right)$ & $0,43\left( \pm 5,3 \times 10^{-2}\right)$ \\
\hline Agua & $0,042\left( \pm 8,3 \times 10^{-3}\right)$ & $1,59\left( \pm 6,7 \times 10^{-2}\right)$ \\
\hline
\end{tabular}

Para conocer las interacciones superficiales que han tenido lugar tras la lubricación con las emulsiones de líquidos próticos derivados de ácidos grasos, se ha realizado un estudio mediante microscopía electrónica de barrido.

En el caso de la lubricación con agua, la micrografía SEM de la huella de desgaste (Figura 141) muestra el importante desgaste abrasivo que ha sufrido la superficie de acero inoxidable AISI 316L. Se observa además el notable aumento de la concentración de oxígeno en el interior de la huella debido a la oxidación del hierro tras la eliminación, en el ensayo tribológico, de la capa de óxidos protectores que posee el acero inoxidable.

a)

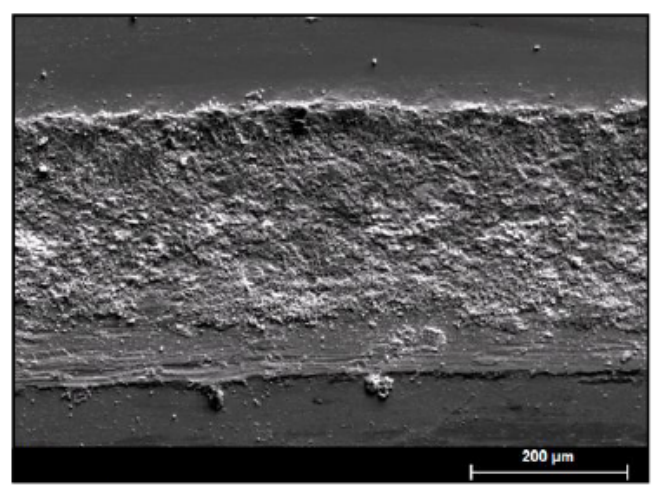

b)

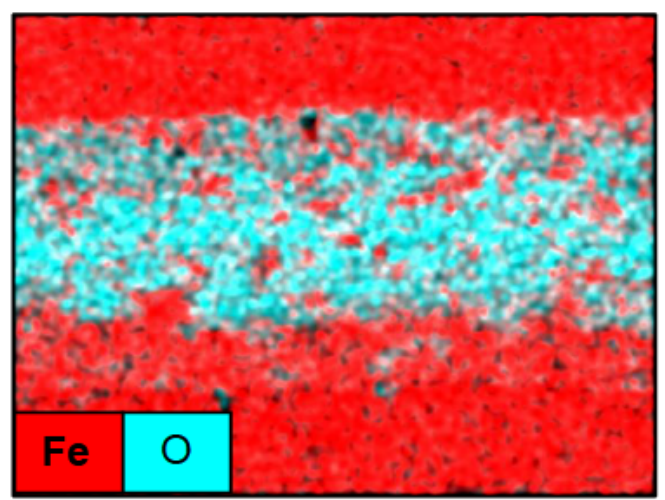

Figura 141. a) Micrografía SEM de la huella desgaste sobre AISI 316L tras lubricación con agua a velocidad constante; b) Mapa elemental de Fe y $\mathrm{O}$

En el análisis en línea de oxígeno y hierro (Figura 142) se muestra con más detalle el incremento de oxígeno en el interior de la huella y la disminución del porcentaje de hierro. 


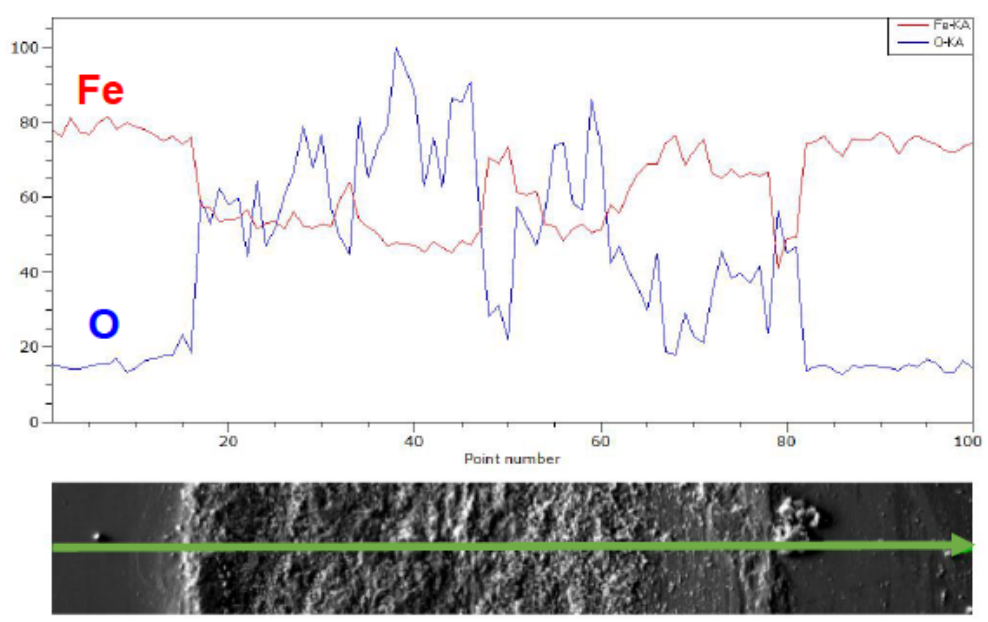

Figura 142. Análisis en línea de Fe y O sobre la huella de desgaste

La gran cantidad de partículas de desgaste obtenidas están principalmente compuestas por óxidos de hierro y cromo (Figura 143).

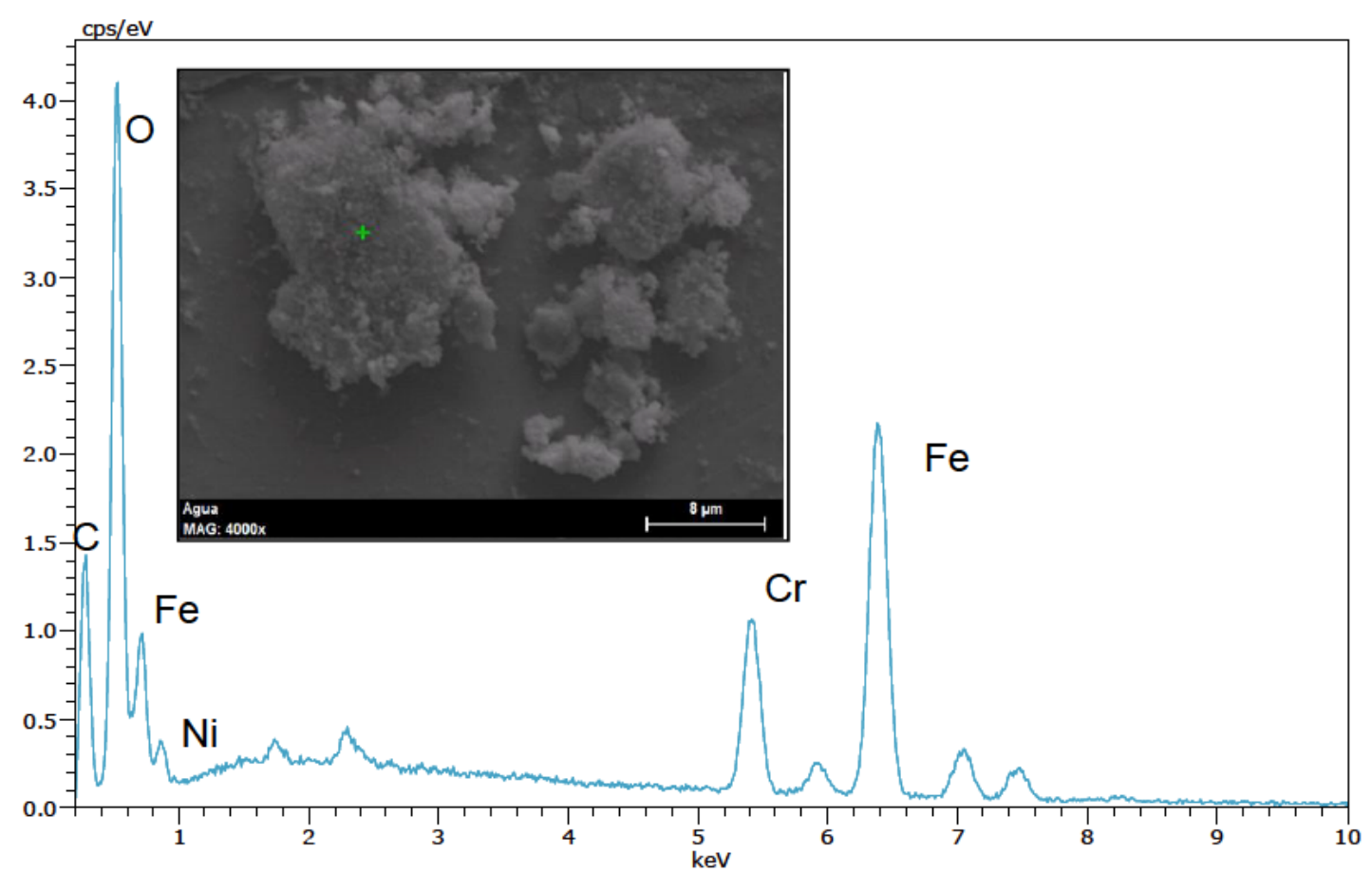

Figura 143. Micrografía SEM y análisis puntual de las partículas de desgaste

En la Figura 144 se observa la huella de desgaste sobre el disco de acero AISI $316 \mathrm{~L}$ tras lubricación con WDEs. Se observan marcas de desgaste abrasivo severo y fractura. En los mapas elementales de $\mathrm{Fe}$ y $\mathrm{O}$ obtenidos mediante EDX se observa acumulación de oxígeno en el interior de la huella de desgaste. 
a)

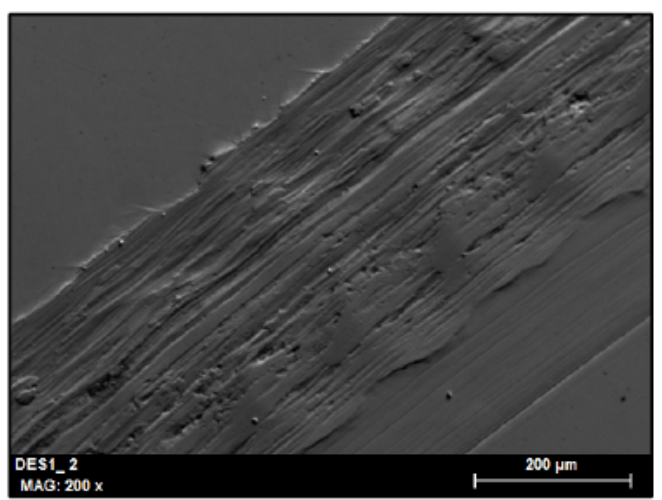

b)

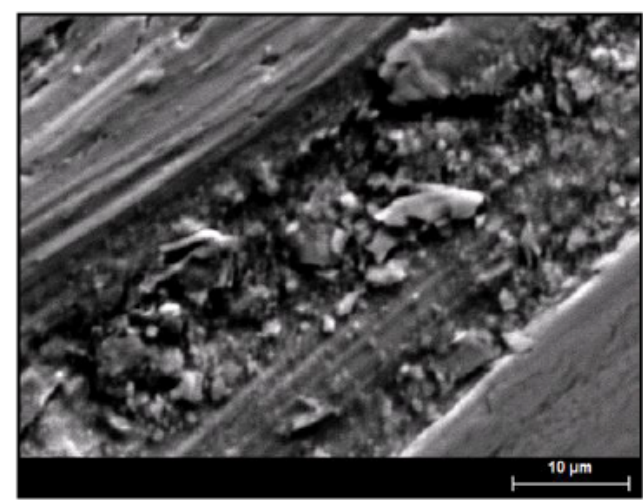

c)

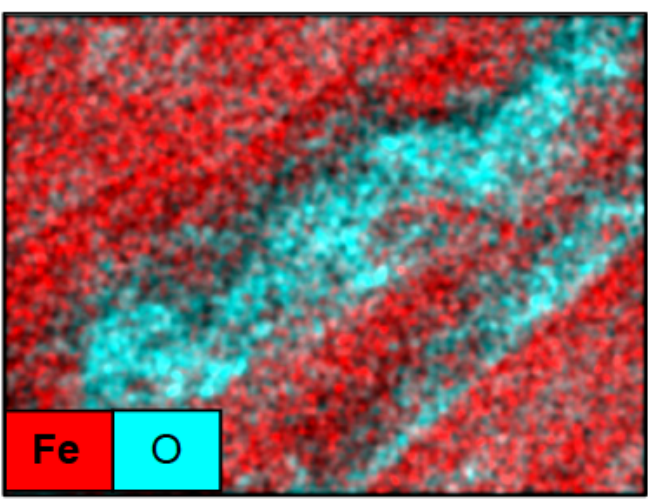

Figura 144. a) Micrografía SEM de la huella de desgaste sobre AISI 316L tras lubricación con WDES a velocidad constante; b) Detalle de la huella; c) Mapa elemental de Fe y $O$

En el estudio de la huella tras lubricación con WMEs (Figura 145a), no se observa un desgaste tan severo como en el caso anterior, aunque sí se pueden ver marcas paralelas típicas del desgaste abrasivo y deformación plástica de material en los bordes. El estudio composicional de la superficie de desgaste muestra mayor concentración de oxígeno en la huella (Figura 145b).

a)

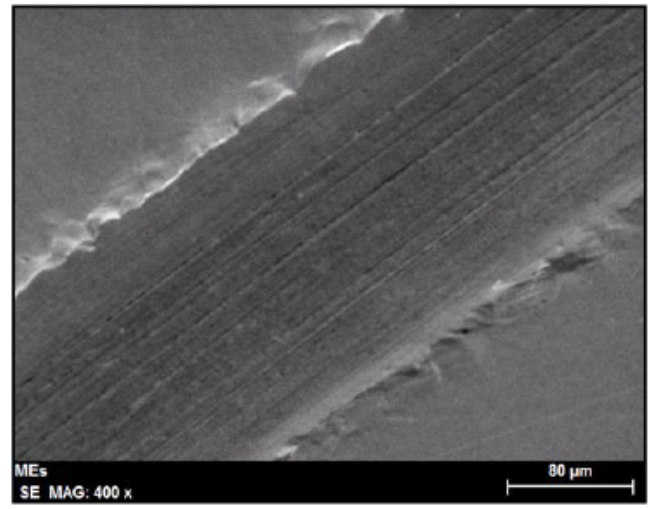

b)

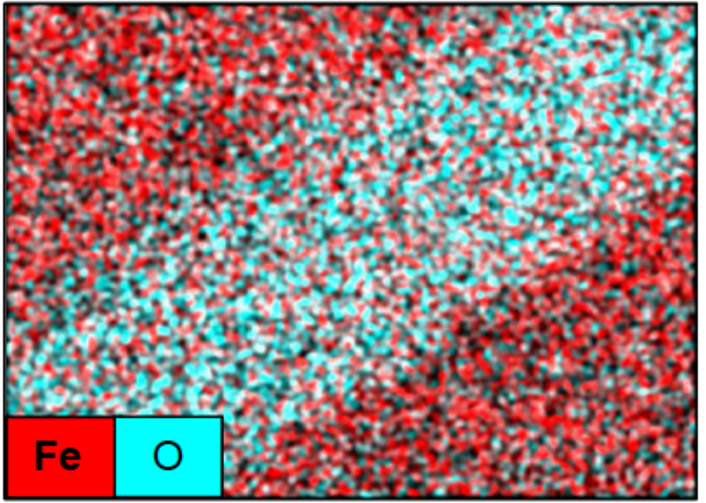

Figura 145. a) Micrografía SEM de la huella de desgaste sobre AISI 316L tras lubricación con WMES a velocidad constante; b) Mapa elemental de Fe y $O$ 
En el mapa elemental de la huella tras la lubricación con WDPa (Figura 146), se observa una huella de desgaste pulida, libre de marcas de abrasión (Figura 146a) y menor contenido de oxígeno (Figura 146b), lo que está de acuerdo con la baja tasa de desgaste y rugosidad encontradas tras el ensayo tribológico realizado con este lubricante.

a)

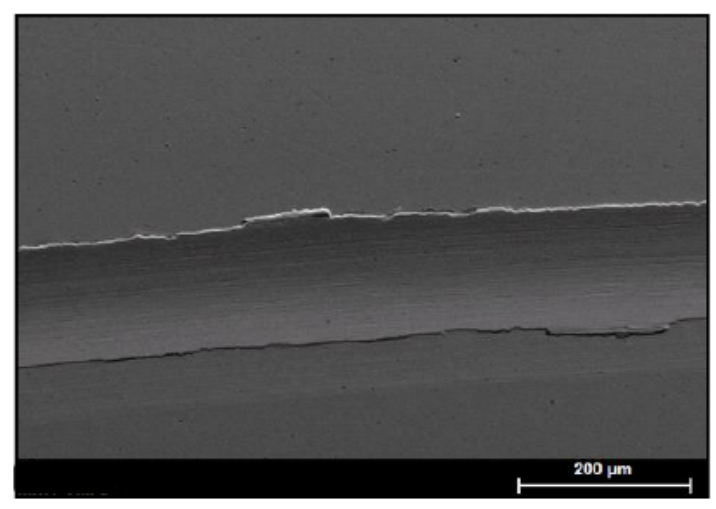

b)

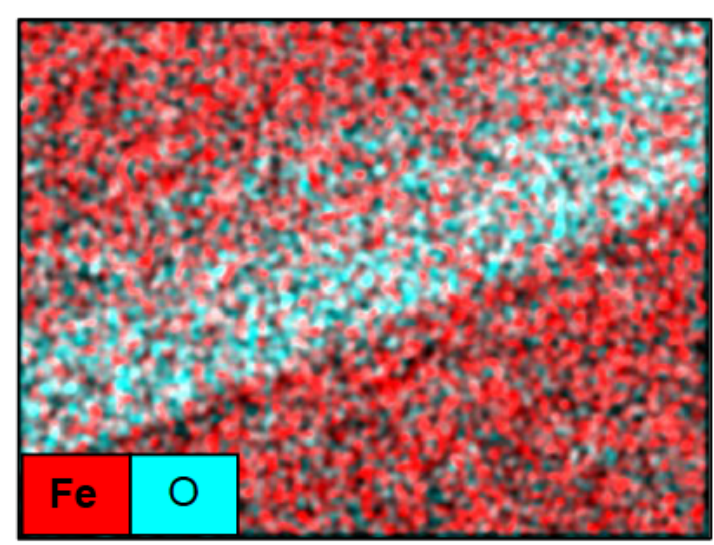

Figura 146. a) Micrografía SEM de la huella de desgaste sobre AISI 316L tras lubricación con WDPa a velocidad constante; b) Mapa elemental de Fe y $O$

Además, en este caso, el ánalisis en línea con EDX no muestra cambios significativos de las concentraciones de hierro, oxígeno y carbono dentro y fuera de la huella como se puede observar en la Figura 147.

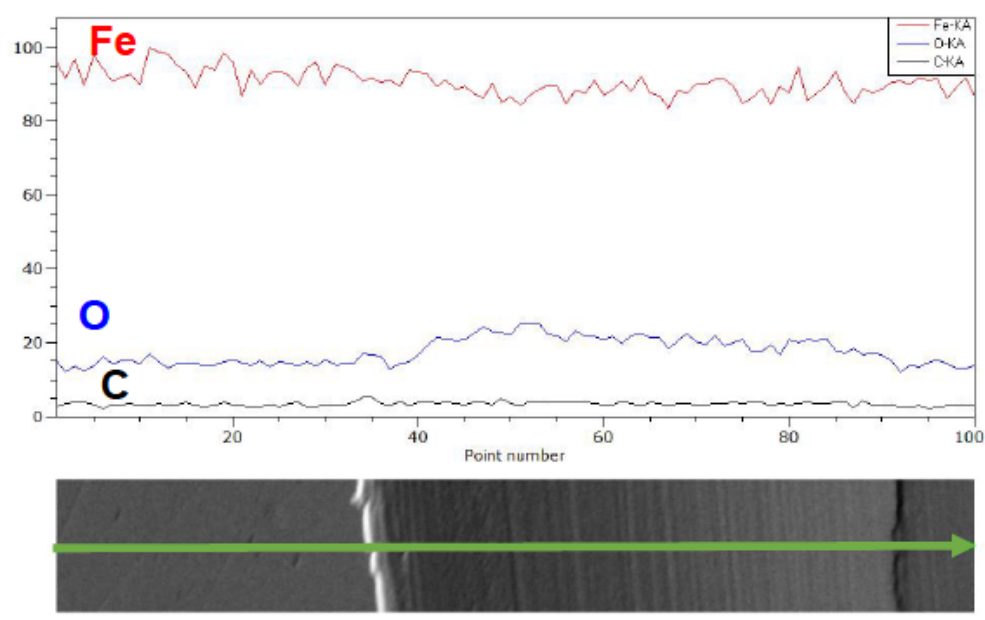

Figura 147. Análisis en línea de Fe, O y C cruzando la huella de desgaste tras lubricación con WDPa

El análisis elemental semicuantitativo realizado en un punto en el interior de la huella confirma los resultados anteriormente descritos. 


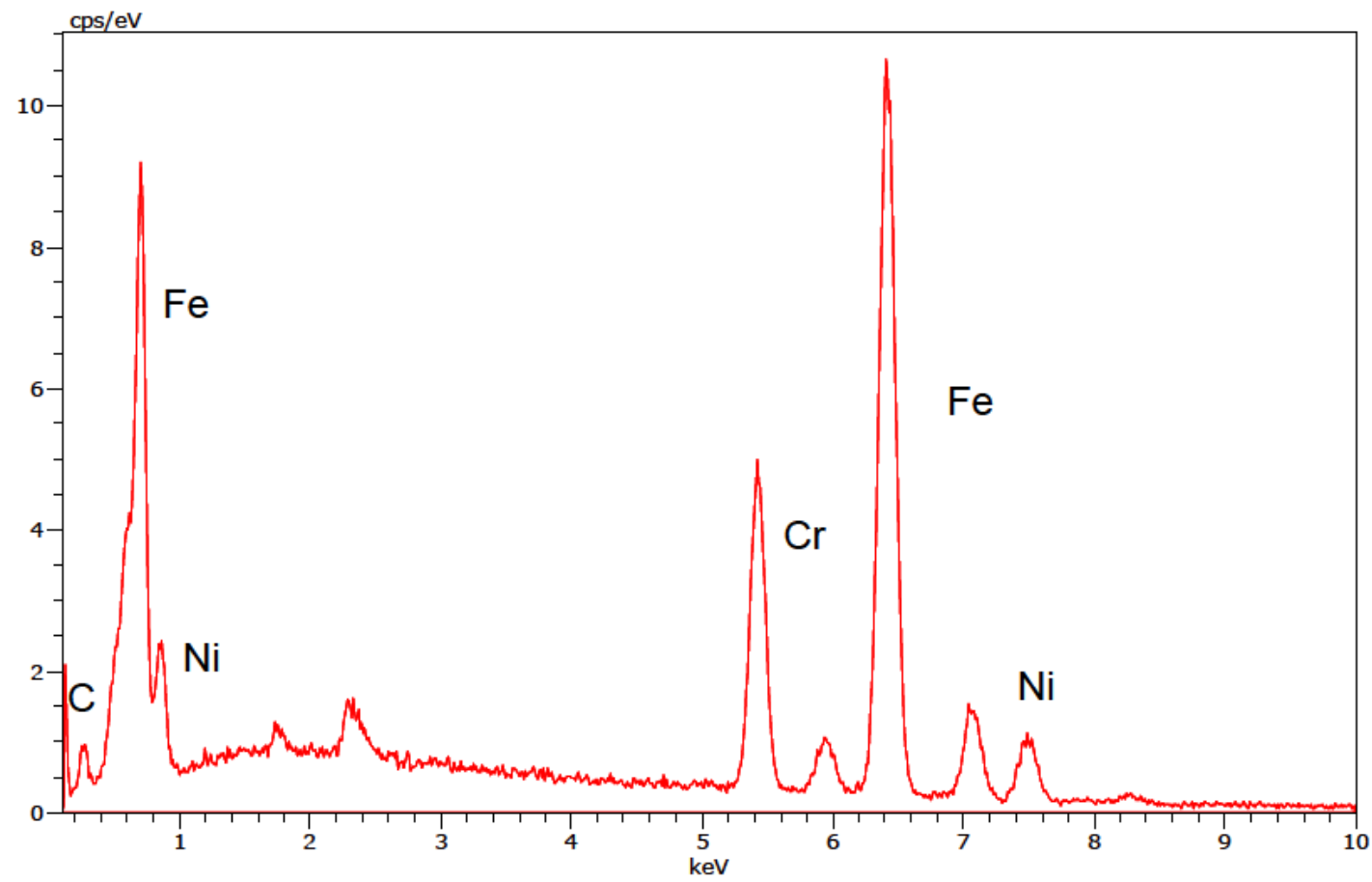

Figura 148. Espectro EDX dentro de la huella de desgaste tras lubricación con WDPa

La interacción del líquido iónico con la superficie de acero se ha estudiado en el caso de la lubricación con WMEs mediante análisis XPS, ya que el daño obtenido tras la lubricación con WDEs era muy severo y para WDPa demasiado suave. De esta forma, la superficie de acero tras la lubricación con WMEs era la más idónea para llevar a cabo el análisis. En primer lugar, se muestran los resultados obtenidos para el líquido iónico MEs (Figura 149).
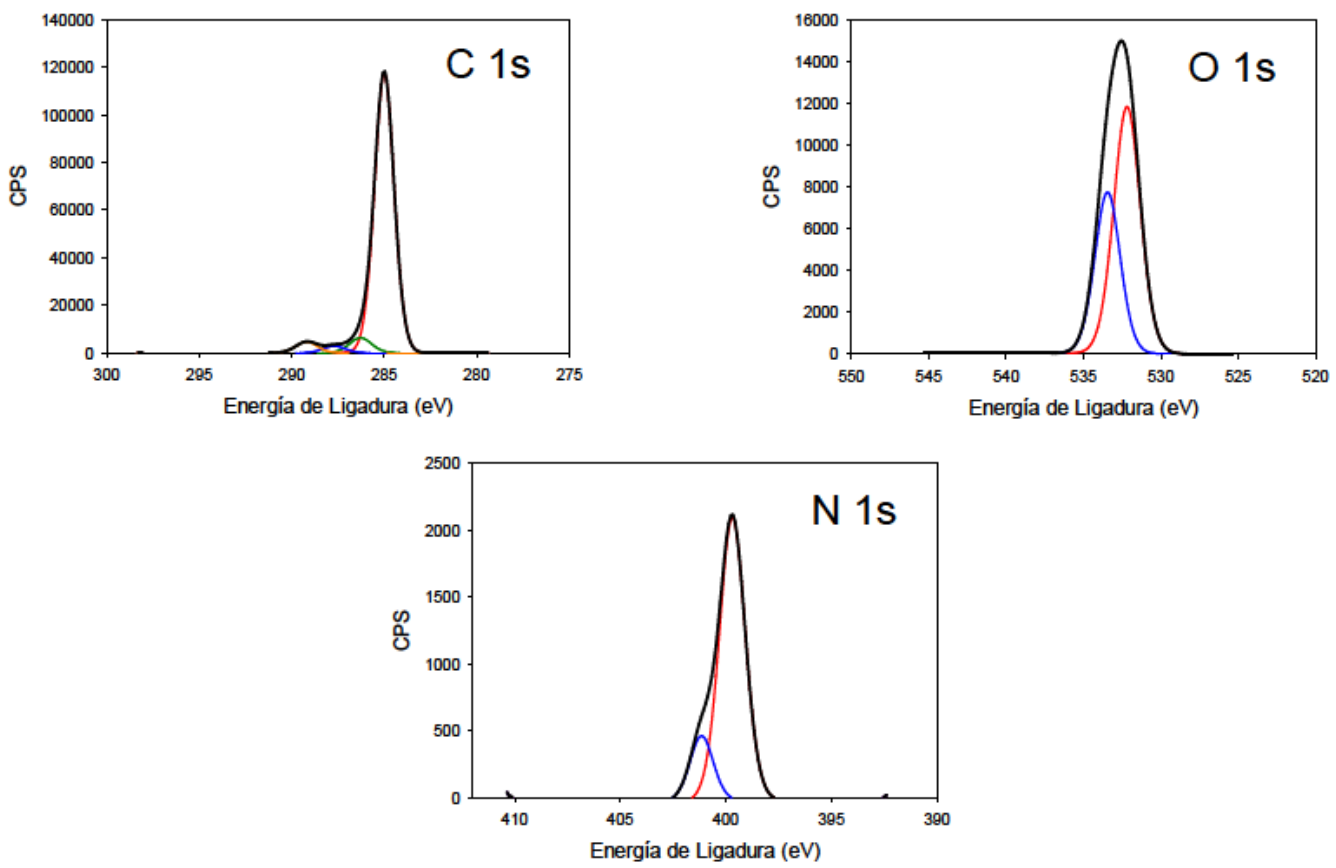

Figura 149. Análisis XPS del líquido iónico MEs 
Como se puede observar en la Tabla 38, el líquido iónico presenta dos picos de $\mathrm{O}$ con energías de 532,19 eV y 533,45 eV que se pueden asignar a los grupos $\mathrm{O}-\mathrm{H}$ y C-O respectivamente. En el caso del nitrógeno, aparece una banda a 399,7 eV correspondiente al catión amonio. Con respecto al carbono, aparecen cuatro picos, uno a $285 \mathrm{eV}$ correspondiente al grupo alquílico, otro a $286,29 \mathrm{eV}$ del C-N, a $287,71 \mathrm{eV}$ que se puede asignar al enlace C-O y finalmente la energía de ligadura a 289,2 eV, debida al grupo C(O)O.

Tabla 38. Análisis XPS del líquido iónico MEs

\begin{tabular}{ccc}
\hline Líquido iónico MEs & Energía de ligadura $(\mathrm{eV})$ & $\%$ atómico \\
\hline C1s & 285,00 & 79,89 \\
\hline C1s & 286,29 & 4,87 \\
\hline C1s & 287,71 & 2,22 \\
\hline C1s & 289,20 & 3,48 \\
\hline N1s & 399,70 & 0,98 \\
\hline N1s & 401,15 & 0,21 \\
\hline O1s & 532,19 & 5,16 \\
\hline O1s & 533,45 & 3,21
\end{tabular}

En la Tabla 39 se observan los resultados obtenidos para el análisis XPS dentro de la huella de desgaste y en la superficie del disco tras lubricación con WMEs.

Comparando los porcentajes elementales dentro y fuera de la huella se observa un aumento del porcentaje de nitrógeno dentro de la misma, lo que puede ser debido a la adsorción del catión amonio en la superficie de la huella.

Los picos de O1s que aparecen a $530,25 \mathrm{eV}$ y $531,74 \mathrm{eV}$ en el disco y a 529,93 y $531,48 \mathrm{eV}$ dentro de la huella pueden asignarse a óxido de hierro $\left(\mathrm{Fe}_{2} \mathrm{O}_{3}\right)$ y a los grupos C-O. Además, estas dos señales aparecen con mayor intensidad en el interior de la huella. La energía de 532,79 eV dentro de la huella se puede asignar al enlace $\mathrm{C}=\mathrm{O}$.

Los porcentajes de los elementos metálicos son superiores en el interior de la huella. Para el Cr2p, las energías a $573,93 \mathrm{eV}, 575,81$ eV y $578,14 \mathrm{eV}$ podrían asignarse al $\mathrm{Cr}$ elemental, $\mathrm{Cr}_{2} \mathrm{p}_{1 / 2}$ del $\mathrm{Cr}_{2} \mathrm{O}_{3}$ y $\mathrm{Cr}_{2} \mathrm{p}_{3 / 2}$ respectivamente. Mientras que la banda a $577,01 \mathrm{eV}$ se podría asignar a sales de cromo o compuestos complejos de cromo y amonio formados posiblemente en la reacción del catión del líquido iónico y la superficie del acero. En el caso del hierro, se observan 
tres bandas, la de menor intensidad a 706,9 eV podría ser asignada al $\mathrm{Fe}$ elemental. La banda a 710,45 eV se podría asignar al Fe2 $\mathrm{p}_{3 / 2}$ del óxido de hierro $\mathrm{Fe}_{2} \mathrm{O}_{3}$, mientras que la banda a $712,35 \mathrm{eV}$ se correspondería con compuestos de coordinación de $\mathrm{Fe}(\mathrm{III})$ (Fe-OC). En el caso del níquel, se observan dos picos, el más intenso se corresponde con Ni elemental y el que posee menor intensidad a hidróxidos de este metal.

Por último, los picos del C1s se corresponderían con carbono alifático (285 eV), enlaces (C-N) a 286,46 eV, la señal asignable a (C-O) se encontraría a 287,96 eV y a 288,74 se situaría el pico correspondiente al grupo carboxilato del anión.

Tabla 39. Análisis XPS dentro y fuera de la huella de desgaste sobre AISI 316L tras lubricación con WMEs

\begin{tabular}{|c|c|c|c|c|}
\hline \multirow[t]{2}{*}{ Elemento } & \multicolumn{2}{|c|}{ Fuera de la huella } & \multicolumn{2}{|c|}{ Dentro de la huella } \\
\hline & $\begin{array}{c}\text { Energía de ligadura } \\
(\mathrm{eV})\end{array}$ & $\%$ atómico & $\begin{array}{c}\text { Energía de ligadura } \\
(\mathrm{eV})\end{array}$ & $\%$ atómico \\
\hline \multirow[t]{4}{*}{ C1s } & 285,00 & 66,64 & 285,00 & 62,06 \\
\hline & 286,13 & 3,67 & 286,46 & 3,54 \\
\hline & 286,96 & 1,03 & 287,96 & 1,39 \\
\hline & 288,43 & 2,73 & 288,74 & 2,16 \\
\hline \multirow[t]{2}{*}{ N1s } & 399,74 & 0,22 & 398,20 & 0,39 \\
\hline & 401,53 & 0,14 & 399,95 & 0,71 \\
\hline \multirow[t]{3}{*}{ 01s } & 530,25 & 11,63 & 529,93 & 13,31 \\
\hline & 531,74 & 9,04 & 531,48 & 10,28 \\
\hline & 533,20 & 0,93 & 532,79 & 1,30 \\
\hline \multirow[t]{4}{*}{$\mathrm{Cr} 2 \mathrm{p}$} & 574,24 & 0,09 & 573,93 & 0,08 \\
\hline & 576,44 & 0,65 & 575,81 & 0,50 \\
\hline & 578,00 & 0,29 & 577,01 & 0,52 \\
\hline & & & 578,14 & 0,19 \\
\hline \multirow[t]{3}{*}{$\mathrm{Fe} 2 \mathrm{p}$} & 707,43 & 0,39 & 706,96 & 0,37 \\
\hline & 710,58 & 1,54 & 710,45 & 2,39 \\
\hline & 712,45 & 0,86 & 712,35 & 0,56 \\
\hline \multirow[t]{2}{*}{$\mathrm{Ni2p}$} & 853,22 & 0,10 & 852,62 & 0,12 \\
\hline & 856,24 & 0,05 & 855,32 & 0,10 \\
\hline
\end{tabular}




\subsection{Estudio tribológico de dispersiones de nanodiamantes en emulsiones de cristales líquidos iónicos próticos en agua en el contacto zafiro-AISI 316 L velocidad constante}

Una vez estudiado el comportamiento tribológico de las emulsiones de un $1 \%$ de líquido iónico derivados de ácidos grasos en agua (apartado 4.1.1.3.3), se ha añadido a dichas emulsiones un $0,1 \%$ de nanodiamantes sólidos, obteniendo las dispersiones NDWDEs, NDWMEs y NDWDPa. Se esta manera, se pretende determinar si la adición de nanofases de carbono ayuda a disminuir el coeficiente de fricción y la tasa de desgaste, teniendo como antecedente el caso del NDWDPa que presenta una disminución de la fricción y el desgaste respecto al WDPa (apartado 3.3.1.9.2).

Por tanto, se han realizado ensayos tribológicos en configuración punzón sobre disco con bola de zafiro sobre discos AISI 316L en las mismas condiciones que los realizados para las emulsiones de los líquidos iónicos en agua. En la Figura 150 se muestran los resultados obtenidos en comparación con el agua.

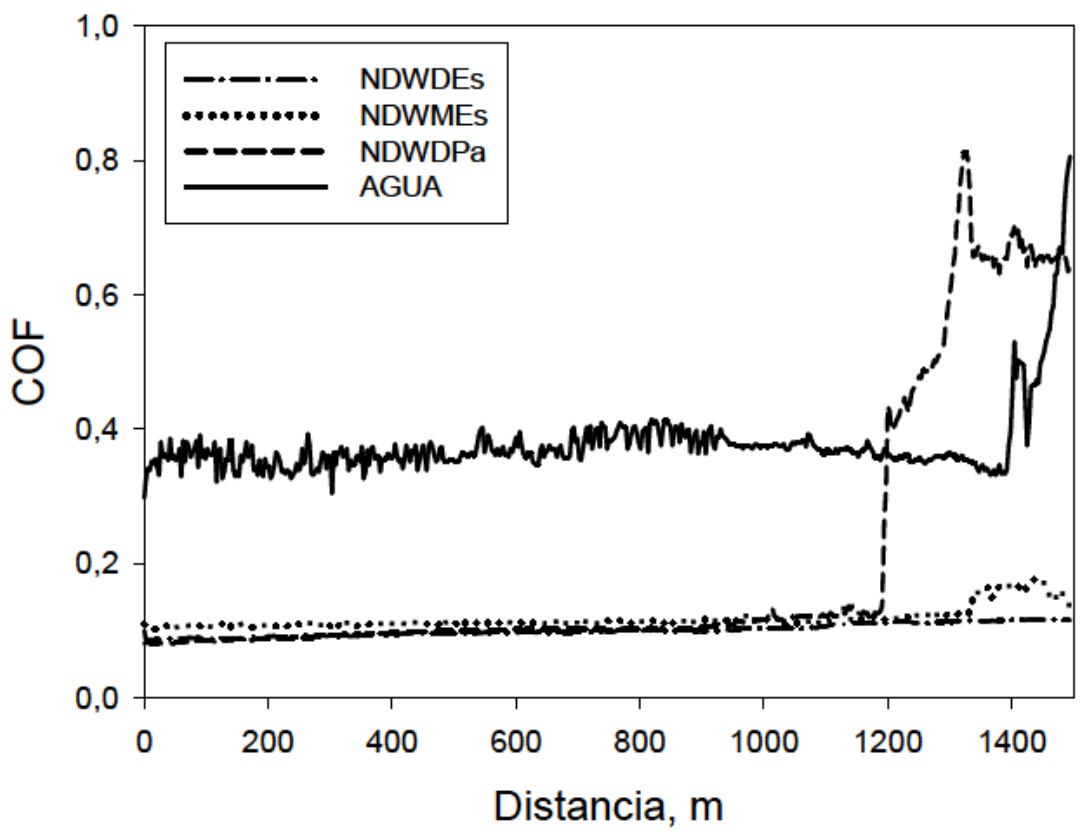

Figura 150. Evolución del coeficiente de fricción con la distancia para NDWDEs, NDWMEs,

NDWDPa y agua en ensayos en el contacto zafiro-AISI 316 a velocidad constante

Durante los 1000 metros iniciales de distancia de deslizamiento, los nuevos lubricantes obtenidos a partir de las emulsiones de líquidos iónicos próticos en agua con un $0,1 \%$ de nanodiamantes son capaces de disminuir significativamente la fricción con respecto al agua. Cuando se emplea como 
lubricante la dispersión NDWDEs, el coeficiente de fricción se mantiene estable durante toda la distancia de deslizamiento, con un valor promedio de 0,101. La otra emulsión que contiene el anión estearato, (NDWMEs) presenta una fricción ligeramente superior, en torno a 0,117.

Sin embargo, para el caso de la dispersión con DPa, una vez transcurridos unos 1200 metros de ensayo se produce la evaporación de la dispersión lubricante produciéndose un aumento significativo del coeficiente de fricción, alcanzando un máximo de 0,8 a los $1320 \mathrm{~m}$. Posteriormente, la fricción se estabiliza en torno a 0,66 , presentando un comportamiento similar al obtenido cuando se emplea agua como lubricante y ésta se evapora.

De hecho, se puede observar el aspecto que presenta la probeta tras $1000 \mathrm{~m}$ de ensayo tribológico con NDWDPa (Figura 151), donde se puede ver la presencia de lubricante líquido y a los 1500 metros, donde esto no ocurre (Figura 152).

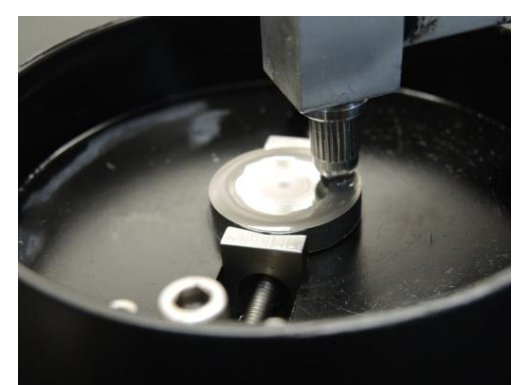

Figura 151. Probeta AISI 316L tras $1000 \mathrm{~m}$ de ensayo usando NDWDPa como lubricante

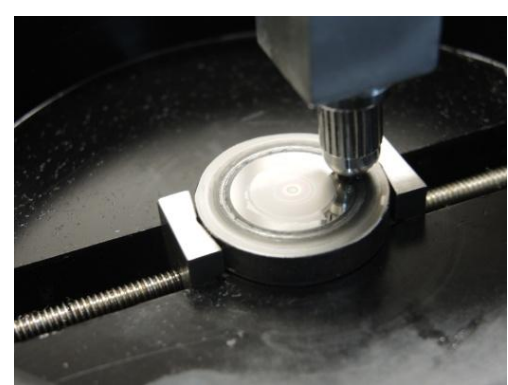

Figura 152. Probeta AISI 316L tras $1500 \mathrm{~m}$ de ensayo usando NDWDPa como lubricante

Se ha observado que el fenómeno descrito para el NDWDPa depende de la humedad ambiental. Cuando se llevaron a cabo los ensayos de larga distancia $(1500 \mathrm{~m})$ para el NDWDPa, la humedad relativa era de $63,2( \pm 0,6) \%$, sin embargo, se ha observado que si esta magnitud está por debajo del $60 \%$ se reduce la distancia de deslizamiento a la que se produce la evaporación del agua y el consiguiente aumento del coeficiente de fricción.

Por tanto, para apreciar con mayor detalle la evolución de los coeficientes de fricción y comparar el comportamiento de los tres lubricantes mientras que se encuentran en fase líquida, en la Figura 153 se muestran los resultados obtenidos para 1000 metros de distancia de deslizamiento. 
El comportamiento tribológico de las dispersiones es muy similar en todos los casos, independiente del líquido iónico empleado. Se puede observar cómo para NDWDEs y NDWDPa la fricción va aumentando desde el comienzo del ensayo, sin embargo, para la dispersión de nanodiamantes en WMEs el coeficiente de fricción permanece aproximadamente constante y con valores superiores a los presentados por las otras nanodispersiones.

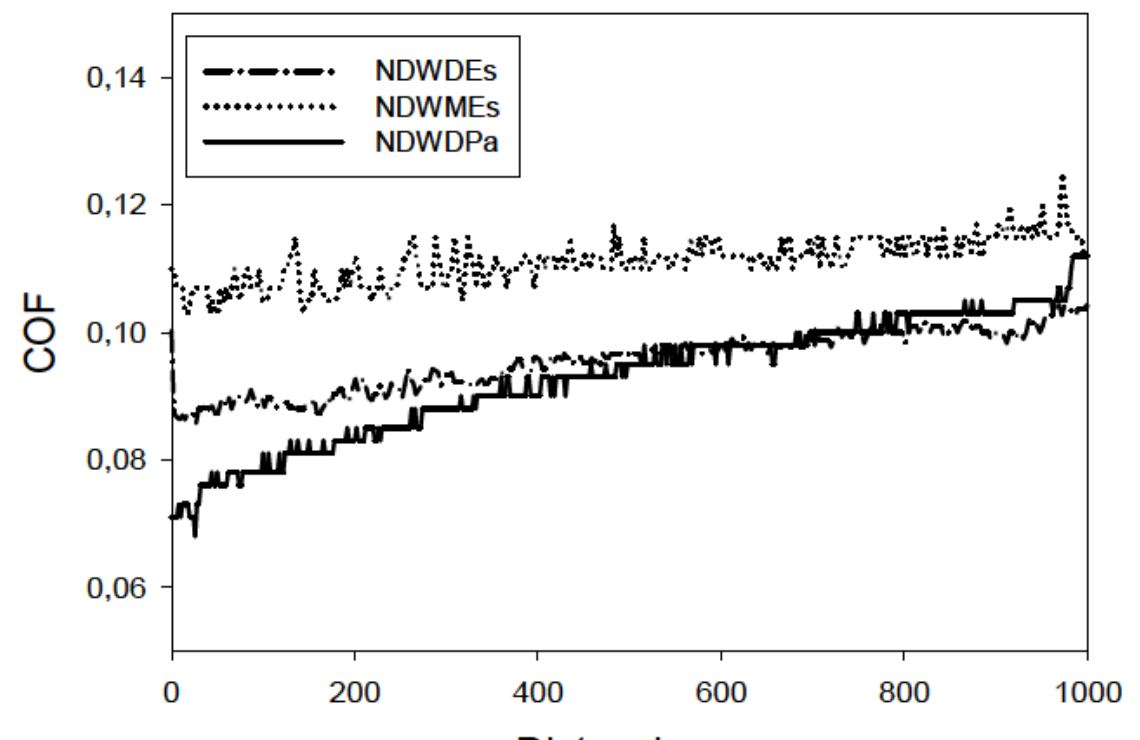

Distancia, $m$

Figura 153. Evolución del coeficiente de fricción para NDWDEs, NDWMEs y NDWDPa tras ensayos a velocidad constante $(1000 \mathrm{~m})$

En la Tabla 40 se recogen los datos del coeficiente de fricción y de la tasa de desgaste medios tras la realización de tres ensayos en las mismas condiciones para cada uno de los lubricantes. La dispersión de NDWDPa proporciona un coeficiente de fricción y una tasa de desgaste superior al resto debido a la evaporación del lubricante en los últimos metros de ensayo. Sin embargo, si se tiene en cuenta sólo la etapa de baja fricción, hasta 1000 m, es la dispersión lubricante que mejores resultados tribológicos presenta.

Tabla 40. Coeficiente de fricción y tasa de desgaste para NDWDEs, NDWMEs, NDWDPa

\begin{tabular}{ccc}
\hline & $\begin{array}{c}\text { Coeficiente de } \\
\text { fricción }\end{array}$ & $\begin{array}{c}\text { Tasa de desgaste } \\
\left(\mathrm{mm}^{3} / \mathbf{N} \cdot \mathbf{m}\right)\end{array}$ \\
\hline NDWDEs & $0,101( \pm 0,015)$ & $5,00 \times 10^{-6}\left( \pm 1,8 \times 10^{-7}\right)$ \\
\hline NDWMEs & $0,117( \pm 0,012)$ & $4,35 \times 10^{-6}\left( \pm 1,2 \times 10^{-7}\right)$ \\
\hline NDWDPa & $0,149( \pm 0,032)$ & $3,85 \times 10^{-5}\left( \pm 2,0 \times 10^{-6}\right)$ \\
\hline NDWDPa (1000 $\mathbf{m})$ & $0,096( \pm 0,002)$ & $2,50 \times 10^{-6}\left( \pm 6,9 \times 10^{-7}\right)$ \\
\hline
\end{tabular}


Si se comparan estos resultados con los obtenidos para las emulsiones sin nanofases de carbono, no se ha producido una reducción significativa en los coeficientes de fricción con la adición de los nanodiamantes. En todos los casos, es la dispersión derivada del ácido palmítico la que mejores resultados antifricción presenta. Con respecto a la tasa de desgaste, ésta es superior al añadir un $0,1 \%$ de nanodiamantes. Lo que podría deberse a la dificultad de dispersar esta nanofase, que posee una gran dureza, en las emulsiones acuosas de líquido iónico.

En la Figura 154 se muestra la topografía superficial de las huellas de desgaste y la sección transversal tras los ensayos realizados con las dispersiones de líquidos iónicos y nanodiamantes en agua. Se observa una mayor profundidad y acumulación de material tras la lubricación con NDWMEs.
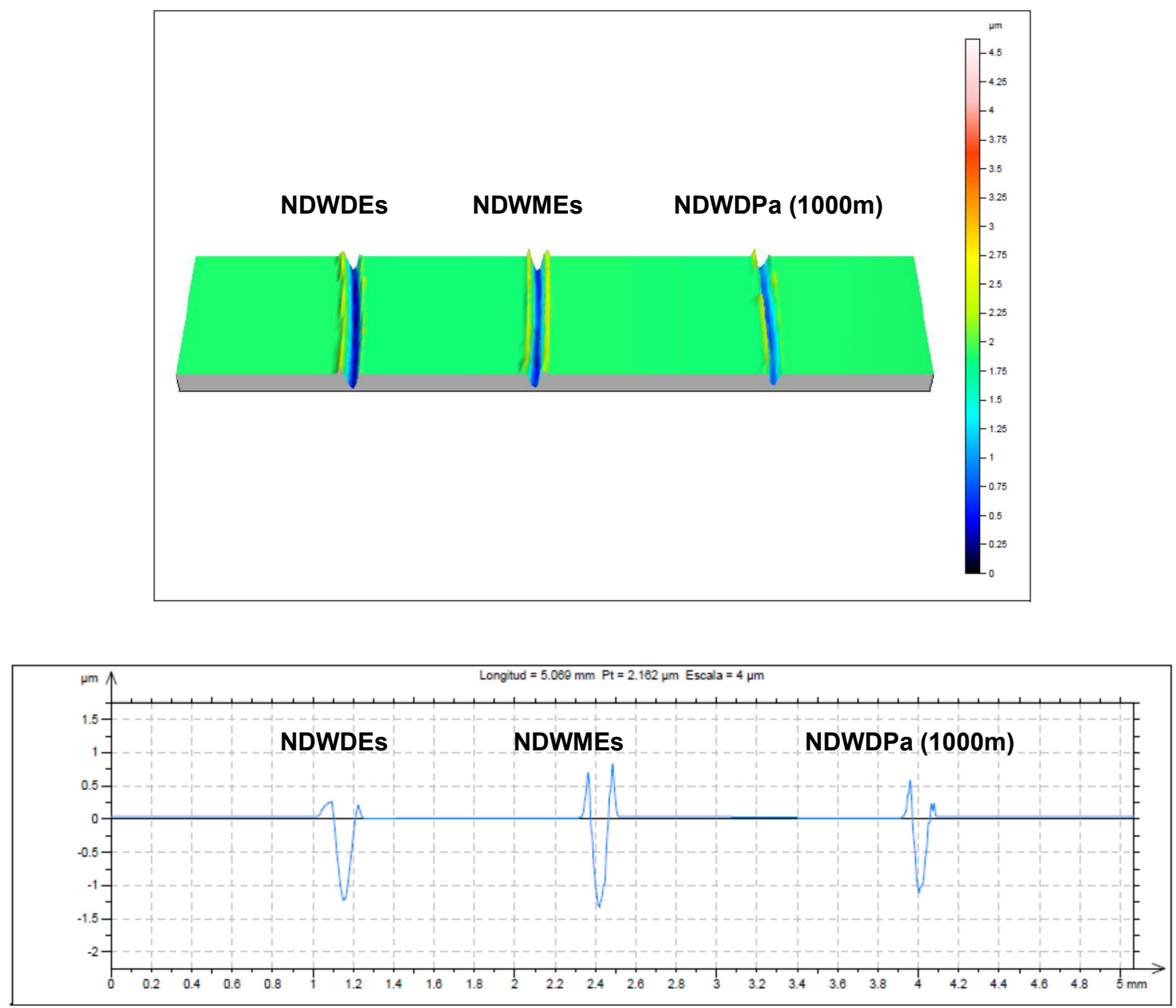

Figura 154. Topografía superficial y sección transversal de las huellas de desgaste sobre acero AISI 316L tras lubricación con NDWDEs, NDWMEs y NDWDPa a velocidad constante 
Se ha realizado un análisis de la superficie de las huellas de desgaste obtenidas tras la lubricación con las dispersiones de nanodiamantes en las emulsiones de líquido iónico.

En primer lugar, se muestra una micrografía SEM de la huella de desgaste sobre el disco de acero tras lubricación con NDWDEs, observándose líneas de abrasión en el interior de la huella, así como deformación plástica en los bordes (Figura 155a).

En las imágenes de los mapas elementales de esta huella se observa un ligero incremento de la concentración de $\mathrm{C}$ y $\mathrm{O}$ en el interior de la misma, quizás debido a la presencia de líquido iónico y la nanofase de carbono (Figura 155c y d).

a)

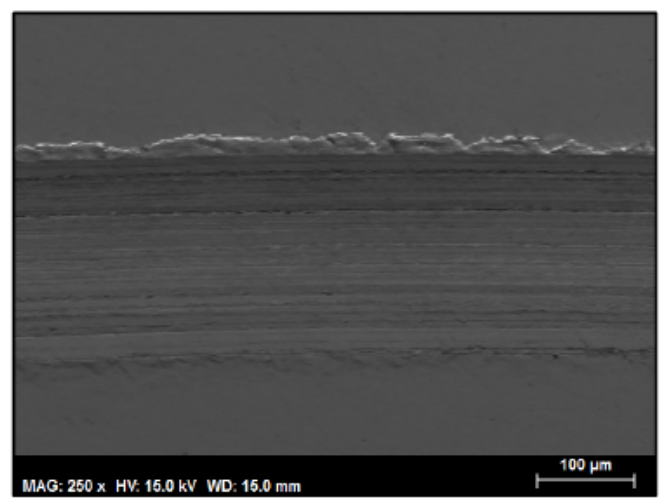

c)

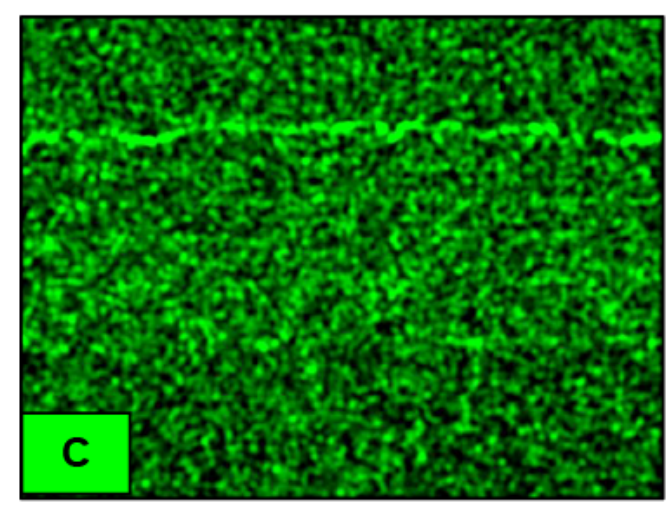

b)

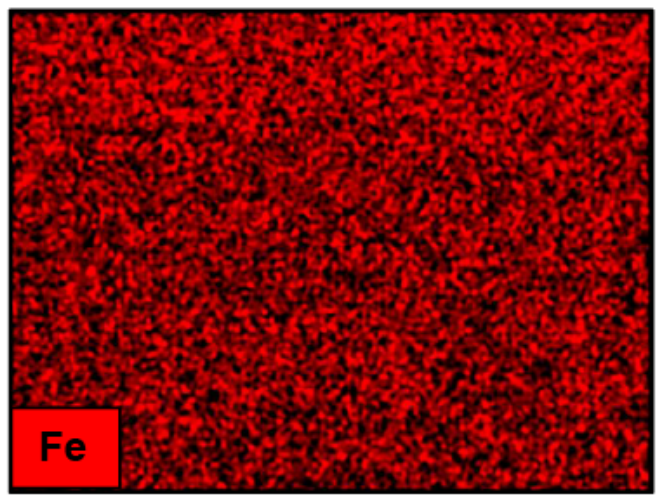

d)

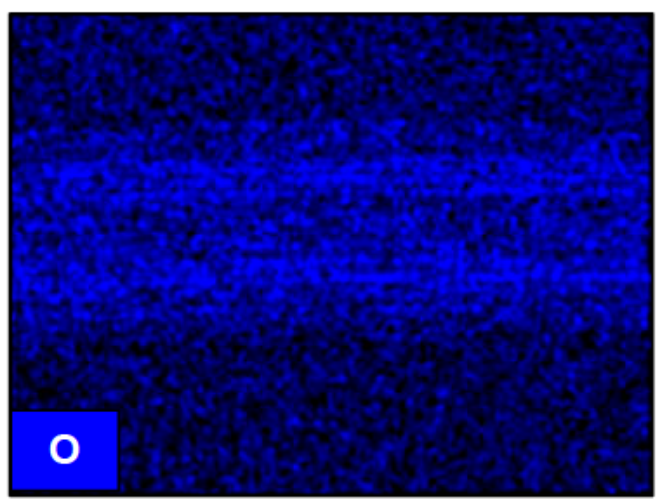

Figura 155. a) Micrografía SEM de la huella de desgaste sobre AISI 316L tras lubricación con NDWDEs a velocidad constante; b) Mapa elemental de Fe; c) Mapa elemental de C;

d) Mapa elemental de $O$ 
Los resultados obtenidos tras la lubricación con NDWMES son similares a los mostrados anteriormente. Se observan marcas de abrasión en el interior de la huella, y en este caso, el mapa elemental de oxígeno muestra un significativo incremento de la concentración de este elemento en la huella.

a)

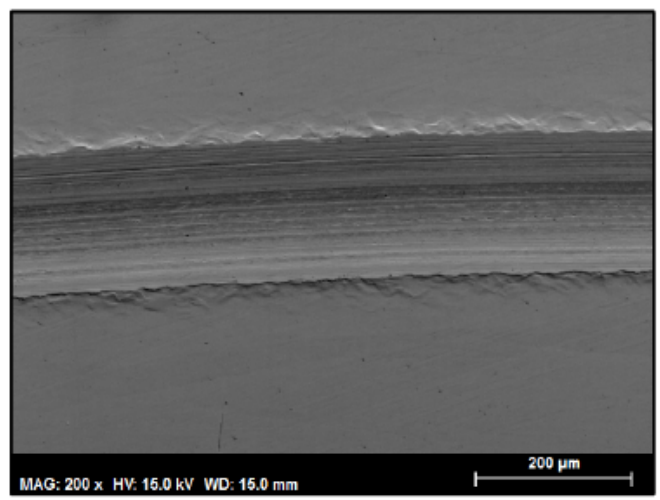

c)

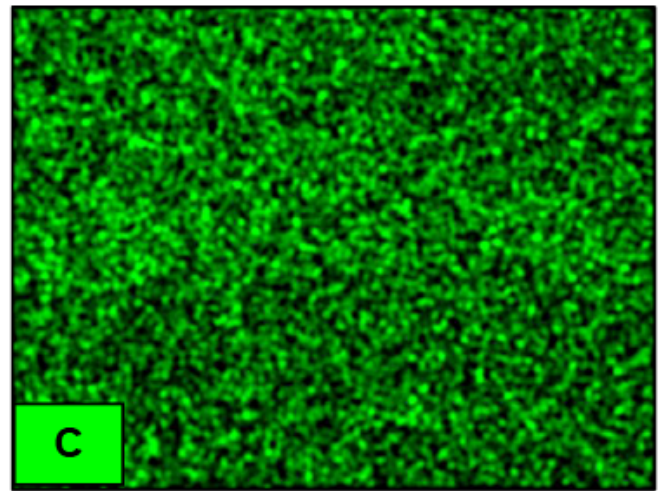

b)

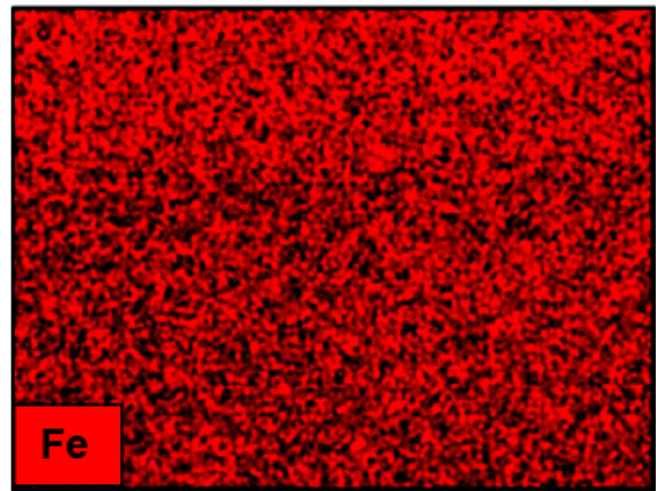

d)

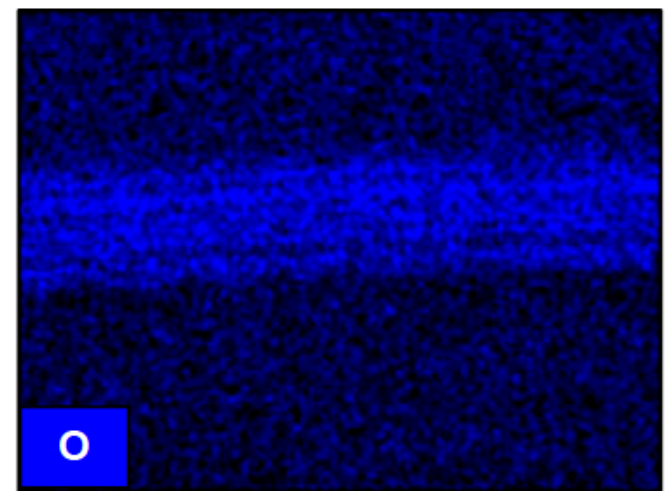

Figura 156. a) Micrografía SEM de la huella de desgaste sobre AISI 316L tras lubricación con NDWMEs a velocidad constante; b) Mapa elemental de Fe; c) Mapa elemental de C; d) Mapa elemental de $\mathrm{O}$

El análisis mediante microscopía electrónica de barrido de la huella de desgaste, obtenida tras el ensayo tribológico empleando NDWDPa como lubricante durante $1000 \mathrm{~m}$, se muestra en la Figura 157. En este caso, los mapas elementales de $\mathrm{C}$ y $\mathrm{O}$ son muy similares dentro y fuera de la huella. 
a)

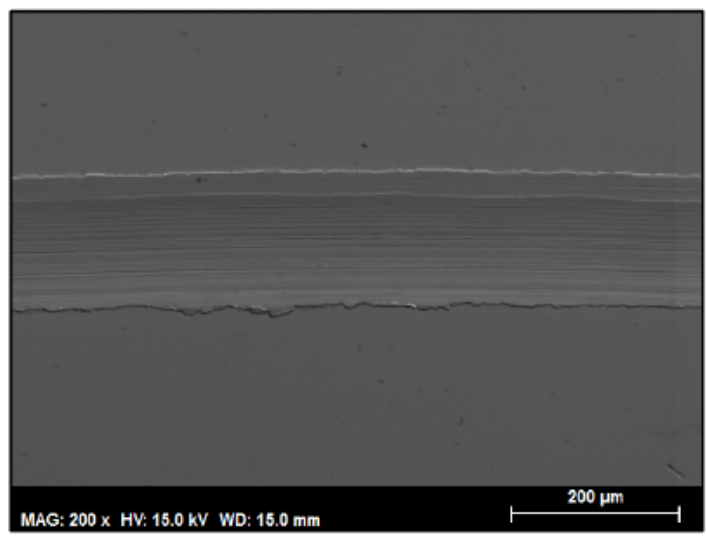

c)

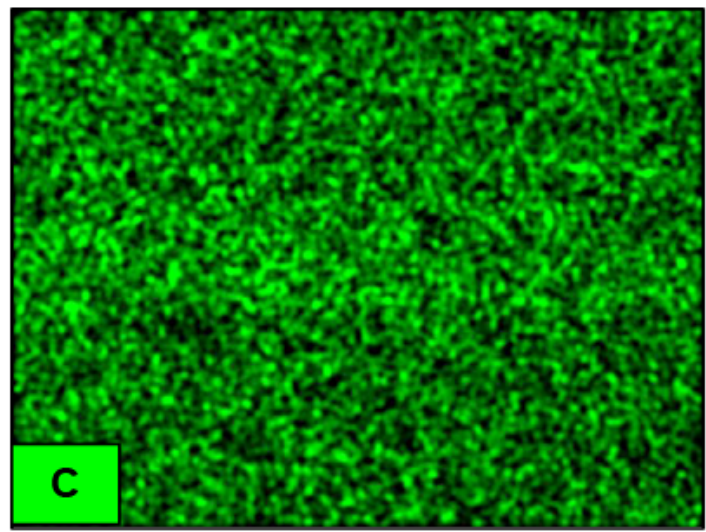

b)

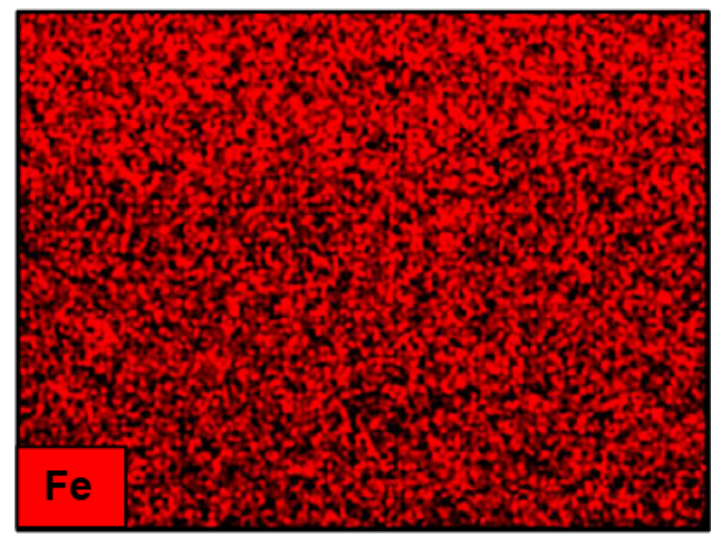

d)

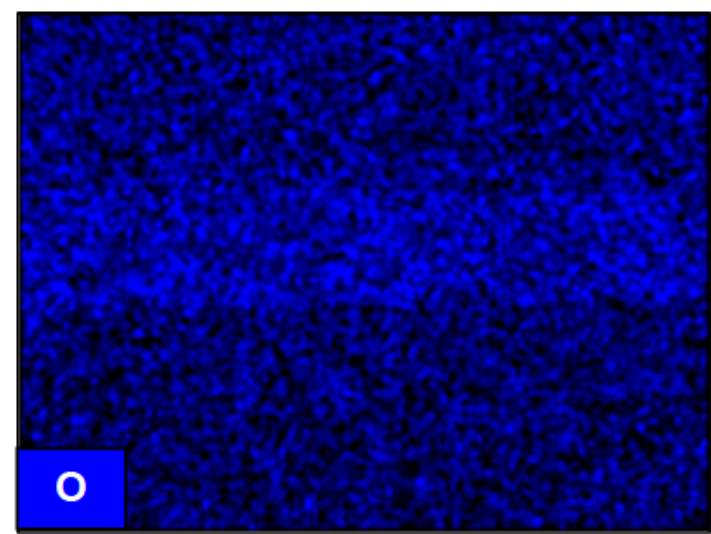

Figura 157. a) Micrografía SEM de la huella de desgaste sobre AISI 316L tras lubricación con NDWDPa a velocidad constante; b) Mapa elemental de Fe; c) Mapa elemental de C;

d) Mapa elemental de $\mathrm{O}$

\subsubsection{Conclusiones}

Se han estudiado cristales líquidos iónicos derivados de ácidos grasos como aditivos lubricantes en agua. Los resultados de las medidas de espesores de película lubricante y coeficientes de fricción permiten extraer las siguientes conclusiones.

1) En todos los casos, el incremento en el espesor de película mejora el comportamiento de los lubricantes.

2) En el caso del agua pura, tomada como referencia, se obtienen espesores de película negativos, lo que indica que se produce desgaste como consecuencia del fallo del lubricante. Además, el espesor de película disminuye y el coeficiente de fricción aumenta con el incremento del número de ciclos de desplazamiento.

3) En contraste, cuando se añade al agua uno de los cristales líquidos iónicos, el espesor de película aumenta con el número de deslizamientos, confirmando la formación de una película lubricante en la interfase. El 
menor coeficiente de fricción se obtiene para el aditivo derivado del palmitato.

4) La adición de nanodiamantes a la emulsión de palmitato de bis(2hidroxietilamonio) incrementa el espesor de película, pero sólo reduce el coeficiente de fricción en el primer ciclo de desplazamiento. Esto se atribuye a la baja estabilidad de la dispersión de nanodiamantes bajo las condiciones de deslizamiento.

En el estudio de la influencia de la velocidad de deslizamiento sobre la capacidad lubricante de las emulsiones de cristales líquidos iónicos en agua, se han alcanzado las siguientes conclusiones:

5) En lubricación del contacto acero-acero a baja velocidad, el agua pura presenta altos coeficientes de fricción y baja resistencia eléctrica en el contacto. Cuando la velocidad se incrementa por encima de $100 \mathrm{~mm} / \mathrm{s}$, se produce una transición a coeficientes de fricción más bajos y resistencia eléctrica mayor, lo que está de acuerdo con la mejora de la eficacia de los lubricantes al aumentar el espesor de película en la interfase.

6) La adición de los cristales líquidos iónicos reduce en un $75-80 \%$ el coeficiente de fricción con respecto al agua, en todo el rango de velocidades de deslizamiento estudiado. Así mismo, la resistencia eléctrica alcanza valores inferiores a los obtenidos en el caso del agua. Ambos aditivos reducen las tasas de desgaste con respecto al agua en un orden de magnitud.

7) Para contactos zafiro-acero, velocidades mayores de $100 \mathrm{~m} / \mathrm{s}$ incrementan el coeficiente de fricción. La mayor reducción de fricción se consigue para la combinación del aditivo derivado de palmitato con nanodiamantes.

Estos resultados demuestran la capacidad los de líquidos iónicos próticos, derivados de ácidos grasos y medioambientalmente compatibles, para mejorar la eficacia de lubricantes base agua. 


\subsubsection{Dispersiones con el líquido iónico prótico DSu}

\subsubsection{Disolución de líquido iónico prótico DSu en agua}

Se ha estudiado el comportamiento tribológico del líquido iónico prótico succinato de di[bis(2-hidroxietil)amonio], otro líquido iónico no tóxico y derivado de un ácido biocompatible. Se ha empleado como lubricante en el contacto zafiro-acero inoxidable AISI $316 \mathrm{~L}$, así como la disolución al $1 \%$ de este líquido iónico en agua.

La disolución obtenida se ha empleado como lubricante externo y en forma de película fina obtenida mediante la evaporación controlada del agua de la disolución en una estufa de vacío (3.2.1.7).

\subsubsection{1. Ángulo de contacto}

En primer lugar se ha determinado el ángulo de contacto de la disolución con un $1 \%$ de DSu en agua (Tabla 41) y se han comparado los resultados obtenidos con los presentados por el líquido iónico puro y el agua.

Tabla 41. Ángulos de contacto de DSu, Agua y Agua+1\%DSu sobre AISI 316L

\begin{tabular}{|c|c|c|c|}
\hline & $\begin{array}{l}\text { Ángulos de } \\
\text { contacto }\end{array}$ & Inicial & Final \\
\hline $\begin{array}{l}\text { DSu sobre } \\
\text { acero AISI } \\
\text { 316L }\end{array}$ & $\begin{array}{l}\text { Ángulo Inicial } \\
89,6( \pm 1,9)^{\circ} \\
\text { Ángulo Final } \\
57,1( \pm 3,0)^{\circ}\end{array}$ & & \\
\hline $\begin{array}{l}\text { Agua+1\%DSu } \\
\text { sobre acero } \\
\text { AISI } 316 \mathrm{~L}\end{array}$ & $\begin{array}{l}\text { Ángulo Inicial } \\
47,3( \pm 3,8)^{\circ} \\
\text { Ángulo Final } \\
37,4( \pm 3,8)^{\circ}\end{array}$ & & \\
\hline $\begin{array}{l}\text { Agua sobre } \\
\text { acero AISI } \\
316 \mathrm{~L}\end{array}$ & $\begin{array}{l}\text { Ángulo Inicial } \\
48,2( \pm 2,1)^{\circ} \\
\text { Ángulo Final } \\
42,4( \pm 1,8)^{\circ}\end{array}$ & & \\
\hline
\end{tabular}


Se puede concluir que el valor de ángulo de contacto inicial de la disolución Agua $+1 \% D$ Su es similar al que presenta el agua, aunque el ángulo final tras 5 minutos sea inferior. La mayor mojabilidad de esta disolución sobre el acero inoxidable AISI $316 \mathrm{~L}$ podría suponer un mejor comportamiento tribológico.

\subsection{Estudio tribológico}

Se han realizado ensayos tribológicos punzón sobre disco para comparar la evolución del coeficiente de fricción del líquido iónico DSu y la disolución de $1 \%$ en peso de DSu en agua, tras lubricación en película gruesa y en capa fina, tal y como se recoge en la Figura 158.

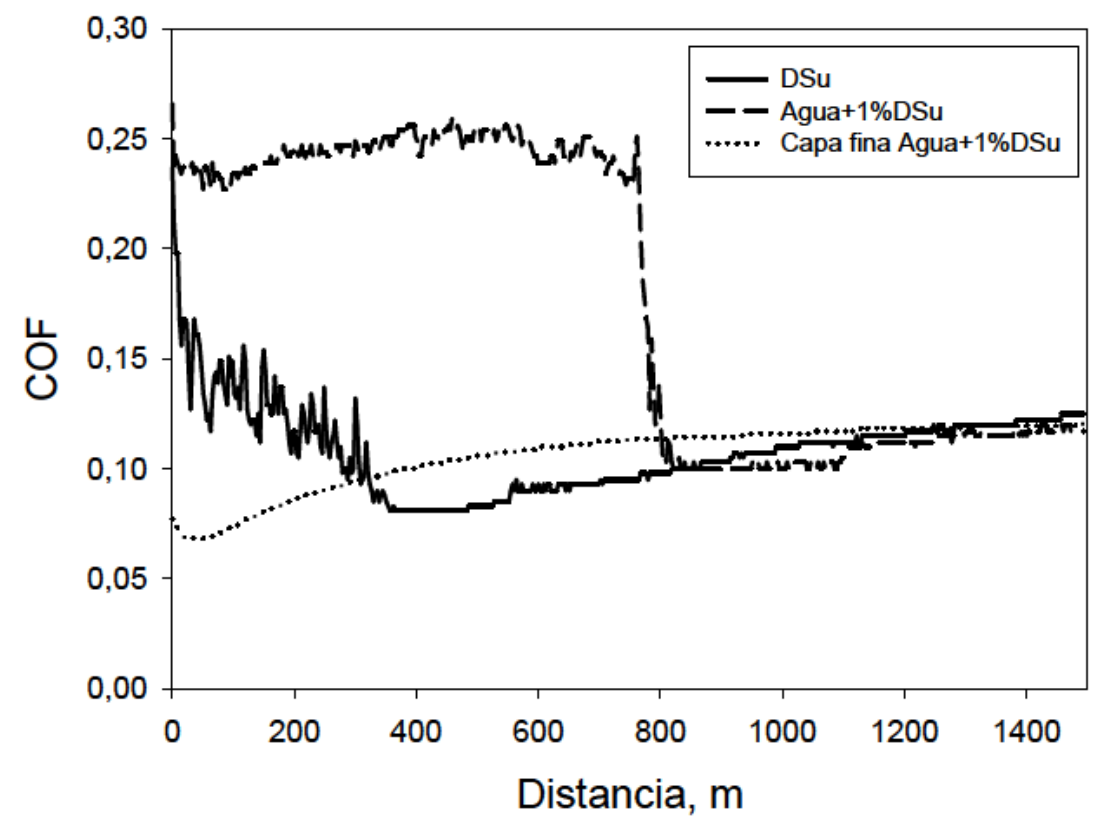

Figura 158. Evolución del coeficiente de fricción con la distancia de deslizamiento para DSu, Agua $+1 \%$ DSu y Capa fina de Agua $+1 \%$ DSu

La curva de fricción del líquido iónico puro presenta una etapa de alta fricción hasta una distancia de deslizamiento de 350 metros, estabilizándose después en un valor de 0,11 .

Como se puede observar, al emplear la disolución de Agua+1\%DSu como lubricante, existe una etapa inicial de alta fricción con un coeficiente de 0,24 ( \pm $0,01)$. Como consecuencia de la evaporación del agua de la disolución, en torno a los 800 metros de distancia de deslizamiento, la fricción se reduce drásticamente hasta alcanzar el valor de fricción del líquido iónico puro. Este tipo de comportamiento ya ha sido descrito para otros líquidos iónicos próticos 
[235] como el citrato de tri[bis(2-hidroxietil)amonio] (DCi) [234] y el succinato de di[2-hidroxietilamonio] (MSu) [102] para el contacto zafiro-acero.

La disminución de la fricción en la segunda fase del ensayo podría deberse a la creación de una capa de DSu homogénea y de poco espesor que cubre la probeta de acero tras la evaporación del agua, debido a la alta temperatura que se alcanza en el contacto.

En el caso de emplear una capa fina de DSu, obtenida tras la evaporación controlada (apartado 3.3.1.6) del agua de la disolución de Agua+1\%DSu, el coeficiente de fricción al principio del ensayo es muy bajo y se va incrementando hasta estabilizarse en un valor en torno a 0,1 al final del ensayo. Con este método se logra crear una superficie autolubricante mediante una película delgada de manera que los coeficientes de fricción y las tasas de desgaste obtenidas son muy inferiores a los que se obtienen en presencia de agua (Tabla 42). Esto podría deberse a la formación de una película adsorbida ordenada de moléculas del líquido iónico DSu.

Tabla 42. Coeficientes de fricción y tasas de desgaste tras lubricación con DSu, Agua+1\%DSu en película gruesa y en capa fina

\begin{tabular}{cccc}
\hline & $\begin{array}{c}\text { Coeficiente de } \\
\text { fricción } \\
\mathbf{0 - 1 5 0 0 ~} \mathbf{~}\end{array}$ & $\begin{array}{c}\text { Coeficiente de } \\
\text { fricción } \\
\mathbf{8 0 0 - 1 5 0 0 ~} \mathbf{m}\end{array}$ & $\begin{array}{c}\text { Factor de desgaste } \\
\left(\mathbf{m m}^{3} / \mathbf{N} \cdot \mathbf{m}\right)\end{array}$ \\
\hline DSu & $0,12( \pm 0,01)$ & $0,11( \pm 0,007)$ & $\begin{array}{c}2,64 \times 10^{-5} \\
\left( \pm 1,0 \times 10^{-6}\right)\end{array}$ \\
\hline Agua+1\%DSu & $0,18( \pm 0,01)$ & $0,11( \pm 0,005)$ & $\begin{array}{c}1,87 \times 10^{-5} \\
\left( \pm 1,5 \times 10^{-6}\right)\end{array}$ \\
\hline $\begin{array}{c}\text { Capa fina } \\
\text { Agua+1\%DSu }\end{array}$ & $0,10( \pm 0,01)$ & & $\begin{array}{c}1,57 \times 10^{-7} \\
\left( \pm 2,2 \times 10^{-8}\right)\end{array}$ \\
\hline
\end{tabular}

En la Figura 159 se puede observar la notable diferencia en el factor de desgaste obtenido al emplear el mismo lubricante (Agua+1\%DSu) en forma de película gruesa o de capa fina. De hecho, al emplear la capa fina, se logra una disminución de la tasa de desgaste del $99,16 \%$ con respecto a la lubricación con la disolución de líquido iónico en agua. 
María Dolores Avilés González

Universidad Politécnica de Cartagena

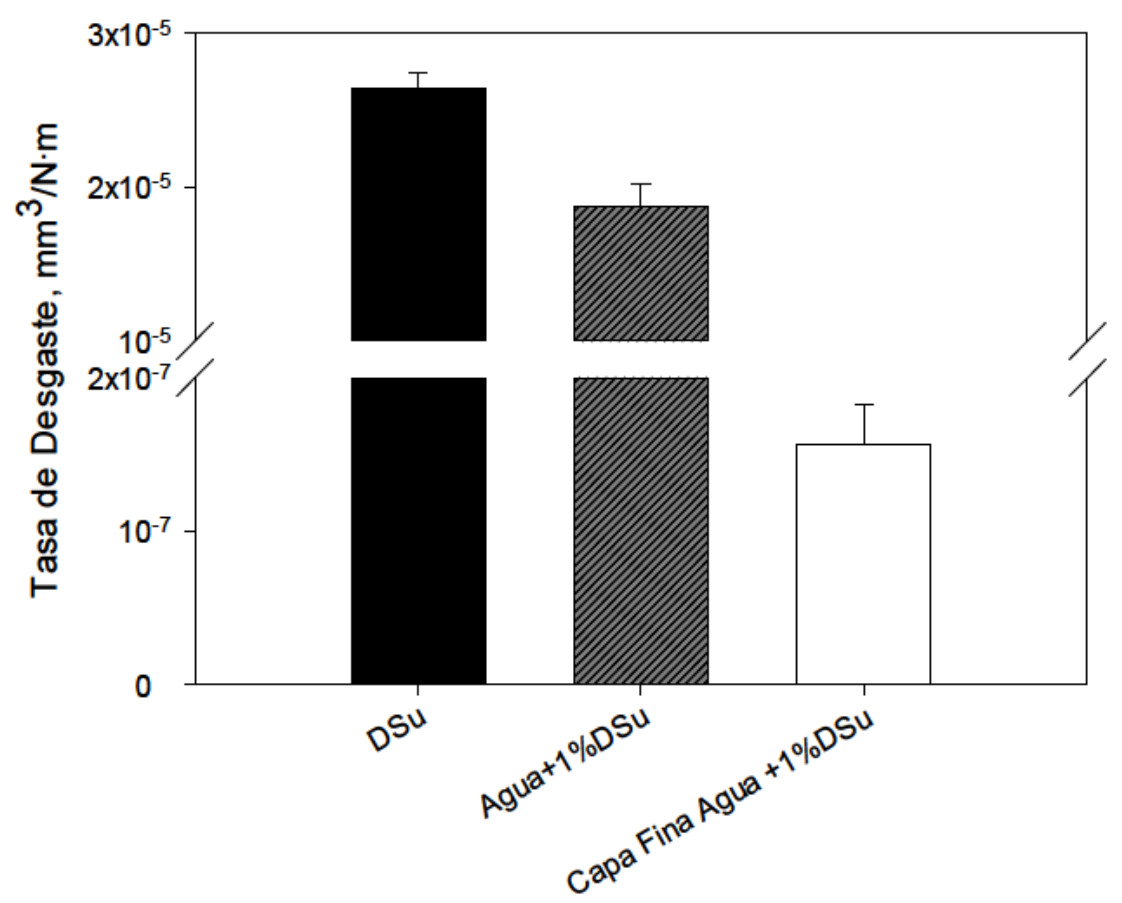

Figura 159. Tasas de desgaste sobre discos de acero inoxidable obtenidas tras lubricación con DSu y Agua+1\%DSu en capa fina y película gruesa

Las imágenes de la topografía superficial y de las secciónes transversales de las huellas de desgaste muestran el imperceptible desgaste obtenido tras la lubricación con la capa fina. Mientras que tras la lubricación con líquido iónico o la disolución con agua, se obtiene un desgaste muy severo con acumulación de material en los bordes de la huella.
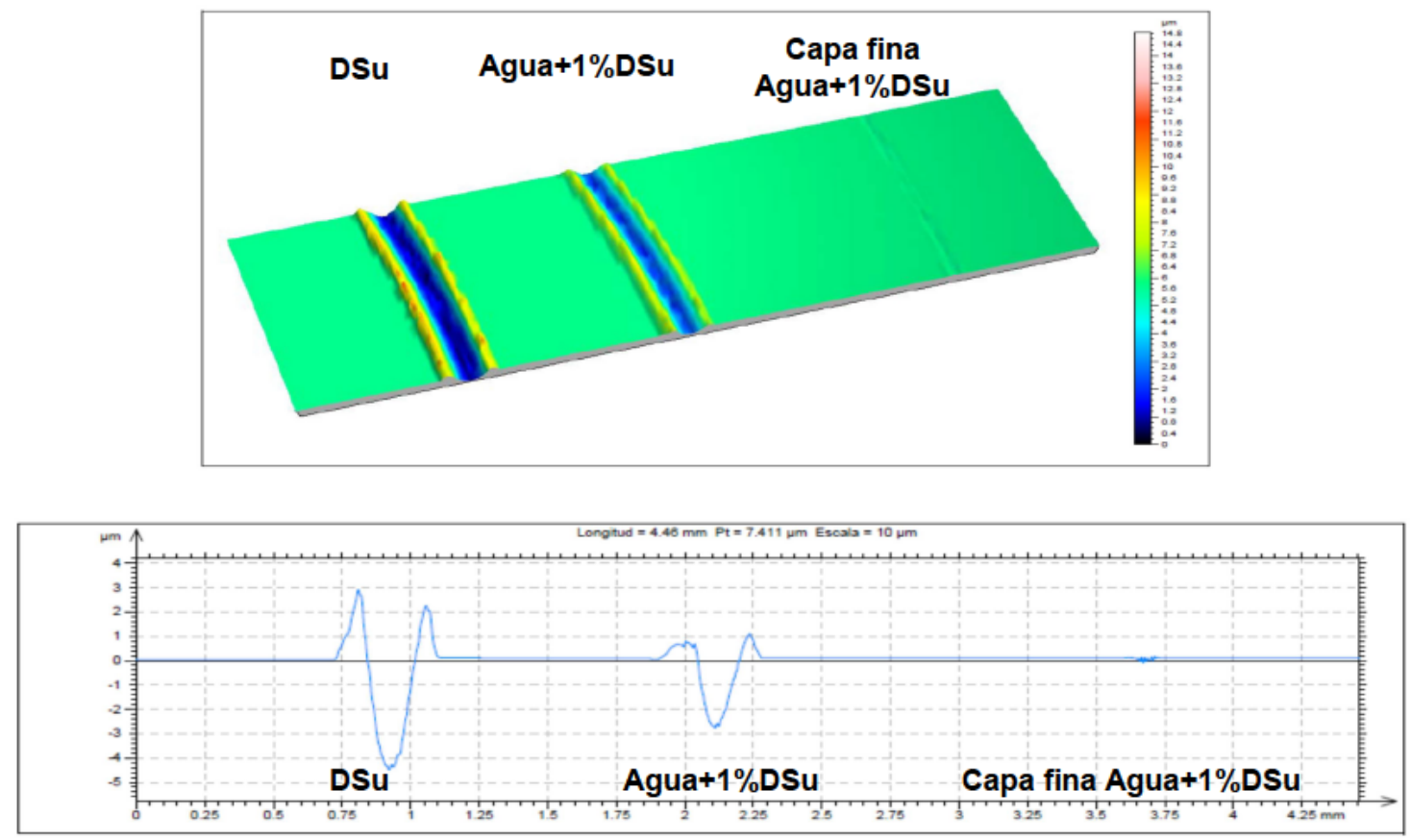

Figura 160. Perfiles superficiales en 3D de las huellas de desgaste y sección transversal tras lubricación con DSu, Agua+1\%DSu y capa fina de agua+1\%DSu 
En la Figura 161 se muestra el análisis realizado mediante microscopía electrónica de barrido y EDX de la huella de desgaste obtenida tras los ensayos tribológicos empleando el líquido iónico DSu como lubricante. La superficie de la huella sobre el disco de acero muestra marcas paralelas de abrasión y deformación plástica en los bordes. En los mapas elementales se observa un ligero aumento de la concentración de oxígeno y carbono en los bordes de la huella.

a)

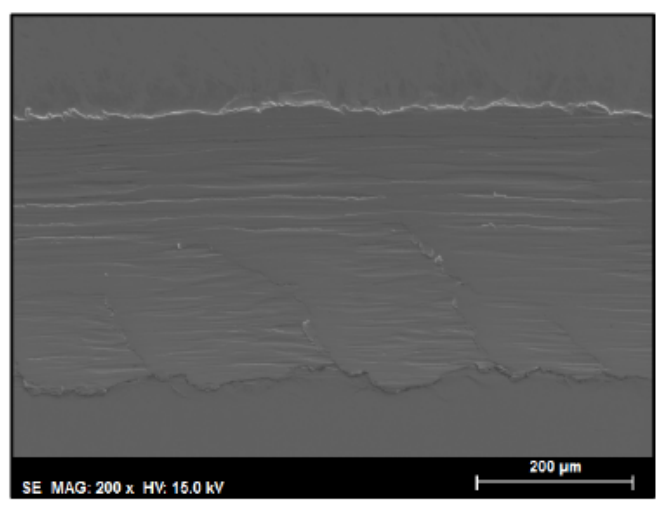

c)

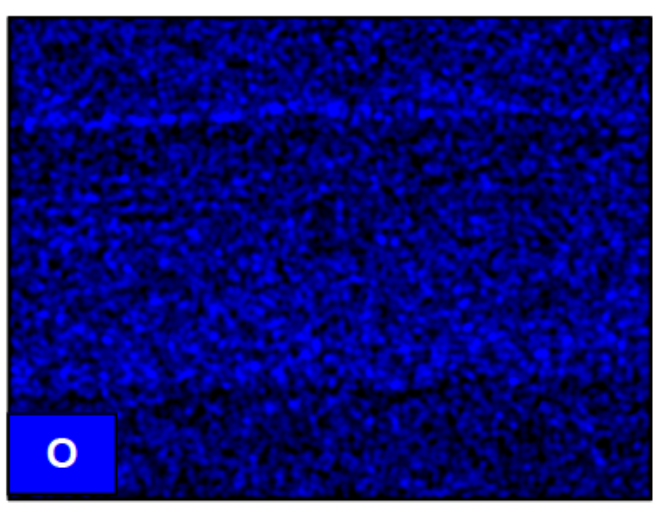

b)

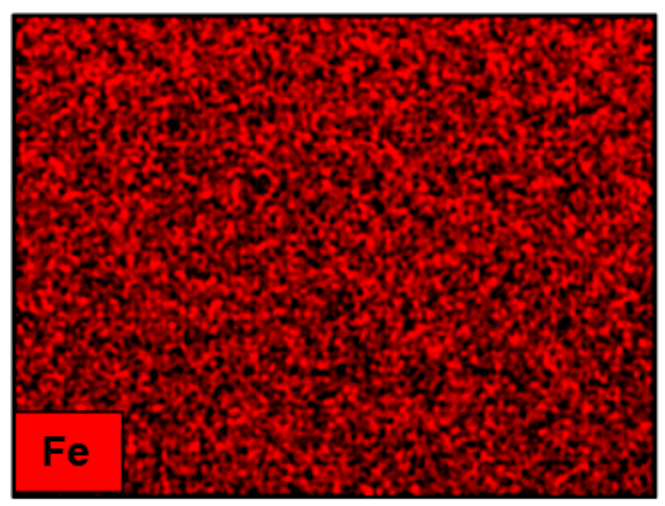

d)

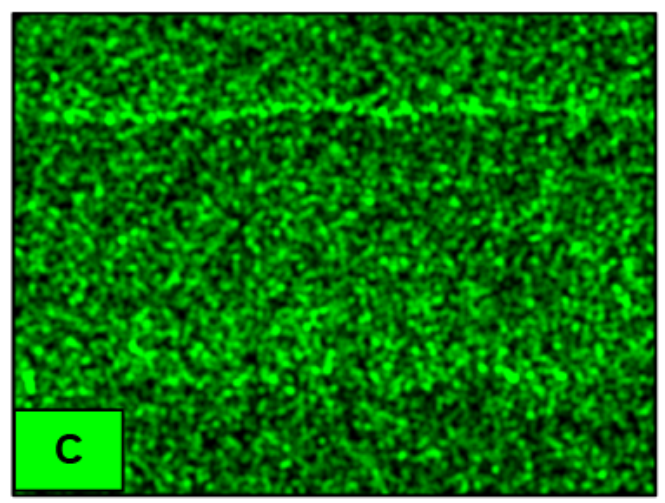

Figura 161. a) Micrografía SEM de la huella de desgaste tras lubricación con DSu. Mapas elementales: b) Hierro; c) Oxígeno; d) Carbono

En la Figura 162a se muestra la huella de desgaste sobre el disco de AISI 316L cuando se emplea la disolución de Agua+1\%DSu como lubricante. Se observa un desgaste moderado, con deformación plástica en los bordes de la huella aunque menor que el obtenido en el caso del DSu (Figura 161). Tras el análisis EDX realizado en la superficie de acero inoxidable (Figura 162b), se puede observar sólo un ligero aumento de la concentración de oxígeno, que puede ser debida a la oxidación en presencia de agua. 
a)

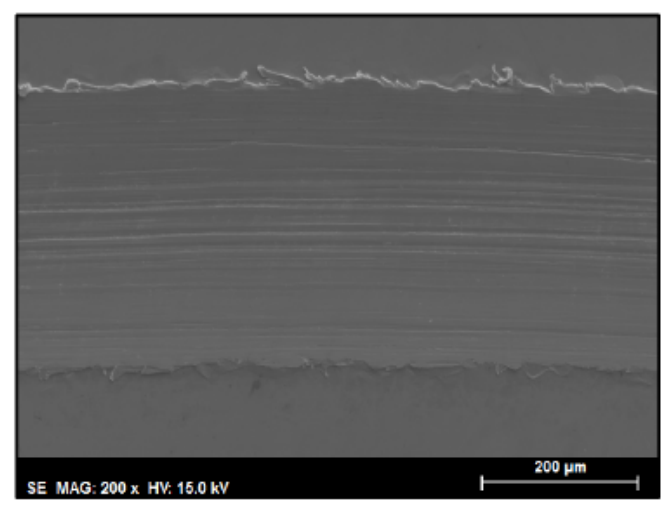

b)

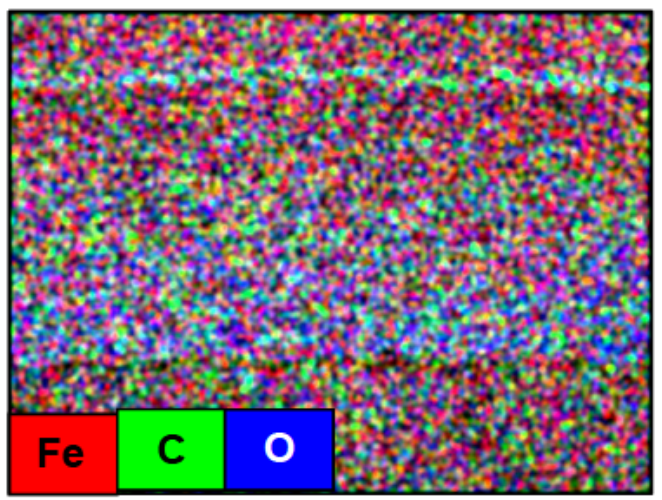

Figura 162. a) Micrografía SEM de la huella de desgaste tras lubricación con Agua+1\%DSu;

b) Mapa elemental de $\mathrm{Fe}, \mathrm{C}$ y $\mathrm{O}$

En la Figura 163 se muestra la huella de desgaste obtenida tras el ensayo realizado con la capa fina de Agua+1\%DSu. La huella de desgaste es inapreciable y no se producen cambios en la composición al analizarla de forma semicuantitativa mediante EDX.

a)

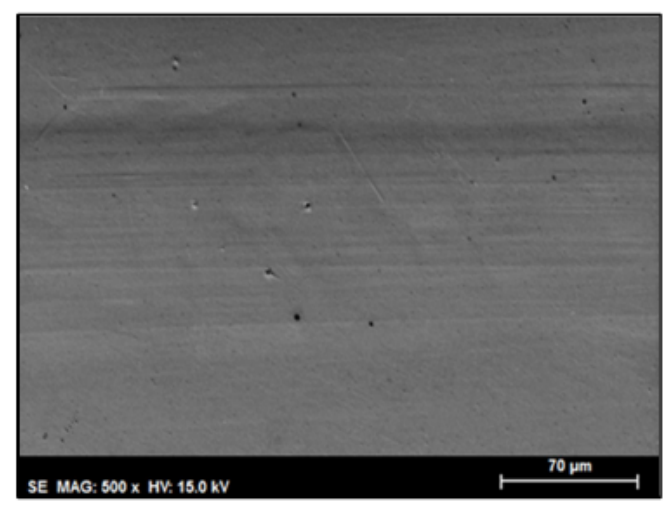

b)

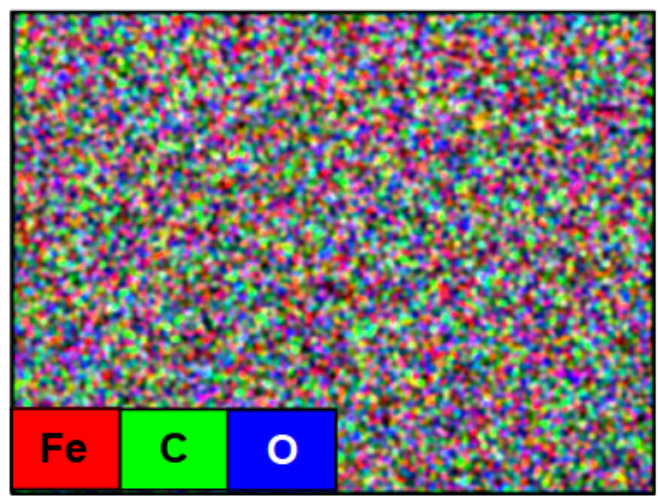

Figura 163. a) Micrografía SEM de la huella de desgaste tras lubricación con capa fina de Agua+1\%DSu; b) Mapa elemental de Fe, C y O

Con el fin de estudiar las interacciones entre el líquido iónico y la superficie de acero tras el ensayo tribológico con la capa fina de Agua+1\%DSu se ha comparado el espectro Raman del líquido iónico puro (Figura 164) con el obtenido en una zona del interior de la huella de desgaste (Figura 165). 


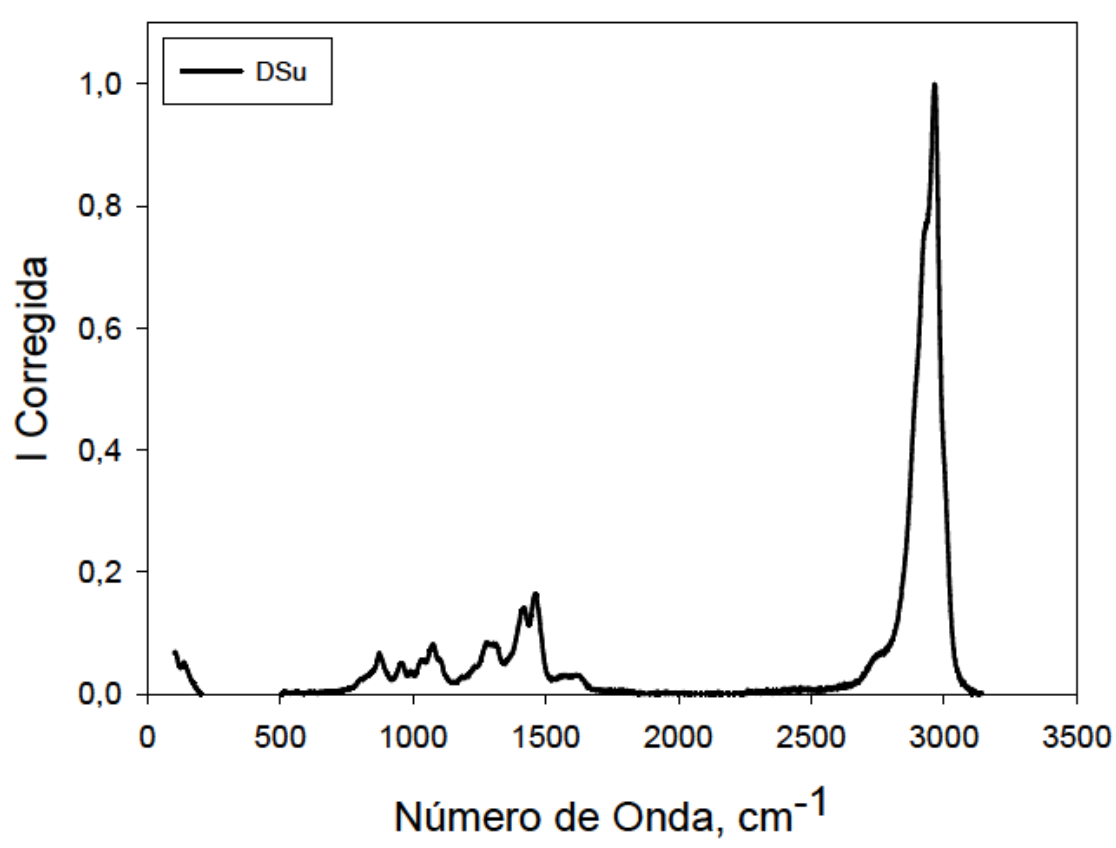

Figura 164. Espectro Raman del líquido iónico DSu

Con respecto al líquido iónico DSu, presenta ciertas bandas con mayor intensidad, que pueden ser asignadas a los grupos funcionales presentes en su estructura (Tabla 43).

Tabla 43. Asignación de bandas del espectro Raman del líquido iónico DSu

\begin{tabular}{|c|c|}
\hline $\begin{array}{l}\text { Número de onda } \\
\left(\mathrm{cm}^{-1}\right)\end{array}$ & Grupo funcional/Vibración \\
\hline 2964,15 & $v(C-H)[295]$ \\
\hline 1614,62 & $v(C=0)[296]$ \\
\hline 1460,76 & $\overline{\operatorname{oas}}\left(\mathrm{CH}_{3}\right)$ [295] \\
\hline 1419,54 & v (COO) [297] \\
\hline 1277,55 & $v(\mathrm{C}-\mathrm{N})$ y $\bar{\delta}(\mathrm{N}-\mathrm{H})[298]$ \\
\hline 1079,10 & v $(\mathrm{C}-\mathrm{O}-\mathrm{C})$ y $\bar{\delta}(\mathrm{C}-\mathrm{O}-\mathrm{H})$ [299] \\
\hline
\end{tabular}

Tras la lubricación con la capa fina obtenida a partir de Agua+1\%DSu (Figura 165), se puede observar cómo aparece la banda característica del O-H $\left(3054,77 \mathrm{~cm}^{-1}\right)$ [300]. El pico asignable a la vibración de los enlaces $\mathrm{v}(\mathrm{C}-\mathrm{H})$ $\left(2912 \mathrm{~cm}^{-1}\right)$ es muy intenso, pudiendo ser debido a la formación de una capa de líquido iónico adsorbida sobre la superficie del acero. También aparecen las señales correspondientes a las vibraciones $\mathrm{v}(\mathrm{C}=\mathrm{O})$ y $\mathrm{C}-\mathrm{O}\left(1599,02 \mathrm{~cm}^{-1}\right.$ y 1076 $\mathrm{cm}^{-1}$ ) y se pueden observar picos asignables a la formación de óxidos, principalmente de $\mathrm{Fe}_{2} \mathrm{O}_{3}\left(273,8 \mathrm{~cm}^{-1}\right)$ [301] . 


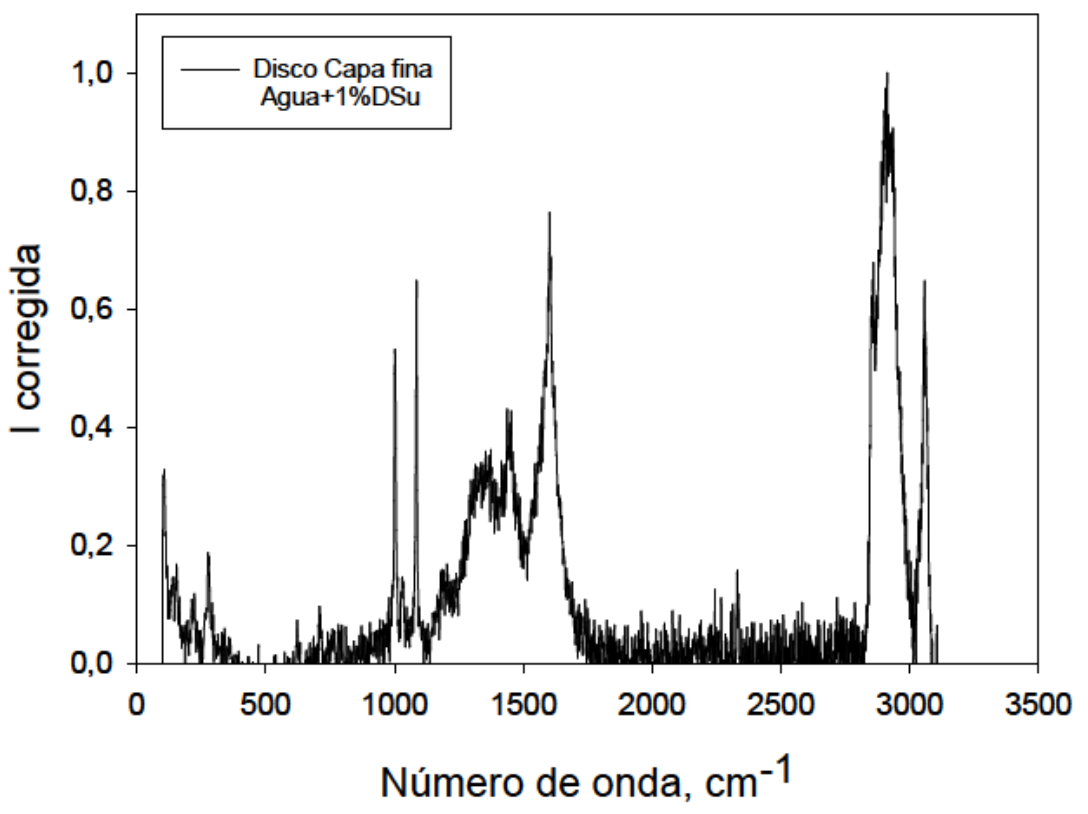

Figura 165. Espectro Raman de una zona del interior de la huella de desgaste tras lubricación con capa fina agua $+1 \% \mathrm{DSu}$

También se han estudiado las interacciones superficiales mediante espectroscopía XPS. En este caso, no ha sido posible analizar el líquido iónico puro, debido a restricciones del equipo, pero se pueden comparar los resultados obtenidos con los que aparecen en la bibliografía [102] para el líquido iónico MSu, el succinato de di[2-hidroxietilamonio], un líquido iónico prótico con el mismo anión que el DSu.

El líquido iónico MSu presenta tres picos de similar intensidad asignables a las energías de ligadura del $\mathrm{O} 1 \mathrm{~s}$ a $531,38 \mathrm{eV}, 532,11 \mathrm{eV}$ y 533,07 eV, correspondientes a los grupos $\mathrm{C}=\mathrm{O}, \mathrm{O}-\mathrm{H}$ y $\mathrm{C}-\mathrm{O}$ respectivamente, presentes en las moléculas de líquido iónico. El pico N1s del catión de amonio aparece a $399,67 \mathrm{eV}$ mientras que las energías correspondientes a C1s que aparecen a $285,00 \mathrm{eV}, 286,14 \mathrm{eV}, 287,86 \mathrm{eV}$ y $288,93 \mathrm{eV}$, son asignables a los carbonos alquílicos, y a los enlaces $\mathrm{C}-\mathrm{O}, \mathrm{C}-\mathrm{N}$ y $\mathrm{C}=\mathrm{O}$ respectivamente.

Los resultados de XPS correspondientes a la superficie de acero inoxidable AISI $316 \mathrm{~L}$ después de los ensayos de lubricación con capa fina de Agua+1\%DSu, dentro y fuera de la huella, se recogen en la Tabla 44. 
Tabla 44. Análisis XPS dentro y fuera de la huella del disco de acero tras lubricación con capa fina Agua+1\%DSu

\begin{tabular}{|c|c|c|c|c|}
\hline \multirow[b]{2}{*}{ Elemento } & \multicolumn{2}{|c|}{ Fuera de la huella } & \multicolumn{2}{|c|}{ Dentro de la huella } \\
\hline & $\begin{array}{c}\text { Energía de ligadura } \\
\qquad(\mathrm{eV})\end{array}$ & $\%$ atómico & $\begin{array}{l}\text { Energía de ligadura } \\
\qquad(\mathrm{eV})\end{array}$ & $\%$ atómico \\
\hline \multirow{3}{*}{ C1s } & 285,00 & 26,42 & 285,00 & 30,69 \\
\hline & 286,50 & 9,75 & 286,41 & 8,48 \\
\hline & 288,69 & 4,80 & 288,7 & 4,78 \\
\hline \multirow{2}{*}{ N1s } & 397,62 & 0,29 & 398,29 & 0,30 \\
\hline & 400,21 & 0,92 & 400,02 & 1,27 \\
\hline \multirow{3}{*}{ 01s } & 530,22 & 12,51 & 530,25 & 12,40 \\
\hline & 531,84 & 27,71 & 531,95 & 28,39 \\
\hline & 533,33 & 2,81 & 533,70 & 1,28 \\
\hline \multirow{3}{*}{ Cr2p } & 574,22 & 0,87 & 574,20 & 0,76 \\
\hline & 576,36 & 3,97 & 576,50 & 4,08 \\
\hline & 577,72 & 2,73 & 578,00 & 1,68 \\
\hline \multirow{4}{*}{ Fe2p } & 706,89 & 1,52 & 706,98 & 1,60 \\
\hline & 707,64 & 2,07 & 707,95 & 1,25 \\
\hline & 710,26 & 2,79 & 710,54 & 2,58 \\
\hline & 712,67 & 0,83 & 712,82 & 0,46 \\
\hline
\end{tabular}

Con respecto a los porcentajes de hierro, el pico más intenso, tanto dentro como fuera de la huella, posee una energía de ligadura en torno a $710 \mathrm{eV}$, asignable a $\mathrm{Fe} 2 \mathrm{p}_{3 / 2}$ de los óxidos de hierro $\left(\mathrm{FeO}\right.$ y $\left.\mathrm{Fe}_{3} \mathrm{O}_{4}\right)$.

La energía de ligadura para el $\mathrm{Cr} 2 \mathrm{p}$ a $576 \mathrm{eV}$ corresponde al $\mathrm{Cr} 2 \mathrm{p}_{1 / 2}$ del $\mathrm{Cr}_{2} \mathrm{O}_{3}$, y es ligeramente superior en el interior de la huella. A 577,7 eV aparece un pico que podría asignarse a sales complejas de cromo y amonio, debidas posiblemente a la reacción del amonio del catión del líquido iónico con la superficie metálica [302].

Se puede observar cómo en este caso, no se ha producido un aumento del porcentaje de oxígeno en el interior de la huella, por lo que no ha habido oxidación dentro de la misma. Se pueden ver picos a 530,2 eV correspondientes a la formación de óxidos de cromo y hierro. El pico más intenso de los correspondientes al oxígeno se podría asignar a los hidróxidos del catión de amonio del DSu. Esta banda aparece a 531,95 eV en la huella y a su homólogo a 531,84 eV en el disco, y presenta mayor intensidad en el interior 
de la huella. El pico de $\mathrm{N}$ 1s de mayor energía corresponde a nitrógeno del catión orgánico de amonio.

Finalmente, la energía de ligadura del C1s a $285 \mathrm{eV}$ se corresponde con carbonos alifáticos presentes en el líquido iónico o a posible contaminación. Mientras que los picos 286 y $288,7 \mathrm{eV}$ son posiblemente debidos a los grupos carboxilato del anión.

\subsubsection{Dispersiones del líquido iónico prótico DSu con grafeno}

Anteriormente se han mostrado los resultados tribológicos correspondientes a la lubricación con el líquido iónico succinato de di[bis(2-hidroxietil)amonio] (DSu), tanto en capa fina como en película gruesa.

Debido a los prometedores resultados obtenidos, también se ha caracterizado y estudiado el comportamiento frente a fricción y desgaste de dos dispersiones de grafeno al 0,1 y 0,05\% en peso, en este líquido iónico.

\subsection{Caracterización de las dispersiones}

\subsection{Análisis térmico}

Con el fin de determinar la temperatura de degradación (Td) de los nuevos nanofluidos, considerándola como la temperatura a la cual pierden el $50 \%$ de su peso, se ha realizado un ensayo termogravimétrico en las condiciones que se indican en el apartado 3.3.1.8.1.

En la Figura 166 se puede observar la evolución de la pérdida de peso con la temperatura para el líquido iónico DSu y sus dispersiones con grafeno al 0,1 y $0,05 \%$. En todos los casos la evolución es similar, no se aprecian diferencias significativas entre el líquido iónico puro y sus dispersiones con grafeno. 


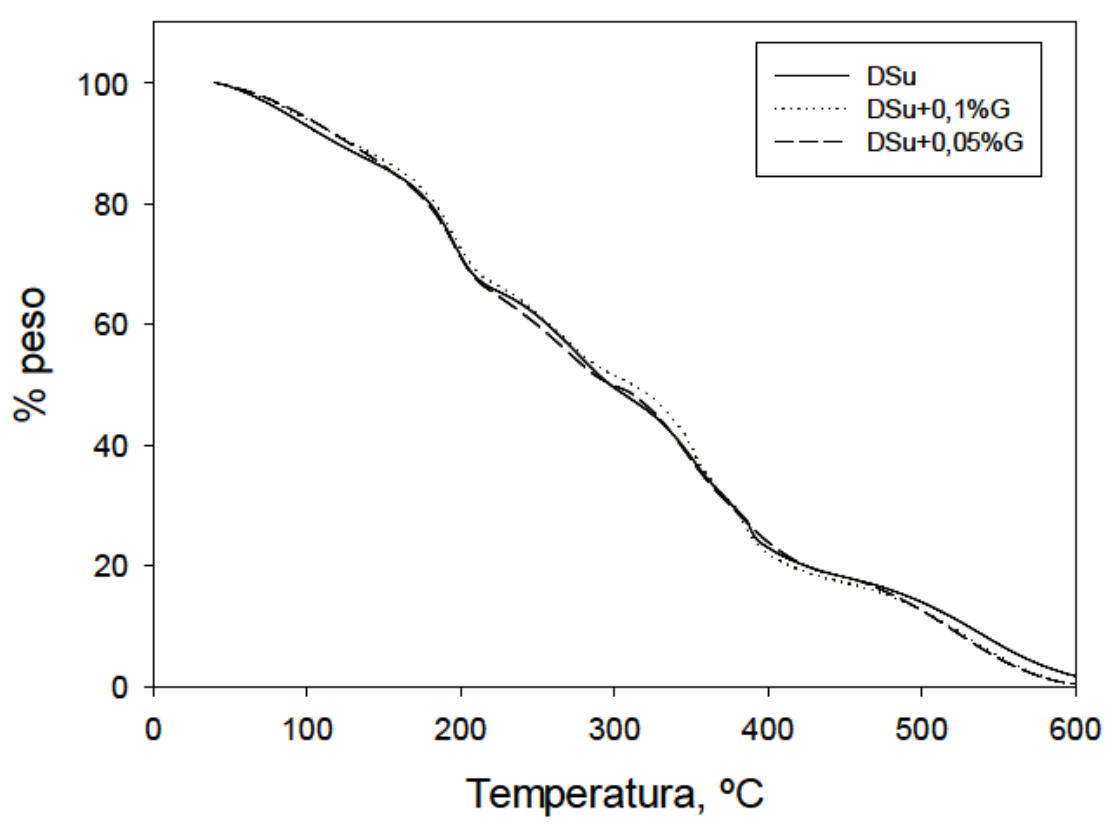

Figura 166. Evolución de la pérdida de peso con la temperatura para DSu, DSu+0,1\%G y

DSu+0,05\%G

Estudiando con mayor detalle el valor obtenido para la temperatura de degradación (Tabla 45), es posible observar cómo la dispersión que contiene mayor porcentaje de grafeno posee una temperatura de degradación superior. En el caso de DSu+0,05\% de grafeno la temperatura es similar a la obtenida para el líquido puro de partida.

Tabla 45. Temperaturas de degradación para DSu y sus dispersiones con grafeno

\begin{tabular}{cc}
\hline & $\operatorname{Td}\left({ }^{\circ} \mathbf{C}\right)(\Delta m=-50 \%)$ \\
\hline DSu & 297,02 \\
\hline DSu+0,1\%G & 311,78 \\
\hline DSu+0,05\%G & 298,53 \\
\hline
\end{tabular}

\subsection{Estudio reológico}

Se ha realizado un estudio del comportamiento reológico del líquido iónico prótico DSu y sus dispersiones con grafeno ya que conocer dicho comportamiento es de notable importancia para predecir su posible aplicación como lubricantes.

Para ello, se han realizado ensayos de flujo bajo la configuración plato sobre plato a diferentes temperaturas, 25,40 y $100^{\circ} \mathrm{C}$, siguiendo el procedimiento descrito en el punto 3.3.1.7. 
Para una temperatura de $25^{\circ} \mathrm{C}$ (Figura 167) se puede observar que tanto el líquido iónico como las dispersiones con un $0,1 \%$ y $0,05 \%$ de grafeno presentan un comportamiento Newtoniano. La viscosidad permanece constante con la velocidad de cizalla. Además, el nanofluido con mayor porcentaje de grafeno presenta un valor de viscosidad más elevado que el del DSu. Sin embargo, cuando la concentración es del $0,05 \%$ en peso, el comportamiento reológico de la mezcla es similar al que presenta el líquido iónico sin aditivos.

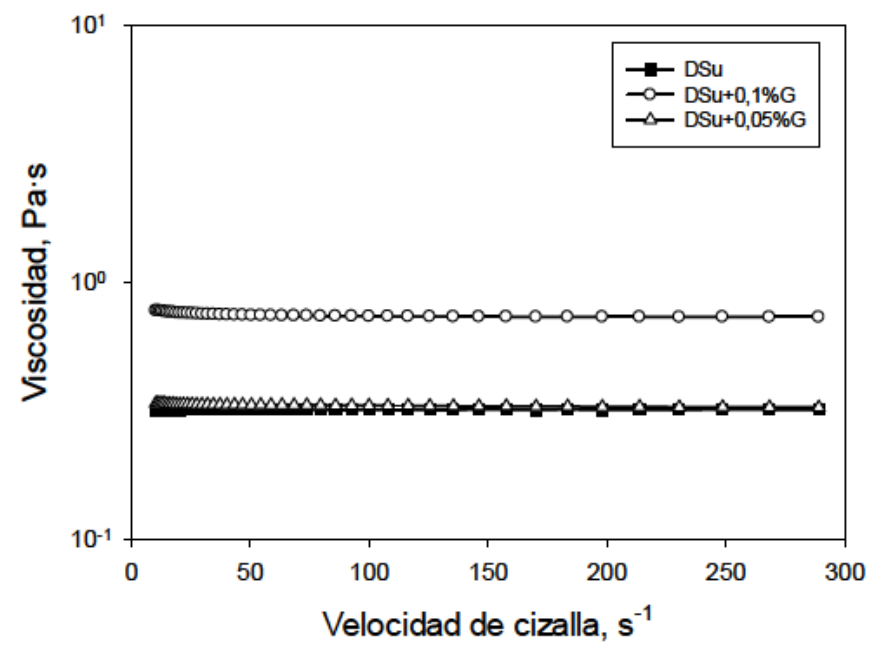

Figura 167. Evolución de la viscosidad con la velocidad de cizalla a $25^{\circ} \mathrm{C}$ para DSu y sus dispersiones con grafeno

Si se eleva la temperatura hasta $40^{\circ} \mathrm{C}$, los nanofluidos siguen presentando el mismo comportamiento Newtoniano y como se esperaba, el valor de la viscosidad disminuye, como se puede observar en la Tabla 46. Al igual que ocurría a $25^{\circ} \mathrm{C}$ la dispersión con un $0,1 \%$ de DSu presenta un valor más elevado de viscosidad.

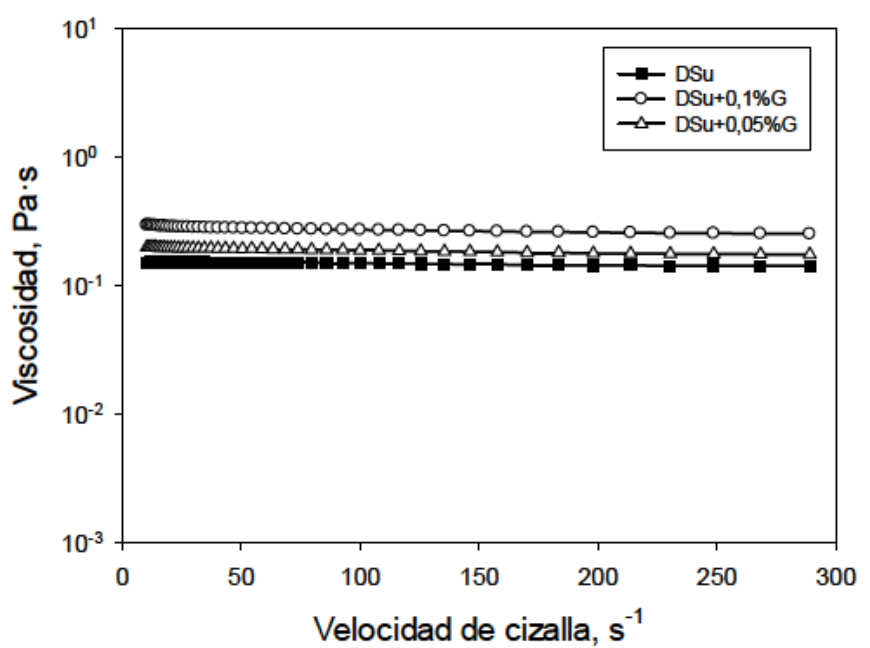

Figura 168. Evolución de la viscosidad con la velocidad de cizalla a $40^{\circ} \mathrm{C}$ para DSu y sus dispersiones con grafeno 
En la Figura 169 se muestra la evolución de la viscosidad con la velocidad de cizalla a $100^{\circ} \mathrm{C}$ para DSu, DSu $+0,1 \%$ de grafeno y DSu $+0,05 \%$ de grafeno, presentando un comportamiento similar al mostrado a temperaturas más bajas.

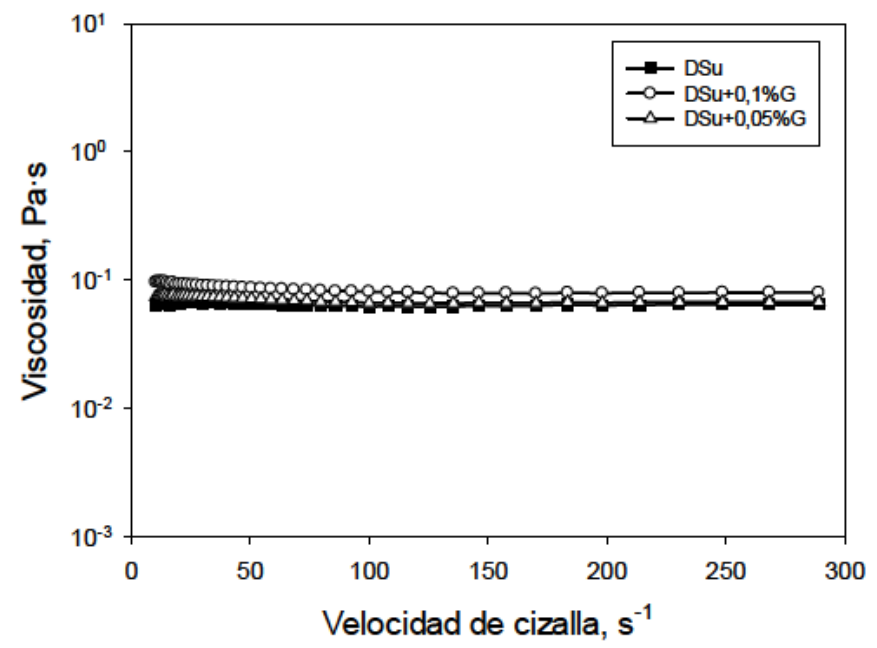

Figura 169. Evolución de la viscosidad con la velocidad de cizalla a $100^{\circ} \mathrm{C}$ para DSu y sus dispersiones con grafeno

Como se puede comprobar en la Tabla 46, tanto para el líquido iónico como para las dispersiones, el aumento de la temperatura supone la disminución del valor de viscosidad. A temperaturas más altas, la agitación de las moléculas de la dispersión provoca el debilitamiento de las interacciones entre el líquido iónico y el grafeno, haciendo que la probabilidad de que las partículas superen el valor umbral de energía de activación del proceso viscoso aumente, lo que hace que la materia fluya.

Por tanto, la diferencia entre los valores de viscosidad del líquido iónico y sus dispersiones se puede apreciar mejor a temperaturas bajas. La diferencia entre las viscosidades de los nanofluidos aumenta cuando la temperatura es menor, mientras que para los ensayos a temperaturas elevadas la viscosidad es muy similar.

Tabla 46. Valores de viscosidad (Peak Hold) obtenidos para DSu y sus dispersiones con grafeno a distintas temperaturas

\begin{tabular}{cccc}
\hline & \multicolumn{3}{c}{ Viscosidad (Pa.s) } \\
\cline { 2 - 4 } & $\mathbf{2 5 ^ { \circ } \mathbf { C }}$ & $\mathbf{4 0 ^ { \circ } \mathrm { C }}$ & $\mathbf{1 0 0 ^ { \circ } \mathbf { C }}$ \\
\hline DSu & $0,29( \pm 0,01)$ & $0,13( \pm 0,02)$ & $0,03( \pm 0,01)$ \\
\hline DSu+0,1\%G & $0,69( \pm 0,02)$ & $0,21( \pm 0,02)$ & $0,03( \pm 0,01)$ \\
\hline DSu+0,05\%G & $0,32( \pm 0,03)$ & $0,15( \pm 0,02)$ & $0,03( \pm 0,003)$ \\
\hline
\end{tabular}


Además, es necesario comentar que la viscosidad de las dispersiones es mayor que la del líquido iónico puro DSu. Esto podría deberse a que al agregar grafeno se forma una estructura mucho más ordenada y, por tanto, existe un mayor número de interacciones entre el líquido iónico y grafeno, las cuales habría que romper para que provocar que el material fluya. Este aumento en la viscosidad podría mejorar la capacidad de los lubricantes de soportar carga.

\subsection{3. Ángulo de contacto}

Se ha determinado el valor del ángulo de contacto del líquido iónico DSu y de las dispersiones con un $0,1 \%$ y $0,05 \%$ en peso de grafeno sobre acero inoxidable AISI 316L. Los resultados inicial y tras cinco minutos se muestran en la Tabla 47.

Tabla 47. Ángulo de contacto del líquido iónico DSu y sus dispersiones con grafeno sobre AISI $316 \mathrm{~L}$

\begin{tabular}{|c|c|c|c|}
\hline & $\begin{array}{l}\text { Ángulos de } \\
\text { contacto }\end{array}$ & Inicial & Final \\
\hline $\begin{array}{l}\text { DSu sobre } \\
\text { acero AISI } \\
\quad 316 \mathrm{~L}\end{array}$ & $\begin{array}{l}\text { Ángulo inicial } \\
89,6( \pm 1,9)^{\circ} \\
\text { Ángulo final } \\
57,1( \pm 3,0)^{\circ}\end{array}$ & & \\
\hline $\begin{array}{c}\text { DSu+0,1\%G } \\
\text { sobre acero } \\
\text { AISI 316L }\end{array}$ & $\begin{array}{l}\text { Ángulo inicial } \\
87,1( \pm 1,7)^{\circ} \\
\text { Ángulo final } \\
64,2( \pm 3,7)^{\circ}\end{array}$ & & \\
\hline $\begin{array}{c}\text { DSu+0,05\%G } \\
\text { sobre acero } \\
\text { AISI } 316 \mathrm{~L}\end{array}$ & $\begin{array}{l}\text { Ángulo inicial } \\
83,6( \pm 1,1)^{\circ} \\
\text { Ángulo final } \\
64,1( \pm 1,8)^{\circ}\end{array}$ & & \\
\hline
\end{tabular}

De los resultados obtenidos se puede concluir que en todos los casos el ángulo de contacto es menor de $90^{\circ}$, por lo que los lubricantes mojan al acero. La presencia de nanofase conlleva una disminución del ángulo de contacto inicial, sin embargo, los valores de ángulo final son mayores que en el caso del líquido 
iónico puro de partida. Es decir, la presencia de grafeno disminuye la interacción del DSu con la superficie.

\subsection{Espectroscopía Raman}

La espectroscopía Raman es una de las técnicas que permite caracterizar los alótropos del carbono ya que proporciona información extremadamente sensible de la estructura geométrica y las uniones entre las moléculas.

En la Figura 170 se muestra el espectro Raman del grafeno empleado. Este nanomaterial presenta dos señales características, las bandas $G$ y $2 D$. Además, como ocurre en este caso, puede aparecer la banda $D$ en grafeno con defectos.

La banda $G$ es un modo de vibración en plano de los átomos de carbono con hibridación $\mathrm{sp}^{2}$ de los que se compone una lámina de grafeno. La posición de esta banda es extremadamente sensible del número de láminas presentes en la muestra.

La banda D representa un modo de "respiración" anular de los anillos de carbono $\mathrm{sp}^{2}$, aunque para estar activo el anillo debe estar adyacente a un borde de grafeno o un defecto. La intensidad de la banda $D$ es directamente proporcional a la cantidad de defectos del material.

La banda $2 \mathrm{D}$ es el segundo orden de la banda $\mathrm{D}$. Es el resultado de un proceso vibratorio de dos redes de fonones, pero a diferencia de la banda $D$, no necesita ser activado por la proximidad a un defecto. Por tanto, la banda $2 \mathrm{D}$ siempre aparece en los espectros de grafeno, incluso si no hay defectos [303]. 


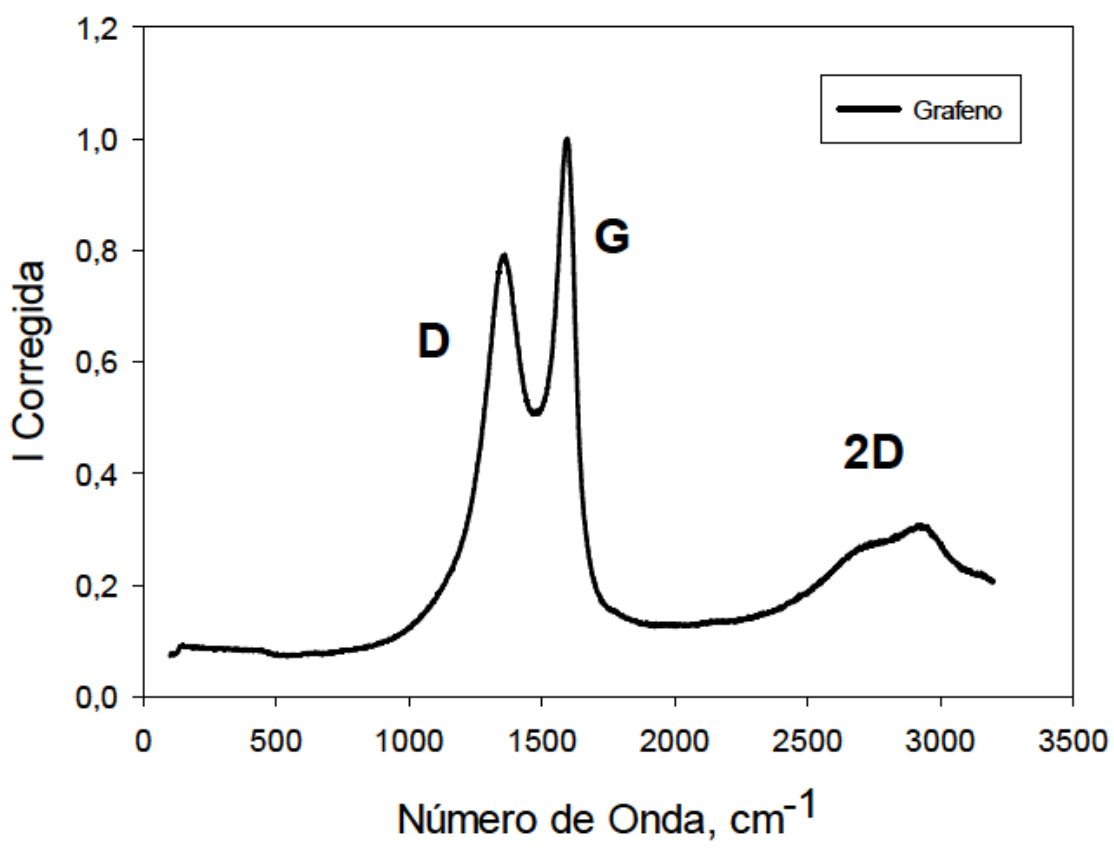

Figura 170. Espectro Raman de grafeno

La relación $\mathrm{I}_{2 \mathrm{D}} / \mathrm{I}_{\mathrm{G}}$ permite determinar el número de láminas de una muestra de grafeno. Si esta relación es superior a 1,6, se trata de una única capa de grafeno. En el caso que sea aproximadamente de 0,8, 0,3 0 0,07 la muestra tendrá dos, tres o más de cuatro capas, respectivamente. En función de los resultados mostrados en la Tabla 48, el grafeno empleado constará de 3 capas.

Como la relación de intensidades entre $\mathrm{I}_{\mathrm{D}} / \mathrm{I}_{\mathrm{G}}$ es un indicador de los defectos presentes en la muestra de grafeno [304], se ha obtenido a partir del espectro Raman de las partículas de las dispersiones con un $0,1 \%$ y $0,05 \%$ de grafeno mediante lavado con etanol de alta pureza y centrifugación para eliminar el líquido iónico, según lo descrito en el punto 3.3.1.10.

En la Figura 171 se puede observar una comparativa de los espectros de las partículas de grafeno obtenidas de las dispersiones con el grafeno de partida. 


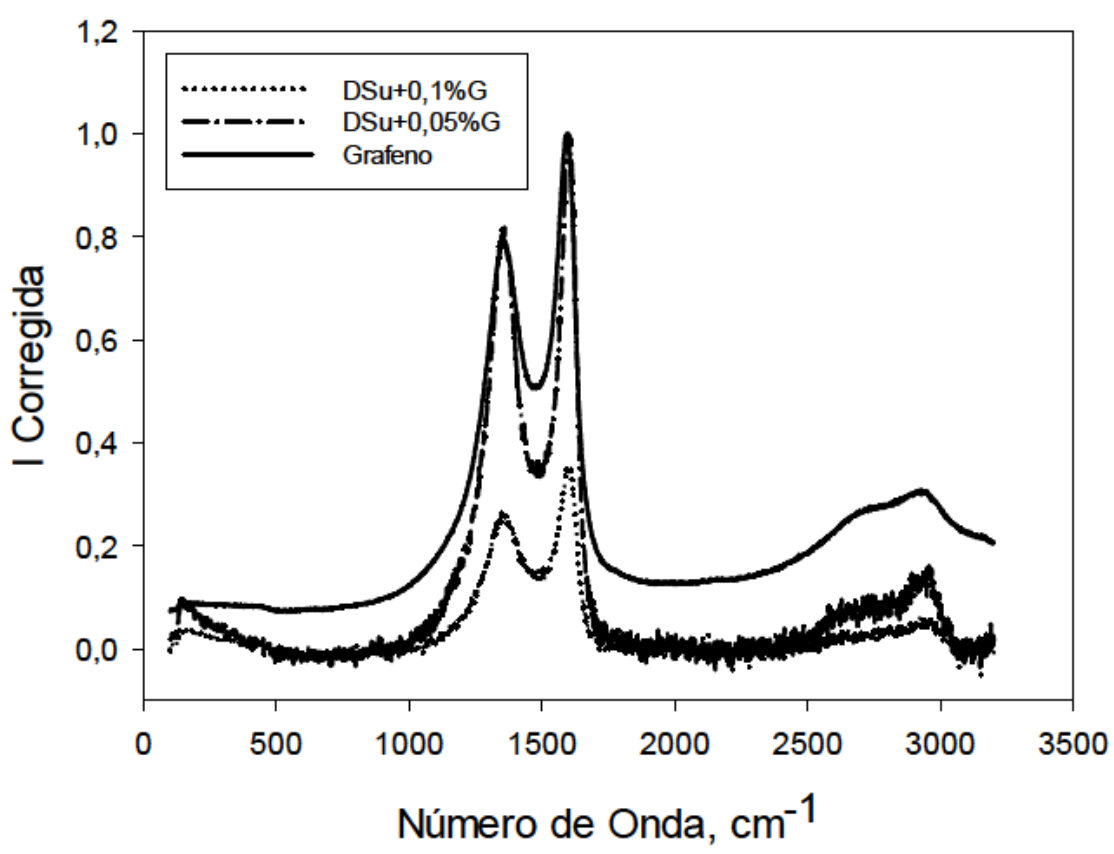

Figura 171. Comparativa de los espectros Raman de grafeno, partículas $\mathrm{DSu}+0,1 \% \mathrm{G}$ y partículas DSu+0,05\%G

Tal y como se puede observar en la Tabla 48, el grafeno procedente de las dispersiones con líquido iónico presenta la banda $\mathrm{D}$ desplazada hacia valores inferiores de número de onda y la banda $G$ hacia valores superiores, aunque estos cambios no son significativos. En el caso de la banda 2D, ésta se solapa con la banda más intensa que presenta el líquido iónico DSu (apartado 4.1.2.1.2), de manera que en el caso de que queden restos de líquido iónico, el valor de intensidad de esta banda se vería afectado, por lo que no se ha considerado.

Tabla 48. Números de onda y relación de intensidades de los espectros Raman de grafeno, DSu+0,1\%G y DSu+0,05\%G

\begin{tabular}{cccccc}
\hline & \multicolumn{3}{c}{ Número de onda $\left(\mathbf{c m}^{-1}\right)$} & \multicolumn{2}{c}{ Relación de intensidades } \\
\hline Material & Banda D & Banda G & Banda 2D & $I_{D} / I_{G}$ & $I_{\mathbf{2 D}} / I_{G}$ \\
\hline Grafeno & 1361,2 & 1596,6 & 2951,6 & 0,79 & 0,31 \\
\hline DSu+0,1\%G & 1352,0 & 1602,8 & - & 0,86 & - \\
\hline DSu+0,05\%G & 1359,8 & 1601,3 & - & 0,84 & - \\
\hline
\end{tabular}

El valor de la relación de intensidades $\mathrm{I}_{\mathrm{D}} / \mathrm{I}_{\mathrm{G}}$ es de 0,79 en el caso del grafeno puro, lo que podría deberse a la presencia de óxidos de grafeno [305]. Este valor es superior para las partículas que han estado en contacto con el líquido iónico, posiblemente debido al aumento de defectos en estas muestras [306]. 


\subsection{Estudio tribológico}

Se ha realizado el estudio tribológico empleando el líquido iónico DSu como lubricante, así como las dispersiones de DSu+0,1\%G y DSu+0,05\%G preparadas según lo expuesto anteriormente (3.3.1.3). Los ensayos de fricción se realizaron en el par zafiro-AISI 316L bajo la configuración punzón sobre disco en el tribómetro ISC en las condiciones que se muestran en el apartado 3.3.1.9.3.

La evolución del coeficiente de fricción con la distancia de deslizamiento empleando el líquido iónico DSu y sus dispersiones con grafeno, se muestra en la Figura 172.

Como ya se indicó anteriormente (apartado 4.1.2.1.2), cuando se emplea el líquido iónico DSu el coeficiente de fricción es elevado en los primeros 350 metros de distancia de deslizamiento y posteriormente se mantiene constante en torno a 0,11 .

La adición de un $0,1 \%$ de grafeno hace que el periodo de alta fricción inicial se prolongue durante 650 metros, pero al igual que ocurre con el DSu, el valor del coeficiente de fricción se estabiliza al final del ensayo. Sin embargo, cuando el porcentaje de grafeno añadido es inferior (DSu+0,05\%), no existe ese periodo inicial de alta fricción, manteniéndose el coeficiente de fricción con un valor medio de 0,106 .

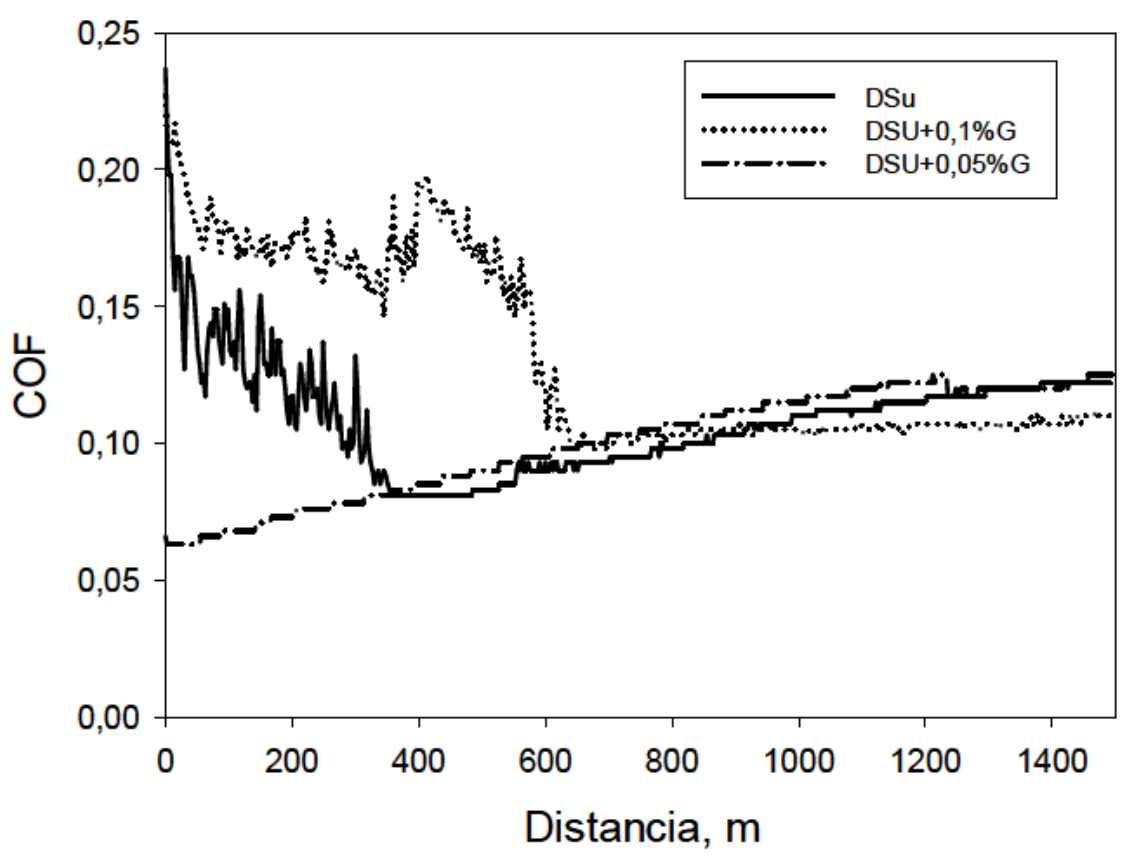

Figura 172. Evolución del coeficiente de fricción con la distancia de deslizamiento para DSu, DSu+0,1\%G y DSu+0,05\%G 
El período de fricción inicial que se produce en el ensayo con el líquido iónico puro podría deberse al tiempo que tarda en formarse una capa de moléculas del líquido iónico adsorbida sobre la superficie de acero inoxidable debido a las fuerzas de atracción de las cargas positivas. Este tiempo podría verse incrementado por la presencia de la nanofase en un porcentaje del $0,1 \%$, pero, si el porcentaje de nanofase es menor $(0,05 \%)$, la viscosidad es inferior, como se demuestra en el estudio reológico, de manera que se reduce la fricción interna entre las moléculas y las interacciones catión-anión. Esto hace que el comportamiento tribológico de esta dispersión sea el mejor.

En la Tabla 49 se muestran los coeficientes de fricción medios, tras 3 ensayos, para la distancia total de deslizamiento, así como los valores de factor de desgaste para DSu y sus dispersiones con grafeno.

En el caso de añadir un porcentaje de grafeno de un 0,1\% en peso al líquido iónico prótico, tanto la fricción como el factor de desgaste se ven incrementados con respecto al DSu puro, principalmente debido a la etapa inicial de alta fricción. En el caso de la dispersión con un porcentaje inferior de nanofase no es posible cuantificar el desgaste producido sobre la probeta de acero.

Tabla 49. Coeficientes de fricción y factor de desgaste para DSu y sus dispersiones con grafeno

\begin{tabular}{ccc}
\hline & Coeficiente de fricción & Factor de desgaste $\left(\mathrm{mm}^{3} / \mathbf{N} \cdot \mathbf{m}\right)$ \\
\hline DSu & $0,12( \pm 0,009)$ & $2,64 \times 10^{-5}\left( \pm 1,0 \times 10^{-6}\right)$ \\
\hline DSu+0,1\%G & $0,14( \pm 0,003)$ & $6,92 \times 10^{-5}\left( \pm 4,3 \times 10^{-6}\right)$ \\
\hline DSu+0,05\%G & $0,10( \pm 0,007)$ & No medible \\
\hline
\end{tabular}

En la Figura 173 es posible observar la topografía superficial de las huellas de desgaste tras los ensayos tribológicos realizados sobre los discos de acero inoxidable AISI 316L. Los resultados mostrados están de acuerdo con los datos de fricción y desgaste obtenidos para el DSu y sus dispersiones con grafeno. Existe un importante daño superficial tras la lubricación con la dispersión con mayor porcentaje de grafeno y un desgaste no medible, en el caso de la dispersión con un $0,05 \%$ de grafeno. 

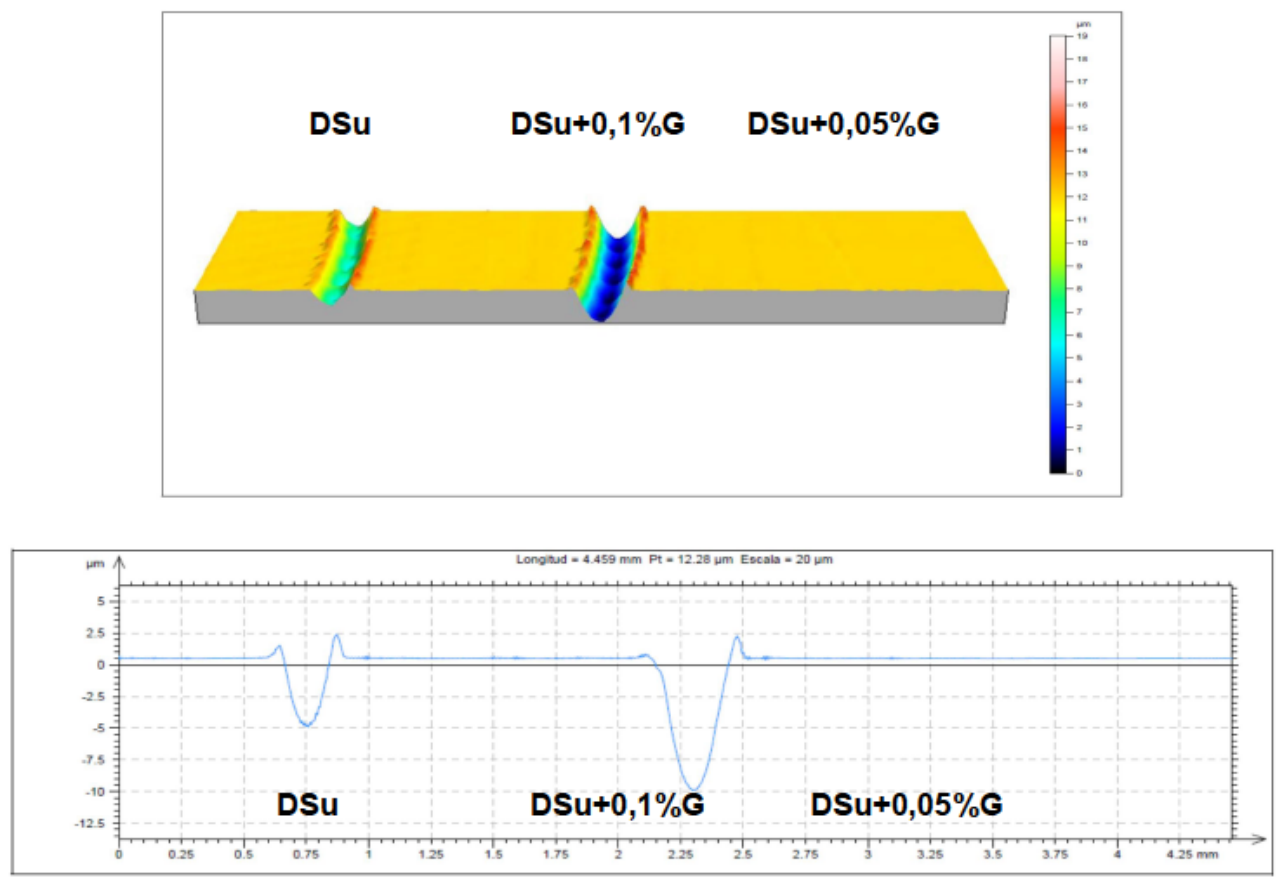

Figura 173. Topografía superficial y perfil transversal de las huellas de desgaste obtenidas tras lubricación con DSu, DSu+0,1\%G y DSu+0,05\%G

Tras la lubricación con DSU $+0,1 \% \mathrm{G}$, el estudio SEM y EDX muestra concentraciones de carbono y oxígeno ligeramente mayores en la huella de desgaste (Figura 174), observándose además marcas de abrasión debido al desgaste severo que sufre el acero durante la etapa inicial de alta fricción.
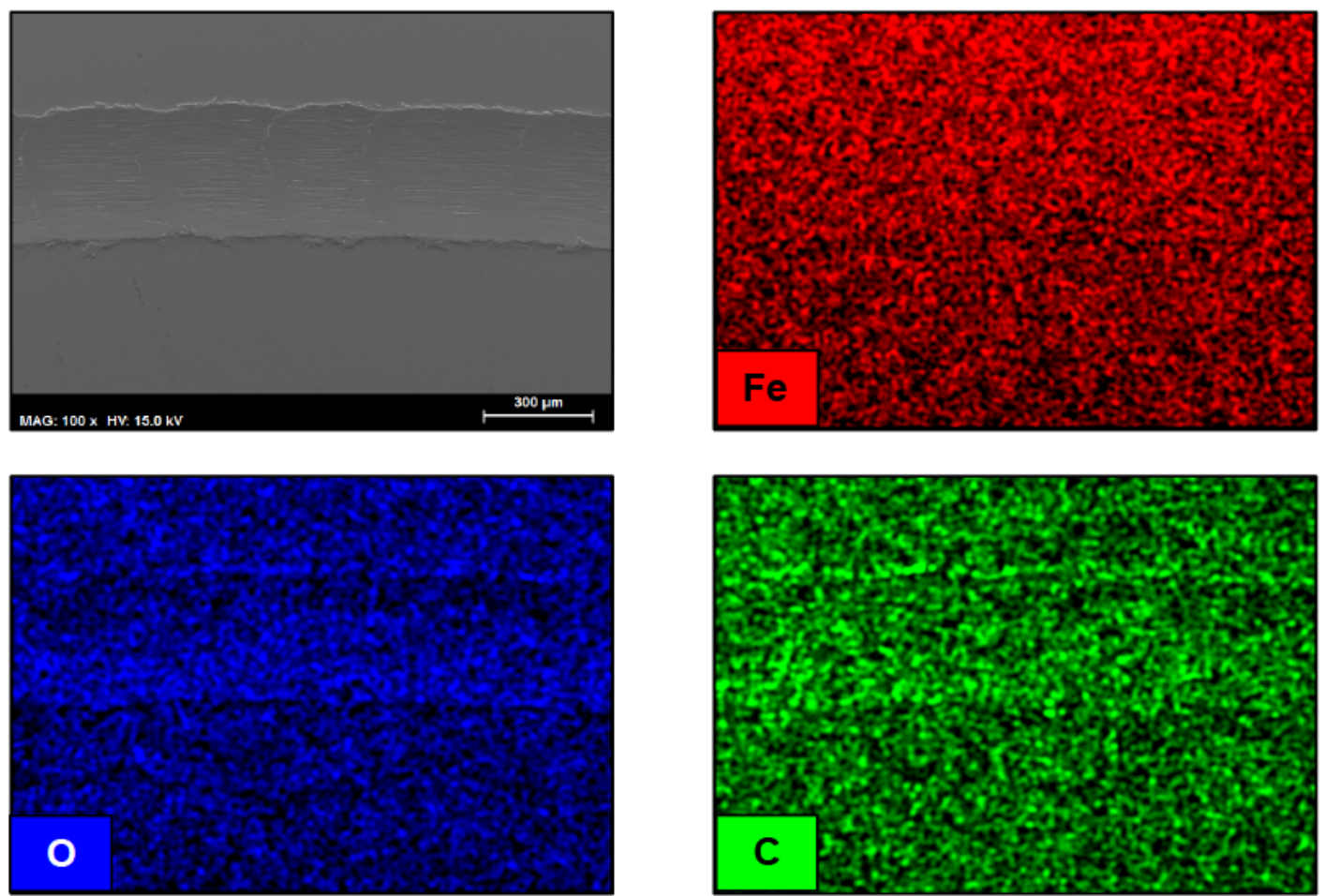

Figura 174. Micrografía SEM y mapas elementales de hierro, oxígeno y carbono de la huella de desgaste tras lubricación con DSu+0,1\%G 
Sin embargo, en el caso de emplear la dispersión de DSu+0,05\%G como lubricante, la huella de desgaste obtenida es prácticamente inapreciable y no se observan cambios en la composición superficial, como se puede comprobar en la Figura 175.
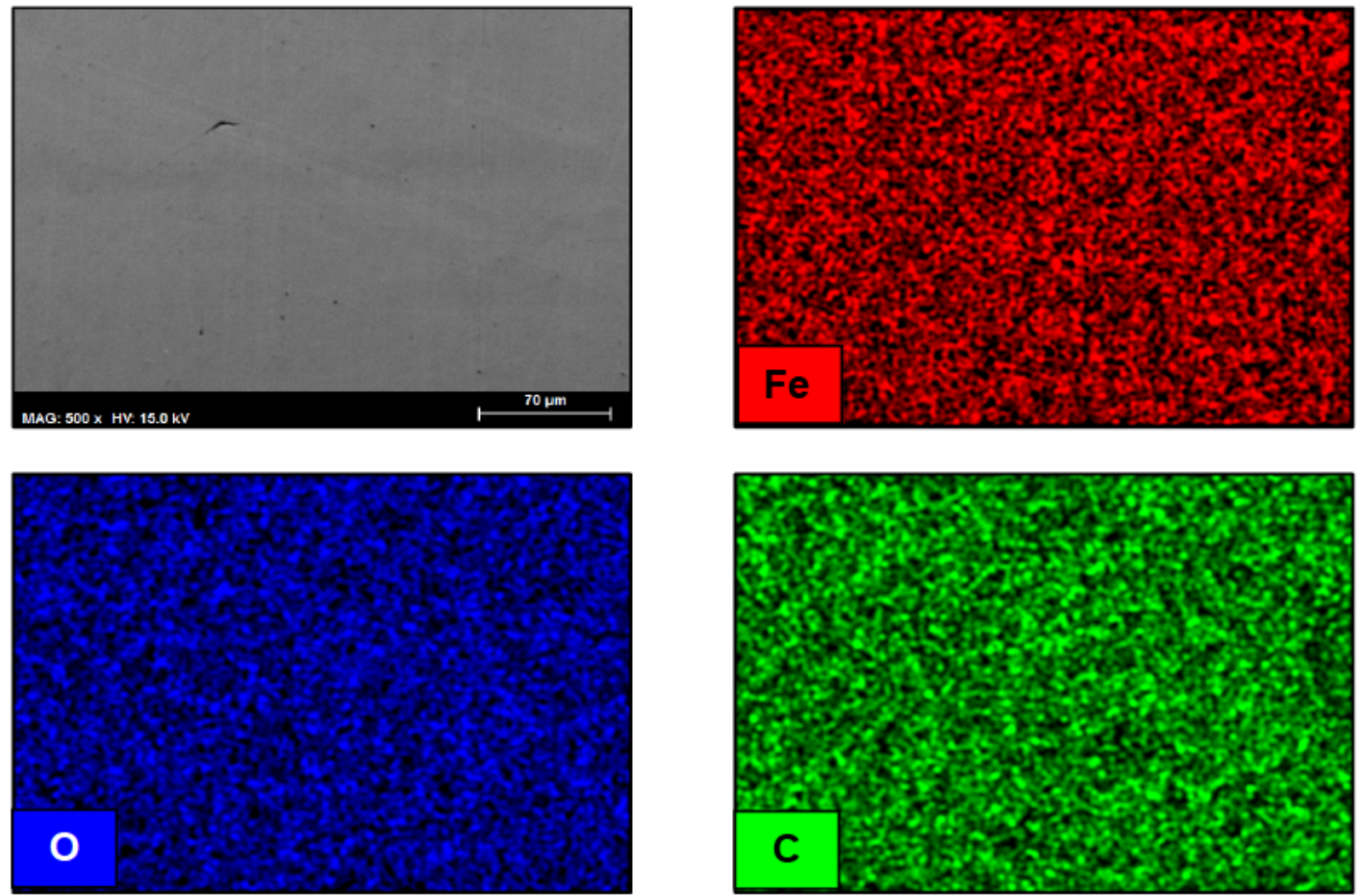

Figura 175. Micrografía SEM y mapas elementales de hierro, oxígeno y carbono de la huella de desgaste tras lubricación con $\mathrm{DS} u+0,05 \% \mathrm{G}$

También se ha realizado el estudio Raman de la huella de desgaste obtenida tras la lubricación con la dispersión DSu+0,05\%G (Figura 176), dónde se compara con el espectro del grafeno y del líquido iónico de partida.

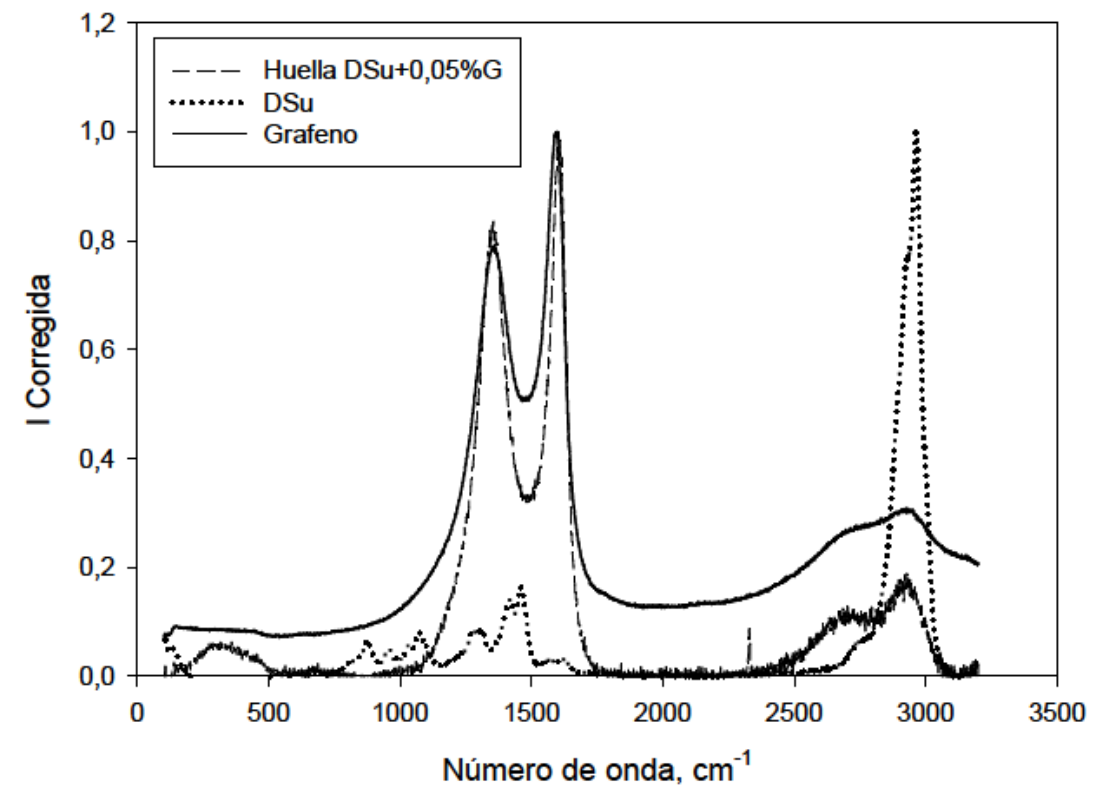

Figura 176. Espectros Raman en la huella de desgaste de DSu+0,05\%G, DSu y grafeno 
Es posible observar la presencia de grafeno en el interior de la huella, ya que aparecen los picos característicos de las bandas $D\left(1341,04 \mathrm{~cm}^{-1}\right)$ y $\mathrm{G}(1602,56$ $\mathrm{cm}^{-1}$ ) de este nanomaterial. También, es posible observar la presencia de la banda $2 \mathrm{D}$, con un hombro a $2733,27 \mathrm{~cm}^{-1}$ y un pico máximo a $2914,94 \mathrm{~cm}^{-1}$ que se solapa con la banda característica de los enlaces $\mathrm{C}-\mathrm{H}$ que presenta el líquido iónico.

Con el fin de estudiar la interacción del líquido iónico DSu con grafeno, se han observado las partículas de ambas dispersiones, DSu+0,1\%G y DSu+0,05\%G mediante microscopía electrónica de transmisión y se han comparado con las partículas de desgaste obtenidas tras la lubricación.

El grafeno procedente de la dispersión de DSu con un 0,1\% de grafeno, antes del ensayo tribológico se muestra en la Figura 177a. Se observa la presencia de partículas de desgaste en la superficie del grafeno tras el ensayo (Figura 177b).

a)

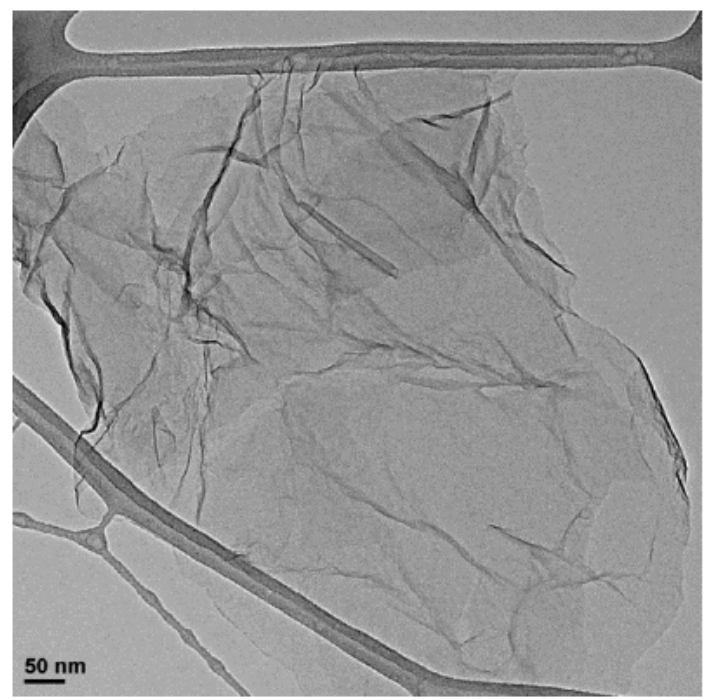

b)

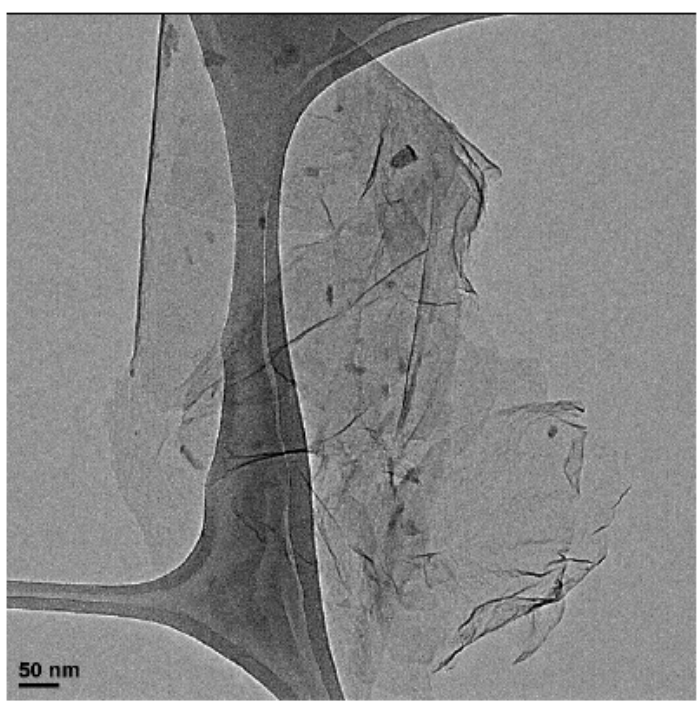

Figura 177. Micrografías TEM de las partículas de grafeno de DSu+0,1\%G; a) antes del ensayo tribológico; b) después del ensayo

La Figura 178 se muestra una micrografía TEM de las partículas de grafeno obtenidas de la dispersión de $0,05 \%$ de grafeno en DSu. En este caso, no se han encontrado partículas de desgaste tras la lubricación, ya que efectivamente, no se ha producido desgaste en el disco (Figura 178b). 
a)

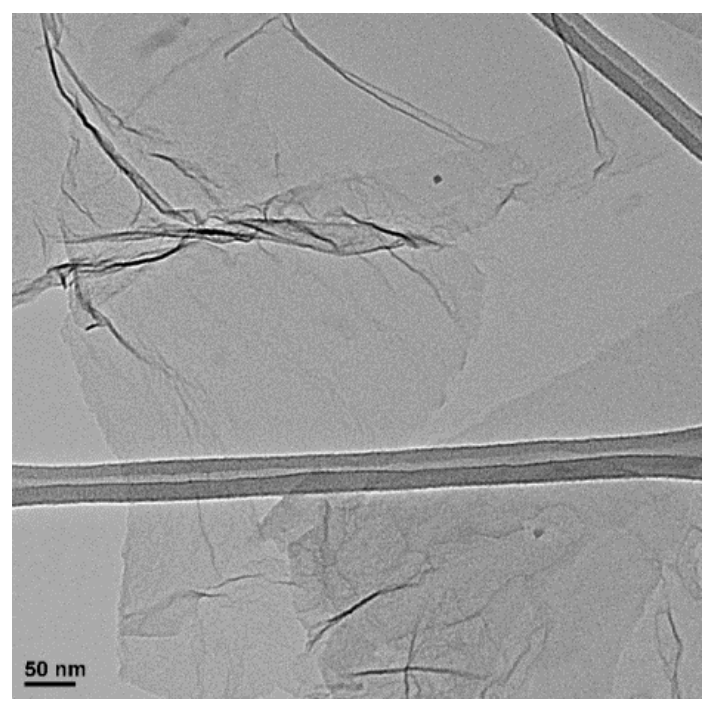

b)

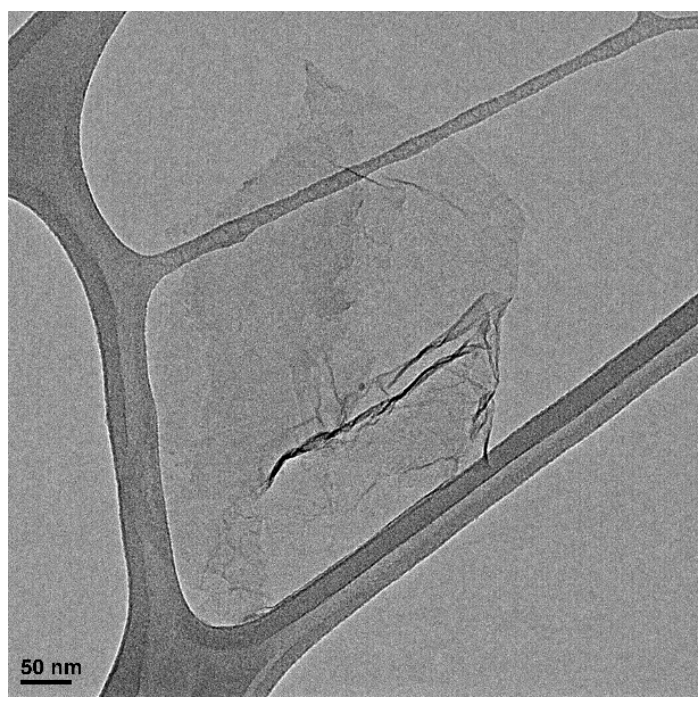

Figura 178. Micrografías TEM de las partículas de grafeno de DSu+0,05\%G; a) antes del ensayo tribológico; b) después del ensayo

\subsubsection{Conclusiones}

Se ha utilizado un líquido iónico prótico derivado del anión biocompatible succinato como aditivo en agua, tanto en lubricación con película gruesa, como en lubricación con capa fina obtenida mediante la evaporación del agua de una disolución que contiene un $1 \%$ en peso del líquido iónico, previamente depositada sobre una superficie de acero inoxidable.

La capa fina elimina el período inicial de alta fricción que se registra en el caso de la lubricación con película gruesa, tanto para el líquido iónico puro como para la disolución en agua.

Otra estrategia para eliminar el período inicial de alta fricción y reducir la tasa de desgaste ha sido la dispersión de grafeno. Una concentración del 0,05\% de grafeno en el líquido iónico, no sólo reduce el coeficiente de fricción sino que previene el desgaste.

La protección frente al desgaste se debe a la formación de una capa sobre la superficie del acero, que contiene tanto grafeno como líquido iónico. 


\subsubsection{Dispersiones de líquido iónico prótico $\mathrm{DCi}$ con nanodiamantes}

El principal objetivo de este capítulo es obtener, caracterizar y estudiar el comportamiento tribológico de una nueva dispersión con el $0,1 \%$ en peso de nanodiamantes (procedentes de una disolución comercial con un $4 \%$ en peso de nanodiamantes en agua) en líquido iónico prótico citrato de tri[bis(2hidroxietil)amonio], DCi, derivado de un ácido biocompatible.

Para evitar la etapa inicial de alta fricción y desgaste severo que presentan estos líquidos iónicos en los ensayos tribológicos en presencia de agua [102], se han creado capas límite mediante la técnica de spin coating y mediante evaporación del agua en una estufa de vacío antes de realizar los ensayos tribológicos.

Como se ha visto en el caso del líquido iónico prótico DSu (apartado 4.1.2), la obtención de capas finas permite disminuir considerablemente la cantidad de líquido iónico a emplear con respecto a los ensayos de lubricación con película gruesa, lo que conlleva una reducción del coste económico.

\subsubsection{Caracterización de la dispersión}

\subsection{Análisis térmico}

Se ha realizado el análisis termogravimétrico de la nueva dispersión de DCi con un $0,1 \%$ de nanodiamantes (ND+DCi) y se ha comparado su comportamiento con el obtenido para el líquido iónico puro DCi (Figura 179). 


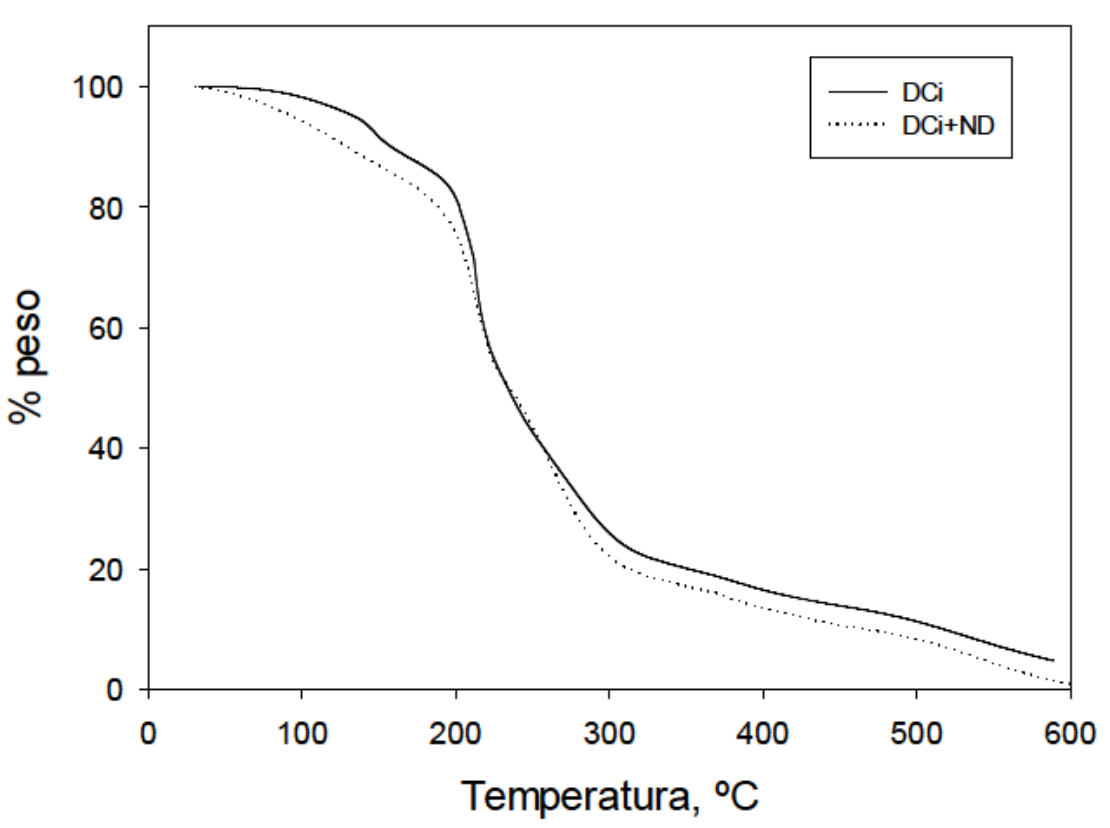

Figura 179. Termogravimetría de DCi y ND+DCi

En la Tabla 50 se puede observar cómo la temperatura de degradación, a la cual la muestra pierde un $50 \%$ de su peso, disminuye al añadir la nanofase de carbono, haciendo que la estabilidad de la muestra se reduzca, aunque no de forma significativa. Esto puede deberse al contenido en agua de los nanodiamantes.

Tabla 50. Temperaturas de degradación para DCi y DCi+ND

\begin{tabular}{cc}
\hline & $\operatorname{Td}\left({ }^{\circ} \mathrm{C}\right)(\Delta \mathrm{m}=-50 \%)\left({ }^{\circ} \mathrm{C}\right)$ \\
\hline DCi & 234,00 \\
\hline DCi+ND & 225,13 \\
\hline
\end{tabular}

\subsection{Estudio reológico}

Se ha llevado a cabo un estudio para determinar cómo la adición de un 0,1\% de nanodiamantes modifica el comportamiento reológico del nuevo nanofluido a diferentes temperaturas $\left(25^{\circ} \mathrm{C}, 40^{\circ} \mathrm{C}\right.$ y $\left.100^{\circ} \mathrm{C}\right)$.

Para ello, se han realizado estudios de flujo en configuración plato sobre plato del líquido iónico $\mathrm{DCi}$ y de la dispersión de $0,1 \%$ de nanodiamantes en DCi (DCi+ND) a las temperaturas anteriormente mencionadas, siguiendo el procedimiento indicado en el apartado 3.3.1.7. 
En la Figura 180 se observa la evolución de la viscosidad con la velocidad de cizalla para el líquido iónico prótico DCi y la dispersión (DCi+ND) a $25^{\circ} \mathrm{C}$.

Ambos nanofluidos presentan un comportamiento Newtoniano desde valores de velocidad de cizalla de 10 a $300 \mathrm{~s}^{-1}$, ya que la viscosidad es independiente de la velocidad de cizalla. Se puede ver, además, que la adición de los nanodiamantes supone un aumento de la viscosidad, presentando el líquido iónico puro un valor de viscosidad promedio de 1,93 $\mathrm{Pa} \cdot \mathrm{s}$, mientras que la dispersión muestra un valor de 2,29 Pa·s (Tabla 51).

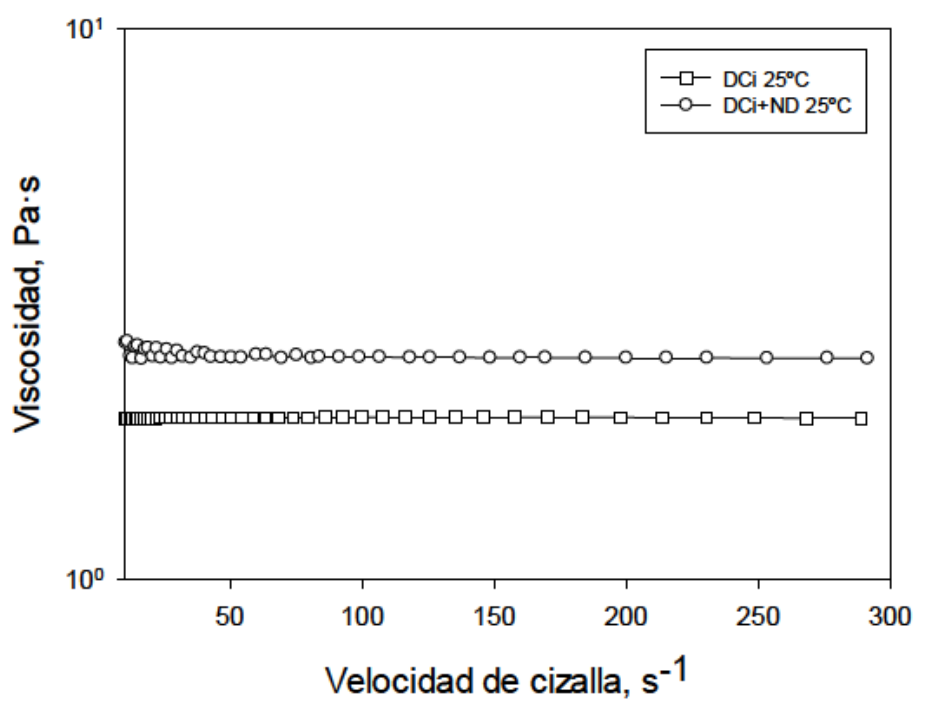

Figura 180. Evolución de la viscosidad con la velocidad de cizalla a $25^{\circ} \mathrm{C}$ para $\mathrm{DCi}$ y dispersión $\mathrm{DCi}+\mathrm{ND}$

Cuando la temperatura es de $40^{\circ} \mathrm{C}$ (Figura 181), se observa que la dispersión de DCi+ND presenta un valor inferior de viscosidad con respecto al líquido iónico puro de partida, aunque los resultados son muy similares (Tabla 51). El aumento de la temperatura no implica cambios en el comportamiento Newtoniano de ambos lubricantes y como se esperaba, los valores de viscosidad son inferiores a los presentados a $25^{\circ} \mathrm{C}$. 


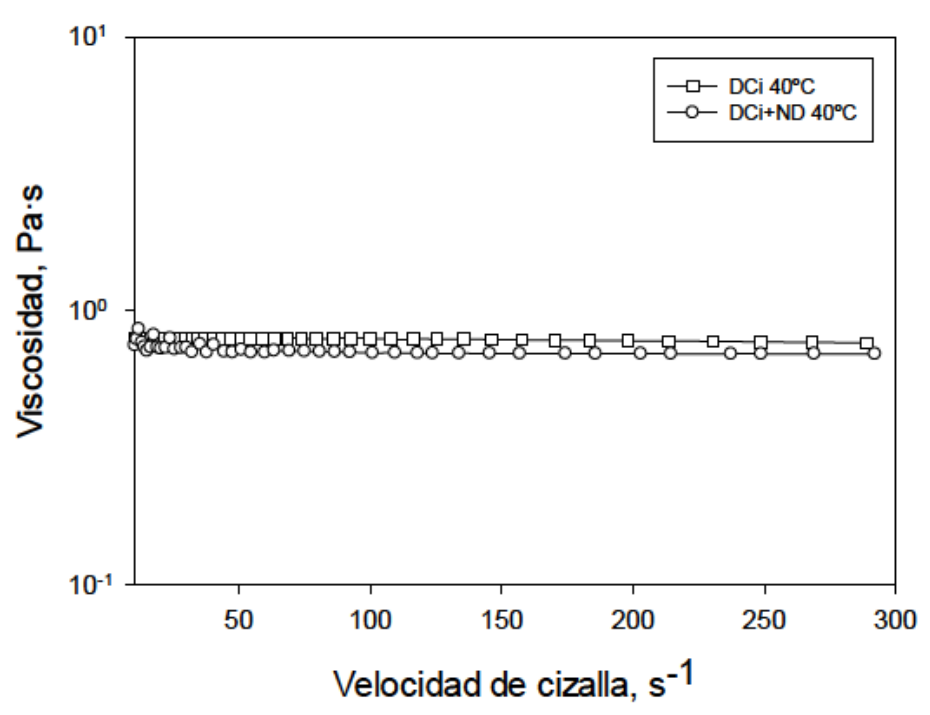

Figura 181. Evolución de la viscosidad con la velocidad de cizalla a $40^{\circ} \mathrm{C}$ para DCi y dispersión $\mathrm{DCi}+\mathrm{ND}$

En la Figura 182 se muestran los resultados obtenidos en los ensayos de flujo con gradiente de cizalla desde 10 a $300 \mathrm{~s}^{-1}$ para DCi y DCi+ND a $100^{\circ} \mathrm{C}$. Al igual que ocurría a $40^{\circ} \mathrm{C}$, a $100^{\circ} \mathrm{C}$ el valor de la viscosidad del líquido iónico puro es superior al de la dispersión con nanodiamantes (Tabla 51).

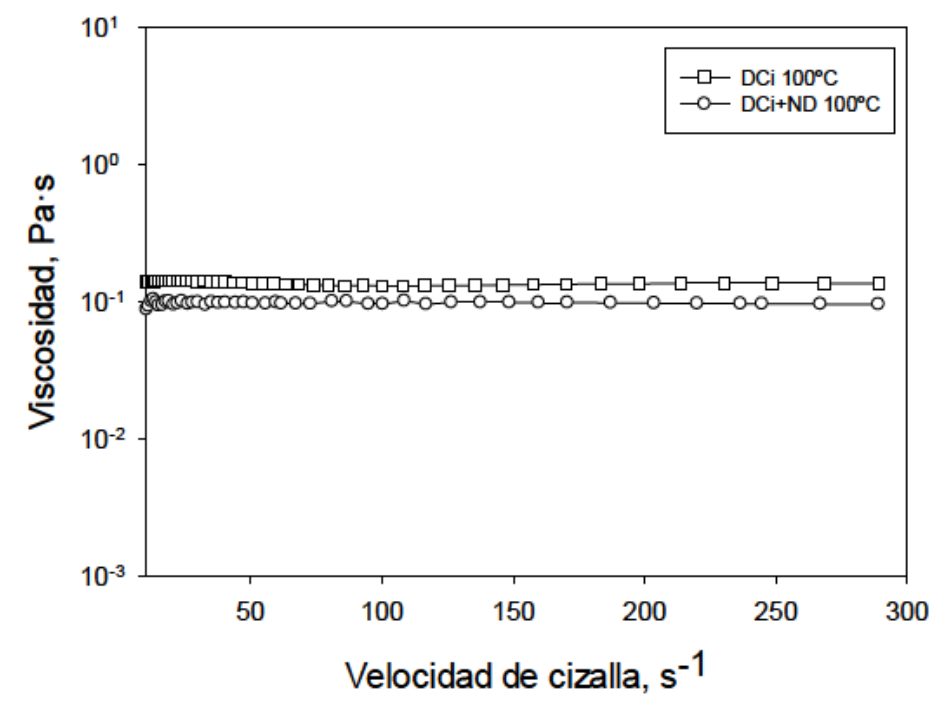

Figura 182. Evolución de la viscosidad con la velocidad de cizalla a $100^{\circ} \mathrm{C}$ para $\mathrm{DCi}$ y dispersión $\mathrm{DCi}+\mathrm{ND}$

En definitiva, se observa en todos los casos el comportamiento Newtoniano de los nanofluidos y la disminución del valor de la viscosidad con el aumento de la temperatura. 
Tabla 51. Valores de viscosidad (Peak Hold) para DCi y DCi+ND a distintas temperaturas

\begin{tabular}{cccc}
\hline & \multicolumn{3}{c}{ Viscosidad (Pa·s) } \\
\cline { 2 - 4 } & $\mathbf{2 5 ^ { \circ } \mathbf { C }}$ & $\mathbf{4 0 ^ { \circ } \mathbf { C }}$ & $\mathbf{1 0 0 ^ { \circ } \mathbf { C }}$ \\
\hline $\mathbf{D C i}$ & $1,90( \pm 0,1)$ & $0,73( \pm 0,02)$ & $0,09( \pm 0,01)$ \\
\hline DCi+ND & $2,30( \pm 0,3)$ & $0,65( \pm 0,04)$ & $0,04( \pm 0,001)$
\end{tabular}

A $25^{\circ} \mathrm{C}$, la dispersión presenta mayor viscosidad que el líquido iónico sin aditivos, lo que podría predecir una mejora en el comportamiento tribológico debido al aumento de su capacidad de soportar carga.

\subsubsection{3. Ángulo de contacto}

Se ha determinado el valor del ángulo de contacto sobre AISI 316L del nanofluido con un $0,1 \%$ de nanodiamantes en DCi y se ha comparado con el valor obtenido para $\mathrm{DCi}$.

Como se observa en la Tabla 52 la dispersión $\mathrm{DCi}+\mathrm{ND}$ presenta un valor de ángulo de contacto inicial inferior al del líquido iónico puro, sin embargo, una vez transcurridos 5 minutos, es similar en ambos casos. Además, tanto DCi como $\mathrm{DCi}+\mathrm{ND}$ presentan un ángulo inferior a $90^{\circ}$, por lo que ambos líquidos mojan al acero inoxidable AISI 316L.

Tabla 52. Ángulos de contacto de DCi y de la dispersión DCi+ND sobre acero inoxidable

\section{AISI 316L}

\begin{tabular}{|c|c|c|c|}
\hline & $\begin{array}{l}\text { Ángulo de } \\
\text { contacto }\end{array}$ & Inicial & Final \\
\hline $\begin{array}{c}\text { DCi } \\
\text { sobre } \\
\text { acero } \\
\text { AISI } \\
316 \mathrm{~L}\end{array}$ & $\begin{array}{l}\text { Ángulo inicial: } \\
93,1( \pm 1,1)^{\circ} \\
\text { Ángulo final: } \\
78,2( \pm 0,1)^{\circ}\end{array}$ & & \\
\hline $\begin{array}{c}\text { DCi+ND } \\
\text { sobre } \\
\text { acero } \\
\text { AISI } \\
316 \mathrm{~L}\end{array}$ & $\begin{array}{l}\text { Ángulo inicial: } \\
83,5( \pm 2,3)^{\circ} \\
\text { Ángulo final: } \\
77,3( \pm 0,9)^{\circ}\end{array}$ & & \\
\hline
\end{tabular}




\subsubsection{Estudio tribológico}

Una vez caracterizada la dispersión, se ha llevado a cabo el estudio tribológico de la misma mediante ensayos punzón sobre disco del par zafiro-AISI 316L en las condiciones que se indican en el punto 3.3.1.9.3.

Los ensayos tribológicos se han realizado empleando como lubricantes la dispersión de $\mathrm{DCi}$ con un $0,1 \%$ de nanodiamantes ( $\mathrm{DCi}+\mathrm{ND}$ ) en película gruesa, y las capas finas de este mismo lubricante obtenidas mediante la técnica de spin coating y por evaporación de agua en la estufa de vacío. La preparación de estas capas finas se indicaba en el apartado 3.3.1.6.

En la Figura 183 se muestra la evolución del coeficiente de fricción frente a la distancia de deslizamiento para los casos indicados y se compara su comportamiento con el que presenta el líquido iónico prótico de partida (DCi) [234].

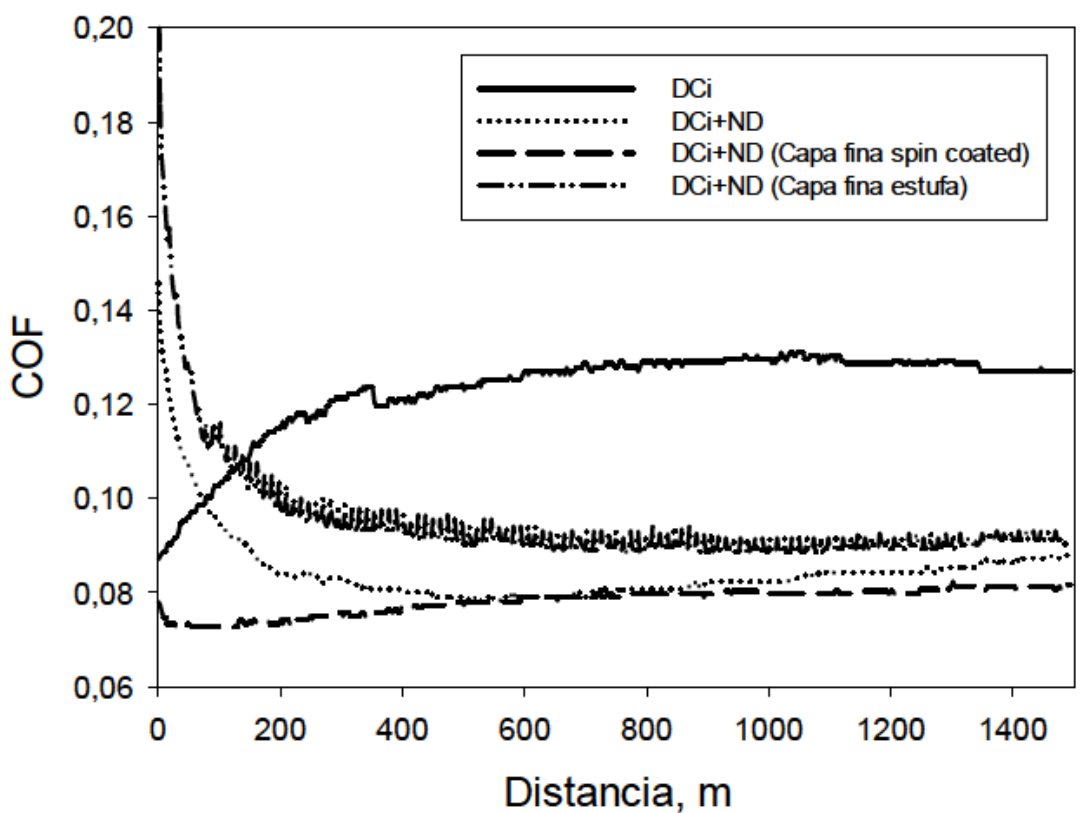

Figura 183. Evolución del coeficiente de fricción con la distancia para los lubricantes DCi y

$\mathrm{DCi}+\mathrm{ND}$

La dispersión DCi+ND muestra un alto coeficiente de fricción en los primeros 100 metros de ensayo. Éste rápidamente se reduce hasta alcanzar el estado estacionario con un valor de fricción en torno a 0,07 y 0,08 hasta el final del ensayo a $1500 \mathrm{~m}$. El valor medio de fricción obtenido tras tres ensayos en las mismas condiciones de deslizamiento es de 0,09 como queda reflejado en la Tabla 53, lográndose una disminución en torno a un $30 \%$ con respecto al 
líquido iónico DCi sin aditivos [101]. Es necesario remarcar que esta significativa reducción del coeficiente de fricción, se ha logrado al añadir una muy pequeña cantidad de nanofase $(0,1 \%)$.

En el caso de emplear la dispersión en forma de capa fina mediante la técnica de spin coating (DCi+ND capa fina spin coated) se logra eliminar el periodo de alta fricción inicial. Además, este es el lubricante que presenta el menor coeficiente de fricción durante toda la distancia de deslizamiento, con un valor de 0,08 (Tabla 53).

La capa fina obtenida mediante la evaporación del agua que contenía la dispersión en la estufa de vacío no es tan eficiente, mostrando el valor de fricción más elevado tanto al inicio del ensayo como durante toda la distancia de deslizamiento. Por tanto, este método parece ser menos efectivo que el de spin coating para la eliminación de agua y la formación de una capa fina uniforme.

Con respecto al desgaste, los valores obtenidos para todos los lubricantes son muy similares, del orden de $10^{-7} \mathrm{~mm} / \mathrm{N} \cdot \mathrm{m}$, y superiores a los obtenidos para DCi puro. Los perfiles topográficos de las huellas de desgaste obtenidos mediante perfilometría óptica se muestran en las Figuras 184, 185 y 186 están en concordancia con los valores tan reducidos de tasa de desgaste obtenidos.

Tabla 53. Coeficientes de fricción y tasas de desgaste para DCi, DCi+ND y las diferentes capas finas

\begin{tabular}{ccc}
\hline & $\begin{array}{c}\text { Coeficiente de } \\
\text { fricción }\end{array}$ & $\begin{array}{c}\text { Tasa de desgaste } \\
\left(\mathbf{m m}^{3} / \mathbf{N} \cdot \mathbf{m}\right)\end{array}$ \\
\hline DCi & $0,12( \pm 0,01)$ & $2,14 \times 10^{-7}\left( \pm 4 \times 10^{-9}\right)$ \\
\hline DCi+ND & $0,09( \pm 0,01)$ & $3,81 \times 10^{-7}\left( \pm 3,3 \times 10^{-8}\right)$ \\
\hline $\begin{array}{c}\text { DCi+ND (capa fina spin } \\
\text { coated) }\end{array}$ & $0,08( \pm 0,001)$ & $4,04 \times 10^{-7}\left( \pm 4,0 \times 10^{-8}\right)$ \\
\hline $\mathbf{D C i + N D ~ ( c a p a ~ f i n a ~ e s t u f a ) ~}$ & $0,09( \pm 0,01)$ & $3,85 \times 10^{-7}\left( \pm 3,1 \times 10^{-8}\right)$ \\
\hline
\end{tabular}


Capítulo 4. Resultados y discusión

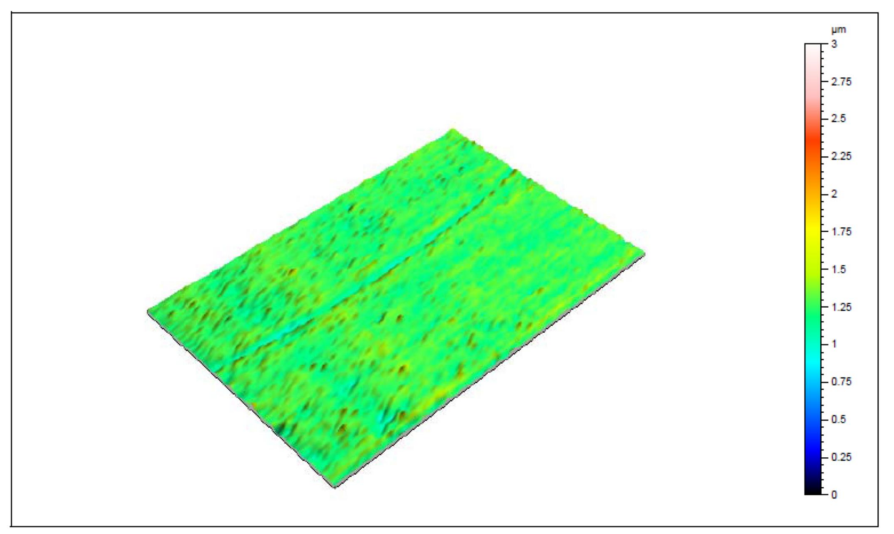

Figura 184. Topografía superficial de la huella de desgaste sobre el disco de acero tras ensayo con $\mathrm{DCi}+\mathrm{ND}$

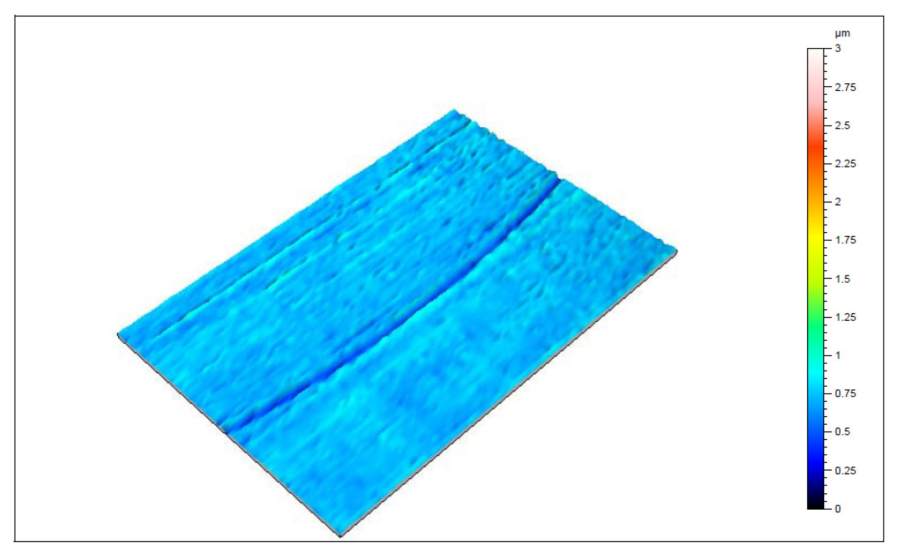

Figura 185. Topografía superficial de la huella de desgaste sobre el disco de acero tras ensayo con DCi+ND (capa fina spin coated)

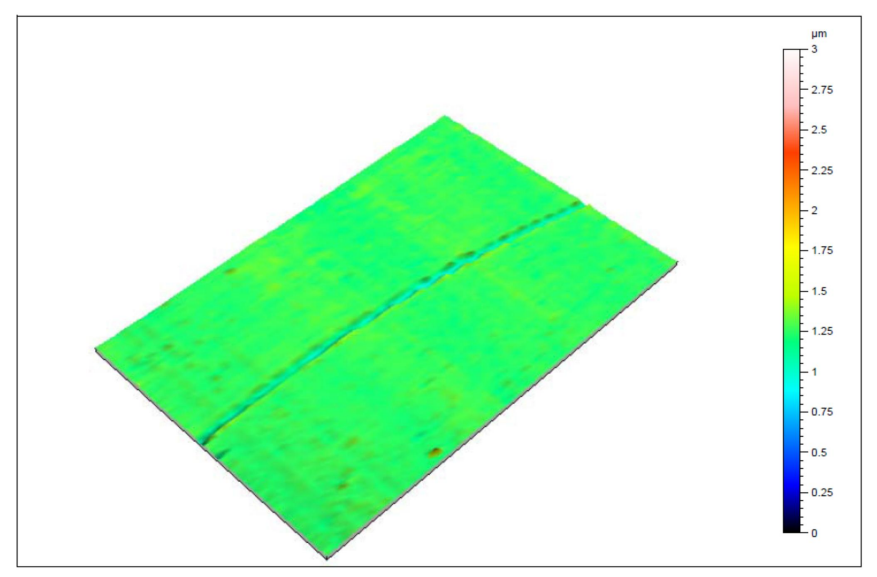

Figura 186. Topografía superficial de la huella de desgaste sobre el disco de acero tras ensayo con DCi+ND (capa fina estufa) 


\subsubsection{Estudio XPS}

Para estudiar con mayor profundidad las interacciones superficiales que han tenido lugar en los ensayos tribológicos en el contacto zafiro-acero empleando como lubricante la dispersión del líquido iónico prótico DCi con un $0,1 \%$ de nanodiamantes se ha realizado un análisis XPS. Para ello, se ha empleado el equipo ESCA5701 de Physical Electronics (3.2.2.22).

Como se puede observar en la Tabla 54, la superficie de acero tras la lubricación con DCi+ND muestra unos valores de energía de ligadura similares tanto dentro como fuera de la huella, lo que corresponde a la presencia de DCi y óxidos metálicos. Los tres picos correspondientes a la señal de C1s de 285 a $288 \mathrm{eV}$ son asignables a carbono alifático y a C-O y COO, respectivamente. La señal $\mathrm{N} 1 s$ corresponde al enlace $\mathrm{N}-\mathrm{H}$ del catión amonio del líquido iónico prótico. Las tres energías de ligadura del O1s, desde 530 a $534 \mathrm{eV}$ pueden asignarse a óxidos, O-H y C-O respectivamente. Los picos más abundantes de Fe2p y Cr2p se corresponden con la presencia de óxidos de hierro y cromo [294].

Tabla 54. Análisis XPS dentro y fuera de la huella del disco de acero tras lubricación con

$$
\mathrm{DCi}+\mathrm{ND}
$$

\begin{tabular}{|c|c|c|c|c|}
\hline \multirow[b]{2}{*}{ Elemento } & \multicolumn{2}{|c|}{ Fuera de la huella } & \multicolumn{2}{|c|}{ Dentro de la huella } \\
\hline & $\begin{array}{l}\text { Energía de ligadura } \\
\qquad(\mathrm{eV})\end{array}$ & $\%$ Atómico & $\begin{array}{c}\text { Energía de Ligadura } \\
(\mathrm{eV})\end{array}$ & \% Atómico \\
\hline \multirow{3}{*}{ C1s } & 285,0 & 51,1 & 285,0 & 50 \\
\hline & 286,3 & 5,5 & 286,4 & 10,3 \\
\hline & 288,6 & 3,1 & 288,7 & 6,1 \\
\hline N1s & 400,0 & 0,6 & 400,2 & 0,8 \\
\hline \multirow{3}{*}{ 01s } & 530,2 & 17 & 530,3 & 6,0 \\
\hline & 531,9 & 16,1 & 532,2 & 23,0 \\
\hline & 533,8 & 1,0 & 534,1 & 1,5 \\
\hline \multirow{3}{*}{ Cr2p } & 574,1 & 0,1 & 574,5 & 0,05 \\
\hline & 576,4 & 1,0 & 576,6 & 0,5 \\
\hline & 578,1 & 0,4 & 578,5 & 0,1 \\
\hline \multirow{4}{*}{$\mathrm{Fe} 2 \mathrm{p}$} & 707,3 & 0,5 & 707,1 & 0,2 \\
\hline & 710,7 & 2,6 & 708,9 & 0,3 \\
\hline & 712,9 & 0,6 & 711,0 & 1,0 \\
\hline & 719,2 & 0,2 & 713,6 & 0,3 \\
\hline
\end{tabular}


La principal diferencia existente entre los resultados obtenidos dentro y fuera de la huella es el menor porcentaje de oxígeno, cromo y hierro en el interior de la huella con respecto a la superficie de acero inoxidable. Sin embargo, el carbono y el nitrógeno presentes en el lubricante se encuentran en mayor proporción dentro de la huella.

\subsubsection{Análisis morfológico}

Se ha llevado a cabo un estudio morfológico de los nanodiamantes antes y después del ensayo tribológico mediante microscopía electrónica de transmisión.

En la Figura 187 se observan los nanodiamantes antes del ensayo tribológico, donde se puede observar claramente la morfología redondeada típica de esta nanofase de carbono [198].

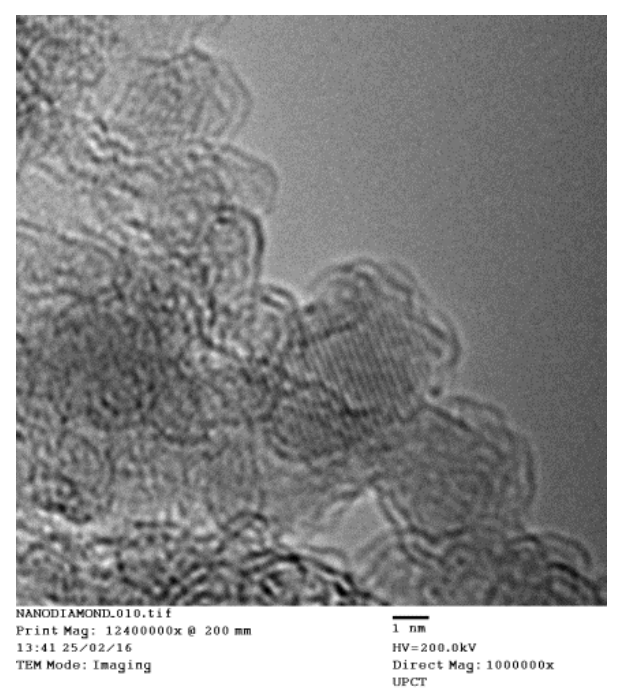

Figura 187. Micrografía TEM de los nanodiamantes antes del ensayo tribológico

Una vez finalizado el ensayo, las nanopartículas que se pueden observar en la huella de desgaste presentan una estructura de capas (Figura 188). 


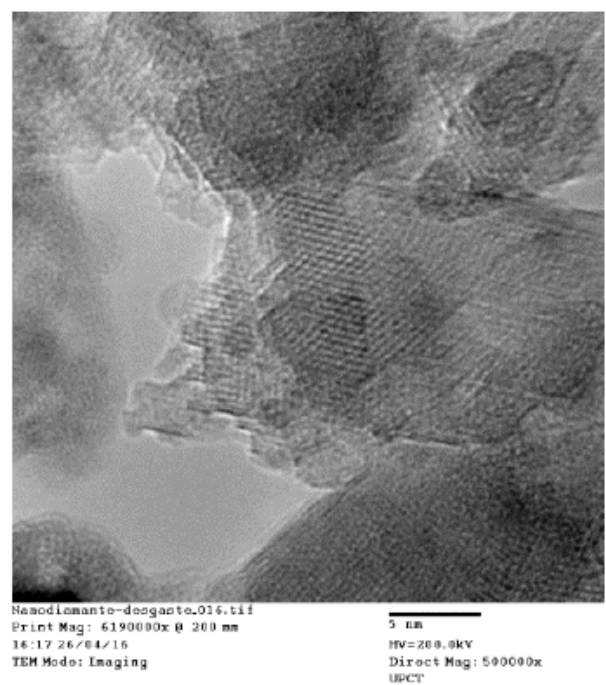

Figura 188. Micrografía TEM de los nanodiamantes después del ensayo tribológico

Este cambio en la morfología de las nanopartículas está relacionado con los resultados obtenidos mediante espectroscopía Raman confocal. Como se puede observar en la Figura 189 se ha producido un desplazamiento de la banda $\mathrm{G}$ asignable al $\mathrm{C} \mathrm{sp}{ }^{2}[55]$ debido a la presencia de estructuras grafíticas laminares desde $1581,0 \mathrm{~cm}^{-1}$ a $1602,8 \mathrm{~cm}^{-1}$ [307]. La banda $\mathrm{C} \mathrm{sp}$ aparece a $1362,0 \mathrm{~cm}^{-1}$ para los nanodiamantes y a $1364,4 \mathrm{~cm}^{-1}$ para las nanopartículas dentro de la huella de desgaste tras la lubricación con (DCi+ND).

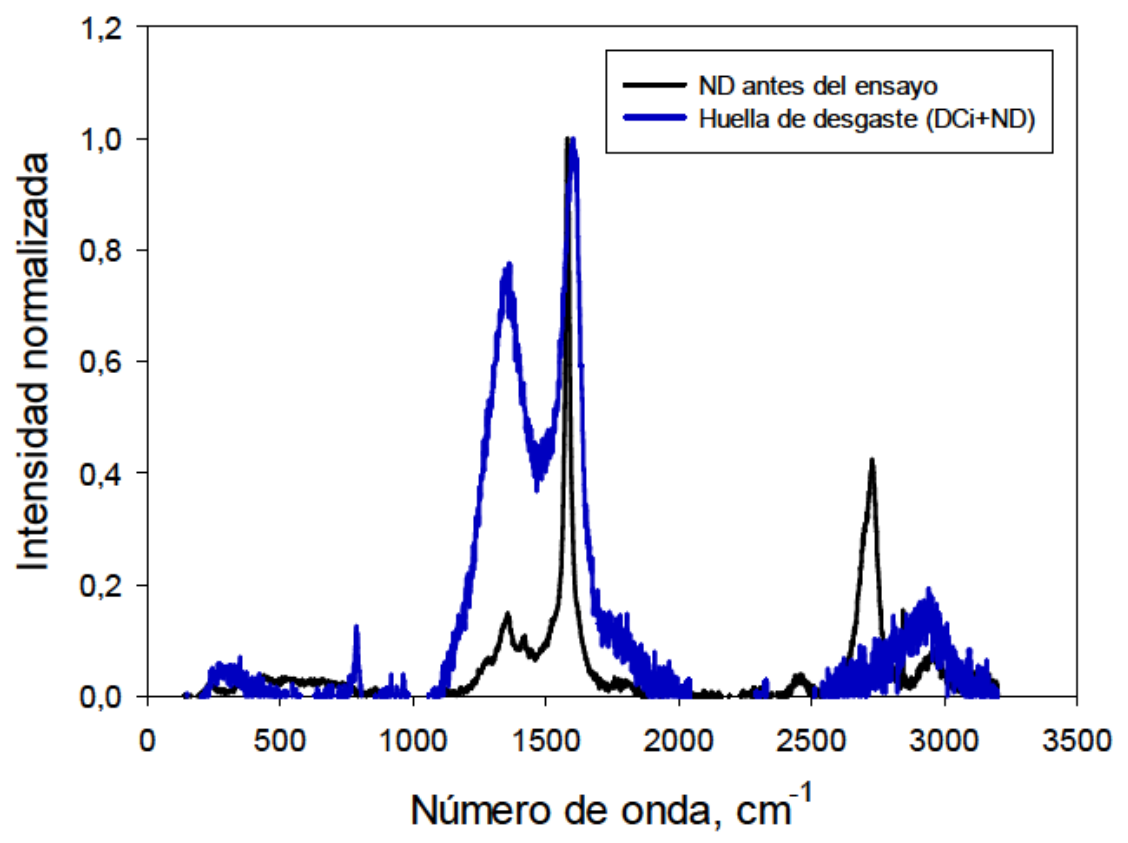

Figura 189. Espectros Raman de los nanodiamantes antes del ensayo y en la huella de desgaste obtenida en la probeta de acero tras el ensayo tribológico con $\mathrm{DCi}+\mathrm{ND}$ 
Estos resultados pueden ser explicados por la expulsión de los nanodiamantes de la zona de contacto, permaneciendo únicamente las nanoestructuras grafíticas en el interior de la huella.

\subsubsection{Conclusiones}

Cuando se añade una suspensión de nanodiamantes en agua al líquido iónico derivado de citrato, se consigue una reducción del coeficiente de fricción, pero no así de la tasa de desgaste, lo que podría deberse a la presencia de agua.

Cuando se utilizan lubricantes de capa fina formada sobre la superficie del acero por evaporación de agua previa al deslizamiento, se obtienen tasas de desgaste similares y coeficientes de fricción menores que en el caso de los lubricantes de película gruesa. Esto se atribuye a la formación de una capa adsorbida sobre la superficie que ofrece menor resistencia al deslizamiento. 


\subsubsection{Dispersiones de líquidos iónicos apróticos derivados del catión 1- etil-3-metilimidazolio con grafeno}

Aunque los líquidos iónicos derivados del catión imidazolio han sido estudiados como lubricantes en multitud de contactos diferentes, en este trabajo se va a caracterizar y estudiar el comportamiento reológico y tribológico de dos líquidos iónicos que poseen este catión, pero dos aniones diferentes, uno totalmente orgánico y otro fluorado: el líquido iónico dicianamida de 1-etil-3-metilimidazolio [EMIM][DCA] y el bis(trifluorometilsulfonilimida) de 1-etil-3-metilimidazolio [EMIM][TFSI].

En general, los líquidos iónicos empleados como lubricantes poseen heteroátomos como flúor, azufre o fósforo en sus aniones. Estos elementos son reactivos, potencialmente corrosivos y contaminantes, sin embargo, el anión dicianamida es totalmente orgánico, biocompatible y respetuoso con el medio ambiente. Por tanto, surge la necesidad de comparar las propiedades reológicas y tribológicas de un líquido iónico libre de haluros como el [EMIM] [DCA], con otro que posee estos elementos en su composición y que ya ha mostrado buenas propiedades como lubricante [55].

Además, se ha estudiado el comportamiento de las dispersiones de grafeno al $1 \%$ y al $0,5 \%$ en peso en estos líquidos iónicos, dados los resultados previos que han demostrado la mejora de las propiedades frente a fricción y desgaste de los nanofluidos creados a partir de grafeno y líquido iónico [255] [308].

\subsubsection{Caracterización de las dispersiones}

\subsection{Análisis térmico}

Para la determinación de la temperatura de degradación de los líquidos iónicos derivados del catión 1-etil-3-metilimidazolio, se han realizado análisis termogravimétricos siguiendo el procedimiento descrito en el apartado 3.3.1.8.1.

La pérdida de peso que sufren [EMIM][DCA] y las dispersiones con grafeno se muestran en la Figura 190. Se observa que la adición de nanofase produce una etapa de pérdida de peso inicial. 


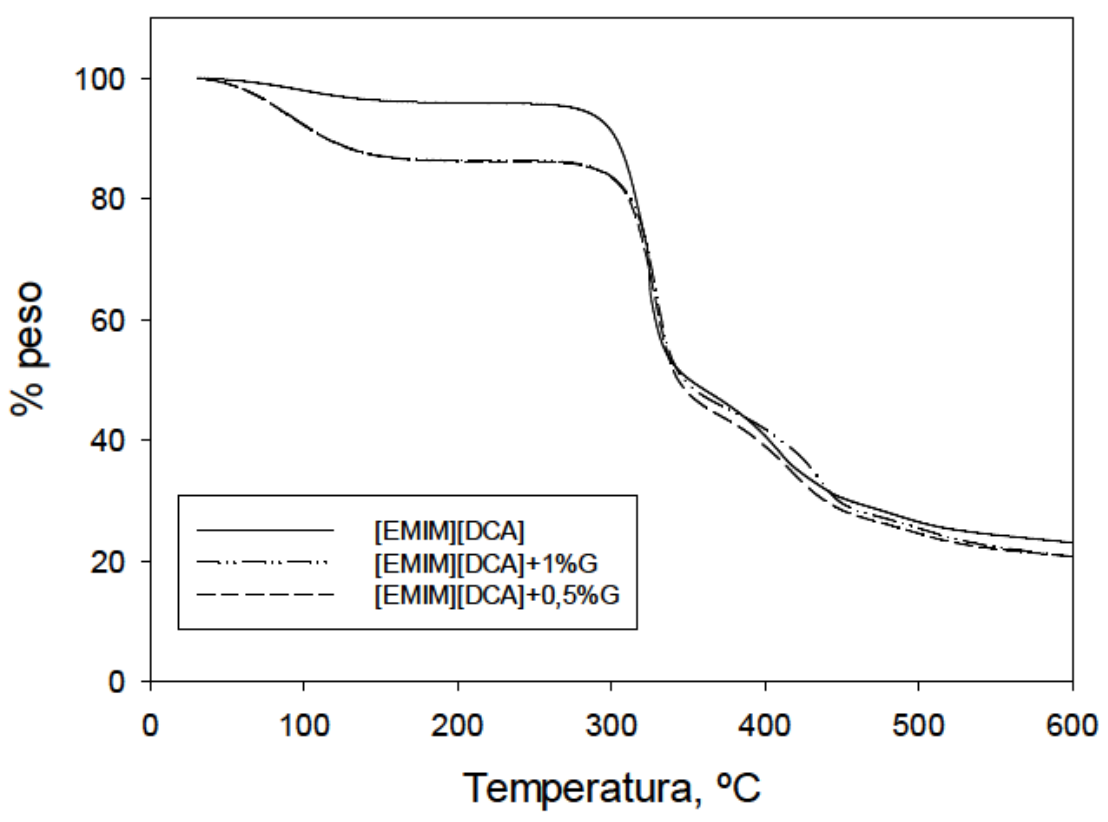

Figura 190. Análisis termogravimétrico de $[E M I M][D C A]$ y sus dispersiones con grafeno

En la Tabla 55 se recogen los valores de temperaturas de degradación obtenidas para [EMIM][DCA] y las dispersiones de grafeno al $1 \%$ y al $0,5 \%$. Es posible observar cómo la adición de la nanofase disminuye el valor de la temperatura de degradación, debida a la pérdida de peso inicial.

Tabla 55. Temperatura de degradación de [EMIM][DCA] y sus dispersiones con grafeno

\begin{tabular}{cc}
\hline & $\operatorname{Td}\left({ }^{\circ} \mathrm{C}\right)(\Delta \mathrm{m}=-\mathbf{5 0} \%)$ \\
\hline [EMIM][DCA] & 361,51 \\
\hline [EMIM][DCA]+1\%G & 348,45 \\
\hline [EMIM][DCA]+0,5\%G & 344,58 \\
\hline
\end{tabular}

En el caso del líquido iónico [EMIM][TFSI], la evolución de la pérdida de masa con la temperatura para la dispersión con un $0,5 \%$ de grafeno muestra una tendencia similar a la presentada por el líquido iónico sin aditivos. Sin embargo, para la dispersión con un $1 \%$ de grafeno la curva se desplaza hacia temperaturas más bajas (Figura 191). 


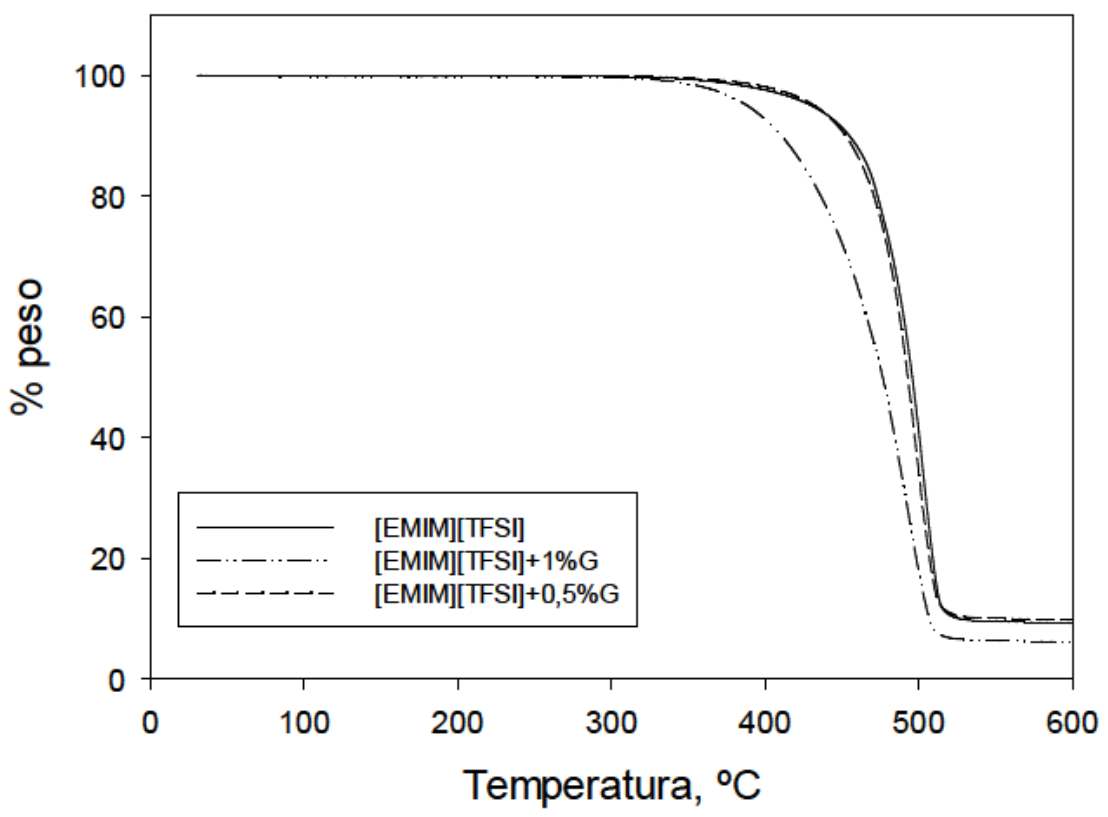

Figura 191. Análisis termogravimétrico de [EMIM][TFSI] y sus dispersiones con grafeno

En la Tabla 56 se recogen los valores de temperatura de degradación para las dispersiones de grafeno en [EMIM][TFSI] y se comparan con las obtenidas para el líquido iónico sin aditivos. La adición de un $0,5 \%$ de grafeno no implica variaciones en la temperatura de degradación. Sin embargo, cuando la concentración de nanofase es superior, la estabilidad del nanofluido disminuye.

Tabla 56. Temperatura de degradación de [EMIM][TFSI] y sus dispersiones con grafeno

\begin{tabular}{cc}
\hline & $\operatorname{Td}\left({ }^{\circ} \mathrm{C}\right)(\Delta \mathrm{m}=-50 \%)$ \\
\hline [EMIM][TFSI] & 484,1 \\
\hline [EMIM][TFSI]+1\%G & 465,4 \\
\hline [EMIM][TFSI]+0,5\%G & 481,4 \\
\hline
\end{tabular}

\subsubsection{2. Ángulo de contacto}

Se han medido los ángulos de contacto de los líquidos iónicos [EMIM][DCA] y [EMIM][TFSI] y sus dispersiones con grafeno al $1 \%$ y al $0,5 \%$ sobre discos de acero inoxidable AISI $316 \mathrm{~L}$. Se puede observar en la Tabla 57 que [EMIM][TFSI] y sus dispersiones presentan ángulos de contacto inferiores a los del líquido iónico con el catión dicianamida. 
Capítulo 4. Resultados y discusión

Tabla 57. Ángulos de contacto de [EMIM][DCA], [EMIM][TFSI] y sus dispersiones con grafeno sobre AISI 316L

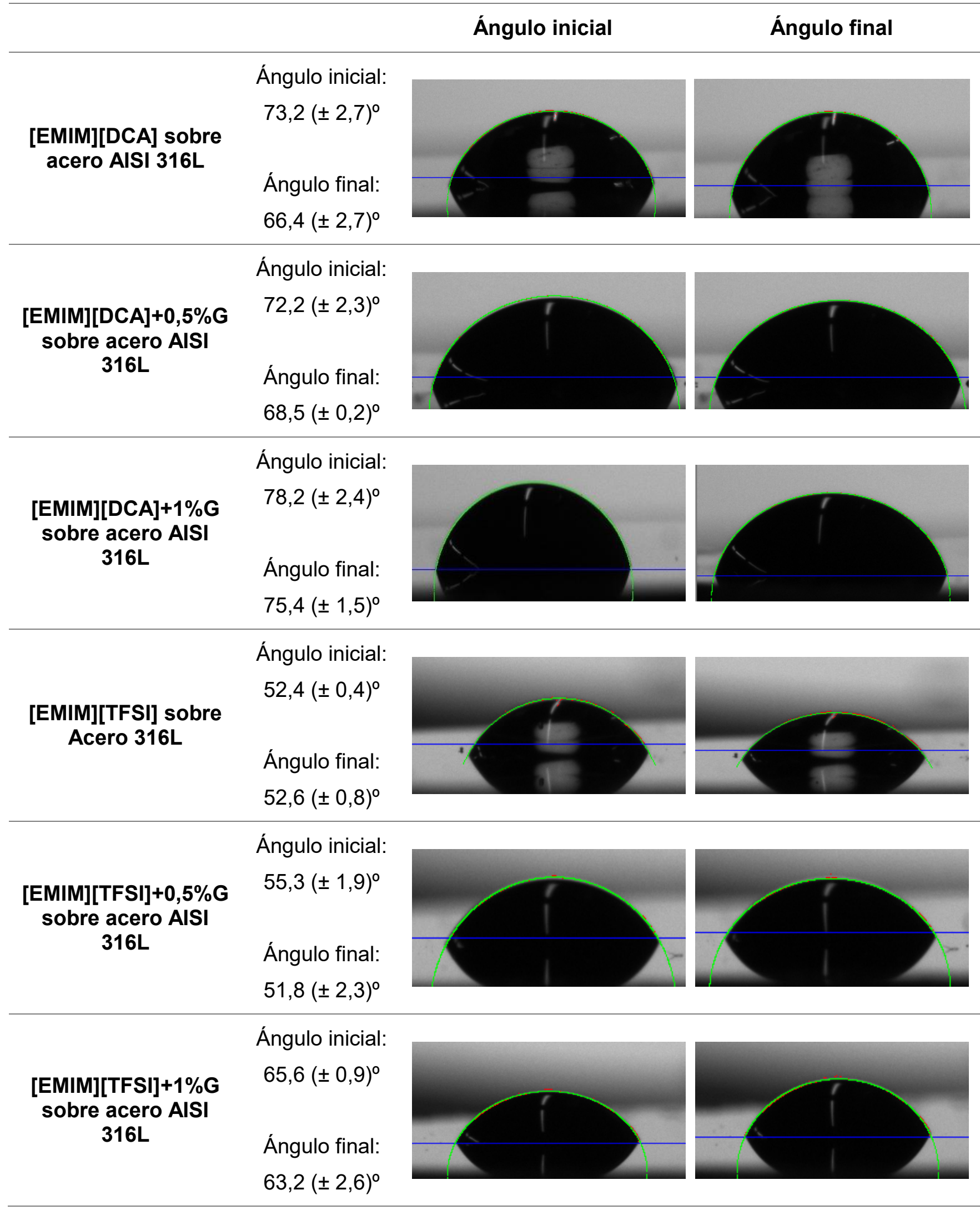


La adición de un 0,5\% de grafeno a los líquidos iónicos no implica diferencias significativas en el ángulo de contacto, ni inicial ni final. Sin embargo, a mayores concentraciones de nanofase de carbono (1\%) el ángulo de contacto aumenta, presentando una menor mojabilidad con la superficie de acero.

\subsubsection{Estudio reológico}

\subsection{Efecto de la velocidad de cizalla}

La Figura 192 muestra la dependencia de la viscosidad con el incremento de la velocidad de cizalla a temperatura ambiente para [EMIM][DCA] y para [EMIM][TFSI] y sus correspondientes dispersiones de grafeno al 0,5 y $1 \%$.

Como se esperaba, [EMIM][DCA] presenta unos valores de viscosidad mucho más bajos que [EMIM][TFSI], y conforme aumenta el porcentaje de grafeno añadido el valor de la viscosidad también aumenta, siendo este incremento más significativo en el caso de [EMIM][TFSI].

En particular, la adición de un $0,5 \%$ en peso de grafeno al líquido iónico [EMIM][TFSI] supone un incremento de la viscosidad a $500 \mathrm{~s}^{-1}$ del $70,5 \%$ con respecto al líquido iónico sin aditivos y en el caso de [EMIM][DCA], de un $48,5 \%$, mientras que en el caso de las dispersiones con un $1 \%$ de grafeno, el aumento es de un $269 \%$ para [EMIM][TFSI] y un $151 \%$ para [EMIM][DCA].

Ambos líquidos iónicos presentan un comportamiento Newtoniano, con una viscosidad que permanece constante con el aumento de la velocidad de cizalla. Sin embargo, las dispersiones con grafeno son fluidos no Newtonianos, los cuales presentan comportamientos de shear thinning particularmente pronunciados a bajo gradiente de cizalla. Cuando la velocidad aumenta, la viscosidad de las dispersiones de líquido iónico y grafeno muestran un comportamiento similar al de los líquidos iónicos puros. Estos resultados pueden ser atribuidos a la mayor homogeneidad de las dispersiones de grafeno y a la ausencia de aglomerados de gran tamaño que se oponen al flujo. 
a)

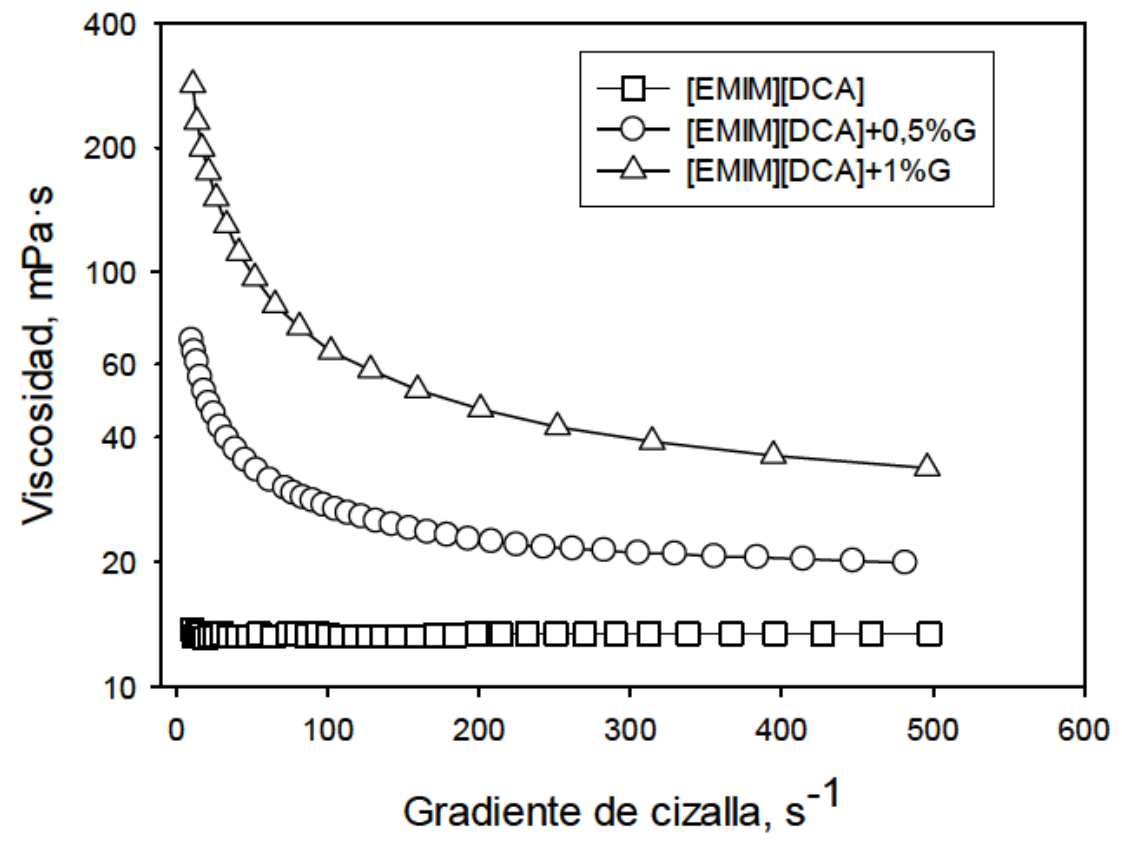

b)

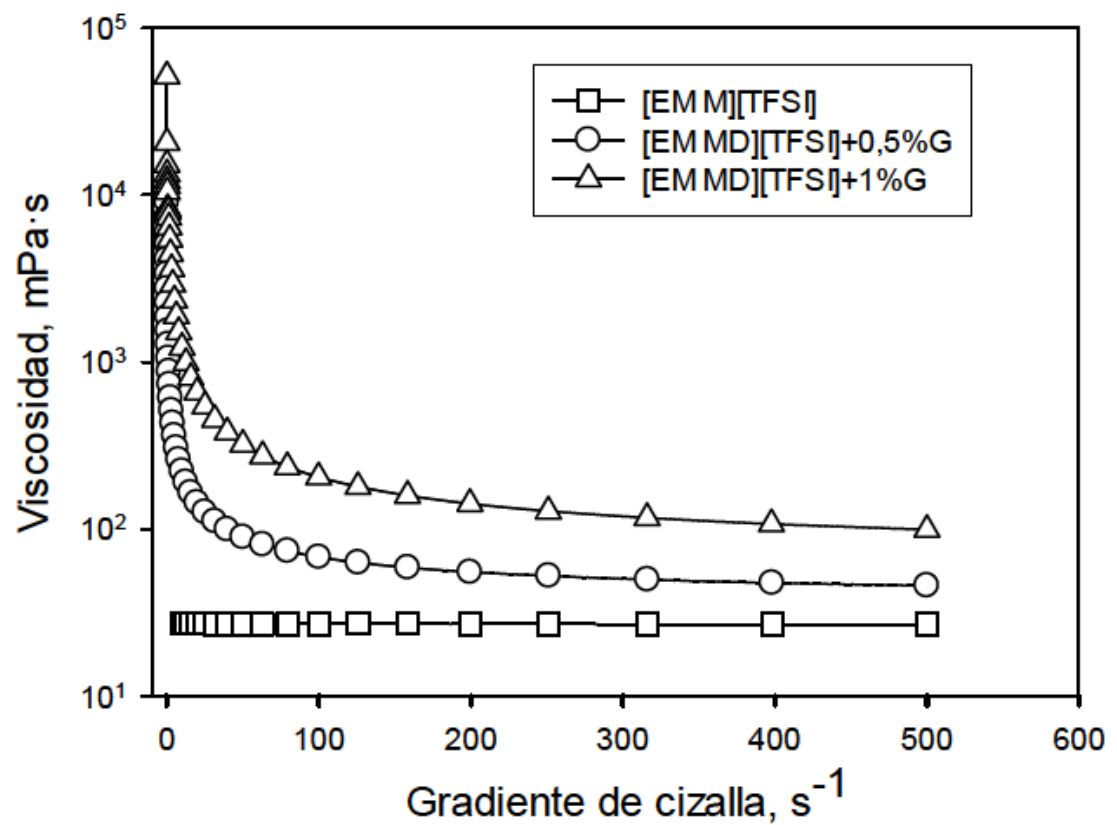

Figura 192. Evolución de la viscosidad con la velocidad de cizalla a $25^{\circ} \mathrm{C}$ : a) [EMIM][DCA] y sus dispersiones con grafeno; b) [EMIM][TFSI] y sus dispersiones con grafeno

\subsection{Valores de viscosidad en función de la temperatura}

\subsection{Líquidos iónicos}

La Figura 193 muestra la disminución de la viscosidad con el incremento de la temperatura para [EMIM][DCA] y [EMIM][TFSI], para un rango de temperaturas 
María Dolores Avilés González

Universidad Politécnica de Cartagena

entre 25 y $120^{\circ} \mathrm{C}$. Los resultados están en concordancia con los obtenidos por otros autores, tanto en el caso de [EMIM][DCA] [309][310] como de [EMIM][TFSI] [311]-[313].

a)

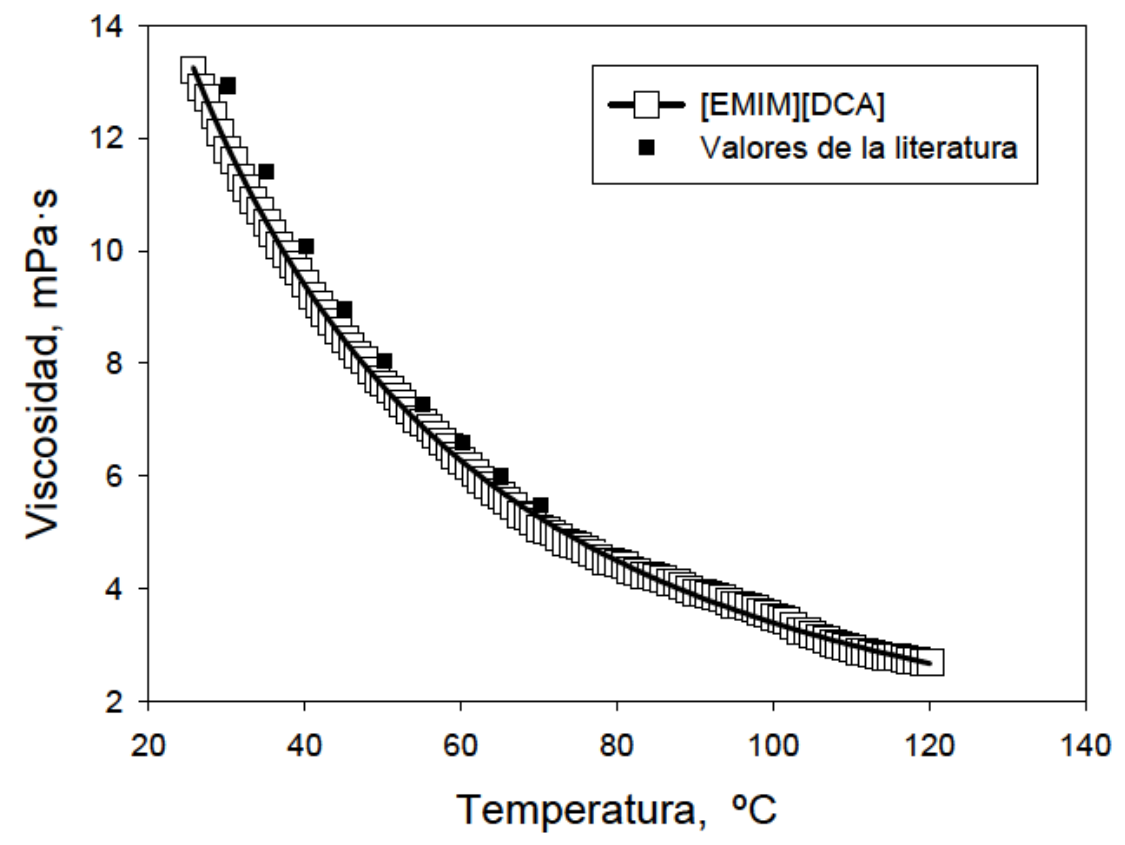

b)

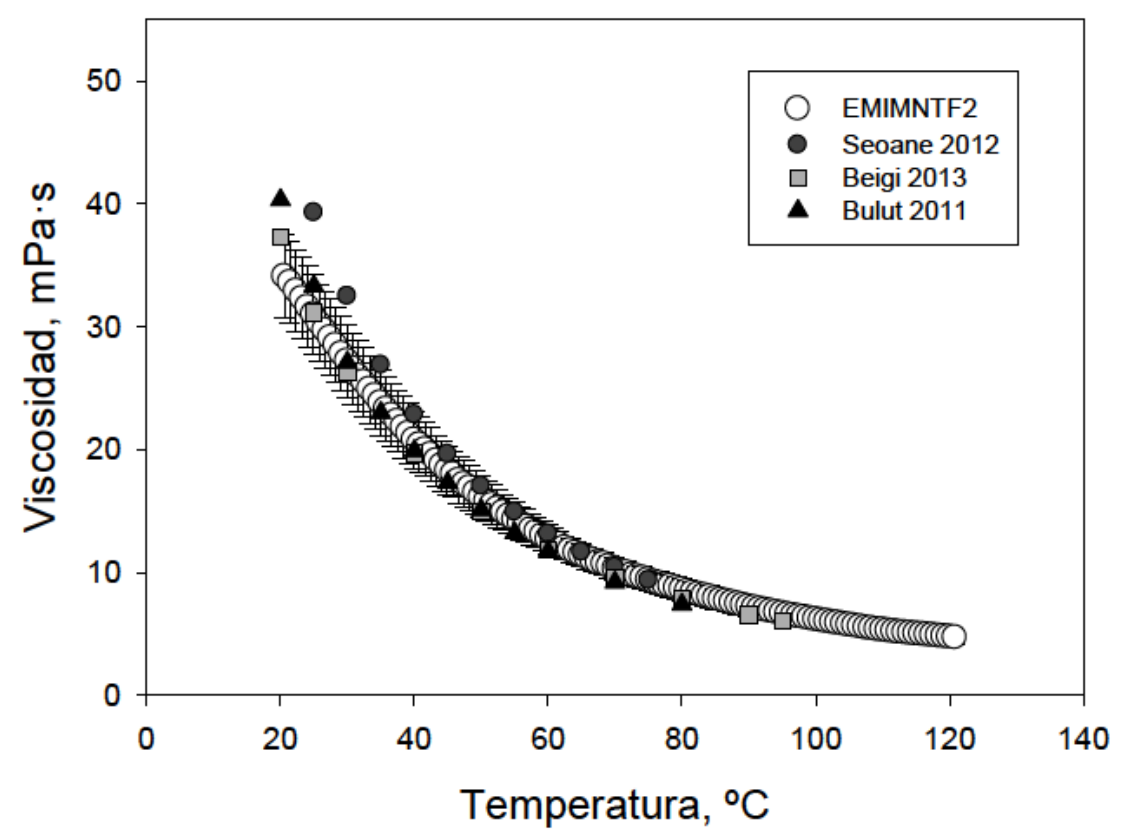

Figura 193. Evolución de la viscosidad con la temperatura para: a) [EMIM][DCA];

b) [EMIM][TFSI]

Shi et al. [314] han establecido la relación entre la conductividad eléctrica y el valor de la viscosidad dinámica de líquidos iónicos que contienen el catión 1etil-3-metilimidazolio ([EMIM]). Cuando el anión es la dicianamida, el líquido 
iónico ([EMIM][DCA]) muestra el valor de conductividad más elevado y el de viscosidad más bajo.

Los modelos moleculares de Weber y Kirchner [315], para los líquidos iónicos etilmetildicianamida, concuerdan con los fuertes enlaces de hidrógeno que presenta [EMIM][DCA] entre el anión dicianamida y el anillo de imidazolio. Sin embargo, los valores de viscosidad experimentales se correlacionan con la dinámica catión-catión.

\subsection{Dispersiones líquido iónico+grafeno}

Resultados previos han mostrado una reducción de la viscosidad de los líquidos iónicos con la adición de bajas concentraciones de grafeno $(0,005$ o $0,01 \%$ de grafeno a $\left[\mathrm{BMIM}\left[\mathrm{BF}_{4}\right][316]\right.$ o 0,03 y $0,06 \%$ de grafeno a $[\mathrm{HMIM}]\left[\mathrm{BF}_{4}\right]$ [317]).

En este caso, la adición de un $0,5 \%$ de grafeno al líquido iónico [EMIM][DCA] (Figura 194) incrementa la viscosidad con respecto al líquido iónico puro y muestra el comportamiento esperado, es decir, la viscosidad va disminuyendo conforme aumenta la temperatura hasta $84^{\circ} \mathrm{C}$. Desde esta temperatura hasta el final del ensayo, la viscosidad permanece constante presentado un valor medio de $18,9 \mathrm{mPa} \cdot \mathrm{s}$. El hecho de que la viscosidad permanezca constante con la temperatura difiere del comportamiento del líquido iónico de partida, sin embargo, dicho comportamiento ya ha sido descrito para otros nanofluidos iónicos o ionanofluidos [317].

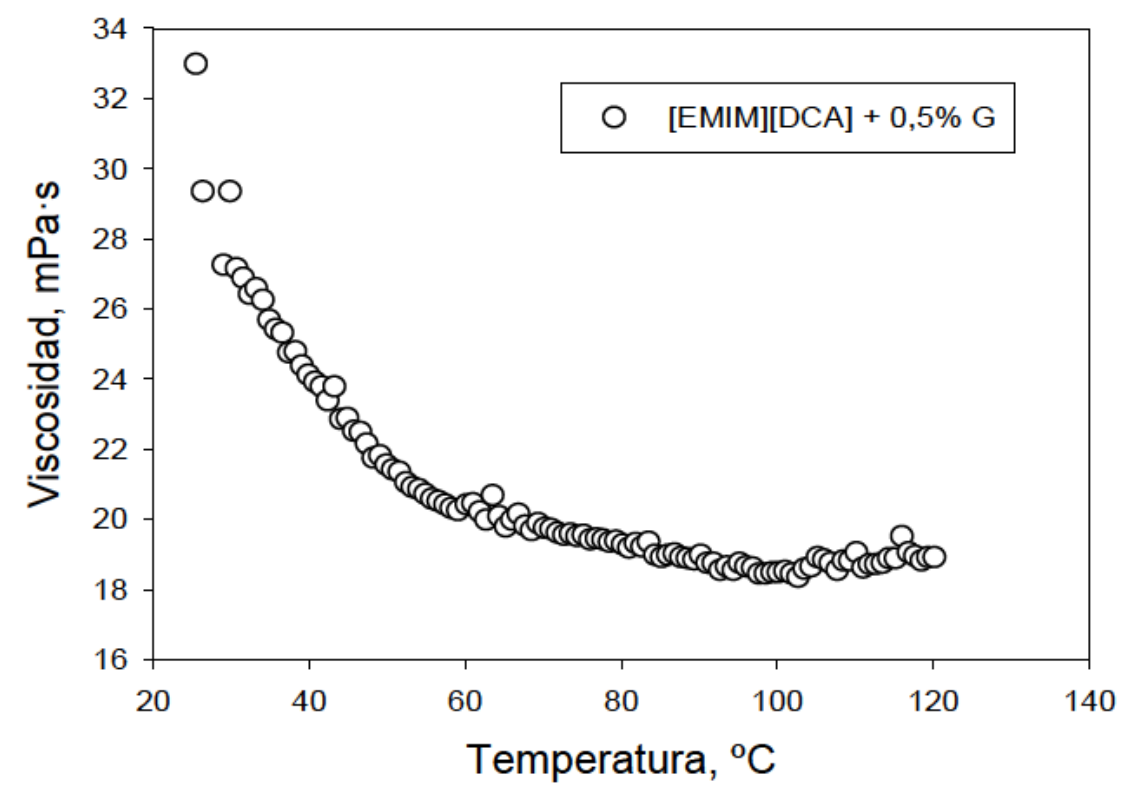

Figura 194. Evolución de la viscosidad con la temperatura para [EMIM][DCA]+0,5\%G 
Por otro lado, cuando se añade un porcentaje del $1 \%$ de grafeno al [EMIM][DCA] (Figura 195), la viscosidad se incrementa con respecto al líquido iónico puro y a la dispersión con un $0,5 \%$ de grafeno, ya que un incremento en la concentración de la nanofase provoca un aumento de la tensión de cizalla y, por tanto, un aumento de la viscosidad [318]. Sin embargo, no hay precedentes en la bibliografía de este comportamiento para los nanofluidos descritos en el presente trabajo.

Además, la variación de la viscosidad con la temperatura para esta dispersión de $[E M I M][D C A]$ con un $1 \%$ de grafeno muestra una tendencia anómala. Como se puede observar en la Figura 195, la viscosidad sólo disminuye con el aumento de la temperatura entre $25^{\circ} \mathrm{C}$ y $30^{\circ} \mathrm{C}$, hasta alcanzar un valor mínimo de $91,7 \mathrm{mPa} \cdot \mathrm{s}$. Desde $30^{\circ} \mathrm{C}$ hasta $120^{\circ} \mathrm{C}$, los valores de viscosidad de la dispersión muestran un incremento lineal con el aumento de la temperatura, con una pendiente de $2 \times 10^{-4}$, en un comportamiento sin precedentes.

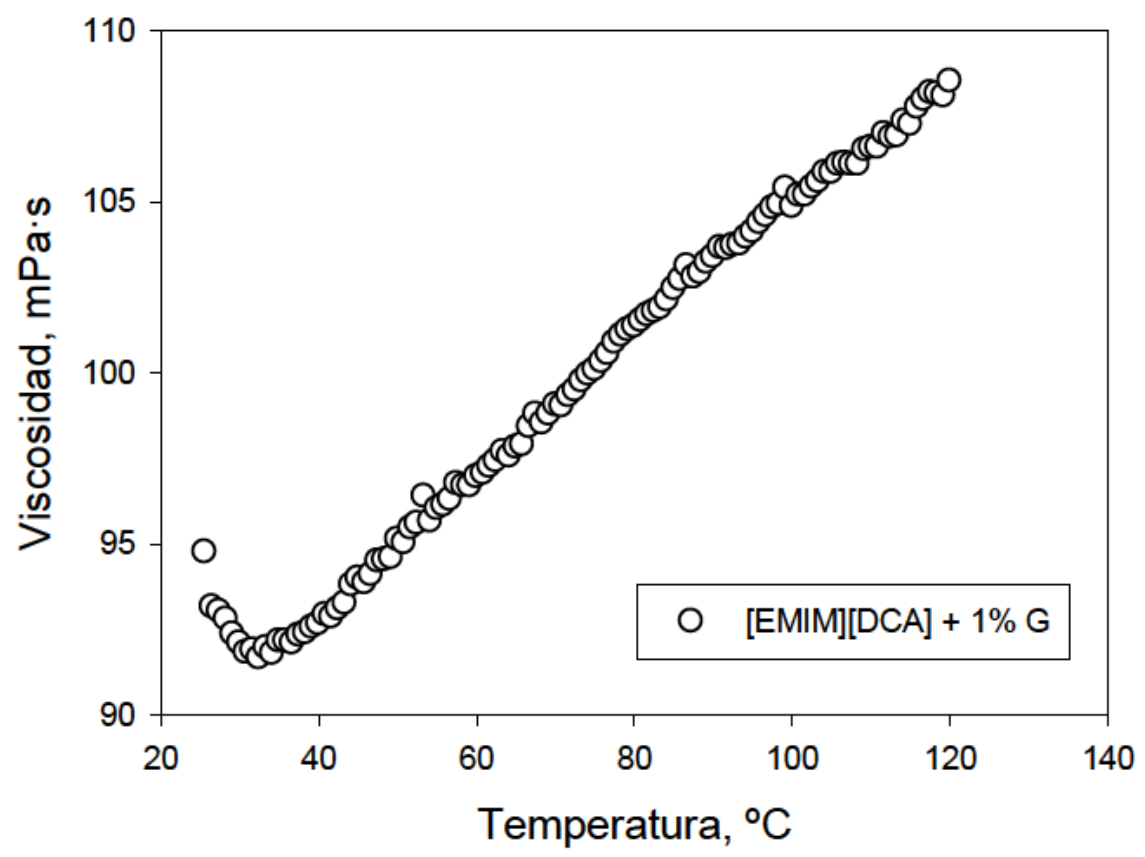

Figura 195. Evolución de la viscosidad con la temperatura para [EMIM][DCA]+1\%G

A la vista de los resultados obtenidos para [EMIM][DCA], en el caso de [EMIM][TFSI] se ha llevado a cabo el estudio de viscosidad para un mayor rango de concentraciones de grafeno.

La adición de bajas concentraciones de grafeno ( 0,05 y $0,1 \%$ en peso) al líquido iónico [EMIM][TFSI] no produce cambios significativos en el 
comportamiento reológico con respecto al líquido iónico sin aditivos como se puede observar en la Figura 196.

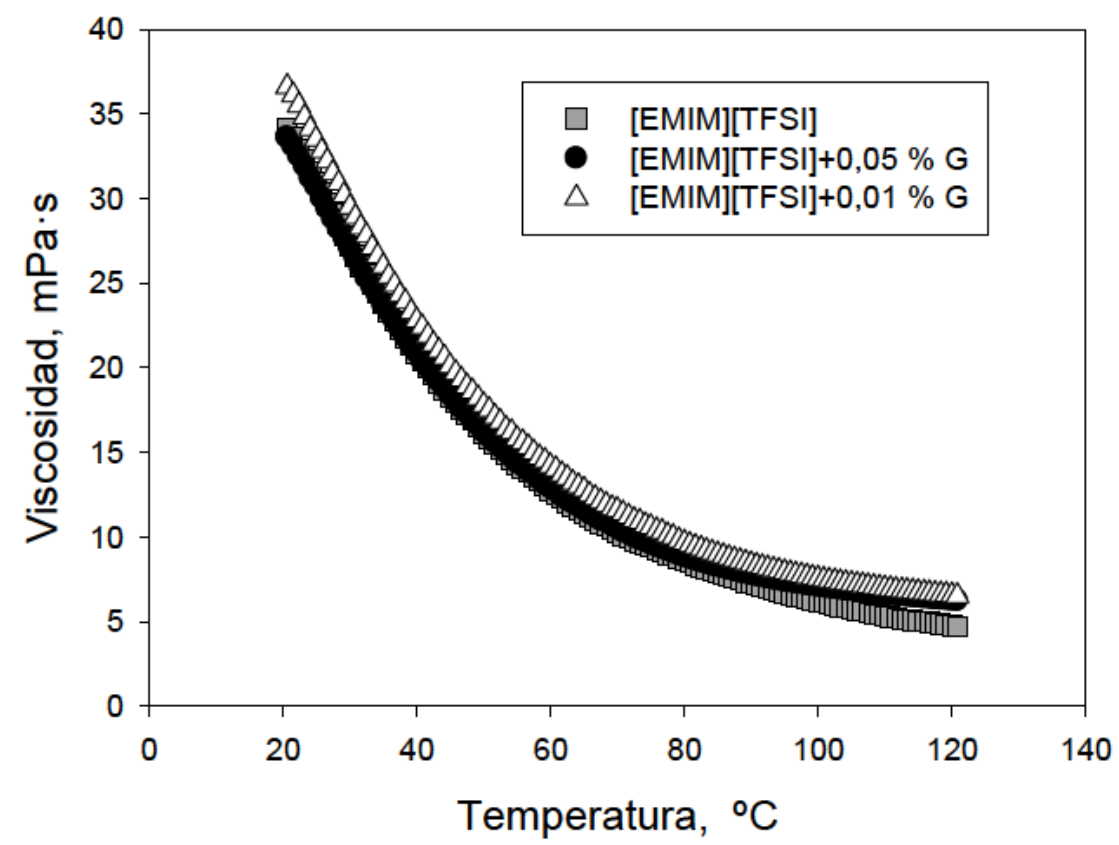

Figura 196. Evolución de la viscosidad con la temperatura para las dispersiones de [EMIM][TFSI] con grafeno a baja concentración

Cuando el contenido de grafeno en la dispersión de [EMIM][TFSI] aumenta, la evolución de la viscosidad con la temperatura es similar a la descrita para [EMIM][DCA]+grafeno.

Para [EMIM][TFSI]+0,5\%G (Figura 197), la viscosidad se hace asintótica con la temperatura y permanece constante, con un valor de $53 \mathrm{mPa} \cdot \mathrm{s}$ desde $112^{\circ} \mathrm{C}$ hasta $120^{\circ} \mathrm{C}$. Al igual que mostraban los estudios llevados a cabo por Kheireddin et al. [318], los valores de viscosidad aumentan conforme aumenta la concentración de grafeno en todo el rango de temperatura. Una concentración de grafeno superior al $0,5 \%$ no solo impide el movimiento de las moléculas de líquido iónico, sino que además produce un incremento lineal de la viscosidad conforme la temperatura aumenta desde $57^{\circ} \mathrm{C}$ hasta $120^{\circ} \mathrm{C}$. El valor de la pendiente se incrementa con el aumento del porcentaje de grafeno, desde 0,59 para [EMIM][TFSI]+0,75\%G hasta 1,21 para [EMIM][TFSI]+1\%G (Figura 197). 


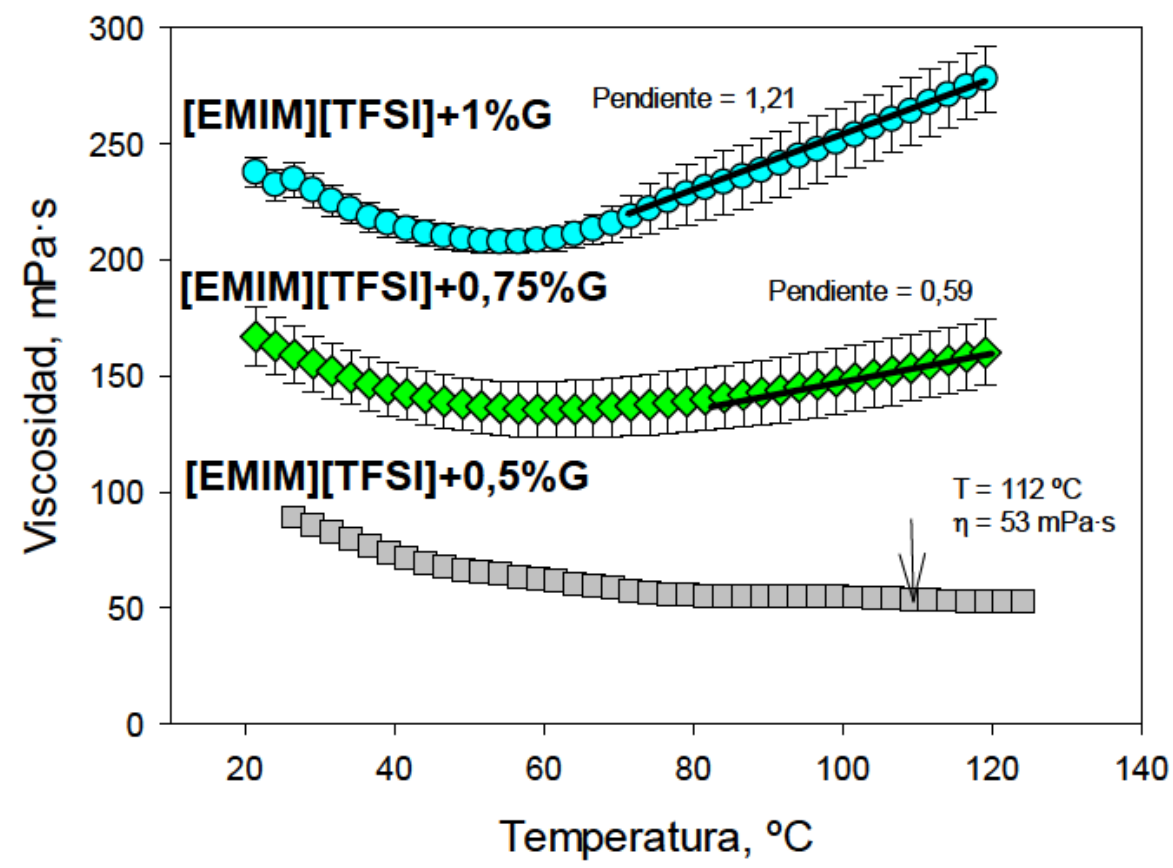

Figura 197. Evolución de la viscosidad con la temperatura para las dispersiones de [EMIM][TFSI] con grafeno

Estos resultados son atribuidos a las fuertes interacciones entre las láminas de grafeno y las moléculas de líquido iónico. De hecho, estas interacciones podrían ser responsables de que la disminución de la fluidez con la temperatura sea un proceso totalmente reversible para [EMIM][DCA]+0,5\%G (Figura 198) y [EMIM][TFSI]+1\%G y altamente reversible para [EMIM][DCA]+1\%G (Figura 199).

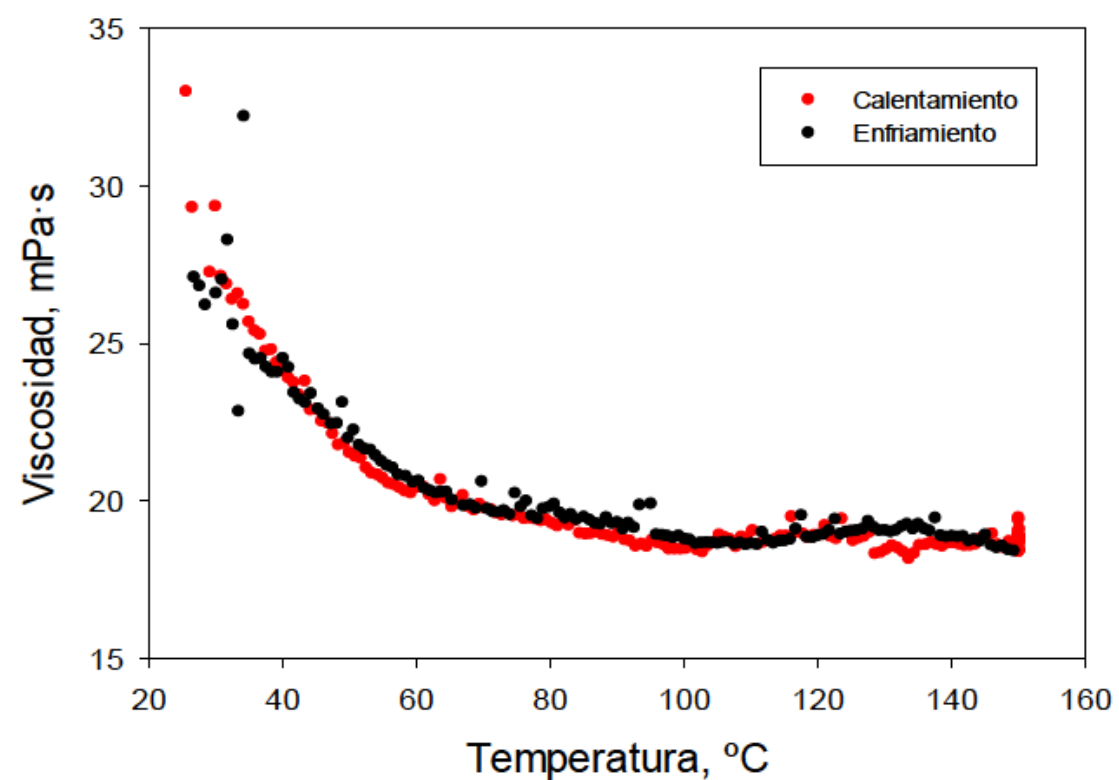

Figura 198. Evolución de la viscosidad en el ciclo de calentamiento-enfriamiento para [EMIM][DCA]+0,5\% G 


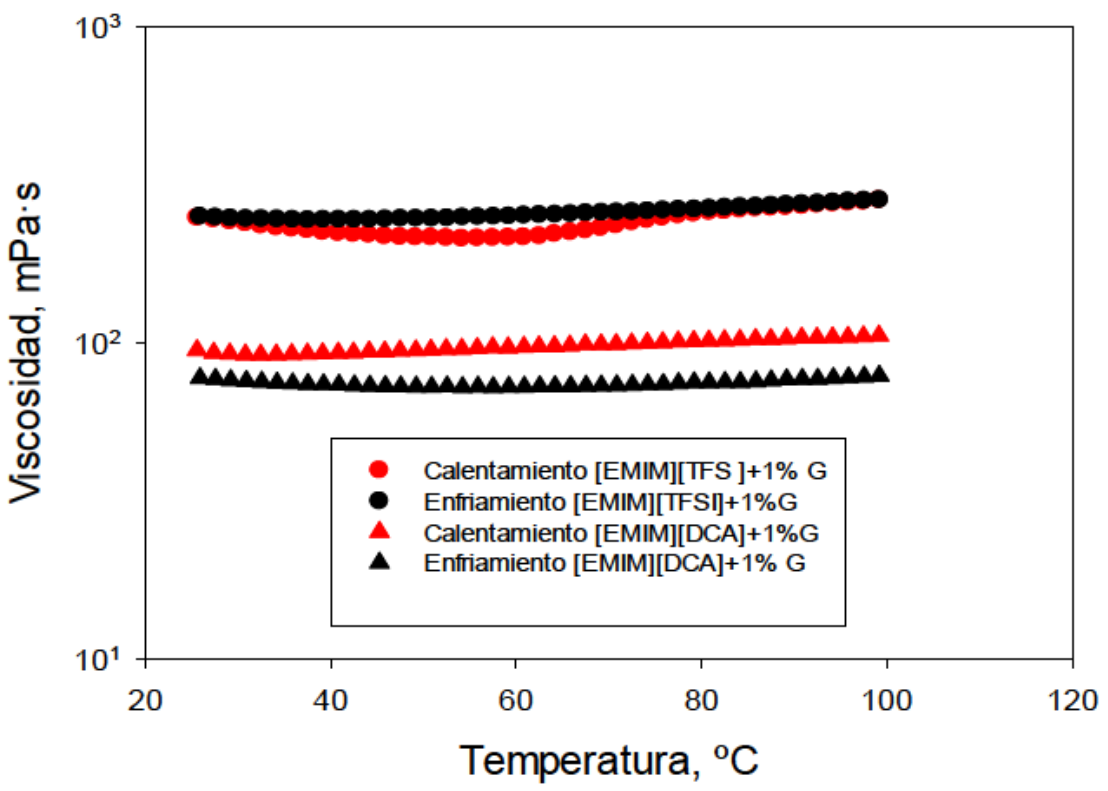

Figura 199. Evolución de la viscosidad en el ciclo de calentamiento-enfriamiento para los líquidos iónicos $+1 \% \mathrm{G}$

Entre las pocas observaciones previamente descritas del inusual comportamiento reológico que presentan las dispersiones de grafeno en [EMIM][TFSI] y [EMIM][DCA], se encuentra la realizada por Kalur et al. [319]. En este trabajo se concluye que el aumento de la viscosidad con la temperatura se debe al crecimiento de micelas en soluciones surfactantes catiónicas.

Chagnes et al. [320] encontraron un aumento de la viscosidad con la temperatura a bajas concentraciones del líquido iónico nitrato de etilamonio en agua y metanol. Ellos atribuyeron estos resultados a la formación de enlaces de hidrógeno entre las moléculas de líquido iónico y metanol.

Una dependencia lineal de la viscosidad con la temperatura ha sido recientemente descrita para disoluciones acuosas de líquidos iónicos [321]. Estos resultados se explican debido a las heterogeneidades dinámicas de los sistemas, las cuales cambian la organización estructural de las moléculas de los líquidos iónicos con la formación de agregados. Sin embargo, en el presente estudio no se ha observado la formación de grandes agregados 0 segregación de nanofase, ya que se ha confirmado la estabilidad de las dispersiones durante un largo periodo de tiempo (Figura 200). 
a)

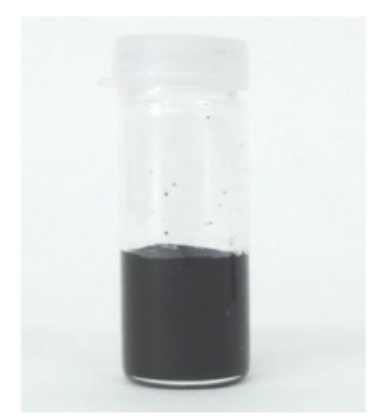

b)

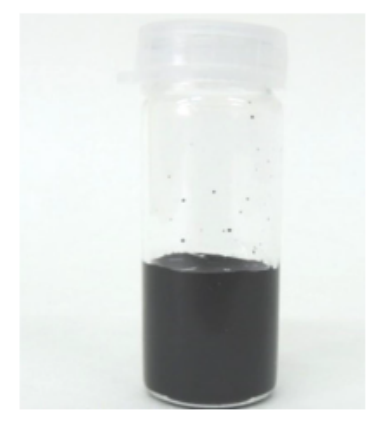

c)

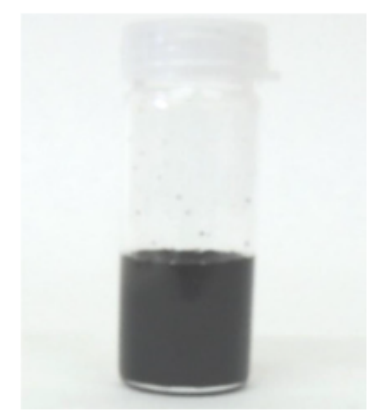

Figura 200. Dispersiones de [EMIM][DCA] $+1 \% G$ a temperatura ambiente: $a$ ) Inicial; b) Tras 30 días; c) Tras 60 días

Se han obtenido partículas de grafeno procedentes de las dispersiones de grafeno en [EMIM][TFSI], siguiendo el procedimiento descrito en el apartado 3.3.1.10. Tras su secado, se han estudiado mediante microscopía electrónica de barrido (Figura 201) y EDX.

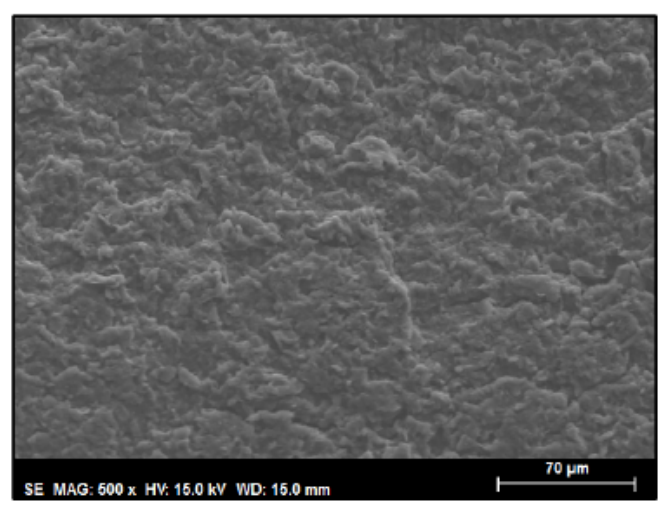

Figura 201. Micrografía SEM de partículas de grafeno de la dispersión de [EMIM][TFSI]+grafeno

En los mapas elementales (Figura 202) se puede observar la presencia de flúor, oxígeno y azufre, elementos presentes en el líquido iónico, confirmándose la adsorción de [EMIM][TFSI] en el grafeno. 

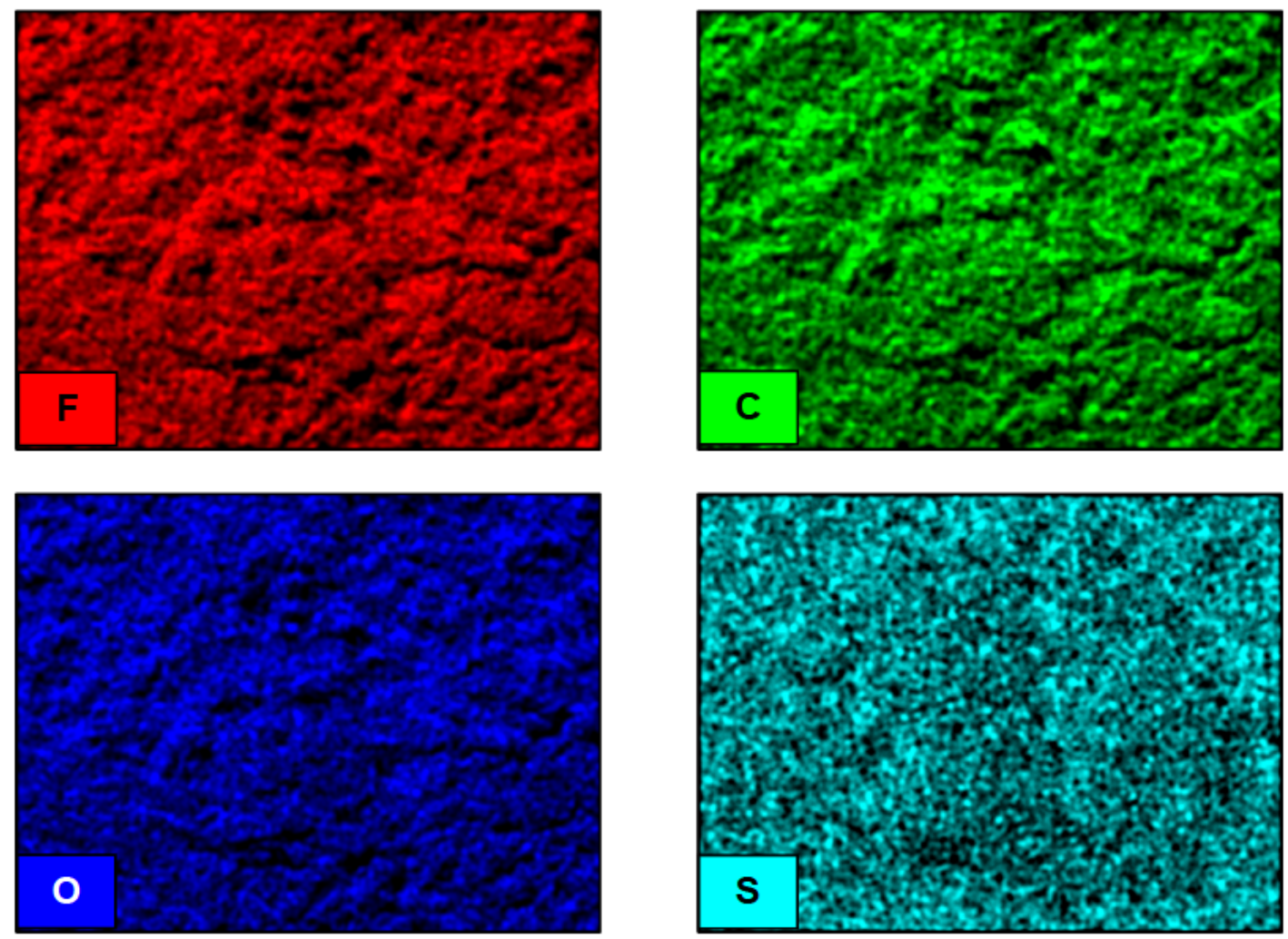

Figura 202. Mapas elementales de F, C, O y S de las partículas de grafeno obtenidas de la dispersión de [EMIM][TFSI]+grafeno

La adsorción de los líquidos iónicos de imidazolio ha sido estudiada mediante modelos moleculares [322]. Los resultados indican que la fortaleza de los enlaces de hidrógeno entre el catión y el anión en los líquidos iónicos disminuye y por tanto, aumenta la adsorción sobre la superficie del grafeno, mostrando interacciones $\pi-\pi$ y $\mathrm{C}-\mathrm{H}-\pi$. Los resultados de los análisis termoquímicos indican que la energía de adsorción de los líquidos iónicos en grafeno es negativa y la adsorción ocurre de forma espontánea. Además, la adsorción de los líquidos iónicos en grafeno reduce la entropía del sistema debido a la disminución de la movilidad de las moléculas de líquido iónico. Los resultados de dinámica molecular obtenidos por Pensado et al. [323] para el líquido iónico tiocianato de 1-etil-3-metilimidazolio en una superficie de grafeno muestran que tanto aniones como cationes están presentes en la primera capa de iones.

\subsection{Correlación de la viscosidad}

Se han propuesto diferentes modelos para predecir el valor de la viscosidad de líquidos con constituyentes iónicos en función de la temperatura, siendo los más comúnmente empleados el modelo de Arrhenius para electrolitos no 
asociados, el de Litovitz [324] para líquidos asociados y el de Vogel-FulcherTammann-Hesse (VFTH) [325]-[327] para fluidos con temperatura de transición vítrea.

Los fluidos que presentan una buena correlación con la ley de Arrhenius se llaman "strong glass formers" mientras que aquellos que presentan una desviación del comportamiento definido por Arrhenius se clasifican como "fragile glass formers". Los líquidos iónicos muestran comportamientos frágiles o intermedios [328].

Por tanto, el modelo VFTH es el propuesto para líquidos iónicos [329] y permite determinar la variación de la viscosidad (n) con la temperatura (T) según la Ecuación 5.

$$
\eta=A \cdot e^{k /\left(T-T_{0}\right)}
$$

\section{Ecuación 5. Modelo de VFTH}

Siendo A la viscosidad a temperatura infinita, $T_{0}$ la temperatura de transición vítrea "ideal" a la cual el volumen libre de líquido desaparece, el transporte de líquido se hace imposible [330] y la entropía configuracional del líquido desaparece y $\mathrm{k}$ es una constante relacionada con la energía de activación de Arrhenius.

Como se puede observar en la Tabla 58, los valores de viscosidad para los líquidos iónicos puros y las dispersiones de grafeno a baja concentración de [EMIM][TFSI], entre $25^{\circ} \mathrm{C}$ y $120^{\circ} \mathrm{C}$, muestran una buena correlación con el modelo VFTH, como ha sido previamente observado en diferentes trabajos usando otros líquidos iónicos [312], [331].

Tabla 58. Parámetros para la obtención de la viscosidad para líquidos iónicos y dispersiones con grafeno según el modelo VFTH

\begin{tabular}{ccccc}
\hline Fluido & $\begin{array}{c}\mathbf{A} \\
(\mathbf{m P a} \cdot \mathbf{s})\end{array}$ & $\begin{array}{c}\mathbf{k} \\
\mathbf{( K )}\end{array}$ & $\begin{array}{c}\mathbf{T}_{\mathbf{0}} \\
\mathbf{( K )}\end{array}$ & $\mathbf{R}^{\mathbf{2}}$ \\
\hline [EMIM][DCA] & $13 \pm 1$ & $809 \pm 40$ & $122 \pm 5$ & 0,9993 \\
\hline [EMIM][TFSI] & $8 \pm 1$ & $1200 \pm 100$ & $90 \pm 9$ & 0,9976 \\
\hline [EMIM][TFSI]+0,05\%G & $120 \pm 10$ & $330 \pm 20$ & $198 \pm 3$ & 0,9939 \\
\hline [EMIM][TFSI]+0,1\%G & $100 \pm 7$ & $400 \pm 20$ & $186 \pm 4$ & 0,9951 \\
\hline
\end{tabular}


En este caso es la primera vez que se determina el comportamiento reológico de dispersiones con baja concentración de grafeno en líquido iónico.

\subsubsection{Estudio tribológico}

El elevado incremento de la viscosidad producido por el grafeno, podría aumentar el coeficiente de fricción de las dispersiones de líquido iónico y esta nanofase con respecto al líquido iónico puro. Por otro lado, el aumento de la viscosidad podría incrementar la capacidad de soportar carga de estos fluidos, además de reducir el desgaste.

Se han realizado ensayos tribológicos a $25^{\circ} \mathrm{C}$ bajo la configuración punzón sobre disco con el par zafiro-acero en las condiciones que se detallan en el apartado 3.3.1.9.3.

En la Figura 203 se muestra la evolución del coeficiente de fricción con respecto a la distancia de deslizamiento para el líquido iónico [EMIM][DCA]. Como se puede observar, el coeficiente de fricción va aumentando con la distancia hasta permanecer en un valor relativamente más estable a partir de los $800 \mathrm{~m}$ de distancia recorrida.

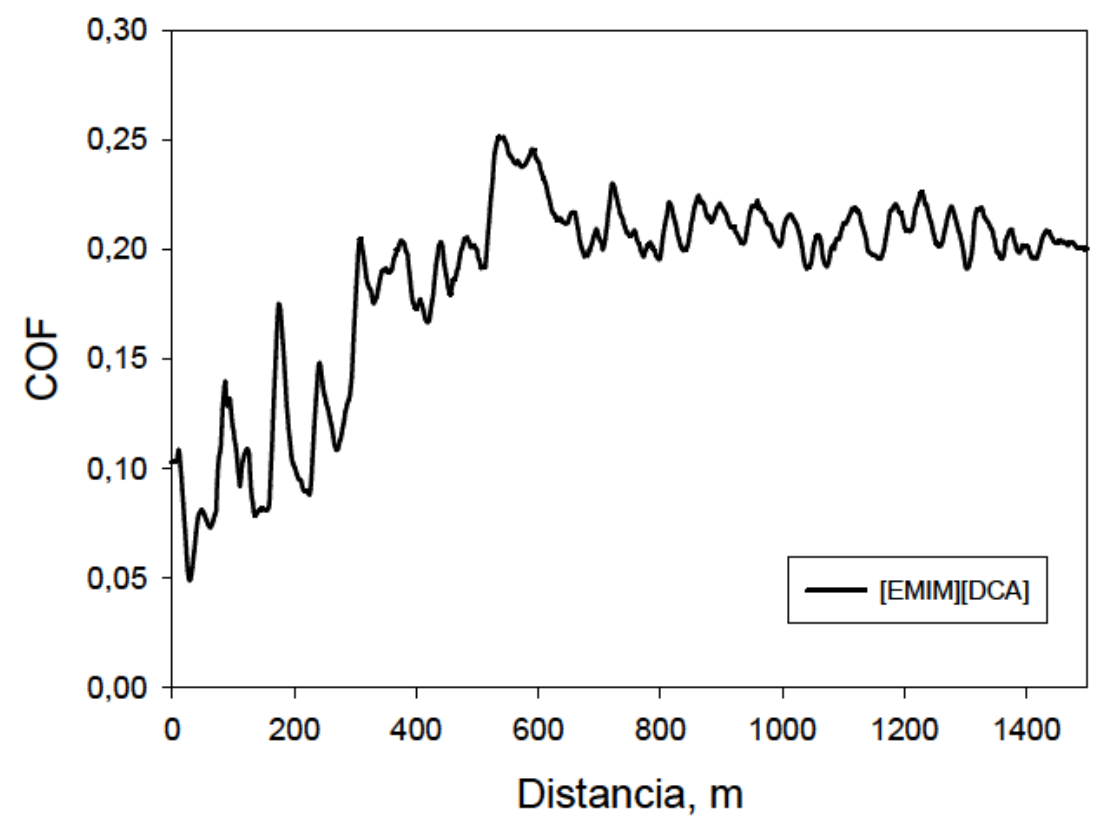

Figura 203. Evolución del coeficiente de fricción con la distancia para [EMIM][DCA]

Para la lubricación con la dispersión de un $0,5 \%$ de grafeno en [EMIM][DCA], se observa un aumento y disminución del coeficiente de fricción al inicio del 
María Dolores Avilés González

Universidad Politécnica de Cartagena

ensayo, lográndose la estabilización del coeficiente a los $400 \mathrm{~m}$ de distancia recorrida, en un valor promedio de 0,17 (Figura 204).

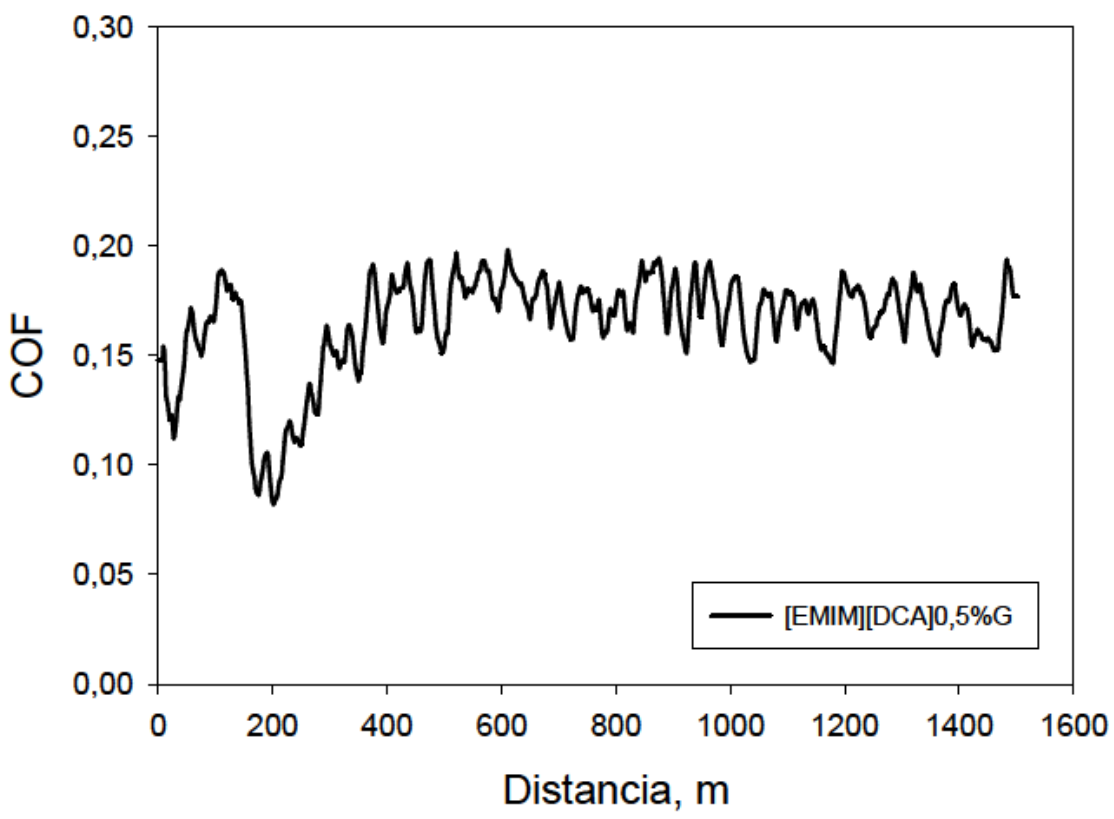

Figura 204. Evolución del coeficiente de fricción con la distancia para [EMIM][DCA]+0,5\%G

En el caso de emplear la dispersión [EMIM][DCA]+1\%G (Figura 205), se observa una etapa inicial donde el coeficiente de fricción disminuye, pero, una vez superados los $60 \mathrm{~m}$ de distancia de deslizamiento, el coeficiente de fricción aumenta, obteniéndose un promedio de 0,17.

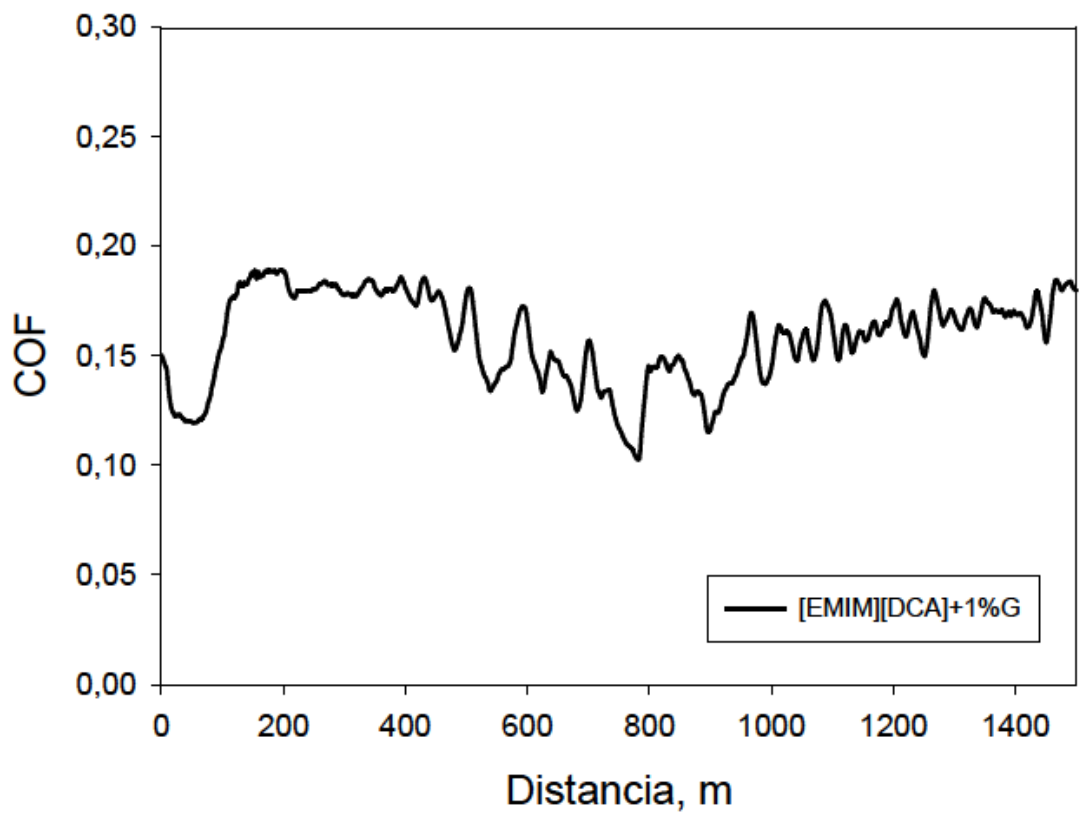

Figura 205. Evolución del coeficiente de fricción con la distancia para [EMIM][DCA]+1\%G 
Como se muestra en la Tabla 59, donde se recogen los coeficientes de fricción y tasas de desgaste medias de [EMIM][DCA] y sus dispersiones con grafeno. Ambas dispersiones de [EMIM][DCA]+G reducen el coeficiente de fricción con respecto al líquido iónico puro, aunque no de forma significativa. De hecho, no existe una relación directa entre el incremento de la viscosidad con el incremento de la concentración de grafeno y los coeficientes de fricción. Sin embargo, esta relación viscosidad-porcentaje de grafeno si explicaría la disminución del desgaste con la presencia de esta nanofase, la cual reduce el contacto entre las asperezas y evita el incremento de la fricción.

Tabla 59. Coeficientes de fricción y tasas de desgaste para [EMIM][DCA] y sus dispersiones con grafeno

\begin{tabular}{ccc}
\hline & Coeficiente de fricción & $\begin{array}{c}\text { Factor de desgaste } \\
\left(\mathbf{m m}^{3} / \mathbf{N} \cdot \mathbf{m}\right)\end{array}$ \\
\hline [EMIM][DCA] & 0,190 & $2,76 \times 10^{-5}$ \\
$( \pm 0,003)$ & $\left( \pm 1,0 \times 10^{-6}\right)$ \\
\hline [EMIM][DCA]+0,5\%G & 0,170 & $1,26 \times 10^{-5}$ \\
& $( \pm 0,02)$ & $\left( \pm 5 \times 10^{-7}\right)$ \\
\hline [EMIM][DCA]+1\%G & 0,170 & $1,24 \times 10^{-5}$ \\
$( \pm 0,012)$ & $\left( \pm 5 \times 10^{-7}\right)$ \\
\hline
\end{tabular}

En las imágenes de la Figura 206 se observan las micrografías ópticas de las huellas de desgaste sobre la superficie de acero inoxidable AISI 316 L tras los ensayos tribológicos contra un punzón con bola de zafiro en presencia de [EMIM][DCA] y sus correspondientes dispersiones con grafeno.

a)

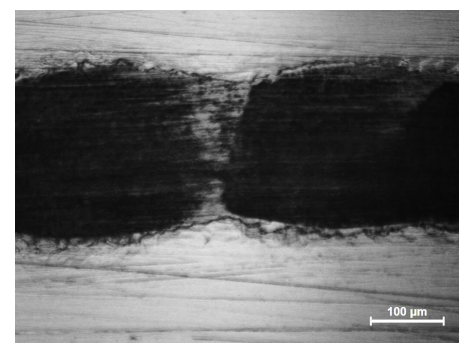

b)

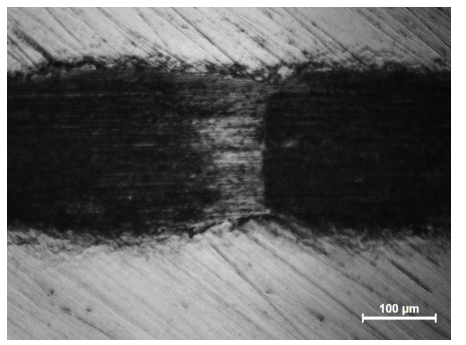

c)

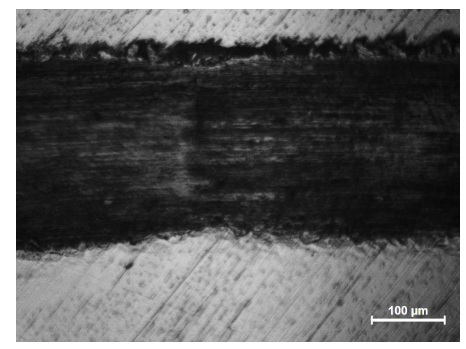

Figura 206. Micrografías ópticas de las huellas de desgaste sobre discos de acero tras lubricación con: a) [EMIM][DCA]; b) [EMIM][DCA]+0,5\%G; c) [EMIM][DCA]+1\%G

Como se puede observar, se ha producido en todos los casos un desgaste severo que se muestra con más detalle en las imágenes de topografía superficial en 3D obtenidas mediante microperfilometría óptica (Figura 207). 


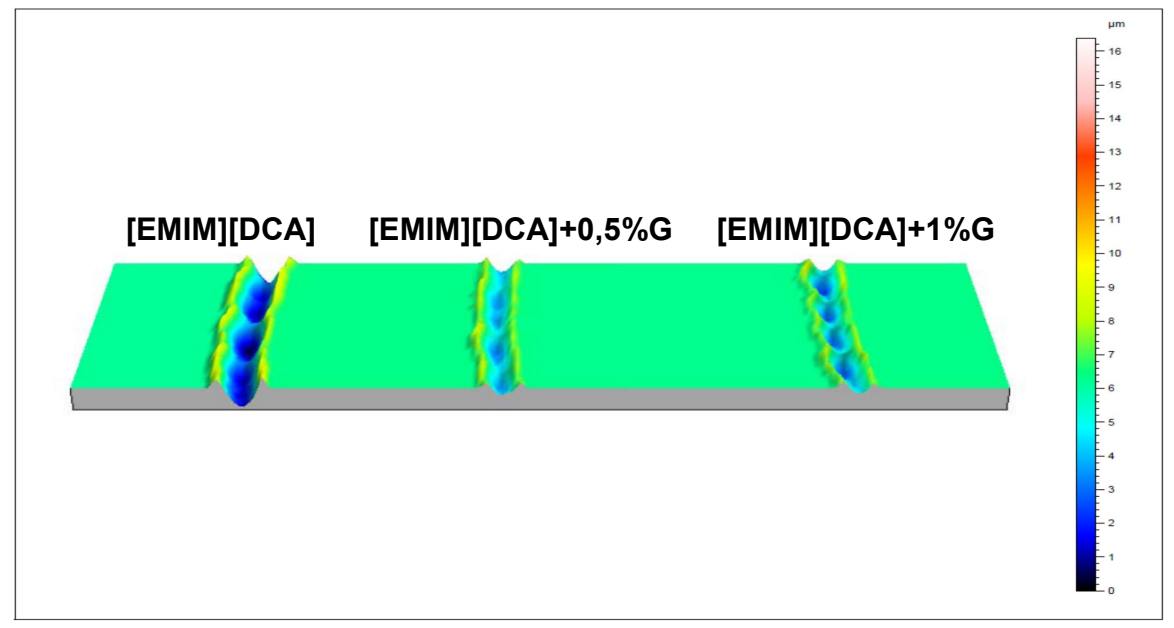

Figura 207. Topografía superficial sobre discos de acero tras lubricación con [EMIM][DCA];

$[\mathrm{EMIM}][\mathrm{DCA}]+0,5 \% \mathrm{G}$ y $[\mathrm{EMIM}][\mathrm{DCA}]+1 \% \mathrm{G}$

En los perfiles de la sección transversal de la huellas (Figura 208), se observa la gran anchura y profundidad de las huellas, con acumulación de material en los bordes.

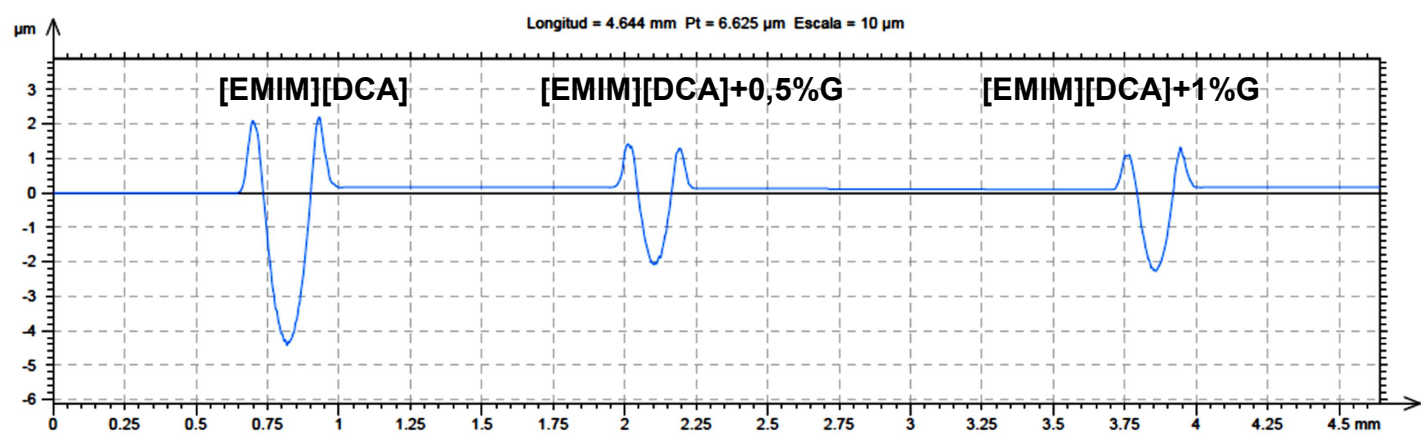

Figura 208. Sección transversal de las huellas de desgaste sobre discos de acero tras lubricación con [EMIM][DCA]; [EMIM][DCA]+0,5\%G y [EMIM][DCA]+1\%G

También se ha analizado el comportamiento de [EMIM][TFSI] como lubricante externo, así como el de sus dispersiones con grafeno en distintas proporciones y en las mismas condiciones que [EMIM][DCA].

Como se observa en la Figura 209, el coeficiente de fricción cuando se emplea [EMIM][TFSI] presenta una etapa inicial donde se observan pequeñas fluctuaciones, hasta unos $600 \mathrm{~m}$ de distancia, obteniendo un valor medio de 0,09 . 


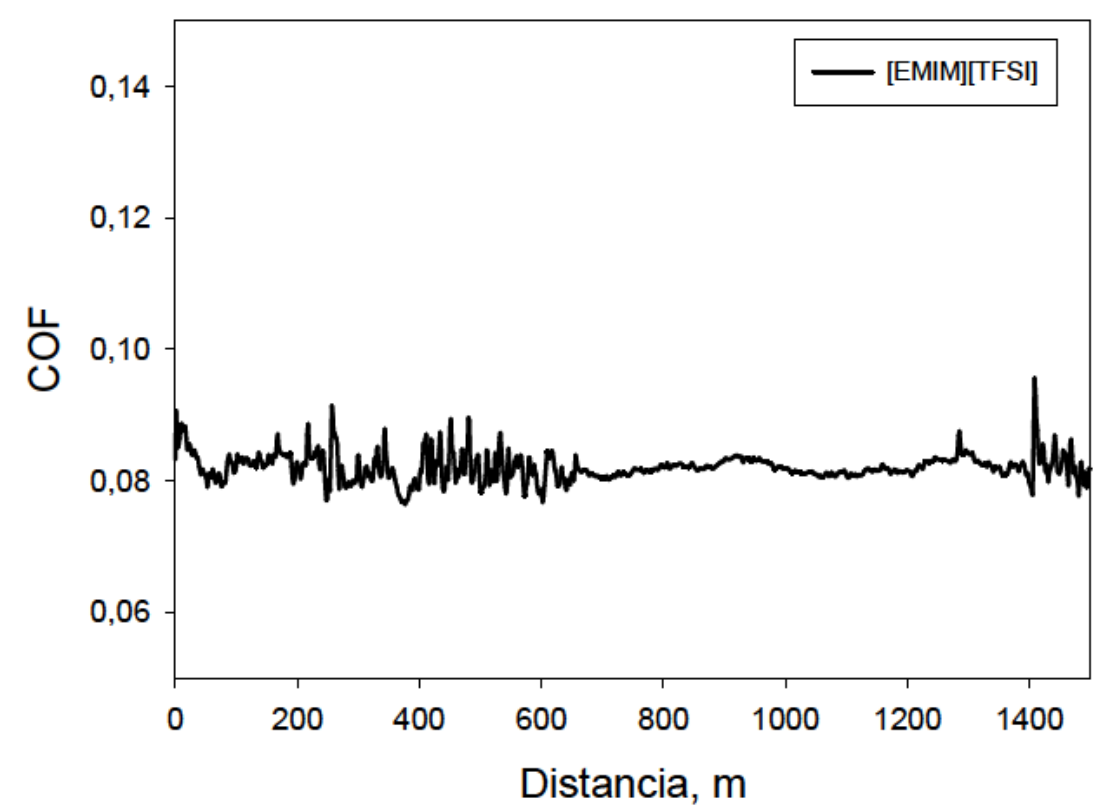

Figura 209. Evolución del coeficiente de fricción con la distancia para [EMIM][TFSI]

En el caso de emplear la dispersión con un $0,5 \%$ de grafeno en este líquido iónico (Figura 210), el coeficiente de fricción permanece constante durante toda la distancia de deslizamiento, obteniéndose una reducción del $20 \%$ con respecto al presentado por el líquido iónico sin aditivos.

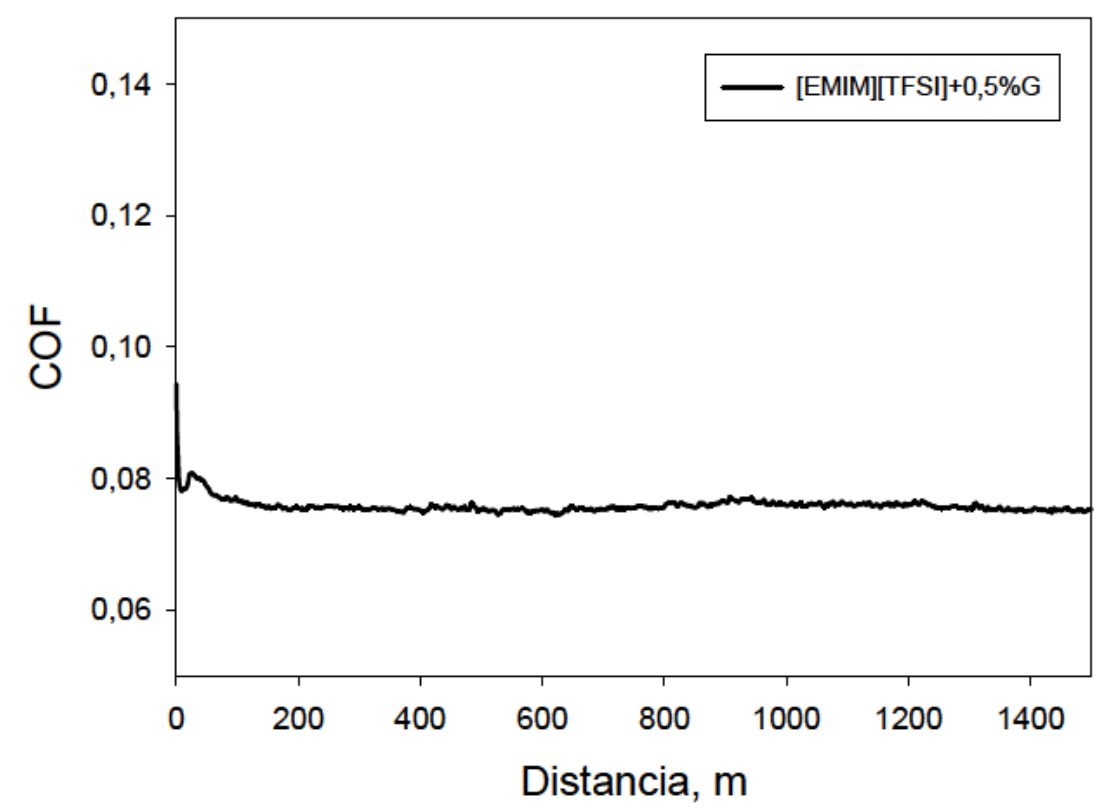

Figura 210. Evolución del coeficiente de fricción con la distancia para [EMIM][TFSI]+0,5\%G

Cuando el lubricante empleado es la dispersión [EMIM][TFSI]+1\%G (Figura 211), se observa una breve etapa inicial $(35 \mathrm{~m})$ donde el coeficiente de fricción disminuye, estabilizándose en un valor promedio de 0,09. 


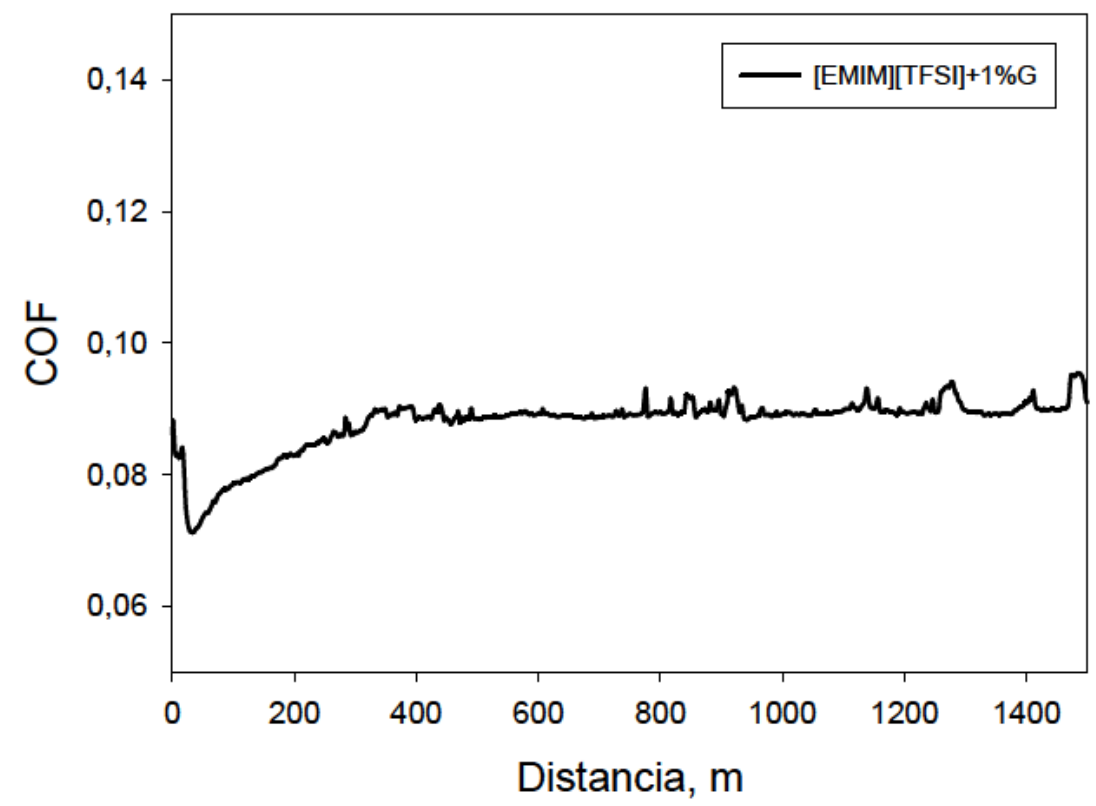

Figura 211. Evolución del coeficiente de fricción con la distancia para [EMIM][TFSI]+1\%G

Al igual que ocurría para [EMIM][DCA], el líquido iónico presenta un mayor valor de coeficiente de fricción promedio y la dispersión que presenta un mejor comportamiento es la que posee un $0,5 \%$ de grafeno.

Una vez realizados los ensayos tribológicos se han estudiado las huellas de desgaste generadas. Como se puede ver tanto en la Tabla 60 como en las micrografías ópticas de la Figura 212, no es posible observar huellas de desgaste sobre la superficie del acero inoxidable AISI 316L tras la lubricación con los nanofluidos de [EMIM][TFSI]+grafeno. La alta viscosidad de estos nanofluidos podría prevenir el contacto directo de las asperezas superficiales en las condiciones de deslizamiento estudiadas.

Tabla 60. Coeficientes de fricción y tasas de desgaste para [EMIM][TFSI] y sus dispersiones con grafeno

\begin{tabular}{ccc}
\hline & Coeficiente de fricción & $\begin{array}{c}\text { Factor de desgaste } \\
\left(\mathbf{m m}^{3} / \mathbf{N} \cdot \mathbf{m}\right)\end{array}$ \\
\hline [EMIM][TFSI] & $\begin{array}{c}0,10 \\
( \pm 0,01)\end{array}$ & $\begin{array}{c}1,66 \times 10^{-6} \\
\left( \pm 1,8 \times 10^{-7}\right)\end{array}$ \\
\hline [EMIM][TFSI]+0,5\%G & $\begin{array}{c}0,080 \\
( \pm 0,005)\end{array}$ & - \\
\hline [EMIM][TFSI]+1\%G & $\begin{array}{c}0,090 \\
( \pm 0,004)\end{array}$ & - \\
\hline
\end{tabular}


a)

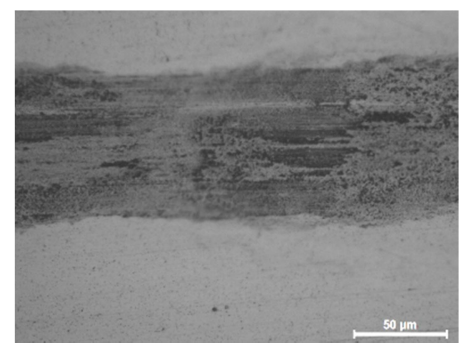

b)

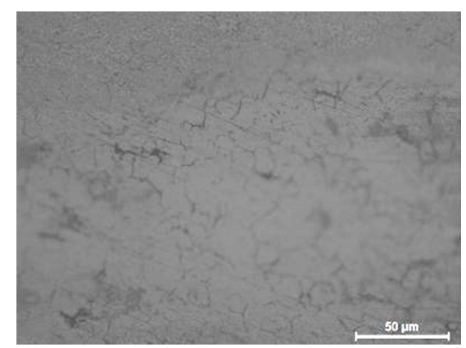

c)

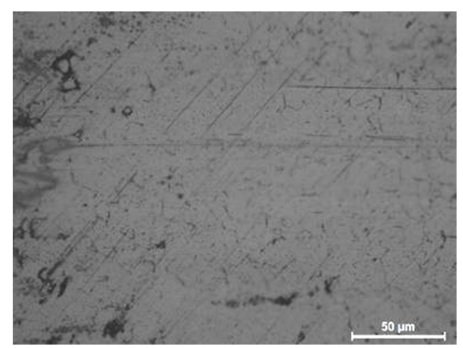

Figura 212. Micrografías ópticas de las huellas de desgaste sobre discos de acero tras lubricación con: a) [EMIM][TFSI]; b) [EMIM][TFSI]+0,5\%G; c) [EMIM][TFSI]+1\%G

En la Figura 213 se puede observar la topografía superficial y la sección transversal de la huella de desgaste tras la lubricación con [EMIM][TFSI]. Los resultados obtenidos están de acuerdo con la reducción del desgaste con respecto al líquido iónico [EMIM][DCA].
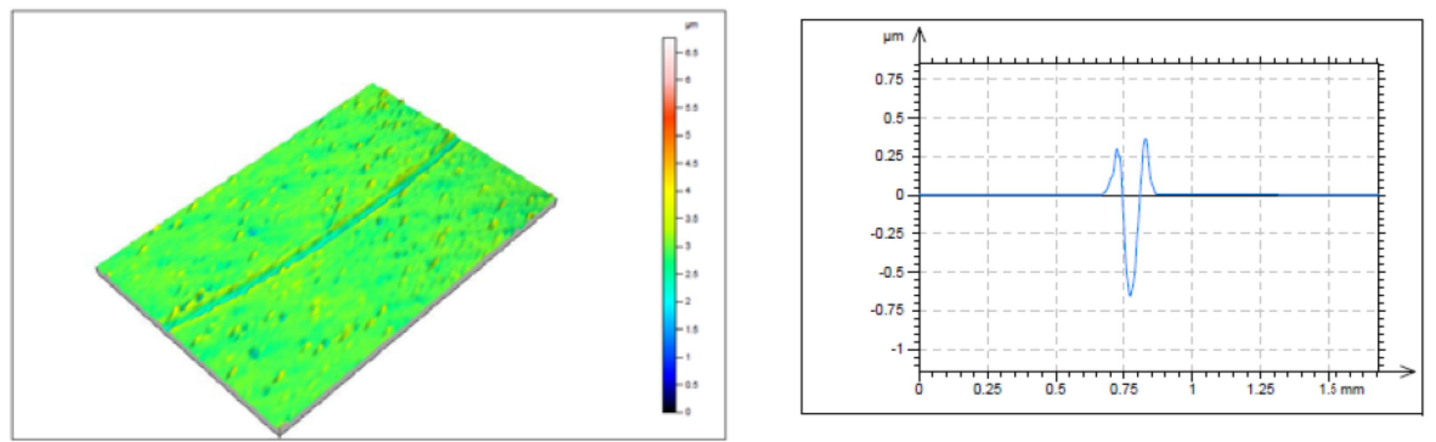

Figura 213. Topografía superficial sobre discos de acero tras lubricación con [EMIM][TFSI]

Con el fin de estudiar las interacciones entre los nanofluidos y la superficie de acero se ha empleado la técnica de espectroscopía Raman.

En la Figura 214 se comparan los espectros Raman del grafeno de partida, de la dispersión [EMIM][TFSI] $+0,5 \% \mathrm{G}$ y de una zona en el interior de la huella de desgaste tras lubricación con esta dispersión. Se pueden observar las bandas características que presenta el grafeno, la banda $D$, la banda $G$ y la banda $2 D$ $\left(1360,1598\right.$ y $2952 \mathrm{~cm}^{-1}$, respectivamente) tanto en la huella de desgaste como en la dispersión. La relación de intensidad $I_{D} / l_{G}$ en ambos casos es de 0,8, similar a la que posee el grafeno. 


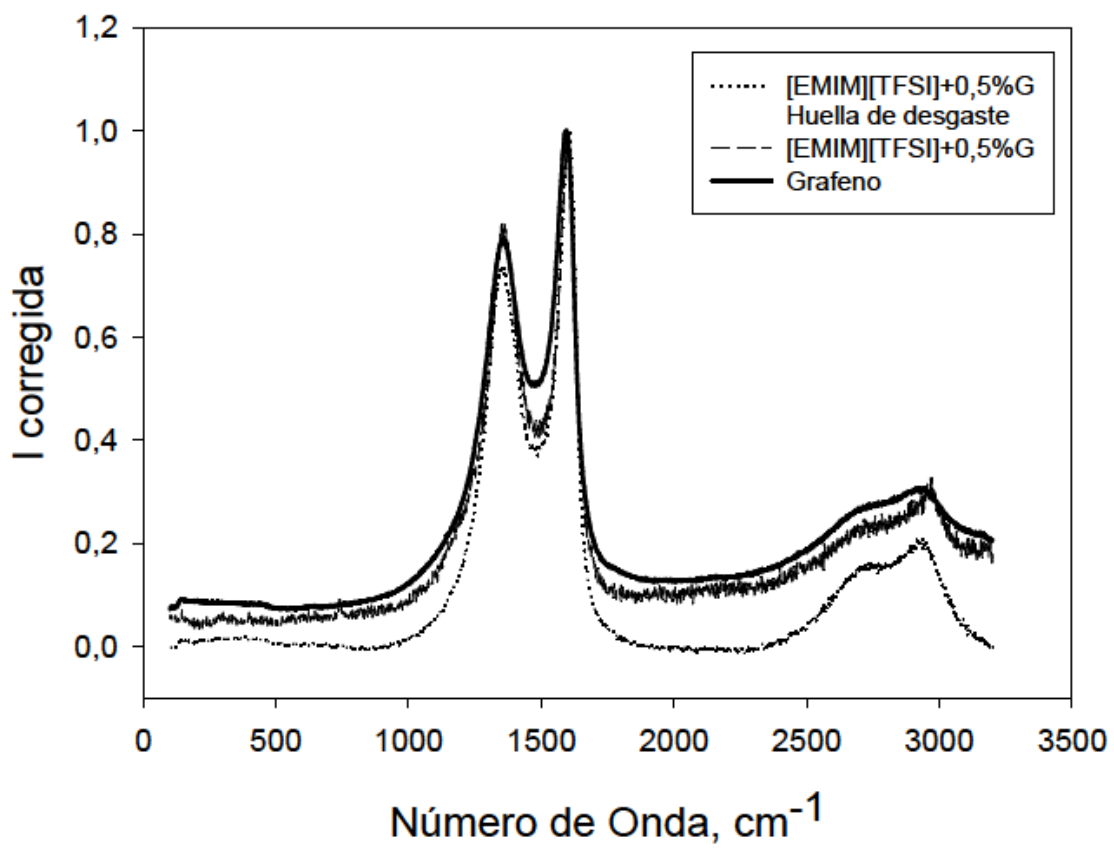

Figura 214. Espectros Raman de grafeno, [EMIM][TFSI]+0,5\%G y huella de desgaste tras lubricación con [EMIM][TFSI]+0,5\%G

En el caso de la lubricación con la dispersión de [EMIM][TFSI]+1\%G (Figura 215), los espectros Raman tanto de la propia dispersión como de una zona dentro de la huella de desgaste presentan las bandas características del grafeno como ocurría para la dispersión con menor concentración de nanofase.

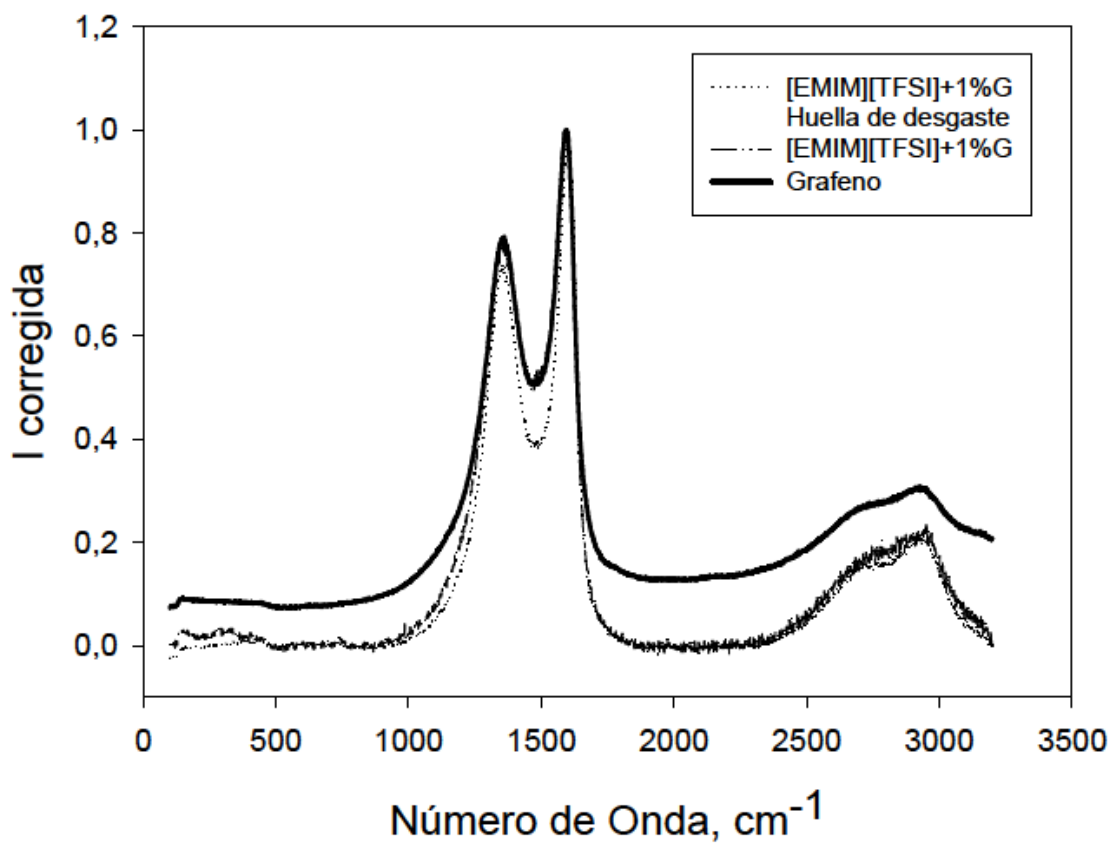

Figura 215. Espectros Raman de grafeno, [EMIM][TFSI]+1\%G y huella de desgaste tras lubricación con [EMIM][TFSI]+1\%G 
Aunque la superficie de desgaste sobre los discos de acero inoxidable tras la lubricación con las dispersiones de [EMIM][TFSI]+grafeno presentaban desgaste despreciable, los espectros Raman de las huellas muestran bandas asignables a la presencia de grafeno.

Para el estudio de superficies tras la lubricación con [EMIM][DCA] y sus dispersiones de grafeno también se ha empleado la espectroscopía Raman. En la Figura 216 se muestra el espectro del líquido iónico puro, que presenta una banda característica en torno a $2198,4 \mathrm{~cm}^{-1}$, correspondiente a las uniones C-N y otra banda a $2962,89 \mathrm{~cm}^{-1}$ asignable a los enlaces $\mathrm{C}-\mathrm{H}$.

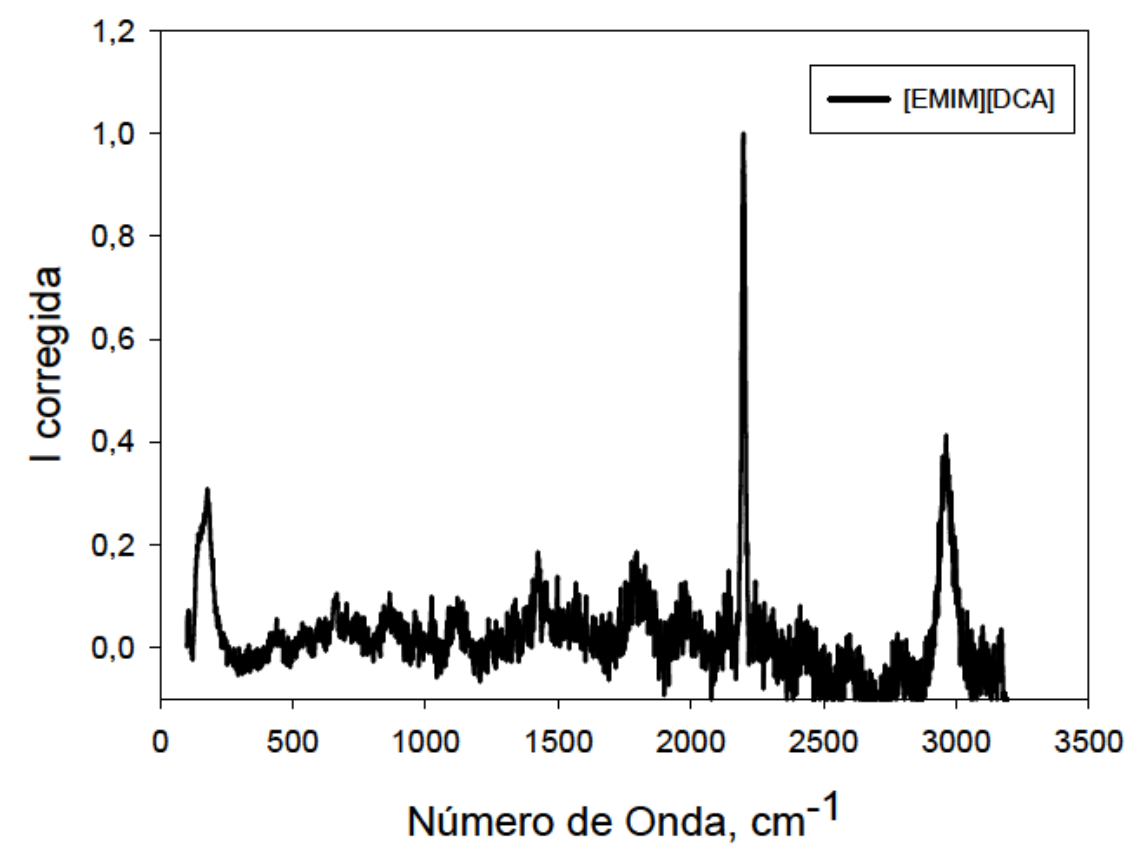

Figura 216. Espectro Raman del líquido iónico [EMIM][DCA]

En el caso de [EMIM][DCA]+1\% G, en la Figura 217 se puede observar cómo el espectro Raman de la dispersión se corresponde perfectamente con la suma de los espectros del líquido iónico [EMIM][DCA] y el grafeno de partida. 
María Dolores Avilés González

Universidad Politécnica de Cartagena

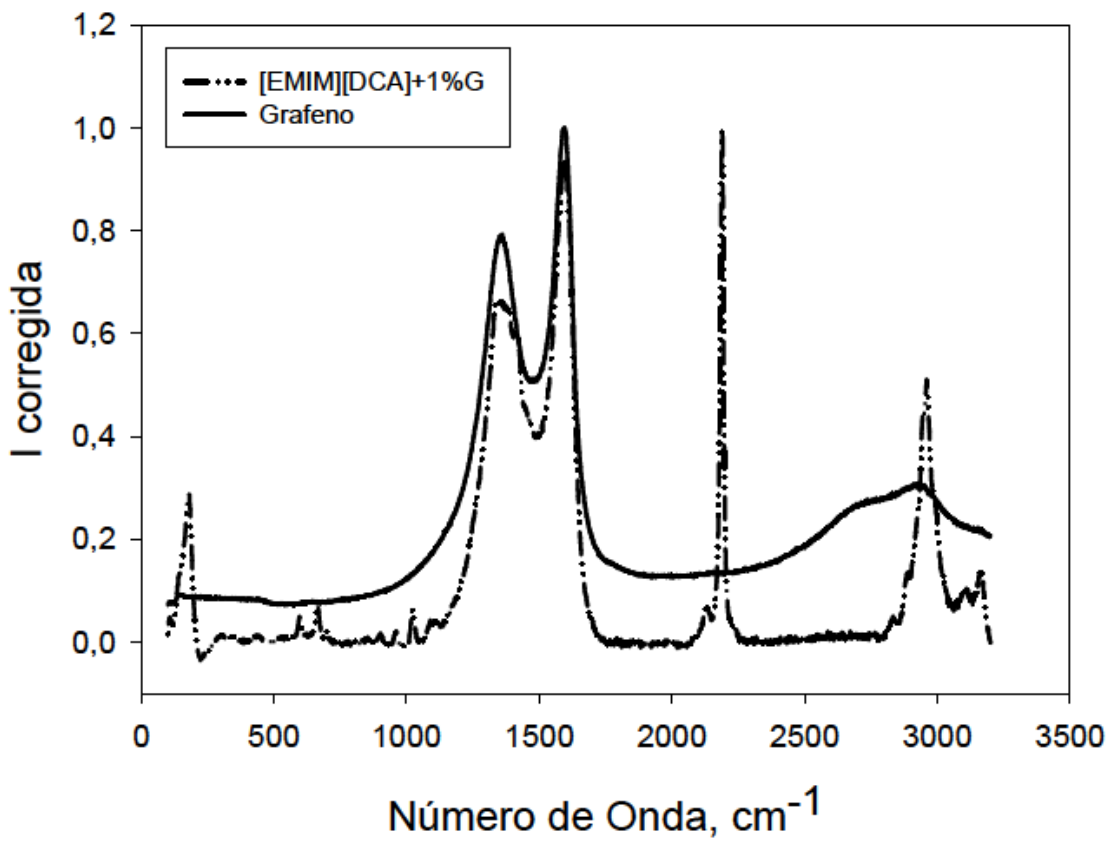

Figura 217. Espectros Raman de grafeno y dispersión [EMIM][DCA]+1\%G

También se ha analizado una zona en el interior de la huella de desgaste (Figura 218). Se puede observar cómo el espectro Raman presenta los picos característicos del grafeno.

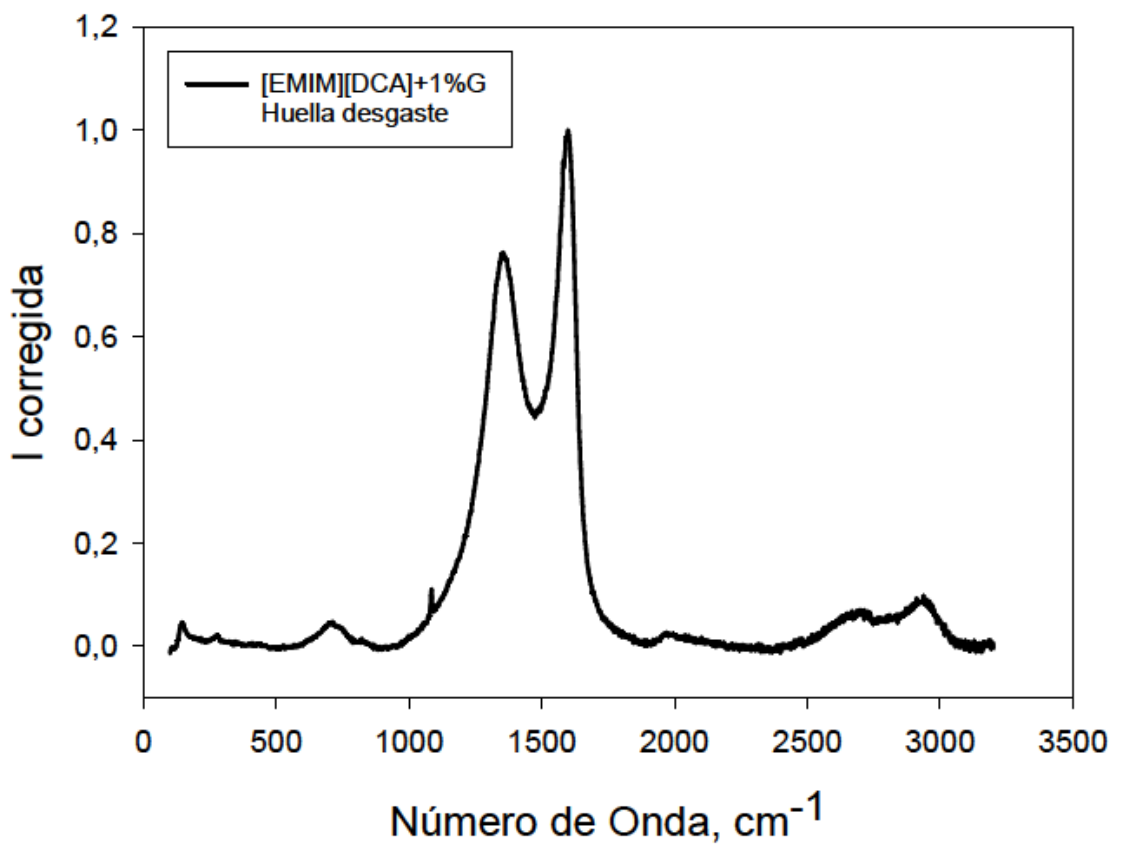

Figura 218. Espectro Raman en el interior de la huella de desgaste tras lubricación con $[\mathrm{EMIM}][\mathrm{DCA}]+1 \% \mathrm{G}$ 
Tanto los resultados obtenidos para las dispersiones con grafeno en [EMIM][DCA] como en [EMIM][TFSI] muestran la presencia de una capa de grafeno en la superficie del acero cuya presencia ha sido confirmada mediante el análisis EDX de la huella (Figura 219). La formación durante el ensayo tribológico de esta capa de grafeno ya había sido observada en trabajos previos [255].

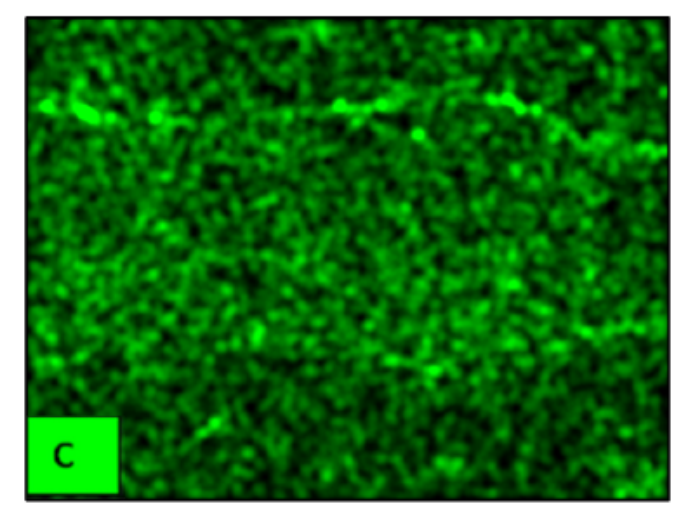

Figura 219. Mapa elemental de C obtenido mediante EDX de la huella sobre el disco de acero tras lubricación con [EMIM][DCA]+grafeno

Restuccia y Righi [332] han propuesto que las propiedades lubricantes del grafeno se deben a su habilidad para pasivar las superficies metálicas, mientras que otros autores [333] proponen que es debido al incremento de la capacidad de soportar carga de las superficies lo que reduce la profundidad de penetración.

El desgaste severo encontrado tras la lubricación con líquido iónico [EMIM][DCA] da lugar a la pérdida de material en forma de partículas de desgaste como las que se muestran en la Figura 220.
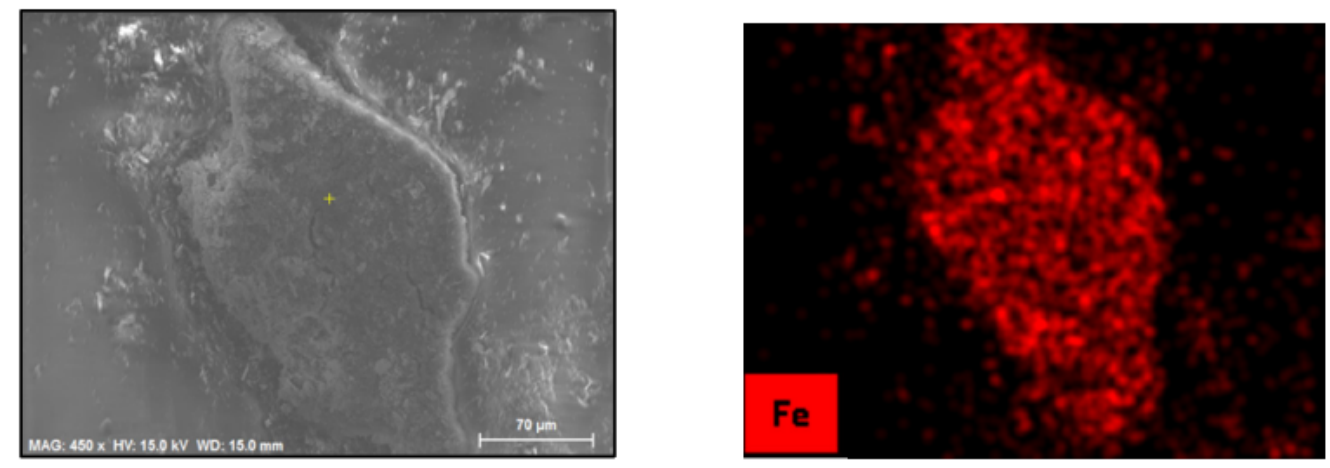

Figura 220. Micrografía SEM y mapa elemental de Fe de las partículas de desgaste obtenidas tras lubricación con [EMIM][DCA] 
El mapa elemental obtenido mediante EDX muestra que estas partículas de desgaste están compuestas principalmente de hierro, procedente del disco de acero inoxidable AISI 316L.

La adición de un $0,5 \%$ o un $1 \%$ de grafeno al líquido iónico [EMIM][DCA] reduce la pérdida de material con respecto al líquido iónico puro como quedaba reflejado en la Tabla 59. En este caso, sólo se han observado partículas de desgaste de tamaño nanométrico y éstas permanecen adheridas a las láminas de grafeno como se muestra en las micrografías obtenidas mediante microscopía electrónica de transmisión (Figura 221).

a)

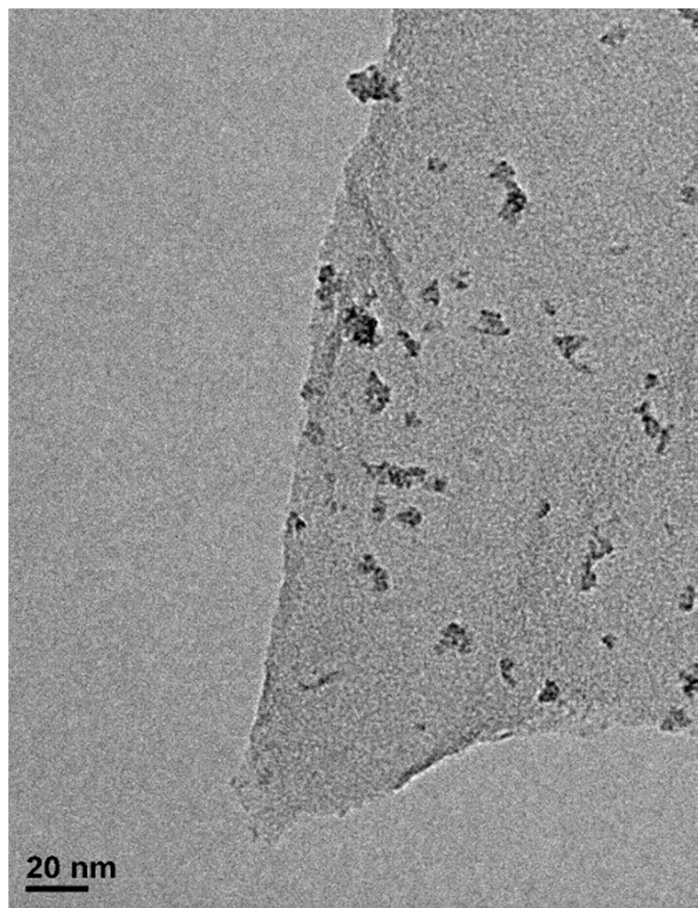

b)

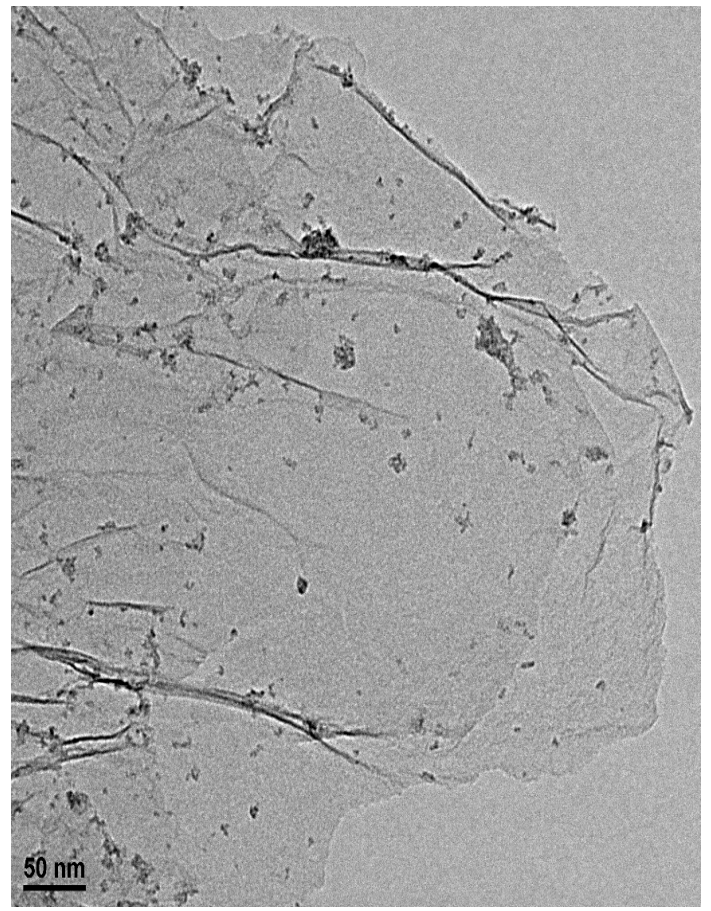

Figura 221. Micrografías TEM de las partículas de desgaste tras lubricación con:

a) $[E M I M][D C A]+0,5 \% G ; b)[E M I M][D C A]+1 \% G$

Por tanto, la capacidad de reducir el desgaste que posee el grafeno puede ser atribuida a la protección de la superficie debido a la formación de una capa sobre la superficie y su capacidad para prevenir la formación de grandes agregados de partículas de desgaste abrasivas. 


\subsubsection{Conclusiones}

En el estudio de líquidos iónicos apróticos comerciales y sus combinaciones con grafeno, se han obtenido las siguientes conclusiones:

$>$ En el estudio del comportamiento reológico de las nuevas dispersiones, se ha encontrado una concentración crítica del $0,5 \%$ de grafeno que genera valores de viscosidad prácticamente constantes en un amplio rango de temperaturas. Concentraciones superiores de grafeno en los líquidos iónicos dan lugar a un comportamiento reológico anómalo, ya que la viscosidad se incrementa de manera lineal al aumentar la temperatura.

$>$ Este comportamiento sin precedentes, se atribuye a la formación de interacciones más fuertes entre la superficie de las láminas de grafeno y las moléculas de líquido iónico, que revierten al disminuir la temperatura.

> La dispersión de grafeno en Bis(trifluorometilsulfonil)imida de 1-etil-3metilimidazolio presenta unas excelentes prestaciones tribológicas, ya que evita el desgaste o daño superficial en el acero. Esto puede atribuirse a la combinación de tres factores: la mayor capacidad para soportar carga de las nuevas dispersiones, la formación de una película de grafeno sobre la superficie y la adhesión de las partículas de desgaste de tamaño nanométrico a las láminas de grafeno, lo que evita la formación de grandes aglomerados y por tanto el daño superficial por abrasión. 


\subsubsection{Dispersiones del líquido iónico tetrafluoroborato de 1-octil-3- metilimidazolio y/o grafeno en aceites lubricantes}

Además del estudio del comportamiento tribológico de líquidos iónicos y las dispersiones de nanofases de carbono en éstos, también se ha estudiado el empleo de dispersiones del líquido iónico tetrafluoroborato de 1-octil-3metilimidazolio y/o grafeno como aditivos en dos tipos de aceites lubricantes.

El líquido iónico [OMIM] $\mathrm{BF}_{4}$ y sus dispersiones con grafeno han sido estudiadas previamente en los contacto acero-zafiro y acero-resina epoxi, así como aditivos en nanocomposites de matriz epoxi, presentando unas excelentes propiedades tribológicas [255], [269]. Además, la dispersión de grafeno y líquido iónico ha sido empleada debido a su miscibilidad en los dos aceites lubricantes estudiados, una base isoparafínica (B), y un aceite lubricante comercial (MO) totalmente formulado y de altas prestaciones.

En general, los lubricantes minerales están formados principalmente por una base lubricante y entre un $5-20 \%$ de aditivos, añadidos para mejorar su rendimiento [20]. Las bases lubricantes minerales, procedentes del petróleo, se clasifican en bases minerales convencionales y bases hidrocraqueadas. Dentro de ese último grupo se encuadra la base isoparafínica, objeto del presente estudio. Los aceites lubricantes comerciales poseen aditivos para mejorar su comportamiento tribológico (modificadores de la fricción, agentes antidesgaste y aditivos para altas presiones), para mejorar sus propiedades reológicas (modificadores de la viscosidad), antioxidantes, detergentes, dispersantes, inhibidores de la corrosión, colorantes, mejoradores de la conductividad, antibióticos, agentes para evitar las emulsiones y antiespumantes.

Por tanto, en este capítulo se estudia el efecto del aceite base cuando se añade grafeno, líquido iónico o la dispersión de grafeno y líquido iónico, empleando para ello una base sin aditivos y en un lubricante totalmente formulado. Además, se pretende determinar la posible sinergia entre los aditivos incorporados.

\subsubsection{Dispersiones en aceite base isoparafínico libre de aditivos}

Se han realizado nuevas dispersiones de líquido iónico [OMIM]BF 4 y/o grafeno en una base lubricante isoparafínica (B) con el objetivo de mejorar sus propiedades tribológicas a $25^{\circ} \mathrm{C}$. 
El estudio reológico, cuyo procedimiento se indica en el apartado 3.3.1.7, refleja que el valor de viscosidad de la base lubricante se ve ligeramente incrementado al añadir los aditivos. Como queda reflejado en la Tabla 61, la dispersión de un $5 \%$ de la mezcla de $\left[\mathrm{OMIM}_{\mathrm{B}} \mathrm{F}_{4}\right.$ con un $0,1 \%$ de grafeno presenta un aumento de la viscosidad de un $14 \%$ con respecto a la base isoparafínica. Las dispersiones $\mathrm{B}+\mathrm{G}$ y $\mathrm{B}+[\mathrm{OMIM}] \mathrm{BF}_{4}$ presentan valores de viscosidad muy similares a $25^{\circ} \mathrm{C}$, siendo la que contiene grafeno ligeramente superior.

Tabla 61. Viscosidad de las dispersiones en base isoparafínica

\begin{tabular}{|c|c|c|c|c|}
\hline \multirow{2}{*}{ Temperatura } & \multicolumn{4}{|c|}{ Viscosidad (mPa·s) (Desviación estándar $\leq 0,003)$} \\
\hline & B & $\mathrm{B}+[\mathrm{OMIM}] \mathrm{BF}_{4}$ & $B+G$ & $\mathrm{~B}+\left([\mathrm{OMIM}] \mathrm{BF}_{4}+\mathrm{G}\right)$ \\
\hline $25^{\circ} \mathrm{C}$ & 43 & 46 & 47 & 49 \\
\hline
\end{tabular}

El comportamiento tribológico de estas dispersiones se ha estudiado mediante ensayos punzón sobre disco en el contacto zafiro-acero inoxidable AISI 316L en las condiciones indicadas anteriormente (apartado 3.3.1.9.3).

En la Figura 222 se muestra la evolución del coeficiente de fricción con la distancia de deslizamiento para las dispersiones de líquido iónico y/o grafeno en el aceite base isoparafínico a $25^{\circ} \mathrm{C}$ y se comparan con los obtenidos para la base sin aditivos. Como se puede observar, el coeficiente de fricción presentado por el aceite base (B) no se ve modificado con la adición del líquido iónico $\left(B+\left[\mathrm{OMIM}_{\mathrm{B}} \mathrm{BF}_{4}\right)\right.$ o grafeno $(B+G)$ de forma separada. Sin embargo, cuando el grafeno está previamente disperso en el líquido iónico $\left(\mathrm{B}+\left([\mathrm{OMIM}] \mathrm{BF}_{4}+\mathrm{G}\right)\right.$ se obtiene una significativa disminución del coeficiente de fricción del 33\% con respecto al aceite base. Estos resultados confirman el efecto sinérgico entre los líquidos iónicos y las nanofases de carbono en la mejora del comportamiento tribológico de los lubricantes [85], [268]. 


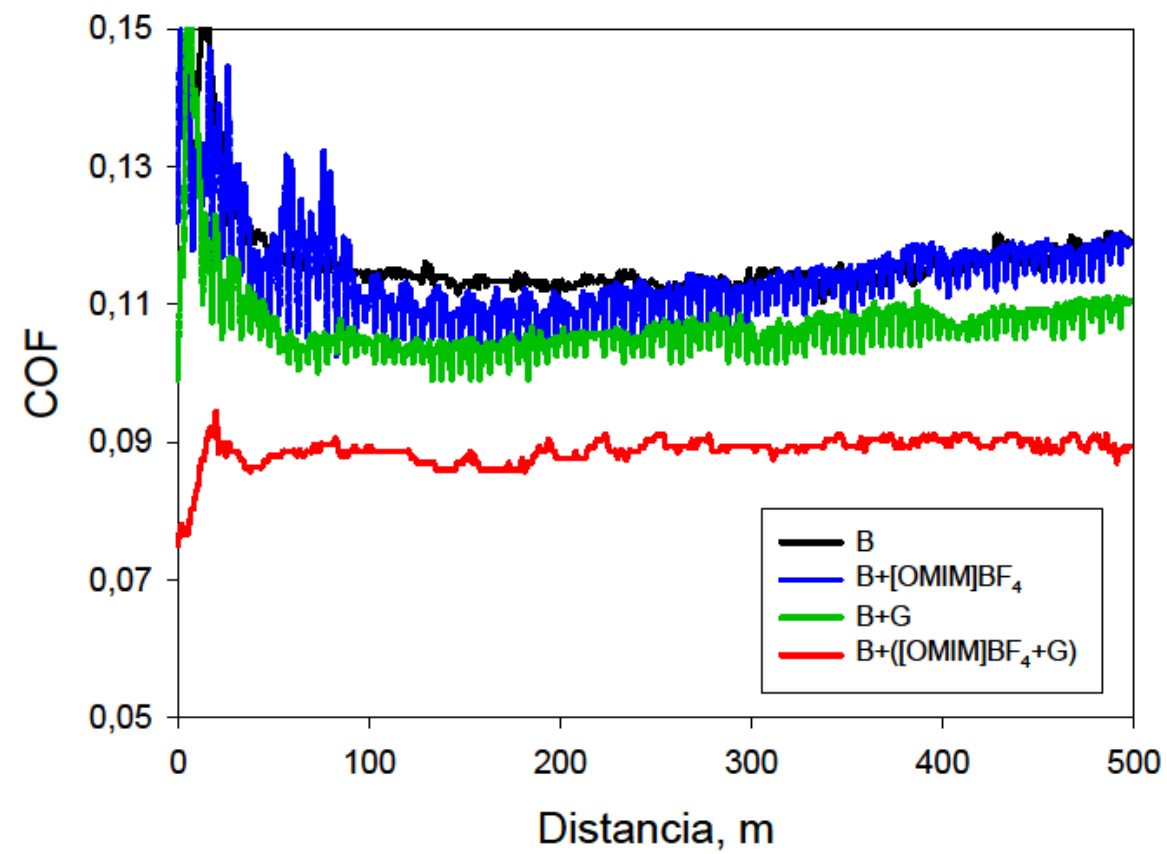

Figura 222. Evolución del coeficiente de fricción con la distancia de deslizamiento para los lubricantes con base isoparafínica a temperatura ambiente

En la Tabla 62 se muestran los coeficientes de fricción medios obtenidos para una distancia de deslizamiento de $500 \mathrm{~m}$ a temperatura ambiente. Además, se recogen los resultados de daño superficial y pérdida de material, determinados mediante las áreas de la sección transversal de las huellas de desgaste de los discos de acero AISI 316L (Figura 223).

Tabla 62. Coeficientes de fricción y áreas de la huella de desgaste para los lubricantes con base isoparafínica

\begin{tabular}{|c|c|c|c|c|}
\hline & $\begin{array}{l}\text { Coeficiente de } \\
\text { fricción }\end{array}$ & $A_{1}\left(\mu m^{2}\right)$ & $\begin{array}{c}A_{2}+A_{3} \\
\left(\mu m^{2}\right)\end{array}$ & $\begin{array}{c}\text { Pérdida de } \\
\text { material } \\
{\left[A_{1}-\left(A_{2}+A_{3}\right)\right]} \\
\left(\mu m^{2}\right)\end{array}$ \\
\hline B & $0,12( \pm 0,01)$ & $121,0( \pm 12,9)$ & $72,0( \pm 13,5)$ & 49,0 \\
\hline $\mathrm{B}+\left[\mathrm{OMIM}_{\mathrm{BF}} \mathrm{F}_{4}\right.$ & $0,12( \pm 0,01)$ & $104,5( \pm 19,7)$ & $66,5( \pm 7,5)$ & 38,0 \\
\hline$B+G$ & $0,11( \pm 0,01)$ & $117,1( \pm 8,1)$ & $99,9( \pm 7,76)$ & 17,2 \\
\hline $\mathrm{B}+\left([\mathrm{OMIM}] \mathrm{BF}_{4}+\mathrm{G}\right)$ & $0,080( \pm 0,002)$ & $22,4( \pm 3,9)$ & $29,2( \pm 3,5)$ & $-6,8$ \\
\hline
\end{tabular}

Como se puede observar, el mejor comportamiento antidesgaste lo presenta la dispersión con los dos aditivos: líquido iónico y grafeno. 


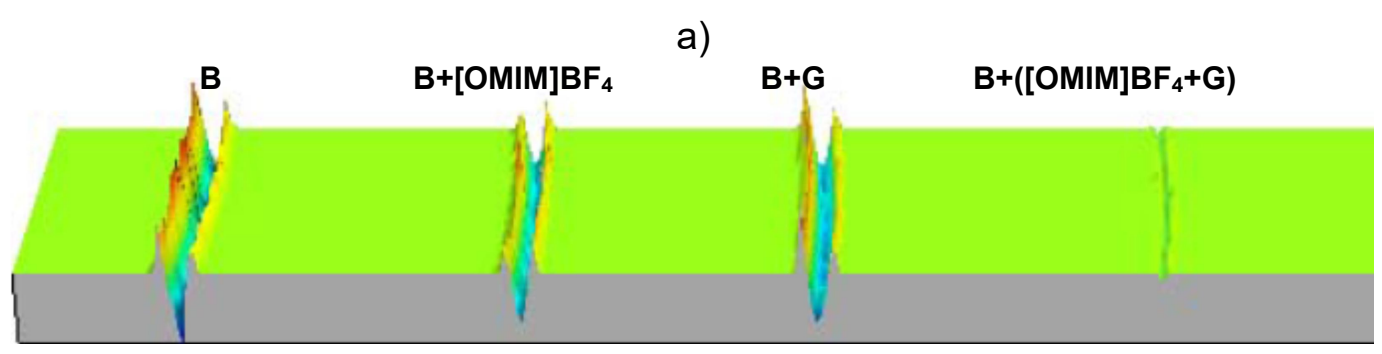

b)

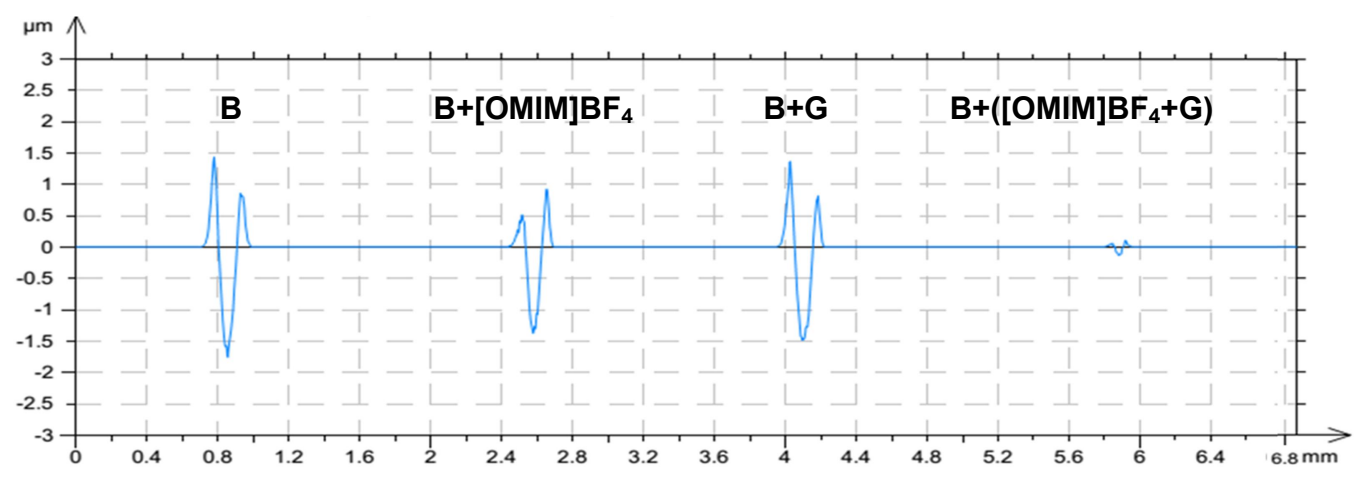

Figura 223. a) Topografía superficial de las huellas de desgaste; b) Sección transversal de las huellas de desgaste para los lubricantes de base isoparafínica a temperatura ambiente

En general, el daño superficial se expresa como la suma de las áreas de desgaste $\left(A_{1}+A_{2}+A_{3}\right)$, sin embargo, la pérdida de material debida al desgaste puede ser cuantificada mediante la diferencia de áreas de hueco y pico $\left(A_{1}\right.$ $\left.\left(A_{2}+A_{3}\right)\right)$. En el caso de la severidad del daño superficial, los diferentes lubricantes se pueden ordenar de la siguiente forma: $(B+G)>B>\left(B+\left([O M I M] B F_{4}\right)>>\left(B+\left([O M I M] B F_{4}+G\right)\right)\right.$. En el segundo caso, cuando se considera la pérdida de material, el orden es: $B>\left(B+\left([O M I M] B F_{4}\right)>\right.$ $>(B+G)>\left(B+\left([O M I M] B F_{4}+G\right)\right)$.

Los lubricantes que contienen grafeno no solo muestran los valores más bajos de pérdida de material, sino que incluso se obtiene un valor negativo para el caso de $\mathrm{B}+\left([\mathrm{OMIM}] \mathrm{BF}_{4}+\mathrm{G}\right)$, debido a la acumulación de más material en los bordes de la huella de desgaste que el eliminado de ella.

Se puede observar además, que el orden de la pérdida de material es el contrario al de la viscosidad de los lubricantes (Tabla 61). La mayor viscosidad de la dispersión $B+\left([\mathrm{OMIM}] \mathrm{BF}_{4}+\mathrm{G}\right)$ podría ser la responsable de la mayor habilidad de soportar carga de este lubricante, evitando el contacto directo entre las asperezas y disminuyendo el coeficiente de fricción.

Se ha realizado el estudio de las huellas de desgaste tras el ensayo tribológico para cada uno de los lubricantes de base isoparafínica mediante microscopía 
óptica, microscopía electrónica de barrido y EDX. Aunque el EDX no es una técnica cuantitativa de ánalisis superficial, si que permite realizar comparativas entre distintas zonas de la muestra. Las concentraciones de hierro, carbono y oxígeno dentro y fuera de la huella se recogen en la Tabla 63.

Tabla 63. Análisis EDX dentro y fuera de la huella de desgaste tras ensayo tribológico de las dispersiones con base lubricante isoparafínica a temperatura ambiente

\begin{tabular}{|c|c|c|c|c|c|c|}
\hline \multirow{2}{*}{ Lubricante } & \multicolumn{3}{|c|}{$\begin{array}{c}\% \text { atómico fuera de la } \\
\text { huella }\end{array}$} & \multicolumn{3}{|c|}{$\begin{array}{c}\% \text { atómico dentro } \\
\text { de la huella }\end{array}$} \\
\hline & $\mathrm{Fe}$ & C & $\mathrm{O}$ & $\mathrm{Fe}$ & $\mathrm{C}$ & $\mathrm{O}$ \\
\hline B & 65,3 & 4,8 & 0,6 & 59,6 & 8,2 & 5,9 \\
\hline $\mathrm{B}+[\mathrm{OMIM}] \mathrm{BF}_{4}$ & 61,4 & 11,5 & 0,4 & 49,3 & 27,7 & 1,1 \\
\hline $\mathbf{B}+\mathbf{G}$ & 60,8 & 11,2 & 0,7 & 49,1 & 16,5 & 12,6 \\
\hline $\mathrm{B}+\left([\mathrm{OMIM}] \mathrm{BF}_{4}+\mathrm{G}\right)$ & 59,1 & 14,4 & 0,3 & 58,3 & 16,1 & 0,1 \\
\hline
\end{tabular}

Cuando se emplea la base sin modificar, se observa un daño superficial severo, con marcas de abrasión en el disco de AISI 316L (Figura 224a). Además se observa transferencia de material en la bola de zafiro (Figura 224b).

a)

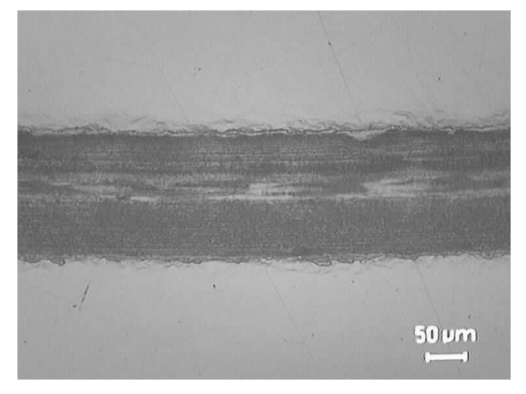

b)

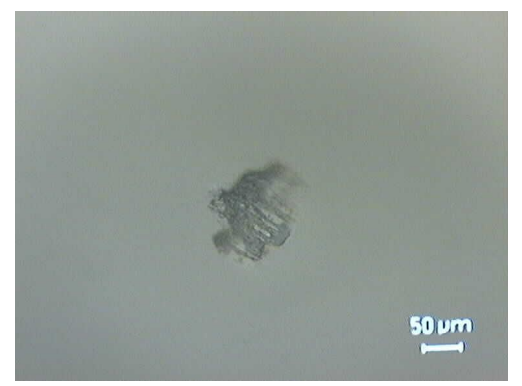

Figura 224. a) Micrografía óptica de la huella de desgaste tras lubricación con B; b) Micrografía óptica de la bola de zafiro

Además, se han obtenido imágenes de SEM y se han realizado análisis EDX tanto en el interior de la huella, como fuera de la misma (Figura 225 y Tabla $63)$. 


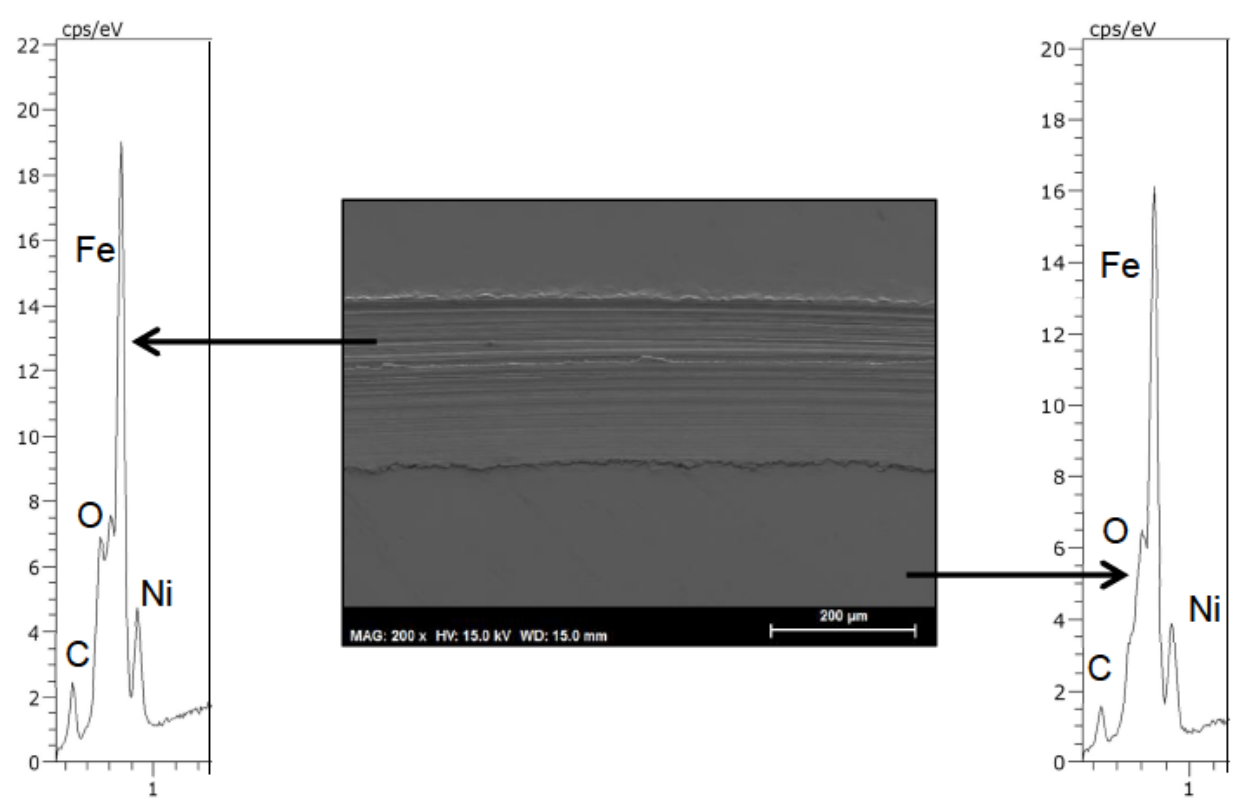

Figura 225. Micrografía SEM y espectros EDX dentro y fuera de la huella de desgaste tras lubricación con B

Como se muestra en los espectros, hay un elevado incremento de la concentración de oxígeno dentro de la huella de desgaste. Esto puede atribuirse a la oxidación del hierro de la superficie debido a la eliminación de la capa protectora del AISI 316L.

Cuando se añade el líquido iónico [OMIM]BF 4 a la base isoparafínica, se observa un ataque superficial menos severo y menos material adherido en la bola de zafiro (Figura 226).

a)

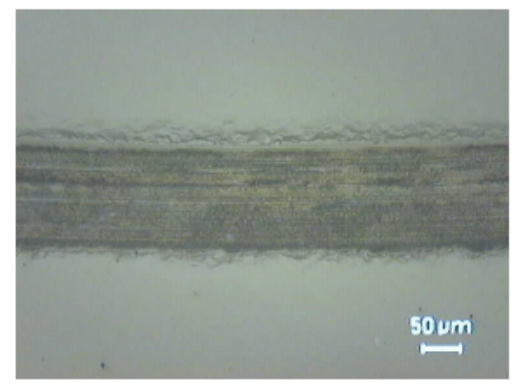

b)

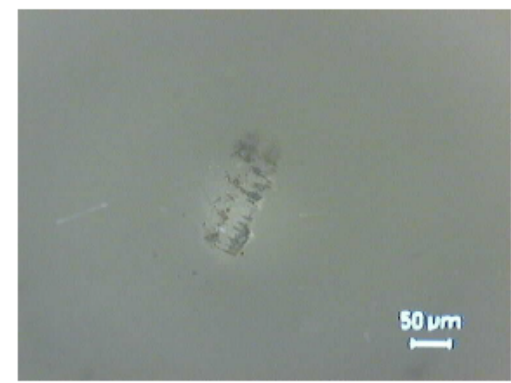

Figura 226. a) Micrografía óptica de la huella de desgaste tras lubricación con $\mathrm{B}+[\mathrm{OMIM}] \mathrm{BF}_{4}$;

b) Micrografía óptica de la bola de zafiro

El análisis EDX (Figura 227 y Tabla 63) no muestra incrementos significativos de la concentración de oxígeno dentro de la huella como se encontró para la lubricación con la base lubricante sin aditivos. 

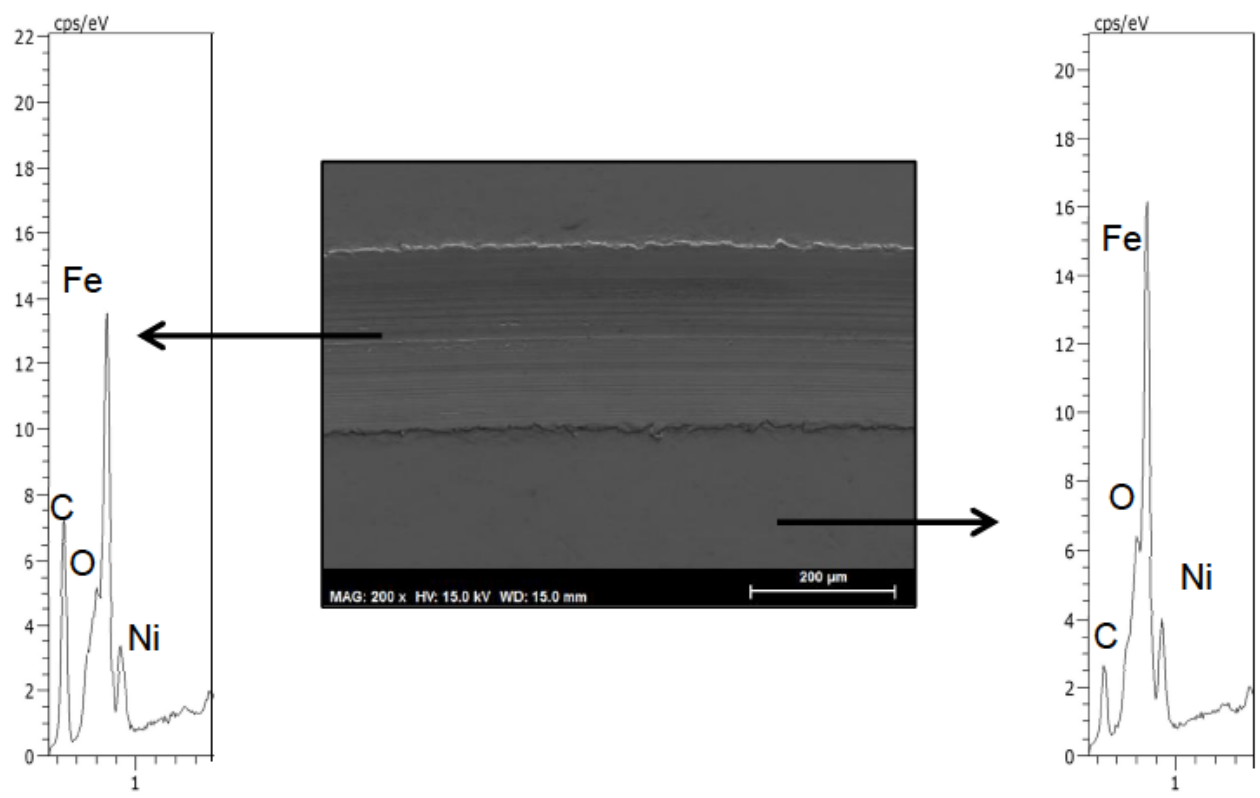

Figura 227. Micrografía SEM y espectros EDX dentro y fuera de la huella de desgaste tras lubricación con $\mathrm{B}+[\mathrm{OMIM}] \mathrm{BF}_{4}$

La lubricación con la dispersión de líquido iónico $[\mathrm{OMIM}] \mathrm{BF}_{4}$ en la base isoparafínica produce un importante incremento del contenido en carbono en el interior de la huella de desgaste, así como la reducción del porcentaje de hierro con respecto a la superficie exterior. Esto se puede atribuir a la capacidad del líquido iónico para evitar la corrosión.

Microscopías ópticas de la huella de desgaste y la bola de zafiro tras el ensayo tribológico empleando el lubricante $B+G$ se muestran en la Figura 228.

a)

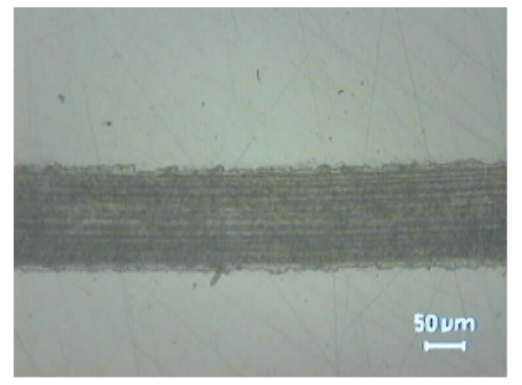

b)

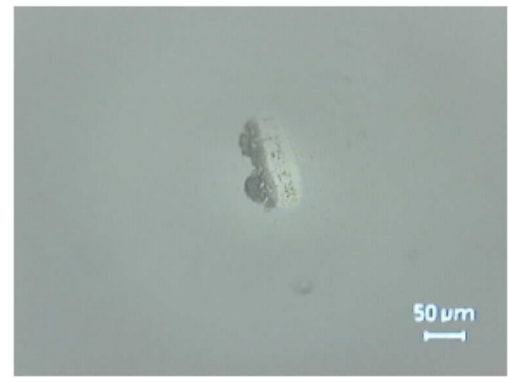

Figura 228. a) Micrografía óptica de la huella de desgaste zafiro tras lubricación con $B+G$;

b) Micrografía óptica de la bola de zafiro

La lubricación con $B+G$ muestra un incremento de los porcentajes de carbono y oxígeno en el interior de la huella de desgaste, con la correspondiente reducción de la concentración de hierro (Tabla 63 y Figura 229). La ausencia 
de líquido iónico impide la protección contra la oxidación del hierro, mientras que la presencia de nanofase de carbono contribuye al aumento de carbono en la superficie. Esto podría explicar el elevado valor de $\left(A_{1}+A_{2}+A_{3}\right)$ obtenido en este caso (Tabla 62).
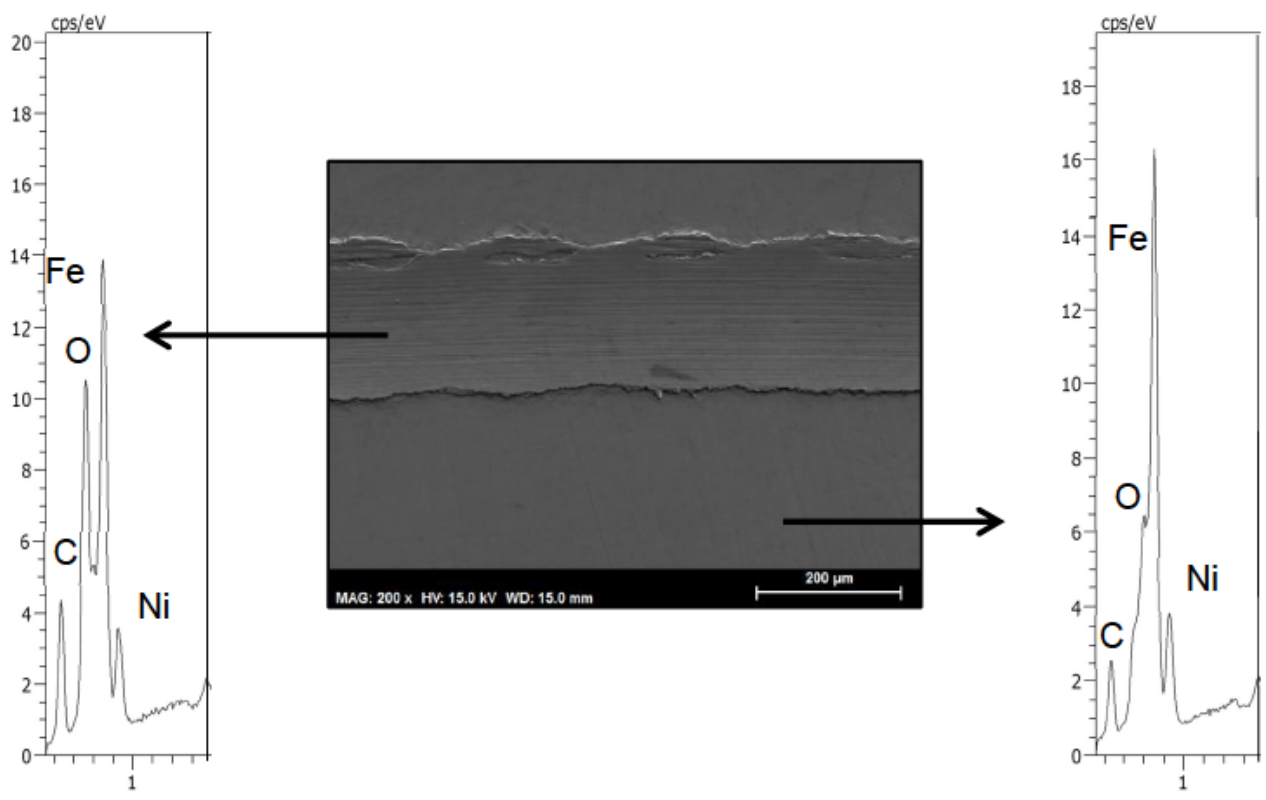

Figura 229. Micrografía SEM y espectros EDX dentro y fuera de la huella de desgaste tras lubricación con $B+G$

Finalmente, la lubricación con $\mathrm{B}+\left([\mathrm{OMIM}] \mathrm{BF}{ }_{4}+\mathrm{G}\right)$ muestra un desgaste o daño superficial despreciable tanto sobre la superficie de acero AISI $316 \mathrm{~L}$ como en la bola de zafiro (Figura 230).

a)

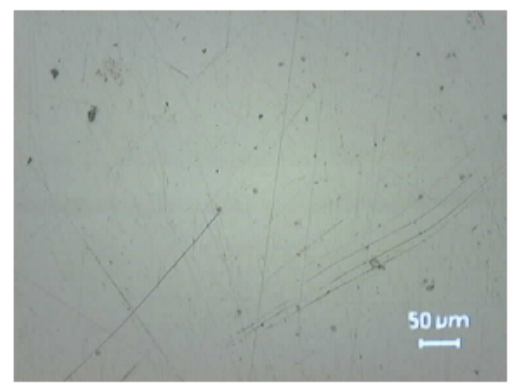

b)

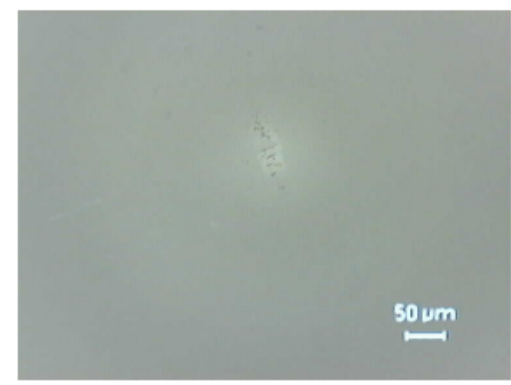

Figura 230. a) Micrografía óptica de la huella de desgaste tras lubricación con $\mathrm{B}+\left([\mathrm{OMIM}] \mathrm{BF}_{4}+\mathrm{G}\right) ;$ b) Micrografía óptica de la bola de zafiro

La ausencia de desgaste está en concordancia con las concentraciones atómicas similares de $\mathrm{C}, \mathrm{Fe}$ y $\mathrm{O}$ observadas tanto dentro de la huella de desgaste como fuera (Figura 231 y Tabla 63). 

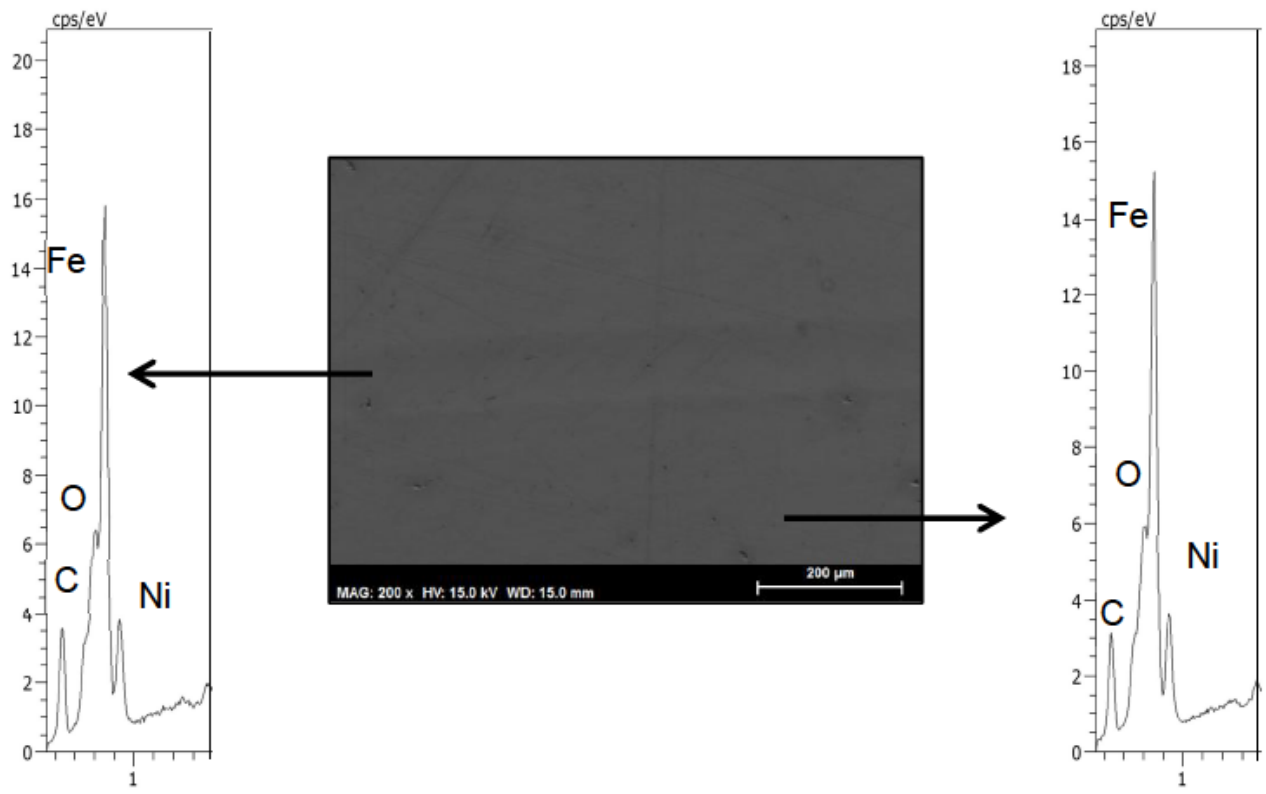

Figura 231. Micrografía SEM y espectros EDX dentro y fuera de la huella de desgaste tras lubricación con $\mathrm{B}+\left([\mathrm{OMIM}] \mathrm{BF}_{4}+\mathrm{G}\right)$

En este caso, la presencia de líquido iónico podría evitar la oxidación [32] mientras que el grafeno podría incrementar la capacidad de soportar carga del lubricante, impidiendo la eliminación de material. Por tanto, quedaría demostrado el efecto sinérgico de ambos aditivos

\subsubsection{Dispersiones en aceite lubricante de alto rendimiento totalmente formulado}

Con el fin de determinar la viabilidad de los aditivos grafeno y líquido iónico [OMIM]BF 4 en un aceite comercial de alto rendimiento (MO) en condiciones de servicio, se aumenta la severidad de las condiciones de contacto con respecto a las empleadas para las dispersiones de base isoparafínica (B) (apartado 3.3.1.9.3), incrementando la carga normal, la distancia de deslizamiento y la temperatura, mientras que se reduce el radio de giro para una misma velocidad lineal.

Se ha determinado la viscosidad de las dispersiones de grafeno y/o líquido iónico en el aceite totalmente formulado y se ha comparado con el valor obtenido para el lubricante base. Los resultados, recogidos en la Tabla 64 muestran que a $150^{\circ} \mathrm{C}$ no se producen cambios en la viscosidad con la adición de la nanofase o el líquido iónico, manteniendo un rango de viscosidad entre 20-22 mPa.s. En este caso, los cambios en el comportamiento tribológico de 
las diferentes dispersiones no pueden ser atribuidos a cambios en la viscosidad.

Tabla 64. Viscosidad de las dispersiones en aceite de motor de alto rendimiento

\begin{tabular}{ccccc}
\hline \multirow{2}{*}{ Temperatura } & \multicolumn{4}{c}{ Viscosidad (mPa-s) $($ Desviación estándar $\leq 0,003)$} \\
\cline { 2 - 5 } & MO & MO+[OMIM]BF $_{4}$ & MO+G & MO+([OMIM]BF $\left._{4}+\mathrm{G}\right)$ \\
\hline $150^{\circ} \mathrm{C}$ & 21 & 21 & 20 & 22 \\
\hline
\end{tabular}

La evolución del coeficiente de fricción con la distancia de deslizamiento para las dispersiones de grafeno y/o líquido iónico en el aceite de motor de alto rendimiento, obtenida en los ensayos tribológicos en configuración punzón sobre disco se muestran en la Figura 232.

Se puede observar que, incluso bajo las severas condiciones de deslizamiento en las que se han llevado a cabo los ensayos, los valores de coeficiente de fricción son muy similares a los obtenidos para la base isoparafínica, cuyos ensayos se realizaron a temperatura ambiente.

Aunque todos los aditivos reducen el coeficiente fricción medio con respecto al lubricante base (MO), se puede observar una reducción del $77 \%$ en el coeficiente de fricción cuando se emplea la dispersión MO+G (Tabla 65 y Figura 232).

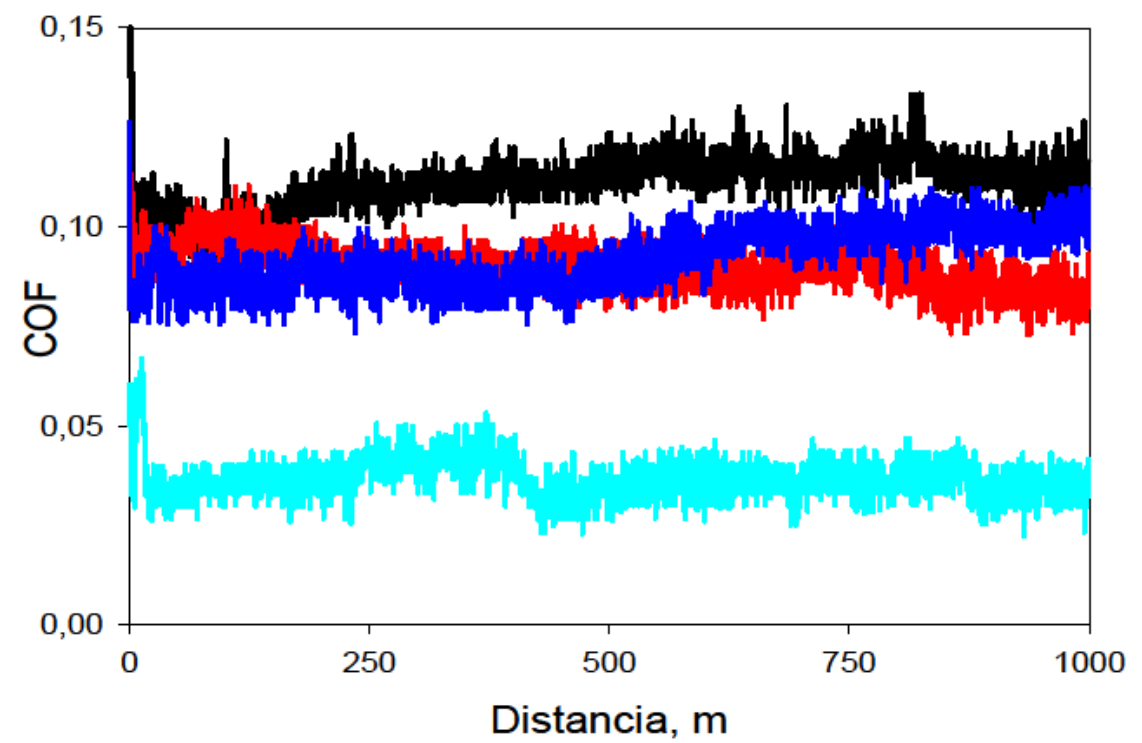

$$
\begin{array}{ll}
\longrightarrow & \mathrm{MO} \\
\mathrm{MO}+[\mathrm{OMIM}] \mathrm{BF}_{4} \\
\\
\mathrm{MO}+\left([\mathrm{OMIM}] \mathrm{BF}_{4}+\mathrm{G}\right) \\
\mathrm{MO}+\mathrm{G}
\end{array}
$$

Figura 232. Evolución del coeficiente de fricción con la distancia de deslizamiento para los lubricantes con aceite de motor de alto rendimiento a $150^{\circ} \mathrm{C}$ 
Además, se puede observar en la Figura 232 que la adición de grafeno produce una disminución del coeficiente de fricción con la distancia recorrida, desde un máximo valor de running-in de 0,06 (tras $10 \mathrm{~m}$ ), hasta alcanzar un mínimo valor de 0,03 tras solo $17 \mathrm{~m}$. El coeficiente de fricción mínimo del ensayo es de 0,02 y se obtiene a $886 \mathrm{~m}$, observándose un valor medio de 0,03 hasta el final del ensayo.

Tabla 65. Coeficientes de fricción y áreas de la huella de desgaste para los lubricantes con aceite de motor de alto rendimiento

\begin{tabular}{|c|c|c|c|c|}
\hline & $\begin{array}{l}\text { Coeficiente } \\
\text { de fricción }\end{array}$ & $A_{1}\left(\mu m^{2}\right)$ & $\begin{array}{c}A_{2}+A_{3} \\
\left(\mu m^{2}\right)\end{array}$ & $\begin{array}{c}\text { Pérdida de } \\
\text { material } \\
{\left[A_{1}-\left(A_{2}+A_{3}\right)\right]} \\
\left(\mu \mathrm{m}^{2}\right)\end{array}$ \\
\hline MO & $0,11( \pm 0,01)$ & $46,48( \pm 2,58)$ & $15,31( \pm 1,16)$ & 19,08 \\
\hline $\mathrm{MO}+[\mathrm{OMIM}] \mathrm{BF}_{4}$ & $0,09( \pm 0,01)$ & $10,82( \pm 2,20)$ & $5,35( \pm 1,68)$ & 5,47 \\
\hline MO+G & $0,03( \pm 0,01)$ & $11,55( \pm 0,58)$ & $13,72( \pm 1,45)$ & $-2,17$ \\
\hline $\mathrm{MO}+\left([\mathrm{OMIM}] \mathrm{BF}_{4}+\mathrm{G}\right)$ & $0,09( \pm 0,01)$ & $10,05( \pm 1,71)$ & $8,01( \pm 1,40)$ & 2,04 \\
\hline
\end{tabular}

La Figura 233 y la Tabla 65 muestran las áreas de la sección transversal de las huellas de desgaste y sus valores numéricos, respectivamente. Todos los aditivos presentan una buen comportamiento antidesgaste con respecto al $\mathrm{MO}$, siendo el lubricante $\mathrm{MO}+\left[\mathrm{OMIM}_{\mathrm{BF}} \mathrm{el}_{4}\right.$ el que presenta un mejor comportamiento, logrando una disminución del $74 \%$ del daño superficial $\left(A_{1}+A_{2}+A_{3}\right)$. Si se cuantifica la pérdida de material $\left(A_{1}-\left(A_{2}+A_{3}\right)\right)$, la mayor capacidad de reducir el desgaste la presentan los lubricantes que poseen grafeno. La mayor cantidad de material acumulado en los bordes de la huella de desgaste $\left(A_{2}+A_{3}\right)$ con respecto al material eliminado $\left(A_{1}\right)$ hace que para la dispersión $M O+G$ se obtenga un valor negativo de pérdida de material debida al desgaste.

Los mecanismos de desgaste que experimentan los discos de AISI 316L podrían ser diferentes en función del aditivo presente. Si está presente el líquido iónico, capas adsorbidas del fluido podrían evitar el contacto entre las asperezas [334], mientras que el grafeno podría formar una capa protectora sobre la huella de desgaste. 
a)

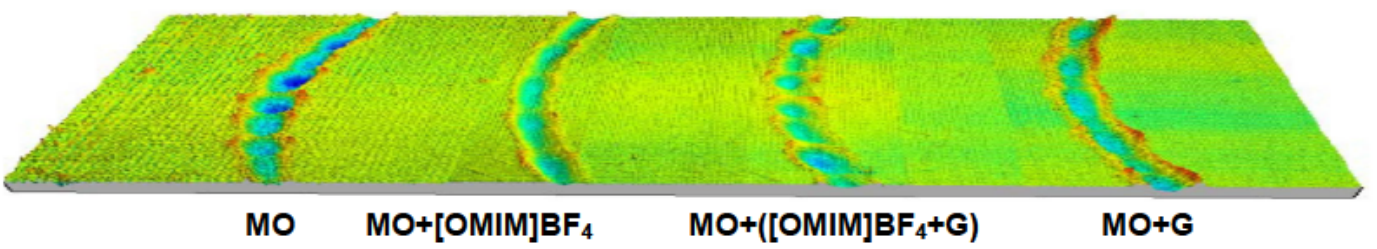

b)

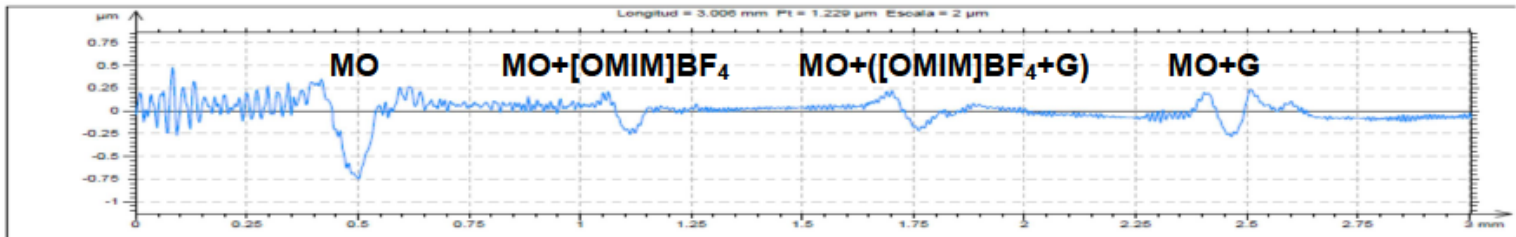

Figura 233. a) Topografía superficial; b) Sección transversal de las huellas de desgaste para los lubricantes de aceite de motor de alto rendimiento a $150^{\circ} \mathrm{C}$

Debido al buen comportamiento tribológico observado para la dispersión $\mathrm{MO}+\mathrm{G}$, se pretende estudiar el mecanismo que ha tenido lugar sobre los discos de acero usando este lubricante.

La Figura 234 muestra las micrografías SEM de las huellas de desgaste tras la lubricación con MO (Figura 234a) y MO+G (Figura 234b). Los mapas elementales indican la presencia de oxígeno dentro de la huella de desgaste tras la lubricación con MO (Figura 234c) atribuida a oxidación y, la presencia de una capa de carbono en el caso de MO+G (Figura 234d).

a)

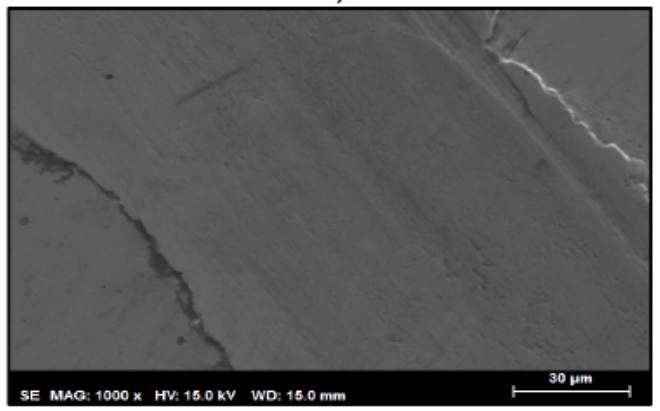

c)

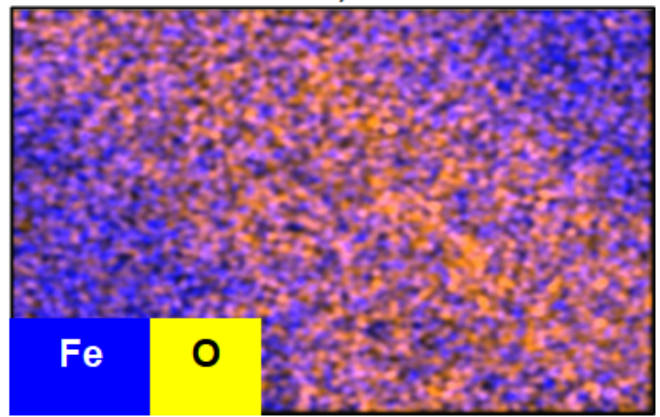

b)

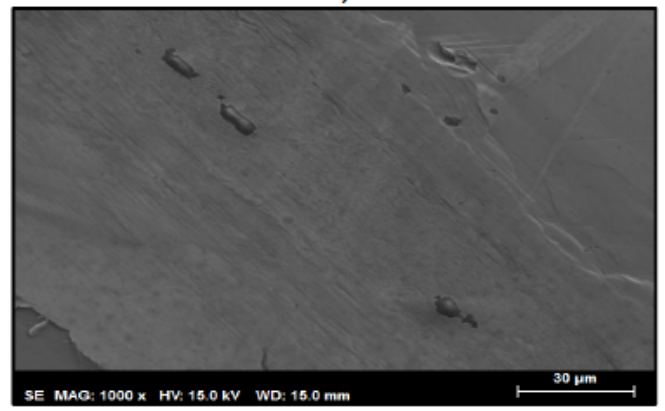

d)

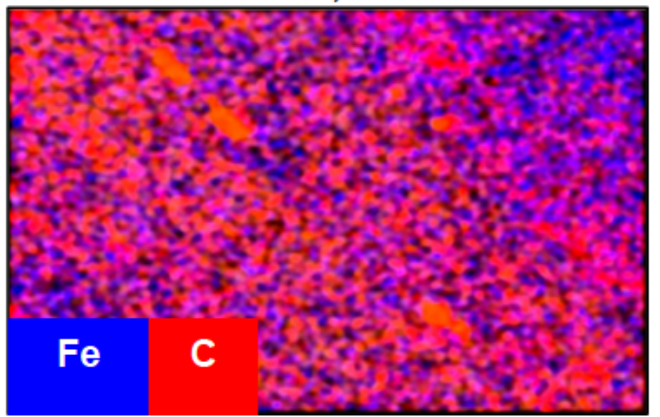

Figura 234. Micrografías SEM de la huellas de desgaste: a) MO; b) MO+G. Mapas elementales: c) $\mathrm{MO} ; \mathrm{d}) \mathrm{MO}+\mathrm{G}$ 
Con el objetivo de establecer la naturaleza de esta capa de carbono en la superficie de la huella de desgaste tras la lubricación con $M O+G$, se ha realizado un estudio superficial mediante XPS y microscopía Raman.

En el espectro XPS (Figura 235), el pico principal para el C1s se observar a $284,6 \mathrm{eV}$ (Scan A), el cual podría corresponderse con el carbono $\mathrm{sp}^{2}$ presente tanto en el lubricante $\mathrm{MO}$ como en el grafeno. El segundo pico principal, a $532,0 \mathrm{eV}$ es asignable a O1s. Estas afirmaciones confirman los resultados de EDX (Figura 234).

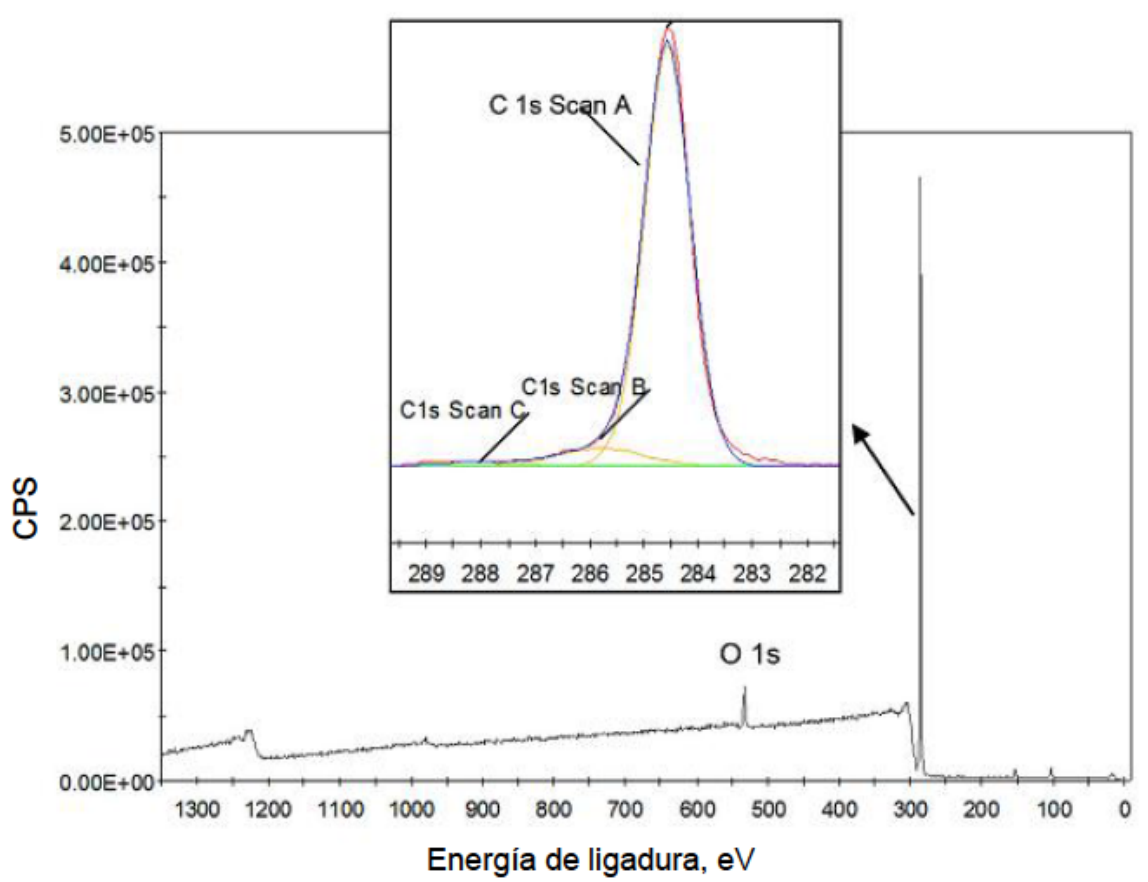

Figura 235. Espectro XPS sobre la huella de desgaste tras lubricación con MO+G

El espectro Raman dentro de la huella de desgaste tras lubricación con $\mathrm{MO}+\mathrm{G}$ se muestra en la Figura 236, donde se compara con los espectros del grafeno y el aceite lubricante MO.

La banda $D$ del grafeno se encuentra a $1361,2 \mathrm{~cm}^{-1}$, la banda $G$ aparece a $1596,6 \mathrm{~cm}^{-1}$ y la banda 2D a $2951,6 \mathrm{~cm}^{-1}$. El aceite MO presenta picos a 1301,0 $\mathrm{cm}^{-1}, 1439,5 \mathrm{~cm}^{-1}, \mathrm{y}$ fuertes bandas a $2852,9 \mathrm{~cm}^{-1}$ y $2892,3 \mathrm{~cm}^{-1}$.

El espectro Raman de la huella de desgaste muestra picos asignables a la banda D y $G$ del grafeno a $1364,2 \mathrm{~cm}^{-1}$ y $1602,6 \mathrm{~cm}^{-1}$ respectivamente, y un pico asignable a MO a $1451,6 \mathrm{~cm}^{-1}$. La relación de intensidades $\mathrm{I}_{\mathrm{D}} / \mathrm{l}_{\mathrm{G}}$ es similar, 0,79 en el caso del grafeno y 0,79 en el interior de la huella de desgaste. La relación $\mathrm{I}_{2 \mathrm{D}} / \mathrm{I}_{\mathrm{G}}$ no ha podido ser comparada debido a la presencia de una banda 
de aceite $(\mathrm{MO})$ en la misma región que la banda $2 \mathrm{D}$ del grafeno. También se han encontrado picos en la huella de desgaste a $1003,7 \mathrm{~cm}^{-1}$ y $3057,7 \mathrm{~cm}^{-1}$ que podrían ser atribuido a nuevas absorciones $\mathrm{C}-\mathrm{H}$ no presentes en el lubricante antes del ensayo tribológico. Estos resultados confirman la modificación de la superficie del acero por el nuevo lubricante que contiene grafeno.

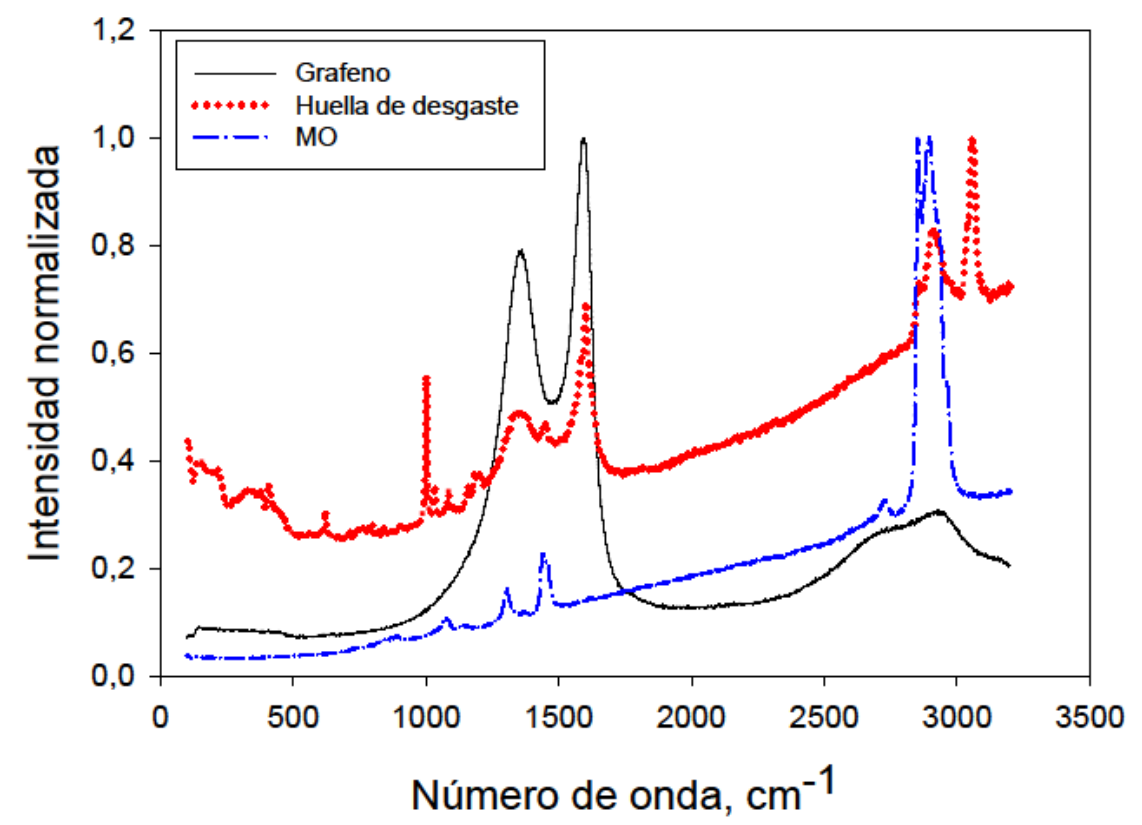

Figura 236. Espectros Raman de grafeno, aceite lubricante de alto rendimiento antes del ensayo y en la huella tras lubricación con $\mathrm{MO}+\mathrm{G}$

\subsubsection{Conclusiones}

La posible aplicación práctica de grafeno, el líquido iónico aprótico 1-octil-3metilimidazolio y la combinación de ambos como aditivos en aceites lubricantes comerciales, se ha estudiado tanto a temperatura ambiente, como a $150^{\circ} \mathrm{C}$.

Cuando se trata de un aceite base isoparafínico sin aditivos, las mejores prestaciones antifricción y desgaste se obtienen cuando se añade un $5 \%$ de la dispersión que contiene un $0,1 \%$ de grafeno en el líquido iónico, gracias a la capacidad del líquido iónico para estabilizar la dispersión de grafeno en el aceite base.

En el caso de un aceite comercial de motor totalmente formulado, una concentración muy baja de grafeno $(0,005 \%)$ es suficiente para reducir el coeficiente de fricción en un $73 \%$, evitando la pérdida de material por desgaste, incluso a $150^{\circ} \mathrm{C}$. Estos buenos resultados se atribuyen a la formación de una capa protectora de grafeno sobre la superficie del acero. 


\subsection{ESTUDIO DE NUEVOS NANOCOMPOSITES DE MATRIZ EPOXI}

\subsubsection{Estudio tribológico de un nanocomposite de resina epoxi con un 9\% de líquido iónico $\mathrm{DCi}$}

Recientemente, se han obtenido nanomateriales de matriz epoxi con distintos porcentajes de líquido iónico aprótico (tetrafluoroborato de 1-octil-3metilimidazolio) con concentraciones inferiores al 12\% [234], de grafeno o grafeno modificado con líquido iónico [269], que presentan un buen comportamiento tribológico y propiedades de autorrecuperación, como es el caso del nanocomposite de resina epoxi con un $9 \%$ de líquido iónico aprótico [OMIM]BF 4 [284]. Sin embargo, los líquidos iónicos apróticos empleados poseen aniones que contienen elementos halógenos que pueden dar lugar a la formación de compuestos altamente contaminantes, por tanto en los últimos tiempos, se está intentado sustituir este tipo de líquidos iónicos por otros libres de haluros, como podrían ser los líquidos iónicos próticos.

El principal objetivo de este estudio es desarrollar un nuevo nanocomposite de matriz epoxi con un $9 \%$ del líquido iónico prótico citrato de tri[bis(2hidroxietil)amonio], con el fin de determinar el efecto de la adición del nanofluido iónico en las características y propiedades tribológicas del polímero de partida. Para ello se ha realizado un estudio de curado, se han determinado las características térmicas y mecánicas, y se ha estudiado el comportamiento tribológico el nuevo nanocomposite (RE+9\%DCi) y se han comparado con las de la resina epoxi sin aditivos (RE), cuyas propiedades se encuentran en la bibliografía [234], [254], [269], [284].

\subsubsection{Estudio de curado del nuevo nanocomposite}

\subsection{Estudio del proceso de curado mediante calorimetría diferencial de barrido (DSC)}

Para determinar el grado de curado de la resina epoxi con un $9 \%$ de DCi (RE+9\%DCi) se han realizado análisis mediante calorimetría diferencial de barrido, siguiendo el método descrito en el apartado 3.3.2.2.1 para conocer la entalpía residual de curado para el nuevo material y se ha comparado con los valores obtenidos para la resina epoxi pura (RE) [234]. 
A continuación, se representa la evolución del proceso de curado con la temperatura para ambos materiales después de 20, 40 y 60 minutos respectivamente (Figura 237)

a)

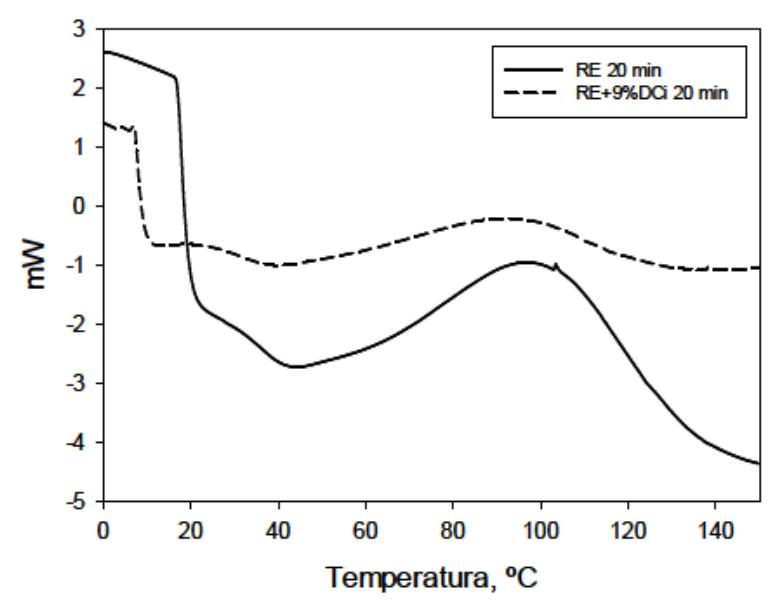

b)

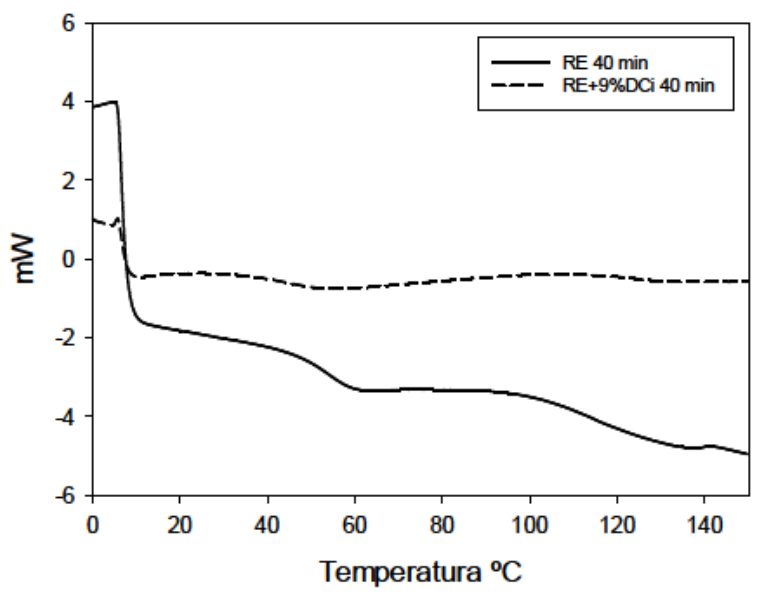

c)

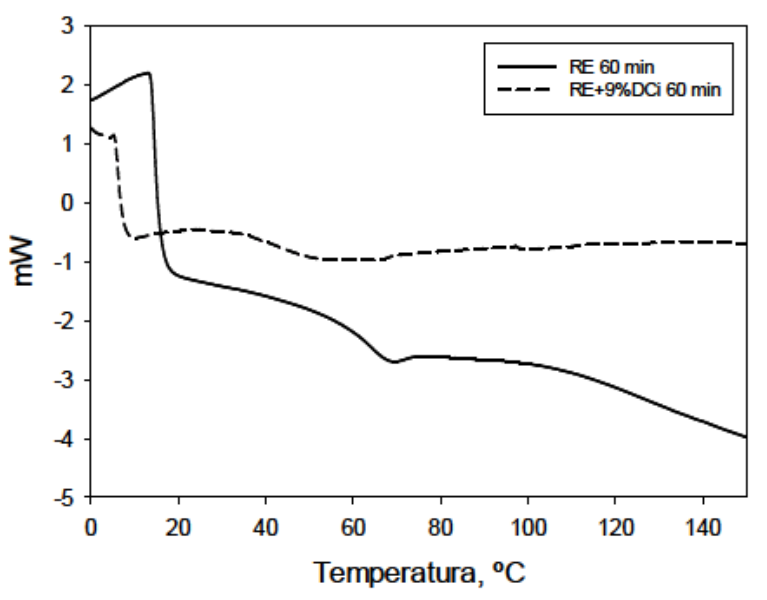

Figura 237. a) Entalpía residual de curado para RE+9\%DCi a $20 \mathrm{~min}$; b) $40 \mathrm{~min}$; c) $60 \mathrm{~min}$ del inicio del curado

En función de los valores de entalpía residual de curado obtenidos (Tabla 66), se puede observar que el líquido iónico prótico DCi actúa como agente endurecedor desde las primeras etapas del proceso de curado. Se logra el curado total del nuevo material después de 60 minutos, con un valor de entalpía residual de curado de $0,90 \mathrm{~J} / \mathrm{g}$. 
Tabla 66. Entalpía residual de curado para RE y RE+9\%DCi

\begin{tabular}{ccc}
\hline Tiempo de curado $\left(\mathbf{6 0 ^ { \circ } \mathrm { C } )}\right.$ & \multicolumn{2}{c}{$\Delta \mathrm{H}(\mathrm{J} / \mathbf{g})$} \\
\cline { 2 - 3 } & RE & $\mathbf{R E + 9 \% D C i}$ \\
\hline $\mathbf{2 0}$ minutos & 56,68 & $\mathbf{2 0 , 8 0}$ \\
\hline $\mathbf{4 0}$ minutos & 9,33 & 6,84 \\
\hline $\mathbf{6 0}$ minutos & 8,51 & 0,90 \\
\hline
\end{tabular}

Estos resultados muestran la aceleración del proceso de curado debido a la presencia del líquido iónico prótico, que podría ser debida a las interacciones iónicas entre las moléculas del líquido iónico y los grupos polares presentes en las cadenas del polímero.

\subsection{Estudio del proceso de curado mediante espectroscopía infrarroja por transformada de Fourier (FTIR)}

Además del estudio del proceso de curado mediante DSC cuyos resultados se han mostrado con anterioridad (Apartado 4.2.1.1.1) se ha analizado el efecto de la adición del líquido iónico $\mathrm{DCi}$ en el proceso de curado mediante espectroscopía infrarroja.

Durante el proceso de curado, los grupos funcionales amina, que forman parte del agente endurecedor, reaccionan con los grupos epoxi del prepolímero dando lugar a grupos hidroxilo, por lo que, estudiando la evolución de las bandas de infrarrojo características $\mathrm{N}-\mathrm{H}, \mathrm{C}-\mathrm{O}$ y $\mathrm{O}-\mathrm{H}$, es posible determinar el grado de curado del nanocomposite.

Las bandas correspondientes a las vibraciones (stretching) simétricas y antisimétricas de las aminas primarias $(\mathrm{N}-\mathrm{H})$ aparecen en el espectro aproximadamente a $3300 \mathrm{~cm}^{-1}$. La banda asignable al grupo hidroxilo $(\mathrm{O}-\mathrm{H})$ se puede observar entre 3500 y $3200 \mathrm{~cm}^{-1}$ y el pico correspondiente a la deformación del grupo epoxi aparece centrado en $915,6 \mathrm{~cm}^{-1}$.

En la Figura 238 se presenta la evolución del espectro infrarrojo de la resina con un $9 \%$ de $\mathrm{DCi}$. 


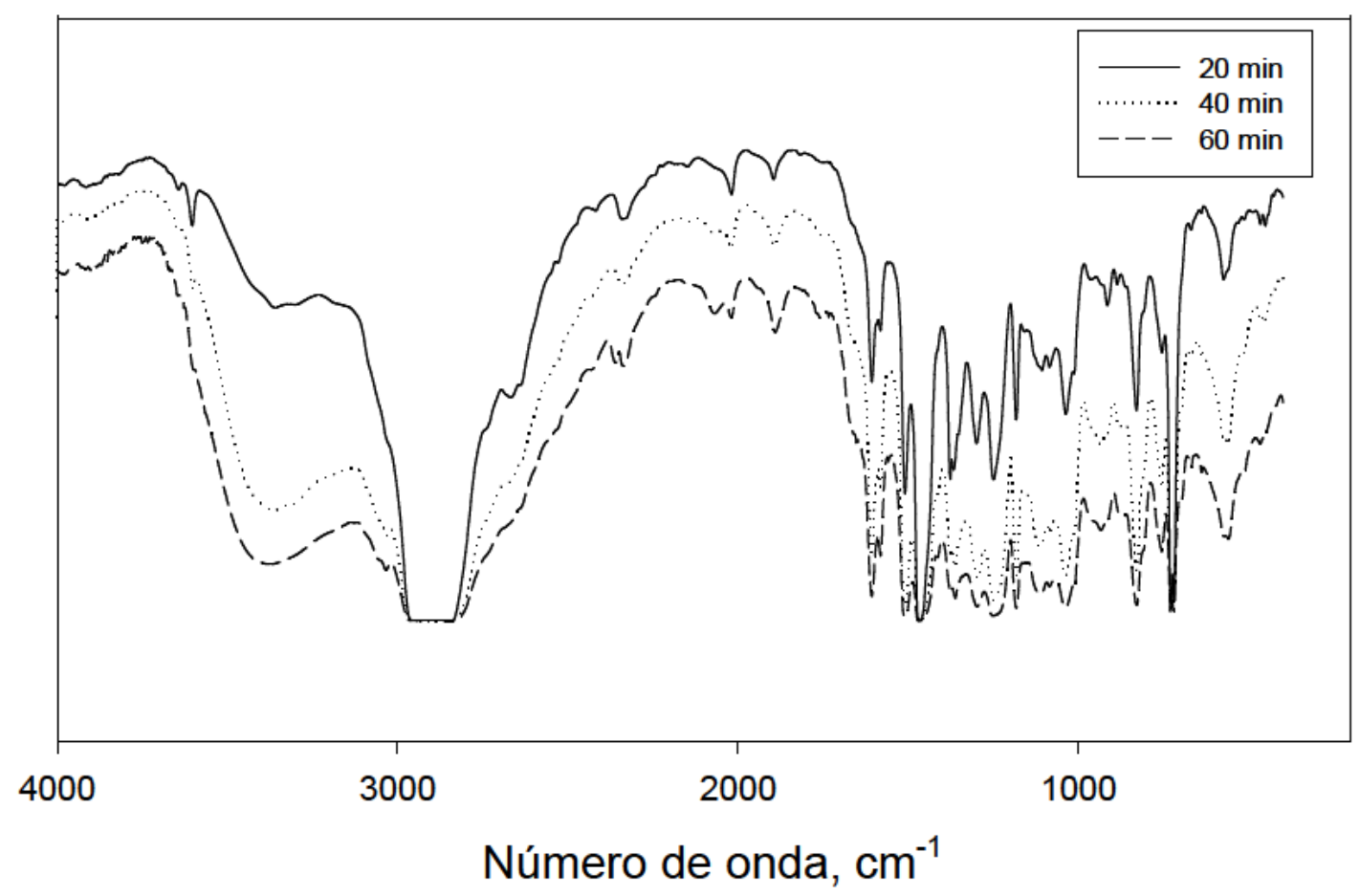

Figura 238. Espectros FTIR del nanocomposite RE+9\%DCi tras 20,40 y 60 minutos del inicio del curado

El pico correspondiente al grupo amino $(\mathrm{N}-\mathrm{H})$ se observa a $3360,04 \mathrm{~cm}^{-1}$ a los 20 minutos de curado, sin embargo, ya a los 40 minutos esta banda desaparece y se puede observar una nueva banda asignable al grupo hidroxilo $(\mathrm{O}-\mathrm{H})$.

En la Figura 239 se muestra con más detalle como en el proceso de curado a $60^{\circ} \mathrm{C}$, el pico correspondiente al enlace C-O $\left(915,6 \mathrm{~cm}^{-1}\right)$ del grupo epoxi va reduciendo su intensidad con el paso del tiempo hasta desaparecer totalmente a los 60 minutos. 


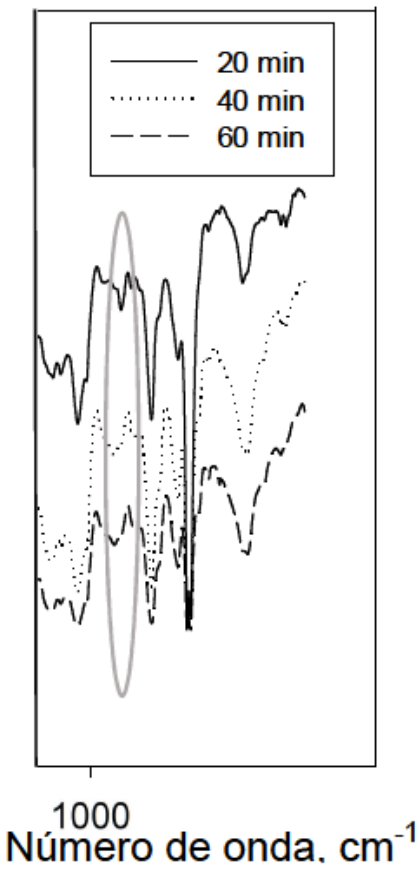

Figura 239. Detalle de la evolución de la banda del grupo epoxi

\subsubsection{Distribución del líquido iónico prótico en la matriz epoxi}

Con el objetivo de conocer la distribución del líquido iónico DCi en el seno de la matriz epoxi, se ha estudiado la superficie de fractura de RE+9\%DCi mediante microscopía electrónica de barrido, previa metalización de la muestra con Pt, observándose la presencia de unas estructuras con forma de gotas esféricas dentro de la matriz epoxi (Figura 240).

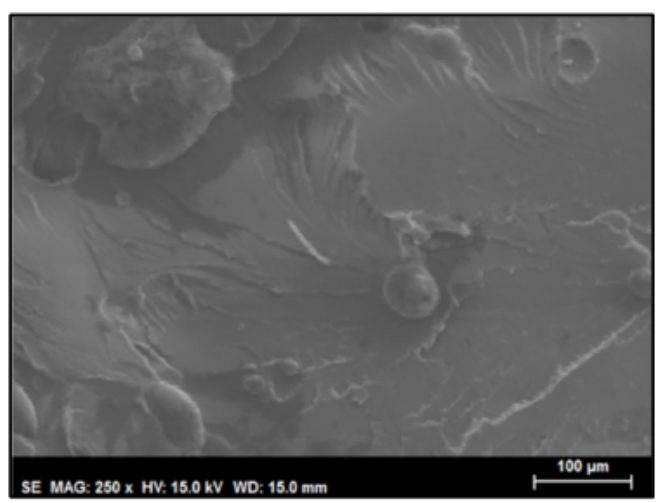

Figura 240. Micrografía SEM de la superficie de fractura de $R E+9 \% D C i$

Se ha obtenido un mapa elemental de esta zona mediante EDX, para determinar la distribución de cada elemento en la muestra. En la Figura 241 se puede observar una zona rica en carbono correspondiente a la matriz epoxi y la 
presencia de microesferas de oxígeno y nitrógeno, que podrían deberse a la presencia del líquido iónico prótico.

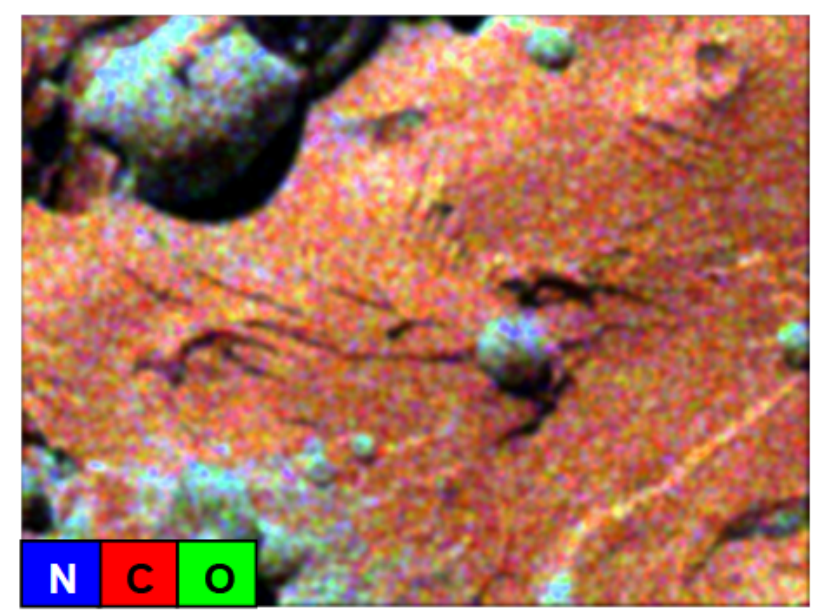

Figura 241. Mapa elemental de la superficie de fractura de $\mathrm{RE}+9 \% \mathrm{DCi}$

Con el fin de confirmar la presencia del líquido iónico en las microesferas observadas en los espectros EDX, se ha realizado un estudio mediante microscopía infrarroja (Apartado 3.2.2.1).

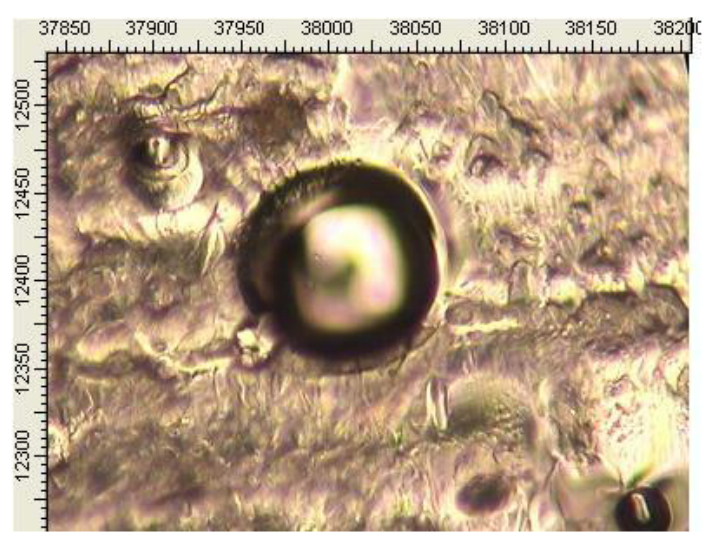

Figura 242. Superficie analizada mediante FTIR de RE+9\%DCi

En la Figura 243 se observa el espectro infrarrojo en transmitancia de la zona de la resina libre de cavidades o estructuras esféricas, correspondiente a la matriz epoxi. 


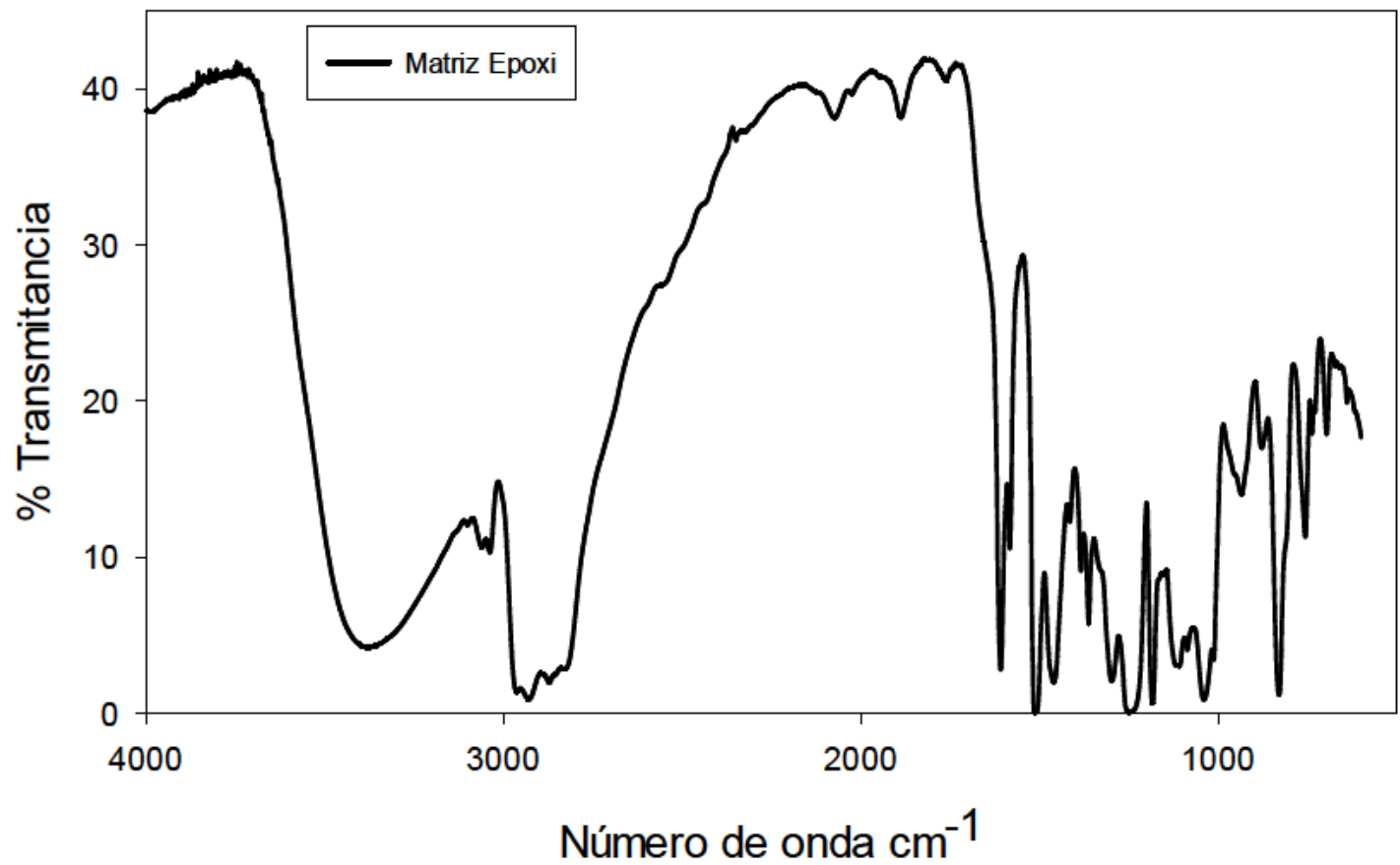

Figura 243. Espectro FTIR de la zona de la resina libre de cavidades

Además, se ha comparado el espectro FTIR del líquido iónico de partida con el obtenido en una de estas microesferas. Pudiéndose concluir que efectivamente, el líquido iónico prótico se encuentra en forma de gotas esféricas en la matriz epoxi, ya que éstas presentan el mismo espectro de transmisión infrarroja que el líquido iónico puro de partida como se puede observar en la Figura 244.

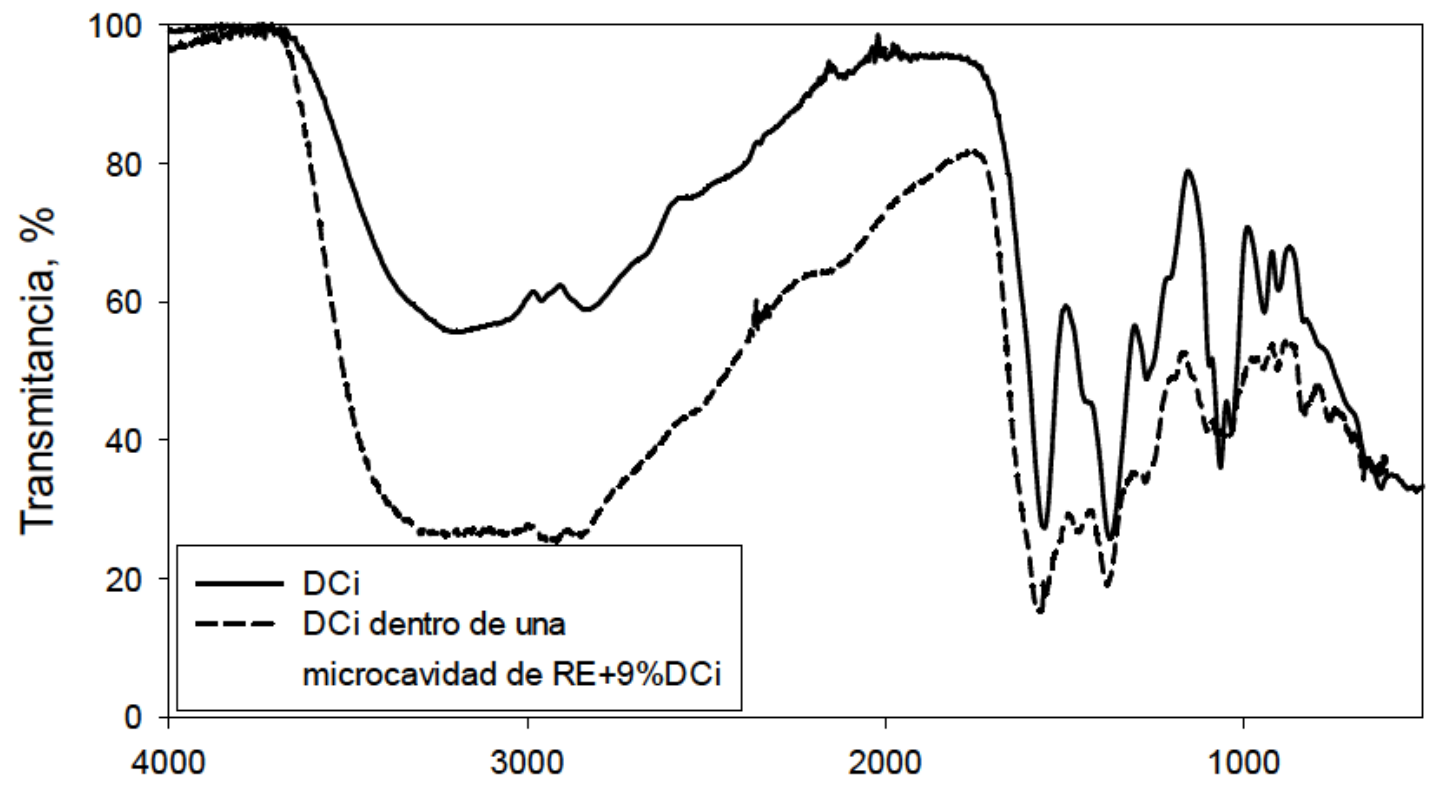

Número de onda, $\mathrm{cm}^{-1}$

Figura 244. Espectro FTIR de DCi y DCi dentro de una microcavidad de RE+9\%DCi 
Con el fin de cuantificar la distribución del líquido iónico prótico en el nuevo material $\mathrm{RE}+9 \% \mathrm{DCi}$, se ha empleado la microperfilometría óptica de no contacto. Como se puede observar gracias a la micrografía superficial mostrada en la Figura 245 , el material presenta un promedio de 38 microesferas $/ \mathrm{mm}^{2}$, siendo el diámetro medio de éstas en la superficie de $53( \pm$ 8) $\mu \mathrm{m}$.

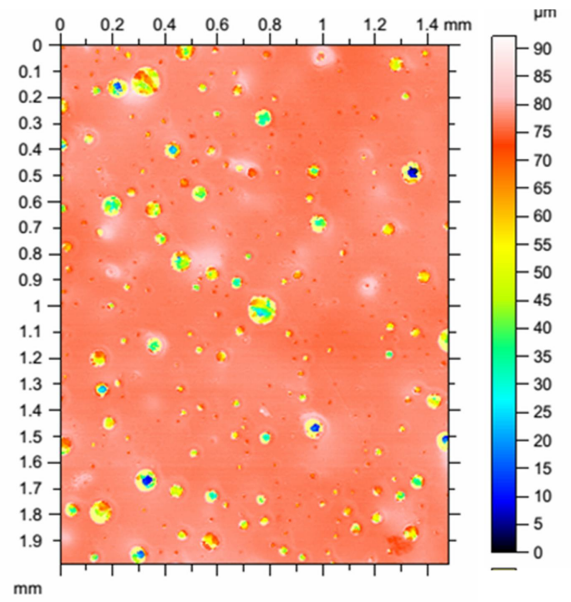

Figura 245. Perfil topográfico de RE+9\%DCi mostrando la distribución de DCi

Además, se ha realizado un estudio de la sección transversal del material de dimensiones $0,36 \times 2,5 \mathrm{~mm}$. Como se puede observar en la Figura 246, el número de microcavidades por unidad de superficie en la sección transversal es de 50 microcavidades $/ \mathrm{mm}^{2}$.

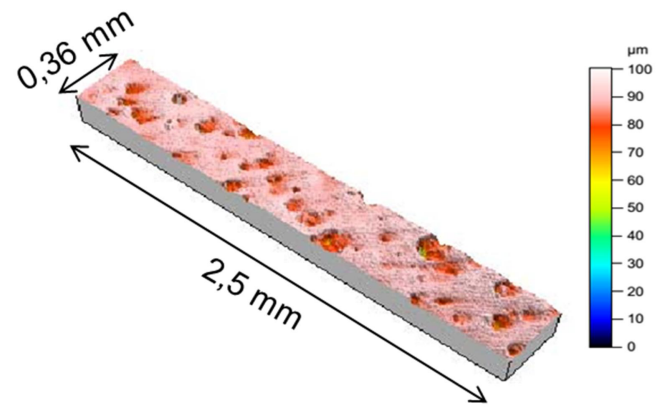

Figura 246. Imagen topográfica de la sección transversal de RE+9\%DCi

Todos los resultados obtenidos en este estudio muestran la influencia de la composición y la polaridad del líquido iónico prótico en la miscibilidad con la matriz epoxi. Este líquido iónico, con tres cationes amonio, presenta una polaridad más alta que el líquido iónico aprótico tetrafluoroborato de 1-octil-3metilimidazolio de cadena larga que ha sido estudiado con anterioridad en las mismas condiciones y que era totalmente miscible en la resina epoxi [81], [284], [335]. 
Por tanto, se podría confirmar que cuanto más polar es el nanofluido iónico, menos miscible es en la matriz epoxi, dando lugar a la formación de cavidades que contienen al líquido iónico.

\subsubsection{Caracterización del nanocomposite}

\subsection{Propiedades térmicas}

Se han empleado las técnicas de calorimetría diferencial de barrido (DSC) y termogravimetría (TGA) para determinar la temperatura de transición vítrea del material $(\mathrm{Tg})$ y su temperatura de degradación $(\mathrm{Td})$, respectivamente.

La temperatura de transición vítrea indica la temperatura a partir de la cual la movilidad de las cadenas poliméricas aumenta, produciéndose la transición de estado rígido a estado elastomérico.

La temperatura de degradación, por su parte, indica la temperatura a la que el material pierde el $50 \%$ de su masa.

\subsection{Calorimetría diferencial de barrido}

En la Figura 247 se muestran los termogramas correspondientes al segundo calentamiento del nuevo nanocomposite de matriz epoxi con el $9 \%$ de DCi y de la resina epoxi sin aditivos según el método descrito en el apartado 3.3.2.2.2.2.

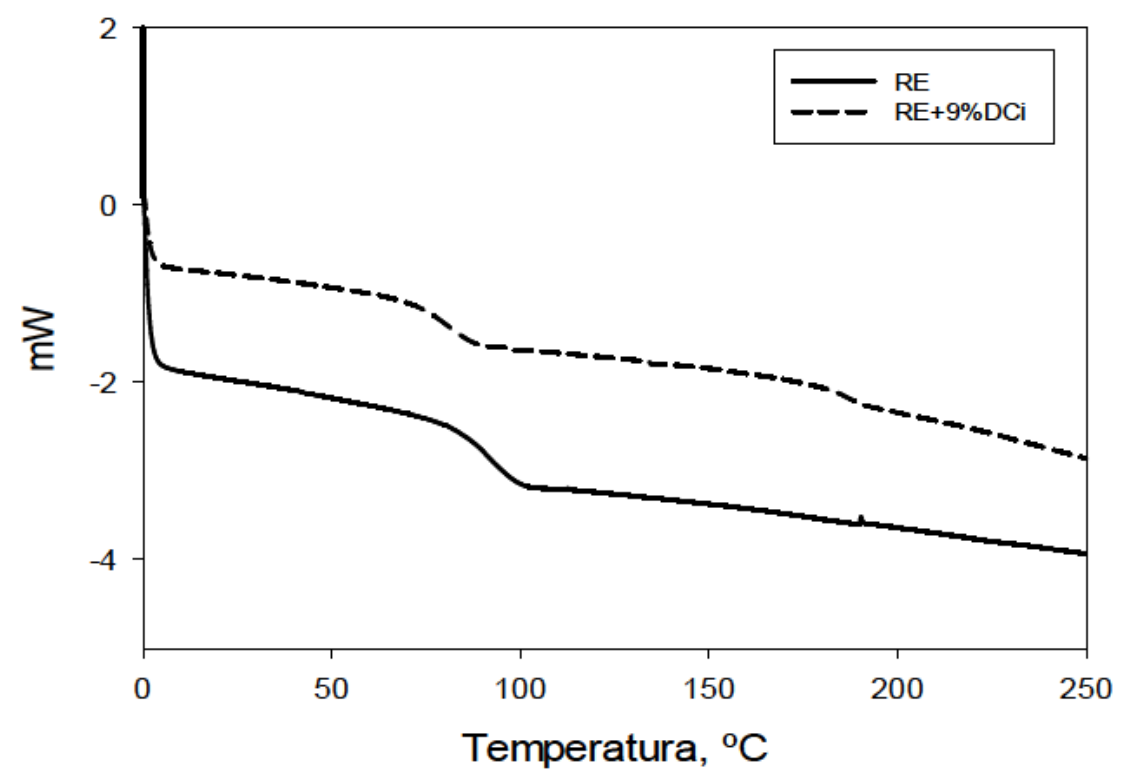

Figura 247. Termograma DSC para RE y RE+9\%DCi

Se han determinado las temperaturas de transición vítrea $(\mathrm{Tg})$, recogidas en la Tabla 67. 
Tabla 67. Valores de temperatura de transición vítrea para $R E$ y $R E+9 \% D C i$

\section{$\operatorname{Tg}\left({ }^{\circ} \mathrm{C}\right)$}

\begin{tabular}{cc}
\hline RE & 91,85 \\
\hline RE+9\%DCi & 82,08 \\
\hline
\end{tabular}

En función de los resultados obtenidos, se observa cómo la adición del líquido iónico prótico $\mathrm{DCi}$ reduce la temperatura de transición vítrea de la resina epoxi alrededor de $10^{\circ} \mathrm{C}$ debido al efecto plastificante del líquido iónico, el cual actúa como un lubricante interno, aumentando la movilidad de las cadenas del polímero.

\subsection{Termogravimetría}

Con el objetivo de conocer el efecto de la adición de líquido iónico prótico a la matriz epoxi en la temperatura de degradación de la resina sin aditivos, se han realizado ensayos de termogravimetría (TGA) siguiendo el método indicado en el apartado 3.3.2.2.2.1.

La Figura 248 muestra las curvas TGA para RE y RE+9\%DCi. En el caso del nuevo nanocomposite, se puede observar una etapa inicial de pérdida de peso de un $9 \%$ por encima de $310,5^{\circ} \mathrm{C}$, que corresponde con el porcentaje de líquido iónico que posee el nuevo material.

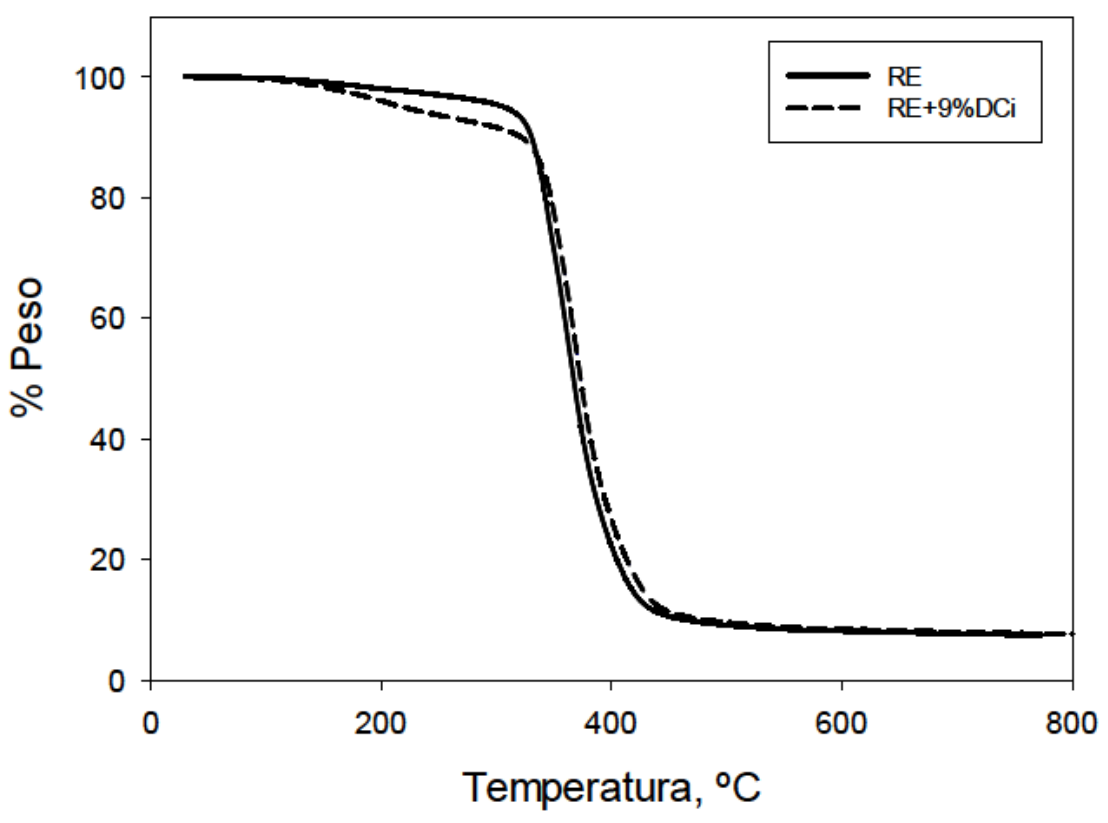

Figura 248. Termograma TGA de RE y RE+9\%DCi 
Además, como se observa en la Tabla 68 , se produce un aumento de la temperatura de degradación, a la que pierde el $50 \%$ de su masa, debido al efecto endurecedor del líquido iónico.

Tabla 68. Valores de temperatura de degradación para RE y RE+9\%DCi

\begin{tabular}{cc}
\hline & $\operatorname{Td}(\Delta \mathrm{m}=-\mathbf{5 0 \%})\left({ }^{\circ} \mathrm{C}\right)$ \\
\hline RE & 343,86 \\
\hline RE+9\%DCi & 372,31
\end{tabular}

\subsection{Dureza}

Se han comparado los valores de dureza en escala Shore D, la empleada normalmente para materiales poliméricos, con una carga de 25 gramos. Como se observa en la Tabla 69 la adición del líquido iónico prótico no conlleva cambios significativos en los valores obtenidos.

Tabla 69. Dureza ShoreD para RE y RE+9\%DCi

\begin{tabular}{cc}
\hline & Dureza Shore D \\
\hline RE & $82,9( \pm 0,3)$ \\
\hline RE+9\%DCi & $77,7( \pm 1,5)$ \\
\hline
\end{tabular}

Debido a la gran cantidad de microcavidades que presentaba la resina $\mathrm{RE}+9 \% \mathrm{DCi}$, también se ha medido la microdureza Vickers con una carga de 25 gramos (Tabla 70). Al igual que en el caso de la dureza Shore D, los valores son similares para ambos materiales.

Tabla 70. Microdureza Vickers para RE y RE+9\%DCi

\begin{tabular}{cc}
\hline & Microdureza Vickers \\
\hline RE & $20,4( \pm 1,0)$ \\
\hline RE+9\%DCi & $21,2( \pm 1,2)$
\end{tabular}

\subsection{Propiedades dinámico-mecánicas}

Las propiedades dinámico-mecánicas del nuevo material se han determinado mediante ensayos DMA siguiendo el método descrito en el apartado 3.3.2.2.3. Se han obtenido curvas que representan la evolución del módulo de almacenamiento ( $\left.E^{\prime}\right)$, el módulo de pérdida $\left(E^{\prime \prime}\right)$ y $\tan (\delta)$ con la temperatura bajo la configuración de viga empotrada. 
En la Figura 249 se comparan los resultados del módulo de almacenamiento, tanto para el nuevo material (RE+9\%DCi) como para la resina epoxi pura $(\mathrm{RE})$. Este parámetro es una medida de la energía que el material almacena, como consecuencia de la deformación a la que está sometido, de forma reversible. Se observa que la adición del $9 \%$ de líquido iónico reduce el valor de E', pero no de forma significativa.

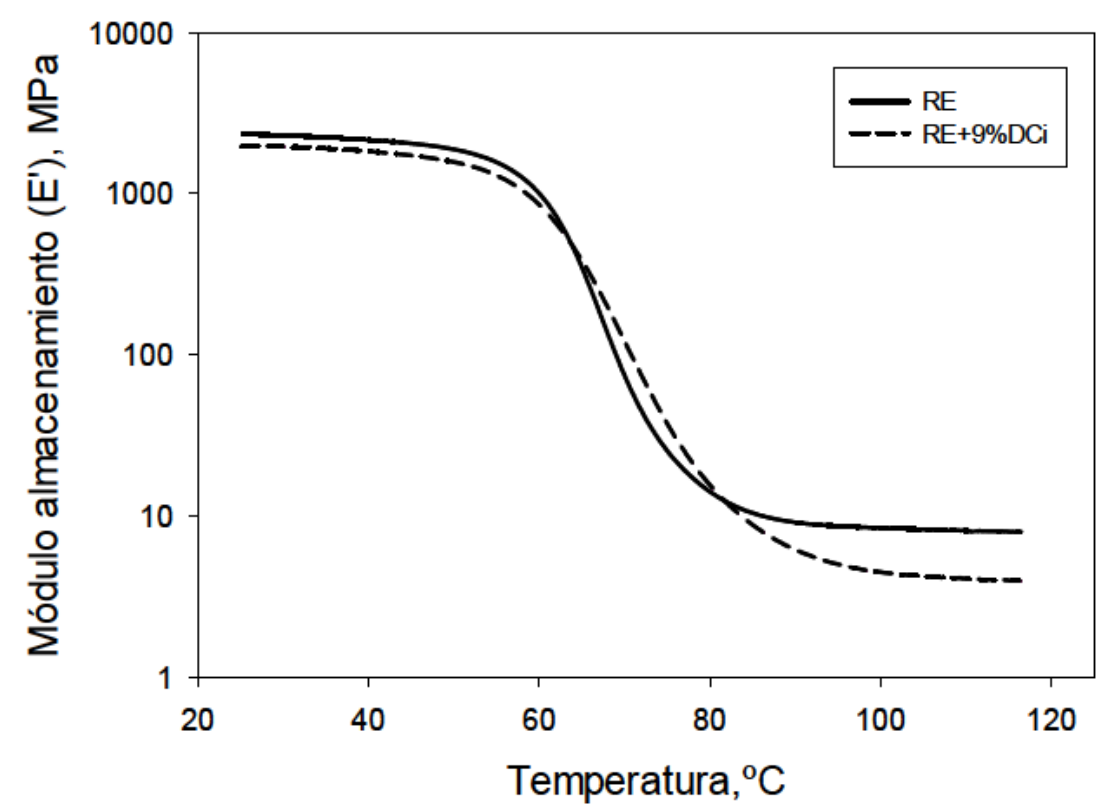

Figura 249. Evolución del módulo de almacenamiento para $R E$ y $R E+9 \% D C i$

En la Tabla 71 se muestran los valores del módulo de almacenamiento, tomado como el valor del onset de la curva. Se puede observar que los valores de temperatura son similares en ambos casos.

Tabla 71. Valores de E' para RE y RE+9\%DCi

\begin{tabular}{ccc}
\hline & \multicolumn{2}{c}{ Módulo de Almacenamiento (onset) } \\
\cline { 2 - 3 } & $\mathrm{E}^{\prime}(\mathrm{MPa})$ & Temperatura $\left({ }^{\circ} \mathrm{C}\right)$ \\
\hline RE & 940,6 & 60,5 \\
\hline RE+9\%DCi & 875,0 & 60,4 \\
\hline
\end{tabular}

En el caso del módulo de pérdida se observa una reducción superior que en el caso del módulo de almacenamiento. La adición de DCi a la resina epoxi supone la disminución de la componente viscosa del material, traduciéndose en una mayor elasticidad del nuevo nanocomposite (Figura 250). 


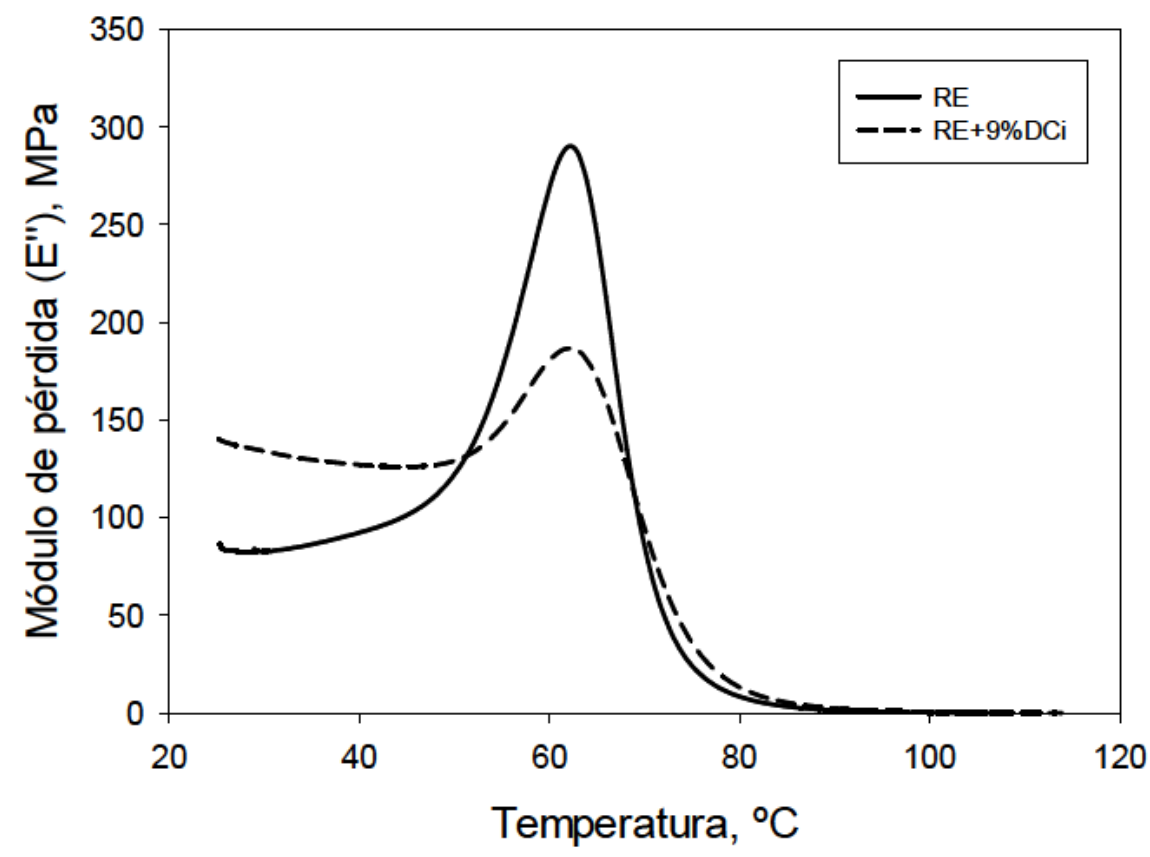

Figura 250. Evolución del módulo de pérdida para RE y RE+9\%DCi

En la Tabla 72 se presentan los valores del módulo de pérdida, calculado como el máximo de la curva E", observándose como el valor de la temperatura es similar al obtenido para la resina epoxi.

Tabla 72. Valores de E" para RE y $\mathrm{RE}+9 \% \mathrm{DCi}$

\begin{tabular}{ccc}
\hline & \multicolumn{2}{c}{ Módulo de pérdida (máximo) } \\
\cline { 2 - 3 } & E" (MPa) & Temperatura $\left({ }^{\circ} \mathrm{C}\right)$ \\
\hline RE & 289,6 & 62,46 \\
\hline RE+9\%DCi & 187,6 & 62,53 \\
\hline
\end{tabular}

Finalmente se representa el valor de la tangente de pérdida o factor de disipación para RE+9\%DCi y se compara con el valor obtenido para RE (Figura 251). Esta propiedad representa la relación entre las componentes viscosa y elástica del material. 


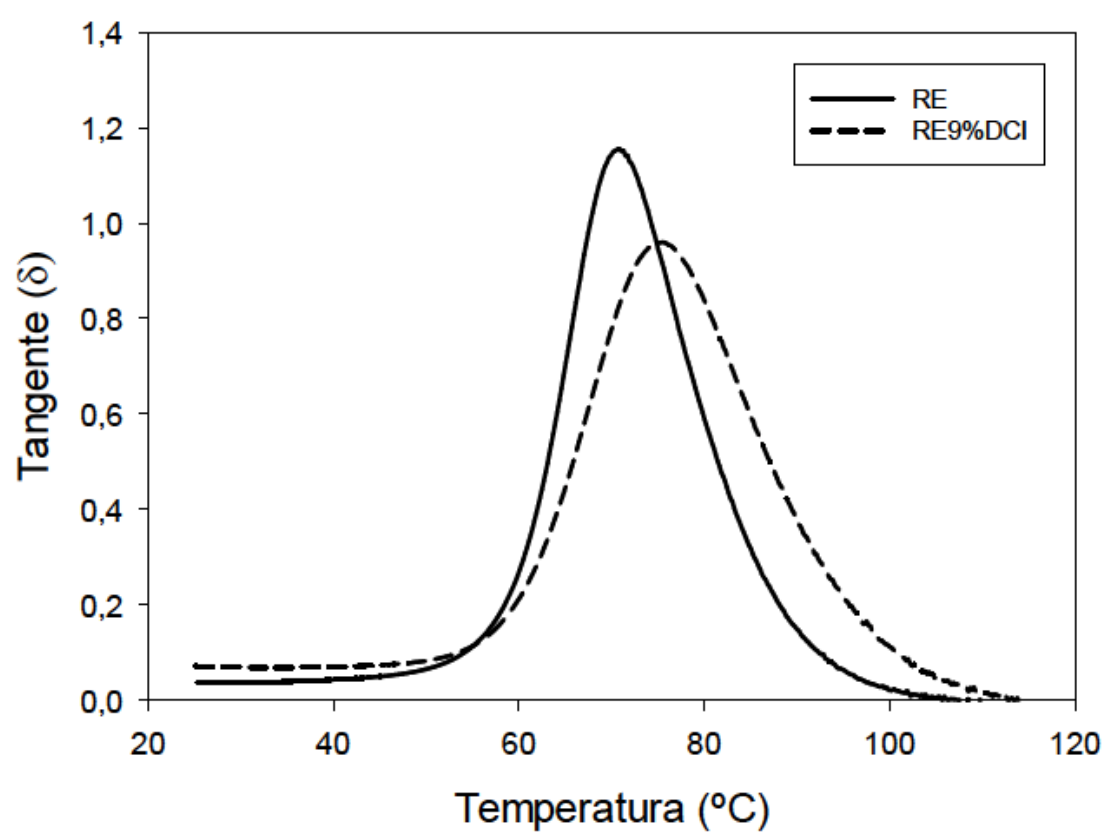

Figura 251. Evolución de la tangente de pérdida para RE y $R E+9 \% D C i$

Como se puede observar en la Tabla 73, el valor máximo de la tangente de pérdida, variable que relaciona el módulo de almacenamiento con el módulo de pérdida, disminuye para el nuevo nanocomposite. La temperatura a la que se produce el máximo de $\tan (\overline{0})$ se desplaza hacia un valor superior, es decir, pasa de $70,9^{\circ} \mathrm{C}$ a $76,1^{\circ} \mathrm{C}$ para $\mathrm{RE}+9 \% \mathrm{DCi}$.

Tabla 73. Valores de $\tan (\bar{\delta})$ para RE y RE+9\%DCi

\begin{tabular}{ccc}
\hline & \multicolumn{2}{c}{ Tangente (ס) (máximo) } \\
\cline { 2 - 3 } & Tan(ס) & Temperatura $\left({ }^{\circ} \mathrm{C}\right)$ \\
\hline RE & 1,16 & 70,9 \\
\hline RE+9\%DCi & 0,97 & 76,1 \\
\hline
\end{tabular}

Las propiedades dinámico-mecánicas que presenta el nuevo material indican un aumento de la ductilidad de éste con respecto a la resina epoxi sin aditivos. Además, la resina con un $9 \%$ de DCi presenta una curva de tan(ס) con mayor anchura que la de la resina pura, lo que podría indicar un incremento de la heterogeneidad de la distribución espacial de la densidad de entrecruzamiento.

\subsection{Conductividad térmica}

Se ha realizado el estudio de la variación de la conductividad térmica (apartado 3.2.2.5) de la resina epoxi con la adición de un $9 \%$ del líquido iónico DCi. Los 
resultados encontrados son similares, aunque el valor de la magnitud es ligeramente superior en el caso de la resina con el 9\% de DCi.

Tabla 74. Valores de conductividad térmica para RE y RE+9\%DCi

\begin{tabular}{cc}
\hline & Conductividad térmica $(\mathrm{W} / \mathrm{m} \cdot \mathrm{K})$ \\
\hline RE & $0,456( \pm 0,006)$ \\
\hline RE+9\%DCi & $0,500( \pm 0,006)$ \\
\hline
\end{tabular}

\subsection{Propiedades eléctricas}

Se ha determinado la resistividad eléctrica del nuevo nanocomposite y de la resina epoxi mediante curvas de intensidad/diferencia de potencial, siguiendo el método descrito en el apartado 3.2.2.10. Se puede observar que ambos materiales presentan una alta oposición al paso de corriente, como se esperaba, ya que, la resina epoxi se emplea como aislante eléctrico, sin embargo, al añadir el líquido iónico prótico la resistividad disminuye un 55,13\% (Tabla 75).

Tabla 75. Valores de resistividad para RE y RE+9\%DCi

\begin{tabular}{cc}
\hline & Resistividad eléctrica $(\boldsymbol{\Omega} \cdot \mathbf{m})$ \\
\hline RE & $2,34 \cdot 10^{7}\left( \pm 3,1 \cdot 10^{6}\right)$ \\
\hline RE+9\%DCi & $1,08 \cdot 10^{7}\left( \pm 2,2 \cdot 10^{6}\right)$ \\
\hline
\end{tabular}

\subsubsection{6. Ángulo de contacto}

Para la determinación de la mojabilidad del líquido iónico prótico $\mathrm{DCi}$ sobre la resina epoxi se ha determinado el ángulo de contacto siguiendo el procedimiento descrito en el apartado 3.2.2.7.

La superficie de la resina presenta una baja mojabilidad en contacto con el líquido iónico prótico debido al elevado ángulo de contacto obtenido, como se puede observar en la Tabla 76. 
Tabla 76. Ángulo de contacto del líquido iónico DCi sobre resina epoxi

Ángulo de contacto
Inicial

Ángulo inicial:

DCi sobre

RE
$91,4( \pm 3,2)^{\circ}$

Ángulo final:

$79,3( \pm 0,4)^{\circ}$
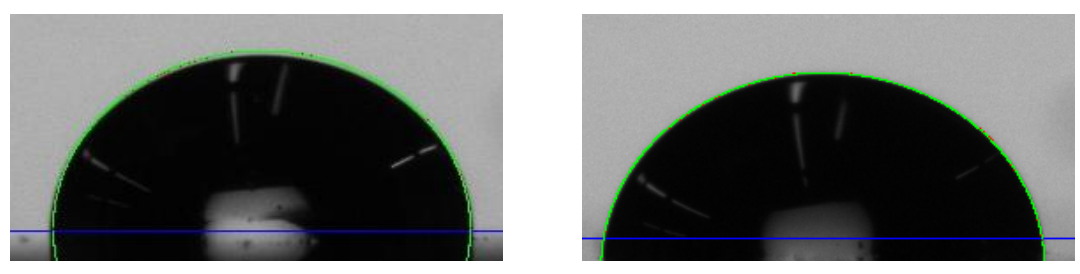

Estos resultados están en concordancia con la baja interacción superficial y miscibilidad del líquido iónico con la matriz epoxi.

Además se ha determinado el ángulo de contacto del agua tipo II con el nuevo nanocomposite RE+9\%DCi, cuyos valores se muestran en la Tabla 77 .

Tabla 77. Ángulo de contacto de agua tipo II sobre resina epoxi+9\%DCi

\begin{tabular}{ccc}
\hline & $\begin{array}{c}\text { Ángulo de } \\
\text { contacto }\end{array}$ & Ángulo inicial \\
& Ángulo inicial: \\
& $81,4( \pm 2,6)^{\circ}$ \\
Agua sobre & \\
RE & Ángulo final: \\
& $57,7( \pm 2,7)^{\circ}$ \\
& Ángulo inicial: \\
& $79,3( \pm 4,9)^{\circ}$ \\
Agua sobre & \\
RE+9\%DCi & Ángulo final: \\
& $61,7( \pm 4,6)^{\circ}$
\end{tabular}

Se puede observar cómo la presencia de un $9 \%$ de líquido iónico no modifica sustancialmente la mojabilidad del agua sobre la resina epoxi.

\subsubsection{Ensayos tribológicos punzón sobre disco}

Se ha llevado a cabo el estudio del comportamiento tribológico del nuevo material de resina epoxi con un 9\% de DCi mediante ensayos de fricción en configuración punzón sobre disco con el par acero inoxidable AISI 316Lnanocomposite, según se especificaba en el apartado 3.3.2.2.4.2. 
En la Figura 252 se presenta la evolución del coeficiente de fricción con la distancia de la resina epoxi (RE/AISI 316L), el nuevo nanocomposite de $\mathrm{RE}+9 \% \mathrm{DCi}(\mathrm{RE}+9 \% \mathrm{DCi} / \mathrm{AISI} 316 \mathrm{~L})$, ambos en contacto en seco. También se muestran los resultados en el contacto acero AISI 316L-resina epoxi, empleando el líquido iónico prótico DCi como lubricante externo (RE/DCi/AISI 316L).

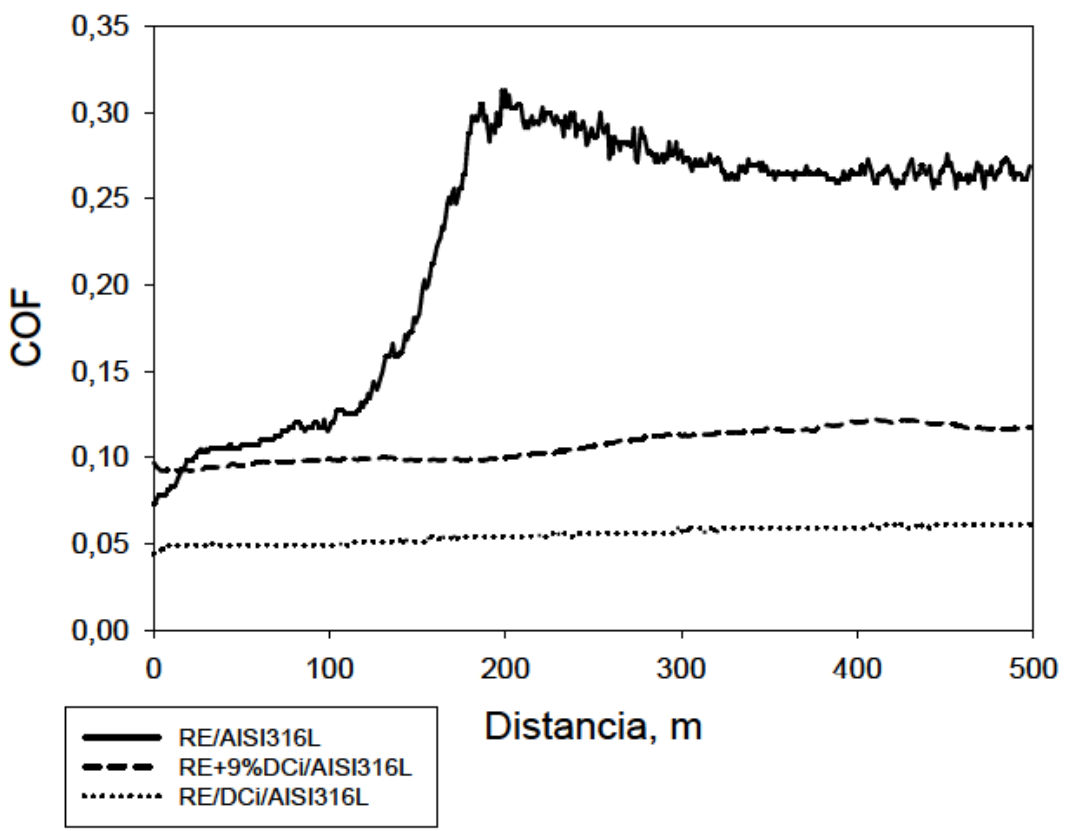

Figura 252. Evolución del coeficiente de fricción con la distancia para RE/AISI 316L y $\mathrm{RE}+9 \% \mathrm{DCl}$ sin lubricante añadido y empleando $\mathrm{DCi}$ como lubricante externo en el contacto RE/DCi/AISI 316L

Se puede observar como para los primeros 100 metros de ensayo los valores de coeficiente de fricción para $R E$ y $R E+9 \% D C i$ son muy similares, correspondiendo en ambos casos al contacto entre la capa superficial de la resina y la bola de acero. Una vez superada esta distancia, en el caso de la resina epoxi pura, el coeficiente de fricción comienza a incrementarse debido al severo daño superficial que ésta experimenta, mostrando un incremento exponencial de la fricción con la distancia hasta alcanzar un valor máximo de 0,31 después de $200 \mathrm{~m}$ de ensayo [269].

Sin embargo, para la resina epoxi con un $9 \%$ de $\mathrm{DCi}$, la evolución del coeficiente de fricción se mantiene aproximadamente constante, presentando un valor medio de 0,1 tras los 500 metros de ensayo. La presencia del líquido iónico DCi en el seno de la matriz epoxi hace que no se produzca el incremento de fricción que experimenta la resina epoxi, manteniéndose éste entre unos valores de 0,09 y 0,11 . Por tanto, si se comparan ambos materiales, se obtiene 
una reducción máxima del coeficiente de fricción a los 200 m (68\%), y una reducción del $56 \%$ al final del ensayo (500 m).

Los valores obtenidos son muy significativos, ya que la adición de un $9 \%$ de líquido iónico aprótico (tetrafluoroborato de 1-octil-3-metilimidazolio) a la resina epoxi, sólo disminuye el coeficiente de fricción en un $27 \%$ y en el caso de añadir un $0,1 \%$ de grafeno a la resina la reducción del coeficiente de fricción alcanzada es de un $53 \%$ [269].

El buen comportamiento lubricante del líquido iónico DCi se confirma cuando se emplea como lubricante externo en el contacto AISI 316L-resina epoxi pura, con un coeficiente de fricción que permanece aproximadamente constante durante todo el ensayo, con un valor medio de fricción de 0,06 (Figura 252).

Una vez finalizado el ensayo tribológico, se lleva a cabo el estudio de las superficies de desgaste. Cuando se emplea el líquido iónico DCi como lubricante externo no ha sido posible cuantificar el desgaste que se ha producido debido a la suave huella que aparece en la superficie de la resina epoxi (flecha en la Figura 253a). Como se puede observar en la micrografía SEM, la huella de desgaste presenta la misma apariencia que los defectos superficiales que posee el material, mientras que la bola de acero inoxidable AISI 316L no posee ningún daño como se muestra en la Figura 253b.

a)

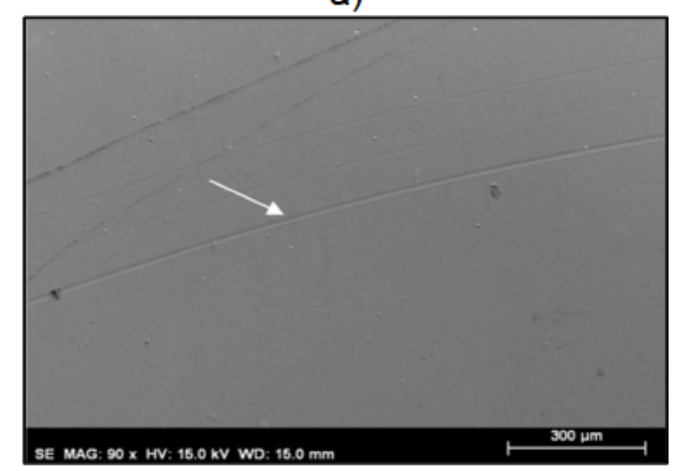

b)

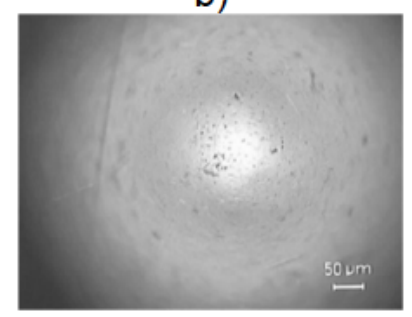

Figura 253. a) Micrografía SEM de la huella de desgaste de RE empleando DCi como lubricante externo; b) Micrografía óptica de la bola de acero AISI 316 L después del ensayo 
En el caso de la resina epoxi, se puede observar cómo este material presenta un desgaste severo (Figura 254), con una tasa de desgaste de $8,1 \cdot 10^{-4}$ $\mathrm{mm}^{3} / \mathrm{N} \cdot \mathrm{m}$, como ya había sido descrito por Sanes et al. [336].

a)

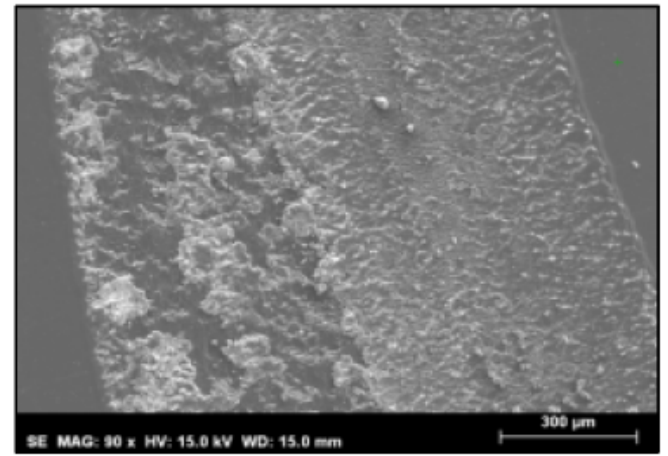

b)

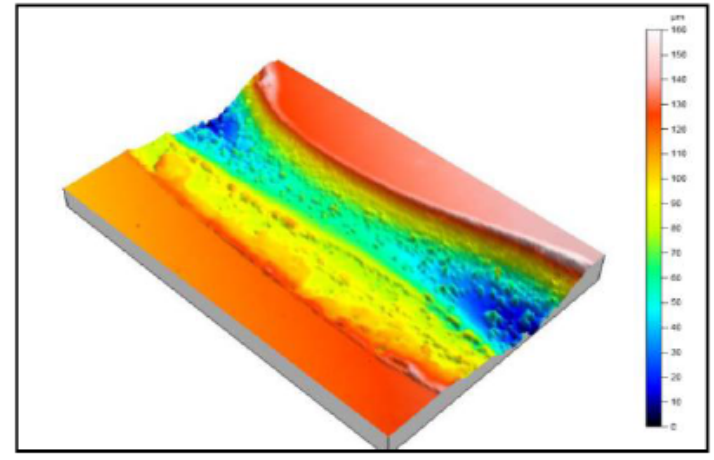

Figura 254. Huella de desgaste sobre RE tras ensayo en seco contra AISI 316L; a) Micrografía SEM; b) Imagen de perfilometría [269]

En la Figura 255 se puede observar el desgaste que ha sufrido la bola de acero inoxidable AISI 316L tras el ensayo tribológico en seco frente a la resina epoxi.

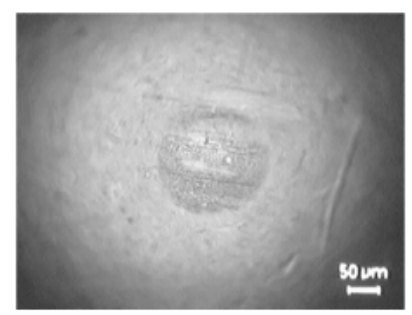

Figura 255. Micrografía óptica de la bola de acero AISI 316L después del ensayo en seco contra la resina epoxi.

Sin embargo, para el caso de la $\mathrm{RE}+9 \% \mathrm{DCi}$, las imágenes de SEM de la zona por la que ha pasado la bola de acero inoxidable durante el ensayo tribológico, muestran una región limpia y pulida como se puede ver en la zona marcada entre las líneas de la Figura 256a.

a)

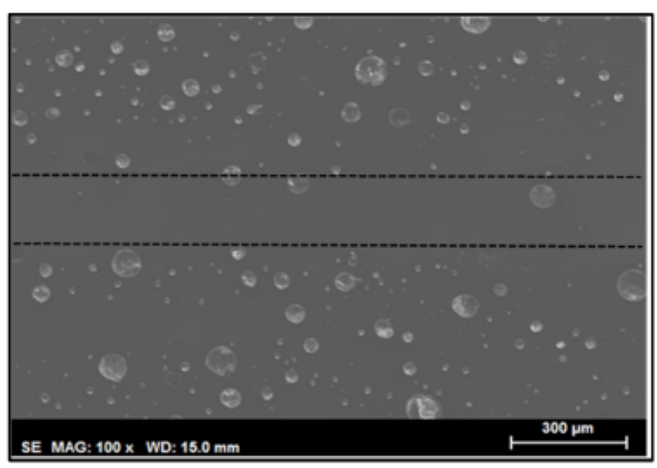

b)

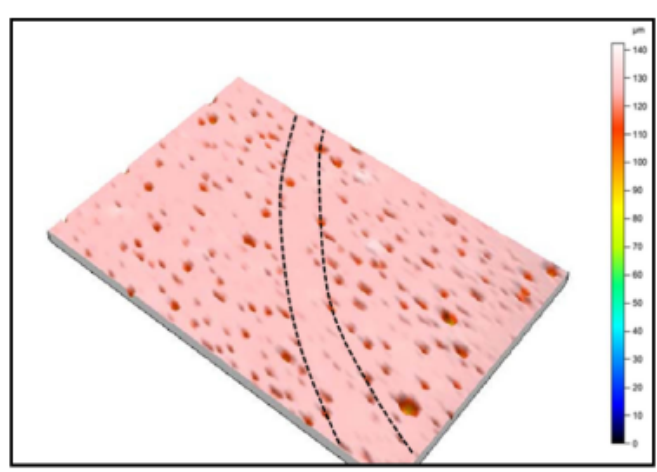

Figura 256. a) Micrografía SEM de RE+9\%DCi tras ensayo tribológico; b) Imagen de perfilometría de la zona de deslizamiento sobre RE+9\%DCi 
La única diferencia que se aprecia después del deslizamiento de la bola de acero sobre la RE+9\%DCi es la casi completa ausencia de cavidades o poros superficiales con respecto a la superficie inicial del nuevo material (Figura 257).

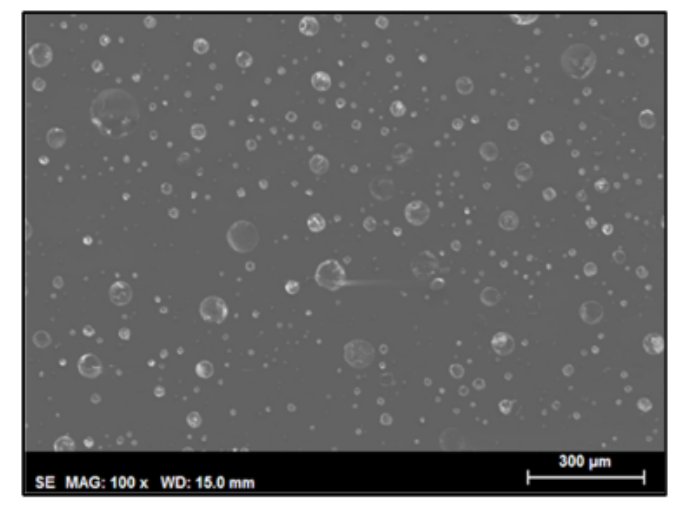

Figura 257. Micrografía SEM de RE+9\%DCi antes del ensayo tribológico

Estos resultados tribológicos podrían deberse a la liberación del líquido iónico, albergado en las microcavidades, una vez que el material está sometido a una determinada carga. Además, como puede observarse en la micrografía óptica de la bola de acero tras el ensayo tribológico (Figura 258) la superficie de acero permanece intacta en estas condiciones.

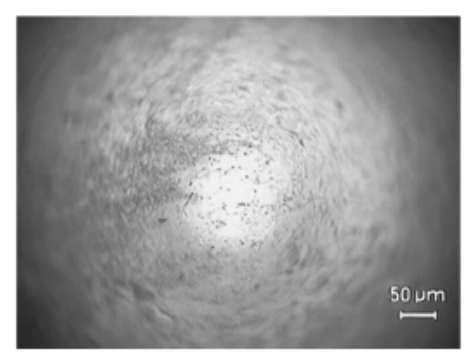

Figura 258. Micrografía óptica de la bola de acero AISI 316L tras el ensayo tribológico frente $\mathrm{RE}+9 \% \mathrm{DCi}$

También se ha confirmado el buen comportamiento de este nuevo material frente a fricción y desgaste a mayores distancias de deslizamiento. El bajo coeficiente de fricción medio obtenido (aproximadamente de 0,10 ) y la ausencia de desgaste medible también se han observado tras realizar ensayos con una distancia de deslizamiento de $1000 \mathrm{~m}$.

Es importante destacar que no se ha producido segregación de DCi procedente de la superficie de RE+9\%DCi en ausencia de carga, por tanto, el nuevo material RE+9\%DCi podría ser considerado como un material autolubricante, 
donde sólo se libera el líquido iónico cuando es necesario, es decir, cuando se aplica carga.

Estudios recientes muestran el carácter autolubricante de recubrimientos poliméricos debido a la liberación de líquidos iónicos apróticos que contienen flúor que se encuentran microencapsulados en el interior de la matriz epoxi [337], [338]; o sin microencapsulación en el caso de emplear líquidos iónicos derivados del imidazolio de cadena larga [276]. Sin embargo, es la primera vez que un líquido iónico prótico libre de haluros y no encapsulado se dispersa en la matriz epoxi, mostrando no solo un comportamiento autolubricante, sino además resistente al desgaste.

\subsubsection{Conclusiones}

Se ha obtenido un nuevo material autolubricante a partir de una matriz de resina epoxi modificada por dispersión de un líquido iónico prótico derivado del anión citrato. El líquido iónico actúa como agente de curado y tiene un efecto plastificante, incrementando la ductilidad del material. La reducción de los coeficientes de fricción se atribuye a la acción lubricante del líquido iónico bajo carga. Tras el deslizamiento, la zona de contacto presenta un acabado más pulido debido a la liberación del fluido y al cierre de las cavidades en las que se alojaba.

\subsubsection{Caracterización y estudio tribológico de recubrimientos y films de resina epoxi con nanofases y nanofluidos.}

\subsubsection{Recubrimientos de resina epoxi con nanofases y nanofluidos sobre resina epoxi}

Debido a la creciente necesidad de mejorar las propiedades mecánicas, eléctricas y térmicas de las resinas epoxi, se desarrollan recubrimientos de nuevos nanocomposites de matriz epoxi, formados a partir de grafeno y líquido iónico y se compara con recubrimientos de resina epoxi sin aditivos. Para la obtención de estos recubrimientos se emplea la técnica del spin coating, que ha demostrado su efectividad en la obtención de recubrimientos a gran escala, uniformes y reproducibles [339].

Con la creación de recubrimientos se pretende modificar las propiedades de la superficie conservando las características del sustrato, disminuyendo así la cantidad de material necesaria. 


\subsection{Medida de la rugosidad y el espesor de los recubrimientos sobre resina epoxi}

Una vez obtenidos los recubrimientos mediante spin coating, según el procedimiento descrito en el apartado 3.3.2.1.2, se ha medido la rugosidad y el espesor de dichos recubrimientos.

En el caso de la rugosidad, los valores obtenidos se presentan en la Tabla 78.

Tabla 78. Rugosidad de los recubrimientos de RE, RE+9\%[OMIM]BF $4, R E+0,05 \% G$ y

$\mathrm{RE}+9 \%\left([\mathrm{OMIM}] \mathrm{BF}_{4}+0,1 \% \mathrm{G}\right)$

\begin{tabular}{|c|c|}
\hline $\begin{array}{l}\text { Recubrimiento } \\
\text { de la probeta }\end{array}$ & $\mathbf{R}_{\mathrm{a}}(\boldsymbol{\mu m})$ \\
\hline RE & $0,18( \pm 0,02)$ \\
\hline $\mathrm{RE}+9 \%[\mathrm{OMIM}] \mathrm{BF}_{4}$ & $0,12( \pm 0,01)$ \\
\hline RE+0,05\%G & $1,89( \pm 0,30)$ \\
\hline $\mathrm{RE}+9 \%\left([\mathrm{OMIM}] \mathrm{BF}_{4}+0,1 \% \mathrm{G}\right)$ & $0,12( \pm 0,01)$ \\
\hline
\end{tabular}

La rugosidad presentada por el recubrimiento de RE $+0,05 \% \mathrm{G}$ es un $90 \%$ superior a la que posee la resina epoxi sin aditivos, debido a la baja dispersión del grafeno en la matriz epoxi, sobre todo cuando se emplean pequeñas cantidades, como en este caso. Los recubrimientos que poseen líquido iónico $[\mathrm{OMIM}] \mathrm{BF}{ }_{4}$ presentan los menores valores de rugosidad.

4.2.2.1.1.1. Espesor del recubrimiento de resina epoxi sin aditivos (RE) sobre resina epoxi

En el caso del recubrimiento de resina epoxi sobre sustrato de resina epoxi, se han tomado imágenes mediante microscopía óptica de la sección transversal de la pieza recubierta. A partir de las micrografías obtenidas (Figura 259) se ha medido el espesor del recubrimiento, obteniendo un valor de 115,2 $\pm 3,0 \mu \mathrm{m}$. 


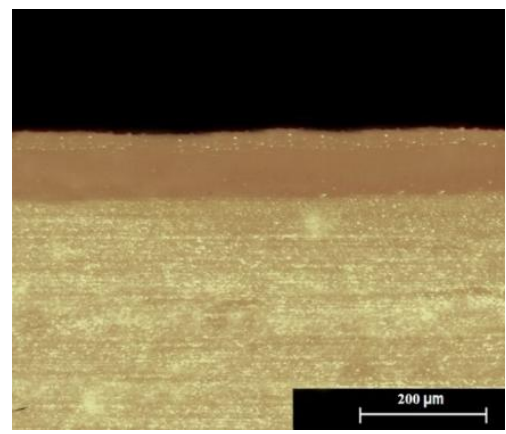

Figura 259. Sección transversal del recubrimiento de RE sobre resina epoxi

4.2.2.1.1.2. Espesor de recubrimiento de resina epoxi y grafeno $(R E+0,05 \% G)$ sobre resina epoxi

Para obtener las medidas de espesor del recubrimiento del nanocomposite de resina epoxi con un $0,05 \%$ de grafeno sobre resina epoxi se ha empleado el procedimiento expuesto anteriormente.

En la micrografía que se observa en la Figura 260 , se puede apreciar la existencia de defectos y heterogeneidades en la capa de recubrimiento. Se ha medido un espesor de $82,4 \pm 7,8 \mu \mathrm{m}$ obteniéndose una cierta variabilidad en los resultados debido a la baja dispersión del grafeno.

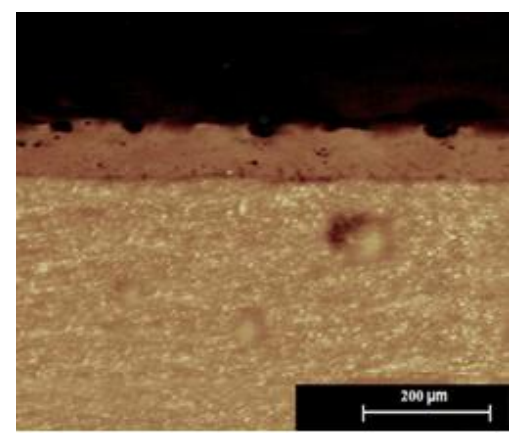

Figura 260. Sección transversal del recubrimiento de RE+0,05\%G sobre resina epoxi

4.2.2.1.1.3. Espesor de recubrimiento de resina epoxi y líquido iónico ( $R E+9 \%$ $[\mathrm{OMIM}] \mathrm{BF}_{4}$ ) sobre resina epoxi

Cuando el nanocomposite posee líquido iónico, como en este caso, es posible determinar el espesor del recubrimiento y la dispersión del líquido iónico en éste mediante microscopía electrónica de barrido (SEM), ya que [OMIM]BF 4 posee iones flúor en su estructura. 
Por ello, se han realizado micrografías para medir el espesor del recubrimiento y mapas elementales mediante EDX, previa metalización con platino (Figura 261). De esta manera, se ha medido el espesor del recubrimiento, resultando ser de 73,6 $\pm 1,8 \mu \mathrm{m}$ y se ha podido comprobar la distribución del líquido iónico dentro de la capa e identificar más claramente los límites de la misma.

a)

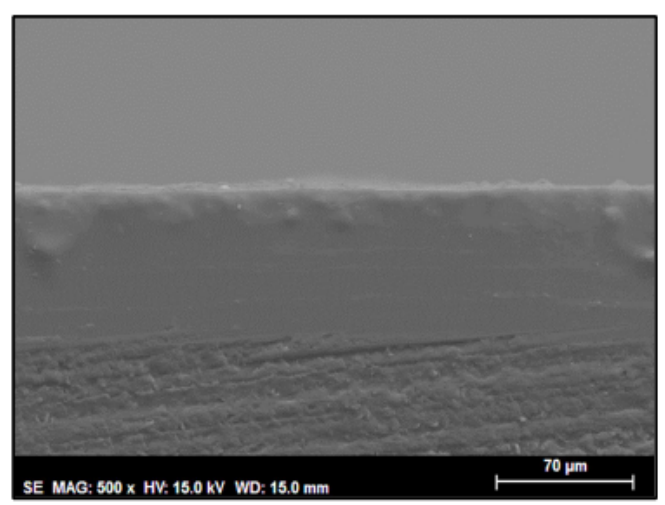

b)

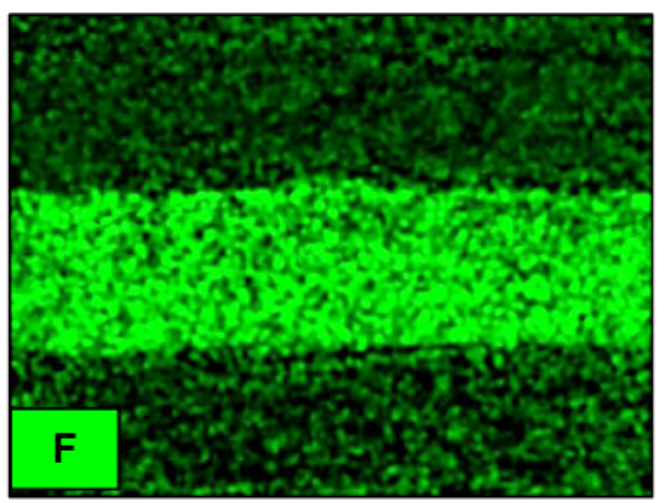

c)

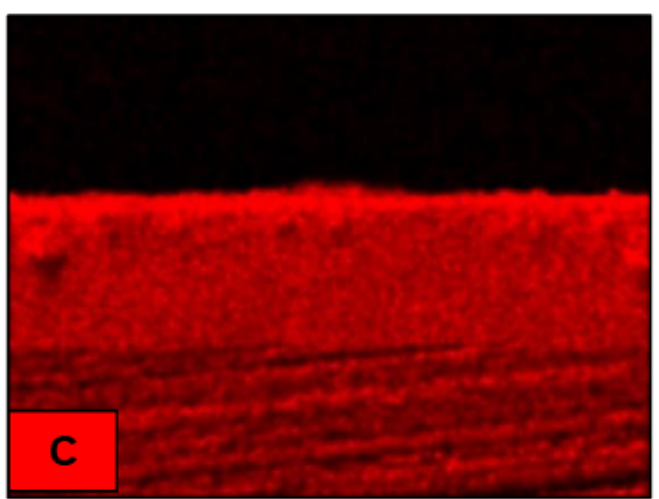

Figura 261. a) Micrografía SEM de la sección transversal del recubrimiento de $\mathrm{RE}+9 \%[\mathrm{OMIM}] \mathrm{BF}_{4}$; b) Mapa elemental de flúor; c) Mapa elemental de carbono

Además, se ha realizado un análisis elemental en línea de flúor para poder obtener una visión más precisa de la distribución de este elemento a lo largo de la sección transversal de la probeta recubierta como se muestra en la Figura 262. 

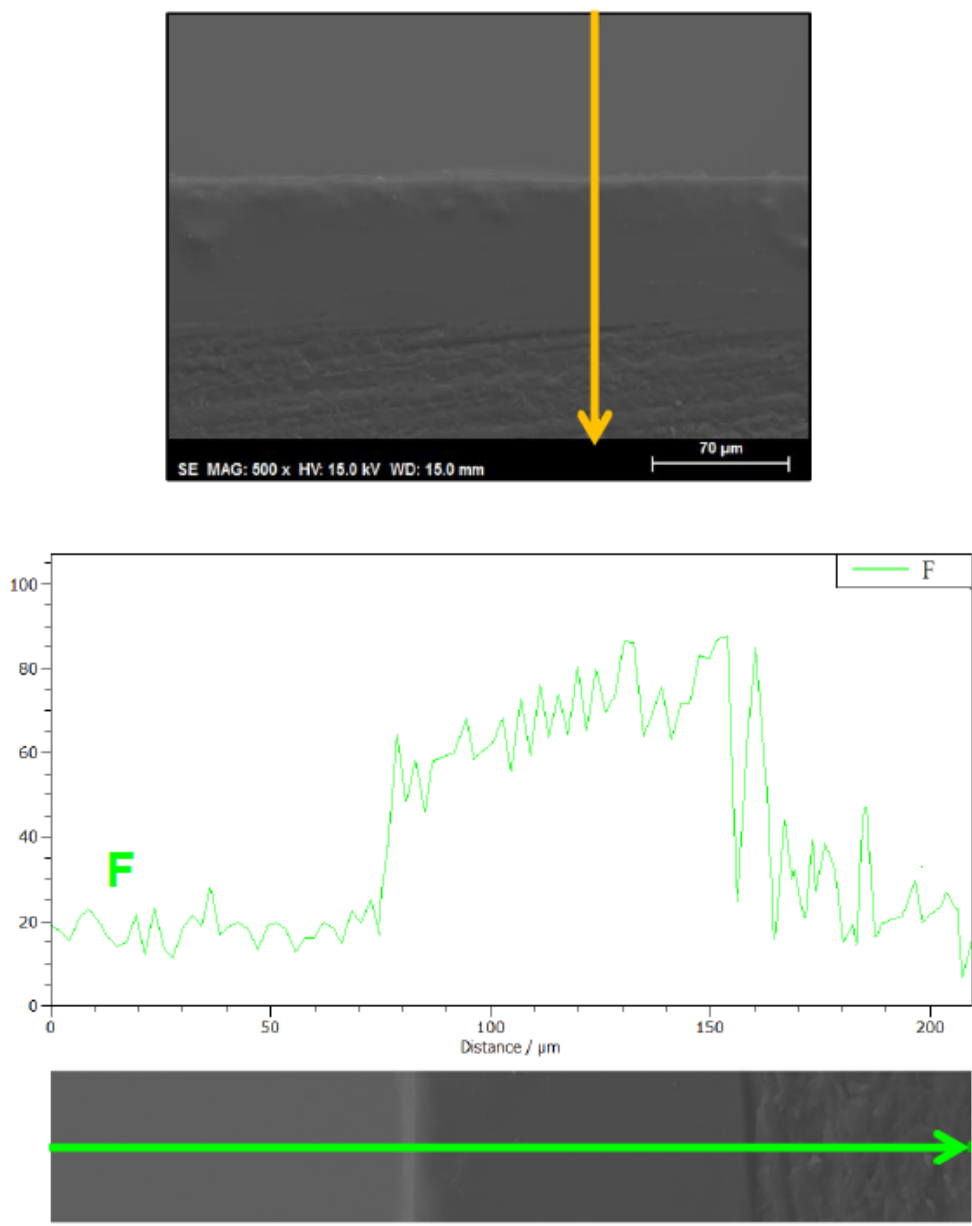

Figura 262. Análisis en línea de flúor en el recubrimiento de $\mathrm{RE}+9 \%[\mathrm{OMIM}] \mathrm{BF}{ }_{4}$ sobre $\mathrm{RE}$

El flúor se concentra, como era de esperar, en la zona del recubrimiento. De esta manera los cambios de concentración de flúor coinciden con los cambios sustrato-recubrimiento.

4.2.2.1.1.4. Espesor de recubrimiento de resina epoxi, grafeno y líquido iónico $\left(\mathrm{RE}+9 \%\left([\mathrm{OMIM}] \mathrm{BF}_{4}+0,1 \% \mathrm{G}\right)\right)$ sobre resina epoxi

En este tipo de recubrimiento se intenta determinar la influencia de la presencia de una pequeña cantidad grafeno en el nanocomposite que ya poseía nanofluido iónico.

Se ha realizado un estudio mediante SEM, obteniendo micrografías donde ha sido posible medir el espesor del recubrimiento, resultando de $98,8 \pm 3,1 \mu \mathrm{m}$. Además, se ha llevado a cabo un análisis composicional de flúor y carbono mediante EDX para conocer la distribución del flúor contenido en el líquido iónico en la muestra (Figura 263). 
a)

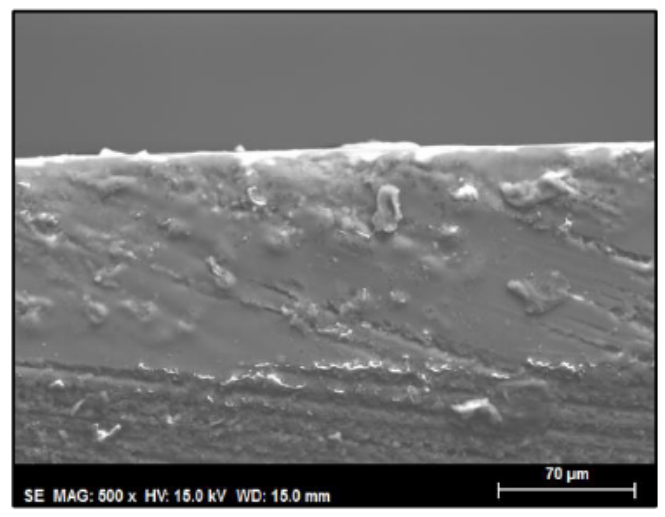

b)

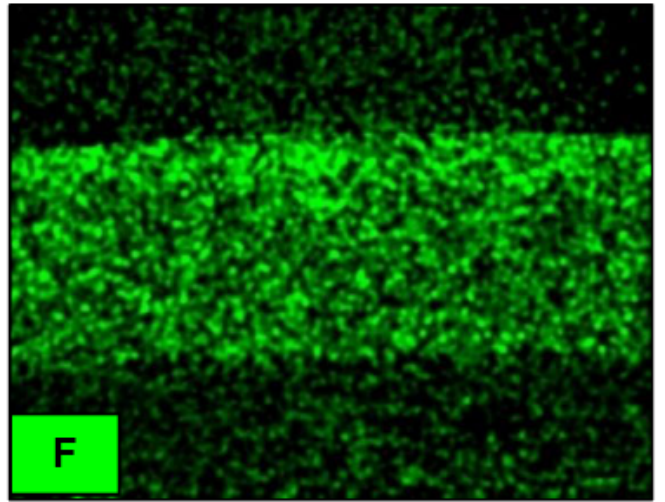

c)

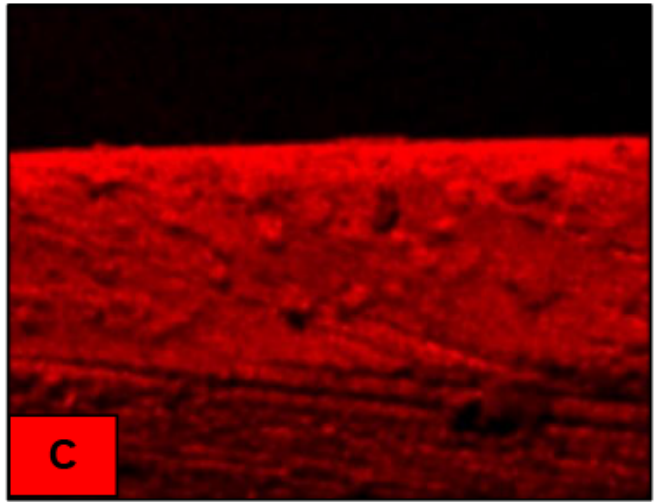

C

Figura 263. a) Micrografía SEM de la sección transversal del recubrimiento de

$\mathrm{RE}+9 \%\left([\mathrm{OMIM}] \mathrm{BF}_{4}+0,1 \% \mathrm{G}\right)$; b) Mapa elemental de flúor; c) Mapa elemental de carbono

En la Figura 263a se observa cómo la capa de recubrimiento tiene un acabado superficial diferente del resto de la sección transversal de la probeta. En este caso, y a diferencia de la micrografía obtenida para el recubrimiento que solo posee líquido iónico (Figura 261a), se aprecia mayor cantidad de irregularidades, quizás debido a la presencia de grafeno en este recubrimiento.

Puede observarse en el mapa elemental de flúor que la máxima concentración de este elemento se encuentra en la zona del recubrimiento, mientras que el carbono está presente en toda la muestra.

Se ha realizado, además, un análisis en línea para determinar la distribución del flúor a lo largo de la sección transversal de la probeta y se ha confirmado que la zona del recubrimiento es la que posee una mayor concentración de flúor (Figura 264). 

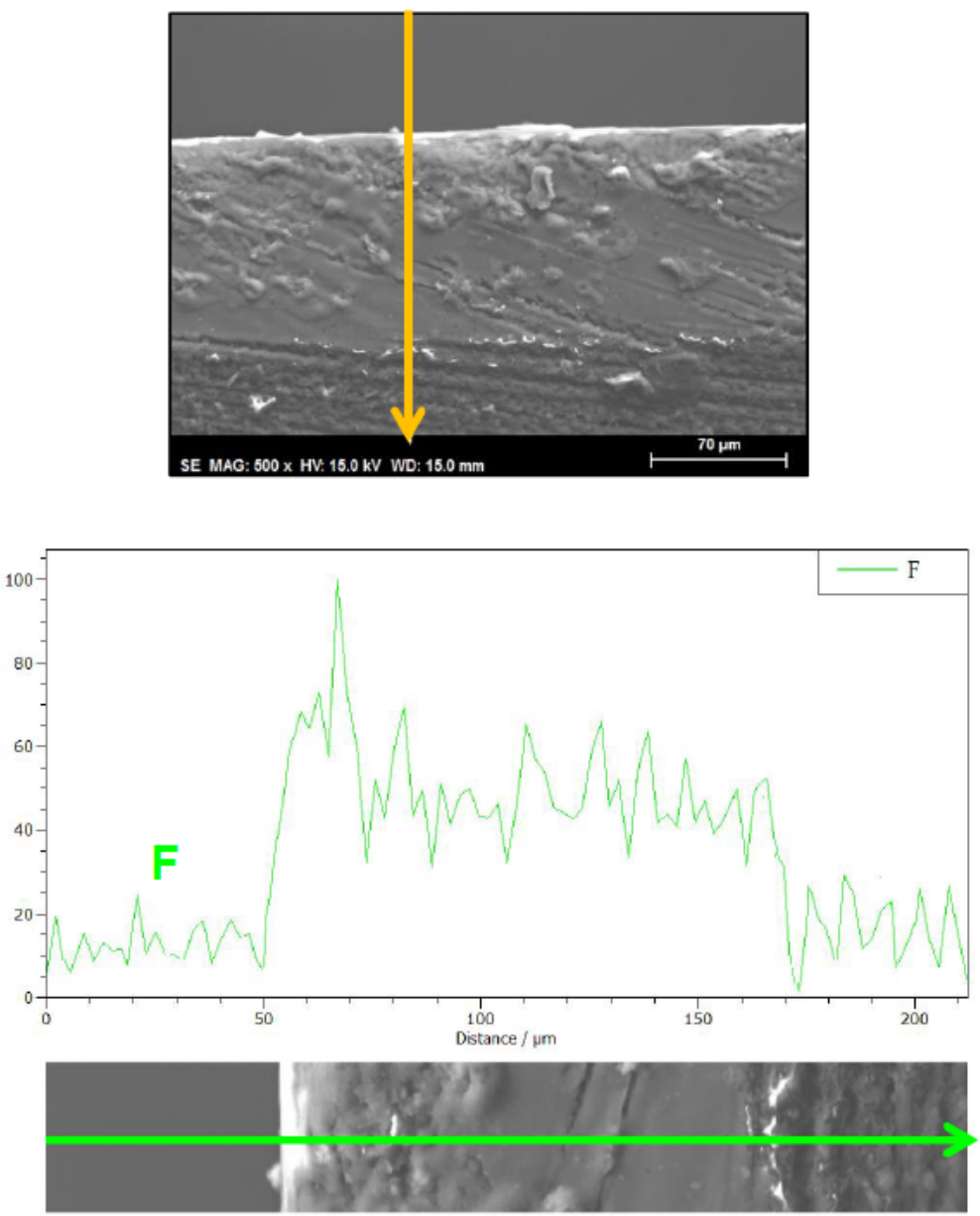

Figura 264. Análisis en línea de flúor en el recubrimiento de $\mathrm{RE}+9 \%\left([\mathrm{OMIM}] \mathrm{BF}{ }_{4}+0,1 \% \mathrm{G}\right)$ sobre RE

En la Tabla 79 se recogen los valores de espesor obtenidos mediante microscopía óptica y electrónica de barrido para los recubrimientos de RE, $\mathrm{RE}+0,05 \% \mathrm{G}, \mathrm{RE}+9 \%[\mathrm{OMIM}] \mathrm{BF}_{4}$ y $\mathrm{RE}+9 \%\left([\mathrm{OMIM}] \mathrm{BF}_{4}+0,1 \% \mathrm{G}\right)$ sobre resina epoxi.

Tabla 79. Medidas de espesor obtenidas para los recubrimientos sobre resina epoxi

\begin{tabular}{cc}
\hline Recubrimiento & Espesor medio $(\boldsymbol{\mu m})$ \\
\hline RE & $115,2( \pm 3,0)$ \\
\hline RE+9\%[OMIM]BF 4 & $73,6( \pm 1,8)$ \\
\hline RE+0,05\%G & $82,4( \pm 7,8)$ \\
\hline RE+9\%([OMIM]BF $\left.{ }_{4}+\mathbf{0 , 1} \% \mathbf{G}\right)$ & $98,8( \pm 3,1)$ \\
\hline
\end{tabular}

Como se puede observar, el mayor espesor lo presenta el recubrimiento de resina epoxi, seguido del que posee grafeno y líquido iónico, mientras que el que posee menor espesor es el que únicamente posee un $9 \%$ de [OMIM]BF quizás debido a la mayor fluidez del material al no poseer nanofases sólidas 
dispersas. Aunque todos los nanocomposites que actúan como recubrimientos de la resina epoxi se han preparado en las mismas condiciones, éstos presentan diferentes espesores debido a que los valores de densidad, viscosidad y velocidad de curado se ven alterados por la presencia de nanofases dispersas [234].

\subsubsection{2. Ángulo de contacto}

Se ha medido el ángulo de contacto de agua tipo II sobre los diferentes recubrimientos sobre matriz epoxi. Siguiendo el procedimiento descrito en el apartado (3.2.2.7), se miden los ángulos inicial y tras cinco minutos (ángulo final). Los resultados obtenidos se muestran en la Tabla 80.

Tabla 80. Ángulos de contacto iniciales y tras 5 minutos de agua tipo II en distintos

recubrimientos sobre RE

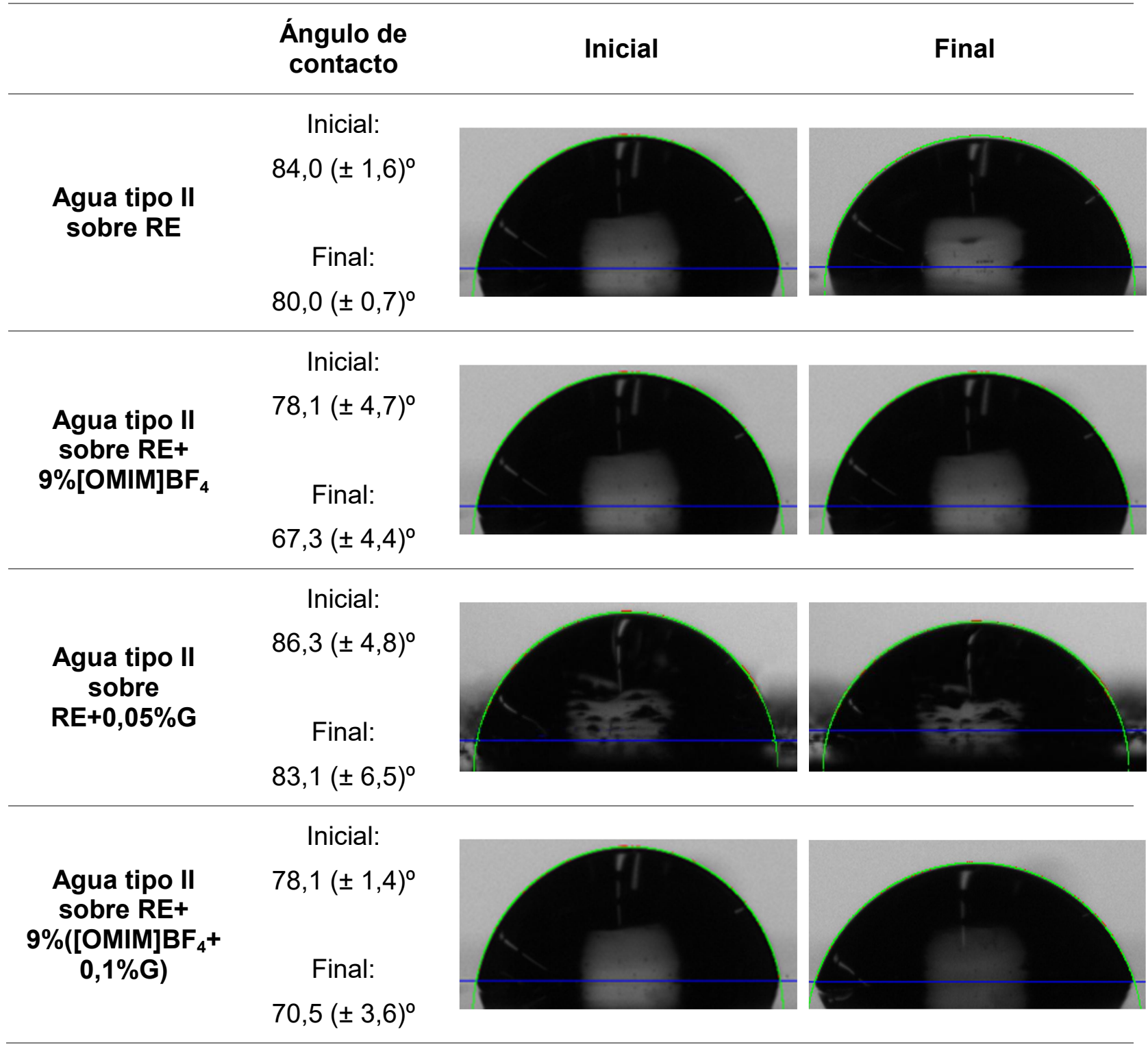


Se puede observar cómo la adición de $9 \%$ de líquido iónico supone la disminución del ángulo de contacto, tanto inicial como final con respecto al presentado por la resina epoxi sin aditivos. Este comportamiento también se observa en el recubrimiento que además posee grafeno, por tanto, se puede afirmar que el líquido iónico [OMIM]BF ${ }_{4}$ contribuye a aumentar la mojabilidad del agua sobre el recubrimiento.

El recubrimiento que posee un mayor ángulo de contacto es el recubrimiento de $R E+0,05 \% G$, quizás debido a la mayor rugosidad.

\subsection{Estudios de rayado}

Se ha realizado un estudio de rayado para estudiar la resistencia a la abrasión de los distintos recubrimientos sobre matriz epoxi. Para ello, se han llevado a cabo ensayos de multirrayado según el procedimiento descrito en el punto 4.1.2.1.2.

El ensayo de multirrayado permite comprobar la respuesta que ofrece la superficie recubierta al aplicar una fuerza de rayado constante en múltiples pasadas. De esta manera, se comprueba la resistencia a la abrasión que presentan los diferentes recubrimientos sobre resina epoxi.

En la Figura 265 se muestra la evolución de la profundidad de penetración en función del número de rayados, aplicando $5 \mathrm{~N}$ de carga. Puede observarse que en todos los casos el valor de penetración se estabiliza asintóticamente para un determinado número de rayados.

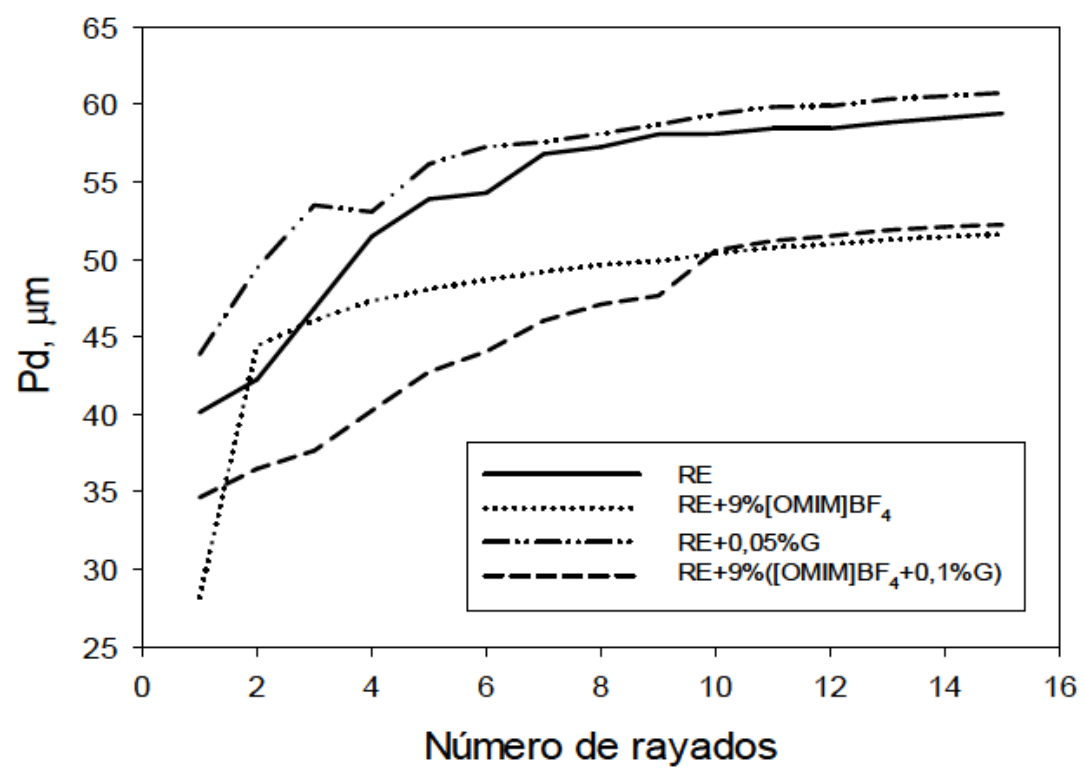

Figura 265. Evolución de la profundidad de penetración en ensayos de multirrayado para los recubrimientos de $\mathrm{RE}, \mathrm{RE}+9 \%[\mathrm{OMIM}] \mathrm{BF}_{4}, \mathrm{RE}+0,05 \% \mathrm{G}$ y $\mathrm{RE}+9 \%\left([\mathrm{OMIM}] \mathrm{BF}{ }_{4}+0,1 \% \mathrm{G}\right)$ 
El recubrimiento de resina epoxi sin aditivos presenta mayores valores de profundidad de penetración, estabilizándose en torno a la séptima pasada consecutiva del indentador. Este comportamiento es similar al presentado por $\mathrm{RE}+0,05 \% \mathrm{G}$, aunque presenta valores de profundidad ligeramente superiores. En el caso de añadir el líquido iónico [OMIM]BF 4 , los valores de profundidad de penetración se estabilizan ya en la segunda pasada, quizás debido a la reducción de la fragilidad que experimenta el material con la adición del líquido iónico. Sin embargo, al añadir una pequeña cantidad de grafeno al nanocomposite se retarda considerablemente este efecto.

Con respecto a la evolución de la profundidad residual con el número de pasadas, se muestra en la Figura 266 cómo los valores obtenidos siguen la misma tendencia presentada para la profundidad de penetración.

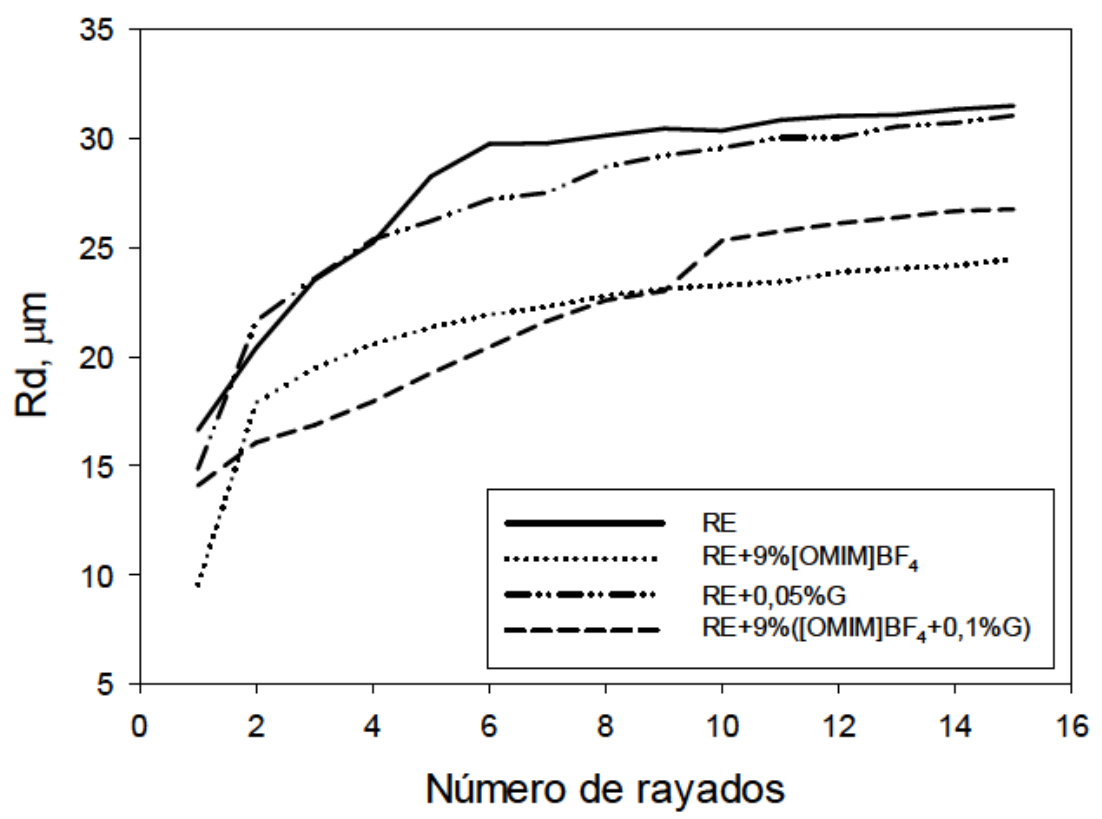

Figura 266. Evolución de la profundidad residual en ensayos de multirrayado para los recubrimientos de RE, RE+9\%[OMIM]BF $4, \mathrm{RE}+0,05 \% \mathrm{G}$ y $\mathrm{RE}+9 \%\left([\mathrm{OMIM}] \mathrm{BF}_{4}+0,1 \% \mathrm{G}\right)$

En este caso, el recubrimiento de resina epoxi sin aditivos presenta unos valores de profundidad residual superiores al resto de recubrimientos, mientras que, los que poseen líquido iónico en su composición son los que presentan menor profundidad residual.

A partir de los valores de profundidad de penetración y profundidad residual se obtiene el porcentaje de recuperación viscoelástica de los diferentes materiales (Figura 267). 


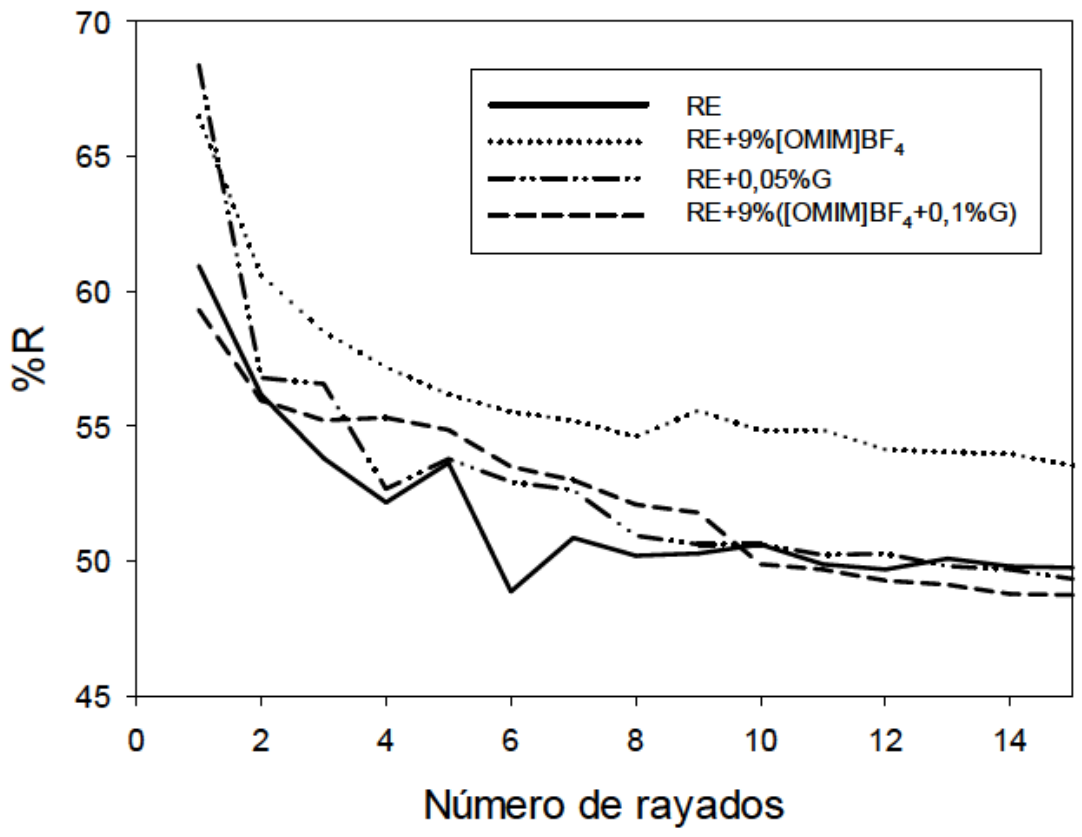

Figura 267. Evolución del porcentaje de recuperación viscoelástica en ensayos de multirrayado para los recubrimientos de RE, RE+9\%[OMIM]BF $4, \mathrm{RE}+0,05 \% \mathrm{G}$ y $\mathrm{RE}+9 \%\left([\mathrm{OMIM}] \mathrm{BF}_{4}+0,1 \% \mathrm{G}\right)$ sobre resina epoxi

Se puede observar cómo la adición de grafeno no contribuye significativamente a la mejora del porcentaje de recuperación de la resina epoxi. En cambio, añadir un $9 \%$ de $\left[\mathrm{OMIM}_{\mathrm{BF}}\right.$ al nanocomposite que actúa como recubrimiento tiene un efecto recuperador, como ya ha sido descrito con anterioridad [284]. Si se añade una pequeña cantidad de grafeno al líquido iónico se anula este efecto recuperador del líquido iónico.

En la Figura 268 se puede apreciar la evolución del coeficiente de fricción en los distintos recubrimientos según el número de rayados.

Según los resultados de coeficiente de fricción obtenidos se puede observar cómo el recubrimiento con un $0,05 \%$ de grafeno es el que presenta un valor de coeficiente fricción más alto. Esto es debido posiblemente, a la elevada rugosidad de este recubrimiento. Sin embargo, el resto de materiales presentan un coeficiente cercano a 0,2 al final del ensayo. En el caso del recubrimiento con $\mathrm{RE}+9 \%\left[\mathrm{OMIM}_{\mathrm{BF}} \mathrm{F}_{4}\right.$ se observa que el coeficiente de fricción se reduce considerablemente ya en el segundo rayado. 


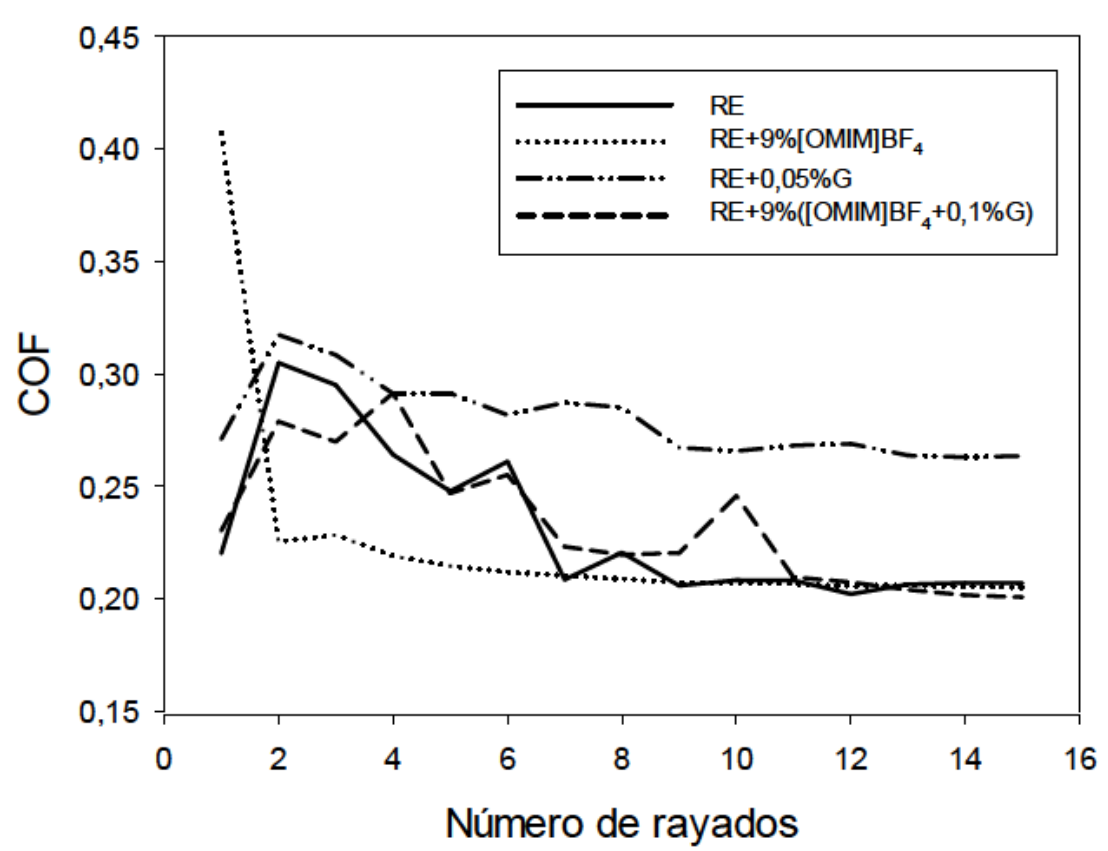

Figura 268. Evolución del coeficiente de fricción en ensayos de multirrayado para los recubrimientos de RE, RE+9\%[OMIM]BF $4, \mathrm{RE}+0,05 \% \mathrm{G}$ y $\mathrm{RE}+9 \%\left([\mathrm{OMIM}] \mathrm{BF}_{4}+0,1 \% \mathrm{G}\right)$

Se muestran en la Tabla 81 los valores obtenidos al final del ensayo, es decir, para el rayado número 15.

Tabla 81. Valores obtenidos para el rayado número 15 para los recubrimientos de RE, $\mathrm{RE}+9 \%[\mathrm{OMIM}] \mathrm{BF}, \mathrm{RE}+0,05 \% \mathrm{G}$ y $\mathrm{RE}+9 \%\left([\mathrm{OMIM}] \mathrm{BF}_{4}+0,1 \% \mathrm{G}\right)$ sobre resina epoxi

\begin{tabular}{ccccc}
\hline $\begin{array}{c}\text { Recubrimientos } \\
\text { sobre } \\
\text { resina epoxi }\end{array}$ & $\begin{array}{c}\text { Profundidad de } \\
\text { penetración, } \\
\text { Pd }(\boldsymbol{\mu m})\end{array}$ & $\begin{array}{c}\text { Profundidad } \\
\text { residual, } \\
\mathbf{R d}(\boldsymbol{\mu m})\end{array}$ & $\begin{array}{c}\text { \%Recuperación } \\
\text { viscoelástica, } \\
\% \mathbf{R}\end{array}$ & $\begin{array}{c}\text { Coeficiente } \\
\text { de fricción, } \\
\text { COF }\end{array}$ \\
\hline $\mathbf{R E}$ & $59,43( \pm 3,30)$ & $31,48( \pm 2,70)$ & $49,75( \pm 5,00)$ & $0,21( \pm 0,01)$ \\
\hline $\mathbf{R E + 9 \% [ O M I M ] B F _ { 4 }}$ & $48,63( \pm 2,17)$ & $23,79( \pm 6,49)$ & $51,39( \pm 10,99)$ & $0,20( \pm 0,01)$ \\
\hline $\mathbf{R E + 0 , 0 5 \% G}$ & $60,75( \pm 7,20)$ & $31,03( \pm 6,60)$ & $49,33( \pm 5,30)$ & $0,26( \pm 0,03)$ \\
\hline $\mathbf{R E + 9 \% ( [ O M I M ] B F _ { 4 } +}$ & $52,23( \pm 1,20)$ & $26,75( \pm 1,20)$ & $48,74( \pm 4,30)$ & $0,20( \pm 0,02)$ \\
\hline $\mathbf{0 , 1 \% G )}$ & & & &
\end{tabular}

Según los resultados obtenidos, se puede ver que el recubrimiento $\mathrm{RE}+9 \%\left[\mathrm{OMIM}_{\mathrm{B} F} \mathrm{~F}_{4}\right.$ es el que presenta mejor comportamiento frente a la abrasión, un menor coeficiente de fricción y mayor porcentaje de recuperación viscoelástica.

Es el recubrimiento de $\mathrm{RE}+0,05 \% \mathrm{G}$ el que presenta el máximo valor de profundidad de penetración, además del mayor valor de coeficiente de fricción. 
Para $\mathrm{RE}+9 \%\left([\mathrm{OMIM}] \mathrm{BF}_{4}+0,1 \% \mathrm{G}\right)$ el comportamiento es intermedio entre los de $\mathrm{RE}+9 \%[\mathrm{OMIM}] \mathrm{BF}_{4}$ y $\mathrm{RE}+0,05 \% \mathrm{G}$.

En la Figura 269 se muestra una comparativa de las huellas obtenidas tras los ensayos de multirrayado a $5 \mathrm{~N}$. Las imágenes han sido obtenidas mediante microscopía óptica.

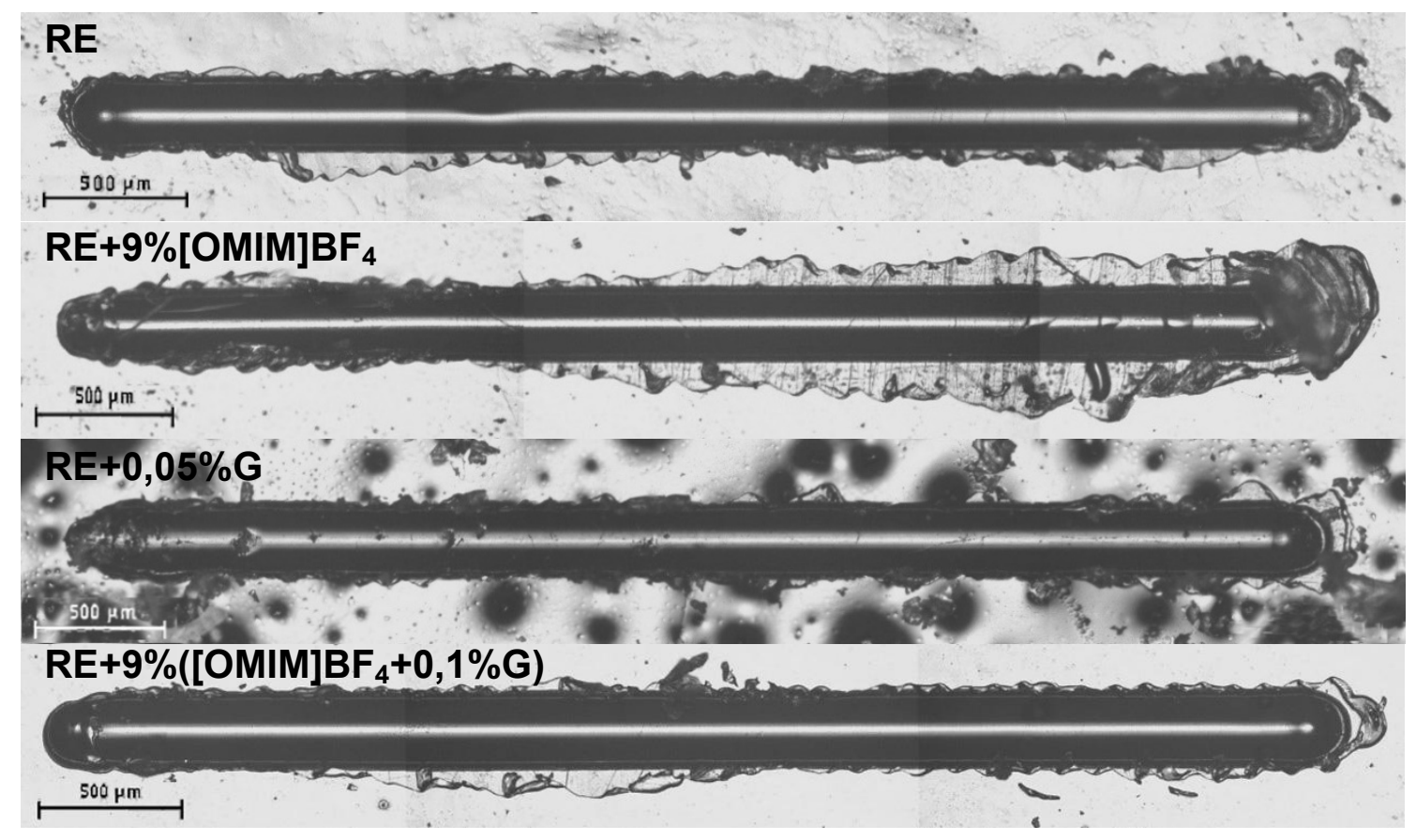

Figura 269. Micrografías ópticas de las huellas tras multirrayado a $5 \mathrm{~N}$ para recubrimientos de RE, RE+9\%[OMIM]BF 4 , RE+0,05\%G y RE+9\%([OMIM]BF $4+0,1 \% G)$

En todos los casos se observa acumulación de material en la parte final de la huella debido al desplazamiento del indentador.

\subsection{Daño superficial}

A partir de las huellas generadas en el ensayo de multirrayado a $5 \mathrm{~N}$ se ha calculado el daño superficial experimentado por los recubrimientos mediante perfilometría óptica.

Como se presenta en las Figuras 270, 271, 272 y 273, el valor del daño superficial tras el ensayo de abrasión se calcula como la suma de las áreas exterior $\left(A_{2}+A_{3}\right.$, en verde) e interior $\left(A_{1}\right.$, en rojo) de la sección transversal de las huellas. 

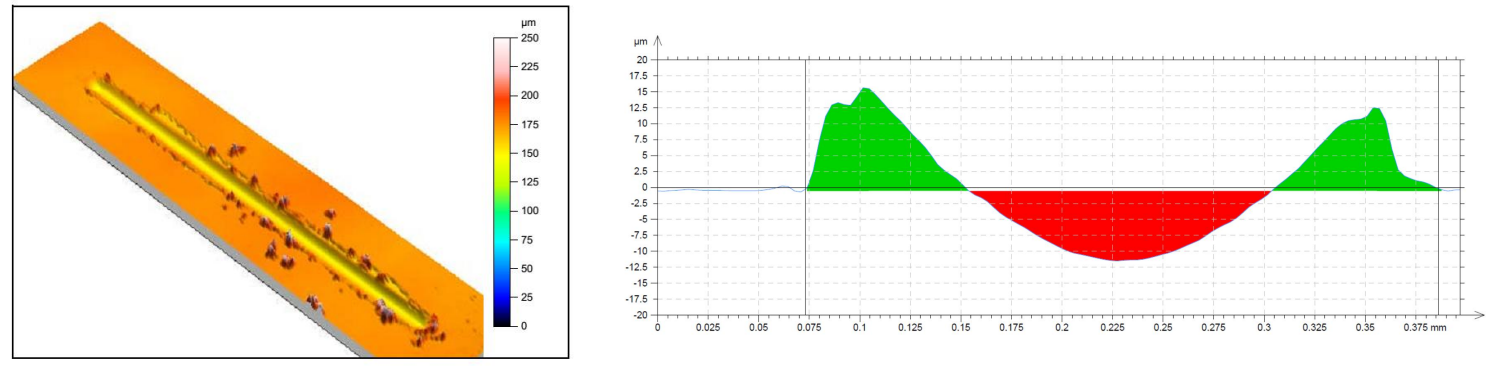

Figura 270. Sección transversal de la huella sobre el recubrimiento de RE
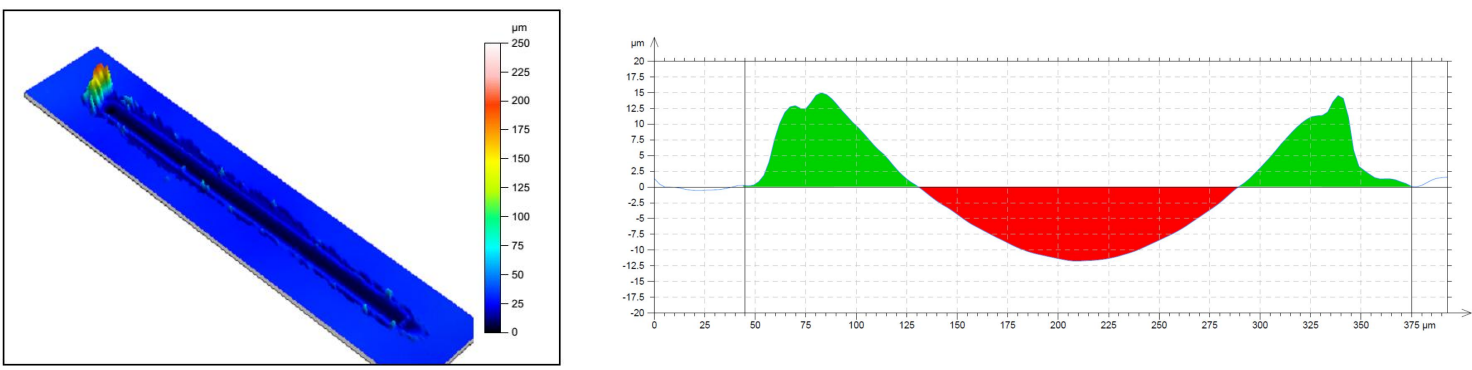

Figura 271. Sección transversal de la huella sobre el recubrimiento de $\mathrm{RE}+9 \%\left[\mathrm{OMIM}_{\mathrm{B}} \mathrm{F}_{4}\right.$
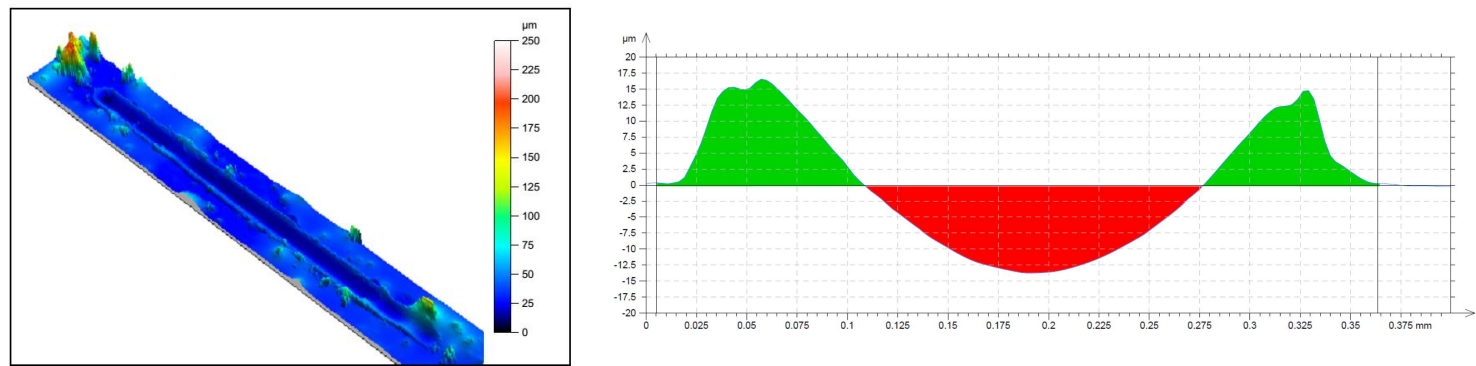

Figura 272. Sección transversal de la huella sobre el recubrimiento de RE+0,05\%G
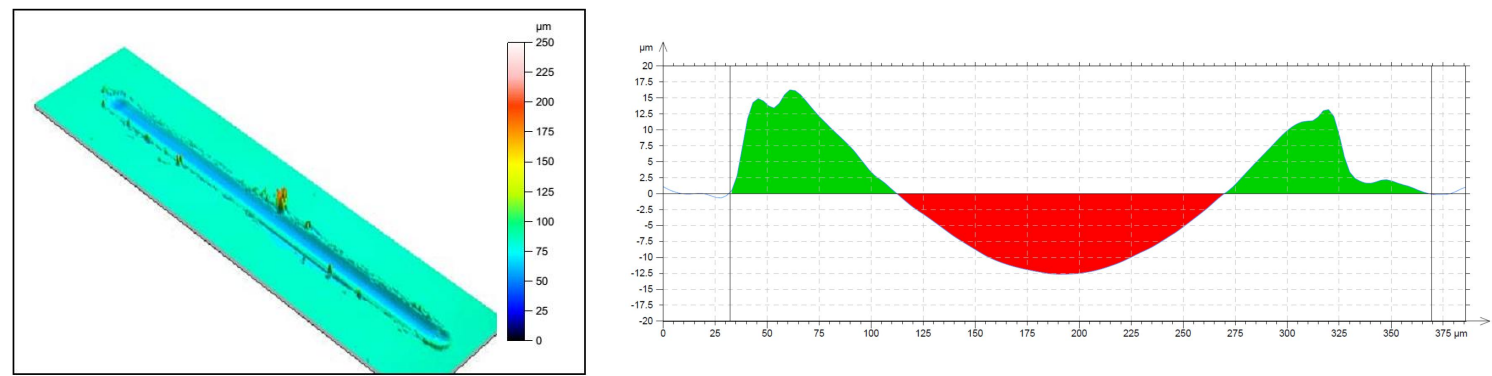

Figura 273. Sección transversal de la huella sobre el recubrimiento de $\mathrm{RE}+9 \%\left([\mathrm{OMIM}] \mathrm{BF}_{4}+0,1 \% \mathrm{G}\right)$

En la Tabla 82 se muestran los valores de daño superficial obtenidos para los diferentes recubrimientos tras los ensayos de multirrayado con $5 \mathrm{~N}$ de carga.

Por un lado, destaca el efecto de la adición de líquido iónico en la reducción del daño superficial. El grafeno, sin embargo, contribuye a aumentar el daño superficial generado en los ensayos debido a que los agregados de grafeno no dispersados incrementan la abrasión durante el proceso de rayado. 
Tabla 82. Daño superficial de los distintos recubrimientos sobre resina epoxi

\begin{tabular}{|c|c|}
\hline & Daño superficial \\
\hline Recubrimiento & $\begin{array}{c}A_{1}+A_{2}+A_{3} \\
\left(\mu m^{2}\right)\end{array}$ \\
\hline RE & $3555( \pm 175)$ \\
\hline $\mathrm{RE}+9 \%[\mathrm{OMIM}] \mathrm{BF}_{4}$ & $3191( \pm 201)$ \\
\hline RE $+0,05 \% G$ & $3689( \pm 95)$ \\
\hline $\mathrm{RE}+9 \%\left([\mathrm{OMIM}] \mathrm{BF}_{4}+0,1 \% \mathrm{G}\right)$ & $3218( \pm 55)$ \\
\hline
\end{tabular}

\subsubsection{Recubrimientos de resina epoxi con nanofases y nanofluidos sobre acero AISI 1015.}

Con el objetivo de mejorar la durabilidad y proteger el sustrato metálico, se han preparado recubrimientos de una o dos capas sobre discos de acero AISI 1015 de nuevos nanocomposites (apartado 3.3.2.1.3). Estos nuevos materiales de matriz epoxi se han obtenido mediante dispersión de un $9 \%$ del líquido iónico prótico oleato de bis(2-hidroxietil)amonio (DO) en la matriz epoxi y a partir de la adición de un $9 \%$ de una dispersión de un $0,1 \%$ de grafeno en $\mathrm{DO}$.

Su comportamiento tribológico se ha comparado con el obtenido para recubrimientos de resina epoxi sin aditivos y con los recubrimientos de matriz epoxi con un $9 \%$ del líquido iónico aprótico tetrafluoroborato de 1-octil-3metilimidazolio con un $0,1 \%$ de grafeno [234].

Con empleo del líquido iónico prótico como aditivo de la matriz epoxi se pretende sustituir los compuestos que contienen flúor por aditivos lubricantes más respetuosos con el medio ambiente.

\subsection{Recubrimientos de una capa}

\subsection{Medidas del espesor del recubrimiento}

Se han realizado medidas de espesor empleando imágenes de microscopía electrónica de barrido del corte transversal de las probetas recubiertas. Los valores de espesor se presentan en la Tabla 83. 
Con respecto a los resultados obtenidos, se puede afirmar que la presencia únicamente del líquido iónico prótico $\mathrm{DO}$ en la matriz epoxi disminuye el valor del espesor del recubrimiento, lo que podría ser debido a la presencia de fase líquida, lo que supone una mayor fluidez del nanocomposite. Cuando el recubrimiento contiene una pequeña cantidad de grafeno se produce un aumento del espesor del recubrimiento, siendo un $60 \%$ superior en el caso del recubrimiento de $\mathrm{RE}+9 \%\left([\mathrm{OMIM}] \mathrm{BF}_{4}+0,1 \% \mathrm{G}\right)$.

Tabla 83. Espesor de los recubrimientos de nanocomposites de matriz epoxi de una capa sobre acero AISI 1015

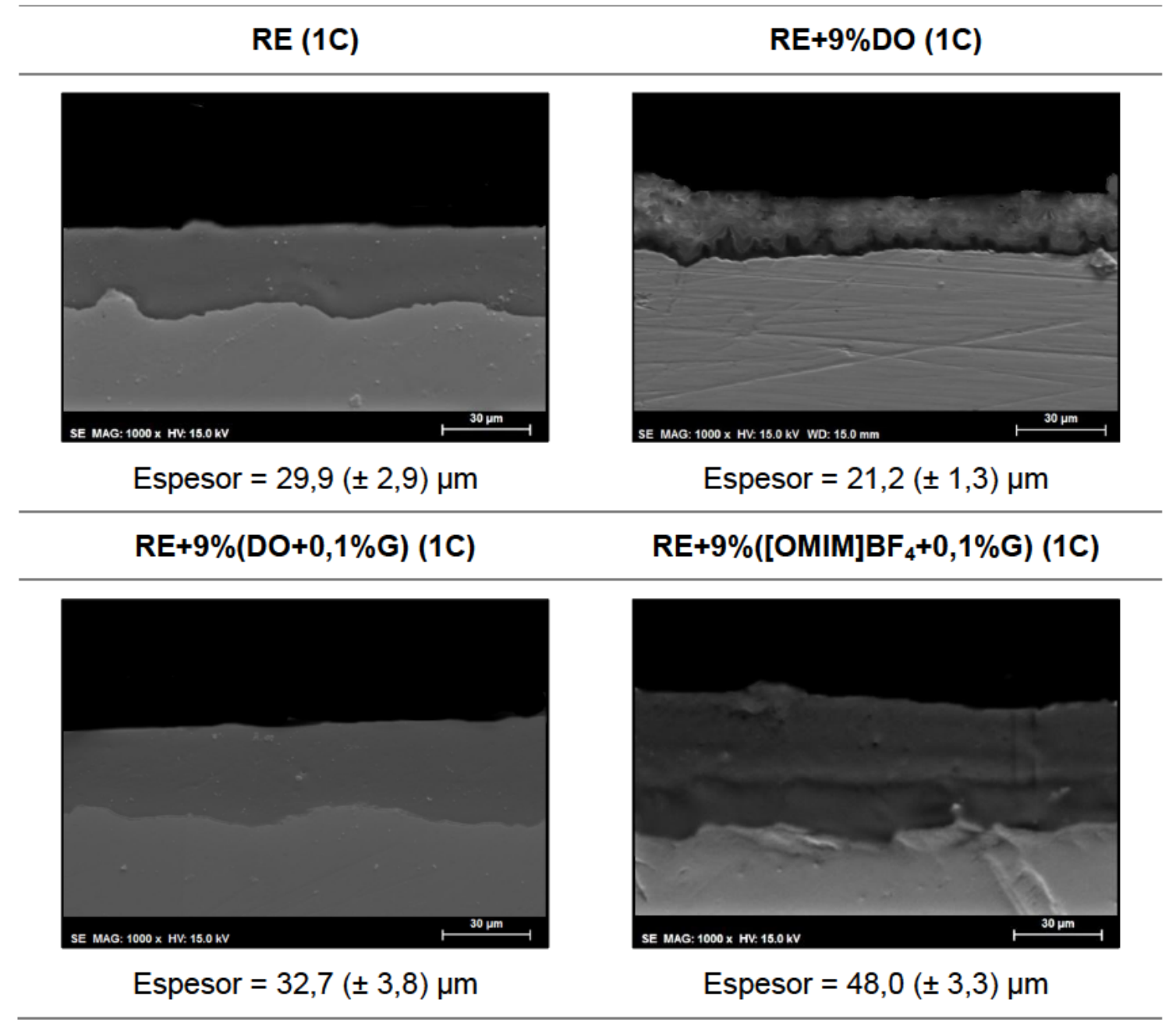

\subsection{Medidas del ángulo de contacto}

Se ha medido el ángulo de contacto de agua tipo II sobre los nuevos recubrimientos de una capa, obteniéndose los resultados que se muestran en la Tabla 84. 
Tabla 84. Ángulo de contacto de agua tipo II sobre recubrimientos de una capa de matriz epoxi sobre acero AISI 1015

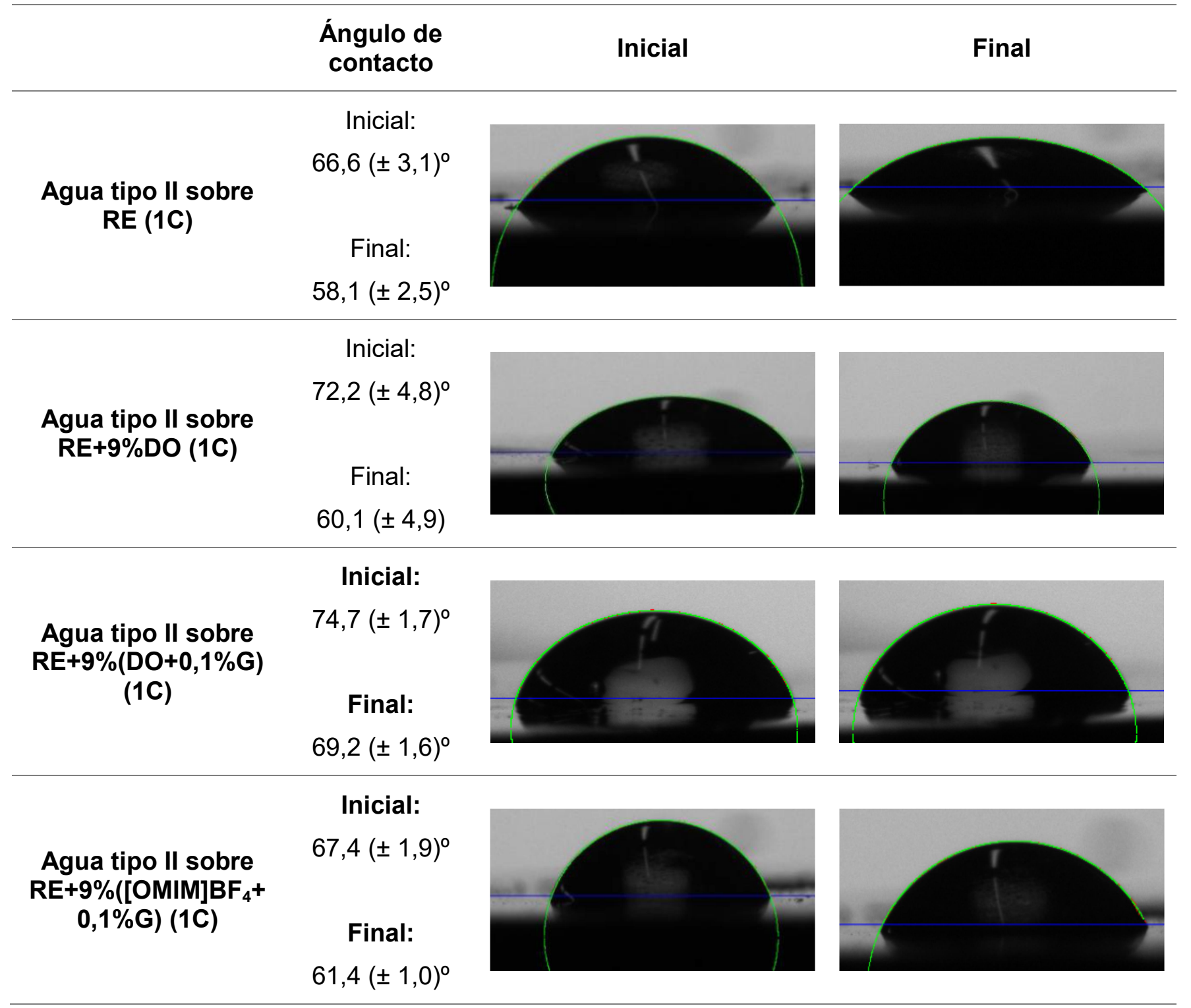

La presencia de líquido iónico prótico y/o grafeno en los recubrimientos sobre resina epoxi provoca un aumento del ángulo de contacto del agua, tanto inicial como final. La adición de grafeno al recubrimiento que posee el líquido iónico derivado del ácido oleico no modifica sustancialmente el valor del ángulo de contacto. Este hecho también se observa en el caso de la adición de un $9 \%$ de la dispersión del líquido iónico aprótico $\left[\mathrm{OMIM}_{\mathrm{B} F}\right.$ con un $0,1 \%$ de grafeno, donde los ángulos de contacto obtenidos son bastante similares.

Se ha determinado además, la mojabilidad de los nuevos nanocomposites sobre el sustrato metálico. Para ello, se ha medido el ángulo de contacto instantáneo, una vez que han transcurrido tres minutos, que es el tiempo que 
transcurre desde que se ponen en contacto el prepolímero y el agente de curado hasta que se realiza el recubrimiento mediante spin coating.

Se puede observar en la Tabla 85 cómo es el nanocomposite RE+9\%DO el que posee una menor mojabilidad sobre el acero AISI 1015, debido al elevado ángulo de contacto que presenta. Este hecho coincide con el menor espesor de la capa de recubrimiento cuando se emplea este nanocomposite con líquido iónico prótico. Sin embargo, la adición de grafeno hace que el ángulo obtenido sea muy similar al presentado por la resina.

Tabla 85. Ángulo de contacto de los nanocomposites sobre acero AISI 1015

\begin{tabular}{cc}
\hline Ángulo de \\
contacto
\end{tabular}

\subsection{Estudio superficial}

La rugosidad superficial de los recubrimientos de matriz epoxi ha sido determinada mediante perfilometría óptica en un área de $2 \mathrm{~mm} \times 2 \mathrm{~mm}$, según la norma ISO 25178 [340], obteniendo los resultados mostrados en la Tabla 86. En la misma tabla se muestran los valores de rugosidad lineal $\left(R_{a}\right)$, obtenidos como una media aritmética de tres medidas de $2 \mathrm{~mm}$ de longitud, según la norma ISO 4287 [341].

Se puede observar cómo la adición de líquido iónico prótico hace que la rugosidad superficial del recubrimiento sea similar o inferior a la presentada por el recubrimiento de resina sin modificar. Sin embargo, el recubrimiento que contiene líquido iónico [OMIM]BF 4 y grafeno presenta una rugosidad superficial muy inferior. 
Con respecto a la rugosidad lineal, las diferencias entre el recubrimiento de resina sin modificar y el que posee el líquido iónico DO y grafeno son más acentuadas, siendo este último el recubrimiento más rugoso en ambos casos. La presencia de únicamente líquido iónico prótico DO reduce la rugosidad superficial con respecto al recubrimiento de resina epoxi y la adición de líquido iónico aprótico y grafeno permite obtener valores de rugosidad muy bajos, del mismo orden que los obtenidos sobre sustratos de resina epoxi (Tabla 78).

Tabla 86. Rugosidad superficial y lineal de los recubrimientos de una capa sobre AISI 1015

\begin{tabular}{|c|c|c|}
\hline Recubrimiento & $S_{a}(\mu \mathrm{m})$ & $\mathbf{R}_{\mathrm{a}}(\boldsymbol{\mu m})$ \\
\hline RE (1C) & 0,96 & $0,84( \pm 0,2)$ \\
\hline RE+9\%DO (1C) & 0,75 & $0,73( \pm 0,004)$ \\
\hline $\mathrm{RE}+9 \%(\mathrm{DO}+0,1 \% \mathrm{G})(1 \mathrm{C})$ & 0,98 & $1,04( \pm 0,25)$ \\
\hline $\mathrm{RE}+9 \%\left([\mathrm{OMIM}] \mathrm{BF}_{4}+0,1 \% \mathrm{G}\right)(1 \mathrm{C})$ & 0,44 & $0,20( \pm 0,06)$ \\
\hline
\end{tabular}

Además, se ha determinado la densidad de defectos, definida como el porcentaje de área (con respecto a una superficie de $10 \mathrm{~mm} \times 10 \mathrm{~mm}$ ) de los defectos con una profundidad de al menos $6 \mu \mathrm{m}$ por debajo del perfil medio superficial (Tabla 87 ).

Tabla 87. Topografía superficial y porcentaje de área de defectos en los recubrimientos de una capa sobre AISI 1015

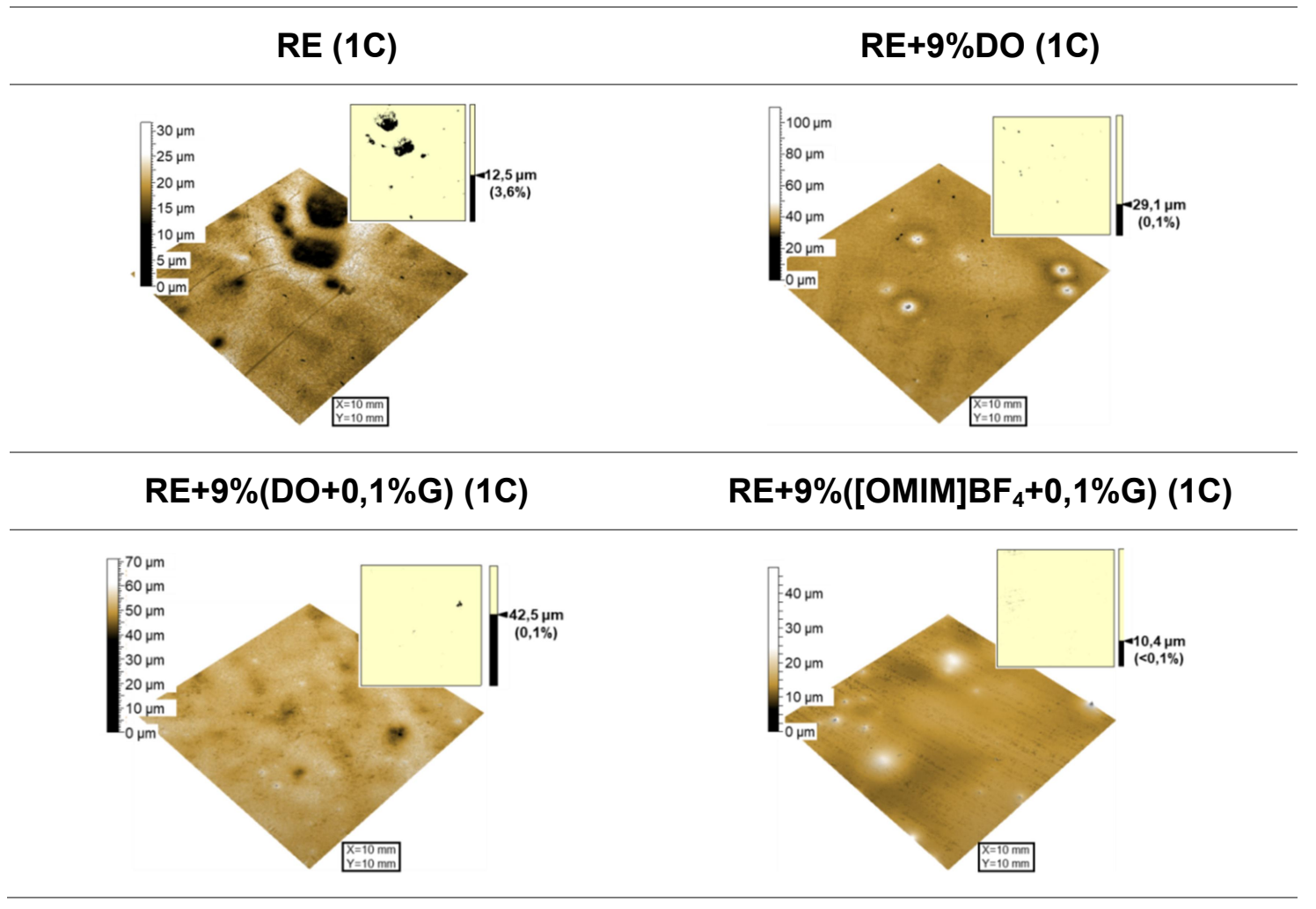


Los nuevos nanocomposites empleados como recubrimientos presentan un porcentaje de área de defectos de un $0,1 \%$. Un valor muy inferior al presentado por el recubrimiento de resina epoxi sin aditivos $(3,6 \%)$.

\subsection{Estudio tribológico}

Se han realizado ensayos tribológicos punzón sobre disco con bola de acero inoxidable AISI 316L, con una distancia de deslizamiento de $500 \mathrm{~m}$ sobre los recubrimientos estudiados con una carga de $0,5 \mathrm{~N}$ y se ha medido la resistencia eléctrica en el contacto con el fin de determinar cuándo se produce la rotura del recubrimiento protector.

En la Figura 274 se puede observar la evolución del coeficiente de fricción y la resistencia eléctrica en el contacto para el recubrimiento de resina epoxi sobre acero AISI 1015. Con respecto al coeficiente de fricción, el valor inicial es de 0,1 , sin embargo, al aumentar la distancia alcanza un máximo de 0,53 a los $148,6 \mathrm{~m}$. Después, disminuye ligeramente y se mantiene aproximadamente constante hasta el final del ensayo.

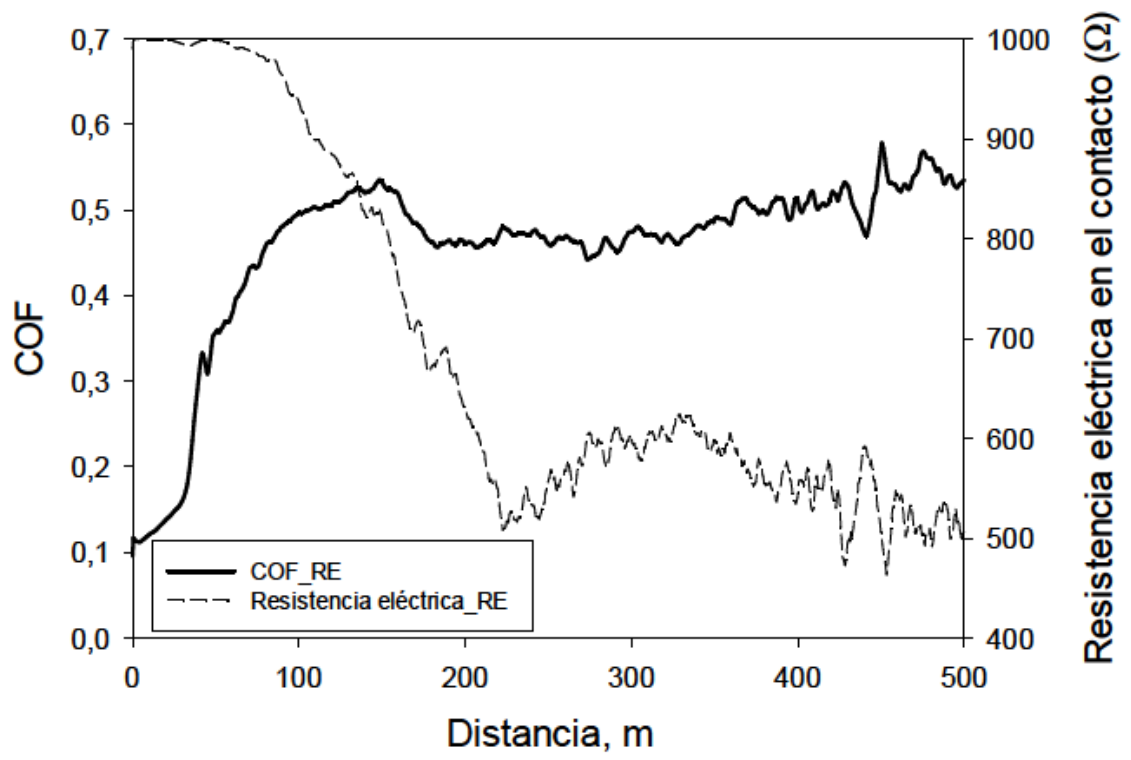

Figura 274. Evolución del coeficiente de fricción y de la resistencia eléctrica en el contacto durante el ensayo tribológico en el recubrimiento de RE sobre AISI 1015

Gracias al módulo de medida de resistencia eléctrica en el contacto que posee el tribómetro, es posible determinar el fallo o rotura de la capa de recubrimiento y comprobar que este cambio se corresponde con las variaciones en el coeficiente de fricción. Se puede observar cómo al principio del ensayo el valor de la resistencia es de $1000 \Omega$, lo que indica que no hay contacto eléctrico entre las superficies conductoras del disco de acero recubierto y la bola de AISI 
316L. Sin embargo, conforme el valor del coeficiente de fricción va aumentando, se produce la disminución de la resistencia, indicativo de la rotura del recubrimiento, quedando el acero del disco al descubierto.

En la Figura 275 se muestra una comparativa de la evolución de los coeficientes de fricción obtenidos tras los ensayos tribológicos punzón sobre disco para los recubrimientos estudiados.

Se puede observar que los recubrimientos de resina sin aditivos o con presencia de líquido iónico prótico presentan una evolución similar. Experimentan un aumento progresivo del coeficiente de fricción hasta alcanzar un valor máximo que posteriormente se estabiliza, aunque en todos los casos se produce la rotura de la capa protectora dejando al descubierto el acero del sustrato (Figura 276).

La presencia del líquido iónico prótico derivado del ácido oleico en RE+9\%DO incrementa ligeramente el periodo inicial de baja fricción.

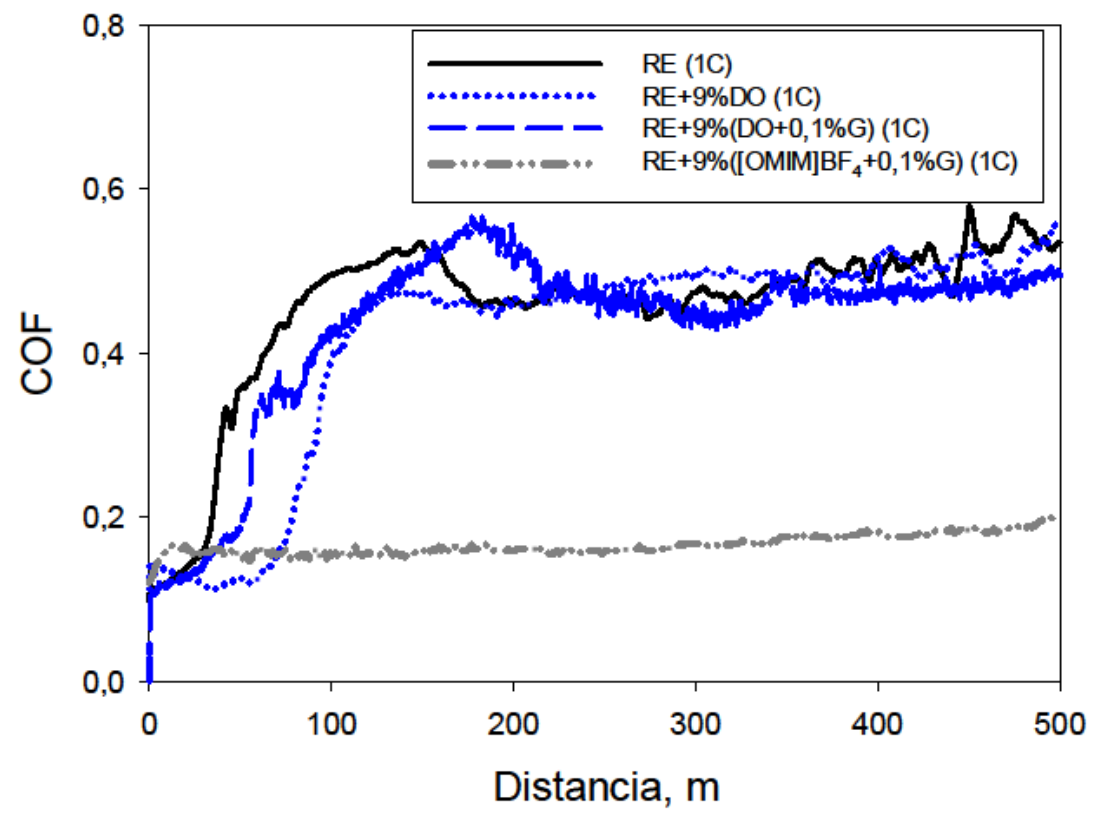

Figura 275. Evolución del coeficiente de fricción con la distancia para los recubrimientos de RE, $\mathrm{RE}+9 \% \mathrm{DO}$ y $\mathrm{RE}+9 \%(\mathrm{DO}+0,1 \% \mathrm{G})$ y $\mathrm{RE}+9 \%\left([\mathrm{OMIM}] \mathrm{BF}_{4}+0,1 \% \mathrm{G}\right)$ sobre acero AISI 1015

En el caso del recubrimiento de matriz epoxi con líquido aprótico [OMIM] $\mathrm{BF}_{4}$ y grafeno, no se produce la rotura de la capa protectora, obteniéndose un coeficiente de fricción constante a lo largo de toda la distancia recorrida, con un valor promedio de 0,17 . Este buen comportamiento podría atribuirse a la 
capacidad de este líquido iónico en acelerar el proceso de curado de la resina epoxi [284].

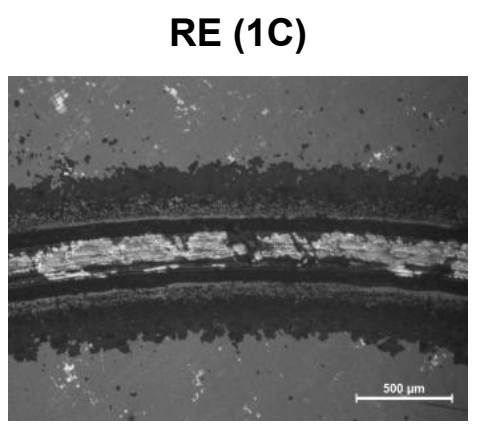

$R E+9 \%(D O+0,1 \% G)(1 C)$

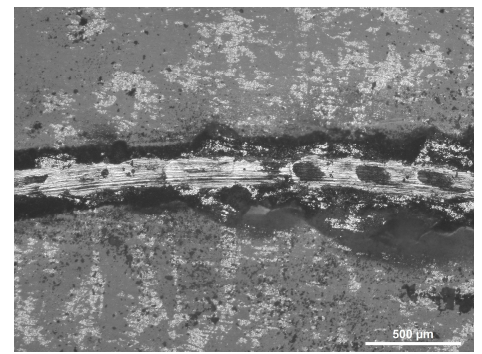

RE+9\%DO (1C)

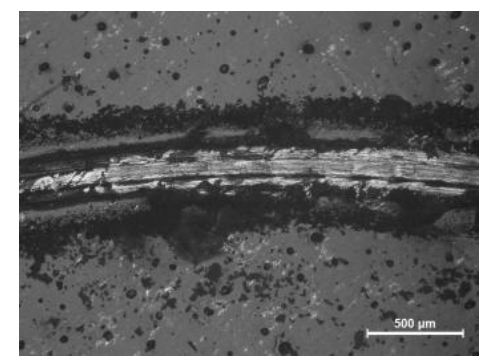

RE+9\%([OMIM]BF $4+0,1 \% G)(1 \mathrm{C})$

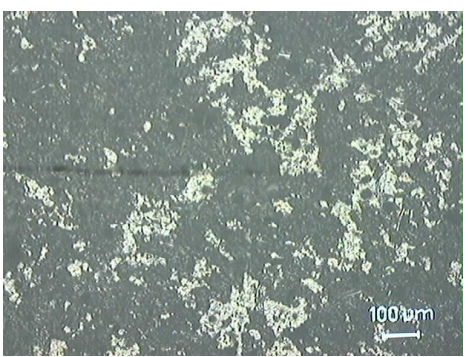

Figura 276. Micrografías ópticas de las huellas tras ensayo tribológico de los recubrimientos de una capa de $R E, R E+9 \% D O, R E+9 \%(D O+0,1 \% G)$ y $R E+9 \%\left([O M I M] B_{4}+0,1 \% G\right)$

En la Tabla 88 se muestran los coeficientes de fricción y el daño superficial obtenidos tras los ensayos tribológicos. No hay apenas variación en el coeficiente de fricción promedio para los recubrimientos de matriz epoxi que poseen líquido iónico prótico y la resina sin aditivos, mientras que el recubrimiento con $\mathrm{RE}+9 \%\left([\mathrm{OMIM}] \mathrm{BF}_{4}+0,1 \% \mathrm{G}\right)$ presenta una reducción del $61 \%$ con respecto al recubrimiento de resina epoxi. En los casos en los que se ha producido la rotura del recubrimiento, se ha podido cuantificar el daño superficial, que es superior en el caso de emplear el recubrimiento de resina epoxi sin aditivos.

Tabla 88. Coeficientes de fricción y daño superficial para los recubrimientos de RE, RE+9\%DO y $R E+9 \%(D O+0,1 \% G)$ de una capa sobre acero AISI 1015

\begin{tabular}{|c|c|c|}
\hline & $\begin{array}{l}\text { Coeficiente de } \\
\text { fricción }\end{array}$ & $\begin{array}{c}\text { Daño superficial } \\
\left(A_{1}+A_{2}+A_{3}\right) \\
\left(\mathrm{mm}^{2}\right)\end{array}$ \\
\hline RE (1C) & $0,44( \pm 0,04)$ & $9,54 \times 10^{-3}\left( \pm 8,0 \times 10^{-5}\right)$ \\
\hline RE+9\%DO (1C) & $0,42( \pm 0,01)$ & $5,92 \times 10^{-3}\left( \pm 1,3 \times 10^{-4}\right)$ \\
\hline RE+9\%(DO+0,1\%G) (1C) & $0,42( \pm 0,03)$ & $5,14 \times 10^{-3}\left( \pm 6,8 \times 10^{-4}\right)$ \\
\hline RE+9\%([OMIM]BF $4+0,1 \% G)(1 C)$ & $0,17( \pm 0,02)$ & - \\
\hline
\end{tabular}




\subsection{Recubrimientos de doble capa}

Aunque los resultados tribológicos presentados por el recubrimiento $\mathrm{RE}+9 \%\left([\mathrm{OMIM}] \mathrm{BF}_{4}+0,1 \% \mathrm{G}\right)$ han sido buenos, el acero al carbono del sustrato puede experimentar corrosión o tribocorrosión debido al flúor presente en el líquido iónico. Por tanto, con el objetivo de mejorar las propiedades tribológicas de los recubrimientos con líquido iónico prótico $\mathrm{DO}$, se han realizado recubrimientos de doble capa siguiendo el procedimiento descrito en el apartado 3.3.2.1.3.

\subsection{Espesor de los recubrimientos}

En la Tabla 89 se muestran las micrografías SEM del corte transversal de los recubrimientos de doble capa. En este caso, los valores de espesor son superiores a los presentados por los recubrimientos de una capa.

Tabla 89. Espesor de los recubrimientos de doble capa de RE, RE+9\%DO y

$\mathrm{RE}+9 \%(\mathrm{DO}+0,1 \% \mathrm{G})$ sobre acero AISI 1015

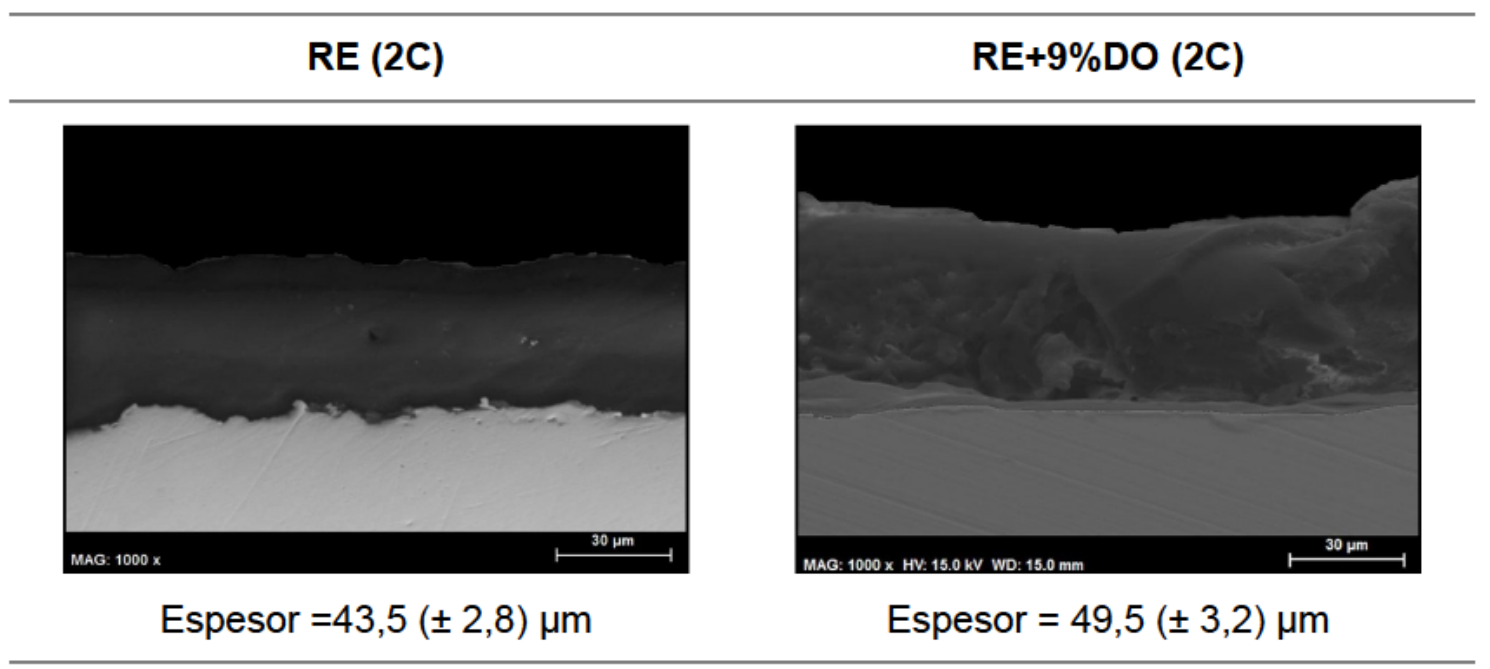

RE+9\%(DO+0,1\%G) (2C)

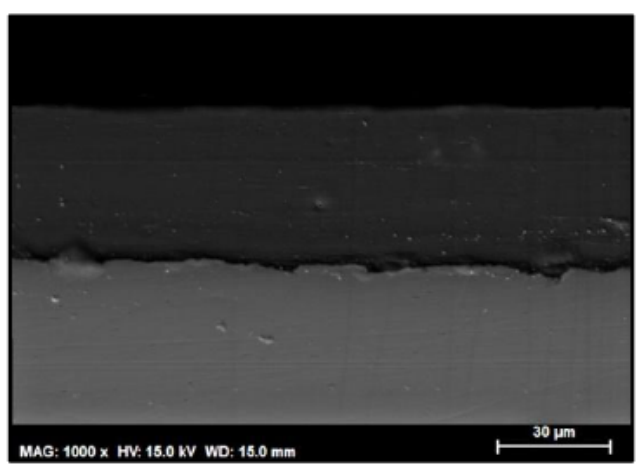

Espesor $=44,2( \pm 0,8) \mu \mathrm{m}$ 


\subsection{Medida del ángulo de contacto}

Se ha medido el ángulo de contacto del agua tipo II sobre los recubrimientos de doble capa (Tabla 90). El ángulo de contacto sobre los recubrimientos de doble capa que poseen líquido iónico derivado del ácido oleico experimenta una variación en torno al 10\% una vez transcurridos 5 minutos. Este resultado está de acuerdo con la mayor hidrofilicidad del líquido iónico prótico.

Tabla 90. Ángulo de contacto de agua tipo II sobre recubrimientos de doble capa de matriz epoxi sobre acero AISI 1015

\begin{tabular}{|c|c|c|c|}
\hline & $\begin{array}{c}\text { Ángulo } \\
\text { de contacto }\end{array}$ & Inicial & Final \\
\hline $\begin{array}{c}\text { Agua tipo II } \\
\text { sobre RE (2C) }\end{array}$ & $\begin{array}{c}\text { Inicial: } \\
73,8( \pm 4,7)^{\circ} \\
\text { Final: } \\
70,0( \pm 4,2)^{\circ}\end{array}$ & & \\
\hline $\begin{array}{l}\text { Agua tipo II } \\
\text { sobre } \\
\text { RE+9\%DO (2C) }\end{array}$ & $\begin{array}{c}\text { Inicial: } \\
69,0( \pm 4,2)^{\circ} \\
\text { Final: } \\
62,8( \pm 4,0)^{\circ}\end{array}$ & & \\
\hline $\begin{array}{c}\text { Agua tipo II } \\
\text { sobre } \\
\text { RE+9\%(DO+0,1 } \\
\% G)(2 C)\end{array}$ & $\begin{array}{c}\text { Inicial: } \\
68,8( \pm 5,8)^{\circ} \\
\text { Final: } \\
61,1( \pm 5,5)^{\circ}\end{array}$ & & \\
\hline
\end{tabular}

\subsection{Estudio superficial}

Se han obtenido los valores de rugosidad superficial y lineal de los distintos recubrimientos de doble capa mediante perfilometría (Tabla 91). Debido a la adición de líquido iónico a la matriz epoxi, la rugosidad superficial se incrementa con respecto a la presentada por el recubrimiento de resina epoxi sin modificar. El mismo comportamiento se ha encontrado al estudiar la rugosidad lineal, siendo en este caso el recubrimiento de RE+9\%(DO+0,1\%G) el que presenta el valor de rugosidad más elevado. 
Tabla 91. Rugosidad superficial y lineal de los recubrimientos de matriz epoxi de doble capa sobre AISI 1015

\begin{tabular}{ccc}
\hline Recubrimiento & $\mathbf{S}_{\mathbf{a}}(\boldsymbol{\mu m})$ & $\mathbf{R}_{\mathrm{a}}(\boldsymbol{\mu m})$ \\
\hline $\mathbf{R E}(\mathbf{2 C})$ & 0,76 & $0,77( \pm 0,10)$ \\
\hline $\mathbf{R E + 9 \% D O}(\mathbf{2 C})$ & 1,64 & $1,40( \pm 0,11)$ \\
\hline $\mathbf{R E + 9 \% ( D O + 0 , 1 \% G ) ( 2 C )}$ & 1,15 & $1,50( \pm 0,20)$ \\
\hline
\end{tabular}

Este comportamiento es diferente al presentado por los recubrimientos de una única capa, donde la rugosidad superficial de los recubrimientos de los nuevos nanocomposites era igual o inferior a la observada para la resina epoxi.

Al igual que para los recubrimientos de una capa, se ha determinado el porcentaje de área de defectos de los recubrimientos de doble capa.

Tabla 92. Topografía superficial y porcentaje de área de defectos en los recubrimientos de doble capa sobre AISI 1015

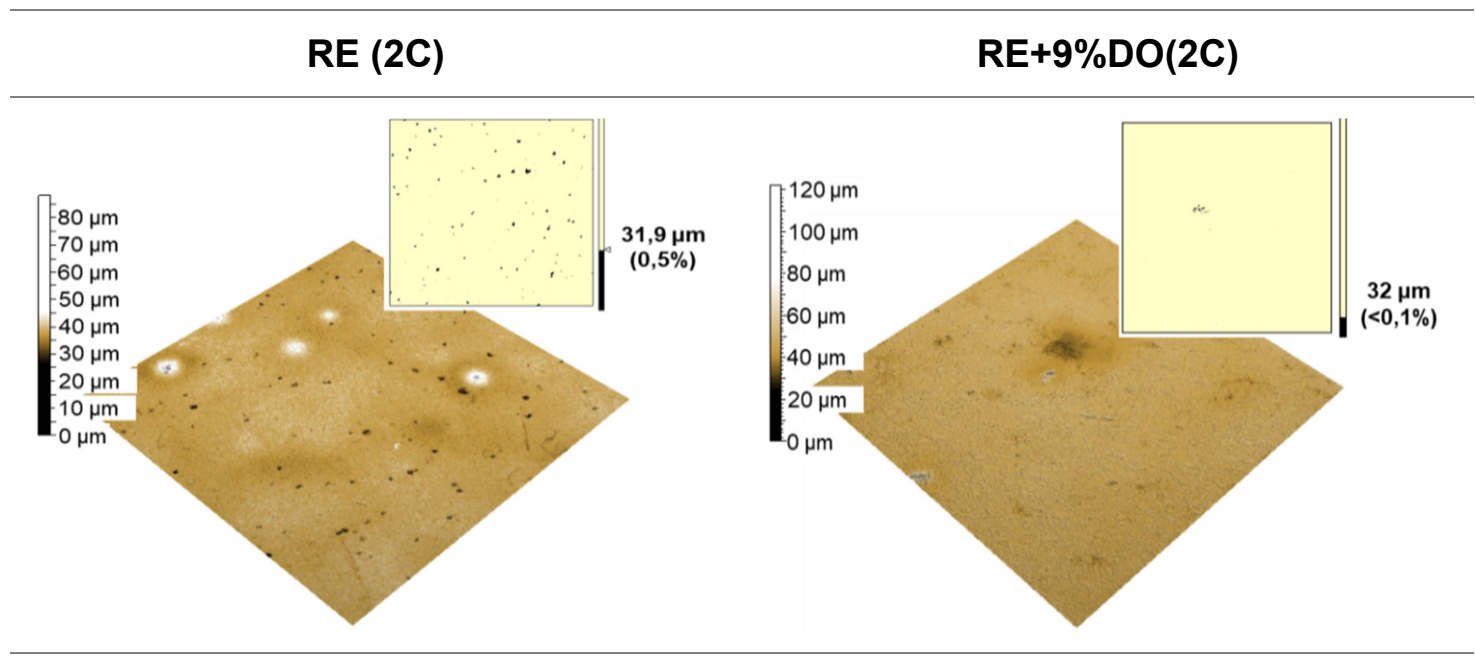

$R E+9 \%(D O+0,1 \% G)(2 C)$

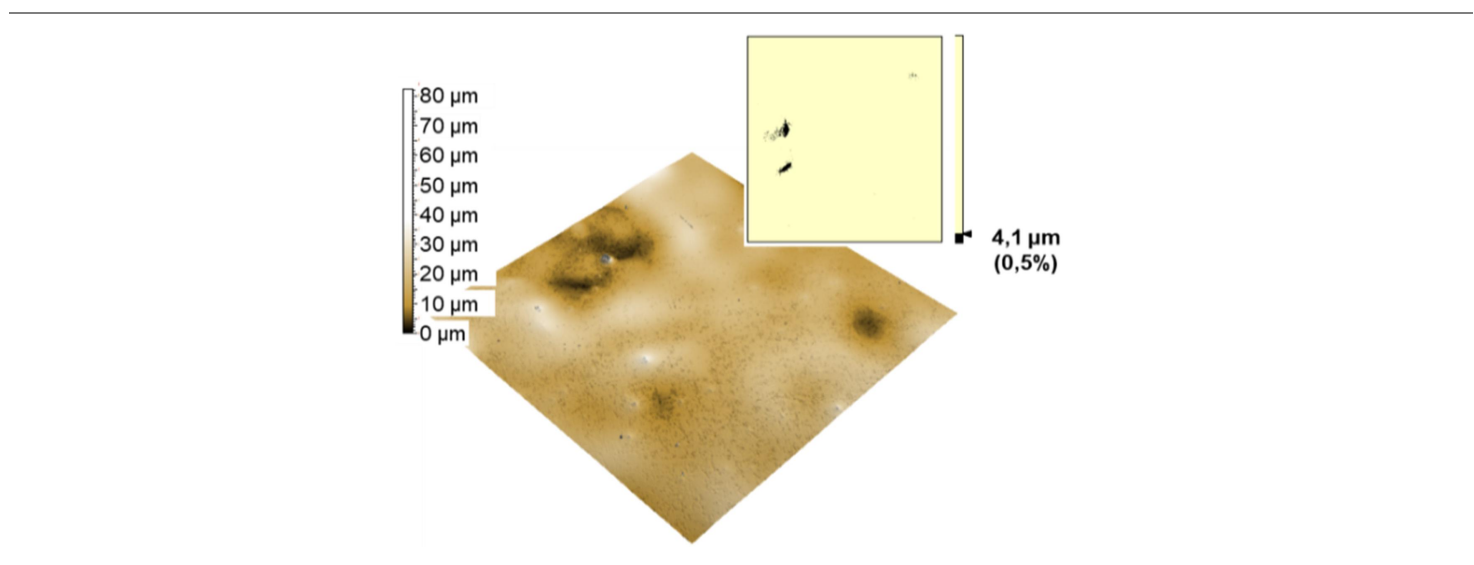


El empleo de una segunda capa de RE reduce la rugosidad superficial y el porcentaje de defectos con respecto a los recubrimientos de una capa de RE (4.2.2.2.1.3). Ésto podría ser debido al llenado de los defectos con la creación de una nueva capa, así como al segundo curado, que incrementa la densidad de entrecruzamiento. Si se compara en función del nanocomposite, los recubrimientos con DO de doble capa tienen un porcentaje de defectos similar o inferior al presentado por los recubrimientos de doble capa de resina epoxi sin modificar. En este caso, es el nanocomposite de RE+9\%DO el que presenta una menor área de defectos $(0,1 \%)$.

\subsection{Estudio tribológico}

Se han realizado ensayos bajo la configuración punzón sobre disco en el contacto metal-polímero para los recubrimientos de doble capa de RE, $\mathrm{RE}+9 \% \mathrm{DO}$ y $\mathrm{RE}+9 \%(\mathrm{DO}+0,1 \% \mathrm{G})$ en las mismas condiciones que los ensayos para una capa.

Como se puede ver en la Figura 277, para el caso del recubrimiento de doble capa de resina epoxi sobre acero AISI 1015 presenta una etapa inicial de baja fricción hasta $90 \mathrm{~m}$ de distancia recorrida. A partir de este momento se incrementa exponencialmente hasta llegar a un valor máximo de 0,6 a los 200 metros y posteriormente el valor del coeficiente de fricción se mantiene en un valor promedio de 0,55 .

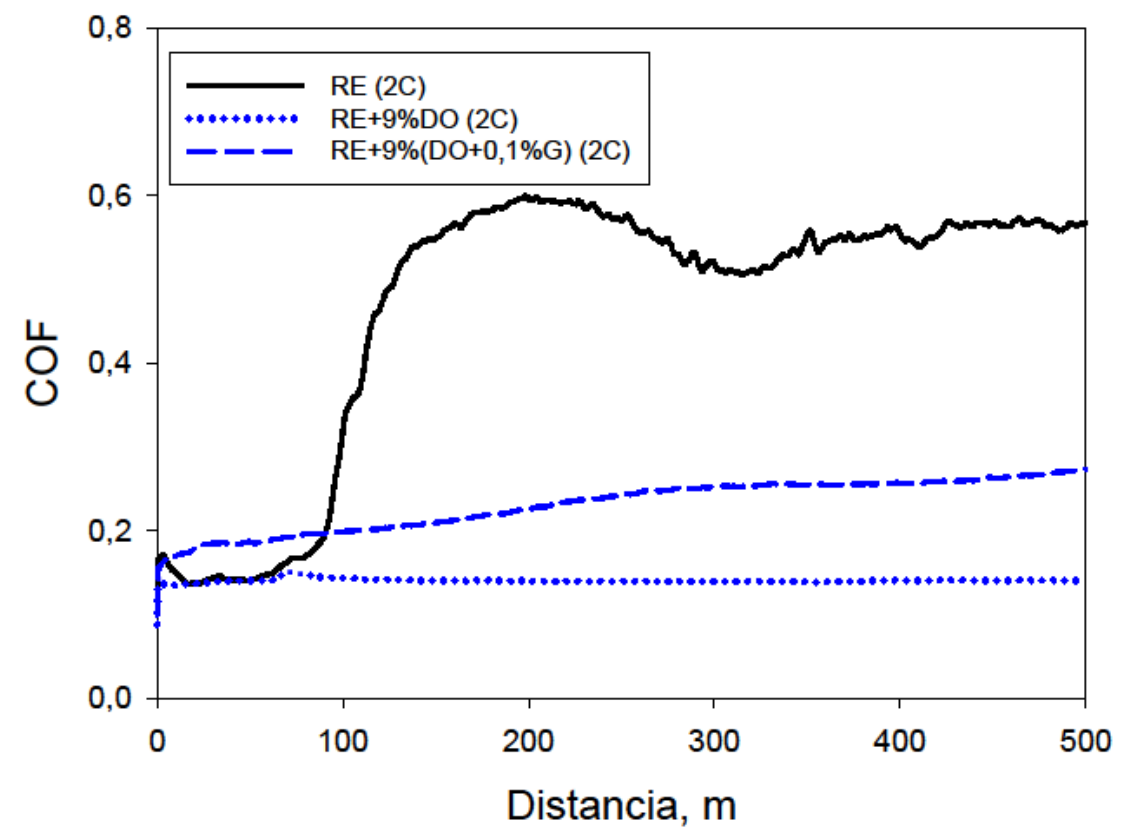

Figura 277. Evolución del coeficiente de fricción con la distancia para los recubrimientos de doble capa de RE, RE+9\%DO y RE+9\%(DO+0,1\%G) sobre acero AISI 1015 
En el caso del recubrimiento de doble capa de resina epoxi con un $9 \%$ de DO no se produce la rotura del recubrimiento, presentando un coeficiente de fricción constante durante toda la distancia de deslizamiento. Con respecto al recubrimiento de doble capa de resina epoxi con un $9 \%$ de la dispersión de un $0,1 \%$ de grafeno con $\mathrm{DO}$, tampoco se ha producido la rotura de la capa, aunque el coeficiente de fricción va aumentando progresivamente hasta presentar un valor de 0,27 a los $500 \mathrm{~m}$.

En la Figura 278 se observa con más detalle el coeficiente de fricción obtenido en el ensayo tribológico sobre el recubrimiento de doble capa de RE+9\%DO sobre discos de acero AISI 1015. En este caso, el coeficiente de fricción se mantiene aproximadamente constante durante todo el ensayo y no se producen cambios en el valor de resistencia eléctrica en el contacto, por tanto, se confirma que no se ha producido la rotura de la capa protectora de recubrimiento.

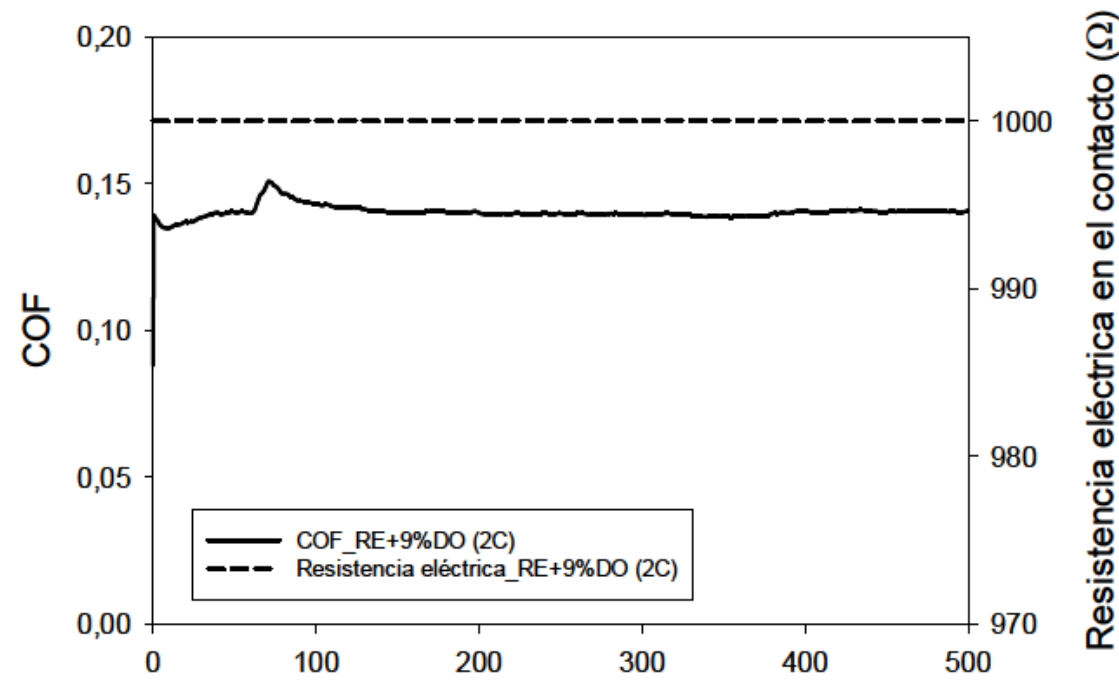

Distancia, $m$

Figura 278. Evolución del coeficiente de fricción y resistencia eléctrica en el contacto con la distancia para el recubrimiento de doble capa de RE+9\%DO sobre acero AISI 1015

Los valores promedio del daño superficial y los valores del coeficiente de fricción para 500 metros de distancia de deslizamiento se presentan en la Tabla 93. El daño superficial se ha calculado como la suma de las áreas de la sección transversal de las huellas.

Se puede observar cómo el coeficiente de fricción obtenido para el recubrimiento con doble capa de resina epoxi es similar al obtenido para el recubrimiento de una capa, mientras que, en el caso de la resina con $\mathrm{DO}$, al no producirse la rotura del recubrimiento, el valor de coeficiente de fricción es un 
$65 \%$ inferior. Con respecto al daño superficial, sólo ha sido posible medirlo en el caso del recubrimiento de RE.

Tabla 93. Coeficientes de fricción y daño superficial para los recubrimientos de doble capa de RE, RE+9\%DO y RE+9\%(DO+0,1\%G) sobre acero AISI 1015

\begin{tabular}{ccc}
\hline & Coeficiente de fricción & $\begin{array}{c}\text { Daño superficial }\left(\mathrm{A}_{1}+\mathrm{A}_{2}+\mathrm{A}_{3}\right) \\
\left(\mathrm{mm}^{2}\right)\end{array}$ \\
\hline $\operatorname{RE}(\mathbf{2 C})$ & $0,46( \pm 0,05)$ & $1,26 \times 10^{-2}\left( \pm 1 \times 10^{-4}\right)$ \\
\hline $\mathbf{R E + 9 \% D O}(2 \mathrm{C})$ & $0,14( \pm 0,01)$ & - \\
\hline RE+9\%(DO+0,1\%G) (2C) & $0,23( \pm 0,02)$ & - \\
\hline
\end{tabular}

En la Figura 279 se observan las micrografías SEM de las huellas de desgaste obtenidas tras el ensayo tribológico sobre los recubrimientos de doble capa.

a) RE

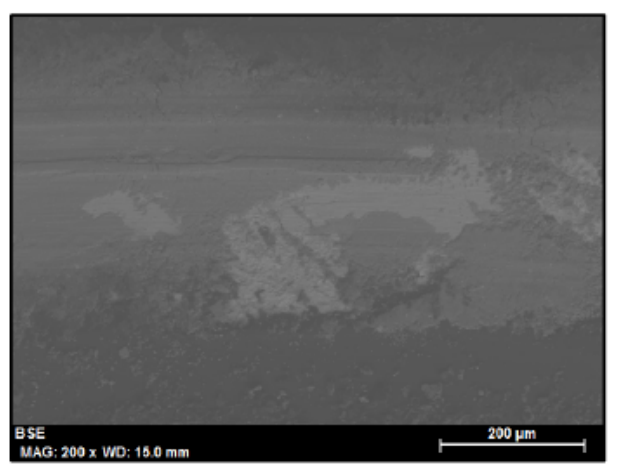

b) $\mathrm{RE}+9 \% \mathrm{DO}$

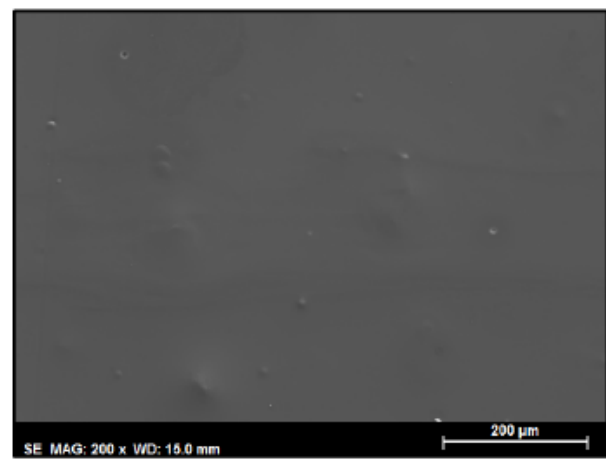

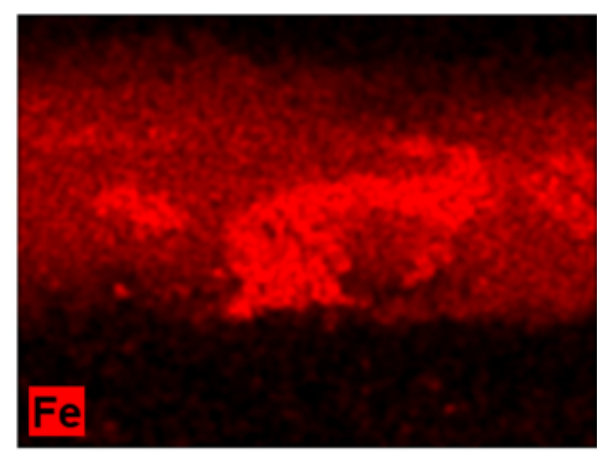

c) $\mathrm{RE}+9 \%(\mathrm{DO}+0,1 \% \mathrm{G})$

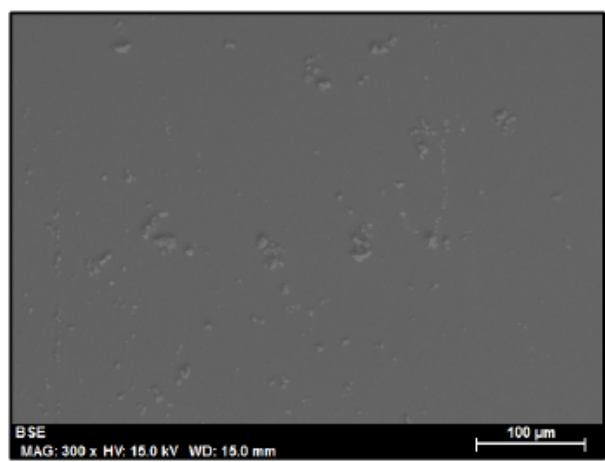

Figura 279. Micrografías SEM de las huellas de desgaste tras ensayo tribológico sobre recubrimientos de doble capa: a) $\mathrm{RE}$; b) $\mathrm{RE}+9 \% \mathrm{DO}$; c) $\mathrm{RE}+9 \%(\mathrm{DO}+0,1 \% \mathrm{G})$

Para los recubrimientos de doble capa de resina epoxi con líquido iónico prótico no se ha producido la rotura de la capa protectora, ya que las micrografías superficiales de los recubrimientos de RE+9\%DO y RE+9\%(DO+0,1\%G) no presentan diferencias dentro y fuera de la huella de desgaste (Figura 279b y Figura 279c). 
En el caso del doble recubrimiento de RE (Figura 279a), se aprecia un daño superficial severo quedando el acero del sustrato al descubierto, como muestra el mapa elemental de Fe.

Las imágenes de perfilometría óptica (Figura 280) muestran una importante deformación plástica en la huella de desgaste del recubrimiento de doble capa de resina epoxi y la ausencia de daño superficial medible para los recubrimientos de $R E+9 \% D O(2 C)$ y $R E+9 \%(D O+0,1 \% G)(2 C)$.

\section{a) RE}

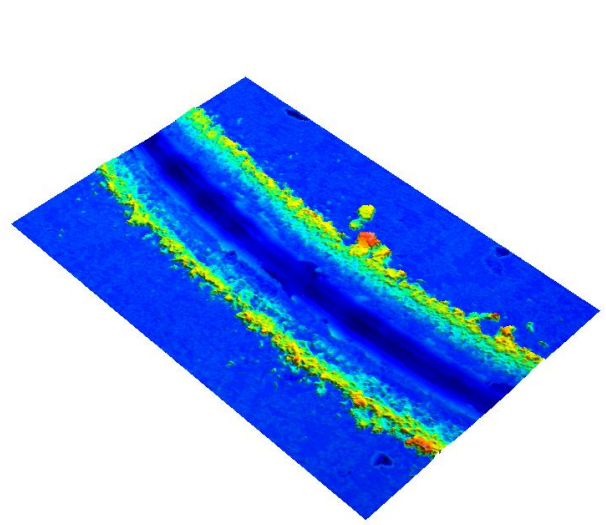

RE+9\%DO

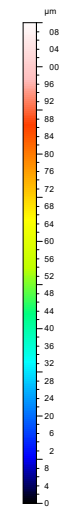

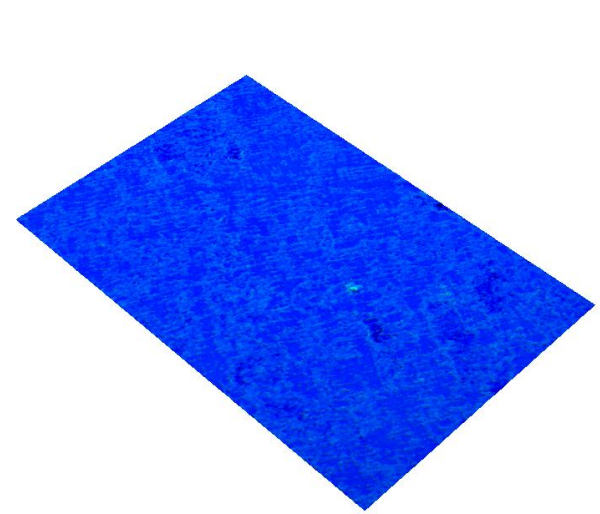

\section{$\mathrm{RE}+9 \%(\mathrm{DO}+0,1 \% \mathrm{G})$}

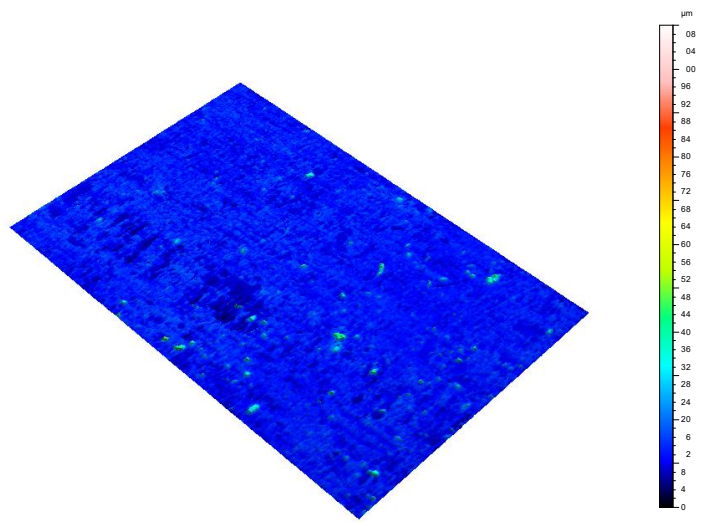

Figura 280. Topografía superficial de las huellas de desgaste en recubrimientos de doble capa:

a) RE; b) RE+9\%DO; c) RE+9\%(DO+0,1\%G) 


\subsubsection{Caracterización de distintos nanocomposites de matriz epoxi en forma de film}

Se han obtenido films de bajo espesor de los nanocomposites de matriz epoxi empleados como recubrimientos sobre matriz epoxi mediante el procedimiento descrito en el punto 3.3.2.1.4.

Estos films se han caracterizado térmicamente y se ha realizado además su análisis dinámico mecánico.

\subsection{Espesor de los films}

Se ha determinado el espesor de los films con ayuda de un micrómetro Mitutoyo modelo 227-221, obteniendo los valores que se recogen en la Tabla 94.

Tabla 94. Espesor de los films de los distintos nanocomposites de matriz epoxi

\begin{tabular}{cc}
\hline Film & Espesor $(\mathbf{m m})$ \\
\hline RE & $0,041( \pm 0,005)$ \\
\hline RE+9\%[OMIM]BF 4 & $0,055( \pm 0,007)$ \\
\hline RE+0,05\%G & $0,090( \pm 0,009)$ \\
\hline RE+9\%([OMIM]BF $\mathbf{4}+\mathbf{0 , 1 \% G )}$ & $0,037( \pm 0,002)$
\end{tabular}

Los films con grafeno poseen un espesor superior al presentado por los otros nanocomposites, quizás por la baja dispersión de la nanofase en la matriz epoxi.

\subsection{Análisis térmico}

Para llevar a cabo la caracterización térmica de los diferentes films de matriz epoxi, se han realizado dos análisis, por un lado, se ha determinado la temperatura de degradación mediante termogravimetría y se ha encontrado la temperatura de transición vítrea mediante calorimetría diferencial de barrido.

\subsection{Termogravimetría}

Con el fin de determinar si la presencia de nanofases y nanofluidos dispersos en la matriz epoxi modifica la temperatura de degradación de los materiales, entendiendo ésta como la temperatura a la cual el peso se reduce a la mitad, 
se ha llevado a cabo un análisis TGA. El método empleado se ha indicado previamente en el apartado 3.3.2.2.2.1.

En la Figura 281 se comparan los termogramas de los cuatro materiales en forma de films.

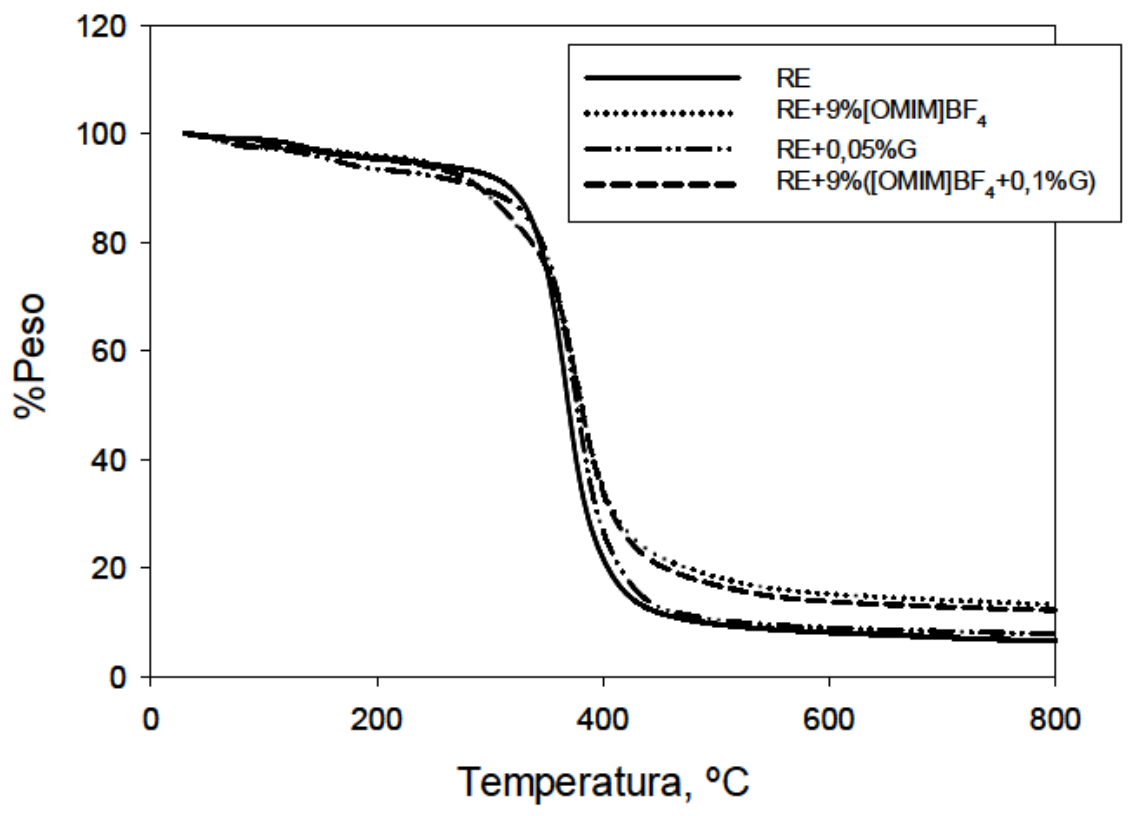

Figura 281. Evolución de la pérdida de peso con la temperatura para los films de RE,

$\mathrm{RE}+9 \%[\mathrm{OMIM}] \mathrm{BF}{ }_{4}, \mathrm{RE}+0,05 \% \mathrm{G}$ y $\mathrm{RE}+9 \%\left([\mathrm{OMIM}] \mathrm{BF}_{4}+0,1 \% \mathrm{G}\right)$

Como se muestra en la Tabla 95, tanto la adición de nanofase como de nanofluido hacen que la resina epoxi sea más estable, debido al aumento de la temperatura de degradación. Este incremento es menos pronunciado en el caso de añadir sólo grafeno.

Tabla 95. Temperatura de degradación para los distintos nanocomposites en forma de films

\begin{tabular}{cc}
\hline Material & $\operatorname{Td}\left({ }^{\circ} \mathrm{C}\right)(\Delta \mathrm{m}=-\mathbf{5 0} \%)$ \\
\hline RE & 369,17 \\
\hline RE+9\%[OMIM]BF & 381,00 \\
\hline RE+0,05\%G & 377,00 \\
\hline RE+9\%([OMIM]BF $\left.{ }_{4}+\mathbf{0 , 1} \% \mathrm{G}\right)$ & 380,83 \\
\hline
\end{tabular}

Si se comparan los resultados con los obtenidos con los presentados para los nanomateriales de la misma composición pero de mayor espesor, es posible observar que los films de $\mathrm{RE}, \mathrm{RE}+9 \%\left[\mathrm{OMIM}_{\mathrm{B}} \mathrm{BF}_{4}\right.$ presentan mayor temperatura de degradación que los nanocomposites de $3 \mathrm{~mm}$ de espesor, $25,3^{\circ} \mathrm{C}$ y $28,5^{\circ} \mathrm{C}$ 
superior, respectivamente [269]. También se ha observado para $\mathrm{RE}+9 \%\left(\left[\mathrm{OMIM}_{\mathrm{B}} \mathrm{BF}_{4}+0,1 \% \mathrm{G}\right)\right.$, que presenta una temperatura de descomposición de $358,80^{\circ} \mathrm{C}$.

\subsection{Calorimetría diferencial de barrido}

La técnica de la calorimetría diferencial de barrido (DSC) ha sido empleada para la determinación de la temperatura de transición vítrea (Tg). En los materiales poliméricos a esta temperatura se produce una pseudotransición termodinámica en la que se reduce la densidad, dureza, rigidez y elongación del material.

En la Figura 282 se muestran los termogramas correspondientes al segundo calentamiento experimentado por los films de RE, RE+9\%[OMIM]BF 4 , $\mathrm{RE}+0,05 \% \mathrm{G} \quad \mathrm{R} \quad \mathrm{R}+9 \%\left([\mathrm{OMIM}] \mathrm{BF}_{4}+0,1 \% \mathrm{G}\right)$ obtenidos siguiendo el procedimiento descrito en el apartado (3.3.2.2.2.2).

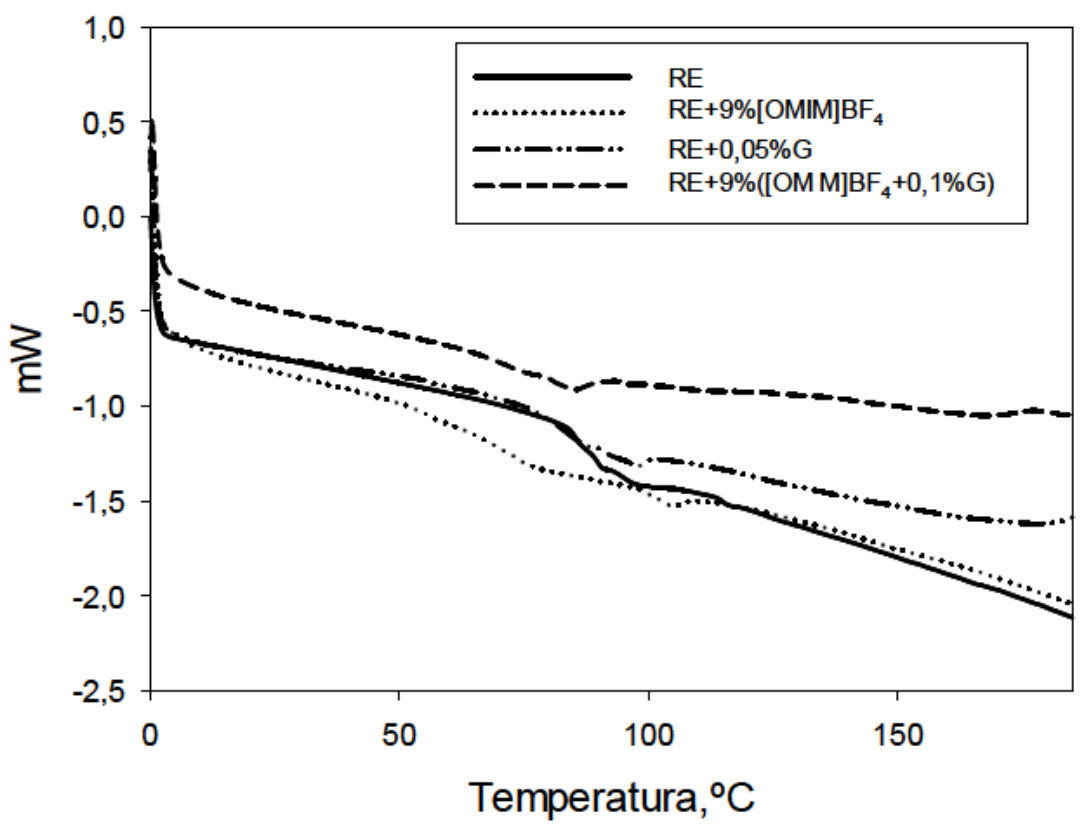

Figura 282. DSC para films de RE, RE+9\%[OMIM]BF $4, R E+0,05 \% G$ y $\mathrm{RE}+9 \%\left([\mathrm{OMIM}] \mathrm{BF}_{4}+0,1 \% \mathrm{G}\right)$

En la Tabla 96, se muestran los valores de temperatura de transición vítrea (Tg) para los distintos nanocomposites. Se observa que la adición de líquido iónico disminuye la $\mathrm{Tg}$, debido a su efecto plastificante [269]. La menor reducción tiene lugar en el caso del grafeno, mientras que la combinación de ambos aditivos da lugar a un valor intermedio. 
Tabla 96. Temperatura de transición vítrea de los nanocomposites en forma de films

\begin{tabular}{cc}
\hline Material & $\operatorname{Tg}\left({ }^{\circ} \mathbf{C}\right)$ \\
\hline RE & 90,1 \\
\hline RE+9\%[OMIM]BF 4 & 85,5 \\
\hline RE+0,05\%G & 88,7 \\
\hline RE+9\%([OMIM] BF $_{4}+\mathbf{0 , 1 \% G )}$ & 87,2
\end{tabular}

En el caso de la Tg, el valor que presenta el film de resina epoxi es similar al obtenido para el nanocomposite de mayor espesor. Sin embargo, cuando se añade el líquido iónico la $\mathrm{Tg}$ del nanocomposite con $3 \mathrm{~mm}$ de espesor es de $68,5^{\circ} \mathrm{C}$ [269]. El mismo comportamiento se ha encontrado para el caso del film con líquido iónico y grafeno, cuya temperatura de transición vítrea es de $13,8^{\circ} \mathrm{C}$, superior a la que presenta el nanocomposite $\left(73,4^{\circ} \mathrm{C}\right)$.

\subsection{Análisis dinámico-mecánico}

Con el fin de determinar el comportamiento dinámico-mecánico de los films se ha empleado un módulo de tensión especial para films, que dispone el equipo DMA.

De esta forma es posible conocer la evolución de las curvas de módulo de almacenamiento (E'), de pérdida (E') y la relación entre ambos $(\tan (\delta))$, con la temperatura.

En la Figura 283 se observa la evolución del módulo de almacenamiento (E') de los nanocomposites con la temperatura. Se puede ver cómo el módulo disminuye drásticamente, debido a la transición de material polimérico desde temperaturas en las que presenta un comportamiento vítreo a temperaturas con comportamiento elastomérico. Esto es debido a que aumentos en la temperatura provocan que la movilidad de las cadenas poliméricas se incremente, proporcionando una mayor capacidad de deformación elástica. 


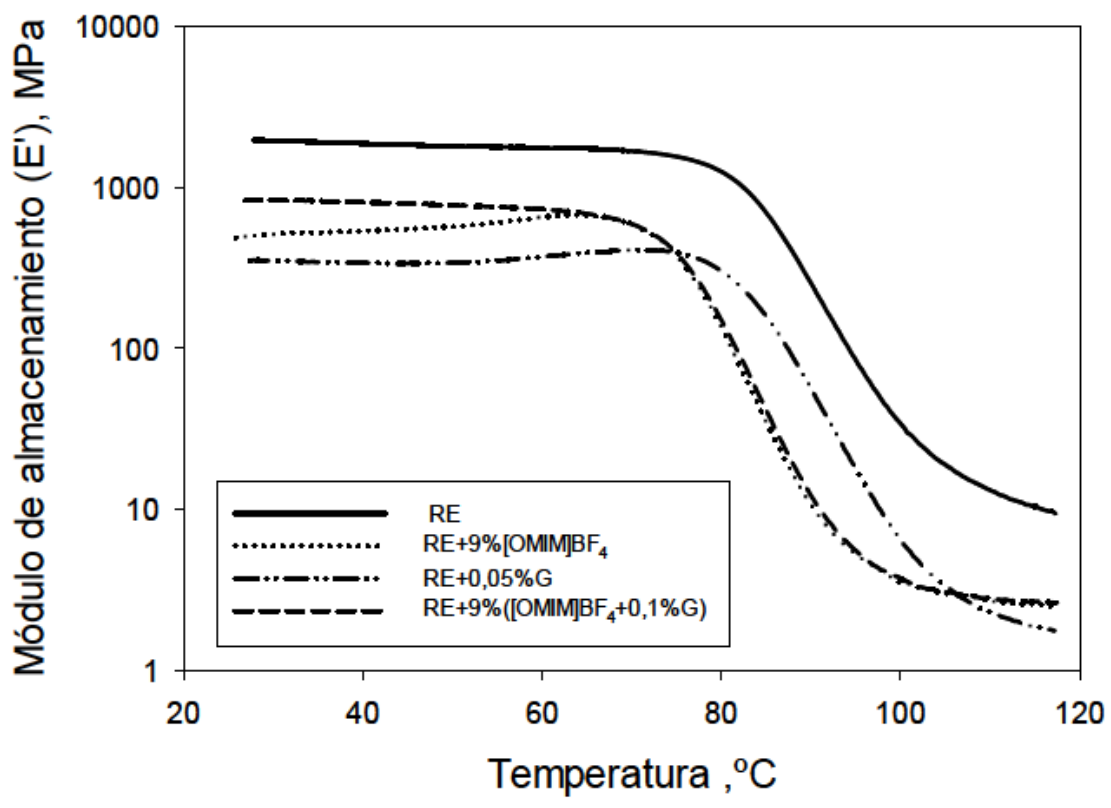

Figura 283. Evolución del módulo de almacenamiento con la temperatura para films de RE, $\mathrm{RE}+9 \%[\mathrm{OMIM}] \mathrm{BF}{ }_{4}, \mathrm{RE}+0,05 \% \mathrm{G}$ y $\mathrm{RE}+9 \%\left([\mathrm{OMIM}] \mathrm{BF}_{4}+0,1 \% \mathrm{G}\right)$

La resina epoxi sin aditivos posee mayor módulo de almacenamiento ( $E$ ') en todo el intervalo de temperatura. La adición de líquido iónico o grafeno contribuye a disminuir el valor de este parámetro.

La evolución del módulo de pérdida (E") con la temperatura se muestra en la Figura 284.

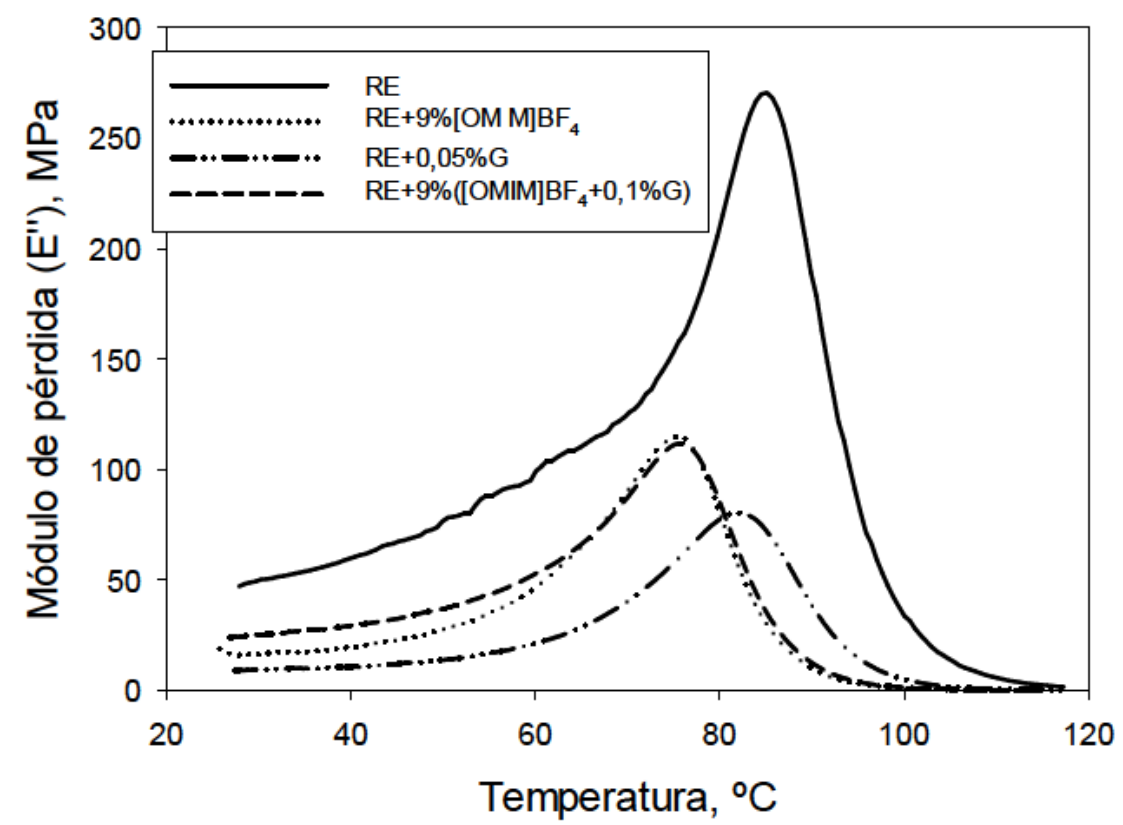

Figura 284. Evolución del módulo de pérdida con la temperatura para films de RE, $\mathrm{RE}+9 \%[\mathrm{OMIM}] \mathrm{BF}{ }_{4}, \mathrm{RE}+0,05 \% \mathrm{G}$ y RE+9\%([OMIM]BF $\left.4+0,1 \% \mathrm{G}\right)$ 
Se puede observar cómo al añadir, ya sea líquido iónico [OMIM]BF 4 o grafeno, la resina epoxi pierde en cierta medida su capacidad de disipar energía. Además, tal y como se había observado en el caso del módulo de almacenamiento, la adición de líquido iónico desplaza la temperatura de transición vítrea del material hacia la izquierda.

También se ha obtenido el valor de la tangente de delta $(\tan (\overline{0}))$, el parámetro que permite medir la capacidad del material para disipar energía mecánica en función de la temperatura. Este valor se obtiene a partir de los módulos de almacenamiento y de pérdida.

En la Figura 285 se muestra la misma tendencia observada anteriormente. La adición de líquido iónico provoca el desplazamiento de las curvas hacia temperaturas más bajas, aunque el valor máximo de la tangente se mantiene prácticamente igual. La adición de grafeno, por su parte, supone una disminución importante del valor máximo de $\tan (\bar{\delta})$, mientras que la temperatura a la cual se alcanza el máximo es similar al de la resina epoxi sin aditivos.

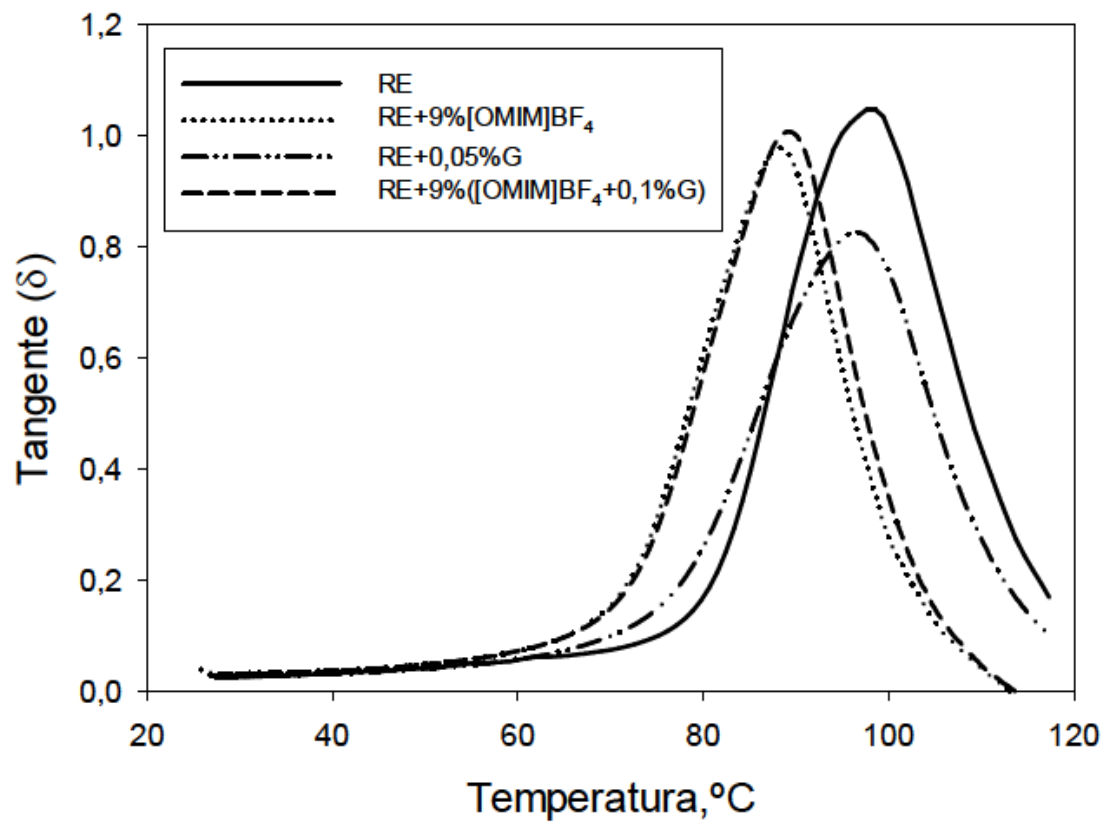

Figura 285. Evolución de la tan(ס) con la temperatura para films de RE, RE+9\%[OMIM]BF $\mathrm{RE}+0,05 \% \mathrm{G}$ y $\mathrm{RE}+9 \%\left([\mathrm{OMIM}] \mathrm{BF}{ }_{4}+0,1 \% \mathrm{G}\right)$

Los valores de temperatura de transición y de módulos de comportamiento dinámico-mecánico de cada nanocomposite en forma de film se muestran en la Tabla 97. 
Tabla 97. Propiedades dinámico-mecánicas de films de RE, RE+9\%[OMIM]BF 4 , RE+0,05\%G y $\mathrm{RE}+9 \%\left([\mathrm{OMIM}] \mathrm{BF}_{4}+0,1 \% \mathrm{G}\right)$

\begin{tabular}{|c|c|c|c|c|c|c|}
\hline \multirow[b]{2}{*}{ Material } & \multicolumn{2}{|c|}{$\begin{array}{c}\text { E' (MPa) } \\
\text { Transición en Onset }\end{array}$} & \multicolumn{2}{|c|}{$\begin{array}{c}\text { E'”(MPa) } \\
\text { Transición en pico } \\
\text { máximo }\end{array}$} & \multicolumn{2}{|c|}{$\begin{array}{c}\operatorname{Tan}(\delta) \\
\text { Transición en pico } \\
\text { máximo }\end{array}$} \\
\hline & $\mathrm{T}\left({ }^{\circ} \mathrm{C}\right)$ & $E^{\prime}$ & $\mathrm{T}\left({ }^{\circ} \mathrm{C}\right)$ & E’ & $\mathrm{T}\left({ }^{\circ} \mathrm{C}\right)$ & $\operatorname{Tan}(\delta)$ \\
\hline RE & $\begin{array}{c}81,26 \\
( \pm 1,54)\end{array}$ & $\begin{array}{l}1056,10 \\
( \pm 94,48)\end{array}$ & $\begin{array}{c}83,48 \\
( \pm 2,43)\end{array}$ & $\begin{array}{l}277,76 \\
( \pm 6,95)\end{array}$ & $\begin{array}{c}97,08 \\
( \pm 2,96)\end{array}$ & $\begin{array}{c}1,00 \\
( \pm 0,05)\end{array}$ \\
\hline RE+9\%[OMIM]BF 4 & $\begin{array}{c}74,08 \\
( \pm 0,42)\end{array}$ & $\begin{array}{c}392,61 \\
( \pm 40,19)\end{array}$ & $\begin{array}{c}74,94 \\
( \pm 0,16)\end{array}$ & $\begin{array}{c}112,73 \\
( \pm 10,68)\end{array}$ & $\begin{array}{c}87,89 \\
( \pm 0,36)\end{array}$ & $\begin{array}{c}0,97 \\
( \pm 0,02)\end{array}$ \\
\hline$R E+0,05 \% G$ & $\begin{array}{c}79,51 \\
( \pm 1,41)\end{array}$ & $\begin{array}{l}306,63 \\
( \pm 5,86)\end{array}$ & $\begin{array}{c}80,91 \\
( \pm 1,24)\end{array}$ & $\begin{array}{c}79,63 \\
( \pm 9,12)\end{array}$ & $\begin{array}{c}93,19 \\
( \pm 2,58)\end{array}$ & $\begin{array}{c}0,84 \\
( \pm 0,01)\end{array}$ \\
\hline $\mathrm{RE}+9 \%\left([\mathrm{OMIM}] \mathrm{BF}_{4}+0,1 \% \mathrm{G}\right)$ & $\begin{array}{c}74,74 \\
( \pm 0,26)\end{array}$ & $\begin{array}{c}404,22 \\
( \pm 20,99)\end{array}$ & $\begin{array}{c}75,65 \\
( \pm 0,12)\end{array}$ & $\begin{array}{c}118,33 \\
( \pm 7,50)\end{array}$ & $\begin{array}{c}88,72 \\
( \pm 0,72)\end{array}$ & $\begin{array}{c}1,01 \\
( \pm 0,01)\end{array}$ \\
\hline
\end{tabular}

El comportamiento dinámico-mecánico de los films con $9 \%$ de líquido iónico o $9 \%$ de líquido iónico y $0,1 \%$ de grafeno es muy similar debido a la baja proporción relativa de grafeno presente. Cuando sólo se añade grafeno, se obtiene la mayor reducción de las propiedades dinámico-mecánicas. La mayor área bajo las curvas de módulo de pérdida y de $\tan (\delta)$ indican una restricción de la movilidad de las cadenas y una menor homogeneidad de la distribución del aditivo en la matriz.

\subsubsection{Conclusiones}

Se ha puesto a punto un método de spin coating para la aplicación de capas finas y recubrimientos superficiales de resina epoxi modificada por líquidos iónicos próticos y apróticos, grafeno o dispersiones de grafeno en líquidos iónicos.

La adición de los líquidos iónicos incrementa la ductilidad de la resina epoxi.

En el caso el sustrato de acero, una sola capa de recubrimiento con el líquido iónico aprótico derivado de imidazolio es suficiente para reducir la fricción y prevenir el desgaste.

Para obtener resultados similares con el líquido iónico prótico derivado del anión oleato, es necesario aplicar una doble capa de recubrimiento sobre el sustrato de acero. 
La mejora de la resistencia a la abrasión y al desgaste por deslizamiento de los nuevos recubrimientos está de acuerdo con los resultados obtenidos para los materiales compuestos de resina epoxi modificados en todo su volumen, pero permiten localizar los aditivos sólo en la capa superficial, allí donde son necesarios para la mejora de las prestaciones tribológicas, con el consiguiente ahorro de material, al mismo tiempo que se conservan las características del sustrato sin modificar. 
5. CONCLUSIONES 



\section{CONCLUSIONES}

Se han estudiado cristales líquidos iónicos derivados de ácidos grasos como aditivos lubricantes en agua. Los resultados de las medidas de espesores de película lubricante y coeficientes de fricción permiten extraer las siguientes conclusiones.

> En todos los casos, el incremento en el espesor de película mejora el comportamiento de los lubricantes.

$>$ En el caso del agua pura, tomada como referencia, se obtienen espesores de película negativos, lo que indica que se produce desgaste como consecuencia del fallo del lubricante. Además, el espesor de película disminuye y el coeficiente de fricción aumenta con el incremento del número de ciclos de desplazamiento.

$>$ En contraste, cuando se añade al agua uno de los cristales líquidos iónicos, el espesor de película aumenta con el número de deslizamientos, confirmando la formación de una película lubricante en la interfase. El menor coeficiente de fricción se obtiene para el aditivo derivado del palmitato.

> La adición de nanodiamantes a la emulsión de palmitato de bis(2hidroxietilamonio) incrementa el espesor de película, pero sólo reduce el coeficiente de fricción en el primer ciclo de desplazamiento. Esto se atribuye a la baja estabilidad de la dispersión de nanodiamantes bajo las condiciones de deslizamiento.

En el estudio de la influencia de la velocidad de deslizamiento sobre la capacidad lubricante de las emulsiones de cristales líquidos iónicos en agua, se han alcanzado las siguientes conclusiones:

> En lubricación del contacto acero-acero a baja velocidad, el agua pura presenta altos coeficientes de fricción y baja resistencia eléctrica en el contacto. Cuando la velocidad se incrementa por encima de $100 \mathrm{~mm} / \mathrm{s}$, se produce una transición a coeficientes de fricción más bajos y resistencia eléctrica mayor, lo que está de acuerdo con la mejora de la eficacia de los lubricantes al aumentar el espesor de película en la interfase.

- La adición de los cristales líquidos iónicos reduce en un $75-80 \%$ el coeficiente de fricción con respecto al agua, en todo el rango de velocidades de deslizamiento estudiado. Así mismo, la resistencia eléctrica alcanza valores inferiores a los obtenidos en el caso del agua. Ambos aditivos reducen los tasas de desgaste con respecto al agua en un orden de magnitud.

Para contactos zafiro-acero, velocidades mayores de $100 \mathrm{~m} / \mathrm{s}$ incrementan el coeficiente de fricción. La mayor reducción de fricción se consigue para la combinación del aditivo derivado de palmitato con nanodiamantes. 
Estos resultados demuestran la capacidad de los líquidos iónicos próticos, derivados de ácidos grasos y medioambientalmente compatibles para mejorar la eficacia de lubricantes base agua.

Se ha utilizado un líquido iónico prótico derivado del anión biocompatible succinato como aditivo en agua, tanto en lubricación con película gruesa, como en lubricación con capa fina obtenida mediante la evaporación del agua de una disolución que contiene un $1 \%$ en peso del líquido iónico, previamente depositada sobre una superficie de acero inoxidable.

La capa fina elimina el período inicial de alta fricción que se registra en el caso de la lubricación con película gruesa, tanto para el líquido iónico puro como para la disolución en agua.

Otra estrategia para eliminar el período inicial de alta fricción y reducir la tasa de desgaste ha sido la dispersión de grafeno. Una concentración del 0,05\% de grafeno en el líquido iónico, no sólo reduce el coeficiente de fricción sino que evita el desgaste.

> La protección frente al desgaste se debe a la formación de una capa sobre la superficie del acero, que contiene tanto grafeno como líquido iónico.

Las conclusiones derivadas del estudio del comportamiento tribológico de dispersiones de nanodiamantes en el líquido iónico citrato de tri[bis(2hidroxietil)amonio] son las siguientes:

> Cuando se añade una suspensión de nanodiamantes en agua al líquido iónico derivado de citrato, se consigue una reducción del coeficiente de fricción, pero no así de la tasa de desgaste, lo que podría deberse a la presencia de agua.

> Cuando se utilizan lubricantes de capa fina formada sobre la superficie del acero por evaporación de agua previa al deslizamiento, se obtienen tasas de desgaste similares y coeficientes de fricción menores que en el caso de los lubricantes de película gruesa. Esto se atribuye a la formación de una capa adsorbida sobre la superficie que ofrece menor resistencia al deslizamiento.

En el estudio de líquidos iónicos apróticos comerciales y sus combinaciones con grafeno, se han alcanzado las siguientes conclusiones:

En el estudio del comportamiento reológico de las nuevas dispersiones, se ha encontrado una concentración crítica del $0,5 \%$ de grafeno que genera valores de viscosidad prácticamente constantes en un amplio rango de temperaturas. Concentraciones superiores de grafeno en los líquidos iónicos dan lugar a un comportamiento reológico anómalo, ya que la viscosidad se incrementa de manera lineal al aumentar la temperatura. 
$>$ Este comportamiento sin precedentes, se atribuye a la formación de interacciones más fuertes entre la superficie de las láminas de grafeno y las moléculas de líquido iónico, que revierten al disminuir la temperatura.

La dispersión de grafeno en Bis(trifluorometilsulfonil)imida de 1-etil-3metilimidazolio presenta unas excelentes prestaciones tribológicas, ya que evita el desgaste o daño superficial en el acero. Esto puede atribuirse a la combinación de tres factores: la mayor capacidad para soportar carga de las nuevas dispersiones, la formación de una película de grafeno sobre la superficie y la adhesión de las partículas de desgaste de tamaño nanométrico a las láminas de grafeno, lo que evita la formación de grandes aglomerados y por tanto el daño superficial por abrasión.

La posible aplicación práctica de grafeno, el líquido iónico aprótico 1-octil-3metilimidazolio y la combinación de ambos como aditivos en aceites lubricantes comerciales, se ha estudiado tanto a temperatura ambiente como a $150^{\circ} \mathrm{C}$.

$>$ Cuando se trata de un aceite base isoparafínico sin aditivos, las mejores prestaciones antifricción y desgaste se obtienen cuando se añade un $5 \%$ de la dispersión que contiene un $0,1 \%$ de grafeno en el líquido iónico, debido a la capacidad del líquido iónico para estabilizar la dispersión de grafeno en el aceite base.

$>$ En el caso de un aceite comercial de motor totalmente formulado, una concentración muy baja de grafeno $(0,005 \%)$ es suficiente para reducir el coeficiente de fricción en un $73 \%$, evitando la pérdida de material por desgaste, incluso a $150^{\circ} \mathrm{C}$. Estos buenos resultados se atribuyen a la formación de una capa protectora de grafeno sobre la superficie del acero.

Se ha obtenido un nuevo material autolubricante a partir de una matriz de resina epoxi modificada por dispersión de un líquido iónico prótico derivado del anión citrato. El líquido iónico actúa como agente de curado y tiene un efecto plastificante, incrementando la ductilidad del material. La reducción de los coeficientes de fricción se atribuye a la acción lubricante del líquido iónico bajo carga. Tras el deslizamiento, la zona de contacto presenta un acabado más pulido debido a la liberación del fluido y al cierre de las cavidades en las que se alojaba.

Se ha puesto a punto un método de spin coating para la aplicación de capas finas y recubrimientos superficiales de resina epoxi modificada por líquidos iónicos próticos y apróticos, grafeno o dispersiones de grafeno en líquidos iónicos.

La adición de los líquidos iónicos incrementa la ductilidad de la resina epoxi. 
DEn el caso el sustrato de acero, una sola capa de recubrimiento con el líquido iónico aprótico derivado de imidazolio es suficiente para reducir la fricción y prevenir el desgaste.

> Para obtener resultados similares con el líquido iónico prótico derivado del anión oleato, es necesario aplicar una doble capa de recubrimiento sobre el sustrato de acero.

$>$ La mejora de la resistencia a la abrasión y al desgaste por deslizamiento de los nuevos recubrimientos está de acuerdo con los resultados obtenidos para los materiales compuestos de resina epoxi modificados en todo su volumen, pero permiten localizar los aditivo sólo en la capa superficial, allí donde son necesarios para la mejora de las prestaciones tribológicas, con el consiguiente ahorro de material, al mismo tiempo que se conservan las características del sustrato sin modificar. 


\subsection{CONCLUSIONS}

Ionic liquid crystals derived from fatty acid have been studied in water. Friction coefficients and lubrication film thickness measurements draw the following main conclusions:

$>$ In all cases, higher values of film thickness improve the lubricity of the lubricant.

> For pure water, taken as a reference, negative film thickness values were obtained, showing wear as a consequence of the lubricant failure. Film thickness decreases and friction coefficient increases with increasing number of sliding motion.

> In contrast, when the ionic liquid crystals are added to water, film thickness values increase with the number of sliding motion, which means that boundary films of the lubricants were formed in the interface. The lowest friction coefficient is obtained for the additive derived from palmitate.

> Addition of nanodiamonds to the emulsion of bis(2-hidroxyethilammonium) palmitate increases film thickness, but reduces friction coefficient only for the first sliding motion. This could be attributed to the low stability of the nanodiamond dispersion at the sliding conditions.

In the study of the influence of sliding velocity on the lubricating capacity of emulsions of ionic liquid crystals in water, the following conclusions have been reached:

> In steel-steel lubrication at low sliding speed, water as neat lubricant presents high friction coefficients and low contact electrical resistance. A transition to lower friction coefficients and higher contact resistance is observed for sliding speed higher than $100 \mathrm{~mm} / \mathrm{s}$, what is in agreement with the improvement of the efficiency of the lubricants when the lubricant film thickness increases.

> Addition of 1 weight percent of ionic liquid crystals reduces friction coefficients in $75-80 \%$ with respect to water in the whole range of sliding speeds. Moreover, the electrical resistance reaches lower values than those obtained in the case of water. All additives reduce the wear rates in at least one order of magnitude with respect to water.

$>$ In sapphire-steel contacts, friction coefficients increase for sliding speed higher than $100 \mathrm{~mm} / \mathrm{s}$. The highest friction coefficient reduction is achieved by the combination of palmitate derivate additive and nanodiamonds.

These results confirm the ability of protic ionic liquids, derived from fatty acids and environmentally compatible to improve the effectiveness of water-based lubricants.

A protic ionic liquid derived from the biocompatible anion succinate has been used as an additive in water, both in thick film and in thin layer lubrication obtained by evaporating the water from a solution containing $1 \%$ weight of the ionic liquid, previously deposited on a stainless steel surface. 
A thin film eliminates the high friction period during running-in, which appears both for the neat ionic liquid and for the solution of the ionic liquid in water lubricants.

Another strategy to eliminate the initial period of high friction and reduce the wear rate has been the dispersion of graphene. A concentration of $0.05 \%$ graphene in the ionic liquid not only reduces the coefficient of friction but also prevents wear.

$>$ The protection against wear is due to the formation of a layer in the steel surface, which contains graphene and ionic liquid.

The conclusions derived from the study of the tribological behavior of dispersions of nanodiamonds in the ionic liquid tri[bis(2-hydroxyethyl) ammonium]citrate are the following:

$>$ When a suspension of nanodiamonds in water is added to the protic ionic liquid, derivate from citrate, a reduction of the friction coefficient is achieved, but not of the wear rate, which could be due to the presence of water.

$>$ If thin films boundary lubrication films generated on the steel surface before the sliding by evaporation of water are used, similar wear rates and lower friction coefficients are obtained than in the case of thick film lubricants. This is attributed to the formation of an adsorbed layer on the surface that offers less resistance to the motion.

In the study of aprotic commercial ionic liquids and their combinations with graphene, the following conclusions have been obtained:

$>$ In the study of the rheological behavior of the new dispersions, a critical concentration of $0.5 \%$ of graphene has been found, which generates practically constant viscosity values over a wide range of temperatures. Higher concentrations of graphene in the ionic liquids give rise to an anomalous rheological behavior, since the viscosity increases linearly when the temperature increases.

$>$ This unprecedented behavior is attributed to the formation of stronger interactions between the surface of the graphene sheets and the ionic liquid molecules, which revert when the temperature decreases

$>$ Dispersion of graphene in 1-ethyl-3-methylimidazolium bis(trifluoromethanosulfonyl)imide presents excellent tribological performance, because it prevents the wear or superficial damage in the steel. This can be attributed to the combination of three factors: the increase of the load bearing ability of the dispersions, the formation of a graphene layer on the surface and the adhesion of the nano-sized wear particles to 
the graphene sheets, which prevents the formation of large agglomerates and prevents surface damage by abrasion.

The possible practical application of graphene, the 1-octyl-3-methylimidazolium aprotic ionic liquid and the combination of both as additives in commercial lubricating oils, has been studied both at room temperature and at $150^{\circ} \mathrm{C}$.

$>$ In the case of the isoparaffinic base oil without additives, the best friction reducing and wear preventing results are obtained when a $5 \%$ of the dispersion which contains a $0.1 \%$ of graphene in the ionic liquid is added, due to the ability of the ionic liquid to stabilize the graphene dispersion in the base oil.

$>$ In the case of the fully-formulated oil, an extremely low concentration of added graphene $(0.005 \%)$ is enough to reduce the friction coefficient up to $73 \%$, preventing material loss even at $150^{\circ} \mathrm{C}$. This good performance is attributed to the formation of a protective layer that contains graphene in the steel surface.

A new self-lubricating material has been obtained from a modified epoxy resin matrix by dispersing the protic ionic liquid derived from the citrate anion. The ionic liquid acts as a curing agent and has a plasticizing effect, increasing the ductility of the material. The reduction of friction coefficients is attributed to the lubricating action of the ionic liquid under load. After the sliding, the contact area has a more polished finish due to the release of the fluid and the closing of the cavities in which it was housed.

A spin coating method has been developed for the creation of thin layers and surface coatings of epoxy resin modified by protic and aprotic ionic liquids, graphene or graphene dispersions in ionic liquids.

$>$ In the case of the steel substrate, a single coating layer with the imidazolium-derived aprotic ionic liquid is enough to reduce friction and prevent wear.

> To obtain similar results with the protic ionic liquid derived from the oleate anion, it is necessary to apply a double coating layer on the steel substrate.

> The improvement of the abrasion and sliding wear resistance of the new coatings is in agreement with the results obtained for the modified epoxy resin materials in all their volume, but they allow to locate the additives only in the superficial layer, there where they are necessary for the improvement of the tribological performances, with the consequent saving of material, keeping unmodified the characteristics of the substrate at the same time. 



\section{LÍNEAS FUTURAS DE TRABAJO}





\section{LÍNEAS FUTURAS DE TRABAJO}

1) Estudiar el comportamiento tribológico de líquidos iónicos y de los nuevos nanofluidos en contacto acero-acero en condiciones de deslizamiento lineal oscilatorio.

En esta línea se ha comenzado a trabajar durante la estancia de investigación llevada a cabo en el Rochester Institute of Technology, EEUU (Abril-Julio de 2018). Se ha estudiado el comportamiento tribológico del líquido iónico DSu, una disolución de DSu en agua y capas finas obtenidas a partir de la disolución de este líquido iónico en el contacto acero AISI 52100-AISI 52100 (Figura 286).

a)

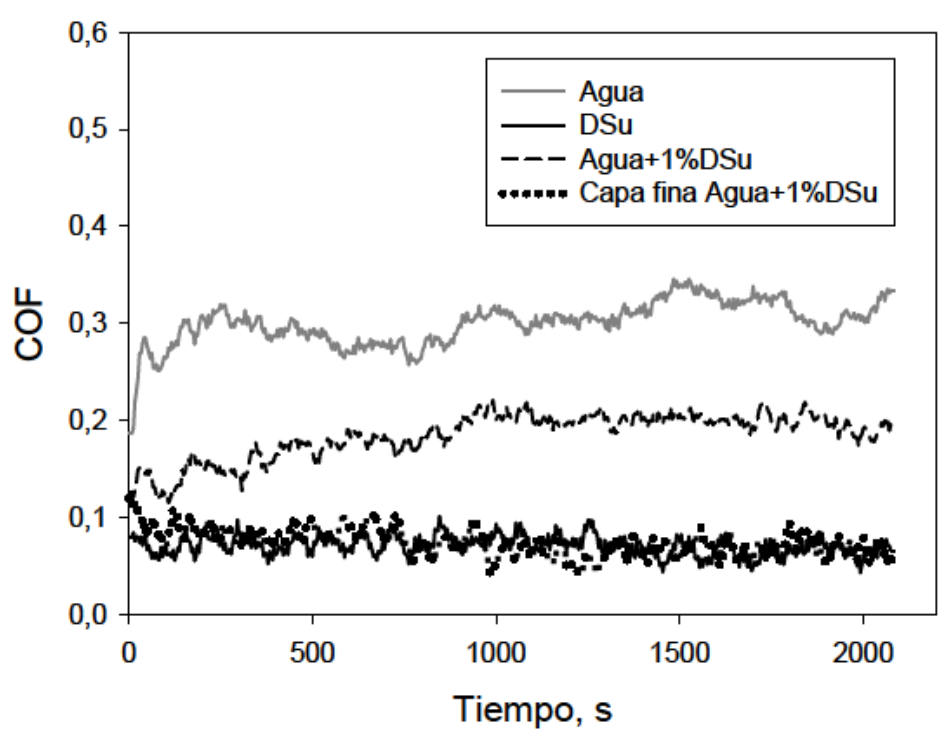

b)

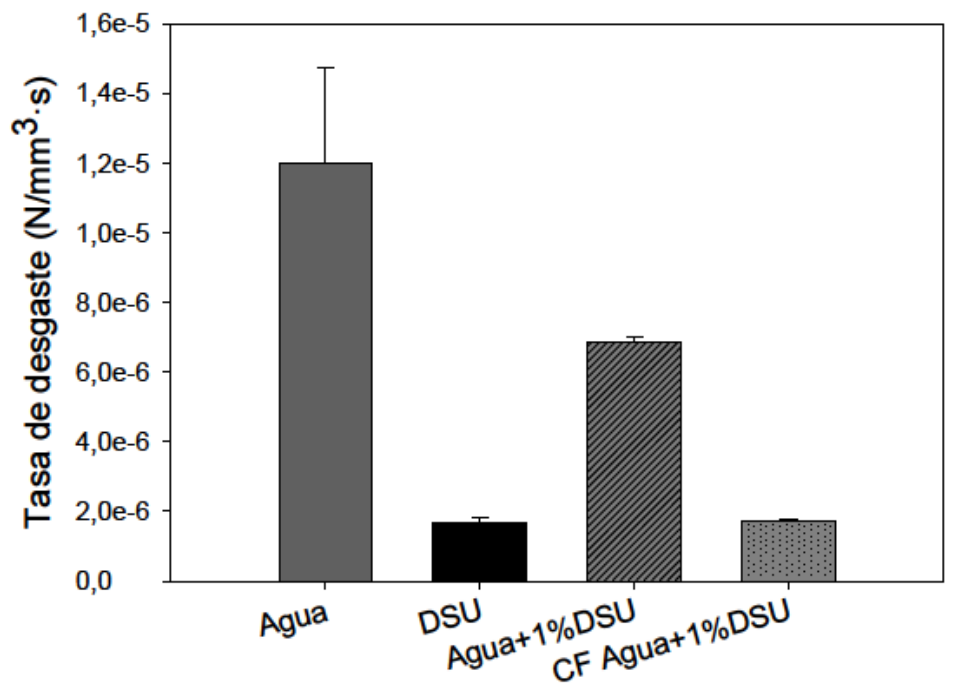

Figura 286. Ensayos tribológicos lineales oscilatorios empleando agua, DSu, Agua+1\%DSu y capas finas de DSu en el contacto AISI 52100-AISI 52100; a) Evolución del coeficiente de fricción; b) Tasa de desgaste 
Como se puede observar, los resultados obtenidos tras los ensayos lineales oscilatorios, con $3 \mathrm{~N}$ de carga y $2 \mathrm{~mm}$ de longitud de la huella son muy prometedores. Éstos muestran una reducción significativa del coeficiente de fricción (Figura 286a) y de la tasa de desgaste (Figura 286b).

2) Empleo de las técnicas de microscopía AFM y FIB-SEM para la caracterización y estudio de nanofases, recubrimientos y films.

También durante la estancia en el Rochester Institute of Technology, se han realizado estudios de AFM de los films de matriz epoxi, encontrándose diferentes estructuras en función del aditivo empleado (Figura 287).

a)

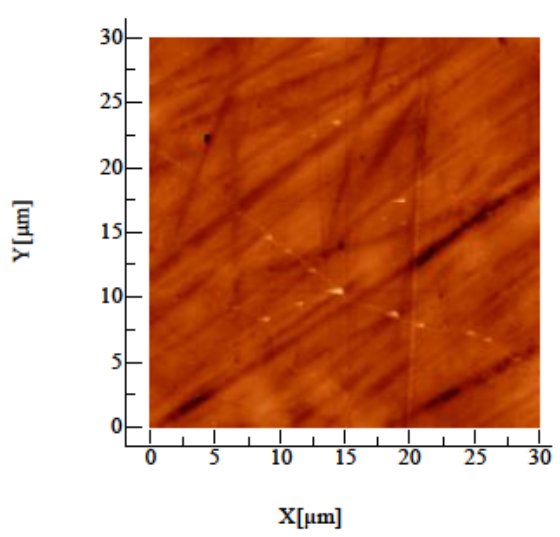

c)

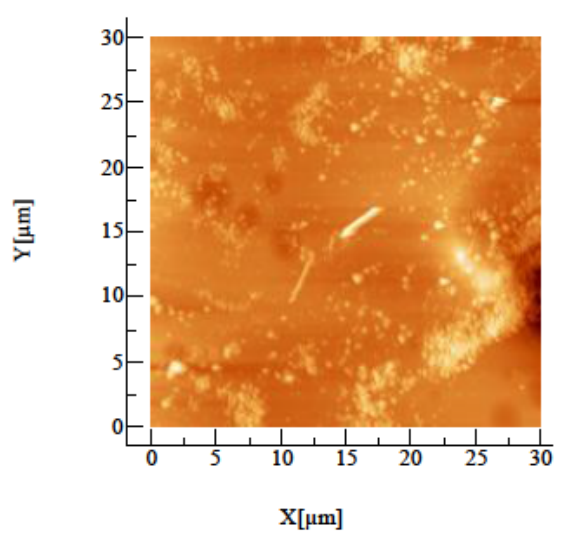

b)
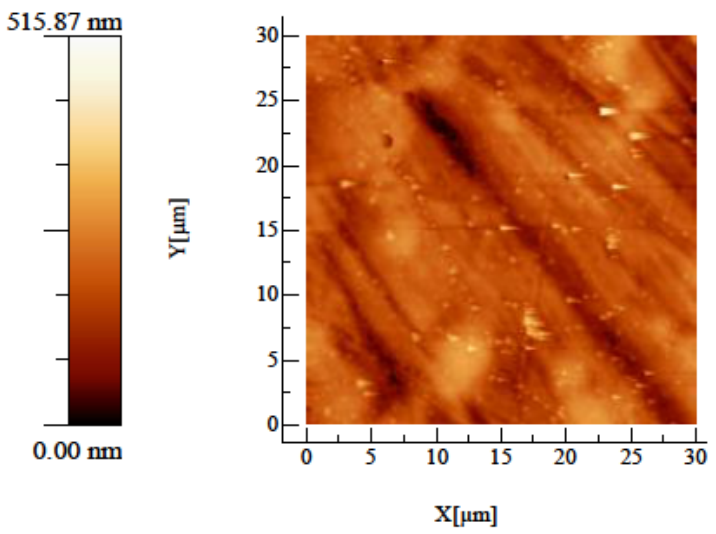

d)
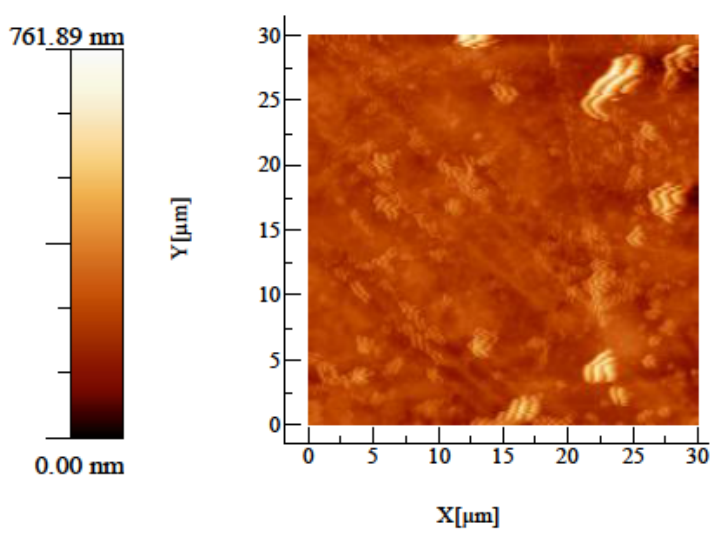
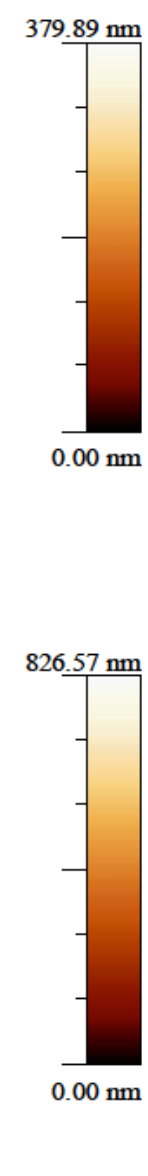

Figura 287. Imágenes AFM. a) Film RE; b) Film RE+9\%[OMIM]BF 4 ; c) Film RE+0,05\%G;

d) $\mathrm{RE}+9 \%\left([\mathrm{OMIM}] \mathrm{BF}_{4}+0,1 \% \mathrm{G}\right)$

3) Obtención, caracterización y estudio del comportamiento tribológico de nuevos nanocomposites con líquidos iónicos y/o nanofases de carbono en matriz termoplástica.

4) Colaboración con otros grupos para la obtención de modelos teóricos para determinar las interacciones nanofluido-nanofase.

5) Continuar la colaboración con la Dra Iglesias, del Rochester Institute of Technology en la obtención y estudio tribológico de nuevos lubricantes. 


\section{REFERENCIAS BIBLIOGRÁFICAS}





\section{REFERENCIAS BIBLIOGRÁFICAS}

[1] I. M. Hutchings, Tribology. Friction and Wear of Engineering Materials, $1^{\text {a }}$ Ed. Londres, Reino Unido: Taylor \& Francis, 1992.

[2] T. Mang, K. Bobzin, y T. Bartels, «Industrial tribology: Tribosystems, wear and surface engineering, lubrication», Ind. Tribol. Tribosystems, Wear Surf. Eng. Lubr., 2010.

[3] H. Jost, Lubrication (tribology) education and research: a report on the present position and industry's needs. London: H.M. Stationery Off, 1966.

[4] «Tribology savings fail to live up to promise - Article». [En línea]. Disponible en: https://www.theengineer.co.uk/inspiration/tribology-savings-fail-to-live-up-topromise/. [Accedido: 09-mar-2018].

[5] I. Tzanakis, M. Hadfield, B. Thomas, S. M. Noya, I. Henshaw, y S. Austen, «Future perspectives on sustainable tribology», Renew. Sustain. Energy Rev., vol. 16, pp. 4126-4140, 2012.

[6] M. Nosonovsky y B. Bhushan, «Green tribology: principles, research areas and challenges», Philos. Trans. R. Soc. A Math. Phys. Eng. Sci., vol. 368, pp. 46774694, 2010.

[7] S. A. R. Hashmi, U. K. Dwivedi, y N. Chand, "Graphite modified cotton fibre reinforced polyester composites under sliding wear conditions», Wear, vol. 262, pp. 1426-1432, 2007.

[8] C. M. Taylor, «Automobile engine tribology-design considerations for efficiency and durability», Wear, vol. 221, pp. 1-8, 1998.

[9] B. Bhushan, Introduction to tribology, $2^{\text {a }}$ Ed. Nueva York, EEUU: John Wiley \& Sons, 2013.

[10] N. Canter y M. Anderson, «The ten greatest events in Tribology History», Tribol. Lubr. Technol., pp. 38-47, 2005.

[11] I. M. Hutchings, "Leonardo da Vinci's studies of friction», Wear, vol. 360-361, pp. 51-66, 2016.

[12] F. Findik, "Latest progress on tribological properties of industrial materials», Mater. Des., vol. 57, pp. 218-244, 2014.

[13] D. Tabor, «Friction, lubrication and wear», en Mechanical design handbook, measurement, analysis, and control of dynamic systems, $2^{\mathrm{a}}$ Ed., Nueva York, EEUU: McGraw-Hill Education, 2006, pp. 1-26.

[14] P. J. Blau, «The significance and use of the friction coefficient», Tribol. Int., vol. 34, pp. 585-591, 2001.

[15] ASM Handbook. Friction, Iubrication, and wear technology. Ohio, EEUU: ASM International, 2017.

[16] K. Kato y K. Adachi, «Wear Mechanisms», Mod. Tribol. Handbook., p. 1760, 2001.

[17] H. Jost, «Tribology: How a word was coined 40 years ago», Tribol. Lubr. Technol., vol. 62, pp. 24-28, 2006.

[18] J. A. Williams, «Wear modelling: analytical, computational and mapping: a continuum mechanics approach», Wear, vol. 225-229, pp. 1-17, 1999.

[19] A. Devaraju, «A critical review on different types of wear of materials», Int. J. Mech. Eng. Technol., vol. 6, pp. 77-83, 2015. 
[20] I. Minami, «Molecular science of lubricant additives», Appl. Sci., vol. 7, p. 445, 2017.

[21] M. Palacio y B. Bhushan, «A review of ionic liquids for green molecular lubrication in nanotechnology», Tribol.Lett., vol. 40, p. 247, 2010.

[22] L. Ma y J. Luo, «Thin film lubrication in the past 20 years», Friction, vol. 4, pp. 280-302, 2016.

[23] G. W. Stachowiak y A. W. Batchelor, «Hydrodinamic lubrication», en Engineering Tribology, $3^{\text {a }}$ Ed., Massachusetts, USA: Burlington, 2006, pp. 103204.

[24] S. Z. Wen, Principle of tribology. Pekín, China: Tsinghua University Press, 1991.

[25] J. B. Luo, X. C. Lu, y S. Z. Wen, «Developments and unsolved problems in nano-lubrication», Prog. Nat. Sci., vol. 11, pp. 180-183, 2001.

[26] J. B. Luo, «Study on the measurement and experiments of thin film lubricationTesis Doctoral», Tsinghua University, China, 1994.

[27] Y. Zhou y J. Qu, "lonic liquids as lubricant additives: A review», ACS Appl. Mater. Interfaces, vol. 9, pp. 3209-3222, 2017.

[28] M. D. Bermúdez, A. E. Jiménez, J. Sanes, y F. J. Carrión, «lonic liquids as advanced lubricant fluids», Molecules, vol. 14, pp. 2888-2908, 2009.

[29] S. Zhang, Q. Zhang, Y. Zhang, Z. Chen, M. Watanabe, y Y. Deng, «Beyond solvents and electrolytes: lonic liquids-based advanced functional materials», Prog. Mater. Sci., vol. 77, pp. 80-124, 2016.

[30] M. Amde, J. F. Liu, y L. Pang, «Environmental application, fate, effects, and concerns of ionic liquids: A review», Environ. Sci. Technol., vol. 49, pp. 1261112627, 2015.

[31] G. J. Maximo, R. J. B. N. Santos, J. A. J. A. Lopes-Da-Silva, M. C. Costa, A. J. A. Meirelles, J. A. P. Coutinho, A. P. Coutinho, y J. A. P. Coutinho, «Lipidic Protic Ionic Liquid Crystals», ACS Sustain. Chem. Eng., vol. 2, pp. 672-682, 2014.

[32] C. Verma, E. E. Ebenso, y M. A. Quraishi, «lonic liquids as green and sustainable corrosion inhibitors for metals and alloys: An overview», J. Mol. Liq., vol. 233, pp. 403-414, 2017.

[33] A. E. Somers, P. C. Howlett, D. R. MacFarlane, y M. Forsyth, «A Review of Ionic Liquid Lubricants», Lubricants, vol. 1, pp. 3-21, 2013.

[34] R. Ratti, «lonic liquids: Synthesis and applications in catalysis», Adv. Chem., vol. 2014, pp. 1-16, 2014.

[35] T. Torimoto, T. Tsuda, K. I. Okazaki, y S. Kuwabata, «New frontiers in materials science opened by ionic liquids», Adv. Mater., vol. 22, pp. 1196-1221, 2010.

[36] J. S. Wilkes, «A short history of ionic liquids-from molten salts to neoteric solvents», Green Chem., vol. 4, pp. 73-80, 2002.

[37] P. Walden, «Ueber die Molekulargrösse und elektrische Leitfähigkeit einiger geschmolzenen Salze», Bull. del'Académie Impériale des Sci. St.-pétersbg., vol. 8, pp. 405-422, 1914.

[38] P. T. Anastas y N. Eghbali, «Green chemistry: Principles and practice», Chem. Soc. Rev., vol. 39, pp. 301-312, 2010.

[39] P. T. Anastas y J. B. Zimmerman, «Design through the 12 principles of green engineering», IEEE Eng. Manag. Rev., vol. 35, p. 16, 2007. 
[40] A. A. Shamsuri y R. Daik, «Applications of ionic liquids and their mixtures for preparation of advanced polymer blends and composites: A short review», Rev. Adv. Mater. Sci., vol. 40, pp. 45-59, 2015.

[41] H. Olivier-Bourbigou, M. Magda, y D. Morvan, «lonic liquids and catalysis: Recent progress from knowledge to applications», Appl. Catal. A, vol. 373, pp. 156, 2010.

[42] G. Quijano, A. Couvert, y A. Amrane, «lonic liquids: Applications and future trends in bioreactor technology», Bioresour. Technol., vol. 101, pp. 8923-8930, 2010.

[43] R. G. Reddy, «Novel applications of ionic liquids in materials processing», J. Phys. Conf. Ser., vol. 165, pp. 1-6, 2009.

[44] H. Xiao, «lonic liquid lubricants: basics and applications», Tribol. Trans., vol. 60, pp. 20-30, 2017.

[45] H. Zhao, «Innovative applications of ionic liquids as "green" engineering liquids», Chem. Eng. Commun., vol. 193, pp. 1660-1677, 2006.

[46] R. Singh, M. Sharma, R. Mamgain, y D. S. Rawat, «lonic liquids: a versatile medium for palladium-catalyzed reactions», J. Braz. Chem. Soc., vol. 19, pp. 357-379, 2008.

[47] T. Fukushima y T. Aida, «lonic liquids for soft functional materials with carbon nanotubes», Chem. - A Eur. J., vol. 13, pp. 5048-5058, 2007.

[48] Z. D. Petrović, L. Čomić, O. Stefanović, D. Simijonović, y V. P. Petrović, "Antimicrobial activity of the ionic liquids triethanolamine acetate and diethanolamine chloride, and their corresponding $\mathrm{Pd}(\mathrm{II})$ complexes», J. Mol. Liq., vol. 170, pp. 61-65, 2012.

[49] R. L. Vekariya, «A review of ionic liquids: Applications towards catalytic organic transformations», J. Mol. Liq., vol. 227, pp. 44-60, 2017.

[50] T. Tsuda y C. L. Hussey, «Electrochemical applications of room-temperature ionic liquids», Electrochem. Soc. Interface, vol. 16, pp. 42-49, 2007.

[51] F. Zhou, Y. Liang, y W. Liu, «lonic liquid lubricants: designed chemistry for engineering applications», Chem Soc Rev, vol. 38, pp. 2590-2599, 2009.

[52] N. V Plechkova y K. R. Seddon, «Applications of ionic liquids in the chemical industry», Chem. Soc. Rev., vol. 37, pp. 123-150, 2008.

[53] V. Gauchot, W. Kroutil, y A. R. Schmitzer, «Highly recyclable chemo/biocatalyzed cascade reactions with ionic liquids: One-pot synthesis of chiral biaryl alcohols», Chem. - A Eur. J., vol. 16, pp. 6748-6751, 2010.

[54] A. Gómez-Ramírez, M. T. López-López, F. González-Caballero, y J. D. G. Durán, "Stability of magnetorheological fluids in ionic liquids», Smart Mater. Struct., vol. 20, p. 45001, 2011.

[55] C. Ye, W. Liu, Y. Chen, y L. Yu, «Room-temperature ionic liquids: a novel versatile lubricant.», Chem. Commun. (Camb)., pp. 2244-2245, 2001.

[56] P. G. Smith, «High-temperature molten-salt lubricated hydrodynamic journal bearings», ASLE Trans., vol. 4, pp. 263-274, 1961.

[57] J. S. Wilkes y M. J. Zaworotko, «Air and water stable 1-ethyl-3methylimidazolium based ionic liquids», J. Chem. Soc. Chem. Commun., vol. 13, pp. 965-967, 1992.

[58] C. Ye, W. Liu, Y. Chen, y L. Yu, «Room-temperature ionic liquids: a novel 
versatile lubricant», Chem. Commun., pp. 2244-2245, 2001.

[59] W. Liu, C. Ye, Q. Gong, H. Wang, y P. Wang, «Tribological performance of room-temperature ionic liquids as lubricant», Tribol. Lett., vol. 13, pp. 81-85, 2002.

[60] S. A. S. Amiril, E. A. Rahim, y S. Syahrullail, "A review on ionic liquids as sustainable lubricants in manufacturing and engineering: Recent research, performance, and applications», J. Clean. Prod., vol. 168, pp. 1571-1589, 2017.

[61] R. González, M. Bartolomé, D. Blanco, J. L. Viesca, A. Fernández-González, y A. H. Battez, «Effectiveness of phosphonium cation-based ionic liquids as lubricant additive», Tribol. Int., vol. 98, pp. 82-93, 2016.

[62] A. Hernández Battez, M. Bartolomé, D. Blanco, J. L. Viesca, A. FernándezGonzález, y R. González, "Phosphonium cation-based ionic liquids as neat lubricants: Physicochemical and tribological performance», Tribol. Int., vol. 95, pp. 118-131, 2016.

[63] M. Moosavi, F. Khashei, A. Sharifi, y M. Mirzaei, «The effects of temperature and alkyl chain length on the density and surface tension of the imidazoliumbased geminal dicationic ionic liquids», J. Chem. Thermodyn., vol. 107, pp. 1-7, 2017.

[64] R. Gusain, P. Gupta, S. Saran, y O. P. Khatri, «Halogen-free Bis(imidazolium)/Bis(ammonium)-Di[bis(salicylato)borate] ionic liquids as energy-efficient and environmentally friendly lubricant additives», ACS Appl. Mater. Interfaces, vol. 6, pp. 15318-15328, 2014.

[65] W. C. Barnhill, H. Luo, H. M. Meyer, C. Ma, M. Chi, B. L. Papke, y J. Qu, «Tertiary and quaternary ammonium-phosphate ionic liquids as lubricant additives», Tribol. Lett., vol. 63:22, pp. 1-11, 2016.

[66] G. M. J. Al Kaisy, M. I. A. Mutalib, J. M. Leveque, y T. V. V. L. N. Rao, «Novel low viscosity ammonium-based ionic liquids with carboxylate anions: Synthesis, characterization, and thermophysical properties», J. Mol. Liq., vol. 230, pp. 565573, 2017.

[67] M. García-Mardones, I. Bandrés, M. C. López, I. Gascón, y C. Lafuente, «Experimental and theoretical study of two pyridinium-based ionic liquids», J. Solution Chem., vol. 41, pp. 1836-1852, 2012.

[68] H. Arora y P. M. Cann, «Lubricant film formation properties of alkyl imidazolium tetrafluoroborate and hexafluorophosphate ionic liquids», Tribol. Int., vol. 43, pp. 1908-1916, 2010.

[69] C. Zhang, S. Zhang, L. Yu, P. Zhang, Z. Zhang, y Z. Wu, «Tribological behavior of 1-methyl-3-hexadecylimidazolium tetrafluoroborate ionic liquid crystal as a neat lubricant and as an additive of liquid paraffin», Tribol. Lett., vol. 46, pp. 4954, 2012.

[70] M. Yao, M. Fan, Y. Liang, F. Zhou, y Y. Xia, «Imidazolium hexafluorophosphate ionic liquids as high temperature lubricants for steel-steel contacts», Wear, vol. 268, pp. 67-71, 2010.

[71] J. C. J. Bart, E. Gucciardi, y S. Cavallaro, «Advanced lubricant fluids», en Biolubricants, Cambridge, Reino Unido: Woodhead Publishing, 2013, pp. 824846.

[72] V. Popov, Contact Mechanics and Friction. Berlin, Alemania: Springer, 2017.

[73] L. Zhang, D. Feng, y B. Xu, «Tribological characteristics of alkylimidazolium diethyl phosphates ionic liquids as lubricants for steel-steel contact», Tribol. 
Lett., vol. 34, pp. 95-101, 2009.

[74] A. E. Jiménez, M. D. Bermúdez, P. Iglesias, F. J. Carrión, y G. Martínez-Nicolás, «1-N-alkyl-3-methylimidazolium ionic liquids as neat lubricants and lubricant additives in steel-aluminium contacts», Wear, vol. 260, pp. 766-782, 2006.

[75] R. Lhermerout, C. Diederichs, y S. Perkin, «Are Ionic Liquids Good Boundary Lubricants? A Molecular Perspective», Lubricants, vol. 6, p. 9, 2018.

[76] H. Xiao, D. Guo, S. Liu, G. Pan, y X. Lu, «Film Thickness of Ionic Liquids under High Contact Pressures as a Function of Alkyl Chain Length», Tribol.Lett., vol. 41, p. 471, 2011.

[77] R. Dong, P. Wen, S. Zhang, C. Zhang, W. Sun, M. Fan, D. Yang, F. Zhou, y W. Liu, "The synthesis and tribological properties of dicarboxylic acid ionic liquids», Tribol. Int., vol. 114, pp. 132-140, 2017.

[78] M. Deetlefs, M. Fanselow, y K. R. Seddon, «lonic liquids: the view from Mount Improbable», RSC Adv., vol. 6, pp. 4280-4288, 2016.

[79] S. Zhu, R. Chen, Y. Wu, Q. Chen, X. Zhang, y Z. Yu, «A mini-review on greenness of ionic liquids», Chem. Biochem. Eng. Q., vol. 23, pp. 207-211, 2009.

[80] D. Zhao, Y. Liao, y Z. Zhang, «Toxicity of Ionic Liquids», CLEAN Soil, Air, Water, vol. 35, pp. 42-48, 2007.

[81] B. Peric, J. Sierra, E. Martí, R. Cruañas, y M. A. Garau, «A comparative study of the terrestrial ecotoxicity of selected protic and aprotic ionic liquids», Chemosphere, vol. 108, pp. 418-425, 2014.

[82] B. Peric, J. Sierra, E. Martí, R. Cruañas, M. A. Garau, J. Arning, U. BottinWeber, S. Stolte, Cruan, M. A. Garau, J. Arning, U. Bottin-Weber, S. Stolte, y Eco, «(Eco)toxicity and biodegradability of selected protic and aprotic ionic liquids», J. Hazard. Mater., vol. 261, pp. 99-105, 2013.

[83] A. Jordan y N. Gathergood, «Biodegradation of ionic liquids - a critical review», Chem. Soc. Rev., vol. 44, pp. 8200-8237, 2015.

[84] J. Kulhavy, R. Andrade, S. Barros, J. Serra, y M. Iglesias, «Influence of temperature on thermodynamics of protic ionic liquid 2-hydroxy diethylammonium lactate (2-HDEAL) + short hydroxylic solvents», J. Mol. Liq., vol. 213, pp. 92-106, 2016.

[85] M.D. Avilés, N. Saurín, J. Sanes, F. J. Carrión, y M. D. Bermúdez, «lonanocarbon lubricants. The combination of ionic liquids and carbon nanophases in tribology», Lubricants, vol. 5, p. 14, 2017.

[86] T. L. Greaves y C. J. Drummond, «Protic ionic liquids: Evolving structureproperty relationships and expanding applications», Chem. Rev., vol. 115, pp. 11379-11448, 2015.

[87] N. Bicak, «A new ionic liquid: 2-hydroxy ethylammonium formate», J. Mol. Liq., vol. 116, pp. 15-18, 2005.

[88] T. L. Greaves, A. Weerawardena, C. Fong, I. Krodkiewska, y C. J. Drummond, «Protic ionic liquids: Solvents with tunable phase behavior and physicochemical properties», J. Phys. Chem. B, vol. 110, pp. 22479-22487, 2006.

[89] V. H. Álvarez, S. Mattedi, M. Martin-Pastor, M. Aznar, y M. Iglesias, «Synthesis and thermophysical properties of two new protic long-chain ionic liquids with the oleate anion», Fluid Phase Equilib., vol. 299, p. 42, 2010.

[90] I. Cota, R. Gonzalez-Olmos, M. Iglesias, y F. Medina, «New short aliphatic chain 
ionic liquids: Synthesis, physical properties, and catalytic activity in aldol condensations», J. Phys. Chem. B, vol. 111, pp. 12468-12477, 2007.

[91] M. Iglesias, A. Torres, R. Gonzalez-Olmos, y D. Salvatierra, «Effect of temperature on mixing thermodynamics of a new ionic liquid: \{2-Hydroxy ethylammonium formate (2-HEAF) + short hydroxylic solvents\}», J. Chem. Thermodyn., vol. 40, pp. 119-133, 2008.

[92] D. Camargo, R. S. Andrade, G. A. Ferreira, H. Mazzer, L. Cardozo-Filho, y M. Iglesias, "Investigation of the rheological properties of protic ionic liquids», J. Phys. Org. Chem., vol. 29, pp. 604-612, 2016.

[93] C. Ravazzano, K. Lima, R. S. Andrade, y M. Iglesias, «Volumetric and Acoustic Study of a Short Protic lonic Liquids Binary Mixture: 2- Hydroxy Ethyl Ammonium Formate ( 2-HEAF ) + 2-Hydroxy Diethyl Ammonium Acetate ( 2HDEAA )», Int. J. Thermodyn., vol. 19, pp. 244-250, 2016.

[94] R. S. Andrade, A. Carreras, y M. Iglesias, «Influence of temperature on thermodynamics for binary mixtures of short aliphatic protic ionic liquids», J. Serbian Chem. Soc., vol. 82, pp. 1155-1174, 2017.

[95] R. S. Andrade, D. Torres, F. R. Ribeiro, B. G. Chiari-Andréo, J. A. Oshiro Junior, y M. Iglesias, "Sustainable Cotton Dyeing in Nonaqueous Medium Applying Protic lonic Liquids», ACS Sustain. Chem. Eng., vol. 5, pp. 8756-8765, 2017.

[96] R. Hayes, S. Imberti, G. G. Warr, y R. Atkin, «How water dissolves in protic ionic liquids», Angew. Chemie - Int. Ed., vol. 51, pp. 7468-7471, 2012.

[97] T. L. Greaves, A. Weerawardena, I. Krodkiewska, y C. J. Drummond, «Protic ionic liquids: Physicochemical properties and behavior as amphiphile selfassembly solvents», J. Phys. Chem. B, vol. 112, pp. 896-905, 2008.

[98] A. A. C. Toledo Hijo, G. J. Maximo, M. C. Costa, R. L. Cunha, J. F. B. Pereira, K. A. Kurnia, E. A. C. Batista, y A. J. A. Meirelles, «Phase behavior and physical properties of new biobased ionic liquid crystals», J. Phys. Chem. B, vol. 121, pp. 3177-3189, 2017.

[99] P. Berton, K. Bica, y R. D. Rogers, «lonic liquids for consumer products: Dissolution, characterization, and controlled release of fragrance compositions", Fluid Phase Equilib., vol. 450, pp. 51-56, 2017.

[100] A. A. C. Toledo Hijo, G. J. Maximo, M. C. Costa, E. A. C. Batista, y A. J. A. Meirelles, "Applications of ionic liquids in the food and bioproducts industries", ACS Sustain. Chem. Eng., vol. 4, pp. 5347-5369, 2016.

[101] N. Saurín, M.D. Avilés, T. Espinosa, J. Sanes, F.J. Carrión, M.D. Bermúdez, y P. Iglesias, "Carbon nanophases in ordered nanofluid lubricants», Wear, vol. 377, pp. 747-755, 2017.

[102] T. Espinosa, M. Jimenez, J. Sanes, A. E. Jimenez, M. Iglesias, y M. D. Bermudez, «Ultra-low friction with a protic ionic liquid boundary film at the waterlubricated sapphire-stainless steel interface», Tribol. Lett., vol. 53, pp. 1-9, 2014.

[103] T. Espinosa, J. Sanes, A.-E. Jiménez, y M.-D. Bermúdez, «Protic ammonium carboxylate ionic liquid lubricants of OFHC copper», Wear, vol. 303, pp. 495509, 2013.

[104] H. Kondo, «Protic ionic liquids with ammonium salts as lubricants for magnetic thin film media», Tribol. Lett., vol. 31, pp. 211-218, 2008.

[105] M. R. O. Vega, K. Parise, L. B. Ramos, U. Boff, S. Mattedi, L. Schaeffer, y C. F. Malfatti, «Protic ionic liquids used as metal-forming green lubricants for aluminum: Effect of anion chain length», Mater. Res., vol. 20, pp. 675-687, 2017. 
[106] Y. Shi y R. Larsson, «Non-corrosive and biomaterials protic ionic liquids with high lubricating performance», Tribol. Lett., vol. 63:1, pp. 1-7, 2016.

[107] J. Qu, J. J. Truhan, S. Dai, H. Luo, y P. J. Blau, «lonic liquids with ammonium cations as lubricants or additives», Tribol. Lett., vol. 22, pp. 207-214, 2006.

[108] IUPAC, Compendium of Chemical Terminology (The "Gold Book»), $2^{\text {a }}$ Ed. Oxford, Reino Unido: Publications, Blackwell Scientific, 1997.

[109] W. D. Callister y D. G. Rethwisch, Materials Science and Engineering, $9^{\mathrm{a}}$ Ed. EEUU: John Wiley \& Sons, 2014.

[110] G. Pritchard, Plastics additives, $1^{\text {a }}$ Ed. Bristol, Reino Unido: Springer Netherlands, 1998.

[111] L. W. McKeen, "Introduction to plastics and polymers», en Film Properties of Plastics and Elastomers, Elsevier, 2017, pp. 1-24.

[112] W. Brostow, S. H. Goodman, y J. Wahrmund, «Epoxies», en Handbook of Thermoset Plastics, $3^{\mathrm{a}}$ Ed., Oxford, Reino Unido: Elsevier, 2013, pp. 191-252.

[113] F. L. Jin, X. Li, y S. J. Park, «Synthesis and application of epoxy resins: A review», J. Ind. Eng. Chem., vol. 29, pp. 1-11, 2015.

[114] G. Gibson, «Epoxy Resins», en Brydson's Plastics Materials, $8^{\mathrm{a}}$ Ed., Oxford, Reino Unido: Butterworth-Heinemann, 2017, pp. 773-797.

[115] S. Park y F. Jin, "Synthesis and characterization of UV-curable acrylic resin containing fluorine groups», Polym. Int., vol. 54, pp. 705-709, 2005.

[116] S. J. Tucker, B. Fu, S. Kar, S. Heinz, y J. S. Wiggins, «Ambient cure POSSepoxy matrices for marine composites», Compos. Part A Appl. Sci. Manuf., vol. 41, pp. 1441-1446, 2010.

[117] Z. Ahmad, M. P. Ansell, y D. Smedley, «Effect of nano- and micro-particle additions on moisture absorption in thixotropic room temperature cure epoxybased adhesives for bonded-in timber connections», Int. J. Adhes. Adhes., vol. 30, pp. 448-455, 2010.

[118] F.-L. Jin y S.-J. Park, «Thermal properties of epoxy resin/filler hybrid composites», Polym. Degrad. Stab., vol. 97, pp. 2148-2153, 2012.

[119] H. A. Al-Turaif, «Relationship between tensile properties and film formation kinetics of epoxy resin reinforced with nanofibrillated cellulose», Prog. Org. Coatings, vol. 76, pp. 477-481, 2013.

[120] I. A. Mohammed, M. F. Ali, y W. R. W. Daud, «New class of liquid crystalline epoxy resins: Synthesis and properties», J. Ind. Eng. Chem., vol. 18, pp. 364372, 2012.

[121] S. B. Lee, H. J. Lee, y I. K. Hong, «Diluent filler particle size effect for thermal stability of epoxy type resin», J. Ind. Eng. Chem., vol. 18, pp. 635-641, 2012.

[122] S. Liu, H. Yan, Z. Fang, Z. Guo, y H. Wang, «Effect of graphene nanosheets and layered double hydroxides on the flame retardancy and thermal degradation of epoxy resin», RSC Adv., vol. 4, pp. 18652-18659, 2014.

[123] I. Zaman, T. T. Phan, H.-C. Kuan, Q. Meng, L. T. B. La, L. Luong, O. Youssf, y J. $\mathrm{Ma}$, «Epoxy/graphene platelets nanocomposites with two levels of interface strength», Polymer (Guildf)., vol. 52, pp. 1603-1611, 2011.

[124] C. Bao, Y. Guo, L. Song, Y. Kan, X. Qian, y Y. Hu, «In situ preparation of functionalized graphene oxide/epoxy nanocomposites with effective reinforcements», J. Mater. Chem., vol. 21, pp. 13290-13298, 2011. 
[125] D. Juan, Química industrial. Cartagena, España: Horacio Escarabajal, 2005.

[126] A. Gergely, I. Bertóti, T. Török, É. Pfeifer, y E. Kálmán, «Corrosion protection with zinc-rich epoxy paint coatings embedded with various amounts of highly dispersed polypyrrole-deposited alumina monohydrate particles», Prog. Org. Coatings, vol. 76, pp. 17-32, 2013.

[127] S. Liu, V. S. Chevali, Z. Xu, D. Hui, y H. Wang, «A review of extending performance of epoxy resins using carbon nanomaterials», Compos. Part $B$ Eng., vol. 136, pp. 197-214, 2018.

[128] S. Bobby y M. A. Samad, «Enhancement of tribological performance of epoxy bulk composites and composite coatings using micro/nano fillers: a review», Polym. Adv. Technol., vol. 28, pp. 633-644, 2017.

[129] J. R. Siqueira y O. N. Oliveira, «Carbon-based nanomaterials», en Nanoestructures, $1^{\text {a }}$ Ed., Oxford, Reino Unido: Elsevier, 2017, pp. 233-249.

[130] W. Zhai, N. Srikanth, L. B. Kong, y K. Zhou, "Carbon nanomaterials in tribology», Carbon, vol. 119, pp. 150-171, 2017.

[131] D. Baowan, B. J. Cox, T. A. Hilder, J. M. Hill, y N. Thamwattana, «Geometry and mechanics of carbon nanostructures», en Modelling and Mechanics of CarbonBased Nanostructured Materials, Oxford, Reino Unido: Elsevier, 2017, pp. 1-33.

[132] M. Notarianni, J. Liu, K. Vernon, y N. Motta, «Synthesis and applications of carbon nanomaterials for energy generation and storage», Beilstein $\mathrm{J}$. Nanotechnol., vol. 7, pp. 149-196, 2016.

[133] B. L. Dasari, J. M. Nouri, D. Brabazon, y S. Naher, «Graphene and derivatives Synthesis techniques, properties and their energy applications», Energy, vol. 140, pp. 766-778, 2017.

[134] M. J. Allen, V. C. Tung, y R. B. Kaner, «Honeycomb carbon: A review of graphene», Chem. Rev., vol. 110, pp. 132-145, 2010.

[135] K. S. Novoselov, V. I. Fal'ko, L. Colombo, P. R. Gellert, M. G. Schwab, y K. Kim, «A roadmap for graphene», Nature, vol. 490, pp. 192-200, 2012.

[136] K. S. Novoselov, A. K. K. Geim, S. V. V Morozov, D. Jiang, Y. Zhang, S. V. Dubonos, I. V. Grigorieva, y A. A. Firsov, «Electric field effect in atomically thin carbon films», Science, vol. 306, pp. 666-669, 2004.

[137] E. P. Randviir, D. A. C. Brownson, y C. E. Banks, «A decade of graphene research: Production, applications and outlook», Mater. Today, vol. 17, pp. 426432, 2014.

[138] A. C. Ferrari, «Raman spectroscopy of graphene and graphite: Disorder, electron-phonon coupling, doping and nonadiabatic effects», Solid State Commun., vol. 143, pp. 47-57, 2007.

[139] J. C. Meyer, A. K. Geim, M. I. Katsnelson, K. S. Novoselov, T. J. Booth, y S. Roth, "The structure of suspended graphene sheets», Nature, vol. 446, pp. 6063, 2007.

[140] K. S. Novoselov, D. Jiang, F. Schedin, T. J. Booth, V. V Khotkevich, S. V Morozov, y A. K. Geim, "Two-dimensional atomic crystals», Proc. Natl. Acad. Sci., vol. 102, pp. 10451-10453, 2005.

[141] D. A. C. Brownson, D. K. Kampouris, y C. E. Banks, «Graphene electrochemistry: fundamental concepts through to prominent applications», Chem. Soc. Rev., vol. 41, pp. 6944-6976, 2012.

[142] C. Lee, X. Wei, J. W. Kysar, y J. Hone, «Measurement of the elastic properties 
and intrinsic strength of monolayer graphene», Science, vol. 321 , pp. 385-388, 2008.

[143] J. Peng, W. Gao, B. K. Gupta, Z. Liu, R. Romero-Aburto, L. Ge, L. Song, L. B. Alemany, X. Zhan, G. Gao, S. Vithayathil, B. Kaipparettu, A. Marti, T. Hayashi, J. J. Zhu, y P. M. Ajayan, "Graphene quantum dots derived from carbon fibers», Nano Lett, vol. 12, pp. 844-849, 2012.

[144] J. S. Bunch, S. S. Verbridge, J. S. Alden, A. M. van der Zande, J. M. Parpia, H. G. Craighead, y P. L. McEuen, «Impermeable atomic membranes from graphene sheets», Nano Lett., vol. 8, pp. 2458-2462, 2008.

[145] D. Berman, A. Erdemir, y A. V Sumant, "Graphene: a new emerging lubricant», Mater. Today, vol. 17, pp. 31-42, 2014.

[146] J. Phiri, P. Gane, y T. C. Maloney, «General overview of graphene: Production, properties and application in polymer composites», Mater. Sci. Eng. B, vol. 215, pp. 9-28, 2017.

[147] V. Dhand, K. Y. Rhee, H. Ju Kim, y D. Ho Jung, "A comprehensive review of graphene nanocomposites: Research status and trends», J. Nanomater., vol. 2013, pp. 1-14, 2013.

[148] X. Zhang, B. R. S. Rajaraman, H. Liu, y S. Ramakrishna, «Graphene's potential in materials science and engineering», RSC Adv., vol. 4, pp. 28987-29011, 2014.

[149] F. Bonaccorso, A. Lombardo, T. Hasan, Z. Sun, L. Colombo, y A. C. Ferrari, «Production and processing of graphene and $2 \mathrm{~d}$ crystals», Mater. Today, vol. 15, pp. 564-589, 2012.

[150] A. K. Geim, «Graphene: Status and prospects», Science, vol. 324, pp. 15301534, 2009.

[151] T. Moldt, A. Eckmann, P. Klar, S. V Morozov, A. A. Zhukov, K. S. Novoselov, y C. Casiraghi, «High-yield production and transfer of graphene flakes obtained by anodic bonding», ACS Nano, vol. 5, pp. 7700-7706, 2011.

[152] S. Dhar, A. R. Barman, G. X. Ni, X. Wang, X. F. Xu, Y. Zheng, S. Tripathy, Ariando, A. Rusydi, K. P. Loh, M. Rubhausen, A. H. C. Neto, B. Zyilmaz, y T. Venkatesan, «A new route to graphene layers by selective laser ablation», AIP Adv., vol. 1, p. 022109, 2011.

[153] J. N. Israelachvili, Intermolecular and surface force, $3 .^{a}$ ed. Boston, EEUU: Academic Press, 2011.

[154] Y. Hernandez, V. Nicolosi, M. Lotya, F. M. Blighe, Z. Sun, S. De, I. T. McGovern, B. Holland, M. Byrne, Y. K. Gun'Ko, J. J. Boland, P. Niraj, G. Duesberg, S. Krishnamurthy, R. Goodhue, J. Hutchison, V. Scardaci, A. C. Ferrari, y J. N. Coleman, «High-yield production of graphene by liquid-phase exfoliation of graphite», Nat. Nanotechnol., vol. 3, pp. 563-568, 2008.

[155] O. M. Maragó, F. Bonaccorso, R. Saija, G. Privitera, P. G. Gucciardi, M. A. latì, G. Calogero, P. H. Jones, F. Borghese, P. Denti, V. Nicolosi, y A. C. Ferrari, «Brownian Motion of Graphene», ACS Nano, vol. 4, pp. 7515-7523, 2010.

[156] F. Torrisi, T. Hasan, W. Wu, Z. Sun, A. Lombardo, T. S. Kulmala, G.-W. Hsieh, S. Jung, F. Bonaccorso, P. J. Paul, D. Chu, y A. C. Ferrari, «Inkjet-printed graphene electronics», ACS Nano, vol. 6, pp. 2992-3006, 2012.

[157] T. Hasan, F. Torrisi, Z. Sun, D. Popa, V. Nicolosi, G. Privitera, F. Bonaccorso, y A. C. Ferrari, "Solution-phase exfoliation of graphite for ultrafast photonics», Phys. Status Solidi Basic Res., vol. 247, pp. 2953-2957, 2010. 
[158] B. C. Brodie, "On the Atomic Weight of Graphite», Philos. Trans. R. Soc. London, vol. 149, pp. 249-259, 1859.

[159] W. S. Hummers y R. E. Offeman, «Preparation of Graphitic Oxide», J. Am. Chem. Soc., vol. 80, pp. 1339-1339, 1958.

[160] G. Eda, Y. Y. Lin, C. Mattevi, H. Yamaguchi, H. A. Chen, I. S. Chen, C. W. Chen, y M. Chhowalla, «Blue photoluminescence from chemically derived graphene oxide», Adv. Mater., vol. 22, pp. 505-509, 2010.

[161] K. V Emtsev, F. Speck, T. Seyller, L. Ley, y J. D. Riley, «Interaction, growth, and ordering of epitaxial graphene on $\mathrm{SiC}\{0001\}$ surfaces: A comparative photoelectron spectroscopy study», Phys. Rev. B, vol. 77, p. 155303, 2008.

[162] J. Hass, F. Varchon, J. E. Millán-Otoya, M. Sprinkle, N. Sharma, W. A. de Heer, C. Berger, P. N. First, L. Magaud, y E. H. Conrad, «Why multilayer graphene on $4 \mathrm{H}-\mathrm{SiC}(0001)$ behaves like a single sheet of graphene», Phys. Rev. Lett., vol. 100, p. 125504, 2008.

[163] Z. Sun, Z. Yan, J. Yao, E. Beitler, Y. Zhu, y J. M. Tour, "Growth of graphene from solid carbon sources», Nature, vol. 468, pp. 549-552, 2010.

[164] N. A. Kholin, E. V Rut'kov, y A. Y. Tontegode, "The nature of the adsorption bond between graphite islands and iridium surface», Surf. Sci., vol. 139, pp. 155172, 1984.

[165] N. R. Gall, E. V Rut'kov, y A. Y. Tontegode, «Intercalation of nickel atoms under two-dimensional graphene film on (111)Ir», Carbon, vol. 38, pp. 663-667, 2000.

[166] X. Li, W. Cai, J. An, S. Kim, J. Nah, D. Yang, R. Piner, A. Velamakanni, I. Jung, E. Tutuc, S. K. Banerjee, L. Colombo, y R. S. Ruoff, «Large-area synthesis of high-quality and uniform graphene films on copper foils», Science, vol. 324, pp. 1312-1314, 2009.

[167] A. Y. Cho y J. R. Arthur, "Molecular beam epitaxy», Prog. Solid State Chem., vol. 10, pp. 157-192, 1975.

[168] J. M. Garcia, R. He, M. P. Jiang, J. Yan, A. Pinczuk, Y. M. Zuev, K. S. Kim, P. Kim, K. Baldwin, K. W. West, y L. N. Pfeiffer, «Multilayer graphene films grown by molecular beam deposition», Solid State Commun., vol. 150, pp. 809-811, 2010.

[169] J. Wu, W. Pisula, y K. Müllen, «Graphenes as potential material for electronics», Chem. Rev., vol. 107, pp. 718-747, 2007.

[170] J. Cai, P. Ruffieux, R. Jaafar, M. Bieri, T. Braun, S. Blankenburg, M. Muoth, A. P. Seitsonen, M. Saleh, X. Feng, K. Müllen, y R. Fasel, «Atomically precise bottom-up fabrication of graphene nanoribbons», Nature, vol. 466, pp. 470-473, 2010.

[171] X. Yan, X. Cui, B. Li, y L. Li, «Large, solution-processable graphene quantum dots as light absorbers for photovoltaics», Nano Lett., vol. 10, pp. 1869-1873, 2010.

[172] Y. Wu, Y. Lin, A. A. Bol, K. A. Jenkins, F. Xia, D. B. Farmer, Y. Zhu, y P. Avouris, "High-frequency, scaled graphene transistors on diamond-like carbon», Nature, vol. 472, pp. 74-78, 2011.

[173] Y.-M. Lin, C. Dimitrakopoulos, K. A. Jenkins, D. B. Farmer, H.-Y. Chiu, A. Grill, y P. Avouris, «100-GHz transistors from wafer-scale epitaxial graphene», Science, vol. 327, p. 662, 2010.

[174] F. Bonaccorso, Z. Sun, T. Hasan, y A. C. Ferrari, «Graphene photonics and 
optoelectronics», Nat. Photonics, vol. 4, pp. 611-622, 2010.

[175] A. Capasso, A. E. Del Rio Castillo, H. Sun, A. Ansaldo, V. Pellegrini, y F. Bonaccorso, «Ink-jet printing of graphene for flexible electronics: An environmentally-friendly approach», Solid State Commun., vol. 224, pp. 53-63, 2015.

[176] V. Fal'ko, «Quantum information on chicken wire», Nat. Phys., vol. 3, pp. 151152, 2007.

[177] D. Gunlycke, D. A. Areshkin, J. Li, J. W. Mintmire, y C. T. White, «Graphene Nanostrip Digital Memory Device», Nano Lett., vol. 7, pp. 3608-3611, 2007.

[178] S. Bae, H. Kim, Y. Lee, X. Xu, J.-S. Park, Y. Zheng, J. Balakrishnan, T. Lei, H. Ri Kim, Y. II Song, Y.-J. Kim, K. S. Kim, B. Özyilmaz, J.-H. Ahn, B. H. Hong, y S. lijima, «Roll-to-roll production of 30 -inch graphene films for transparent electrodes», Nat. Nanotechnol., vol. 5, pp. 574-578, 2010.

[179] G. Eda, H. E. Unalan, N. Rupesinghe, G. A. J. Amaratunga, y M. Chhowalla, «Field emission from graphene based composite thin films», Appl. Phys. Lett., vol. 93, p. 233502, 2008.

[180] Z.-S. Wu, S. Pei, W. Ren, D. Tang, L. Gao, B. Liu, F. Li, C. Liu, y H.-M. Cheng, «Field emission of Single-Layer Graphene films prepared by electrophoretic deposition», Adv. Mater., vol. 21, pp. 1756-1760, 2009.

[181] J. Wu, M. Agrawal, H. A. Becerril, Z. Bao, Z. Liu, Y. Chen, y P. Peumans, «Organic light-emitting diodes on solution-processed graphene transparent electrodes», ACS Nano, vol. 4, pp. 43-48, 2010.

[182] N. Papasimakis, Z. Luo, Z. X. Shen, F. De Angelis, E. Di Fabrizio, A. E. Nikolaenko, y N. I. Zheludev, "Graphene in a photonic metamaterial», Opt. Express, vol. 18, pp. 8353-8359, 2010.

[183] Q. Zheng, W. H. Ip, X. Lin, N. Yousefi, K. K. Yeung, Z. Li, y J.-K. Kim, "Transparent conductive films consisting of ultralarge graphene sheets produced by Langmuir-Blodgett assembly», ACS Nano, vol. 5, pp. 6039-6051, 2011.

[184] E. Quesnel, F. Roux, F. Emieux, P. Faucherand, E. Kymakis, G. Volonakis, F. Giustino, B. Martín-García, I. Moreels, S. A. Gürsel, A. B. Yurtcan, V. Di Noto, A. Talyzin, I. Baburin, D. Tranca, G. Seifert, L. Crema, G. Speranza, V. Tozzini, et al., "Graphene-based technologies for energy applications, challenges and perspectives», 2D Mater., vol. 2, p. 030204, 2015.

[185] H. Chen, M. B. Müller, K. J. Gilmore, G. G. Wallace, y D. Li, «Mechanically strong, electrically conductive, and biocompatible graphene paper», Adv. Mater., vol. 20, pp. 3557-3561, 2008.

[186] C. Shan, H. Yang, J. Song, D. Han, A. Ivaska, y L. Niu, «Direct electrochemistry of glucose oxidase and biosensing for glucose based on graphene», Anal. Chem., vol. 81, pp. 2378-2382, 2009.

[187] V. Chandra, J. Park, Y. Chun, J. W. Lee, I.-C. Hwang, y K. S. Kim, «Waterdispersible magnetite-reduced graphene oxide composites for arsenic removal», ACS Nano, vol. 4, pp. 3979-3986, 2010.

[188] P. H. Chen, M. C. Sie, P. Di Jeng, R. C. Wu, y C. Bin Wang, «Graphene sponge as an efficient and recyclable oil sorbent», AIP Conf. Proc., vol. 1877, pp. 0-10, 2017.

[189] G. Galli, «Structure, stability and electronic properties of nanodiamonds», en Computer-based modeling of novel carbon systems and their properties, vol. 3, 
Amsterdam, Holanda: Springer Netherlands, 2010, pp. 37-57.

[190] H. H. Zhang, Y. T. Liu, R. Wang, X. Y. Yu, X. W. Qu, y Q. X. Zhang, «Functionalization of nanodiamond with epoxy monomer», Chinese Chem. Lett., vol. 22, pp. 485-488, 2011.

[191] M. Kohzaki, K. Higuchi, S. Noda, y K. Uchida, «Tribological characteristics of polycrystalline diamond films produced by chemical vapor deposition», J. Mater. Res., vol. 7, pp. 1769-1777, 1992.

[192] A. Y. Vul' y V. I. Sokolov, "Nanocarbon studies in Russia: From fullerenes to nanotubes and nanodiamonds», Nanotechnologies Russ., vol. 4, pp. 397-414, 2009.

[193] V. N. Mochalin y Y. Gogotsi, «Nanodiamond-polymer composites», Diam. Relat. Mater., vol. 58, pp. 161-171, 2015.

[194] A. Krueger, «The structure and reactivity of nanoscale diamond», J. Mater. Chem., vol. 18, pp. 1485-1492, 2008.

[195] B. I. Kharisov, O. V Kharissova, y L. Chávez-Guerrero, «Synthesis techniques, properties and applications of nanodiamonds», Synth. React. Inorganic, Met. Nano-Metal Chem., vol. 40, pp. 84-101, 2010.

[196] A. Shakun, J. Vuorinen, M. Hoikkanen, M. Poikelispää, y A. Das, «Hard nanodiamonds in soft rubbers: Past, present and future - A review», Compos. Part A Appl. Sci. Manuf., vol. 64, pp. 49-69, 2014.

[197] N. Nunn, M. Torelli, G. McGuire, y O. A. Shenderova, «Nanodiamond: A high impact nanomaterial», Curr. Opin. Solid State Mater. Sci., vol. 21, pp. 1-9, 2017.

[198] V. N. Mochalin, O. A. Shenderova, D. Ho, y Y. Gogotsi, «The properties and applications of nanodiamonds», Nat. Nanotechnol., vol. 7, pp. 11-23, 2011.

[199] V. V. Danilenko, "On the history of the discovery of nanodiamond synthesis", Phys. Solid State, vol. 46, pp. 595-599, 2004.

[200] J. Xiao, P. Liu, L. Li, y G. Yang, «Fluorescence origin of nanodiamonds», J. Phys. Chem. C, vol. 119, pp. 2239-2248, 2015.

[201] O. A. Shenderova y N. Nunn, Production and purification of nanodiamonds, 6 . $^{\text {a }}$ ed. Amsterdam, Holanda: Elsevier Inc., 2017.

[202] O. A. Shenderova y D. M. Gruen, Ultrananocrystalline Diamond: Synthesis, Properties and Applications, 2. ${ }^{a}$ ed. Oxford, Reino Unido: Elsevier, 2012.

[203] V. Yu. Dolmatov, «Detonation synthesis ultradispersed diamonds: properties and applications», Russ. Chem. Rev., vol. 70, pp. 607-626, 2001.

[204] V. V. Danilenko, «Synthesis, properties and applications of ultrananocrystalline diamonds", en Proceedings of the NATO ARW on Synthesis, Properties and Applications of Ultrananocrystalline Diamond, vol. 49, Amsterdam, Holanda: Springer Netherlands, 2005, pp. 191-198.

[205] B. Zousman y O. Levinson, «Monodispersed nanodiamonds produced by laser ablation», MRS Proc., vol. 1452, pp. mrss12-1452-ff07-06, 2012.

[206] L. Yang, P. W. May, L. Yin, J. A. Smith, y K. N. Rosser, «Growth of diamond nanocrystals by pulsed laser ablation of graphite in liquid», Diam. Relat. Mater., vol. 16, pp. 725-729, 2007.

[207] A. Krueger y D. Lang, «Functionality is key: Recent progress in the surface modification of nanodiamond», Adv. Funct. Mater., vol. 22, pp. 890-906, 2012.

[208] G. A. Inel, E. M. Ungureau, T. S. Varley, M. Hirani, y K. B. Holt, «Solvent-surface 
interactions between nanodiamond and ethanol studied with in situ infrared spectroscopy», Diam. Relat. Mater., vol. 61, pp. 7-13, 2016.

[209] A. Pentecost, S. Gour, V. Mochalin, I. Knoke, y Y. Gogotsi, «Deaggregation of nanodiamond powders using salt- and sugar-assisted milling», ACS Appl. Mater. Interfaces, vol. 2, pp. 3289-3294, 2010.

[210] O. N. Fedyanina y P. N. Nesterenko, «Regularities of chromatographic retention of phenols on microdispersed sintered detonation nanodiamond in aqueousorganic solvents», Russ. J. Phys. Chem. A, vol. 84, pp. 476-480, 2010.

[211] C. Wu, C. Han, y H. Chang, «Applications of surface functionalized diamond nanoparticles for mass spectrometry based proteomics», J. Chinese Chem. Soc., vol. 57, pp. 583-594, 2013.

[212] Y. Yao y Y. Xue, «Impedance analysis of quartz crystal microbalance humidity sensors based on nanodiamond/graphene oxide nanocomposite film», Sensors Actuators B Chem., vol. 211, pp. 52-58, 2015.

[213] A. M. Schrand, S. A. C. Hens, y O. A. Shenderova, «Nanodiamond particles: Properties and perspectives for bioapplications», Crit. Rev. Solid State Mater. Sci., vol. 34, pp. 18-74, 2009.

[214] E. K. Chow, X.-Q. Zhang, M. Chen, R. Lam, E. Robinson, H. Huang, D. Schaffer, E. Osawa, A. Goga, y D. Ho, «Nanodiamond therapeutic delivery agents mediate enhanced chemoresistant tumor treatment», Sci. Transl. Med., vol. 3, p. 73ra21, 2011.

[215] V. Vaijayanthimala, D. K. Lee, S. V Kim, A. Yen, N. Tsai, D. Ho, H.-C. Chang, y O. A. Shenderova, «Nanodiamond-mediated drug delivery and imaging: challenges and opportunities», Expert Opin. Drug Deliv., vol. 12, pp. 735-749, 2015.

[216] C. Gupta, D. Prakash, y S. Gupta, "Cancer treatment with nano-diamonds», Front. Biosci. (Schol. Ed)., vol. 9, pp. 62-70, 2017.

[217] H. Huang, E. Pierstorff, E. Osawa, y D. Ho, «Protein-mediated assembly of nanodiamond hydrogels into a biocompatible and biofunctional multilayer nanofilm», ACS Nano, vol. 2, pp. 203-212, 2008.

[218] Y. Mo, Y. Wan, A. Chau, y F. Huang, «Graphene/lonic liquid composite films and ion exchange», Sci. Rep., vol. 4, p. 5466, 2015.

[219] I. Minami, «lonic liquids in tribology.», Molecules, vol. 14, pp. 2286-2305, 2009.

[220] A. E. Jiménez y M. D. Bermúdez, «Imidazolium ionic liquids as additives of the synthetic ester propylene glycol dioleate in aluminium-steel lubrication», Wear, vol. 265, pp. 787-798, 2008.

[221] L. Zhu, G. Zhao, y X. Wang, «Investigation on three oil-miscible ionic liquids as antiwear additives for polyol esters at elevated temperature», Tribol. Int., vol. 109, pp. 336-345, 2017.

[222] Y. Wang, Q. Yu, M. Cai, L. Shi, F. Zhou, y W. Liu, «lbuprofen-based ionic liquids as additives for enhancing the lubricity and antiwear of water-ethylene glycol liquid», Tribol. Lett., vol. 65, p. 55, 2017.

[223] K. Janardhanan y P. Iglesias, «Theoretical and experimental study of the friction behavior of halogen-free ionic liquids in elastohydrodynamic regime», Lubricants, vol. 4, p. 16, 2016.

[224] I. Minami, M. Kita, T. Kubo, H. Nanao, y S. Mori, «The tribological properties of ionic liquids composed of trifluorotris(pentafluoroethyl) phosphate as a 
hydrophobic anion», Tribol.Lett., vol. 30, pp. 215-223, 2008.

[225] N. Saurín, I. Minami, J. Sanes, y M. D. Bermúdez, «Study of the effect of tribomaterials and surface finish on the lubricant performance of new halogen-free room temperature ionic liquids», Appl. Surf. Sci., vol. 366, pp. 464-474, 2016.

[226] A. Tomala, A. Karpinska, W. S. M. Werner, A. Olver, y H. Störi, «Tribological properties of additives for water-based lubricants», Wear, vol. 269, pp. 804-810, 2010.

[227] Y. Shi, I. Minami, M. Grahn, M. Björling, y R. Larsson, «Boundary and elastohydrodynamic lubrication studies of glycerol aqueous solutions as green lubricants», Tribol. Int., vol. 69, pp. 39-45, 2014.

[228] Y. Yang, C. Zhang, Y. Dai, y J. Luo, «Tribological properties of titanium alloys under lubrication of SEE oil and aqueous solutions», Tribol. Int., vol. 109, pp. 4047, 2017.

[229] H. Ding, M. Wang, M. Li, K. Huang, S. Li, L. Xu, X. Yang, y J. Xia, «Synthesis of a water-soluble, rubber seed oil-based sulfonate and its tribological properties as a water-based lubricant additive», J. Appl. Polym. Sci., vol. 135, p. 46119, 2017.

[230] B. S. Phillips y J. S. Zabinski, «lonic liquid lubrication effects on ceramics in a water environment», Tribol. Lett., vol. 17, pp. 533-541, 2004.

[231] C. J. Reeves, A. Siddaiah, y P. L. Menezes, «Tribological study of imidazolium and phosphonium ionic liquid-based lubricants as additives in carboxylic acidbased natural oil: Advancements in environmentally friendly lubricants», J. Clean. Prod., vol. 176, pp. 241-250, 2018.

[232] D. Santos, F. Costa, E. Franceschi, A. Santos, C. Dariva, y S. Mattedi, «Synthesis and physico-chemical properties of two protic ionic liquids based on stearate anion», Fluid Phase Equilib., vol. 376, pp. 132-140, 2014.

[233] S. Mattedi, M. Martin-Pastor, M. Aznar, y M. Iglesias, «Synthesis and thermophysical properties of two new protic long-chain ionic liquids with the oleate anion», Fluid Phase Equilib., vol. 299, p. 42, 2010.

[234] N. Saurín Serrano, Estudio tribológico de nuevos nanofluidos iónicos y nanomateriales. Tesis Doctoral. Universidad Politécnica de Cartagena, 2016.

[235] T. Espinosa Rodríguez, Estudio del comportamiento tribológico y de las interacciones de superficie de nuevos nanofluidos iónicos. Universidad Politécnica de Cartagena, 2015.

[236] A. Erdemir, G. Ramirez, O. L. Eryilmaz, B. Narayanan, Y. Liao, G. Kamath, y S. K. R. S. Sankaranarayanan, "Carbon-based tribofilms from lubricating oils», Nature, vol. 536, pp. 67-71, 2016.

[237] D. Berman, S. A. Deshmukh, S. K. R. S. Sankaranarayanan, A. Erdemir, y A. V Sumant, «Macroscale superlubricity enabled by graphene nanoscroll formation», Science, vol. 348, pp. 1118-1122, 2015.

[238] D. Berman, A. Erdemir, A. V Zinovev, y A. V Sumant, «Nanoscale friction properties of graphene and graphene oxide», Diam. Relat. Mater., vol. 54, pp. 91-96, 2015.

[239] E. Sadeghinezhad, M. Mehrali, R. Saidur, M. Mehrali, S. T. Latibari, A. R. Akhiani, y H. S. C. Metselaar, «A comprehensive review on graphene nanofluids: Recent research, development and applications», Energy Convers. Manag., vol. 111, pp. 466-487, 2016.

[240] A. K. Rasheed, M. Khalid, W. Rashmi, T. C. S. M. Gupta, y A. Chan, «Graphene 
based nanofluids and nanolubricants - Review of recent developments», Renew. Sustain. Energy Rev., vol. 63, pp. 346-362, 2016.

[241] P. D. McCrary, P. A. Beasley, S. A. Alaniz, C. S. Griggs, R. M. Frazier, y R. D. Rogers, "Graphene and graphene oxide can "lubricate" ionic liquids based on specific surface interactions leading to improved low temperature hypergolic performance», Angew. Chemie Int. Ed., vol. 51, pp. 9784-9787, 2012.

[242] X. Fan, Y. Xia, L. Wang, y W. Li, «Multilayer graphene as a lubricating additive in bentone grease», Tribol. Lett., vol. 55, pp. 455-464, 2014.

[243] G. J. Lee, J. J. Park, M. K. Lee, y C. K. Rhee, «Stable dispersion of nanodiamonds in oil and their tribological properties as lubricant additives», Appl. Surf. Sci., vol. 415, pp. 24-27, 2017.

[244] V. Y. Dolmatov, «Detonation nanodiamonds in oils and lubricants», en Nanodiamonds: Advanced Material Analysis, Properties and Applications, 6. ${ }^{a}$ ed., Amsterdam, Holanda: Elsevier Inc., 2017, pp. 391-402.

[245] X. Tao, Z. Jiazheng, y X. Kang, «The ball-bearing effect of diamond nanoparticles as an oil additive», J. Phys. D. Appl. Phys., vol. 29, p. 2932, 1996.

[246] C.-C. Chou y S.-H. Lee, «Tribological behavior of nanodiamond-dispersed lubricants on carbon steels and aluminum alloy», Wear, vol. 269, pp. 757-762, 2010.

[247] X. F. Sun, Y. L. Qiao, W. Song, S. N. Ma, y C. H. Hu, «High temperature tribological properties of modified nanodiamond additive in lubricating oil», Phys. Procedia, vol. 50, pp. 343-347, 2013.

[248] O. Elomaa, J. Oksanen, T. J. Hakala, O. A. Shenderova, y J. Koskinen, «A comparison of tribological properties of evenly distributed and agglomerated diamond nanoparticles in lubricated high-load steel-steel contact», Tribol. Int., vol. 71, pp. 62-68, 2014.

[249] A. A. Alias, H. Kinoshita, y M. Fujii, «Tribological properties of diamond nanoparticle additive in water under a lubrication between steel plate and tungsten carbide ball», J. Adv. Mech. Des. Syst. Manuf., vol. 9, pp. 1-9, 2015.

[250] A. H. Battez, R. González, J. L. Viesca, A. Fernández-González, y M. Hadfield, «Lubrication of PVD coatings with ethyl-dimethyl-2-methoxyethylammonium tris(pentafluoroethyl)trifluorophosphate», Tribol. Int., vol. 58, pp. 71-78, 2013.

[251] Y. Kondo, T. Koyama, R. Tsuboi, M. Nakano, K. Miyake, y S. Sasaki, «Tribological Performance of Halogen-Free lonic Liquids as Lubricants of Hard Coatings and Ceramics», Tribol. Lett., vol. 51, pp. 243-249, 2013.

[252] X. Feng y Y. Xia, «Tribological properties of Ti-doped DLC coatings under ionic liquids lubricated conditions», Appl. Surf. Sci., vol. 258, pp. 2433-2438, 2012.

[253] C. Espejo, F. J. Carrion, D. Martinez, y M. D. Bermudez, «Multi-walled carbon nanotube-imidazolium tosylate ionic liquid lubricant», Tribol. Lett., vol. 50, pp. 127-136, 2013.

[254] J. Sanes, F. J. Carrión, y M. D. Bermúdez, «Effect of the addition of room temperature ionic liquid and $\mathrm{ZnO}$ nanoparticles on the wear and scratch resistance of epoxy resin», Wear, vol. 268, pp. 1295-1302, 2010.

[255] N. Saurín, J. Sanes, y M. D. Bermúdez, «New graphene/ionic liquid nanolubricants», Mater. Today Proc., vol. 3, pp. S227-S232, 2016.

[256] X. Fan y L. Wang, «High-performance lubricant additives based on modified graphene oxide by ionic liquids», J. Colloid Interface Sci., vol. 452, pp. 98-108, 
2015.

[257] V. Khare, M.-Q. Pham, N. Kumari, H.-S. Yoon, C.-S. Kim, J.-I. Park, y S.-H. Ahn, "Graphene-ionic liquid based hybrid nanomaterials as novel lubricant for low friction and wear», ACS Appl. Mater. Interfaces, vol. 5, pp. 4063-4075, 2013.

[258] X. Fan, L. Wang, y W. Li, «In situ fabrication of low-friction sandwich sheets through functionalized graphene crosslinked by ionic liquids», Tribol. Lett., vol. 58, p. 12, 2015.

[259] R. Gusain, H. P. Mungse, N. Kumar, T. R. Ravindran, R. Pandian, H. Sugimura, y O. P. Khatri, «Covalently attached graphene-ionic liquid hybrid nanomaterials: synthesis, characterization and tribological application», J. Mater. Chem. A, vol. 4, pp. 926-937, 2016.

[260] L. Zhang, J. Pu, L. Wang, y Q. Xue, «Synergistic effect of hybrid carbon nanotube-graphene oxide as nanoadditive enhancing the frictional properties of ionic liquids in high vacuum», ACS Appl. Mater. Interfaces, vol. 7, pp. 85928600, 2015.

[261] L. Zhang, J. Pu, L. Wang, y Q. Xue, «Frictional dependence of graphene and carbon nanotube in diamond-like carbon/ionic liquids hybrid films in vacuum», Carbon, vol. 80, pp. 734-745, 2014.

[262] N. Saurín, T. Espinosa, J. Sanes, F. J. Carrión, y M. D. Bermúdez, «lonic nanofluids in tribology», Lubricants, vol. 3, pp. 650-663, 2015.

[263] A. C. Kleinschmidt, R. K. Donato, M. Perchacz, H. Benes, V. Stengl, S. C. Amico, y H. S. Schrekker, "UUnrolling" multi-walled carbon nanotubes with ionic liquids: application as fillers in epoxy-based nanocomposites», RSC Adv., vol. 4, pp. 43436-43443, 2014.

[264] C.-L. Park, A. Y. Jee, M. Lee, y S. Lee, «Gelation, functionalization, and solution behaviors of nanodiamonds with ionic liquids.», Chem. Commun., vol. 0, pp. 5576-5578, 2009.

[265] R. F. Alamdari y R. Hatefipour, «Detonation nanodiamond as a new option for reduction of the viscosity of one novel di-azide functionalized monocationic ionic liquid», ChemistrySelect, vol. 1, pp. 6277-6286, 2016.

[266] C. Tang y W. Liu, «Preparation of dual-curable polysiloxane and the properties of its cured films with epoxy resin», J. Plast. Film Sheeting, vol. 26, pp. 241-257, 2010.

[267] R. Voo, M. Mariatti, y L. L. Sim, «Properties of epoxy nanocomposite thin films prepared by spin coating technique», J. Plast. Film Sheeting, vol. 27, pp. 331346, 2011.

[268] J. Sanes, N. Saurín, F. J. Carrión, G. Ojados, y M. D. Bermúdez, «Synergy between single-walled carbon nanotubes and ionic liquid in epoxy resin nanocomposites», Compos. Part B Eng., vol. 105, pp. 149-159, 2016.

[269] N. Saurín Serrano, J. Sanes, y M. D. Bermúdez, «Effect of graphene and ionic liquid additives on the tribological performance of epoxy resin», Tribol. Lett., vol. 56, pp. 133-142, 2014.

[270] D. V Szabó, S. Schlabach, B. Xu, y D. Vollath, «Modifying the surface of nanoparticles by coating», en Surface Engineering, Wiley-Blackwell, 2013, pp. 114.

[271] J. Hahn, M. Friedrich, R. Pintaske, M. Schaller, N. Kahl, D. R. T. Zahn, y F. Richter, "Cubic boron nitride films by d.c. and r.f. magnetron sputtering: layer characterization and process diagnostics», Diam. Relat. Mater., vol. 5, pp. 1103- 
1112, 1996.

[272] Y. I. Song, G. Y. Kim, H. K. Choi, H. J. Jeong, K. K. Kim, C. -M. Yang, S. C. Lim, K. H. An, K. T. Jung, y Y. H. Lee, «Fabrication of carbon nanotube field emitters using a dip-coating method», Chem. Vap. Depos., vol. 12, pp. 375-379, 2006.

[273] C. L. Haynes, A. D. McFarland, M. T. Smith, J. C. Hulteen, y R. P. Van Duyne, «Angle-resolved nanosphere lithography: Manipulation of nanoparticle size, shape and interparticle spacing», J. Phys. Chem. B, vol. 106, pp. 1898-1902, 2002.

[274] T. Okubo, S. Chujo, S. Maenosono, y Y. Yamaguchi, «Microstructure of silica particle monolayer films formed by capillary immersion force», J. Nanoparticle Res., vol. 5, pp. 111-117, 2003.

[275] J. S. Ahn, P. T. Hammond, M. F. Rubner, y I. Lee, «Self-assembled particle monolayers on polyelectrolyte multilayers: particle size effects on formation, structure, and optical properties», Colloids Surfaces A Physicochem. Eng. Asp., vol. 259, pp. 45-53, 2005.

[276] P. Bandeira, J. Monteiro, A. M. Baptista, y F. D. Magalhães, «Influence of oxidized graphene nanoplatelets and [HMIM][NTf2] ionic liquid on the tribological performance of an epoxy-PTFE coating», Tribol. Int., vol. 97, pp. 478-489, 2016.

[277] P. Li, T.-C. Huang, K. L. White, S. Hawkins, M. Kotaki, R. Nishimura, y H.-J. Sue, «Spray-coated epoxy barrier films containing high aspect ratio functionalized graphene nanosheets», RSC Adv., vol. 5, pp. 102633-102642, 2015.

[278] H. Alhumade, A. Yu, A. Elkamel, L. Simon, y A. Abdala, «Enhanced protective properties and UV stability of epoxy/graphene nanocomposite coating on stainless steel», Express Polym. Lett., vol. 10, pp. 1034-1046, 2016.

[279] R. Rohini, K. Lasitha, y S. Bose, «Epoxy composites containing cobalt(II)porphine anchored multiwalled carbon nanotubes as thin electromagnetic interference shields, adhesives and coatings», J. Mater. Chem. C, vol. 4, pp. 352-361, 2016.

[280] V. Kumar, S. K. Sinha, y A. K. Agarwal, «Tribological studies of epoxy and its composite coatings on steel in dry and lubricated sliding», Tribol. - Mater. Surfaces Interfaces, vol. 9, pp. 144-153, 2015.

[281] R. S. Andrade, M. Iglesias, H. Mazzer, y L. Cardozo-filho, «Rheological Study of Polyelectrolytic Protic Ionic Liquids», Int. J. Eng. Res. Technol., vol. 5, pp. 419426, 2016.

[282] J. Kiefer, K. Noack, T. C. Penna, M. C. C. Ribeiro, H. Weber, y B. Kirchner, "Vibrational signatures of anionic cyano groups in imidazolium ionic liquids", Vib. Spectrosc., vol. 91, pp. 141-146, 2017.

[283] J. Kiefer, J. Fries, y A. Leipertz, «Experimental vibrational study of imidazoliumbased ionic liquids: Raman and infrared spectra of 1-ethyl-3-methylimidazolium bis(trifluoromethylsulfonyl)imide and 1-ethyl-3-methylimidazolium ethylsulfate.», Appl. Spectrosc., vol. 61, pp. 1306-1311, 2007.

[284] N. Saurín, J. Sanes, y M. D. Bermúdez, «Self-healing of abrasion damage in epoxy resin-ionic liquid nanocomposites», Tribol. Lett., vol. 58, p. 4, 2015.

[285] G. S. Yur'ev y V. Y. Dolmatov, «X-ray diffraction study of detonation nanodiamonds», J. Superhard Mater., vol. 32, pp. 311-328, 2010.

[286] A. Arcifa, A. Rossi, R. M. Espinosa-Marzal, y N. D. Spencer, «Environmental influence on the surface chemistry of ionic-liquid-mediated lubrication in a 
silica/silicon tribopair», J. Phys. Chem. C, vol. 118, pp. 29389-29400, 2014.

[287] E. F. Smith, F. J. M. Rutten, I. J. Villar-Garcia, D. Briggs, y P. Licence, «lonic liquids in vacuo: Analysis of liquid surfaces using Ultra-High-Vacuum techniques», Langmuir, vol. 22, pp. 9386-9392, 2006.

[288] T. Fukushima, A. Kosaka, Y. Ishimura, T. Yamamoto, T. Takigawa, N. Ishii, y T. Aida, «Molecular ordering of organic molten salts triggered by single-walled carbon nanotubes», Science, vol. 300, pp. 2072-2074, 2003.

[289] Standard Test Method for Wear Testing with a Pin-on-Disk Apparatus. ASTM G99-17. 2016.

[290] Plásticos. Resinas epoxídicas. Parte 2: Preparación de probetas y determinación de propiedades de resinas epóxidas reticuladas. UNE-ENISO3673. 2011.

[291] Differential scanning temperature and glass transition. Determination of glass transition temperature and glass transition step height. ISO11357-2. 2013.

[292] K. P. Menard, Dynamic mechanical analysis: a practical introduction. Boca Ratón, EEUU: CRC Press, 2008.

[293] M. Collado-González, V. Fernández Espín, M. G. Montalbán, R. Pamies, J. G. Hernández Cifre, F. G. Díaz Baños, G. Víllora, y J. García de la Torre, «Aggregation behaviour of gold nanoparticles in presence of chitosan», J. Nanoparticle Res., vol. 17, p. 268, 2015.

[294] «NIST X-ray Photoelectron Spectroscopy Database, version 4.1». [En línea]. Disponible en: https://srdata.nist.gov/xps/main_search_menu.aspx.

[295] A. Martinelli y L. Nordstierna, «An investigation of the sol-gel process in ionic liquid-silica gels by time resolved Raman and 1H NMR spectroscopy», Phys. Chem. Chem. Phys., vol. 14, pp. 13216-13223, 2012.

[296] A. C. Macmillan, T. M. Mcintire, S. A. Epstein, y S. A. Nizkorodov, «Effect of alkyl chain length on hygroscopicity of nanoparticles and thin films of imidazolium-based ionic liquids», J. Phys. Chem. C, vol. 118, pp. 29458-29466, 2014.

[297] Y. J. Hwang y J. G. Lyubovitsky, «The structural analysis of three-dimensional fibrous collagen hydrogels by raman microspectroscopy», Biopolymers, vol. 99, pp. 349-356, 2013.

[298] N. J. Crane, E. Polfer, E. A. Elster, B. K. Potter, y J. A. Forsberg, «Raman spectroscopic analysis of combat-related heterotopic ossification development», Bone, vol. 57, pp. 335-342, 2013.

[299] C. Yohannan Panicker, H. Tresa Varghese, y D. Philip, «FT-IR, FT-Raman and SERS spectra of Vitamin C», Spectrochim. Acta - Part A Mol. Biomol. Spectrosc., vol. 65, pp. 802-804, 2006.

[300] R. L. Frost, A. Lópes, R. Scholz, y Y. Xi, «Infrared and Raman spectroscopic characterization of the arsenate mineral ceruleite Cu2Al7(AsO4)4(OH) 13.11.5(H2O)», Spectrochim. Acta - Part A Mol. Biomol. Spectrosc., vol. 116, pp. 518-523, 2013.

[301] J. Geringer, F. Atmani, y B. Forest, «Friction-corrosion of AISI 316L/bone cement and AISI 316L/PMMA contacts: lonic strength effect on tribological behaviour», Wear, vol. 267, pp. 763-769, 2009.

[302] J. F. Moulder, W. F. Stickle, P. E. Sobol, y K. D. Bomben, Handbook of X-ray photoelectron spectroscopy. Eden Prairie, EEUU, 1992. 
[303] M. Wall, «The Raman spectroscopy of graphene and the determination of layer thickness», Thermo scientific Application note, p. 52252, 2011.

[304] M. M. Lucchese, F. Stavale, E. H. M. Ferreira, C. Vilani, M. V. O. Moutinho, R. B. Capaz, C. A. Achete, y A. Jorio, «Quantifying ion-induced defects and Raman relaxation length in graphene», Carbon, vol. 48, pp. 1592-1597, 2010.

[305] C. T. J. Low, F. C. Walsh, M. H. Chakrabarti, M. A. Hashim, y M. A. Hussain, «Electrochemical approaches to the production of graphene flakes and their potential applications», Carbon, vol. 54, pp. 1-11, 2013.

[306] G. M. Morales, P. Schifani, G. Ellis, C. Ballesteros, G. Martínez, C. Barbero, y H. J. Salavagione, «High-quality few layer graphene produced by electrochemical intercalation and microwave-assisted expansion of graphite», Carbon, vol. 49, pp. 2809-2816, 2011.

[307] K. W. Sun, J. Y. Wang, y T. Y. Ko, «Raman spectroscopy of single nanodiamond: Phonon-confinement effects», Appl. Phys. Lett., vol. 92, pp. 20062009, 2008.

[308] J. Lin, L. Wang, y G. Chen, «Modification of graphene platelets and their tribological properties as a lubricant additive», Tribol. Lett., vol. 41, pp. 209-215, 2011.

[309] E. Quijada-Maldonado, S. Van Der Boogaart, J. H. Lijbers, G. W. Meindersma, y A. B. De Haan, «Experimental densities, dynamic viscosities and surface tensions of the ionic liquids series 1-ethyl-3-methylimidazolium acetate and dicyanamide and their binary and ternary mixtures with water and ethanol at $\mathrm{T}=$ (298.15 to 343.15 K)», J. Chem. Thermodyn., vol. 51, pp. 51-58, 2012.

[310] S. I. Fletcher, F. B. Sillars, N. E. Hudson, y P. J. Hall, «Physical properties of selected ionic liquids for use as electrolytes and other industrial applications», J. Chem. Eng. Data, vol. 55, pp. 778-782, 2010.

[311] R. G. Seoane, S. Corderí, E. Gómez, N. Calvar, E. J. González, E. A. Macedo, y Á. Domínguez, «Temperature dependence and structural influence on the thermophysical properties of eleven commercial ionic liquids», Ind. Eng. Chem. Res., vol. 51, pp. 2492-2504, 2012.

[312] S. Bulut, P. Eiden, W. Beichel, J. M. Slattery, T. F. Beyersdorff, T. J. S. Schubert, y I. Krossing, "Temperature dependence of the viscosity and conductivity of mildly functionalized and non-functionalized [Tf2N]-ionic liquids», Chem PhysChem, vol. 12, pp. 2296-2310, 2011.

[313] A. A. Miran Beigi, M. Abdouss, M. Yousefi, S. M. Pourmortazavi, y A. Vahid, «Investigation on physical and electrochemical properties of three imidazolium based ionic liquids (1-hexyl-3-methylimidazolium tetrafluoroborate, 1-ethyl-3methylimidazolium bis(trifluoromethylsulfonyl) imide and 1-butyl-3methylimidazolium methylsulfate)», J. Mol. Liq., vol. 177, pp. 361-368, 2013.

[314] M. Shi, S. Kou, y X. Yan, «Engineering the electrochemical capacitive properties of graphene sheets in ionic-liquid electrolytes by correct selection of anions", ChemSusChem, vol. 7, pp. 3053-3062, 2014.

[315] H. Weber y B. Kirchner, "Complex structural and dynamical interplay of cyanobased ionic liquids», J. Phys. Chem. B, vol. 120, pp. 2471-2483, 2016.

[316] L. Zhang, L. Chen, J. Liu, X. Fang, y Z. Zhang, «Effect of morphology of carbon nanomaterials on thermo-physical characteristics, optical properties and photothermal conversion performance of nanofluids», Renew. Energy, vol. 99, pp. 888-897, 2016. 
[317] J. Liu, F. Wang, L. Zhang, X. Fang, y Z. Zhang, «Thermodynamic properties and thermal stability of ionic liquid-based nanofluids containing graphene as advanced heat transfer fluids for medium-to-high-temperature applications", Renew. Energy, vol. 63, pp. 519-523, 2014.

[318] B. A. Kheireddin, W. Lu, I. C. Chen, y M. Akbulut, «Inorganic nanoparticle-based ionic liquid lubricants», Wear, vol. 303, pp. 185-190, 2013.

[319] G. C. Kalur, B. D. Frounfelker, B. H. Cipriano, A. I. Norman, y S. R. Raghavan, "Viscosity increase with temperature in cationic surfactant solutions due to the growth of wormlike micelles», Langmuir, vol. 21, pp. 10998-11004, 2005.

[320] A. Chagnes, A. Tougui, B. Carr, y N. Ranganathan, «Abnormal temperature dependence of the viscosity of ethylammonium nitrate - methanol ionic mixtures», J. Solution Chem., vol. 33, pp. 247-255, 2004.

[321] R. Nanda, «Unusual linear dependency of viscosity with temperature in ionic liquid/water mixtures», Phys. Chem. Chem. Phys., vol. 18, pp. 25801-25805, 2016.

[322] M. Shakourian-Fard, Z. Jamshidi, A. Bayat, y G. Kamath, «Meta-hybrid density functional theory study of adsorption of imidazolium- and ammonium-based ionic liquids on graphene sheet», J. Phys. Chem. C, vol. 119, pp. 7095-7108, 2015.

[323] A. S. Pensado, F. Malberg, M. F. C. Gomes, A. A. H. Padua, J. Fernandez, y B. Kirchner, "Interactions and structure of ionic liquids on graphene and carbon nanotubes surfaces», RSC Adv., vol. 4, pp. 18017-18024, 2014.

[324] T. A. Litovitz, «Temperature dependence of the viscosity of associated liquids», J. Chem. Phys., vol. 20, pp. 1088-1089, 1952.

[325] H. Vogel, «The temperature dependence law of the viscosity of fluids», Phys. Zeitschr, vol. 22, pp. 645-646, 1921.

[326] G. S. Fulcher, «Analysis of recent measurements of the viscosity of glasses», J. Am. Ceram. Soc., vol. 8, pp. 339-355, 1925.

[327] G. Tamman y W. Hesse, «The dependency of viscosity on temperature in hypothermic liquids», Z. Anorg. Allg. Chem., vol. 156, pp. 254-257, 1926.

[328] N. Voeltzel, A. Giuliani, N. Fillot, P. Vergne, y L. Joly, «Nanolubrication by ionic liquids: molecular dynamics simulations reveal an anomalous effective rheology», Phys. Chem. Chem. Phys., vol. 17, pp. 23226-23235, 2015.

[329] H. Rodríguez y J. F. Brennecke, «Temperature and composition dependence of the density and viscosity of binary mixtures of water + ionic liquid», J. Chem. Eng. Data, vol. 51, pp. 2145-2155, 2006.

[330] R. A. Carpio, L. A. King, R. E. Lindstrom, J. C. Nardi, y C. L. Hussey, «Density, electric conductivity, and viscosity of several $\mathrm{N}$-alkylpyridinium halides and their mixtures with aluminum chloride», J. Electrochem. Soc., vol. 126, pp. 16441650, 1979.

[331] R. Alcalde, G. García, M. Atilhan, y S. Aparicio, "Systematic study on the viscosity of ionic liquids: Measurement and prediction», Ind. Eng. Chem. Res., vol. 54, p. 10918, 2015.

[332] P. Restuccia y M. C. Righi, «Tribochemistry of graphene on iron and its possible role in lubrication of steel», Carbon, vol. 106, pp. 118-124, 2016.

[333] A. Klemenz, L. Pastewka, S. G. Balakrishna, A. Caron, R. Bennewitz, y M. Moseler, «Atomic scale mechanisms of friction reduction and wear protection by graphene», Nano Lett., vol. 14, pp. 7145-7152, 2014. 
[334] H. Xiao, D. Guo, S. Liu, G. Pan, y X. Lu, «Film Thickness of Ionic Liquids under High Contact Pressures as a Function of Alkyl Chain Length», Tribol. Lett., vol. 41, pp. 471-477, 2011.

[335] N. Hameed, N. V. V. Salim, T. R. R. Walsh, J. S. S. Wiggins, P. M. M. Ajayan, y B. L. L. Fox, «Ductile thermoset polymers via controlling network flexibility», Chem. Commun., vol. 51, pp. 9903-9906, 2015.

[336] J. Sanes, F. J. Carrión-Vilches, y M. D. Bermúdez, «New epoxy-ionic liquid dispersions. Room temperature ionic liquid as lubricant of epoxy resin-stainless steel contacts», E-Polymers, vol. 7, pp. 1-12, 2007.

[337] P. Bandeira, J. Monteiro, A. M. Baptista, y F. D. Magalhães, «Tribological performance of PTFE-based coating modified with microencapsulated [HMIM][NTf2] ionic liquid», Tribol. Lett., vol. 59, p. 13, 2015.

[338] M. Yang, X. Zhu, G. Ren, X. Men, F. Guo, P. Li, y Z. Zhang, «Tribological behaviors of polyurethane composite coatings filled with ionic liquid core/silica gel shell microcapsules», Tribol. Lett., vol. 58, p. 9, 2015.

[339] M. Clausi, M. G. Santonicola, y S. Laurenzi, «Fabrication of carbon-based nanocomposite films by spin-coating process: An experimental and modeling study of the film thickness», Compos. Part A Appl. Sci. Manuf., vol. 88, pp. 8697, 2016.

[340] Aenor, Especificación geométrica de productos (GPS). Calidad superficial: Área. Términos, definiciones y parámetros de calidad. UNE-EN ISO 25178. 2013, pp. 1-56.

[341] Aenor, Especificación geométrica de productos (GPS). Calidad superficial: Método del perfil. Términos, definiciones y parámetros del estado superficial. UNE-EN ISO 42877. 1999, pp. 1-26. 


\subsection{ANÁLISIS DE LA BIBLIOGRAFÍA UTILIZADA}

Se ha realizado un análisis cronológico y en tres categorías de la bibliografía utilizada en el presente trabajo. Las categorías en las que se ha dividido son:

Artículos publicados en revistas científicas

$>$ Libros y capítulos de libros

$>$ Otros (Normas, patentes, comunicaciones a congresos y páginas web)
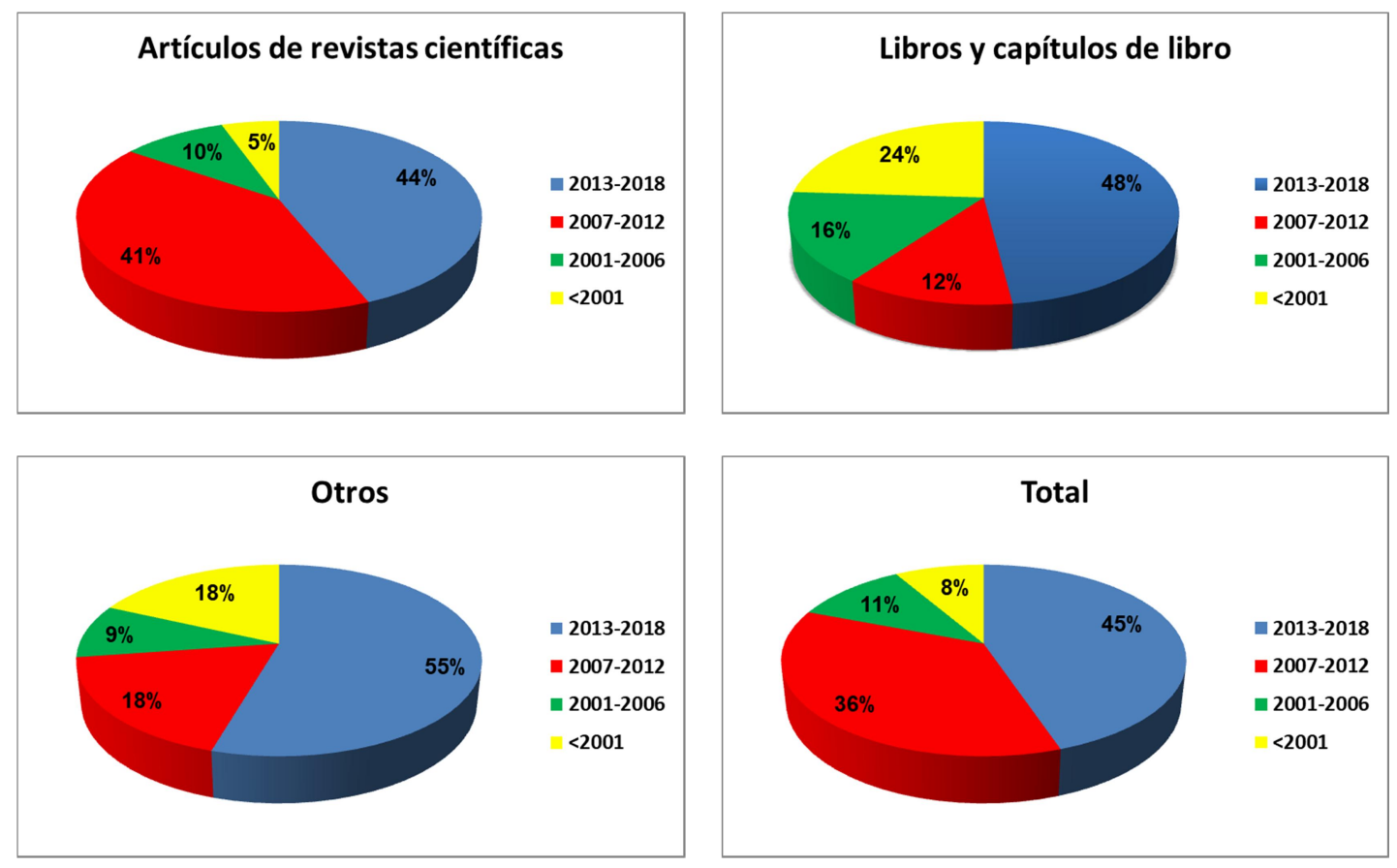

Figura 288. Análisis de la bibliografía empleada

Como se puede observar, en la Figura 288 , el $44 \%$ de los artículos científicos consultados han sido publicados en los últimos 5 años (2013-2018). Siendo un $85 \%$ el porcentaje de los artículos empleados que han sido publicados entre 2007 y 2018.

Con respecto a los libros y capítulos de libros, la mayoría (un 48\%) han sido publicados después de 2013.

En definitiva, el $81 \%$ de la bibliografía consultada en la realización del presente trabajo ha sido publicada en los últimos 10 años. 


\subsection{PRODUCCIÓN CIENTÍFICA DERIVADA DE LA TESIS}

\section{Artículos científicos}

R. Pamies, M. D. Avilés, J. Arias-Pardilla, T. Espinosa, F. J. Carrión, J. Sanes, y M. D. Bermúdez, «Antiwear performance of ionic liquid+graphene dispersions with anomalous viscosity-temperature behavior», Tribol. Int., vol. 122, pp. 200209, 2018 (JCR: Q1).

M. D. Avilés, F. J. Carrión, J. Sanes, y M. D. Bermúdez, «Effects of protic ionic liquid crystal additives on the water-lubricated sliding wear and friction of sapphire against stainless steel», Wear, vol. 408-409, pp. 56-64, 2018 (JCR: Q1).

J. Sanes, M. D. Avilés, N. Saurín, T. Espinosa, F. J. Carrión, y M. D. Bermúdez, «Synergy between graphene and ionic liquid lubricant additives», Tribol. Int., vol. 116, pp. 371-382, 2017 (JCR: Q1).

M.D. Avilés, N. Saurín, J. Sanes, F. J. Carrión, y M. D. Bermúdez, «lonanocarbon lubricants. The combination of ionic liquids and carbon nanophases in tribology», Lubricants, vol. 5, p. 14, 2017.

N. Saurín, M.D. Avilés, T. Espinosa, J. Sanes, F.J. Carrión, M.D. Bermúdez, y P. Iglesias, "Carbon nanophases in ordered nanofluid lubricants», Wear, vol. 377, pp. 747-755, 2017 (JCR: Q1).

M. D. Avilés, N. Saurín, T. Espinosa, J. Sanes, J. Arias-Pardilla, F. J. Carrión, y M. D. Bermúdez, «Self-lubricating, wear resistant protic ionic liquid-epoxy resin», Express Polym. Lett., vol. 11, pp. 219-229, 2017 (JCR: Q1).

M.D. Avilés, F.J. Carrión, M.D. Bermúdez «Nuevo nanocomposite de líquido iónico prótico en matriz epoxi». Anuario de Jóvenes Investigadores UPCT, vol.9, pp.172-175, 2016.

$\underline{\text { Capítulos de libro }}$

M. D. Avilés, N. Saurín, J. Sanes, T. Espinosa, F.J. Carrión, M.D. Bermúdez. «Graphene as a lubricant additive. Effect of the base oil, contact materials and sliding conditions» IX Iberian Conference on Tribology, Conference Proceedings, pp.35-36, 2017. 
M. D. Avilés, F.J. Carrión, J. Sanes, A. E. Jiménez, R. Pamies, I.J. Martínez, J. Arias y M.D. Bermúdez. "lonic Liquids in Tribology» ILMAT IV 4. International Conference on Ionic Liquid-based Materials, Book of Abstracts, pp.8, 2017

\section{Patentes}

Dispersión de grafeno en un líquido iónico cuya viscosidad aumenta con la temperatura. ES 2609671 A1 M. D. Avilés, R. Pamies, T. Espinosa, M.D. Bermúdez y F.J. Carrión.

\section{Congresos}

M. D. Avilés, N. Saurín, A.E. Jiménez, M.D. Bermúdez, F.J. Carrión y J. Sanes. "Tribological characterization of epoxy coatings modified with ionic liquids and graphene", Leeds-Lyon Symposium on Tribology, Comunicación oral, Leeds (Reino Unido), Septiembre 2018.

J. Arias-Pardilla, M.D. Avilés, N. Saurín, I. Martínez-Mateo, L. Mínguez, F.J. Carrión, J. Sanes, M.D. Bermúdez. "Epoxy resin nanocomposites with graphene+ionic liquids", XV Congreso Nacional de Materiales e Iberian Meeting on Materials Science, Comunicación Oral, Salamanca (España), Julio 2018.

M. D. Avilés, R. Pamies, J. Sanes, F.J. Carrión y M.D. Bermúdez. "Grafeno como aditivo lubricante de líquidos iónicos", I Jornadas doctorales UPCT: Doctorado-Empresa, Póster, Cartagena (España), Abril 2018. Premio al mejor póster.

M. D. Avilés, R. Pamies, J. Sanes y M.D. Bermúdez. "Graphene as lubricant additive of ionic liquids", ImagineNano 2018 International Event-Nanospain2018 Conference, Póster, Bilbao (España), Marzo 2018.

M. D. Avilés, F.J. Carrión, J. Sanes, A.E. Jiménez, R. Pamies, I.J. Martínez, J. Arias y M.D. Bermúdez. "Ionic liquids in tribology", $4^{\text {th }}$ International Conferece on Ionic Liquid-based materials, Comunicación Oral, Santiago de Compostela (España), Octubre 2017.

R. Pamies, M. D. Avilés, F.J. Carrión y M.D. Bermúdez. "Viscoelastic behavior of carbon nanotubes-ionic liquids dispersions with potential lubricating applications", $3^{\text {rd }}$ World Congress on Material Science, Engineering, Oil, Gas and Petrochemistry, Comunicación Oral, Barcelona (España), Agosto 2017. 
F.J. Carrión-Vilches, M. D. Avilés, J. Sanes, R. Pamies, M.D. Bermúdez y K. Nakano. "Ionic liquids and carbon nanophases in lubrication", $6^{\text {th }}$ European Conference on Tribology, Comunicación Oral, Ljubljana (Eslovenia) Junio 2017

M. D. Avilés, N. Saurín, J. Sanes, T. Espinosa, F.J. Carrión y M.D. Bermúdez. "Graphene as a lubricant additive. Effect of the base oil, contact materials and sliding conditions", IX Iberian Conference on Tribology (IBERTRIB), Comunicación Oral, Guimaraes (Portugal) Junio 2017.

N. Saurín, M .D. Avilés, T. Espinosa, J. Sanes, F.J. Carrión, M. D. Bermúdez y P. Iglesias. "Carbon nanophases in ordered nanofluid lubricants", Wear of Materials 2017, Comunicación Oral, California (EEUU), Marzo 2017.

N. Saurín, M. D. Avilés, G. Ojados, J. Sanes, F.J. Carrión y M. D. Bermúdez. "Nuevas dispersiones de líquidos iónicos y nanofases de carbono en matrices de polímeros. Caracterización, propiedades y comportamiento tribológico", XIV Congreso Nacional de Materiales, Comunicación Oral, Gijón (España), Junio 2016. 